UNIVERSIDADE DE SÃO PAULO
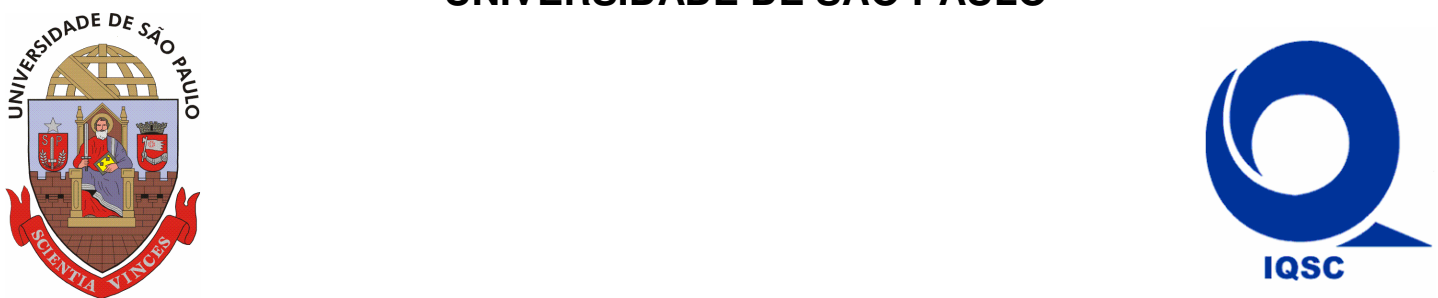

INSTITUTO DE QUÍMICA DE SÃO CARLOS

INFLUÊNCIA DO TAMANHO MOLECULAR APARENTE DAS SUBSTÂNCIAS HÚMICAS AQUÁTICAS NA EFICIÊNCIA DA COAGULAÇÃO COM SULFATO DE ALUMÍNIO E CLORETO FÉRRICO

\title{
Eliane Sloboda
}

Dissertação apresentada ao Instituto de Química de São Carlos, Universidade de São Paulo, como parte dos quesitos para obtenção do Título de Mestre em Ciências (Química Analítica).

Orientadora: Prof $\stackrel{\text { a }}{\text {. Dr }}$. Eny Maria Vieira 


\section{Oedicatória}

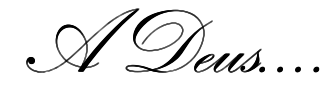

Sos meus pais. Ahna Proman Sloboda e a memoiria de meu pai Sefano. Ploboda. 


\section{AGRADECIMENTOS}

A Deus por nunca me desamparar....

A Prof ${ }^{a}$. Dr ${ }^{a}$. Eny Maria Vieira pela orientação, incentivo, amizade e confiança depositada durante a realização deste trabalho.

Ao Instituto de Química de São Carlos pelo apoio e pela oportunidade oferecida.

Ao Prof. Dr. Luiz Di Bernardo (Engenharia Hidráulica e Saneamento) pela confiança, ajuda e por ter concedido o laboratório onde realizei praticamente todo meu trabalho.

A Prof ${ }^{a}$. Dra . Angela Di Bernardo Dantas pela amizade, incentivo, confiança e ajuda.

Ao CNPq pela concessão da bolsa de mestrado.

Aos meus amigos do Grupo de Química Analítica Aplicada a Medicamentos e Ecossistemas Aquáticos e Terrestres: Gustavo, Ricardo Reis, Ricardo Cabelo, Wilma, Sérgio, Keila, Sandra Falone, Fabiana, Daniel e Flávio (Tio). A todos agradeço pela amizade e companheirismo.

Aos amigos do Laboratório de Saneamento: Marcelo de Julio, Taty, Gustavo, Paulo (Jalaska) e Luis (Paraíba) pelas conversas, pela constante disposição em ajudar-me.

Agradeço ao Paulo Voltan pela ajuda, sugestões e discussões relevantes no trabalho.

Ao Ronaldo pela ajuda, carinho, companheirismo, incentivo, compreensão e por sempre estar ao meu lado.

As secretárias do IQSC Shirley e Vanessa pela amizade, paciência e dedicação.

Aos funcionários do laboratório de Saneamento, Julio, Juliana e Paulo pela contribuição no trabalho e amizade.

Aos amigos do Grupo de Química Ambiental: Raquel, Joel, Elke, Paula, Fabiane e Diva pela amizade e momentos alegres vividos. 
Aos amigos da graduação e que juntos estamos aqui no IQSC: Michelli, Josmar, Marins, Clauco, Helton, Juliana e Adriana. A todos agradeço pela amizade e companheirismo.

As amigas com quem já morei e com quem moro atualmente: Marcela, Ludimila, Juliana, Michelli, Raquel, Estela, Roberta, Maíra e Viviane, pelo acolhimento, pelas conversas, amizade e compreensão.

Aos funcionários do Instituto de Química pela ajuda e suporte técnico oferecido, Renatinha, Cidinha, Silvana, Mauro, Eliane (PAE), Andréia (Pós), Silvia (Pós) e aos funcionários da biblioteca.

A todos meus amigos de Guarapuava, em especial a Daniela (Dany), Rosane (Ro), Roberta e Olga pela amizade e incentivo.

As minhas amigas Elaine e Vera, pela amizade desde adolescência.

A meus amigos do IQSC, Felipe, Renato (Chuck), Sidnei (Pufe), Sandra Alasfur, Wendel, Eduardo, Alexandre (Itapira), Kátia, Luciane (Lu), Leidimara (Leidi) enfim, a todos pela amizade, ajuda e inúmeros momentos de alegria vividos.

Agradeço em especial a amizade da Raquel, da Goretti e da Keila pelos momentos inesquecíveis e por tudo o que passamos juntos.

A minha mãe por ter me dado à vida, pelo amor incondicional, educação, e por sempre acreditar em mim. Por ter vencido a doença e ocupar o lugar de pai e mãe. Agradeço a Deus e a Nossa mãe Aparecida por ter concedido a cura a ela e por estar presente hoje em minha vida.

Ao meu pai que tão cedo partiu da minha vida, mas aos 11 anos que com ele vivi, tive muitos ensinamentos que carrego sempre comigo.

Aos meus irmãos: Jorge, Pe. Valdir, Maria, Pedro, Isabel, Luis Antonio, Bernadeth, Ivete e Edvirges pelo amor, carinho, incentivo, ajuda incondicional e por sempre ter acreditado em mim.

A todos meus sobrinhos e aos afilhados: Breno e a Gabriela.

Aos todos os membros do Grupo de Oração Universitário (GOU) pelo acolhimento, pelas orações e encontros maravilhosos.

Enfim, a todos os colegas que, no dia a dia, ajudaram-me, com ações ou exemplos. 


\section{SUMÁRIO}

LISTA DE FIGURAS i

LISTA DE TABELAS V V

LISTA DE ABREVIATURAS Vi

$\begin{array}{lll}\text { RESUMO } & \text { Vii }\end{array}$

$\begin{array}{lll}\text { ABSTRACT } & \text { Viii }\end{array}$

1 - INTRODUÇÃO 1

2 - REVISÃO BIBLIOGRÁFICA $\quad 5$

2.1 - Distribuição da água no mundo e no Brasil 5

2.2 - Água-meio ambiente - saúde 5

2.3 - Substâncias húmicas $\quad 7$

$\begin{array}{ll}\text { 2.3.1 - Considerações iniciais } & 7\end{array}$

2.3.2 - Classificação das substâncias húmicas $\quad 7$

2.3.3 - Mecanismos propostos para a formação das substâncias húmicas 8

2.3.4 - Estruturas das substâncias húmicas 10

2.3.5 - Importância das substâncias húmicas no meio ambiente 16

2.3.6 - Substâncias húmicas aquáticas 16

2.3.7 - Métodos de extração das substâncias húmicas aquáticas 19

2.3.8 - Fracionamento das substâncias húmicas aquáticas 22

2.3.9 - Caracterização das substâncias húmicas 25 
2.3.9.1 - Composição elementar das substâncias húmicas

2.3.9.2 - Espectroscopia no Ultravioleta-Visível (UV/VIS) 27

2.3.9.3 - Espectroscopia na região do infravermelho (IV) 30

2.3.9.4 - Espectroscopia de ressonância magnética nuclear (RMN) 32

2.4 - Tecnologias de tratamento de água $\quad 37$

2.4.1 - Tecnologias de filtração direta 38

2.4.1.1 - Filtração direta descente (FDD) 38

2.4.1.2 - Filtração direta ascendente (FDA) 39

2.4.1.3 - Dupla filtração 39

2.4.1.4 - Floto-filtração $\quad 40$

2.4.1.5 - Fitração em múltiplas etapas $\quad 40$

2.5 - Coagulação 41

2.6 - Partículas de argilas, substâncias húmicas e suas estabilidades 42

2.6.1 - Estabilidade eletrostática 43

2.6.2 - Estabilização estérica 45

2.7 - Potencial zeta 46

2.8 - Coagulantes químicos $\quad 49$

2.8.1 - Considerações iniciais $\quad 49$

$\begin{array}{ll}2.8 .2 \text { - Cloreto Férrico } & 49\end{array}$

2.8.2.1 - Reações de hidrólise de sais de $\mathrm{Fe}^{3+} \quad 50$

2.8.3 - Sulfato de Alumínio $\quad 55$

2.8.3.1 - Reações de hidrólise de sais de $\mathrm{Al}^{3+}$

2.9 - Mecanismos de coagulação $\quad 59$

2.9.1 - Compressão de dupla camada elétrica 60

2.9.2 - Adsorção - neutralização de cargas $\quad 60$ 
$\begin{array}{ll}2.9 .3 \text { - Varredura } & 62\end{array}$

2.9.4 - Adsorção e formação de pontes 64

2.10 - Diagramas de coagulação $\quad 64$

2.10.1 - Coagulação de águas contendo substâncias húmicas 66

3 - OBJETIVOS $\quad 75$

4 - PARTE EXPERIMENTAL $\quad 76$

4.1 - Etapas deste estudo $\quad 76$

4.2 - Coleta e extração das substâncias húmicas aquáticas 77

4.3 - Extração das SHA e diálise $\quad 78$

4.4 - Fracionamento das SHA por ultrafiltração (UF) 80

4.5 - Liofilização das frações de SHA 83

4.6 - Caracterização das frações SHA

4.6.1 - Determinação do teor de cinzas 83

4.6.2 - Análise elementar $\quad 84$

4.6.3 - Espectroscopia no infravermelho (IV) 84

4.6.4 - Espectroscopia no ultravioleta/visível (UV/VIS) 84

4.6.5 - Ressonância magnética nuclear (RMN) 85

4.6.6 - Determinação de teores de carbono orgânico total (COT) 85

$\begin{array}{ll}\text { 4.6.7-Turbidez } & 86\end{array}$

$\begin{array}{ll}\text { 4.6.8 - Medida de } \mathrm{pH} & 87\end{array}$

4.7 - Preparação das águas de estudo 87

$\begin{array}{ll}\text { 4.7.1 - Ensaios de filtração direta } & 87\end{array}$

4.7.2 - Concentração de alumínio residual

5 - RESULTADOS E DISCUSSÃO

5.1 - Extração das SHA e diálise $\quad 91$ 
5.2 - Caracterização das diferentes frações das SHA

5.2.1 - Composição elementar das frações das SHA 91

5.2.2 - Espectroscopia no Ultravioleta -Visível (UV/VIS) 94

5.2.3 - Espectroscopia na região do infravermelho (IV) 96

5.2.4 - Ressonância magnética nuclear de ${ }^{13} \mathrm{C} \quad 98$

$\begin{array}{ll}5.2 .5 \text { - Teor de cinzas } & 101\end{array}$

5.2.6 - Carbono orgânico total (COT) 102

5.3 - Caracterização da amostra de água coletada no Rio Itapanhaú 103

5.4 - Resultados de coagulação com sulfato de alumínio 105

5.4.1 - Características das amostras de águas de estudo 105

$\begin{array}{ll}5.4 .2 \text { - Diagramas de remoção de cor aparente } & 107\end{array}$

5.4.3 - Diagramas de coagulação das espécies hidrolisadas de alumínio - $\quad 115$ remoção de cor aparente

5.4.4 - Diagramas de remoção de turbidez 121

5.5 - Resultados de coagulação com cloreto férrico 128

5.5.1 - Caracterização das amostras de águas de estudo 128

5.5.2 - Diagramas de remoção de cor aparente 130

5.5.3 - Diagramas de coagulação com as espécies hidrolisadas de ferro 136

5.5.4 - Diagramas de coagulação de remoção de turbidez 138

5.6 - Comparação entre os diagramas do sulfato de alumino e cloreto férrico na 145 remoção de cor aparente da água filtrada

6.0 - CONSIDERAÇÕES FINAIS

7.0 - RECOMENDAÇÕES PARA TRABALHOS FUTUROS 150

8.0 - REFERÊNCIAS BIBLIOGRAFICAS 151

$\begin{array}{ll}\text { ANEXO A } & 163\end{array}$ 
A. 1 - Tabelas referentes aos ensaios de coagulação para a água de estudo 1 , empregando-se sulfato de alumínio como coagulante.

A. 2 - Tabelas referentes aos ensaios de coagulação para a água de estudo 2, 172 empregando-se sulfato de alumínio como coagulante

A. 3 - Tabelas referentes aos ensaios de coagulação para a água de estudo 3, 181 empregando-se sulfato de alumínio como coagulante

A. 4 - Tabelas referentes aos ensaios de coagulação para a água de estudo 4, 190 empregando-se sulfato de alumínio como coagulante

\section{ANEXO B}

B. 1 - Tabelas referentes aos ensaios de coagulação para a água de estudo 1, 198 empregando-se cloreto férrico como coagulante

B. 2 - Tabelas referentes aos ensaios de coagulação para a água de estudo 2, 207 empregando-se cloreto férrico como coagulante

B. 3 - Tabelas referentes aos ensaios de coagulação para a água de estudo 3, 216 empregando-se cloreto férrico como coagulante

B. 4 - Tabelas referentes aos ensaios de coagulação para a água de estudo 4, 225 empregando-se cloreto férrico como coagulante 


\section{LISTA DE FIGURAS}

Figura 1 Mecanismos de formação das substâncias húmicas (STEVENSON, 09 1994).

Figura 2a Estrutura proposta para os AH (SCHULTEN; SCHINITZER, 1993).

Figura 2b Estrutura proposta para os AF (SCHULTEN; SCHINITZER, 1993).

Figura 3 Modelos conceituais propostos para a teoria macromolecular. (a) moléculas das substâncias húmicas aleatoriamente enoveladas (SWIFT, 1989). (b) AH proposto por Schulten e Schnitzer (1995).

Figura 4 Modelos estruturais de isômeros para um dado ácido húmico de solo em 3D propostos por Diallo et al. (2003).

Figura 5 Principais tecnologias de tratamento de água para consumo humano (DI BERNARDO; DANTAS, 2003, p. 33).

Figura 6 Representação esquemática da DCE nas vizinhanças de uma interface sólido-líquido (DI BERNARDO; DANTAS, 2005, p.174).

Figura 7 Configuração esquemática da dupla camada elétrica

(DI BERNARDO; DANTAS, 2005, p.175).

Figura 8 Diagrama de solubilidade do ferro relacionado com o cloreto férrico PA.

Figura 9 Diagrama de solubilidade do alumínio relacionado com o $\mathrm{Al}_{2}\left(\mathrm{SO}_{4}\right)_{3}$. $14,3 \mathrm{H}_{2} \mathrm{O}$.

Figura 10 Caminhos para a coagulação por adsorção e neutralização de carga e por varredura, utilizando sulfato de alumínio (AMIRTHARAJAH; MILLS, 1982).

Figura 11 - Diagrama de coagulação com sulfato de alumínio para remoção de turbidez alta em relação à cor verdadeira (AMIRTHARAJAH ,1989).

Figura 12 Diagrama de coagulação do alumínio para a remoção de cor verdadeira; concentração de ácido húmico $=4 \mathrm{mg} \mathrm{L}^{-1}$; cor verdadeira = $100 \mathrm{uH}$; turbidez = 0 uT (EDWARDS; AMIRTHARAJAH,1985).

Figura 13 Diagrama de coagulação do alumínio para remoção de cor verdadeira; concentração de $\mathrm{AH}=20 \mathrm{mg} \mathrm{L}^{-1}$; cor verdadeira $=450$ $\mathrm{uH}$; turbidez $\cong 0 \mathrm{uT}$ (EDWARDS; AMIRTHARAJAH, 1985).

Figura 14 Diagrama de coagulação para remoção de cor verdadeira 69 (MENDES, 1989). 
Figura 15 Diagrama de coagulação para remoção de cor verdadeira e turbidez; concentração de $\mathrm{AH}=4 \mathrm{mg} \mathrm{L}^{-1}$; cor Verdadeira $=100 \mathrm{uH}$; turbidez = 27 a 30 uT (EDWARDS ; AMIRTHARAJAH, 1985).

Figura 16 Diagrama de coagulação para remoção de cor verdadeira e turbidez; 671 concentração de $\mathrm{AH}=20 \mathrm{mg} \mathrm{L}^{-1}$; cor Verdadeira $=450 \mathrm{uH}$; turbidez = 27 a 30 uT (EDWARDS ; AMIRTHARAJAH, 1985).

Figura 17 Fluxograma das etapas seguidas durante os procedimentos experimentais.

Figura 18 Foto do Rio Itapanhaú-Bertioga-SP.

Figura 19 Foto das instalações de extração das SHA.

Figura 20 Foto da água coletada no Rio Itapanhaú e extrato após diálise.

Figura 21 Foto do sistema de filtração nas membranas de 0,45 $\mu \mathrm{m}$.

Figura 22 Foto do fracionamento das SHA no equipamento de ultrafiltração.

Figura 23 Foto do reator estático (Jarteste).

Figura 24 Porcentagem dos elementos químicos $(\mathrm{C}, \mathrm{H}, \mathrm{N}$ e $\mathrm{O})$ nas frações de SHA.

Figura 25 Espectros no infravermelho das frações de SHA.

Figura 26 Espectros de RMN de ${ }^{13} \mathrm{C}$ para as frações das SHA.

Figura 27 Porcentagem de AH e AF nas frações de SHA.

Figura 28 Diagrama de coagulação com o sulfato de alumínio para remoção de 108 cor aparente da água de estudo 1.

Figura 29 Diagrama de coagulação com o sulfato de alumínio para remoção de 109 cor aparente da água de estudo 2.

Figura 30 Diagrama de coagulação com o sulfato de alumínio para remoção de cor aparente da água de estudo 3.

Figura 31 Diagrama de coagulação com o sulfato de alumínio para remoção de cor aparente da água de estudo 4.

Figura 32 Diagrama de coagulação com as espécies hidrolisadas de alumínio para a região de remoção de cor aparente $\leq 5 \mathrm{uH}$ - fração de SHA menor que $0,45 \mu \mathrm{m}$. 
Figura 33 Diagrama de coagulação com as espécies hidrolisadas de alumínio para a região de remoção de cor aparente $\leq 5 \mathrm{uH}$ - fração de SHA entre $100 \mathrm{kDa}$ e $0,45 \mu \mathrm{m}$.

Figura 34 Diagrama de coagulação com as espécies hidrolisadas de alumínio 117 para a região de remoção de cor aparente $\leq 5 \mathrm{uH}$ - fração de SHA entre $30 \mathrm{kDa}$ e $100 \mathrm{kDa}$.

Figura 35 Diagrama de coagulação com as espécies hidrolisadas de alumínio para a região de remoção de cor aparente $\leq 5 \mathrm{uH}$ - fração de SHA menor que $30 \mathrm{kDa}$.

Figura 36 Diagrama de coagulação com sulfato de alumínio para remoção de turbidez da água de estudo 1.

Figura 37 Diagrama de coagulação com sulfato de alumínio para remoção de turbidez da água de estudo 2 .

Figura 38 Diagrama de coagulação com sulfato de alumínio para remoção de turbidez da água de estudo 3.

Figura 39 Diagrama de coagulação com sulfato de alumínio para remoção de turbidez da água de estudo 4.

Figura 40 Diagrama de coagulação com cloreto férrico para remoção de cor aparente da água de estudo 1 .

Figura 41 Diagrama de coagulação com cloreto férrico para remoção de cor aparente da água de estudo 2 .

Figura 42 Diagrama de coagulação com cloreto férrico para remoção de cor aparente da água de estudo 3 .

Figura 43 Diagrama de coagulação com cloreto férrico para remoção de cor aparente da água de estudo 4.

Figura 44 Diagrama de coagulação com as espécies hidrolisadas de ferro para a região de cor aparente da água filtrada $\leq 5 \mathrm{uH}$ - fração de SHA menor que $0,45 \mu \mathrm{m}$.

Figura 45 Diagrama de coagulação com as espécies hidrolisadas de ferro para a região de cor aparente da água filtrada $\leq 5 \mathrm{uH}$ - fração de SHA entre $100 \mathrm{kDa}$ e $0,45 \mu \mathrm{m}$.

Figura 46 Diagrama de coagulação com as espécies hidrolisadas de ferro para a região de cor aparente da água filtrada $\leq 5 \mathrm{uH}$ - fração de SHA entre $30 \mathrm{kDa}$ e $100 \mathrm{kDa}$. 
Figura 47 Diagrama de coagulação com as espécies hidrolisadas de ferro para região de cor aparente da água $\leq 5 \mathrm{uH}$ - fração de SHA menor que $30 \mathrm{kDa}$.

Figura 48 Diagrama de coagulação com cloreto férrico para remoção de turbidez da água de estudo 1.

Figura 49 Diagrama de coagulação com cloreto férrico para remoção de trubidez da água de estudo 2.

Figura 50 Diagrama de coagulação com cloreto férrico para remoção de 142 turbidez da água de estudo 3.

Figura 51 Diagrama de coagulação com o cloreto férrico para remoção de 143 turbidez da água de estudo 4. 


\section{LISTA DE TABELAS}

Tabela 1 Métodos de extração de SHA mais utilizados (ROCHA; ROSA, 2003; 20 CHOW et al., 2005).

Tabela 2 Comprimento de onda das principais bandas de absorção e atribuições das SH (ROCHA et al., 2000b; STEVENSON, 1994; RICCA et al., 2000).

Tabela 3 Principais grupos funcionais detectados por RMN ${ }^{13} \mathrm{C}$ para as $\mathrm{SH}$ (MALCOLM, 1990; LU ET AL., 2000, CAMPOS, 2004; SANCHES, 2005; SENESI; MIANO, 1992).

Tabela 4 Condições selecionadas para a análise de custos - Vs $=1 \mathrm{~cm} / \mathrm{min}$ e cor aparente $=\leq 20 \mathrm{uH}$ (PAVANELLI, 2001).

Tabela 5 Composição elementar das diferentes frações das SHA e as razões atômicas dos elementos.

Tabela 6 Características espectroscópicas de UVIVIS para as frações das SHA.

Tabela 7 Teores de cinzas nas frações de SHA.

Tabela 8 Massa de carbono nas diferentes frações das SHA e porcentagem de $\mathrm{AH}$ e AF.

Tabela 9 Caracterização da amostra de água coletada no Rio Itapanhaú.

Tabela 10 Características das amostras de água de estudo de 1 a 4, para a realização dos ensaios com o sulfato de alumínio.

Tabela 11 Valores de alumínio residual e cor aparente da água após coagulação e filtração em filtros de laboratório. Tempo de filtração: 20 minutos.

Tabela 12 Valores de $\mathrm{pH}$ de coagulação e dosagens de sulfato de alumínio das 127 regiões de cor aparente $\leq 5,0 \mathrm{uH}$ e turbidez. $\leq 0,5 \mathrm{uT}$.

Tabela 13 Caracterização das amostras de água de estudo de 1 a 4, para a 129 realização dos ensaios com o cloreto férrico.

Tabela 14 Valores de $\mathrm{pH}$ de coagulação e dosagens de cloreto férrico comercial 144 das regiões de cor aparente da água filtrata $\leq 5,0 \mathrm{uH}$ e turbidez. $\leq 0,5$ uT.

Tabela $15 \mathrm{pH}$ de coagulação e dosagens dos coagulantes: sulfato de alumínio e 146 cloreto férrico nas regiões de cor aparente da água filtrada menor ou igual a $5,0 \mathrm{uH}$. 


\section{LISTA DE ABREVIATURAS}

SH - Substâncis húmicas

SHA - Substâncias húmicas aquáticas

Da - Dalton (Dalton: unidade de massa atômica, igual a 1,66 x 10-24 gramas)

AH - Ácidos húmicos

AF - Ácidos fúlvicos

COT - Carbono orgânico total

COD - Carbono orgânico dissolvido

MON - Matéria orgânica natural

MOD - Matéria orgânica dissolvida

MOP - Matéria orgânica particulada

ETA - Estação de tratamento de água

ETAs - Estações de tratamento de água

PZ - Potencial zeta

DCE - Dupla camada elétrica

RMN - Espectroscopia de Ressonância magnética nuclear

UVIVIS - Espectroscopia de Ultravioleta/ Visível

IV - Infravermelho

UF - Ultrafiltração

uH - Unidade de Hazen (mg Pt-Co/L)

UT - Unidade de turbidez

ABEMA - Associação Brasileira de Entidades do Meio Ambiente

IBGE - Instituto Brasileiro de Geográfica e Estatística

CETESB - Companhia de Tecnologia de Saneamento da Secretária do Estado do Meio Ambiente de São Paulo 


\section{RESUMO}

Existem muitos mananciais usados como fonte de abastecimento de água que apresentam cor verdadeira relativamente alta, devido à presença de substâncias húmicas aquáticas (SHA). Para este estudo coletou-se água no Rio Itapanhaú Bertioga/SP, a qual apresentou cor verdadeira na ordem de $300 \mathrm{uH}$. Para a extração das SHA empregou-se a resina XAD 8. Os extratos de SHA foram filtrados em membrana com poros de $0,45 \mu \mathrm{m}$ e após utilizou-se a técnica de ultrafiltração (UF) para o fracionamento do material húmico em diferentes tamanhos moleculares aparentes $\left(F_{1}\right.$ : menor que $0,45 \mu \mathrm{m}, F_{2}$ : entre $100 \mathrm{kDa}$ e $0,45 \mu \mathrm{m}, F_{3}$ : entre 30 e 100 $\mathrm{kDa}, \mathrm{F}_{4}$ : entre 10 e $30 \mathrm{kDa}$ e $\mathrm{F}_{5}$ : entre 5 e $10 \mathrm{kDa}$ ). As frações foram caracterizadas por meio das técnicas de análise elementar, espectroscopia no ultravioleta/visível, infravermelho e ressonância magnética nuclear de ${ }^{13} \mathrm{C}\left(\mathrm{RMN}\right.$ de $\left.{ }^{13} \mathrm{C}\right)$. Os resultados mostraram que as frações $F_{3}, F_{4}$ e $F_{5}$ possuem maior conteúdo de carbonos alifáticos do que carbonos aromáticos e uma porcentagem relativamente alta de oxigênios ligados a grupamentos alquílicos e a ácidos carboxílicos. As frações $F_{1} e$ $\mathrm{F}_{2}$ apresentaram maior grau de condensação de grupamentos aromáticos. No caso dos espectros de RMN de ${ }^{13} \mathrm{C}$, não foi possível verificar diferenças significativas nas diferentes frações de SHA. Verificaram-se picos mais intensos na região de grupos carboxil e alifáticos e menos intenso na região dos aromáticos para todas as frações estudadas. Isso indica que nas SHA há maior conteúdo de grupamentos oxigenados e carbonos alifáticos que nas substâncias húmicas extraídas de turfa. As amostras de água de estudo foram preparadas com água de poço artesiano e com as frações: $F_{1}$ : menor que $0,45 \mu \mathrm{m}, F_{2}$ : entre $100 \mathrm{kDa}$ e $0,45 \mu \mathrm{m}$ e $F_{3}$ : entre 30 e $100 \mathrm{kDa}$ e $F_{4}$ : menor que $30 \mathrm{kDa}$, com cor verdadeira aproximadamente de $100 \mathrm{uH}$ e turbidez em torno de 5,0 uT. Para avaliar a influência dos diferentes tamanhos moleculares aparentes das SHA na eficiência da coagulação foram feitos ensaios de filtração direta em equipamento estático (Jarteste). Os coagulantes empregados neste estudo foram os sulfatos de alumínio e cloreto férrico. Os diagramas de coagulação evidenciaram a influência do tamanho molecular aparente das SHA no processo de coagulação. Para as águas de estudo preparadas com as frações de menor tamanho molecular aparente $\left(F_{3}\right.$ e $\left.F_{4}{ }^{\prime}\right)$, foi necessário maior dosagem de coagulante para se obter remoção da cor aparente menor ou igual a 5,0 uH e mesmo assim, a remoção foi menor. A fração de menor tamanho molecular aparente $\left(F_{4}^{\prime}\right)$ apresentou maior porcentagem de ácidos fúlvicos, e estes apresentam maior quantidade de grupos com carga negativa. Por isso, há necessidade de maior dosagem de coagulante para que ocorra uma eficiente remoção de cor aparente.

Palavras-chave: substâncias húmicas aquáticas, tamanho molecular aparente, coagulação, remoção de cor 


\begin{abstract}
Water sources used to supply the public water system frequently have a relatively high true color intensity due to dissolved aquatic humic substances (AHS). In this study, water samples were collected from the Itapanhaú River (Bertioga, SP, Brazil), which exhibited a true color intensity in the order of 300 Hanzen units. XAD-8 resin was used to extract AHS. The AHS extract was filtered through a membrane with $0.45 \mu \mathrm{m}$ pores, giving fraction $F_{1}$, and this was separated by ultrafiltration into 4 apparent molecular size fractions of humic material: $F_{2}$ from $100 \mathrm{kDa}$ to $0.45 \mu \mathrm{m}, \mathrm{F}_{3}$ from 30 to $100 \mathrm{kDa}, \mathrm{F}_{4}$ from 10 to $30 \mathrm{kDa}$ and $F_{5}$ from 5 to $10 \mathrm{kDa}$. The fractions were characterized by elemental analysis and UV/Vis, infra-red (IR) and carbon 13 nuclear magnetic resonance $\left({ }^{13} \mathrm{C}-\mathrm{NMR}\right)$ spectroscopy. In general, the results showed that the smaller molecular size fractions $\left(F_{3}, F_{4}\right.$ and $\left.F_{5}\right)$ had a higher proportion of aliphatic than aromatic carbon atoms and a relatively high percentage of oxygen atoms bonded to alkyl groups and in carboxylic acids. Conversely, the apparently larger molecules (fractions $F_{1}$ and $F_{2}$ ) showed a higher content of aromatic groups. In the case of the ${ }^{13} \mathrm{C}-\mathrm{NMR}$ spectra, no significant differences could be detected among the fractions. There were stronger peaks in the carboxyl group and aliphatic carbon region and weaker peaks in the aromatic region, indicating that in the AHS as a whole, there is a greater content of oxygenated groups and aliphatic carbon atoms. Water from an artesian well was used to prepare experimental samples of the following molecular size fractions of AHS: $F_{1}<0.45 \mu \mathrm{m}, F_{2}$ from $100 \mathrm{kDa}$ to $0.45 \mu \mathrm{m}$ and $F_{3}$ : from $30 \mathrm{kDa}$ to $100 \mathrm{kDa}$ and $F_{4}{ }^{\prime}:<30 \mathrm{kDa}$, with true color intensity around 100 Hazen units and turbidity around 5.0 NTU. To assess the influence of the apparent molecular size on the efficiency of coagulation, jar test were carried out, using direct filtration. The coagulants employed were aluminum sulfate and ferric chloride. The coagulation diagrams obtained with these products revealed the effects of the molecular size of the AHS on the coagulation process. For the experimental samples, fractions $F_{3}$ e $F_{4}$, a greater dose of coagulant was needed to remove the apparent water color around 5.0 Hanzen units and, even then, the amount removed was smaller. $\mathrm{F}_{4}$ ' also had a higher proportion of fulvic acids, which exhibited a larger number of negatively-charged groups. For these reasons, a high dose of coagulant is necessary to achieve an efficient removal of apparent color.
\end{abstract}

Keywords: Aquatic humic substances, apparent molecular size, coagulation, color removal 


\section{INTRODUÇÃO}

A qualidade de vida da população depende diretamente de água tratada para seu consumo, o que se consegue por meio de estações de tratamento de água (ETAs). Nestas, empregam-se produtos químicos para o tratamento da água; dentre estes se têm os coagulantes que são necessários para a remoção da matéria orgânica e outras partículas coloidais. A matéria orgânica natural (MON) presente na água contêm substâncias com diferentes características, sendo formada por matéria orgânica dissolvida (MOD). A MOD é definida como a fração que atravessa a membrana com poros de $0,45 \mu \mathrm{m}$, e usualmente forma a maior parte da matéria orgânica presente nas águas naturais; a MON também é formada por matéria orgânica particulada (MOP), a qual é definida como o material retido na membrana com poros de $0,45 \mu \mathrm{m}$.

A maior parte do carbono orgânico presente em ambientes aquáticos está na forma de substâncias húmicas (SH), as quais são encontradas em solos, solos turfosos, sedimentos e águas naturais e podem ser classificadas como substâncias de coloração escura, de natureza heterogênea, elevada massa molar, estrutura complexa e indefinida. Essas substâncias são formadas pela degradação química e biológica de resíduos de vegetais e de animais e da atividade de síntese de microrganismos. As $\mathrm{SH}$ podem ser transportadas para as águas naturais por processos de lixiviação e/ou erosão, podendo também ser formadas diretamente no meio aquático por decomposição de plantas e organismos. As SH correspondem a cerca de $50-70 \%$ de toda a MON presente em águas.

As substâncias húmicas aquáticas (SHA) são classificadas como ácidos fúlvicos $(\mathrm{AF})$, ácidos húmicos $(\mathrm{AH})$ e humina, e elas apresentam caráter hidrofóbico 
e são as principais responsáveis pela cor das águas naturais. As SHA servem de substrato para o crescimento de microrganismos e de transporte de contaminantes orgânicos hidrofóbicos e inorgânicos, e aumentam a demanda de coagulantes e desinfetantes.

Em diversos mananciais usados como fonte de captação, a cor verdadeira é relativamente alta devido à presença de SHA e a turbidez é baixa. Devido a essas características, a maior parte das ETAs apresentam problemas de operação, pelo fato da tecnologia de tratamento empregada não se adequar à qualidade da água a ser tratada, requerendo o uso da pré-oxidação, principalmente para a redução de cor. A presença de SHA e o uso de cloro como oxidante no pré-tratamento e póstratamento de água leva à formação de subprodutos orgânicos halogenados, dentre eles, os trialometanos que podem causar sérios danos à saúde humana.

Geralmente, a concentração de SHA é medida por parâmetros indiretos tais como, cor verdadeira, absorbância a $254 \mathrm{~nm}$, entre outros, ou diretamente, pela concentração de carbono orgânico dissolvido (COD). Dessa forma, não se distingue os AH dos AF e, tampouco, o tamanho molecular dessas substâncias.

Águas que apresentam a mesma cor verdadeira poderão requerer condições de coagulação distintas devido aos diferentes tamanhos moleculares das SH presentes em águas naturais. No caso da otimização da coagulação visando à remoção da MOD, resulta uma dosagem de coagulante relativamente alta, além de em muitos casos, ser elevada a dosagem de alcalinizante ou de acidificante para ajustar o pH de coagulação. Isso provavelmente é devido à remoção de moléculas de SHA de tamanhos moleculares aparente variados, entre $10 \mathrm{Da}$ e $100 \mathrm{KDa}$.

Embora haja alguma similaridade entre as SH presentes no solo e na água, a diversidade no ambiente de formação e nos compostos de origem faz com que estas 
apresentem diferenças peculiares. As substâncias húmicas extraídas de turfa (SHT) apresentam predominância de $\mathrm{AH}$ com tamanho molecular aparente geralmente superior a $10 \mathrm{kDa}$ e as SHA são compostas por aproximadamente $80 \%$ de $\mathrm{AF}$ com tamanho molecular aparente menor que $10 \mathrm{kDa}$.

Nos últimos anos houve uma maior atenção para a remoção da MON de águas superficiais, a qual pode ser removida por vários processos, tais como: a coagulação, usualmente empregando sais de ferro e alumínio como coagulantes, utilização de membranas como, microfiltração, ultrafiltração, nanofiltração, osmose reversa, oxidação/biofiltração, resinas de troca iônica e carvão ativado.

O emprego de diferentes técnicas analíticas como análise elementar em relação aos elementos carbono, hidrogênio, nitrogênio e oxigênio, absorbância, ultrafiltração, ressonância magnética nuclear, infravermelho, entre outras, são de grande importância para o conhecimento das propriedades das SHA. Estas técnicas colaboram no entendimento da influência das diferentes características estruturais das SHA nas etapas envolvidas no tratamento de água, notadamente nesse estudo, na etapa de coagulação, a qual é geralmente considerada a etapa mais importante no tratamento de água para abastecimento público.

Nesse estudo o objetivo de estudar a influência das SHA no tratamento de água, especificamente durante a etapa de coagulação, é devido à dificuldade de remover essas substâncias nas ETAs, levando à necessidade da adição de maior quantidade de produtos químicos na água, e principalmente quando é usado o cloro durante a desinfecção da água, leva à formação de subprodutos halogenados, que são prejudiciais à saúde humana. Quando se utiliza o sulfato de alumínio como coagulante, em dosagens elevadas, a concentração de alumínio residual poderá estar acima do valor máximo permitido $\left(0,2 \mathrm{mg} \mathrm{L}^{-1}\right)$ pelo padrão de potabilidade 
(portaria de no 518 de 25 de março de 2004 do Ministério da Saúde). Entre esses problemas apresentados existem outros, como a difícil remoção de cor na água. Por isso, a coagulação é considerada uma das etapas mais importantes durante o tratamento de água. 


\section{REVISÃO BIBLIOGRÁFICA}

\subsection{Distribuição da água no mundo e no Brasil}

Somente na década de 1960 foi possível uma visão de que o Globo Terrestre deveria ser chamado de planeta água. A água ocupa $71 \%$ da superfície do planeta, desse total cerca de $97,5 \%$ constitui-se de água salgada de mares e oceanos e aproximadamente $2,5 \%$ de água doce do total, desta última porcentagem $68,9 \%$ formam calotas polares e geleiras, 29,9 \% estão armazenadas em fontes de águas subterrâneas (aqüíferos), restando apenas 0,3\% de água superficial presente nos rios e lagos e 0,9 \% outros reservatórios como, solo, atmosfera e organismos vivos (REBOUÇAS et al., 2002, p.8).

O Brasil detém aproximadamente $12 \%$ do volume total de água doce do mundo. Desse total, cerca de $80 \%$ está na Amazônia, região do País onde se encontra apenas $5 \%$ da população, sendo os $20 \%$ restante distribuídos desigualmente pelas outras regiões (REBOUÇAS et al., 2002, p.29).

\section{2 Água - meio ambiente - saúde}

As características das águas derivam dos ambientes naturais e antrópicos onde se originam, circulam ou ficam estocadas. Nas últimas décadas a humanidade se defrontou com uma série de problemas ambientais destacando-se a água, pois as demandas estão se tornando cada vez maiores, devido ao crescimento acelerado da população urbana e da industrialização. O surgimento de cidades sem planejamento, a ocupação desordenada de regiões de mananciais e margens de 
rios e principalmente a falta de saneamento básico, são algumas das causas da degradação da qualidade das águas.

Segundo a Associação Brasileira de Entidades do Meio Ambiente (ABEMA), cerca de $80 \%$ dos esgotos, tanto domésticos como industriais do Brasil, não recebem qualquer tipo de tratamento e são dispostos diretamente no mar, rios, lagos e mananciais. De acordo com a Pesquisa Nacional em Saneamento Básico realizada pelo Instituto Brasileiro de Geografia e Estatística (IBGE) em 2000, cerca $28 \%$ das residências urbanas nas grandes regiões do Brasil não é atendida por redes coletoras de esgoto ou fossas sépticas, ficando a maior porcentagem na Região Norte e Nordeste (cerca de 50\%). Isto contribui para a deterioração da água a ser usada como fonte de abastecimento.

Segundo a Companhia de Tecnologia de Saneamento da Secretária do Estado do Meio Ambiente de São Paulo (CETESB), a irrigação corresponde a 73\% do consumo de água, $21 \%$ são para a indústria e apenas $6 \%$ destina-se ao consumo doméstico. Um bilhão e 200 milhões de pessoas (35\% da população mundial) não têm acesso à água tratada e um bilhão e 800 milhões de pessoas $(43 \%$ da população mundial) não contam com serviços adequados de saneamento básico. Diante desses dados, temos a constatação de que dez milhões de pessoas morrem anualmente em decorrência de doenças intestinais transmitidas pela água.

Uma das principais conclusões da pesquisa feita pelo IBGE em 2000 é que apenas $77 \%$ da água consumida pela população brasileira é água tratada. A maioria dos prejuízos decorrentes da qualidade da água produzida nas ETAs está relacionada com a qualidade da água bruta, problema operacional e a escolha inadequada da tecnologia adotada no tratamento. Por isso, é de suma importância 
estudar formas de melhorias no tratamento de água, já que a qualidade de vida está diretamente relacionada com a qualidade da água.

\subsection{Substâncias húmicas}

\subsubsection{Considerações iniciais}

A matéria orgânica presente em solos, turfas, sedimentos e em águas naturais apresenta várias substâncias de diferentes naturezas, as quais se encontram em vários estágios de decomposição, resultantes da degradação química e biológica de resíduos vegetais e animais, e da atividade de síntese de microrganismos. O material originado da degradação resulta em dois grandes grupos. O primeiro, denominado de substâncias não-húmicas, apresenta natureza definida sendo composto por aminoácidos, carboidratos, proteínas, ácidos orgânicos, ceras e resinas de baixa massa molecular. O segundo é composto de substâncias húmicas (SH), que são classificadas como substâncias orgânicas biogênicas, polieletrolíticas com propriedades similares à de biocolóides, de coloração escura, de natureza heterogênea, elevada massa molecular, estrutura complexa e indefinida. (STEVENSON, 1982).

\subsubsection{Classificação das substâncias húmicas}

Os estudos das SH tiveram inicio no fim do século XVIII, com o trabalho pioneiro de Achard em 1786. Neste estudo, o autor dissolveu turfas em solvente alcalino e obteve uma solução escura que precipitava com adição de ácidos. A 
origem do termo "ácidos húmicos" já era comum no tempo de Berzelius em 1839, cuja definição mantém-se até hoje (STEVENSON, 1982).

Saussure ${ }^{1}$ (1804) apud Stevenson (1982) introduziu o termo húmus (derivado do latim, que quer dizer equivalente ao solo) para descrever o material orgânico de coloração escura originado do solo. O autor observou que o húmus era produto de resíduos vegetais, rico em carbono e pobre em hidrogênio e oxigênio.

Oden, em 1919, é reconhecido como o primeiro a usar o termo ácidos fúlvicos para descrever a solubilidade em meio ácido e básico. A classificação para as $\mathrm{SH}$, entretanto, foi modificada por Dutoit e Page (1930), quando substituíram o termo "humus coal" por humina e o termo humus por ácidos humicos (DENNETT, et al., 1995).

A classificação das SHA divide-se em AF, AH e humina de acordo com a solubilidade em diferentes condições de pH. Os AF são solúveis em meio alcalino e ácido; os AH são solúveis em meio alcalino e insolúvel em meio ácido $(\mathrm{pH}<2)$; humina é a fração insolúvel em qualquer intervalo de $\mathrm{pH}$. Dos $\mathrm{AH}$, pode ser extraído o ácido himatomelânico, que é a parte dos $\mathrm{AH}$ solúvel em álcool. Entretanto, os $\mathrm{AF}$ são remanescentes após separação dos $\mathrm{AH}$ por precipitação em meio ácido $(\mathrm{pH}<2)$ e, apresentam cor amarelo-claro e massa molar relativamente baixa em comparação com os AH (STEVENSON, 1982).

\subsubsection{Mecanismos propostos para a formação das substâncias húmicas}

O primeiro estudo com o objetivo de compreender a origem e a natureza química das SH foi feito por Sprengel em 1837. Maillard (1916) ${ }^{2}$ apud Malcolm

\footnotetext{
${ }^{1}$ SAUSSURE, T. Researches chemiques sur la vegetation. Paris, 1804.

${ }^{2}$ MAILLARD, L. C. Synthesis of humus-like substances by the interaction of amino acids and reducing sugars.
} 
(1990) propôs que a formação das SH ocorre durante o processo de decomposição dos resíduos vegetais. A partir daí, surgiu o conceito de humificação, também considerando a formação de SH devido à atividade de microrganismos.

A chamada teoria clássica de Waksmam (1938) propõe que as SH são como ligninas modificadas, mas a maioria dos pesquisadores acredita em um mecanismo relacionado com a formação de quinonas. Malcolm (1990) afirma que a lignina não é o principal precursor das SH de solo e também que há grandes diferenças estruturais entre as $\mathrm{SH}$ de diferentes ambientes como, solos, rios e mar. Apesar dos vários estudos feitos pelos pesquisadores, pouco se sabe sobre a estrutura química dessas complexas substâncias.

A bioquímica de formação das $\mathrm{SH}$ atualmente é pouca compreendida, apesar de existir vários estudos na área, dos quais se destacam Kononova (1966) e Stevenson (1982). A Figura 1 apresenta as quatro vias principais de formação das SH durante a decomposição de resíduos animais e/ou vegetais no solo.

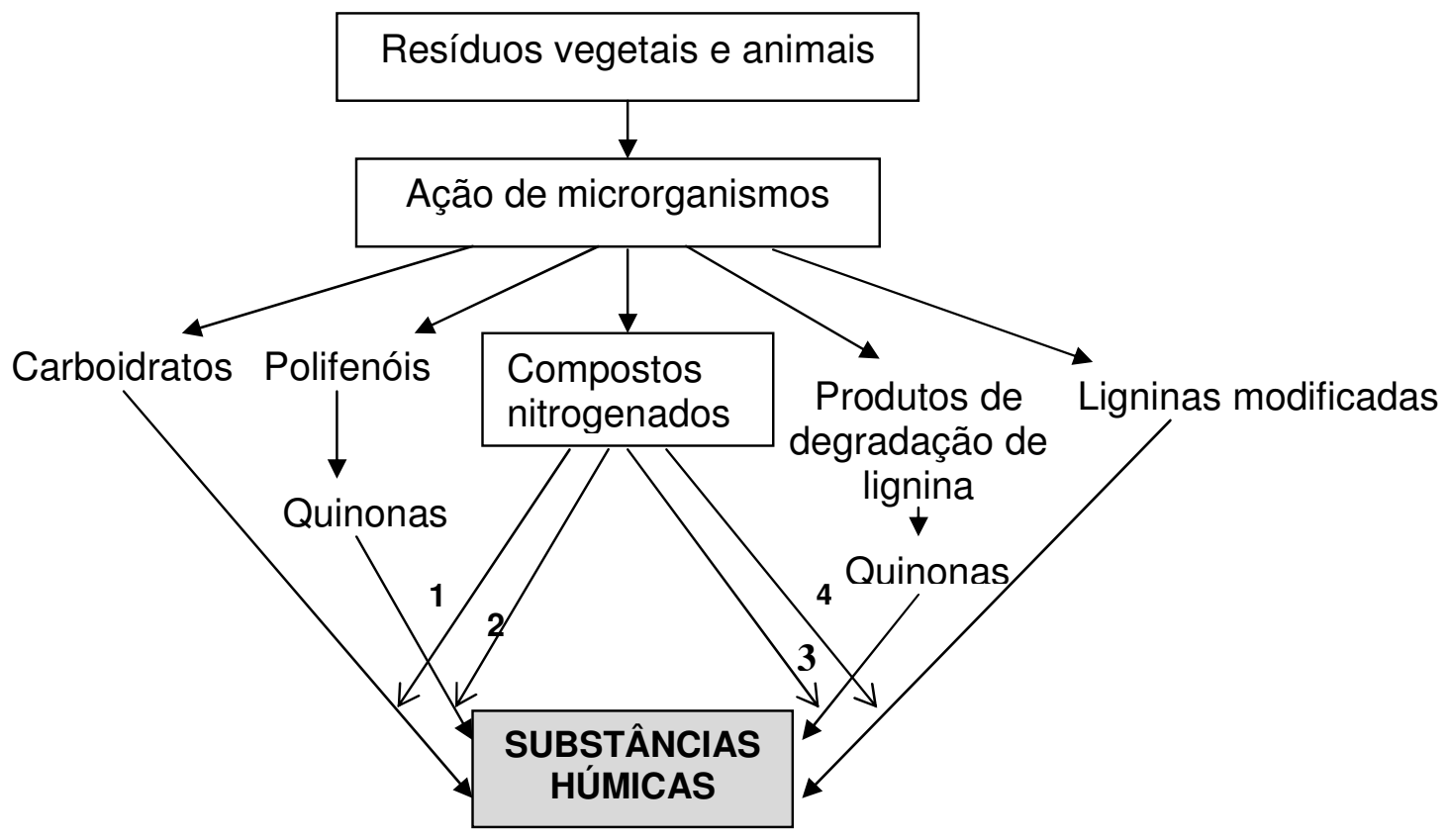

Figura 1 - Mecanismos de formação das substâncias húmicas (STEVENSON, 1994). 
O principal processo para a formação das SH é a oxidação de substratos hidrolisados monoméricos formando polímeros macromoleculares. O mecanismo 1 (Figura 1) é talvez a teoria mais antiga proposta por Maillard em 1916 apud Malcolm (1990), que propõe a formação das SH a partir da polimerização não enzimática por condensação entre aminoácidos e açúcares não-redutores formados como subprodutos da atividade microbiana.

As vias 2 e 3 (Figura 1) são bastante semelhantes, diferenciando-se apenas na fonte de polifenóis, onde na via 2, os polifenóis originam-se de fontes de carbono não-lignínicas ou não-sintetizadas por microrganismos específicos. Na via 3 a fonte de polifenóis é a partir da lignina. Os aldeídos e ácidos fenólicos são formados a partir da degradação parcial do biopolímero, podendo ocorrer recombinações entre si ou com outras moléculas orgânicas, convertendo-se em quinonas. Essas quinonas poderiam reagir e se condensar com a amônia, aminoácidos e proteínas, originando assim as $\mathrm{SH}$.

$\mathrm{Na}$ década de 20 acreditava-se que as $\mathrm{SH}$ seriam derivadas essencialmente de ligninas modificadas. Os mecanismos adaptados por Stevenson (1994) da condensação polimérica de polifenóis e quinonas têm sido os mais aceitos por pesquisadores e pela International Humic Substances Society (IHSS).

\subsubsection{Estruturas das substâncias húmicas}

A estrutura molecular das $\mathrm{SH}$ tem sido investigada ao longo dos anos, e essas pesquisas sugerem várias propostas estruturais para as $\mathrm{SH}$, mas de acordo com Stevenson (1985), nenhuma parece ser satisfatória, permanecendo ainda hoje indefinida. A maior dificuldade encontrada na definição de um modelo para as SH é 
devido à heterogeneidade e complexidade de suas estruturas, principalmente pela falta de uma identidade estrutural genérica, a qual é influenciada pela natureza e pelo mecanismo de decomposição (ROCHA; ROSA, 2003).

Através de estudos de ressonância magnética nuclear (RMN), Schulten e Schnitzer (1993) propuseram um modelo para $\mathrm{AH}$, e neste podem ser observados vários grupos carboxílicos, fenólicos, alcoólicos e grupos nitrogenados como aminas e nitrilas, além de grandes cadeias alifáticas. Os AH e AF são compostos similares, porém, há algumas diferenças entre eles. Os AH possuem um conteúdo maior de carbonos aromáticos, estrutura mais condensada, maior massa molar e menor teor de oxigênio que o AF. Nas Figuras $2 a$ e $2 b$ são apresentadas, respectivamente, as estruturas moleculares dos $\mathrm{AH}$ e AF.

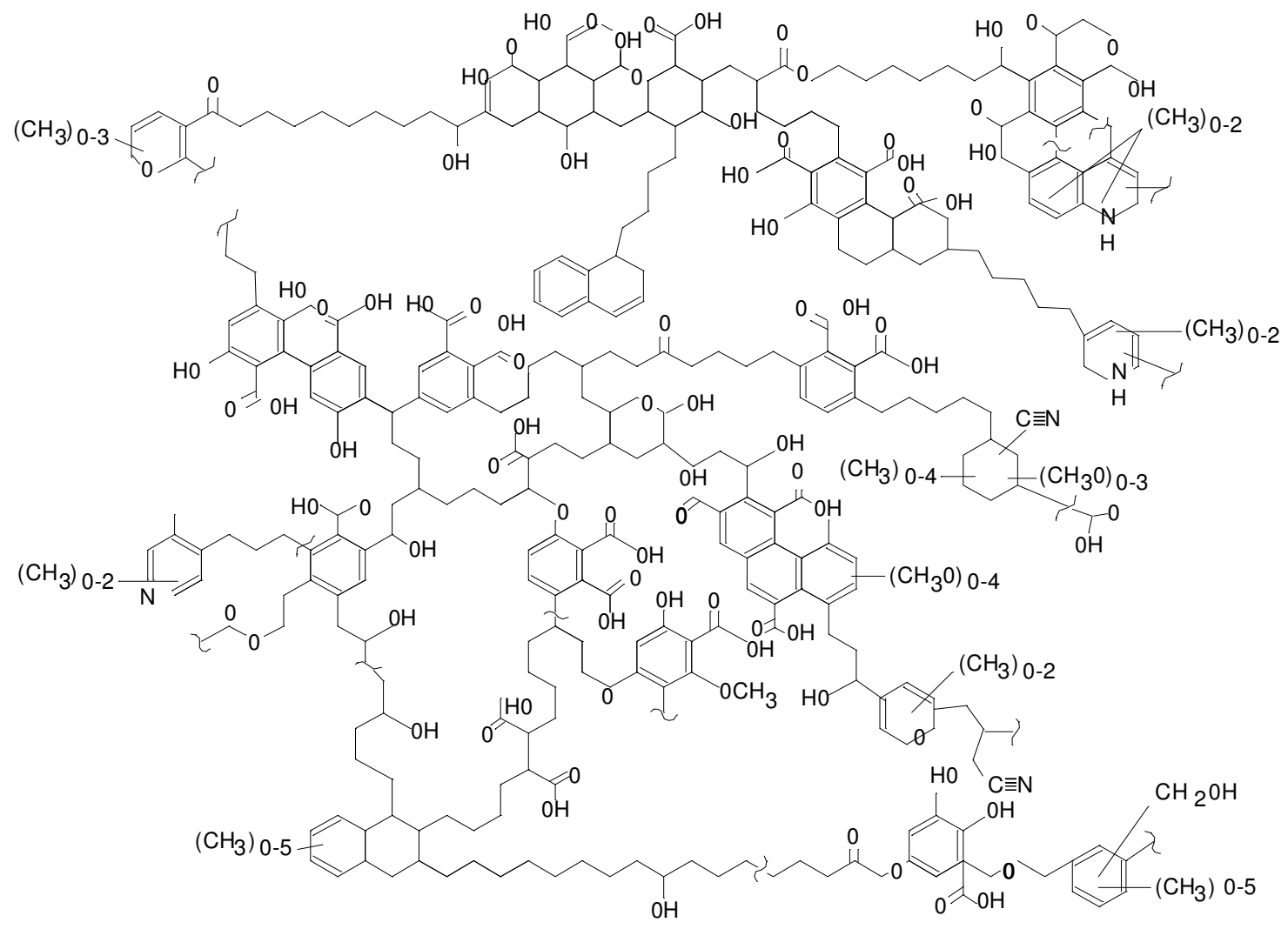

Figura 2 a - Estrutura proposta para os AH (SCHULTEN; SCHNITZER, 1993). 


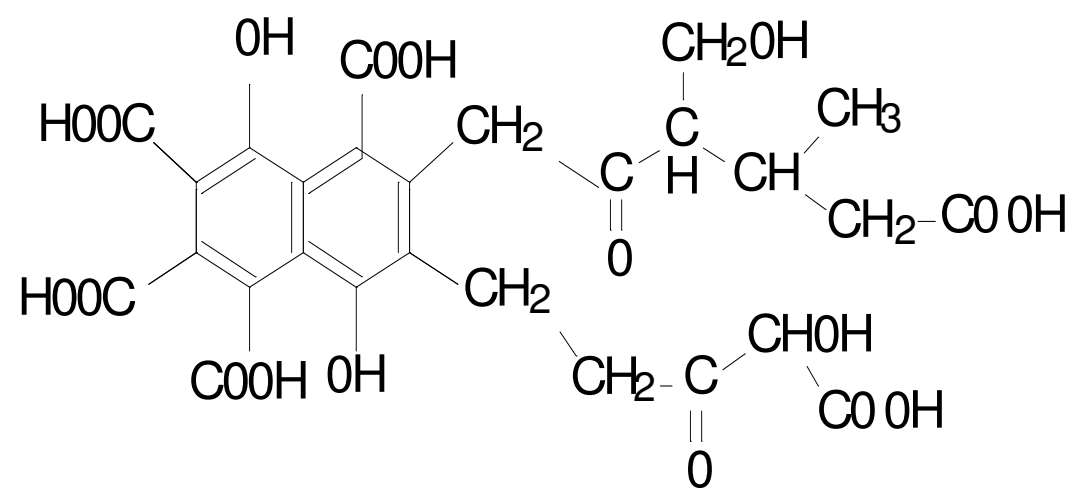

Figura 2b - Estrutura proposta para os AF (SCHULTEN; SCHNITZER, 1993).

Atualmente dois modelos são propostos para explicar as características das $\mathrm{SH}$, entre eles, o modelo macromolecular, no qual as variações conformacionais das SH são similares aos modelos propostos para macromoléculas biológicas, como proteínas, polissacarídeos, ácidos nucléicos e ligninas (Figura 3a) (SWIFT, 1989; 1999). As estruturas dependem da concentração das moléculas húmicas (CHEN; SCHNITZER, 1976), do pH (SENESI et al., 1996) e da concentração iônica do meio (GHOSH; SCHNITZER, 1980; SCHNITZER, 1991). Além dessas características, Schulten e Schnitzer (1995) propõem a existência de "vazios" de diferentes tamanhos, podendo ser hidrofóbicos ou hidrofílicos dentro das moléculas (Figura 3b). Wandruszka (1998) definiu a estrutura das SH como uma estrutura pseudomicelar de natureza polimérica. 


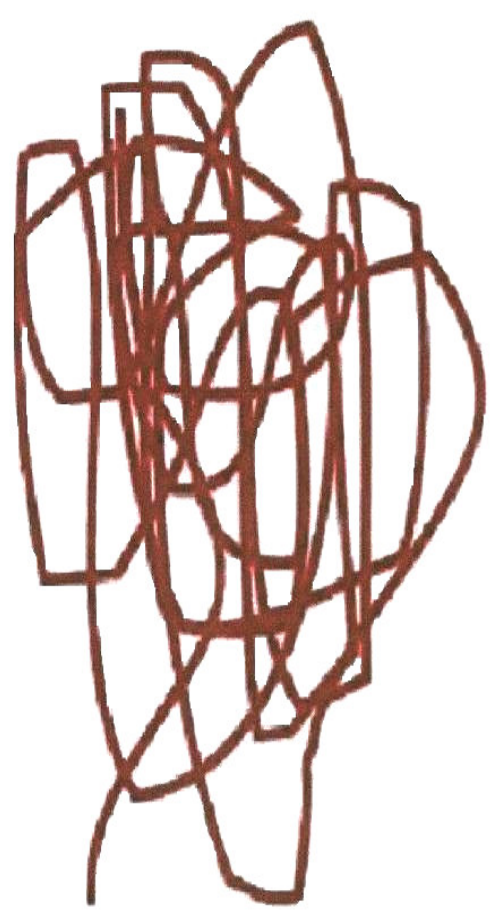

(a)

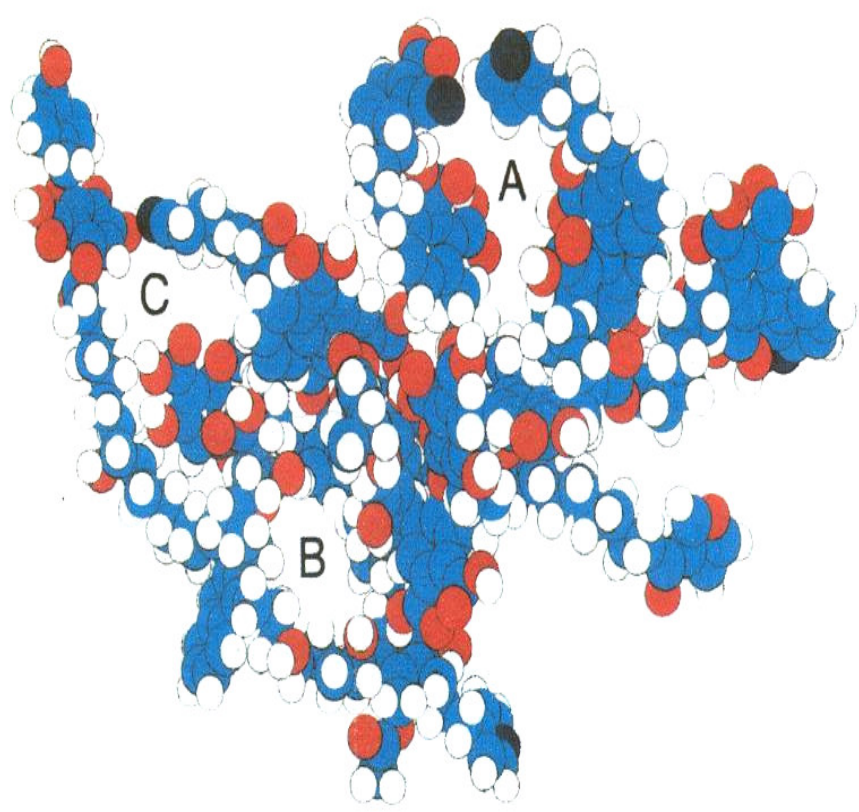

(b)

Figura 3 - Modelos conceituais propostos para a teoria macromolecular. (a) moléculas das substâncias húmicas aleatoriamente enoveladas (SWIFT, 1989). (b) ácido húmico proposto por Schulten e Schnitzer (1995). - carbono; - oxigênio; $\bigcirc$ - hidrogênio, $\bigcirc$ - nitrogênio. As letras A, B e C indicam os espaços "vazios" na molécula capaz de interagir com outros compostos.

O modelo proposto por Piccolo (2001) é chamado de supramolecular. Essa teoria pode ser interpretada como sendo as $\mathrm{SH}$ formadas por pequenas e heterogêneas moléculas de várias origens, auto-organizadas em conformações supramoleculares, o que explicaria o grande tamanho molecular aparente das $\mathrm{SH}$.

De acordo com esse modelo, os AF seriam formados por pequenas moléculas hidrofílicas que permaneceriam dispersas em solução pela repulsão das cargas negativas originadas da dissociação da grande quantidade de grupos ácidos presentes na sua estrutura. As micelas de $\mathrm{AH}$, por outro lado, são constituídas por 
associações de estruturas predominantemente hidrofóbicas, e são estabilizados por ligações fracas, tais como ligações de hidrogênio e/ou interações hidrofóbicas. Estes por apresentarem menor quantidade de grupos funcionais ácidos, poderiam aproximar-se o suficiente para formar agregados de elevada massa molecular, aumentando gradualmente seu tamanho como o decréscimo do $\mathrm{pH}$, até a sua precipitação.

Diallo et al. (2003) utilizando dados experimentais e métodos computacionais, excluíram os modelos nos quais são sugeridos que as SH sejam macromoléculas com alta massa molecular ou mistura de compostos orgânicos complexos e heterogêneos e observaram que as estruturas existentes possuem as características necessárias para formar supramoléculas. Entretanto, os autores não obtiveram modelo de isômero em três dimensões (3D) definitivo para um dado $\mathrm{AH}$. Eles propuseram alguns isômeros prováveis, os quais são apresentados na Figura 4. 


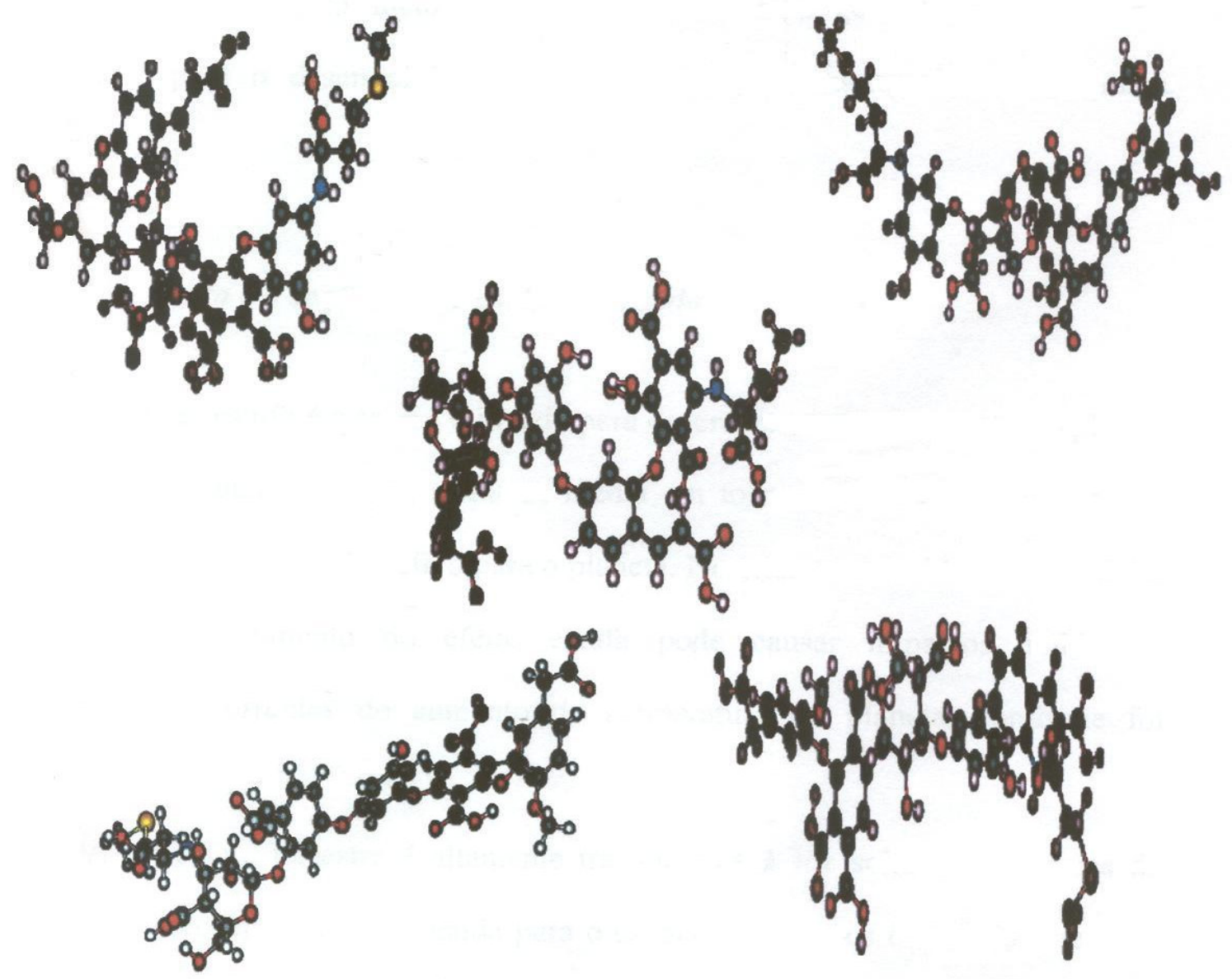

Figura 4 - Modelos estruturais de isômeros para um dado ácido húmico de solo em 3D propostos por Diallo et al. (2003). Átomos de carbono estão em preto, átomos de oxigênio em azul, átomos de enxofre em amarelo e os átomos restantes são de hidrogênio.

Mesmo após vários anos de pesquisa, ainda não foi obtido um modelo que explique consistentemente a estrutura das $\mathrm{SH}$. Por isso, estudos desenvolvendo metodologias de análise e/ou obtendo resultados que contribuem para o desenvolvimento de um modelo são de grande importância. 


\subsubsection{Importância das substâncias húmicas no meio ambiente}

As SH são ambientalmente importantes por várias razões: influenciam no transporte, no acúmulo e na concentração de espécies metálicas no ambiente; formam complexos com metais, reduzindo a toxicidade de certos metais como o cobre $\left(\mathrm{Cu}^{2+}\right)$ e alumínio $\left(\mathrm{Al}^{3+}\right)$ para organismos aquáticos e solos. Dependendo das condições do meio, as SH atuam como redutoras de algumas espécies metálicas para a atmosfera como, por exemplo, o íon mercúrio, $\mathrm{Hg}$ (II) reduzindo para $\mathrm{Hg}(0)$ (Rocha, 2000a). As SH interagem com compostos orgânicos antrópicos através da adsorção, solubilização, hidrólise, processos microbiológicos e fotossensibilizantes. Além da relevância ambiental, as características físicas e químicas das SH de solos contribuem para a retenção do calor no solo, devido a sua coloração escura, estimulando dessa maneira a germinação de sementes e o desenvolvimento de raízes. Favorecem a aeração do solo, devido aos agregados entre $\mathrm{SH}$ e argilas, possuem alta capacidade de retenção de água; aumentam a troca catiônica do solo, fornecem micronutrientes para o crescimento das plantas; evitam a erosão e ajudam a manter a umidade do solo e tem função tamponante em amplos intervalos de $\mathrm{pH}$ ajudando a manter as condições reacionais do solo (ROCHA; ROSA, 2003, p. 37 e 38).

\subsubsection{Substâncias húmicas aquáticas}

As características e propriedades das $\mathrm{SH}$ presentes no solo vêm sendo estudadas por pesquisadores há cerca de duzentos anos (STEVENSON, 1982). Entretanto, o interesse pelo estudo das SHA aumentou nos últimos trinta anos, 
principalmente pela razão da origem da coloração de determinados tipos de águas devido à presença das SHA (THURMAN, 1985a).

A água pode conter substâncias de diferentes origens, concentrações e características. Sua formação pode se dar no ambiente aquático (autóctone) e/ou a partir de plantas terrestres (alóctone). As $\mathrm{SH}$ encontradas em solos e sedimentos são transportadas para as águas naturais por processos de lixiviação e/ou erosão, as quais são formadas pela decomposição da biomassa terrestre, podendo também ser formadas diretamente no meio aquático por decomposição de plantas e de microrganismos aquáticos. Cada sistema aquático tem suas características físicas, químicas e biológicas próprias, como: cor, turbidez, temperatura, $\mathrm{pH}$, alcalinidade, condutividade elétrica, salinidade, nutrientes, algas e microrganismos entre outros parâmetros. Todos esses parâmetros afetam a produção e degradação das SHA. Portanto, o tipo de água (rio, lagos ou mar) e as condições climáticas são fatores determinantes na formação e processos de humificação (THURMAN, 1985a).

A MON pode ser separada em matéria orgânica dissolvida (MOD), matéria orgânica particulada e matéria orgânica coloidal, usando filtros com diferentes tamanhos de poros. A MOD é operacionalmente definida como a fração que atravessa o filtro com poro de $0,45 \mu \mathrm{m}$, formando a maior parte da matéria orgânica em águas naturais (aproximadamente $80 \%$ ). A MOD presente em águas naturais possui vários compostos orgânicos, sendo que a maior parte do carbono orgânico presente em ambientes aquáticos está na forma de $\mathrm{SH}$, as quais correspondem a cerca de $50 \%$ da MOD com tamanho molecular aparente entre $500 \mathrm{Da}$ a $10 \mathrm{kDa}$ e o restante são compostos orgânicos identificáveis que são as substâncias nãohúmicas, tais como: carboidratos, gorduras e hidrocarbonetos (THURMAN et al., 1982). 
Thurman (1985) definiu que a MOP é o carbono orgânico retido na membrana de 0,45 $\mu \mathrm{m}$ presente em zooplancton, algas e sólidos da matéria orgânica, correspondendo a aproximadamente $17 \%$ da MON. A MOP é usualmente removida pelos métodos convencionais de tratamento de água, como a coagulação, filtração e ajuste do $\mathrm{pH}$ (EDZWALD, 1993).

Thurman e Malcolm (1981) definiram as SHA como a porção não especifica, amorfa, constituída de MOD em pH 2 e adsorvente em coluna de resina XAD 8, nãoiônica. A matéria orgânica retida pela resina é eluída com solução de $\mathrm{NaOH} 0,1 \mathrm{~mol}$ $\mathrm{L}^{-1}$ obtendo assim o extrato de SHA. As SHA correspondem a um terço até à metade do MOD presente na água e são constituídas em sua maior parte por ácidos hidrofóbicos.

A fração extraída de $\mathrm{COD}$ em uma amostra depende do tipo de resina utilizada, da quantidade de amostra e do eluente utilizado. Conseqüentemente, amostras extraídas por métodos diferentes não são comparáveis (SARGENTINI,1999).

Embora haja alguma similaridade entre as $\mathrm{SH}$ presentes no solo e na água, a diversidade no ambiente de formação e nos compostos de origem as faz apresentarem diferenças peculiares (ROCHA; ROSA, 2003). Ao contrário das SHT, que apresentam predominância de AH com tamanho molecular aparente geralmente superior a $10 \mathrm{kDa}$, as SHA contêm quantidade apreciável de AF com tamanho molecular aparente menor que $5 \mathrm{kDa}$. No geral, as SHA possuem elevado tamanho molecular aparente, podendo variar desde $200 \mathrm{Da}$ até cerca de $100 \mathrm{kDa}$, estando os AF entre 200 e 2000 Da, enquanto que dos AH é maior que 2000 Da (DI BENARDO; DANTAS, 2005). Thurman et al. (1982) sugerem que esta variação de tamanho molecular aparente seja devido à fonte das $\mathrm{SH}$, à metodologia analítica usada e à 
agregação das $\mathrm{SH}$. Com isso, é necessário fracioná-las em estruturas menores para facilitar o entendimento das suas propriedades e características estruturais, as quais influenciam nos processos de tratamento de água para abastecimento.

\subsubsection{Métodos de extração das substâncias húmicas aquáticas}

Na década de 70, vários adsorventes inorgânicos foram utilizados para extração das SHA, tais como: carbono ativado, alumina, sílica gel, carbonato de cálcio etc. Porém, a taxa de recuperação é baixa devido à dificuldade de eluição e possíveis alterações químicas das $\mathrm{SH}$. O uso de adsorventes orgânicos como, nylon, poliamidas e poliestirenos têm-se mostrado mais eficientes, com altas taxas de recuperação, porém podem causar algumas alterações químicas na amostra.

Vários métodos de extração de SHA são empregados, sendo os principais: precipitação, ultrafiltração, extração por solvente, liofilização e adsorção (AIKEN, 1985; BURBA et al., 1995; ASTER et al., 1996). A Tabela 1 apresenta alguns métodos de extração mais utilizados e suas vantagens e desvantagens. 
Tabela 1 - Métodos de extração de SHA mais utilizados (ROCHA; ROSA, 2003; CHOW et al., 2005).

\begin{tabular}{|c|c|c|}
\hline MÉTODO & VANTAGEM & DESVANTAGEM \\
\hline Liofilização & $\begin{array}{l}\text {-Método brando; } \\
\text { - Alto fator de } \\
\text { concentração. }\end{array}$ & $\begin{array}{l}\text { - Solutos são concentrados, menos os } \\
\text { voláteis. }\end{array}$ \\
\hline Precipitação & $\begin{array}{l}\text { - Eficaz para águas com } \\
\text { alto teor de COD. }\end{array}$ & $\begin{array}{l}\text { - Ineficiente para grandes volumes de } \\
\text { amostra. }\end{array}$ \\
\hline Ultrafiltração & $\begin{array}{l}\text { - Fracionamento dos } \\
\text { solutos por tamanho } \\
\text { molecular; } \\
\text { - Grandes volumes de } \\
\text { amostra. }\end{array}$ & $\begin{array}{l}\text { - Interação com a membrana; } \\
\text { - Entupimento da membrana. }\end{array}$ \\
\hline $\begin{array}{l}\text { Extração com } \\
\text { solventes }\end{array}$ & $\begin{array}{l}\text { - Exclusão de sais } \\
\text { inorgânicos. }\end{array}$ & $\begin{array}{l}\text { - Método lento; } \\
\text { - Interações irreversíveis } \\
\text { amostra/solvente. }\end{array}$ \\
\hline $\begin{array}{l}\text { Resinas XAD } \\
\text { (adsorção) }\end{array}$ & $\begin{array}{l}\text { - Alto fator de } \\
\text { concentração; } \\
\text { - Maior capacidade de } \\
\text { sorção; } \\
\text { - Fácil eluição. }\end{array}$ & $\begin{array}{l}\text { - Uso de ácidos e bases fortes alteram } \\
\text { levemente as características químicas } \\
\text { da MOD, podendo ser irreversíveis; } \\
\text { - Aumenta a polaridade da MOD; } \\
\text { - Degradação oxidativa; } \\
\text { - Contaminações da amostra } \\
\text { proveniente da resina; } \\
\text { - Necessário grande volume de } \\
\text { amostra de água bruta. }\end{array}$ \\
\hline
\end{tabular}

As resinas a base de estireno de polivinilbenzeno (XAD 1, XAD 2 e XAD 4), apresentam menor facilidade de eluição das substâncias húmicas que as resinas a base de éster acrílico (XAD 7 e XAD 8). Essas são as mais hidrofílicas da série e têm maior capacidade adsorvente. As resinas XAD 1 e XAD 2 são mais utilizadas na extração de SH presentes em águas marinhas. As resinas macroporosas de éster 
acrílico XAD 7 e XAD 8 são mais utilizadas para a extração de SH de águas superficiais. Essas resinas apresentam área superficial elevada e em geral, a adsorção dos ácidos orgânicos é determinada pela solubilidade do soluto, pH da solução e a hidrofobicidade. Em baixos valores de $\mathrm{pH}$ os ácidos fracos são protonados e adsorvidos na resina; em pH elevados, os ácidos são ionizados e a desorção é favorecida. Diferenças no tamanho dos poros, área superficial e composição química da resina levam a diferente resultados para um mesmo soluto (AIKEN, 1988).

A extração das SHA utilizando o método cromatográfico em coluna empacotada com resina XAD não-iônicas macroporosas de éster acrílico é atualmente recomendado pela International Humic Substances Society (IHSS).

Chow et al. (2005) comprovaram que a MOD isolada por resina XAD foi menos reativa na formação dos trialometanos do que a MOD presente em fontes de águas naturais. Isso ocorre porque durante o processo de extração as SHA podem sofrer alterações na estrutura química, principalmente devido ao uso de ácidos e bases fortes. Dentre as alterações, podem ocorrer reações de hidrólise de éster e aumento da polaridade das $\mathrm{SH}$, que é indicativo da diminuição da absorbância a 254 $\mathrm{nm}$.

Os problemas de transformação química e degradação oxidativa na matriz podem ser minimizados fazendo a separação sob atmosfera inerte e reduzindo o tempo de permanência da SHA no meio alcalino. (ROCHA; ROSA, 2003).

Chow et al. (2005) apresentaram uma revisão da literatura a respeito do fracionamento das SHA utilizando as resinas XAD 4 e XAD 8. A resina XAD 8 adsorve os ácidos hidrofóbicos da MOD (fração húmica) e os ácidos transfílicos (fração não-húmica) a pH 2,0, e são eluídos com solução de hidróxido de sódio 
( $\mathrm{NaOH}$ ) a pH 13 (AlKEN et al., 1992). As frações hidrofílicas (fração não-húmica) não são adsorvidas na resina XAD 8 (CROUE et al., 2000; LEENHEER; CROUE, 2003). As frações hidrofóbicas neutras e transfílicas neutras são adsorvidas nas resinas XAD 8 e XAD 4, mas não são desorvidas durante a eluição com $\mathrm{NaOH}$, mas podem ser extraídas por solventes orgânicos como a acetonitrila (AIKEN et al., 1992).

Os ácidos hidrofóbicos contêm grupos carboxílicos alifáticos, ácidos aromáticos e fenólicos. Os ácidos transfílicos contêm menor caráter aromático, mas possuem elevado conteúdo de oxigênio e nitrogênio. São compostos por ácidos fortes, ácidos orgânicos polifuncionais e ácidos alifáticos (AIKEN et al., 1992). Os ácidos transfílicos provavelmente são originados tanto por processos autóctones quanto pela degradação de fitoplâncton e microrganismos. As frações hidrofóbicas neutras são formadas por hidrocarbonetos alifáticos e polímeros amorfos, são relativamente estáveis e não-reativas (CROUE et al., 2000).

Thurman (1985), Perdue e Ritchie (2004) indicaram que as frações hidrofóbicas representam aproximadamente $50 \%$ da MOD presentes em águas naturais.

\subsubsection{Fracionamento das substâncias húmicas aquáticas}

Existem vários métodos para a determinação da massa molar e distribuições do tamanho molecular aparente das SH. Algumas metodologias foram desenvolvidas, como a utilização de unidades de ultrafiltração (UF) com fluxo tangencial (BURBA et al., 1995), diferença de solubilidade (ultracentrifugação) (STEVENSON, 1982b; ROSA, et al., 2000), extração com diferentes solventes 
orgânicos (POST; KLAMBERG, 1992), cromatografia de exclusão com base no tamanho molecular (PICCOLO, et al., 1996), eletroforese (DUXBURY, 1989), cromatografia de exclusão com base no tamanho molecular e alta pressão (PICCOLO; CONTE, 1999), osmose reversa (FRIMMEL, 1992), cromatografia com afinidade por metais (KUCKUK; BURBA, 2000 apud ROCHA; ROSA, 2003) e medidas das propriedades coligativas, como pressão osmótica e abaixamento da temperatura de congelamento (STEVENSON, 1982; HAYES et al., 1989; PEURAVUORI et al., 1997).

A UF é uma técnica relativamente recente utilizada para o fracionamento das SHT ou SHA, em razão da possibilidade de minimização de alterações químicas nas SH (BURBA et al., 1998; ROCHA et al., 2000). O fracionamento das SHA em diferentes tamanhos moleculares aparentes por UF é, em princípio, um método mais simples para estudar essa complexa mistura de macromoléculas, utilizando uma série de membranas poliméricas com diâmetros de poros de alguns nanômetros.

Unidades de UF com fluxo tangencial permitem uma filtração relativamente rápida devido ao reduzido processo de obstrução dos poros, pois os compostos acumulados na superfície da membrana são deslocados pelo forte fluxo cruzado.

Em função da distribuição dos diferentes tamanhos moleculares das SH pode ser feita a caracterização de importantes propriedades físicas e químicas das $\mathrm{SH}$, tais como: solubilidade, comportamento de adsorção, acidez, capacidade complexante com íons metálicos, distribuição de grupos funcionais e estruturais entre outras. Do ponto de vista operacional, têm o inconveniente de fornecer um volume de frações relativamente pequeno, dificultando ou até mesmo impedindo maior número de caracterizações de uma mesma amostra (ROCHA et al., 2000). 
Burba et al. (1998) apresentaram uma revisão com 75 artigos a respeito do fracionamento das SHA em diferentes tamanhos moleculares utilizando a UF. Os autores apresentam algumas limitações da técnica, como a grande dependência da qualidade das membranas (tamanho do poro e calibração); no caso do aumento da concentração de SH pode haver polarização ou coagulação do material na superfície da membrana e isso falsifica os resultados; sorção das moléculas de SH na superfície polimérica da membrana; o fracionamento através de membranas com tamanhos menores que $5 \mathrm{kDa}$ pode ser muito lento.

Burba et al. (1995) mostraram os melhores parâmetros para o ultrafracionamento de $\mathrm{SH}$ por meio de membranas polietersulfônicas. Os autores concluíram que para um fracionamento eficiente das $\mathrm{SH}$, estas deveriam possuir concentração aproximadamente de $1 \mathrm{mg} \mathrm{L}^{-1}$ e estar em pH sempre acima de 4,0. Burba et al. (2001) determinaram através da UF as constantes de estabilidade de frações de SHA complexadas com zinco e cobre, mostrando que a estabilidade é maior para tamanho molecular acima de $105 \mathrm{kDa}$. Frimmel et al. (2000), utilizando cromatografia de exclusão por tamanho e cromatografia líquida com detecção de carbono orgânico dissolvido, relataram que as frações de SH são estáveis com o decorrer do tempo. Os autores não observaram mudanças significativas no material durante o período de cinco semanas após o fracionamento, sugerindo assim elevada estabilidade das frações.

Rocha et al. (1999) verificaram através da UF a distribuição de metais em relação aos diferentes tamanhos moleculares aparentes das SHA extraídas do Rio Negro. Concluíram que os metais manganês e cádmio estavam preferencialmente ligados a frações de SHA com maior tamanho molecular aparente entre $10 \mathrm{kDa}$ e 100 kDa. Os autores fizeram o estudo de caracterização das frações de SHA. 
Romão (2003) constatou a eficácia do procedimento de UF com fluxo tangencial e membrana polietersulfônica na compreensão da interação entre a SHT e SHA com cobre $\left(\mathrm{Cu}^{2+}\right)$. A autora verificou que os valores de capacidade de complexação e constantes de estabilidade condicional (K) foram maiores para as SHT em relação às $\mathrm{SHA}$, indicando assim que os procedimentos utilizados não modificaram significativamente as características complexantes originais das amostras.

A nomenclatura para as frações de SH ainda não é bem definida, alguns pesquisadores se referem à massa molecular (CAMPOS, et al., 2004; RATNAWEERA, et al.; 1999), tamanho molecular (BURBA et al., 1998; ROCHA; ROSA, 2003) e outros ainda a tamanho molecular aparente ou massa molecular aparente (AMY; HER, 2004; CARVALHO et al., 2004; MURRAY; PERSONS 2004a, 2004b; CAMPOS et al., 2007).

\subsubsection{Caracterização das substâncias húmicas}

A extração das $\mathrm{SH}$ é de grande importância para se obterem resultados relevantes de caracterização, pois nessa etapa podem ocorrer alterações estruturais nas SH. Como conseqüência, pode haver modificação nas propriedades originais, provavelmente em razão da grande variação do pH durante o processo de extração, na qual inicialmente a água é percolada a pH 2,0 e depois a eluição é feita a pH $13,0$.

Várias técnicas espectroscópicas são utilizadas para caracterizar as $\mathrm{SH}$, como: RMN, UV/VIS, IV, espectroscopia de ressonância paramagnética eletrônica e fluorescência (ROCHA; ROSA, 2003, p.58). 


\subsubsection{Composição elementar das substâncias húmicas}

Os analisadores elementares são baseados na oxidação da amostra em alta temperatura, nos quais os gases resultantes são separados por uma coluna cromatográfica, geralmente com detector de condutividade térmica (SKOOG et al., 2002).

Steelink (1985) estabeleceu que a composição elementar das SH indica a fonte e a natureza do material húmico, além de avaliar a eficiência de extração e purificação das SH obtidas. Ele classificou a composição dos elementos presentes nas SHA em termos das razões atômicas, $\mathrm{H} / \mathrm{C}, \mathrm{O} / \mathrm{C}$ e N/C. A relação $\mathrm{C} / \mathrm{N}$ tem sido utilizada para evidenciar o grau de polimerização dos $\mathrm{AH}$. As razões $\mathrm{H} / \mathrm{C}$ e $\mathrm{C} / \mathrm{H}$ podem fornecer informações a respeito das estruturas e fórmulas moleculares das SH (STEELINK, 1985; BELZILE et al., 1997).

A razão $\mathrm{H} / \mathrm{C}$ é frequentemente associada ao grau de condensação ou de aromaticidade, e esse é relacionado ao grau de humificação, sendo que maiores valores de $\mathrm{H} / \mathrm{C}$ ou menores valores de $\mathrm{C} / \mathrm{H}$ indicam maior quantidade de grupos alifáticos, típicos de materiais menos humificados (STEVENSON, 1992). As razões $\mathrm{O} / \mathrm{C}$ e $\mathrm{C} / \mathrm{N}$ indicam, respectivamente, o teor de grupos oxigenados presentes na molécula e o grau de incorporação de nitrogênio na estrutura. Em geral, amostras mais humificadas apresentam maiores valores de O/C e C/N (STEARMAN et al., 1989). As razões $H / C$ e O/C geralmente são menores para os $A H$ que para os $A F$ (BRAVARD; RIGHI, 1991).

As SHA com maiores teores de oxigênio possuem maiores concentrações de grupos funcionais, tornando-as com características mais hidrofílicas e diminuindo o 
acúmulo de compostos orgânicos não-iônicos. Assim, as SHA apresentam características mais ácidas que as SHT (STEVENSON, 1982b; AIKEN et al., 1985).

Araújo et al. (2002) determinaram à composição elementar de frações húmicas extraídas da água coletada no Rio Itapanhaú - SP. Os autores utilizaram o sistema de ultrafiltração seqüencial em múltiplos estágios e fluxo tangencial para fracionar as SHA em diferentes frações. Dentre as frações estudadas, ou autores concluíram que as SHA com tamanho molecular aparente maior que $100 \mathrm{kDa}$, tiveram a menor razão $\mathrm{H} / \mathrm{C}$ e a maior razão $\mathrm{C} / \mathrm{N}$. Isso indica estruturas mais aromáticas e mais humificadas. Eles verificaram menor porcentagem de $\mathrm{H}$ e $\mathrm{C}$, maior razão $\mathrm{O} / \mathrm{C}$ e menor razão $\mathrm{C} / \mathrm{N}$ na fração menor que $5 \mathrm{kDa}$, supondo uma estrutura mais alifática, maior conteúdo de grupos oxigenados e material menos humificado.

Através da determinação da massa molecular média e análise elementar, foi proposto por Abbt-Braun et al. (1989) uma fórmula molecular para os AF de $\mathrm{C}_{50} \mathrm{H}_{55} \mathrm{H}_{35} \mathrm{~N}_{1}$ (m =1,230 u). Similarmente, Thurman e Malcolm (1983) propuseram um fórmula molecular de $\mathrm{C}_{74} \mathrm{H}_{72} \mathrm{H}_{46} \mathrm{~N}_{0,7}$ (m $\cong 1,700 \mathrm{u}$ ) para os $\mathrm{AF}$ extraído de água superficial.

\subsubsection{Espectroscopia no Ultravioleta-Visível (UV/VIS)}

A espectroscopia no UV/VIS permite identificar transições eletrônicas de elétrons $\pi$ em duplas ligações conjugadas e reações de transferências eletrônicas de elétrons de grupos adjacentes. Estes elétrons absorvem energia na faixa do UV/VIS e os grupos que os têm são chamados cromóforos. A absorção de energia é quantizada e conduz à passagem dos elétrons de orbitais do estado fundamental de 
energia para orbitais de maior energia em um estado excitado. Entretanto, considerando a natureza complexa das $\mathrm{SH}$, essa técnica não possibilita medir ou caracterizar um cromóforo em particular, mas sim, a sobreposição de absorbâncias de vários grupos funcionais (STEVENSON, 1982b). O espectro eletrônico é representado como um gráfico de absorbância em função do comprimento de onda e irradiação. A intensidade de luz é medida por meio da lei de Beer-Lambert para um certo comprimento de onda como mostrado na Equação 1:

$\log _{10}=\underline{\left(\mathrm{I}_{0}\right)}=\varepsilon \mathrm{C} L=A$

Onde:

$\mathrm{I}_{0}=$ radiação incidente na amostra;

I = radiação transmitida pela amostra;

$\mathrm{C}=$ concentração do soluto $\left(\mathrm{mol} \mathrm{L}^{-1}\right)$;

$\varepsilon=$ absortividade molar;

$\mathrm{L}=$ caminho ótico que a radiação percorre pela amostra;

A = Absorbância

A espectroscopia de absorção na região do UV/VIS vem sendo utilizada para caracterizar as $\mathrm{SH}$. A razão entre as absorbâncias nos comprimentos de onda a 465 $\mathrm{nm}$ e a $665 \mathrm{~nm}$ é referida como $\mathrm{E}_{4} / \mathrm{E}_{6}$ (região espectral no VIS). Essa razão fornece indicações do grau de polimerização e da presença de estruturas alifáticas e aromáticas. Ela diminui com o aumento do tamanho molecular aparente das SH e do grau de condensação de constituintes aromáticos (CHEN et al., 1997). Uma alta razão $E_{4} / E_{6}$ indica a predominância de estruturas mais alifáticas. Essa razão é influenciada pelo tamanho da molécula, pelo $\mathrm{pH}$ do meio, pelo teor de oxigênio, carbono, grupos carboxílicos, origem e idade das SH (STEVENSON, 1982). 
No comprimento de 465 nm têm-se a absorbância por grupos alifáticos e no comprimento de onda de $665 \mathrm{~nm}$ por grupos aromáticos. Com o mesmo objetivo, outras razões foram utilizadas, como as absorbâncias em $350 \mathrm{~nm}$ e em $450 \mathrm{~nm}$ (razão $E_{3} / E_{4}$ ), em 254 nm e em 436 nm (razão $E_{2} / E_{4}$ ) e em 254 nm e em 365 nm (razão $E_{2} / E_{3}$ ). As razões na região espectral do UV são mais empregadas para as SHA que para as SH de solo, já que as SHA absorvem mais fortemente na região do UV do que na região do VIS. Isso provavelmente ocorre devido à estrutura das SHA ser menos condensada do que às $\mathrm{SH}$ de solo.

Peravuori e Pihlaja (1997) sugeriram a Equação 2 que relaciona a razão $E_{2} / E_{3}$ e a aromaticidade:

$$
\text { Aromaticidade }=52,5-6,78 \times E_{2} / E_{3} \quad r^{2}=0,82
$$

Esses autores correlacionaram aromaticidade e tamanho molecular aparente das SH utilizando RMN, cromatografia por exclusão por tamanho, entre outras. Mesmo o coeficiente de correlação não sendo muito bom $\left(r^{2}=0,82\right)$, foi possível notar que a quantidade de unidades aromáticas aumenta em função do aumento do tamanho molecular aparente das SH (ROCHA et al., 2000).

Trabalhos recentes com SHA extraídas de amostra de água superficial coletada no Rio Itapanhaú em Bertioga - SP mostraram uma distribuição similar de aromaticidade em frações com diferentes tamanhos moleculares aparentes (ROCHA et al., 2000a).

Devido à superposição de bandas, o espectro de absorção na região UV/VIS de $\mathrm{AH}$ e AF não apresentam bandas bem definidas. Araújo et al. (2002) através da caracterização por UV-VIS das frações de SHA do Rio Itapanhaú - SP, verificaram que as frações $F_{1}(>100 \mathrm{kDa}), F_{2}(100-50 \mathrm{kDa}), F_{3}(50-30 \mathrm{kDa})$ e $F_{4}(30-10$ kDa) apresentaram absorbâncias similares e menores que das $F_{5}\left(10-5\right.$ kDa) e $F_{6}$ 
$(<5 \mathrm{kDa})$. Devido aos maiores valores de absorbâncias das menores frações, $F_{5} \mathrm{e}$ $F_{6}$, essas possuem características menos condensadas, o que também foi verificado através da razão atômica $\mathrm{H} / \mathrm{C}$.

\subsubsection{Espectroscopia na região do infravermelho (IV)}

A espectroscopia no IV é bastante utilizada para caracterizar as $\mathrm{SH}$, fornecendo informações estruturais e funcionais das moléculas.

A absorção da radiação na região do IV pelas SH corresponde à energia de vibração e rotação associada às ligações químicas da molécula. A intensidade de absorção é uma função da variação do momento de dipolo envolvido na vibração da molécula. Existem duas vibrações: a deformação axial (estiramento) a qual envolve mudança contínua na distância interatômica ao longo do eixo da ligação entre dois átomos e as vibrações de deformação angular que são caracterizadas pela mudança no ângulo entre duas ligações (SILVERSTEIN et al., 1994).

Os espectros na região do IV das $\mathrm{SH}$ mostram bandas largas provavelmente devido à sobreposição das bandas de absorção dos constituintes individuais da mistura heterogênea de grupos que constituem as SH (ABBT-BRAUN, 1992).

A Tabela 2 lista os principais comprimentos de onda das bandas de absorção características das SHA e suas atribuições. 
Tabela 2 - Comprimento de onda das principais bandas de absorção e atribuições das SH (ROCHA et al., 2000b; STEVENSON, 1994; RICCA et al., 2000).

\begin{tabular}{cl}
\hline Comprimento de onda $\left(\mathrm{cm}^{-1}\right)$ & \multicolumn{1}{c}{ Atribuições } \\
\hline $3500-3300$ & $\begin{array}{l}\text { Estiramento } \mathrm{OH} \text { (livre e ligado por ligações de } \mathrm{H} \text { ) } \\
\text { de álcoois e/ou fenóis e/ou ácidos carboxílicos }\end{array}$ \\
\hline 3200 & Estiramento $\mathrm{CH}$ de alquenos e/ou aromáticos \\
\hline$\sim 2930-2860$ & Estiramento $\mathrm{CH}$ alifáticos \\
\hline $1710-1720$ & $\mathrm{C}=\mathrm{O}$ de cetonas, aldeídos e $\mathrm{COOH}$ \\
\hline $1630-1650$ & C-O de íons $\mathrm{COO}$ aromáticos, $\mathrm{C}=\mathrm{C}$ de alquenos \\
& e/ou aromáticos, $\mathrm{C}=\mathrm{O}$ e deformação $\mathrm{N}-\mathrm{H}$ das \\
& amidas primárias. \\
\hline$\sim 1580$ & Estiramento $\mathrm{C}=\mathrm{C}$ aromático e/ou $\mathrm{NH}$ \\
\hline $1380-1420$ & C-H alifáticos, OH álcoois e ácidos \\
\hline 1240 & C-O álcoois e fenóis \\
\hline$\sim 1030$ e 1080 & C-O de álcoois, fenóis, éteres, ésteres e $\mathrm{COOH}$ \\
\hline$\sim 950$ & Estiramento de C-O de estruturas \\
& polissacarídicas e estiramento de Si-O \\
& (impurezas do tipo silicato) \\
\hline$\sim 770$ & Estiramento de cadeias alifáticas \\
\hline &
\end{tabular}

Os espectros de IV das SHA caracterizadas por Araújo et al. (2002) mostraram bandas de absorção características de SHA. As frações apresentaram bandas ao redor de $3400 \mathrm{~cm}^{-1}$ referentes ao estiramento $\mathrm{CH}$ de fenóis e/ou ácidos carboxílicos e/ou estiramento $\mathrm{NH}$ de aminas. Na região de $2900 \mathrm{~cm}^{-1}$ apresentaram bandas características de estiramento $\mathrm{CH}$ de grupos alifáticos $\left(\mathrm{CH}_{2}\right.$ e $\left.\mathrm{CH}_{3}\right)$. Nas regiões de 1630 e $1720 \mathrm{~cm}^{-1}$ as bandas são devidas a vibrações de carbonílas de grupos carboxilatos e/ou carboxílicos e/ou cetonas. Bandas em torno de $1385 \mathrm{~cm}^{-1} \mathrm{e}$ na região de $1035-1100 \mathrm{~cm}^{-1}$ estão associadas ao estiramento do grupo carboxilato e ao estiramento da ligação C-O de álcoois, respectivamente. Os autores concluíram que as bandas de absorção para todas as frações estudadas de SHA foram 
praticamente as mesmas, indicando similaridade entre os grupos funcionais presentes nas estruturas das diferentes frações de SHA.

\subsubsection{Espectroscopia de ressonância magnética nuclear (RMN)}

A espectroscopia de ressonância magnética nuclear (RMN) é uma técnica bastante utilizada para estimar a quantidade relativa e tipos de carbonos, alifáticos e aromáticos, assim como grupos fenólicos e carboxílicos das SHA e SH de solo. A estimativa das porcentagens dos diferentes tipos de carbono e prótons é obtida a partir da integração dos picos nas regiões específicas dos espectros. O espectro de RMN é representado pelas freqüências dos picos de absorção e suas intensidades. Os núcleos possuem número quântico spin (l), que corresponde à soma dos spins nucleares de cada partícula (prótons e nêutrons). Em alguns núcleos a carga gira em torno do eixo nuclear gerando um dipolo magnético ao longo do eixo. $O$ momento angular da carga em movimento pode ser descrito em termos de número quântico spin (l). Quando o número de prótons $(Z)$ e o número de massa $(A)$ forem pares, o valor de $\ell$ será igual à zero, pois tanto os prótons como os nêutrons estarão emparelhados, como por exemplo: ${ }^{12} \mathrm{C}$ e ${ }^{16} \mathrm{O}$. Quando Z for ímpar e A for par, o valor de $\ell$ será um número inteiro e restará pelo menos um próton e um nêutron

desemparelhado, por exemplo o ${ }^{14} \mathrm{~N}_{7}(\ell=1)$ e ${ }^{10} \mathrm{~B}_{5}(\ell=3)$. No caso de A ser ímpar, o número quântico $\ell$ será fracionário, pois existirá um número ímpar de prótons ou de nêutrons, como por exemplo para o ${ }^{1} \mathrm{H}_{1}(\ell=1 / 2)$ e ${ }^{13} \mathrm{C}_{6}(\ell=1 / 2)$. Os números de $\ell$ podem ser iguais a $0,1 / 2,1,3 / 2$ etc.

O momento magnético $\mu$ de um núcleo está orientado ao longo do eixo do spin e é proporcional ao momento angular $\mathrm{P}$ conforme mostrado na equação 3: 


$$
\mu=\gamma P=\frac{\gamma}{2 \pi} M_{\ell}
$$

Na qual: $\gamma$ é o fator giromagnético do núcleo, que tem valor diferente para cada tipo de núcleo (por exemplo, para o ${ }^{1} \mathrm{H}=2,6752 \times 10^{8} \mathrm{rad} \mathrm{T}^{-1} \mathrm{~s}^{-1}$ e para $0{ }^{13} \mathrm{C}=$ $\left.6,7283 \times 10^{7} \mathrm{rad} \mathrm{T}^{-1} \mathrm{~s}^{-1}\right)$;

$h=$ constante de Planck $\left(6,62608 \times 10^{-34} \mathrm{~J} \mathrm{~s}\right)$;

$M_{\ell}=$ número quântico magnético de $\operatorname{spin}(\ell, \ell-1, \ldots,-\ell+1,-\ell)$.

Em termos da mecânica quântica, o eixo magnético do núcleo pode assumir $2 \ell+1$, onde $\ell$ determina o número de orientações possíveis (definidos pelo momento magnético spin) em relação ao campo magnético externo $\left(B_{0}\right)$, e cada orientação corresponde a níveis de energia (E), de acordo com a Equação 4:

$$
E=-\gamma \underline{h} \underline{h} \mathrm{M}_{\ell} \mathrm{B}_{0}
$$

Nos casos de átomos com spin nuclear igual a $1 / 2$, como ${ }^{1} \mathrm{H}$ e ${ }^{13} \mathrm{C}$, os valores possíveis de $M_{\ell}$ são $+1 / 2$ e $-1 / 2$. Assim, formam-se dois níveis de energia $\left(E=-1 / 2(\gamma h / 4 \pi) . B_{0}\right.$ e $\left.E=+1 / 2(\gamma h / 4 \pi) . B_{0}\right)$. A diferença de energia entre os dois estados $(\Delta E)$ é dada pela Equação 5:

$$
\Delta \mathrm{E}=h v=\underset{2 \pi}{\gamma} \underline{h} \mathrm{~B}_{0}
$$
transição.

Em que: $v=$ freqüência da radiação eletromagnética em que ocorre a A Equação 5 relaciona a freqüência eletromagnética com a força do campo e pode ser reescrita como:

$$
v=\frac{\gamma \mathrm{B}_{0}}{2 \pi}
$$

Em uma partícula que gira rapidamente em torno de si mesmo, a força aplicada por um campo magnético externo $B_{0}$ provocará um movimento do eixo 
dessa partícula, chamado movimento de precessão, cuja trajetória é circular e em torno do vetor que representa o campo magnético aplicado.

A velocidade angular desse movimento $(\omega)$, em radianos por segundo, é dada pela Equação 7:

$$
\omega=\gamma B_{0}
$$

A velocidade angular pode ser convertida na freqüência de precessão, chamada de freqüência de Larmor, mostrada pela Equação 8:

$$
v_{0}=\frac{\gamma B_{0}}{2 \pi}
$$

A freqüência na qual deve ocorrer a transição deve corresponder à freqüência de Larmor da partícula.

Em um equipamento com magneto de 9,4 $\mathrm{T}$ (campo magnético), os ${ }^{1} \mathrm{H}$ entrarão em ressonância a aproximadamente $400 \mathrm{MHz}$, que é a freqüência $v$ nesse campo magnético, e para $0{ }^{13} \mathrm{C}$ entrarão em ressonância a aproximadamente 100 $\mathrm{MHz}$, pois seu $\gamma$ é aproximadamente quatro vezes menor que o do ${ }^{1} \mathrm{H}$. Quando utilizada a técnica pulsada, os núcleos, sob ação de um campo magnético $B_{0}$, são submetidos periodicamente a pulsos muito curtos de radiação de radiofreqüência intensa. O campo magnético dessa radiação, simbolizado por $\mathrm{B}_{1}$, é perpendicular a $\mathrm{B}_{0}$, e desloca o momento angular resultante da partícula em um ângulo $\alpha$, proporcional à duração do pulso $(\tau)$, conforme a Equação 9:

$$
\alpha=\gamma B_{1} \tau
$$

Geralmente $\alpha$ é igual a 90 graus ou $\pi / 2$ radianos, o qual é atingido no tempo de microsegundos. Quando o pulso é terminado, os núcleos começam a relaxar e retornar às suas posições de equilíbrio. O intervalo entre pulsos é tipicamente de um 
a vários segundos, durante o qual o sinal de radiofreqüência no domínio de tempo, chamado de sinal de decaimento livre de indução (FID), é emitido pelos núcleos à medida que eles relaxam, sendo então detectado.

Pequenas diferenças na freqüência de absorção do núcleo podem ocorrer devido ao seu ambiente químico, isto é, por elétrons e núcleos próximos. Esse efeito é causado por pequenos campos magnéticos gerados pelos elétrons que circulam ao redor dos núcleos. Como conseqüência, os núcleos estão expostos a um campo efetivo um pouco menor que o campo externo, conforme a Equação 10:

$$
B_{\text {efetivo }}=B_{0}-\sigma B_{0}=(1-\sigma) B_{0}
$$

Em que: $\sigma=$ constante de blindagem

A Equação 10 pode ser reescrita em termos de freqüência $v$, na condição de ressonância, dando origem a equação 11:

$$
v=\frac{\gamma B_{0}}{2 \pi}(1-\sigma)=v_{0}(1-\sigma)
$$

Observa-se que $v$ é dependente de $\mathrm{B}_{0}$. Normalmente é utilizado um padrão de referência interno com constante de blindagem maior do que para a maioria dos núcleos. Isso é feito para padronizar os espectros adquiridos em espectrômetros com diferentes valores de $B_{0}$. As freqüências são expressas em termos de uma

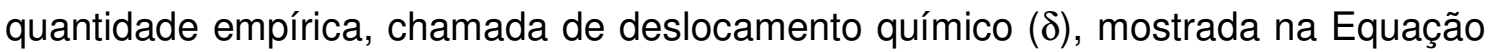
12:

$$
\delta=\frac{\left(v_{\underline{a}}-v_{p}\right) \cdot 10^{6}}{v_{p}}
$$

Os subíndices a e p referem-se à amostra e ao padrão, respectivamente. Apesar de desnecessário, é freqüente o uso de ppm (em alusão a $10^{6}$ ) como unidade de $\delta$ (SILVERSTEIN et al., 1991). 
Existem alguns problemas experimentais nos resultados dos espectros de RMN quando se utiliza a técnica de transformada de Fourier:

- as linhas são extremamente alargadas em dezenas de $\mathrm{Hz}$ pelas interações dipolares magnéticas (homo e heteronucleares) e quadrupolares;

- o deslocamento químico anisotrópico leva a um complexo alargamento de linha $(\mathrm{kHz})$;

- em sólidos os núcleos atômicos apresentam tempos de relaxação spin-rede muito longos, particularmente núcleos raros, como $0{ }^{13} \mathrm{C}$, onde $\gamma$ é pequeno e a abundância natural é muito baixa (CAMPOS, 2005).

Devido a esses problemas, as linhas apresentam baixa intensidade, pois o processo requer longo tempo do instrumento. Assim, foram desenvolvidas as técnicas de desacoplamento (DEC), rotação da amostra em torno do ângulo mágico (MAS) e polarização cruzada (CP).

As principais regiões de absorção por RMN CP/MAS de ${ }^{13} \mathrm{C}$ em estado sólido de grupamentos químicos para as SH são apresentadas na Tabela 3. 
Tabela 3 - Principais grupos funcionais detectados por RMN ${ }^{13} \mathrm{C}$ para as $\mathrm{SH}$ (MALCOLM, 1990; LU ET AL., 2000, CAMPOS, 2004; SANCHES, 2005; SENESI; MIANO, 1992).

\section{Máximo do pico}

\section{Origem do sinal}

(ppm)

32-33 C associado a grupos metileno em longas cadeias alifáticas

e C parafínicos.

57- $59 \quad \mathrm{C}$ alifáticos em grupos metoxílicos $\left(\mathrm{OCH}_{3}\right)$ e nitrogenados

(aminoácidos, peptídeos e proteínas).

73-75 C alifáticos ligados a grupos éter e $\mathrm{OH}$ (carboidratos).

105 Carboidratos (C anomericos de polissacaridios), contribuições de lignina

131 - $133 \quad$ C de anéis aromáticos ligados a grupos alquila e não a elementos eletronegativos como $\mathrm{O}$ e $\mathrm{N}$.

156 C fenólicos ou O-aromáticos, podendo ter também contribuição de $\mathrm{C}$ aromáticos contendo $\mathrm{N}$ ou grupos éteres.

$176 \quad$ C grupos carboxílicos $(-\mathrm{COOH})$

$210 \quad C$ de grupos carboxílicos de ésteres e amidas.

\subsection{Tecnologias de tratamento de água}

Para projetar uma ETA é de suma importância a realização de ensaios de tratabilidade com a água bruta. Os ensaios são feitos em laboratório utilizando reatores estáticos (Jarteste) ou instalações piloto de escoamento contínuo. As tecnologias que poderão ser empregadas se dividem naquelas que necessitam de coagulação e outras que não são precedidas de coagulação, e com ou sem préoxidação. Na Figura 5 é apresentado um fluxograma das principais tecnologias destinadas ao tratamento de água para consumo humano. 


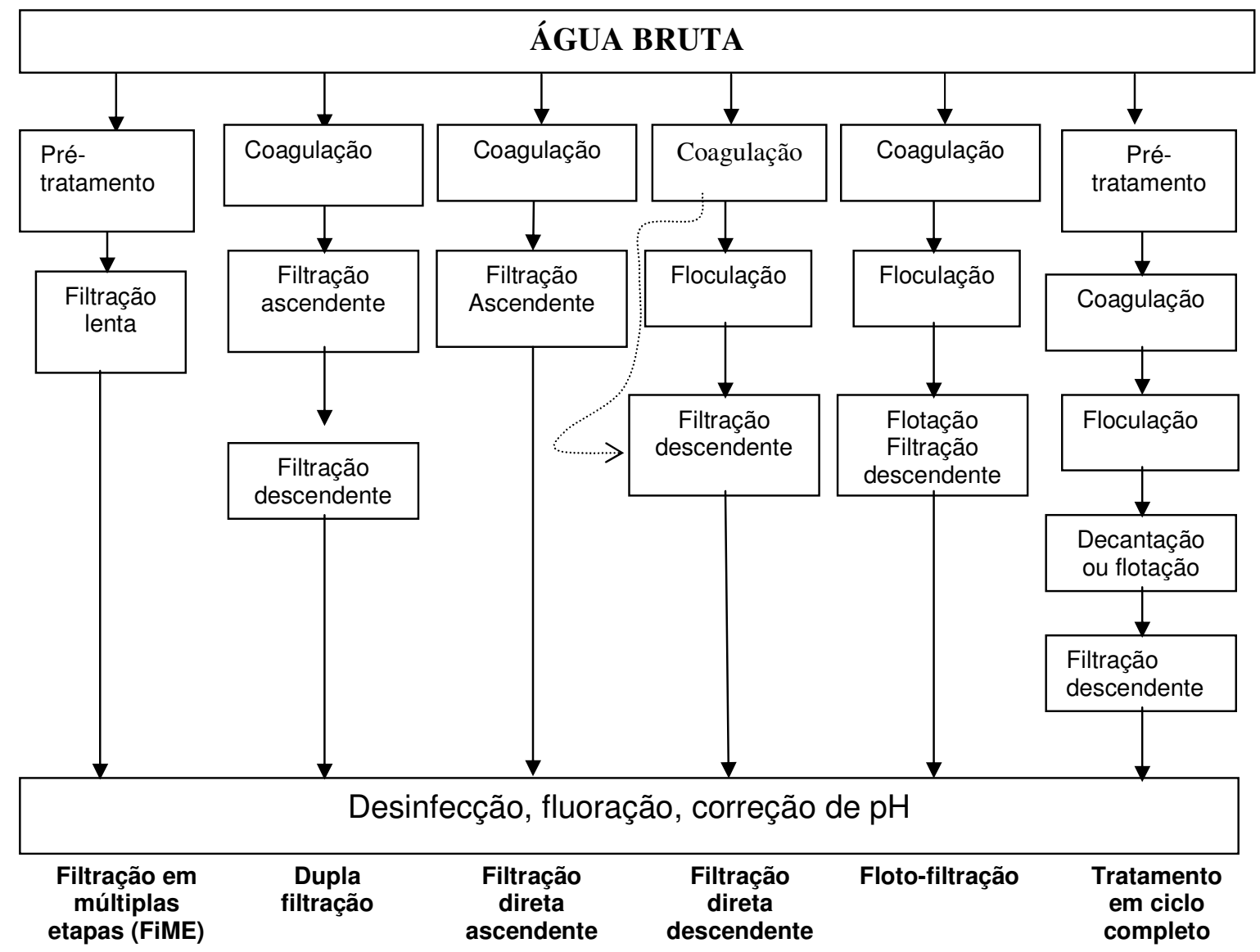

Figura 5 - Principais tecnologias de tratamento de água para consumo humano (DI BERNARDO; DANTAS, 2005).

\subsection{1 - Tecnologias de filtração direta}

\subsubsection{1 - Filtração direta descendente (FDD)}

A filtração consiste na remoção de partículas suspensas e coloidais e de microrganismos presentes na água. As impurezas são retidas ao longo do meio filtrante, através de mecanismos complexos como, de transporte, aderência e desprendimento. Esses mecanismos são influenciados pelas características químicas e físicas das partículas presentes na água e no meio filtrante, da taxa de 
filtração e do método de operação dos filtros. A água bruta pode ser coagulada com sais de alumínio ou de ferro e um polímero auxiliar de floculação ou de filtração, ou empregar um polímero catiônico, no mecanismo de neutralização de cargas. Na etapa de mistura rápida deve ocorrer a formação de pequenos flocos com grande resistência às forças de cisalhamento durante a filtração. O meio filtrante geralmente é constituído de antracito e areia ou somente areia.

A filtração com taxa declinante variável, é adotada a fim de garantir carreiras de filtração com maior duração que à taxa constante. A lavagem do meio filtrante deve ser feita com ar e água (DI BERNARDOS; DANTAS, 2005, p.34).

\subsubsection{Filtração direta ascendente (FDA)}

A água bruta é coagulada no mecanismo de neutralização de cargas e introduzida na parte inferior do meio filtrante (camada de pedregulho e meio filtrante de areia). Na camada de pedregulho ocorre formação intensa de flocos. É necessária a execução de descargas de fundo antes da lavagem dos filtros. As descargas de fundo intermediárias podem ser ou não necessárias. A operação de ETAs de FDA com taxa declinante variável somente é recomendada quando a água bruta apresenta-se com turbidez e cor verdadeira relativamente baixas (DI BERNARDOS; DANTAS, 2005, p.35).

\subsubsection{Dupla filtração}

Nesta tecnologia, tem-se a associação da FDA e FDD. Nos dois filtros o meio filtrante é constituído unicamente de areia com grãos maiores do que quando usada 
somente à tecnologia de FDA. A coagulação da água bruta ocorre no mecanismo de neutralização de cargas e, geralmente, a filtração ascendente é operada com descargas de fundo intermediárias, introduzindo água na interface. Em ETAs maiores, a FDA pode funcionar com taxa constante e a FDD, com taxa declinante (DI BERNARDOS; DANTAS, 2005, p.35).

\subsubsection{Floto-filtração}

A floto-filtração geralmente é usada no tratamento de águas que possuem elevada concentração de algas ou cor verdadeira relativamente alta. A coagulação da água bruta é feita no mecanismo de varredura e em seguida floculada. $\mathrm{Na}$ entrada de cada unidade de floto-filtração tem-se a mistura da água de recirculação (água filtrada, pressurizada e com ar dissolvido). O material sólido flota com a mesma taxa com que o subnadante é filtrado. Geralmente, empregam-se nos filtros taxa e níveis de água constantes e o material flotado é raspado periodicamente (DI BERNARDOS; DANTAS, 2005, p.36).

\subsubsection{Filtração em múltiplas etapas}

A filtração lenta é geralmente procedida de unidades de pré-tratamento (préfiltração dinâmica e pré-filtração com escoamento ascendente ou horizontal, utilizando pedregulho como material filtrante). O emprego de carvão ativado granular em conjunto com a areia fina favorece a remoção da matéria orgânica dissolvida. $O$ uso de mantas sintéticas em conjunto com a areia fina facilita a filtração, podendo operar em taxas de filtração mais elevadas (DI BERNARDOS; DANTAS, 2005, p.36). 
Nas águas usadas neste estudo, às tecnologias prováveis seriam a FDA ou a dupla filtração.

\subsection{Coagulação}

A coagulação é considerada uma etapa de tratamento da água, a qual é feita por meio da adição de produto químico apropriado. Usualmente são utilizados sais de alumínio ou de ferro ou polímeros sintéticos ou vegetais catiônicos. A função desses coagulantes é de desestabilizar várias partículas pequenas, geralmente de tamanho coloidal carregadas negativamente, remover a MOD, induzir a floculação e melhorar a filtração (AWWA COAGULATION COMMITTEE, 1989).

O propósito da mistura rápida é promover dispersão rápida e uniforme dos produtos químicos adicionados na água a ser tratada e causar a desestabilização das partículas na água (AMIRTHARAJAH; MILLS, 1982).

A coagulação resulta em dois fenômenos: químico e físico. O químico consiste na reação do coagulante com a água e na formação de espécies hidrolisadas com carga positiva, a qual depende principalmente da concentração do metal (coagulante) e pH final da mistura rápida. Esse processo ocorre em décimos de segundos ou em até 100 segundos. O processo físico consiste no transporte das espécies hidrolisadas, as quais entram em contato com as impurezas presentes na água. Durante a agitação lenta (floculação) ocorrem choques entre as impurezas,

formando aglomerados (flocos) que podem ser removidos por sedimentação, flotação ou filtração (JOHNSON; AMIRTHARAJAH 1983). 
A coagulação depende das características e impurezas presentes na água, determinadas por meio de parâmetros como: $\mathrm{pH}$, alcalinidade, carbono orgânico, cor verdadeira, turbidez, temperatura, potencial zeta, condutividade elétrica, tamanho e distribuição de tamanhos das partículas em estado coloidal e em suspensão etc. Outros fatores que influenciam na coagulação são: a estabilidade do coagulante $(\mathrm{pH}$, composição, temperatura, idade, tipos de ânions presentes etc), cinética (dependente do tempo de reação), equilíbrio químico (formação das espécies hidrolisadas), área superficial das partículas (função da concentração e tamanho das partículas) e características da superfície (natureza do colóide) (JOHNSON; AMIRTHARAJAH, 1983).

As características da água a ser tratada são de fundamental importância para se determinar qual tecnologia de tratamento de água deverá ser empregada na ETA e quais produtos químicos deverão ser empregados, possibilitando maior eficiência no tratamento e economia. Águas com temperaturas baixas $\left(\leq 10^{\circ} \mathrm{C}\right)$ podem exigir uso de polímeros como coagulante, como um polímero catiônico e, às vezes um sal de ferro (DI BERNARDO; DANTAS, 2005).

\subsection{Partículas de argilas, substâncias húmicas e suas estabilidades}

As argilas são compostas por argilominerais, quartzo, mica, pirita, calcita etc. Os constituintes básicos das argilas contêm silicatos hidratados de alumínio e de ferro e alguns elementos alcalinos e alcalinos terrosos. As principais argilas são:

montmorilonita $\mathrm{Al}(\mathrm{Mg})\left(\mathrm{Si}_{8} \mathrm{O}_{20}\right)(\mathrm{OH})_{4} \times \mathrm{H}_{2} \mathrm{O}$, caulinita $\quad \mathrm{Al}_{4}\left(\mathrm{Si}_{4} \mathrm{O}_{10}(\mathrm{OH})_{8}\right] \quad$ e $\mathrm{Al}_{4}\left(\mathrm{Si}_{4} \mathrm{O}_{6}\right)(\mathrm{OH})_{16}$ e ilita $\mathrm{K}_{\mathrm{y}} \mathrm{A}_{14}\left\{\mathrm{Fe}_{4} \mathrm{Mg}_{16}\right\}\left(\mathrm{Si}_{8} \mathrm{yAl} \mathrm{y}_{\mathrm{y}}\right) \mathrm{O}_{20}$. 
Tanto as partículas de argilas como as moléculas de $\mathrm{SH}$ apresentam cargas negativas em sua superfície. As cargas nas partículas são contrabalanceadas por cargas na fase aquosa, resultando na dupla camada elétrica entre o sólido e a água.

As forças de difusão e eletrostática atuam em torno de cada partícula presente na água em uma camada difusa. As forças elétricas repulsivas e atrativas de van der Waals atuam entre as partículas na solução, produzindo uma barreira de potencial que impede a agregação das partículas. O processo de superação das barreiras repulsivas seguido da agregação é chamado de coagulação (JOHNSON; AMIRTHARAJAH, 1983).

Há duas formas de estabilidade: a eletrostática e estérica. Para cada condição de estabilidade são considerados dois aspectos, estrutura da interface sólido-líquido e forças entre duas interfaces quando próximas entre si.

\subsubsection{Estabilidade eletrostática}

A maior parte das partículas e moléculas de SHA presentes na água são carregadas eletricamente, usualmente negativa, e decorrente de três fenômenos: grupos presentes na superfície sólida podem, ao reagir com a água, receber ou doar prótons; óxido insolúvel na superfície, como a sílica com o grupo silanol (SiOH), pode se tornar positivo ou negativo, como mostrado a seguir:

$$
\begin{aligned}
& \equiv \mathrm{SiOH}_{2}^{+} \leftrightarrows \equiv \mathrm{SiOH}+\mathrm{H}^{+} \\
& \equiv \mathrm{SiOH} \leftrightarrows \equiv \mathrm{SiO}^{-}+\mathrm{H}^{+} \\
& \equiv \mathrm{AlOH}_{2}^{+} \leftrightarrows \equiv \mathrm{AIOH}+\mathrm{H}^{+} \\
& \equiv \mathrm{AIOH} \leftrightarrows \equiv \mathrm{AlO}^{-}+\mathrm{H}^{+}
\end{aligned}
$$


Stum e O'Melia (1968) relataram que as partículas de sílica têm duas características superficiais distintas: são altamente hidratadas especialmente em pH baixo e a presença de grupos silanol. Além disso, o tamanho, a forma, o grau de hidratação e as características de ligante no complexo são propriedades responsáveis pela estabilidade e comportamento da partícula.

As substâncias orgânicas contendo grupos carboxílicos e aminas podem reagir da seguinte forma:

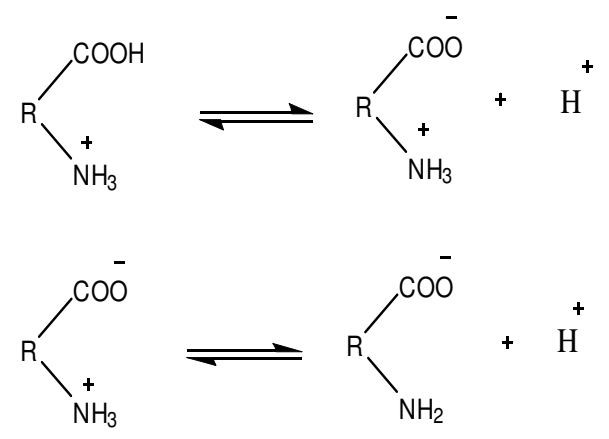

Nessas reações, a carga superficial depende da concentração de prótons $\left(\mathrm{H}^{+}\right)$ ou do $\mathrm{pH}$ da água. Com o aumento do $\mathrm{pH}$, diminui a concentração de prótons, o equilíbrio das reações 1a e 1b deslocam-se para a direita e a superfície sólida ou a molécula orgânica torna-se mais negativa. Para pH acima de 2, a sílica se torna negativa na água, já os grupos carboxílicos e amina geralmente são negativos para pH acima de 4. Grupos superficiais (sílica, por exemplo) também podem reagir na água com outros solutos absorvíveis (íon fosfato, $\mathrm{Ca}^{2+}$, por exemplo), dependendo do $\mathrm{pH}$. Pode ocorrer também a substituição isomórfica na estrutura da partícula, onde tipicamente um átomo de alumínio substitui um átomo de silício durante a formação da plaqueta, resultando carga superficial negativa.

As moléculas de água, cátions e ânions interagem com a superfície da partícula por meio de ligações iônicas, covalente, de hidrogênio, polar e forças de 
van der Waals. Devido a esses fenômenos, através dos quais os colóides se apresentam com carga superficial negativa, ocorre um balanço com íons de carga contrária presentes na água e, por isso, um sistema coloidal não apresenta carga elétrica "líquida" (Di BERNARDO; DANTAS, 2005, p.172-173).

\subsubsection{Estabilização estérica}

A adsorção de polímeros na superfície das partículas coloidais ocorre devido à interação coulombica (carga-carga), por meio de ligações de hidrogênio, interação de Van der Waals ou pela combinação destas. Os polímeros adsorvidos sobre a superfície das partículas afetam as interações repulsivas e as atrativas; no primeiro caso, a repulsão da dupla camada elétrica aumentará se o polímero estiver ionizado e com mesmo sinal das partículas; no segundo caso, o polímero adsorvido pode enfraquecer a força de atração.

Os polímeros adsorvidos tanto podem estabilizar como desestabilizar as partículas presentes na água, dependendo, principalmente, da quantidade relativa de polímero e de partículas, a afinidade entre o polímero com a partícula e a água e do tipo e concentração de eletrólitos presentes (Di BERNARDO; DANTAS, 2005, p.177-178).

\subsection{Potencial zeta}

Williams (1994) discute que a carga superficial, juntamente com o movimento Browniano, conduz à formação da Dupla Camada Elétrica (DCE) modelo que foi proposto por Helmhotz. A DCE é formada pelas cargas superficiais das partículas 
que são contrabalanceadas por cargas na fase aquosa e pelo excesso de íons com carga oposta (contra-íons) adsorvidos na partícula, deixando o meio circundante eletricamente neutro e mais distante da superfície, e por co-íons (íons de mesma carga) distribuídos de maneira difusa no meio polar, por isso um sistema coloidal não apresenta carga elétrica "líquida". O modelo sobre a DCE considerando a interface como um dispositivo armazenador de carga, análogo a um capacitor de placa paralela está representado na Figura 6.

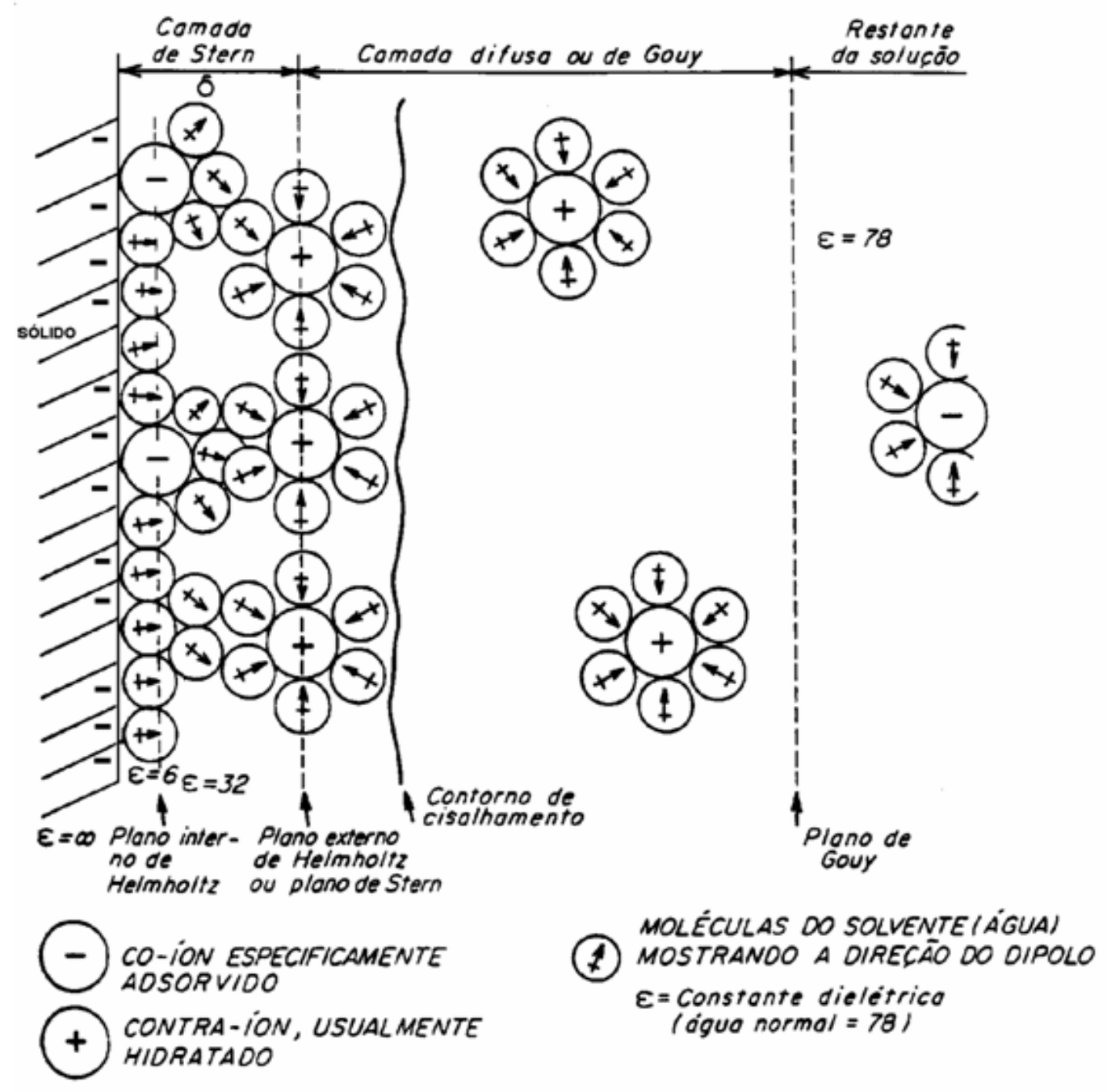

Figura 6 - Representação esquemática da DCE nas vizinhanças de uma interface sólido-líquido (DI BERNARDO; DANTAS, 2005, p.174). 
O potencial zeta (PZ), também é chamado de mobilidade eletroforética ou carga total da superfície medida como carga coloidal ou densidade de carga, indica o potencial da superfície do sistema coloidal e é geralmente considerado como indicativo da estabilidade do material coloidal. Contudo, isso não necessariamente fornece uma indicação da quantidade de coagulante requerida para a desestabilização dos colóides. Porém, a carga da superfície total da água bruta é teoricamente proporcional à demanda do coagulante desde que prevaleça o mecanismo de neutralização de carga. O PZ depende da fonte da água e do pH de coagulação (SHARP et al., 2006). A Figura 7 representa a divisão de dupla camada em duas regiões: camada compacta e camada difusa.

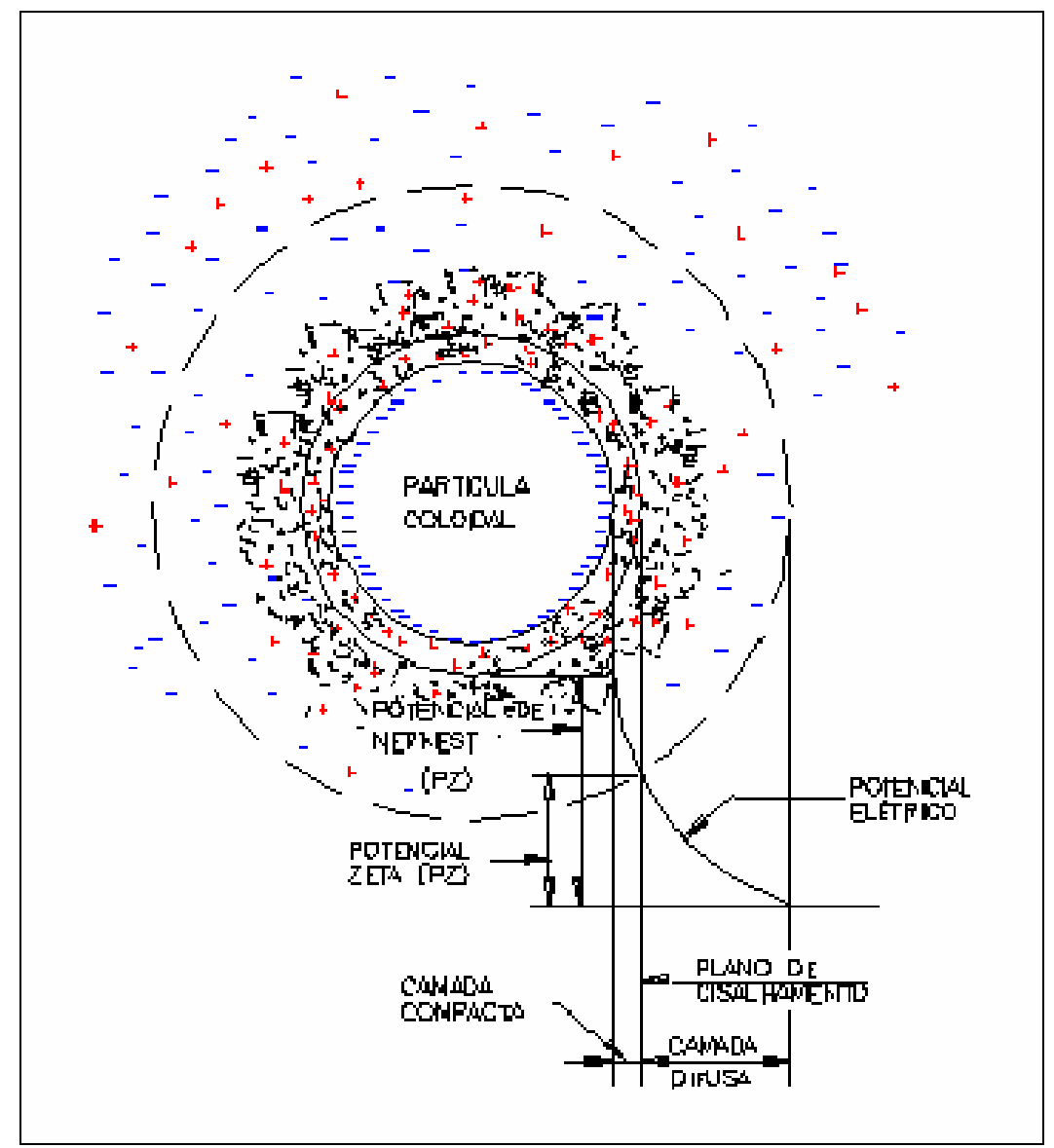

Figura 7 - Configuração esquemática da dupla camada elétrica (DI BERNARDO; DANTAS, 2005, p.175). 
É possível determinar o PZ das partículas em um sistema, através da velocidade com que as partículas atravessam o caminho (trajetória) na dupla camada elétrica numa voltagem especifica. Esta velocidade é conhecida como mobilidade eletroforética (JOHNSON; AMIRTHARAJAH, 1983).

O PZ é calculado pela Equação 13:

$$
P Z=4 \times 10^{6} \pi \mu(V E) / D
$$

Em que: $\mu=$ viscosidade absoluta da água $(\mathrm{P})$

$$
\begin{aligned}
& \mathrm{VE}=\text { velocidade de eletroforese }\left(\mu \mathrm{m} \mathrm{cm} \mathrm{s}^{-1} \mathrm{~V}^{-1}\right) \\
& D=\text { constante dielétrica da água }\left(78,5 \text { a } 25^{\circ} \mathrm{C}\right)
\end{aligned}
$$

O PZ está relacionado com o fluxo da corrente $(\mathrm{mA})$.

A coagulação pode ser realizada, principalmente, nos mecanismos de neutralização de cargas e da varredura. Em ambos os casos, o PZ se aproxima de zero, embora a literatura apresente muitos casos em que é conseguida uma coagulação eficiente mesmo com valores positivos ou negativos desse parâmetro. Williams (1965) estudou 12 amostras de água de diferentes mananciais submetidas à mesma dosagem de sulfato de alumínio de $40 \mathrm{mg} \mathrm{L}^{-1}$. O autor verificou que algumas amostras de água coagulada apresentaram PZ positivo e outros negativos. Dessa forma, é difícil afirmar que a coagulação necessariamente precisa ser efetuada com PZ próximo de zero ou igual à zero (DI BERNARDO; DANTAS, 2005, p.247). 


\subsection{Coagulantes químicos}

\subsubsection{Considerações iniciais}

A seleção do coagulante é baseada nas características da água a ser tratada e o mecanismo de coagulação desejado. As características da água mais consideradas para escolher o coagulante são turbidez, temperatura, concentração de MOD, pH, capacidade tampão, força iônica e concentração de cálcio. A escolha dos coagulantes mais eficientes é avaliada através do uso do equipamento estático Jarteste.

\subsubsection{Cloreto Férrico}

O cloreto férrico PA $\left(\mathrm{FeCl}_{3} \cdot 6 \mathrm{H}_{2} \mathrm{O}\right)$ apresenta massa molar de $270,5 \mathrm{~g} \mathrm{~mol}^{-1} \mathrm{e}$ contêm aproximadamente $59,1 \%$ em massa de $\mathrm{Fe}_{2} \mathrm{O}_{3}$ ou $20,7 \%$ em massa de ferro. O cloreto férrico comercial líquido é o produto comumente usado na prática, o qual em geral apresenta concentração entre 38 e $40 \%$ em massa e massa específica de 1,40 a $1,42 \mathrm{~kg} \mathrm{~L}^{-1}\left(25^{\circ} \mathrm{C}\right)$. A acidez livre máxima é de $0,5 \%$ em massa de $\mathrm{HCl}$ (DI BERNARDO; DANTAS, 2005).

Quando a coagulação é feita com o cloreto férrico e em pH elevados, diminui drasticamente a turbidez e a demanda bioquímica de oxigênio, elimina fosfatos e certa quantidade de outros elementos tóxicos como: mercúrio, chumbo, arsênio, selênio e bário (PAVANELLI, 2001). 


\subsubsection{Reações de hidrólise de sais de $\mathrm{Fe}^{3+}$}

Dependendo do tipo de sal de ferro usado na coagulação, pode-se relacionar a dosagem desse produto com a concentração de ferro e da espécie hidrolisada, possibilitando que, em função da dosagem do produto usado e do $\mathrm{pH}$, que sejam quantificados o precipitado e as espécies hidrolisadas presentes. Os mecanismos de coagulação para os sais de ferro são funções das espécies hidrolisadas de $\mathrm{Fe}^{3+}$ em meio aquoso.

Dempsey (1989) propôs que a formação das espécies hidrolisadas sofre influência de vários fatores como, $\mathrm{pH}$, temperatura da água, presença de partículas e MOD, condições de mistura rápida e o tempo de reação. Outros fatores às vezes considerados são a concentração e a validade da solução preparada do coagulante. As equações de 15 a 19 apresentam as possíveis reações de hidrólise do íon $\mathrm{Fe}^{3+}$ em água isenta de impurezas a $2^{\circ} \mathrm{C}$ e as constantes de equilíbrio $(\mathrm{K})$ representadas em termos da solubilidade das espécies hidrolisadas.

Reações de equilíbrio $\quad \log \mathrm{K}$

$$
\begin{array}{ll}
\mathrm{Fe}(\mathrm{OH})_{3(\mathrm{~s})} \leftrightarrows \mathrm{Fe}^{3+}{ }_{(\mathrm{aq})}+3 \mathrm{OH}^{-}{ }_{(\mathrm{aq})} & -37,5 \\
\mathrm{Fe}^{3+}+\mathrm{H}_{2} \mathrm{O} \leftrightarrows \mathrm{Fe}(\mathrm{OH})^{2+}+\mathrm{H}^{+} & -3,0 \\
\mathrm{Fe}^{3+}+2 \mathrm{H}_{2} \mathrm{O} \leftrightarrows \mathrm{Fe}(\mathrm{OH})_{2}^{+}+2 \mathrm{H}^{+} & -6,4 \\
2 \mathrm{Fe}^{3+}+2 \mathrm{H}_{2} \mathrm{O} \leftrightarrows \mathrm{Fe}_{2}(\mathrm{OH})_{2}^{4+}+2 \mathrm{H}^{+} & -3,1 \\
\mathrm{Fe}^{3+}+4 \mathrm{H}_{2} \mathrm{O} \leftrightarrows \mathrm{Fe}(\mathrm{OH})_{4}^{-}+4 \mathrm{H}^{+} & -23,5 \\
\mathrm{Fe}^{3+}+3 \mathrm{H}_{2} \mathrm{O} \leftrightarrows \mathrm{Fe}(\mathrm{OH})_{3}+3 \mathrm{H}^{+} & -13,5
\end{array}
$$

Todas essas reações seguem a expressão geral apresentada na equação 20: 
$\mathrm{xFe} e^{3+}+\mathrm{yH}_{2} \mathrm{O} \leftrightarrows \mathrm{Fe}_{x}(\mathrm{OH})_{y}{ }^{(3 x-y)+}+\mathrm{y} \mathrm{H}^{+}$

$\mathrm{O}$ íon $\mathrm{Fe}^{3+}$ não existe em águas naturais como íon simples, mas como o aquocomplexo $\mathrm{Fe}\left(\mathrm{H}_{2} \mathrm{O}\right)_{6}{ }^{3+}$ (O'MELIA, 1972). Entretanto, para simplificar a reação, as moléculas de água geralmente não são mostradas. É possível obter a equação para cada espécie de ferro $\left(\mathrm{mol} \mathrm{L}^{-1}\right)$ em equilíbrio com $\mathrm{o} \mathrm{pH}$, como será visto detalhadamente com o sulfato de alumínio PA.

As constantes de equilíbrio são expressas em termos da solubilidade das espécies de $\mathrm{Fe}^{3+}$ e a constante de ionização da água $\left(\mathrm{K}_{\mathrm{w}}\right)$. Por exemplo:

$$
\begin{aligned}
& \mathrm{Fe}^{3+}+\mathrm{H}_{2} \mathrm{O} \leftrightarrows \mathrm{Fe}(\mathrm{OH})^{2+}+\mathrm{H}^{+} \quad \log \mathrm{K}=-3,0 \\
& \mathrm{Fe}(\mathrm{OH})_{3(\mathrm{~s})} \leftrightarrows \mathrm{Fe}^{3+}{ }_{(\mathrm{aq})}+3 \mathrm{OH}_{(\text {(aq) }} \quad \log \mathrm{K}=-37,5 \\
& \underline{\mathrm{H}^{+}+\mathrm{OH}^{-} \leftrightarrows \mathrm{H}_{2}} \underline{\mathrm{O}} \quad \log \mathrm{K}_{\underline{w}}=+14 \\
& \mathrm{Fe}(\mathrm{OH})_{3(\mathrm{~s})} \leftrightarrows \mathrm{Fe}(\mathrm{OH})^{2+}+2 \mathrm{OH}^{-} \quad \mathrm{K}_{\mathrm{s} 2}=-26,50 \\
& \mathrm{~K}_{\mathrm{s} 2}=\frac{\left[\mathrm{Fe}(\mathrm{OH})^{2+}\right]\left[\mathrm{OH}^{-}\right]^{2}}{\left[\mathrm{Fe}(\mathrm{OH})_{(\mathrm{s})}\right]}=\left[\mathrm{Fe}(\mathrm{OH})^{2+}\right]\left[\mathrm{OH}^{-}\right]^{2} \\
& 10^{-3,0}=\frac{\left[\mathrm{Fe}(\mathrm{OH})^{2+}\right]\left[\mathrm{H}^{+}\right]}{\left[\mathrm{Fe}^{3+}\right]} \\
& 10^{-32,34}=\frac{\left[\mathrm{Fe}^{3+}\right]\left[\mathrm{OH}^{-}\right]^{3}}{\left[\mathrm{Fe}(\mathrm{OH})_{3(\mathrm{~s})}\right]} \\
& 10^{-14}=\left[\mathrm{H}^{+}\right]\left[\mathrm{OH}^{-}\right]
\end{aligned}
$$

Assumindo que a atividade do precipitado de $\mathrm{Fe}(\mathrm{OH})_{3(\mathrm{~s})}$ seja igual à unidade, para que a constante de equilíbrio $(K)$ seja expressa em termos da espécie solúvel de $\mathrm{Fe}^{3+}$ e $\mathrm{H}^{+}$, aplica-se o logaritmo em ambos os lados da Equação 21, obtendo-se a Equação 25:

$\log \mathrm{K}_{\mathrm{s} 2}=\log \left[\mathrm{Fe}(\mathrm{OH})^{2+}\right]+2 \log \left[\mathrm{OH}^{-}\right]$ 
Aplicando-se o logaritmo nas Equações 22, 23 e 24, obtém-se:

$-3,0=\log \left[\mathrm{Fe}(\mathrm{OH})^{2+}\right]+\log \left[\mathrm{H}^{+}\right]-\log \left[\mathrm{Fe}^{3+}\right]$

$-37,50=\log \left[\mathrm{Fe}^{3+}\right]+3 \log \left[\mathrm{OH}^{-}\right]$

$+14=-\log \left[\mathrm{H}^{+}\right]-\log \left[\mathrm{OH}^{-}\right]$

$\log \mathrm{K}_{\mathrm{s}}=-26,50=\log \left[\mathrm{Fe}(\mathrm{OH})^{2+}\right]+2 \log \left[\mathrm{OH}^{-}\right]$

Assim:

$\log \left[\mathrm{Fe}(\mathrm{OH})^{2+}\right]=2 \mathrm{pOH}-26,50$

Como:

$-\log \left[\mathrm{H}^{+}\right]-\log \left[\mathrm{OH}^{-}\right]=14$

$\mathrm{pH}+\mathrm{pOH}=14$

$\mathrm{pOH}=14-\mathrm{pH}$

Substituindo o pOH na Equação 26, obtém-se:

$\log \left[\mathrm{Fe}(\mathrm{OH})^{2+}\right]=2(+14-\mathrm{pH})-26,50$

$\log \left[\mathrm{Fe}(\mathrm{OH})^{2+}\right]=1,5-2 \mathrm{pH}$

Para a espécie $\mathrm{Fe}(\mathrm{OH})_{2}$ têm-se:

$$
\begin{aligned}
& \mathrm{Fe}^{3+}+2 \mathrm{H}_{2} \mathrm{O} \leftrightarrows \mathrm{Fe}(\mathrm{OH})_{2}^{+}+2 \mathrm{H}^{+} \quad \log \mathrm{K}=-6,4 \\
& \mathrm{Fe}(\mathrm{OH})_{3(\mathrm{~s})} \leftrightarrows \mathrm{Fe}_{(\mathrm{aq})}^{3+}+3 \mathrm{OH}_{(\mathrm{aq})} \quad \log \mathrm{K}=-37,5 \\
& \underline{2 \mathrm{H}^{+}+2 \mathrm{OH}^{-} \leftrightarrows 2 \mathrm{H}_{2}} \underline{\mathrm{O}} \quad \log \mathrm{K}_{\underline{w}}=-14 \times 2 \\
& \mathrm{Fe}(\mathrm{OH})_{3(\mathrm{~s})} \leftrightarrows \mathrm{Fe}(\mathrm{OH})_{2}^{+}+\mathrm{OH}^{-} \quad \mathrm{K}_{\mathrm{s} 3}=\text { ? } \\
& \mathrm{K}_{\mathrm{s} 2}=\left[\mathrm{Fe}(\mathrm{OH})_{2}{ }^{+}\right]\left[\mathrm{OH}^{-}\right]=\left[\mathrm{Fe}(\mathrm{OH})_{2}^{+}\right]\left[\mathrm{OH}^{-}\right] \\
& {\left[\mathrm{Fe}(\mathrm{OH})_{(\mathrm{s})}\right]} \\
& 10^{-6,4}=\frac{\left[\mathrm{Fe}(\mathrm{OH})^{2+}\right]\left[\mathrm{H}^{+}\right]^{2}}{\left[\mathrm{Fe}^{3+}\right]}
\end{aligned}
$$


$10^{-37,50}=\frac{\left[\mathrm{Fe}^{3+}\right]\left[\mathrm{OH}^{-}\right]^{3}}{\left[\mathrm{Fe}(\mathrm{OH})_{3(\mathrm{~s})}\right]}$

$10^{-28}=\frac{\left[\mathrm{H}^{+}\right]^{2}+\left[\mathrm{OH}^{-}\right]^{2}}{\left[\mathrm{H}_{2} \mathrm{O}\right]^{2}}$

Assumindo que a atividade do precipitado de $\mathrm{Fe}(\mathrm{OH})_{3(\mathrm{~s})}$ seja igual à unidade, para que a constante de equilíbiro (K) seja expressa em termos da espécie solúvel de $\mathrm{Fe}^{3+} \mathrm{e} \mathrm{H}^{+}$, aplica-se o logaritmo em ambos os lados da Equação 28, obtendo-se:

$\log \mathrm{K}_{\mathrm{s} 3}=\log \left[\mathrm{Fe}(\mathrm{OH})_{2}^{+}\right]+\log \left[\mathrm{OH}^{-}\right]$

Aplicando-se o logaritmo nas Equações 29, 30 e 31, obtém-se:

$-6,4=\log \left[\mathrm{Fe}(\mathrm{OH})_{2}^{+}\right]+2 \log \left[\mathrm{H}^{+}\right]-\log \left[\mathrm{Fe}^{3+}\right]$

$-37,50=\log \left[\mathrm{Fe}^{3+}\right]+3 \log \left[\mathrm{OH}^{-}\right]$

$+28=-2 \log \left[\mathrm{H}^{+}\right]-2 \log \left[\mathrm{OH}^{-}\right]$

$\log \mathrm{K}_{\mathrm{s} 3}=-15,90=\log \left[\mathrm{Fe}(\mathrm{OH})_{2}^{+}\right]+\log \left[\mathrm{OH}^{-}\right]$

Assim:

$-15,90-\log \left[\mathrm{OH}^{-}\right]=\log \left[\mathrm{Fe}(\mathrm{OH})_{2}{ }^{+}\right]$

$-15,90+\mathrm{pOH}=\log \left[\mathrm{Fe}(\mathrm{OH})_{2}^{+}\right]$

$-15,90+14-\mathrm{pH}=\log \left[\mathrm{Fe}(\mathrm{OH})_{2}{ }^{+}\right]$

$\log \left[\mathrm{Fe}(\mathrm{OH})_{2}^{+}\right]=-1,90-\mathrm{pH}$

Utilizando o mesmo procedimento para as demais espécies, obtém-se:

$\log \left[\mathrm{Fe}(\mathrm{OH})_{4}{ }^{-}\right]=-19+\mathrm{pH}$

$\log \left[\mathrm{Fe}_{2}(\mathrm{OH})_{2}^{4+}\right]=5,9-4 \mathrm{pH}$

$\log \left[\mathrm{Fe}_{3}(\mathrm{OH})_{4}^{5+}\right]=-9+\mathrm{pH}$

$\log \left[\mathrm{Fe}^{3+}\right]=4,5-3 \mathrm{pH}$

$\log \left[\mathrm{Fe}(\mathrm{OH})_{3}\right]=-9,0$

Utilizando-se as Equações 27, 33 a 38, constrói-se a Figura 8 que mostra o diagrama de solubilidade das espécies hidrolisadas de ferro (III). Os valores da 
concentração em quantidade de matéria de cada espécie estão na ordenada e o pH representado na abscissa. Essas espécies encontram-se em equilíbrio com o precipitado de hidróxido férrico, $\mathrm{Fe}(\mathrm{OH})_{3(\mathrm{~s})}$, como apresentado na Figura 8.

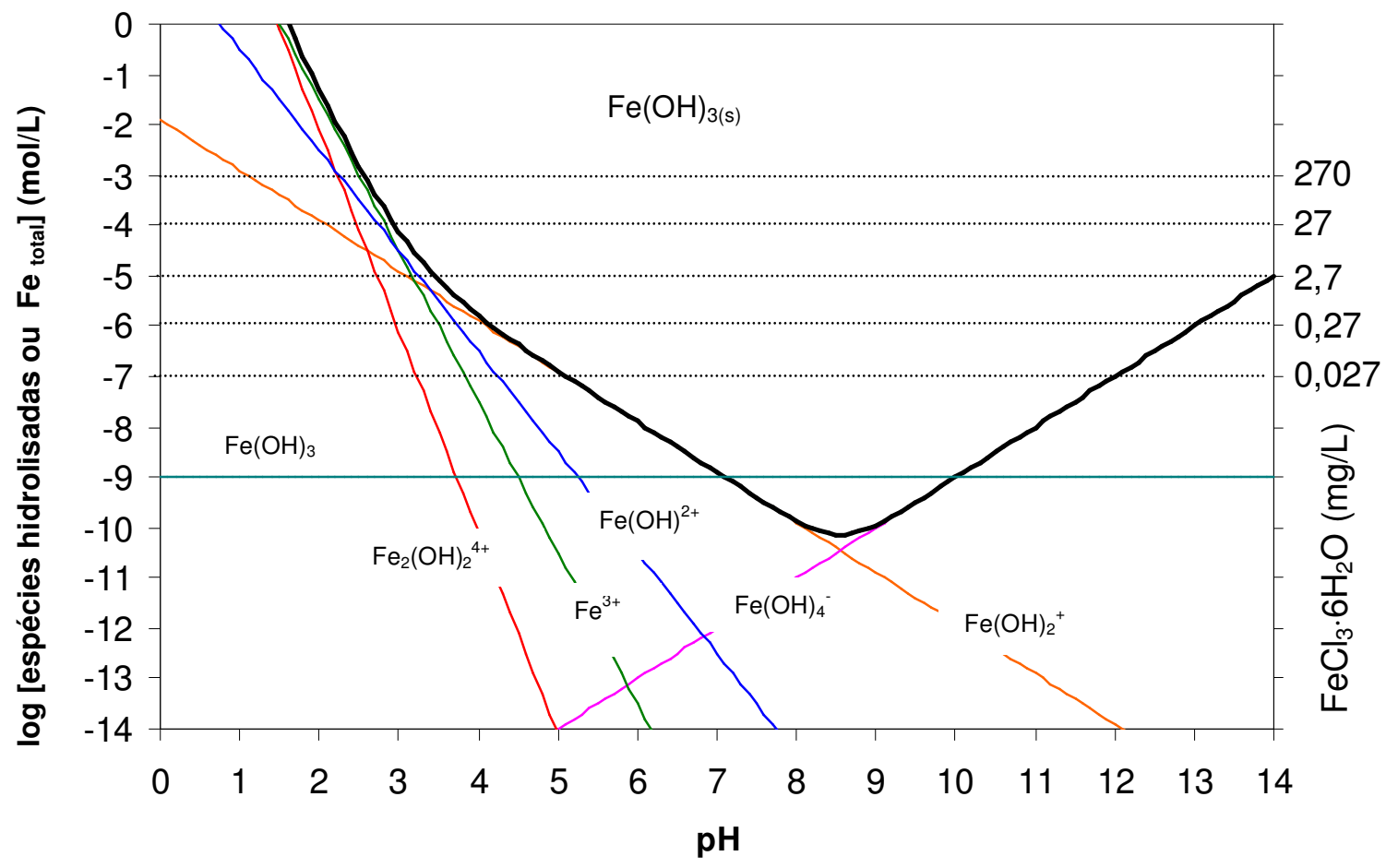

Figura 8 - Diagrama de solubilidade do $\mathrm{Fe}^{3+}$ relacionado com o cloreto férrico .

A concentração total de ferro é dada pela Equação 39:

$$
\mathbf{C}_{\mathbf{T}, \mathrm{Fe}}=\left[\mathrm{Fe}(\mathrm{OH})_{4}\right]+\left[\mathrm{Fe}^{3+}\right]+2\left[\mathrm{Fe}_{2}(\mathrm{OH})_{2}{ }^{4+}\right]+\left[\mathrm{Fe}(\mathrm{OH})_{2}{ }^{+}\right]+\left[\mathrm{Fe}(\mathrm{OH})^{2+}\right]
$$

Se a dosagem do cloreto férrico for igual a $27 \mathrm{mg} \mathrm{L}^{-1}$, observa-se na Figura 8 que a concentração ferro total resulta em $10^{-4} \mathrm{~mol} \mathrm{L^{-1 }}$. Para $\mathrm{pH}$ igual a 8 , a concentração em quantidade de matéria total de ferro dissolvido resulta em $10^{-9} \mathrm{~mol}$ $\mathrm{L}^{-1}$ e a diferença $\left(10^{-4}-10^{-9} \mathrm{~mol} \mathrm{~L}^{-1}\right)$ encontra-se na forma de precipitado; a concentração total de ferro resultante é $5,6 \mathrm{mg} \mathrm{L}^{-1}$. 


\subsubsection{Sulfato de Alumínio}

O sulfato de alumínio PA apresenta a fórmula química $\mathrm{Al}_{2}\left(\mathrm{SO}_{4}\right)_{3} \cdot \mathrm{n} \mathrm{H}_{2} \mathrm{O}(\mathrm{n}=$ 14,3 ou 18). O sulfato de alumínio comercial pode ser adquirido no estado sólido ou líquido. No estado líquido, dependendo da massa específica da solução comercial, têm-se os valores da porcentagem de sulfato de alumínio e de $\mathrm{Al}_{2} \mathrm{O}_{3}$ em massa e a concentração de sulfato de alumínio disponível no produto comercial. A acidez máxima da solução é de $0,5 \%$ em massa.

\subsubsection{Reações de hidrólise de sais de $\mathrm{Al}^{3+}$}

Para valores elevados da dosagem de sulfato de alumínio (geralmente superiores a $30 \mathrm{mg} \mathrm{L}^{-1}$ ) e pH próximo de 6,0 e 8,0 ocorre a formação do precipitado hidróxido de alumínio, $\mathrm{Al}(\mathrm{OH})_{3(\mathrm{~s})}$ mas, em $\mathrm{pH}$ aproximadamente 5,7 pode haver a formação e predominância de espécies poliméricas do tipo $\mathrm{Al}_{13} \mathrm{O}_{4}(\mathrm{OH})_{27}{ }^{4+}$ (DI BERNARDO; DANTAS, 2005, p.182).

Dependendo do tipo de sal de alumínio usado, pode-se relacionar a dosagem desse produto com a concentração em quantidade de matéria de alumínio e da espécie hidrolisada. Isso possibilita que em função da dosagem do produto usado e do $\mathrm{pH}$ sejam quantificados o precipitado e as espécies hidrolisadas presentes. Essas espécies são formadas como intermediárias, antes da formação do precipitado amorfo de hidróxido de alumínio. Essas reações liberam prótons $\left(\mathrm{H}^{+}\right)$, consumindo substâncias responsáveis pela alcalinidade natural da água. Esse consumo, caso 
exista, será aproximadamente $1 \mathrm{mg} \mathrm{L}{ }^{-1}$ de sulfato de alumínio $\left[\mathrm{Al}_{2}\left(\mathrm{SO}_{4}\right)_{3} \cdot 14,3 \mathrm{H}_{2} \mathrm{O}\right]$ para cada $0,5 \mathrm{mg} \mathrm{L}^{-1}$ de carbonato de cálcio $\left(\mathrm{CaCO}_{3}\right)$.

As Equações 40 a 43 e 45 representam as reações de hidrolise do íon $\mathrm{Al}^{3+}$ em água isenta de impurezas a $25^{\circ} \mathrm{C}$.

$$
\begin{aligned}
& \text { Reações de equilíbrio } \quad \log \mathrm{K} \\
& \mathrm{Al}^{3+}+\mathrm{H}_{2} \mathrm{O} \leftrightarrows \mathrm{Al}(\mathrm{OH})^{2+}+\mathrm{H}^{+} \quad-5,02 \\
& 2 \mathrm{Al}^{3+}+2 \mathrm{H}_{2} \mathrm{O} \leftrightarrows \mathrm{Al}_{2}(\mathrm{OH})_{2}^{4+}+2 \mathrm{H}^{+} \quad-6,27 \\
& 6 \mathrm{Al}^{3+}+15 \mathrm{H}_{2} \mathrm{O} \leftrightarrows \mathrm{Al}_{6}(\mathrm{OH})_{15}{ }^{3+}+15 \mathrm{H}^{+} \quad-47,00 \\
& \mathrm{Al}^{3+}+2 \mathrm{H}_{2} \mathrm{O} \leftrightarrows \mathrm{Al}_{8}(\mathrm{OH})_{20}{ }^{4+}+20 \mathrm{H}^{+} \quad-68,7 \\
& \mathrm{Al}(\mathrm{OH})_{3(\mathrm{~s})} \leftrightarrows \mathrm{Al}^{3+}+3 \mathrm{OH}^{-} \quad-32,64 \\
& \mathrm{Al}^{3+}+4 \mathrm{H}_{2} \mathrm{O} \leftrightarrows \mathrm{Al}(\mathrm{OH})_{4}{ }^{-}+4 \mathrm{H}^{+} \quad-23,57
\end{aligned}
$$

Para cada espécie de alumínio $\left(\mathrm{mol} \mathrm{L}^{-1}\right)$ em equilíbrio com o precipitado é possível obter a equação relacionada com o pH.

$\log \mathrm{K}$

$$
\begin{array}{lr}
\mathrm{Al}^{3+}+\mathrm{H}_{2} \mathrm{O} \leftrightarrows \mathrm{Al}(\mathrm{OH})^{2+}+\mathrm{H}^{+} & -5,02 \\
\mathrm{Al}(\mathrm{OH})_{3(\mathrm{~s})} \leftrightarrows \mathrm{Al}^{3+}{ }_{(\mathrm{aq})}+3 \mathrm{OH}_{(\mathrm{aq})}^{-} & -32,64 \\
\mathrm{H}^{+}+\mathrm{OH}^{-} \leftrightarrows \mathrm{H}_{2} \underline{\mathrm{O}} & +14,00 \\
\mathrm{Al}(\mathrm{OH})_{3(\mathrm{~s})} \leftrightarrows \mathrm{Al}(\mathrm{OH})^{2+}+2 \mathrm{OH}^{-} & \mathrm{K}_{\mathrm{s}}=-23,36 \\
\mathrm{~K}=\left[\mathrm{Al}(\mathrm{OH})^{2+}\right]\left[\mathrm{OH}^{-}\right]^{2} /\left[\mathrm{Al}(\mathrm{OH})_{3(\mathrm{~s})}\right. & \\
10^{-5,02}=\left[\mathrm{Al}^{\left.\left.-(\mathrm{OH})^{2+}\right]\left[\mathrm{H}^{+}\right] /[\mathrm{Al})^{3+}\right]}\right. & \\
10^{-32,64}=\left[\mathrm{Al}^{3+}\right]\left[\mathrm{OH}^{-3}\right]^{3 /}\left[\mathrm{Al}(\mathrm{OH})_{3(\mathrm{~s})}\right] &
\end{array}
$$


$10^{-14}=\left[\mathrm{H}^{+}\right]\left[\mathrm{OH}^{-}\right] /\left[\mathrm{H}_{2} \mathrm{O}\right]$

Assumindo que a atividade do precipitado $\mathrm{Al}(\mathrm{OH})_{3(\mathrm{~s})}$ seja igual à unidade, para que a constante de equilíbrio seja expressa em termos da espécie solúvel de $\mathrm{Al}^{3+} \mathrm{e}$ $\mathrm{H}^{+}$, aplica-se o logaritmo com ambos os lados da Equação 46, obtendo-se:

$\log \mathrm{K}=\log \left[\mathrm{Al}(\mathrm{OH})^{2+}\right]+2 \log \left[\mathrm{OH}^{-}\right]$

Como:

$$
\log \left[\mathrm{H}^{+}\right]+\log \left[\mathrm{OH}^{-}\right]=14
$$

$\log \left[\mathrm{H}^{+}\right]=14-\log \left[\mathrm{OH}^{-}\right]$

$\mathrm{pH}=-\log \left[\mathrm{H}^{+}\right]$

Tem-se:

$$
\begin{aligned}
& -23,36=\log \left[\mathrm{Al}(\mathrm{OH})^{2+}\right]+2\left[-14-\log \left(\mathrm{H}^{+}\right)\right] \\
& -23,36=\log \left[\mathrm{Al}(\mathrm{OH})^{2+}\right]-28-2 \log \left[\mathrm{H}^{+}\right]
\end{aligned}
$$

Assim:

$\log \left[\mathrm{Al}(\mathrm{OH})^{2+}\right]=4,64-2 \mathrm{pH}$

Utilizando o mesmo procedimento para as demais espécies, obtém-se:

$\log \left[\mathrm{Al}^{3+}\right]=9,66-3 \mathrm{pH}$

$\log \left[\mathrm{Al}_{6}(\mathrm{OH})_{15}^{3+}\right]=10,96-3 \mathrm{pH}$

$\log \left[\mathrm{Al}_{8}(\mathrm{OH})_{20}^{4+}\right]=8,58-4 \mathrm{pH}$

$\log \left[\mathrm{Al}_{2}(\mathrm{OH})_{2}^{4+}\right]=13,05-4 \mathrm{pH}$

$\log \left[\mathrm{Al}(\mathrm{OH})_{4}^{-}\right]=\mathrm{pH}-13,91$

Por meio das Equações 51 a 56 é possível construir o diagrama de espécies hidrolisadas de alumínio (ordenada) em função do $\mathrm{pH}$ (abscissa), conforme apresenta a Figura 9. 


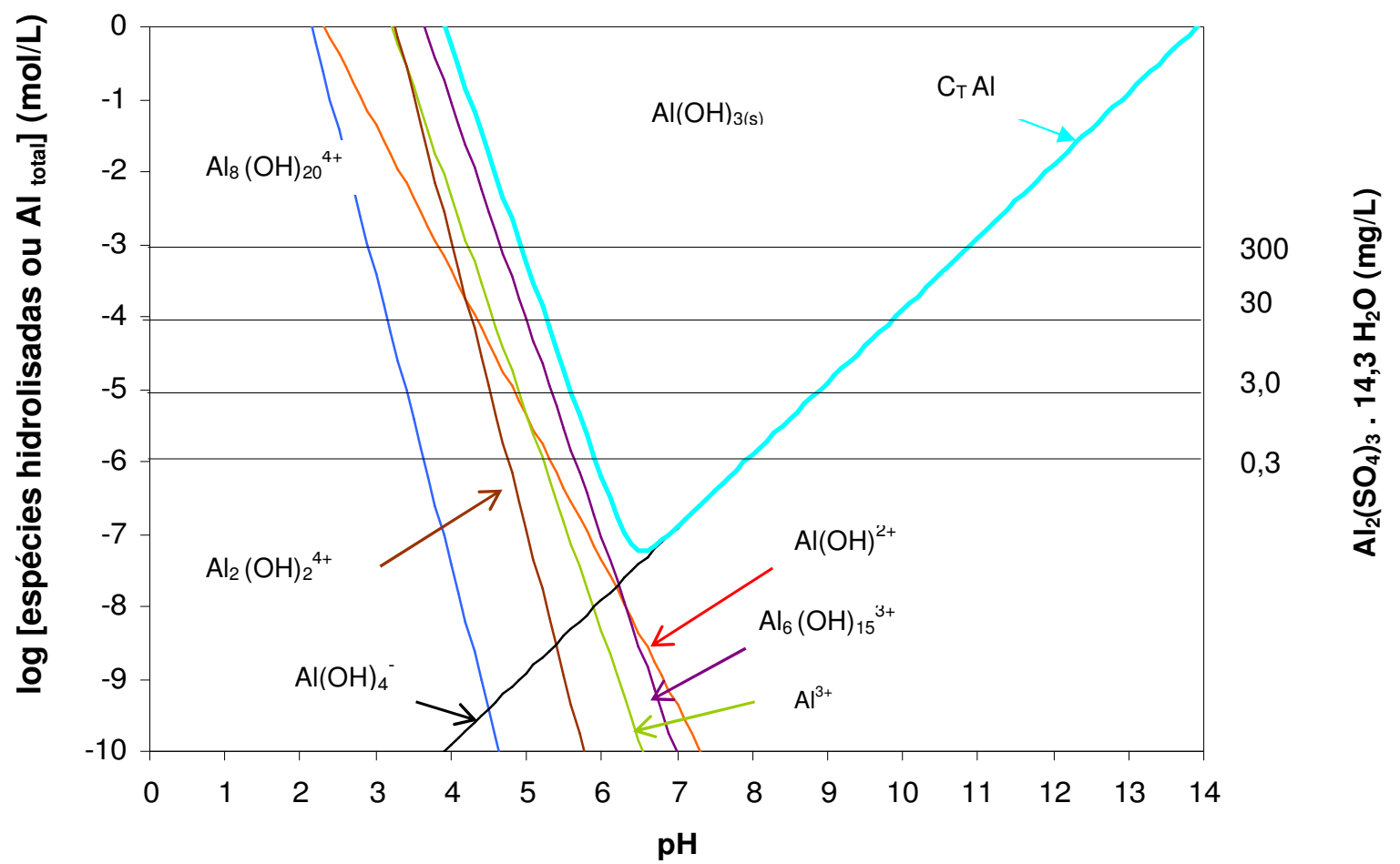

Figura 9 - Diagrama de solubilidade do alumínio relacionado com o $\mathrm{Al}_{2}\left(\mathrm{SO}_{4}\right)_{3} \cdot 14,3$ $\mathrm{H}_{2} \mathrm{O}$.

A concentração de alumínio total é dada pela Equação 57:

$\mathrm{C}_{\mathrm{T}, \mathrm{Al}}=\left[\mathrm{Al}(\mathrm{OH})^{2+}\right]+\left[\mathrm{Al}^{3+}\right]+6\left[\mathrm{Al}_{6}(\mathrm{OH})_{15^{3+}}\right]+8\left[\mathrm{Al}_{8}(\mathrm{OH})_{20}{ }^{4+}\right]+2\left[\mathrm{Al}_{2}(\mathrm{OH})_{2}{ }^{4+}\right]+$ $\left[\mathrm{Al}(\mathrm{OH})_{4}{ }^{-}\right]$

Para cada uma das Equações 52 a 56, assumindo diferentes valores de pH, obtêm-se 0 valor da concentração de cada espécie (aplicando o anti-log). Substituindo-se esses valores na Equação 57, efetuando-se a soma e aplicando-se logaritmo na base 10 ao valor obtido para cada valor de $\mathrm{pH}$, obtém-se a concentração total de Al. Com isso, traçando-se a linha que representa a Equação 57 na Figura 9, obtém-se a região que delimita a formação do precipitado.

Por exemplo, para as Equações 52 a $56 \mathrm{com} \mathrm{pH}=4$, tem-se:

$\log \left[\mathrm{Al}^{3+}\right]=9,66-3 \mathrm{pH}=9,66-3 \times 4=-2,340$

$\left[\left.\mathrm{A}\right|^{3+}\right]=4,571 \times 10^{-3} \mathrm{~mol} \mathrm{~L}^{-1}$ 


$$
\begin{aligned}
& {\left[\mathrm{Al}_{6}(\mathrm{OH})_{15}{ }^{3+}\right]=9,210 \times 10^{-2} \mathrm{~mol} \mathrm{~L}^{-1}} \\
& {\left[\mathrm{Al}_{8}(\mathrm{OH})_{20}{ }^{4+}\right]=3,802 \times 10^{-8} \mathrm{~mol} \mathrm{~L}^{-1}} \\
& {\left[\mathrm{Al}_{2}(\mathrm{OH})_{2}^{4+}\right]=1,122 \times 10^{-3} \mathrm{~mol} \mathrm{~L}^{-1}} \\
& {\left[\mathrm{Al}(\mathrm{OH})_{4}{ }^{4}\right]=1,230 \times 10^{-10} \mathrm{~mol} \mathrm{~L}^{-1}} \\
& {\left[\mathrm{Al}(\mathrm{OH})^{2+}\right]=2,754 \times 10^{-4} \mathrm{~mol} \mathrm{~L}^{-1}}
\end{aligned}
$$

Substituindo esses valores na Equação 57 tem-se:

$$
\mathrm{C}_{\mathrm{T}, \mathrm{Al}}=0,554 \mathrm{~mol} \mathrm{~L}^{-1}
$$

Aplicando o log $(0,554)$ tem-se o valor - 0,256. O mesmo procedimento pode ser adotado para outros valores de $\mathrm{pH}$.

\subsection{Mecanismos da coagulação}

As partículas coloidais, $\mathrm{SH}$ e microrganismos em geral apresentam-se com carga negativa na água, ou as partículas coloidais podem ter polímeros adsorvidos em sua superfície, impedindo a aproximação das mesmas. Por isso, é necessário alterar a força iônica do meio, o que em uma ETA é feito por meio da adição

principalmente de sais de alumínio ou de ferro ou de polímeros sintéticos ou vegetais catiônicos, caracterizando o fenômeno de coagulação (DI BERNARDO; DANTAS, 2005).

Considera-se a coagulação como resultado individual ou combinado da ação de quatro mecanismos de coagulação distintos. Esses mecanismos incluem: compressão de dupla camada elétrica, adsorção e neutralização de carga, varredura, adsorção e formação de pontes. O tipo de interação entre o coagulante 
químico e as partículas coloidais determina os mecanismos de coagulação ( $\mathrm{O}^{\prime}$ MELIA 1972; DEMPSEY, 1984; EDWARDS; AMIRTHARAJAH, 1985).

\subsubsection{Compressão de dupla camada elétrica}

Este mecanismo de coagulação ocorre devido à desestabilização das partículas coloidais através da introdução de um colóide (não tem características de hidrólise e de adsorção, como ocorre com sais de alumínio e ferro) em um sistema coloidal. O aumento na densidade de cargas na camada difusa faz com que o tamanho da esfera diminua, ocorrendo a coagulação por compressão da dupla camada difusa. A elevada força iônica na água aumenta o número de íons na camada difusa, a qual para se manter eletricamente neutra, tem seu volume reduzido (diminuição da espessura), prevalecendo as forças de van der Waals, eliminando a estabilização eletrostática. Por exemplo, esse mecanismo ocorre quando águas doces com força iônica pequena misturam-se com a água do mar, promovendo a formação de depósitos nas desembocaduras.

Destacam-se dois aspectos interessantes sobre esse mecanismo de coagulação: primeiramente, a quantidade de eletrólitos para conseguir-se a coagulação é praticamente independente da concentração de colóides presentes na água; em segundo lugar, para qualquer quantidade adicionada de eletrólitos é impossível causar a reestabilização das partículas coloidais, ou seja, a reversão de carga das mesmas, que passa a ser positiva (EDWARDS; AMIRTHARAJAH, 1985;

DI BERNARDO; DANTAS, 2005). 


\subsubsection{Adsorção - neutralização de cargas}

Neutralização de carga é o mecanismo usado para explicar a ocorrência de interações eletrostáticas entre as partículas contidas na água e o coagulante. Nesse caso, as espécies químicas do coagulante são capazes de serem adsorvidas na superfície das partículas coloidais, as quais possuem carga elétrica contrária à dos colóides.

Amirtharajah (1989) utilizando água preparada em laboratório com turbidez da ordem de 17 uT, obteve resultados de aplicabilidade do diagrama de coagulação do alumínio em instalação piloto de filtração direta descendente em meio filtrante de antracito e areia, com taxa de filtração em torno de $300 \mathrm{~m} / \mathrm{d}$. O autor observou a variação de turbidez depois de 7 horas de filtração, para as dosagens de sulfato de alumínio igual a $5 \mathrm{mg} \mathrm{L}^{-1}$ e $\mathrm{pH}$ de coagulação entre 6,9 e 7,0, e para as dosagens de sulfato de alumínio de $8 \mathrm{mg} \mathrm{L^{-1 }}$ a pH de 6,9 a 7,1. Em ambos os casos, independentemente da dosagem do coagulante, o autor observou que a menor turbidez em todas as profundidades do meio filtrante ocorreu para um valor de $\mathrm{pH}$ de coagulação em torno de 7,0, em que predominava o mecanismo de neutralização de cargas com potencial zeta positivo (região corona).

Segundo Di Bernardo (2005), o mecanismo de adsorção e neutralização de carga deve ser utilizado nas ETAs de filtração direta, pois não há necessidade de formação de flocos para posterior sedimentação ou flotação, mas sim de partículas desestabilizadas que serão retidas no meio granular dos filtros.

Na coagulação de SH empregando a filtração direta a remoção de cor pode ocorrer na região chamada "corona", na qual se tem coagulação no mecanismo de neutralização de carga pelo precipitado com carga positiva. Essa região se encontra 
ao redor da zona de reestabilização dos colóides (reversão de cargas), ocorrendo quando os colóides tornam-se carregados positivamente pelo excesso de íons de carga positiva, geralmente em $\mathrm{pH}$ a partir de 4,8 (AMIRTHARAJAH, 1989). A reestabilização pode ser detectada através de leituras do potencial zeta das partículas.

\subsubsection{Varredura}

Esse mecanismo é comum quando são usados sais de alumínio ou ferro como coagulante. As espécies do precipitado sólido formado são do tipo $\mathrm{Al}(\mathrm{OH})_{3}$ (hidróxido de alumínio) ou $\mathrm{Fe}(\mathrm{OH})_{3}$ (hidróxido de férrico), que interagem com as partículas coloidais e formam flocos maiores do que nos processos de adsorção e neutralização de cargas. Com isso, esses flocos sedimentam mais rapidamente. O mecanismo da varredura, definido por O'Melia et al. (1967) como "sweep coagulation", é intensivamente utilizado nas estações de tratamento de água em que se tem a floculação e a sedimentação (ou flotação) antecedendo a filtração rápida.

No mecanismo de varredura, a mistura lenta é uma das etapas mais importantes, pois, promove o contato entre o precipitado de hidróxido de alumínio ou hidróxido de férrico e as partículas dissolvidas que após estas serão removidas. As interações entre as partículas ocorrem por movimento Browniano, movimento instável (fluídico) e sedimentação. A freqüência das colisões é dependente das propriedades da água como temperatura, densidade, viscosidade, entre outras e das partículas como concentração, tamanho e densidade, além do tipo da mistura (AWWA COAGULATION COMMITTEE, 1989). 
Os mecanismos de coagulação usando sais de metais são dependentes das espécies hidrolisadas do coagulante que atuam para desestabilizar as moléculas das $\mathrm{SH}$ presentes em águas naturais. As espécies hidrolisadas do coagulante e a estabilidade das SHA são determinadas pelo $\mathrm{pH}$ da água (JOHNSON; AMIRTHARAJAH, 1983).

Ambos os mecanismos de coagulação para os sais de ferro e alumínio envolvem a adsorção e a varredura (O' MELIA, 1972; GREGORY, 1978). Os mecanismos das reações de hidrólise e formação dos hidróxidos de alumínio e de hidróxido de ferro são apresentados na Figura 10.

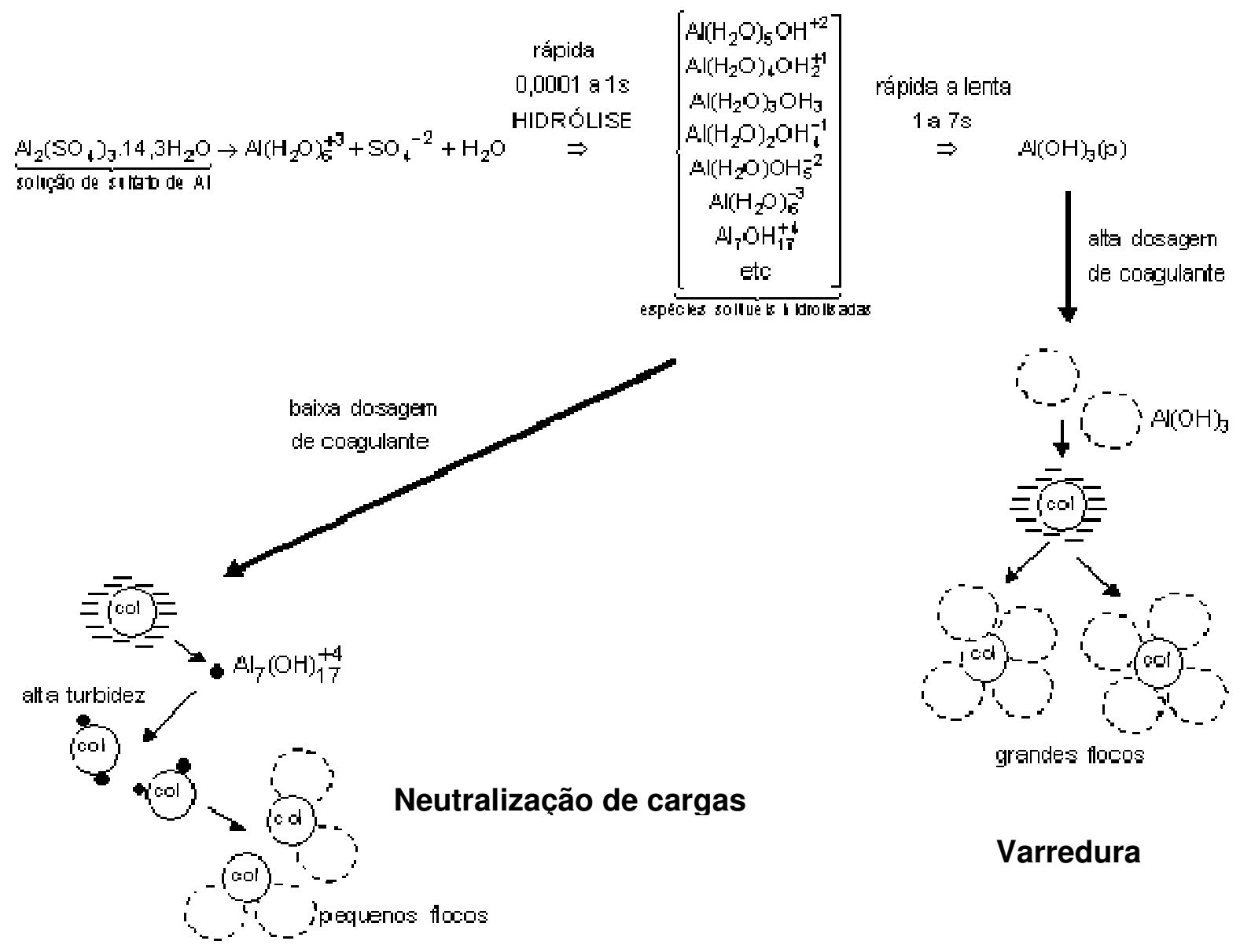

Figura 10 - Caminhos para a coagulação por adsorção e neutralização de carga e por varredura, utilizando sulfato de alumínio (AMIRTHARAJAH; MILLS, 1982). 
Conforme apresentado na Figura 10, a mistura rápida é de fundamental importância no mecanismo de neutralização de cargas, porque as espécies de coagulante entram em contato com as partículas coloidal presentes na água bruta antes da formação do precipitado sólido de hidróxido do metal.

As reações de hidrólise do coagulante influenciam na eficiência de remoção das partículas dissolvidas na água e na formação dos flocos (AWWA COAGULATION COMMITTEE, 1989).

\subsubsection{Adsorção e formação de pontes}

Esse mecanismo ocorre através da adição de polímeros sintéticos ou naturais, de elevada massa molar com sítios ionizáveis, podendo ser classificados como catiônicos, aniônicos e anfóteros. O polímero é adsorvido na superfície das partículas coloidais e isso reduz a carga ou pode haver o "entrelaçamento" das partículas na cadeia do polímero. O’ Melia (1972) afirma que o polímero serve como ponte entre as partículas (DI BERNARDO; DANTAS, 2005, p.182).

\subsection{Diagramas de coagulação}

Amirtharajah e Mills (1982) desenvolveram o diagrama de coagulação para o sulfato de alumínio $\left(\mathrm{Al}_{2}\left(\mathrm{SO}_{4}\right)_{3} \cdot 14,3 \mathrm{H}_{2} \mathrm{O}\right)$ versus $\mathrm{pH}$, como apresentado na Figura 11. Pode-se observar regiões distintas para os diferentes mecanismos de coagulação: adsorção e neutralização de carga e varredura, ou combinação de ambas. Na região de coagulação por varredura, a adsorção das partículas ocorre no 
precipitado de hidróxido de alumínio. Esta região é recomendada para tratamento de água em ciclo completo, pois os flocos são densos e isso facilita a sedimentação.

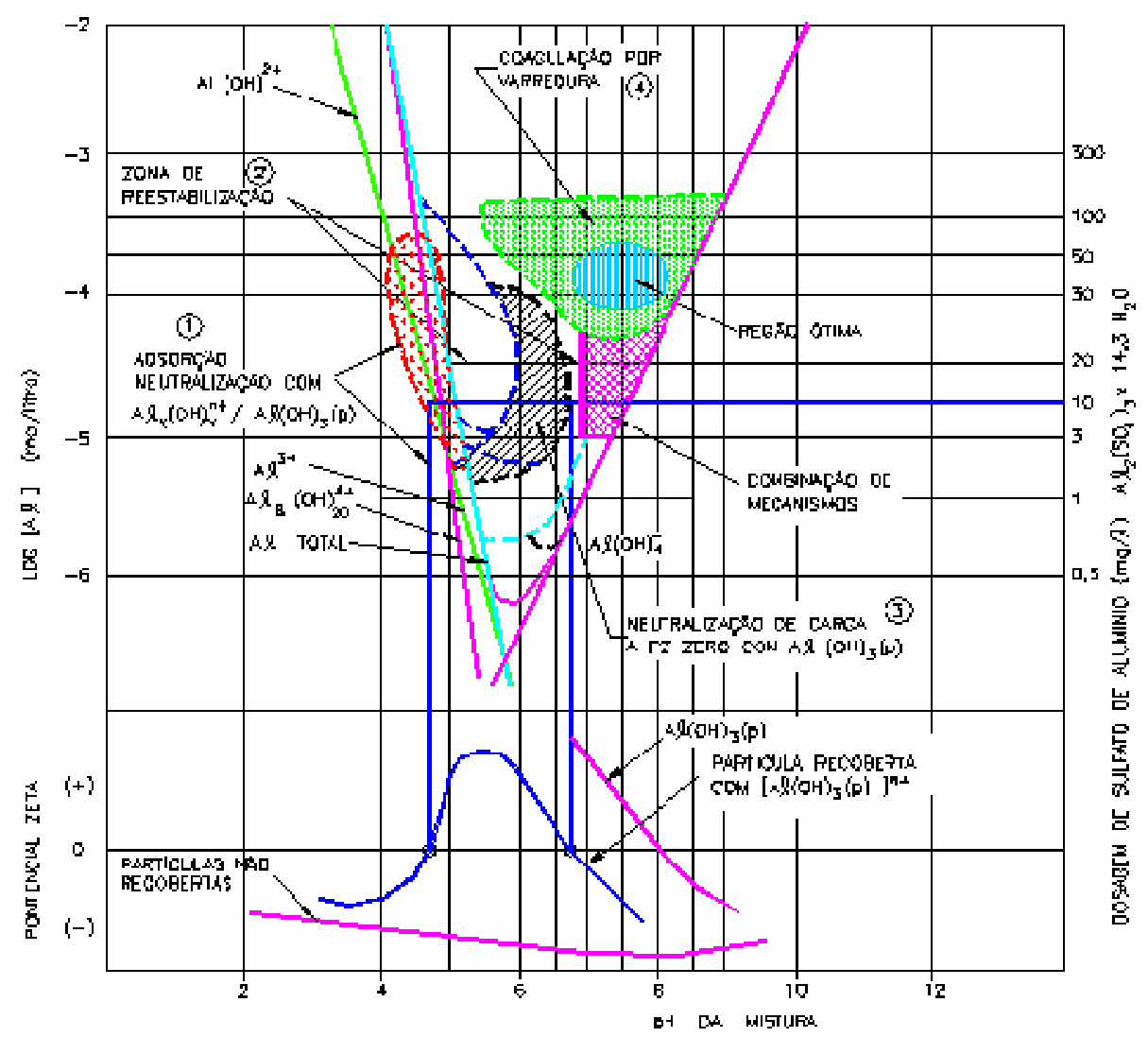

Figura 11 - Diagrama de coagulação com sulfato de alumínio para remoção de turbidez alta em relação à cor verdadeira (AMIRTHARAJAH ,1989).

Como apresentado na Figura 11, existem quatro regiões distintas:

Região 1: nesta região pode ocorrer a neutralização das cargas das partículas coloidais pelas espécies hidrolisadas de alumínio, que são adsorvidas na superfície dos colóides. Com o pH em torno de 4,8, o potencial zeta se aproxima de zero, caracterizando o ponto isoelétrico dos colóides recobertos com espécies de alumínio, e a dosagem de sulfato de alumínio poderá variar entre 3 e $70 \mathrm{mg} \mathrm{L}^{-1}$.

Região 2: para $\mathrm{pH}$ maior que 4,8, o PZ torna-se positivo, assim como os colóides, caracterizando o fenômeno de reestabilização. A desestabilização causa a 
delimitação superior da região de reestabilização, devido à presença de íons $\mathrm{SO}_{4}{ }^{2-} \mathrm{e}$ ao aprisionamento dos colóides reestabilizados em complexos de sulfato de alumínio.

Região 3: quando a dosagem de sulfato de alumínio for igual a $10 \mathrm{mg} \mathrm{L}^{-1}$ e o $\mathrm{pH}$ em torno de 6,8 e o valor do $\mathrm{PZ}$ se aproximar de zero, o ponto isoelétrico é atingido, e quando a região em que o PZ for máximo, acontece a reestabilização. Para a dosagem de coagulante em torno de 3 a $30 \mathrm{mg} \mathrm{L}^{-1}$, há uma região em que ocorre o mecanismo de neutralização de carga pelo hidróxido de alumínio, essa região é considerada ideal para a coagulação quando se aplica a filtração direta.

Região 4: nesta região predomina o mecanismo de coagulação por varredura, com pH em torno de 6,0 a 8,0 e dosagens acima de $30 \mathrm{mg} \mathrm{L}^{-1}$. Este mecanismo é recomendado quando se tem estações com ciclo completo.

\subsubsection{Coagulação de águas contendo substâncias húmicas}

Edwards e Amirtharajah (1985) utilizaram em seus estudos água destilada com a adição de AH para obter cor verdadeira de $100 \mathrm{uH}$ e sem turbidez. Os autores construíram os diagramas de coagulação com base nas seguintes condições: mistura rápida $\left(T_{m r}=1 \mathrm{~min}\right)$; gradiente de mistura rápida $\left(G_{m r}=100\right.$ a $\left.120 \mathrm{~s}^{-1}\right)$; tempo de floculação $\left(T_{f}=20 \mathrm{~min}\right)$; gradiente de floculação $\left(G_{f}=15\right.$ a $\left.20 \mathrm{~s}^{-1}\right)$ e tempo de sedimentação $\left(T_{s}=2 \mathrm{~h}\right)$. Os diagramas foram construídos para diferentes parâmetros (cor, turbidez e concentração de $\mathrm{AH}$ ). As medidas de cor verdadeira foram efetuadas em espectrofotômetro, após centrifugação das amostras. A Figura 12 apresenta o digrama de coagulação com sais de alumínio para remoção de cor verdadeira devido à presença de $\mathrm{AH}$. 


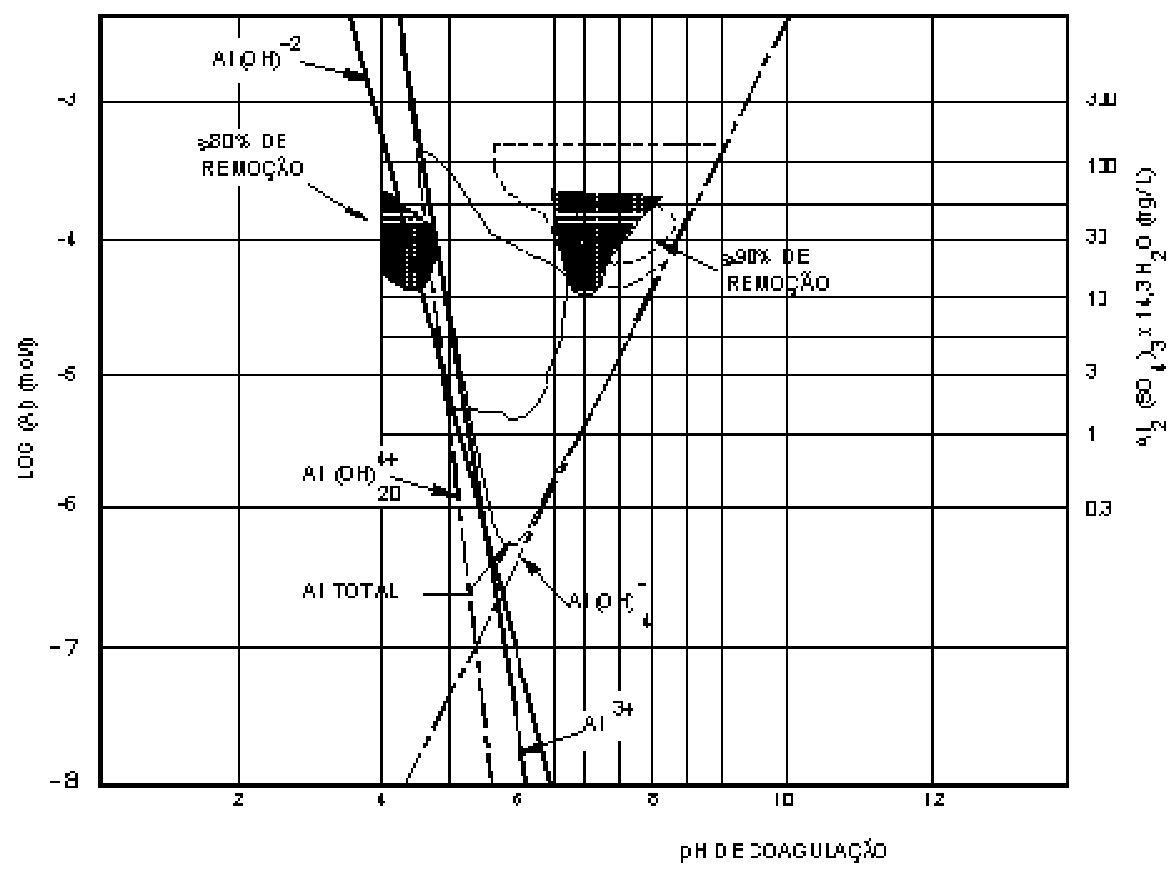

Figura 12 - Diagrama de coagulação com sais de alumínio para a remoção de cor verdadeira; concentração de ácido húmico $=4 \mathrm{mg} \mathrm{L}^{-1}$; cor verdadeira $=$ $100 \mathrm{uH}$; turbidez = 0 uT (EDWARDS; AMIRTHARAJAH,1985).

Os autores observaram na Figura 12 a existência de duas regiões de coagulação eficiente: a região 1, caracterizada para pH de coagulação entre 4,0 e 4,75 e dosagens de sulfato de alumínio entre 10 e $80 \mathrm{mg} \mathrm{L}^{-1}$ e remoção de cor verdadeira em 80\%; a região 2, caracterizada para pH no intervalo de 6,0 a 7,0 e dosagens de sulfato de alumínio maiores que $12 \mathrm{mg} \mathrm{L}^{-1}$ e a remoção de cor verdadeira com eficiência de $90 \%$. Nota-se também uma região de reestabilização entre as duas regiões.

A coagulação das $\mathrm{SH}$ tem sido creditada a dois mecanismos principais quando são utilizados sais de alumínio ou de ferro como coagulantes. Na faixa de pH de 6,0 a 8,0, região em que há predominância do precipitado de hidróxidos, onde a remoção ocorre por adsorção das $\mathrm{SH}$ no precipitado. Quando o pH de coagulação encontra-se na faixa de 4,0 a 5,5 , assume-se que as $\mathrm{SH}$ sejam neutralizadas pelas 
espécies hidrolisadas positivas do alumínio, promovendo a precipitação das SH na forma de humato de alumínio.

A Figura 13 apresenta o diagrama de solubilidade do sulfato de alumínio com maior concentração de $\mathrm{AH}$, e conseqüentemente com cor verdadeira mais elevada e turbidez zero.

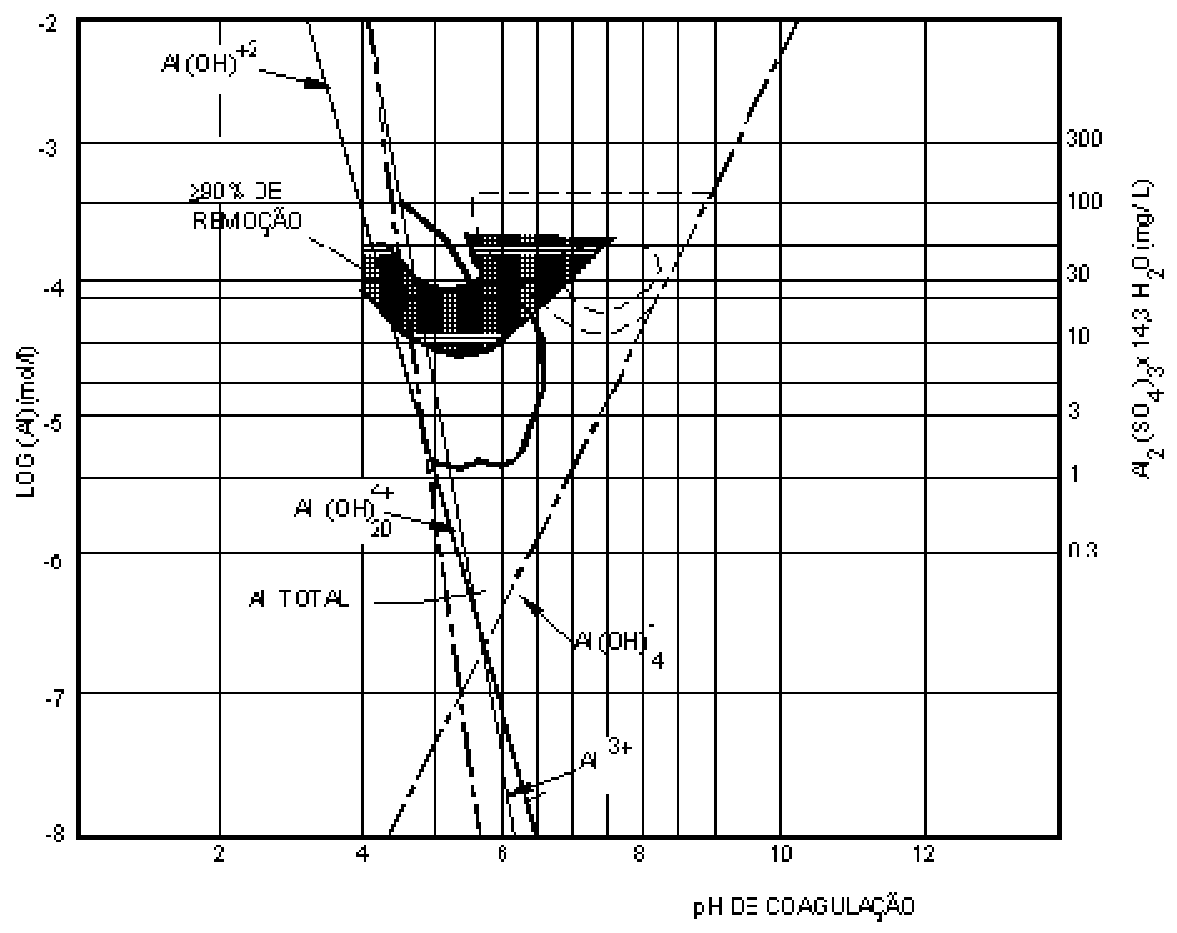

Figura 13 - Diagrama de coagulação do alumínio para remoção de cor verdadeira; concentração de $\mathrm{AH}=20 \mathrm{mg} \mathrm{L}^{-1}$; cor verdadeira $=450 \mathrm{uH}$; turbidez $\cong 0$ UT (EDWARDS; AMIRTHARAJAH, 1985).

Os autores observaram na Figura 13 que apenas existe uma região de coagulação eficiente entre os valores de $\mathrm{pH}$ de 4,5 e 7,5 e dosagens de sulfato de alumínio entre 10 e $50 \mathrm{mg} \mathrm{L}^{-1}$. Notaram também que a faixa de $\mathrm{pH}$ é menor, entre 4,5 e 5,7 e a dosagem de coagulante é menor para se obter a eficiência de $90 \%$ na remoção de cor. Há também duas regiões de reestabilização, uma inferior e outra 
superior a de eficiência de remoção de cor de 90\% (EDWARDS; AMIRTHARAJAH, 1985).

Segundo Dempsey et al. (1984), há um aumento da dosagem do coagulante decorrente do aumento da concentração de $\mathrm{SH}$, quando o mecanismo é de neutralização de carga.

Na Figura 14 tem-se o diagrama de coagulação do alumínio para água com as seguintes características: cor verdadeira $=100 \mathrm{uH}$; cor aparente $=130 \mathrm{uH}$; turbidez $=5 \mathrm{uT}$; alcalinidade $=40 \mathrm{mg} \mathrm{L}^{-1} \mathrm{CaCO}_{3} ; \mathrm{pH}=7,5$; temperatura $=25{ }^{0} \mathrm{C}$ (MENDES, 1989). Os ensaios foram feitos com os seguintes parâmetros: mistura rápida $\left(T m r=10 \mathrm{~s} ; \mathrm{Gmr}=600 \mathrm{~s}^{-1}\right)$; floculação $\left(\operatorname{Tmf}=40 \mathrm{~min} ; \mathrm{Gmf}=10 \mathrm{~s}^{-1}\right)$; sedimentação $\left(\mathrm{Vs}=1 \mathrm{~cm} \mathrm{~min}{ }^{-1}\right)$.

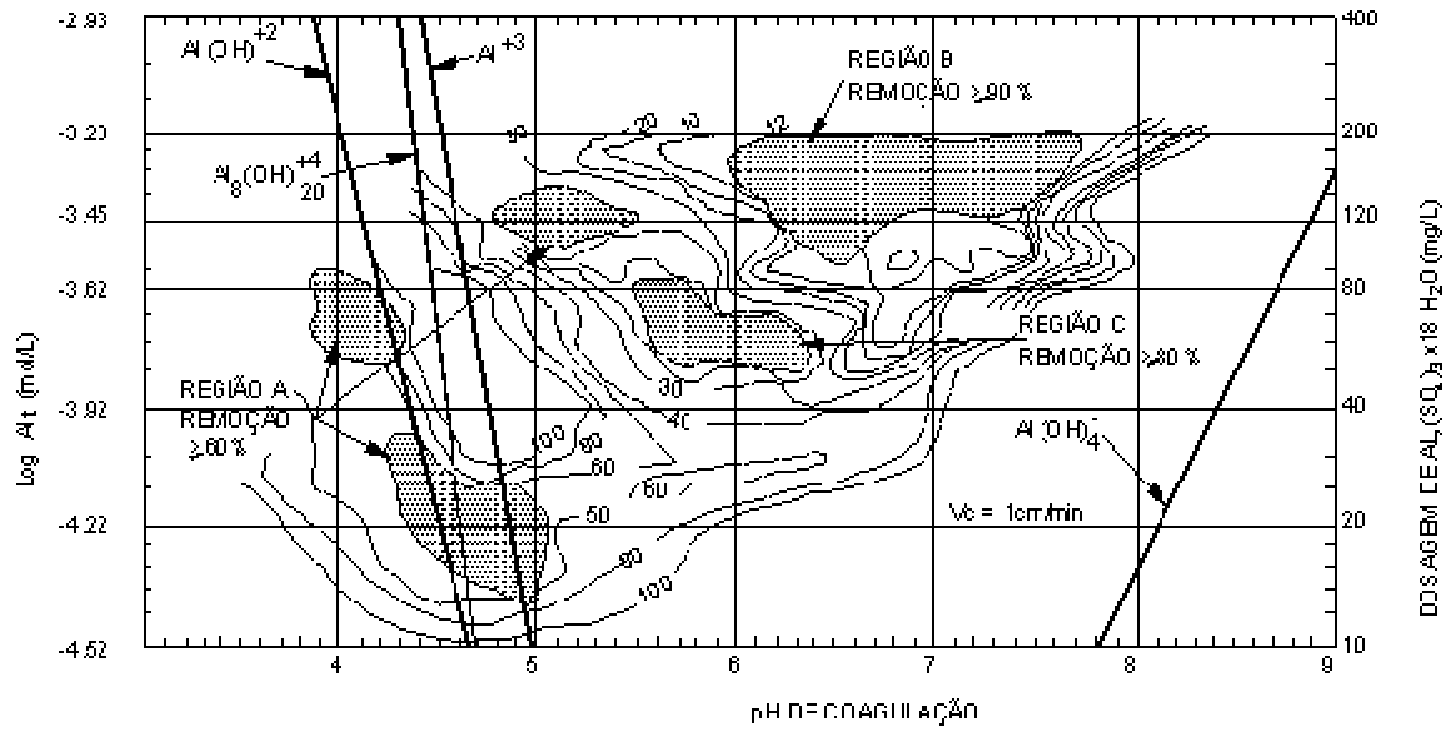

Figura 14 - Diagrama de coagulação para remoção de cor verdadeira (MENDES, 1989).

O autor observou na Figura 14 que na região A existe uma remoção de cor por sedimentação bem menor ( $\geq 60 \%$ ) que na obtida pela região $B(\geq 90 \%)$ ou $C(\geq$ $80 \%$ ). Através desses resultados puderam comprovar a melhor eficiência de remoção de cor com o sulfato de alumínio em pH mais elevados. 
Comparando os resultados apresentados na Figura 12 e na Figura 14, o autor observou que a cor verdadeira para ambas as águas de estudo são iguais a $100 \mathrm{uH}$, porém as diferenças resultam das diferentes $\mathrm{SH}$ usadas nos dois estudos, especialmente em relação ao tamanho molecular, à turbidez e à velocidade de sedimentação.

Amirtharajah et al. (1985) estudaram a influência da turbidez na eficiência da coagulação de água contendo SH. As Figuras 15 e 16 apresentam os diagramas de coagulação para águas de estudo preparadas com água destilada, $\mathrm{AH}$ e caulinita, de modo que a cor verdadeira resultasse de $100 \mathrm{uH}$ e de $450 \mathrm{uH}$ e a turbidez entre 27 e 30 uT.

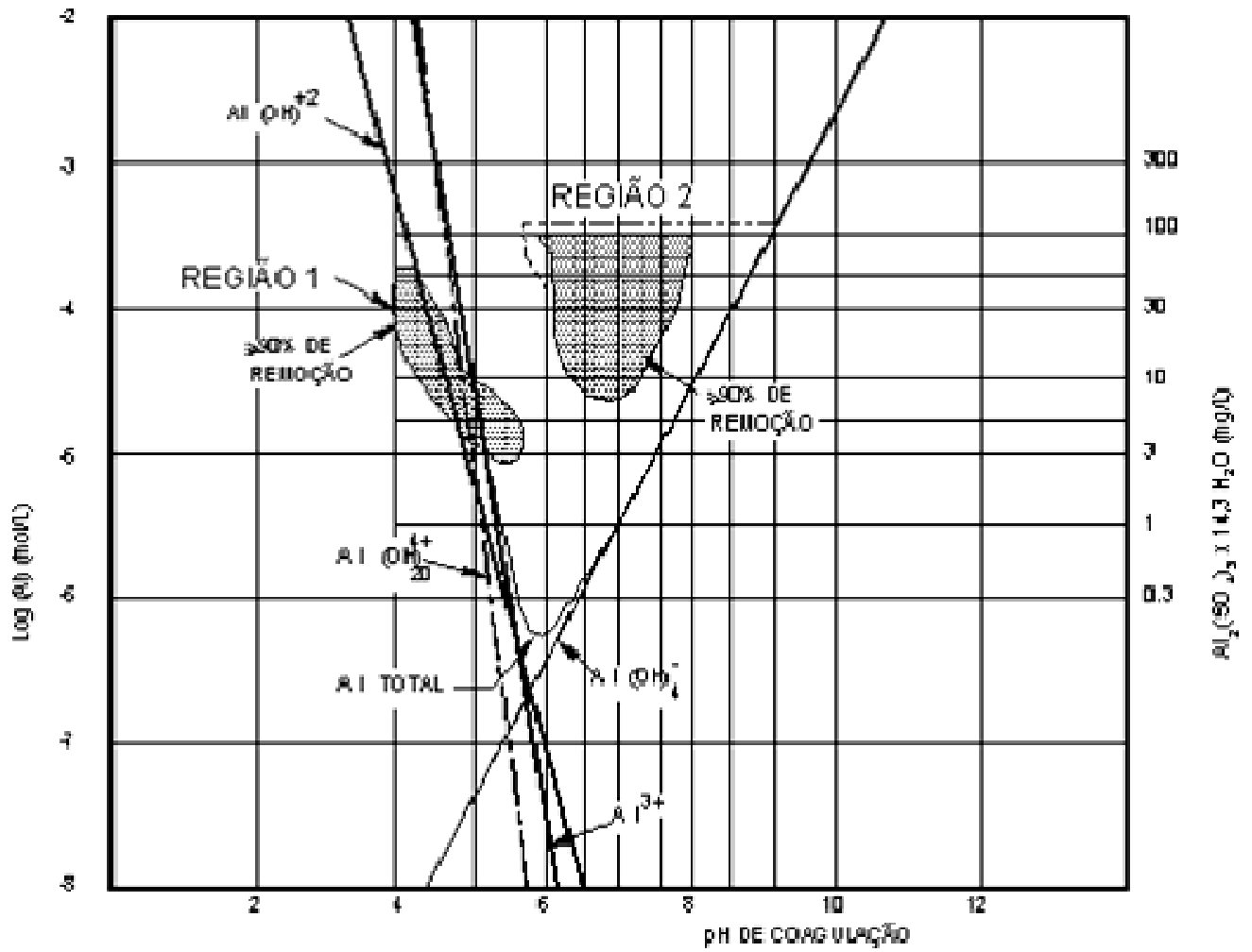

Figura 15 - Diagrama de coagulação para remoção de cor verdadeira e turbidez; concentração de $\mathrm{AH}=4 \mathrm{mg} \mathrm{L}^{-1}$; cor Verdadeira $=100 \mathrm{uH}$; turbidez $=27$ a 30 uT (EDWARDS ; AMIRTHARAJAH, 1985). 


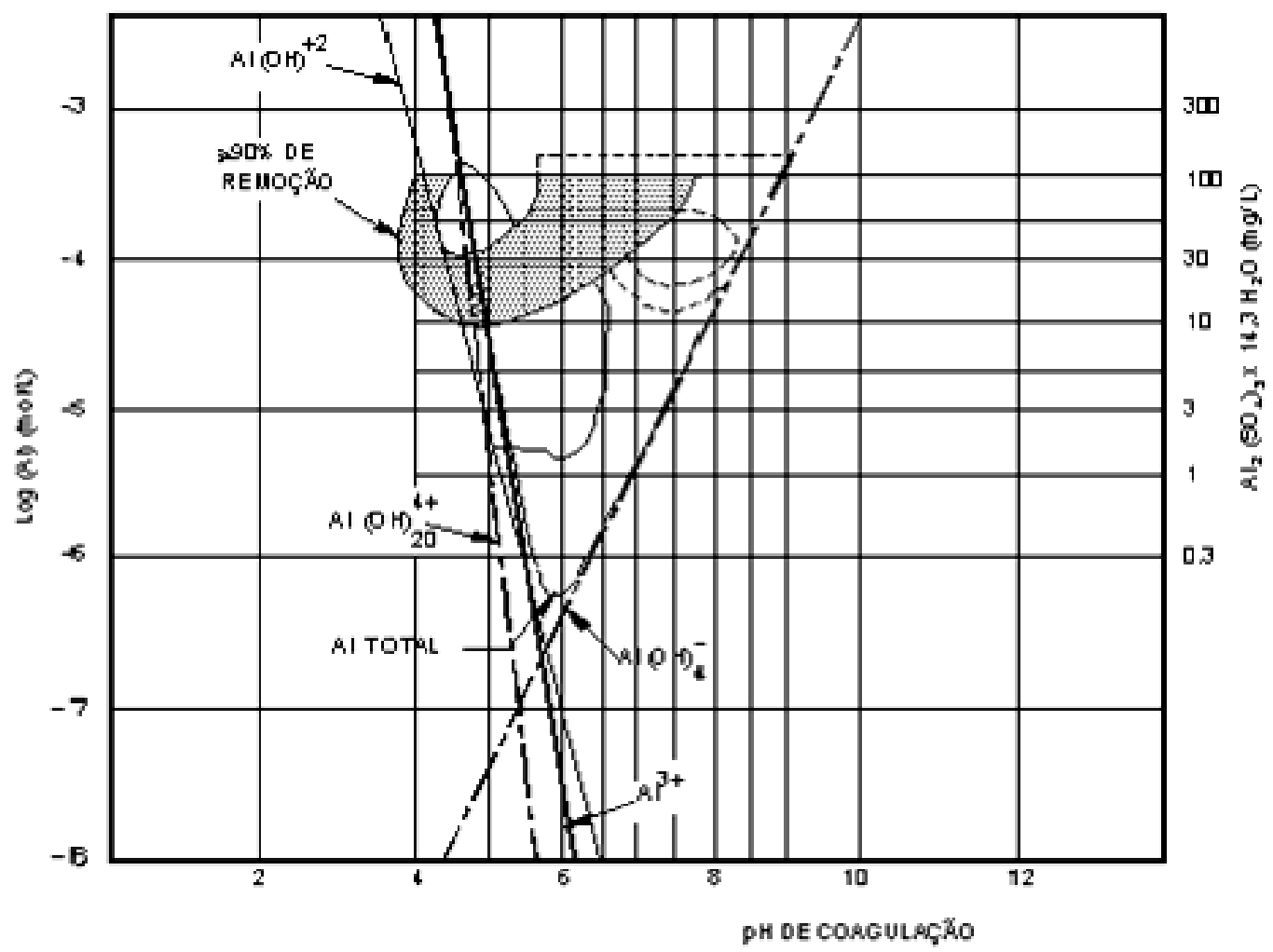

Figura 16 - Diagrama de coagulação para remoção de cor verdadeira e turbidez; concentração de $\mathrm{AH}=20 \mathrm{mg} \mathrm{L}^{-1}$; cor Verdadeira = $450 \mathrm{uH}$; turbidez $=27$ a 30 uT (EDWARDS ; AMIRTHARAJAH, 1985).

Os autores concluíram que para ambos os diagramas (Figuras 15 e 16) houve modificação na região de coagulação eficiente, decorrente da presença de turbidez.

Pavanelli (2001) fez um estudo utilizando a água do poço artesiano, caulinita e $\mathrm{AH}$, e comparou quatro tipos de coagulantes: sulfato de alumínio $\mathrm{Al}_{2}\left(\mathrm{SO}_{4}\right)_{3} \cdot 14,3$ $\mathrm{H}_{2} \mathrm{O}$; cloreto férrico, $\mathrm{FeCl}_{3}$; hidróxicloreto de alumínio, $\mathrm{Al}_{n}(\mathrm{OH})_{m} \mathrm{Cl}_{3 n-m}$ e sulfato férrico, $\mathrm{Fe}_{2}\left(\mathrm{SO}_{4}\right)_{3} \times 8 \mathrm{H}_{2} \mathrm{O}$. Neste estudo a água utilizada apresentou as seguintes características: cor verdadeira = 95 a 105 uH; cor aparente = 150 a 160 uH; turbidez $=6,0$ a 6,5 uT; $\mathrm{pH}=7,5$ a 7,6; alcalinidade $=30 \mathrm{mg} \mathrm{CaCO}_{3} \mathrm{~L}^{-1}$; condutividade elétrica $=50 \mu \mathrm{S} \mathrm{cm}{ }^{-1}$; temperatura $=20 \pm 1{ }^{0} \mathrm{C}$. Também foram utilizados hidróxido 
de sódio e ácido clorídrico para o ajuste do pH de coagulação. Os ensaios foram feitos nas seguintes condições: tempo de mistura rápida $\left(T_{m r}=5 \mathrm{~s}\right)$; gradiente de mistura rápida $\left(G_{m r}=700 \mathrm{~s}^{-1}\right)$; tempo de floculação $\left(T_{m f}=40 \mathrm{~min} ; G_{m f}=10 \mathrm{~s}^{-1}\right)$; sedimentação: velocidade de sedimentação de $1 \mathrm{~cm} \mathrm{~min}{ }^{-1}$. Conforme as condições selecionadas para efetuar a comparação de custos para cada coagulante apresentadas na Tabela 4, o autor concluiu que o cloreto férrico apresentou o menor custo perante os outros coagulantes estudados.

Tabela 4 - Condições selecionadas para a análise de custos: Vs $=1 \mathrm{~cm} \mathrm{~min}^{-1}$ e cor aparente $=\leq 20 \mathrm{uH}$ (PAVANELLI, 2001).

\begin{tabular}{llll}
\hline Coagulante & pH de & Dosagem de & Dosagem de \\
& coagulação & coagulante $\left(\mathrm{mg} \mathrm{L}^{-1}\right)$ & alcalinizante $\left(\mathrm{mg} \mathrm{L}^{-1}\right)$
\end{tabular}

\begin{tabular}{llll}
\hline Sulfato de alumínio & 6,95 & 270 & 44
\end{tabular}

líquido

\begin{tabular}{llll}
\hline Cloreto férrico & 6,40 & 60 & 6,5
\end{tabular}

líquido

$\begin{array}{llll}\text { Hidroxicloreto de } & 6,80 & 60 & 6,5\end{array}$

alumínio

Sulfato férrico

6,40

80

22

líquido

Gregor et al. (1997) concluíram que o controle do pH é um dos fatores mais importantes para maximizar a remoção da MON. Um dos problemas observados nos ensaios feitos na coagulação de água com turbidez baixa é a ineficiência na produção de flocos. Os sítios ativos das partículas coloidais presentes na água natural podem ser fornecidos pela adição de caulinita, a qual também serve para corrigir o pH e alcalinidade da água. Em alguns tipos de água, para manter-se o pH de coagulação desejado, é adicionado uma solução de ácido ou de base, comumente o ácido clorídrico e hidróxido de sódio, respectivamente. 
Sharp et al. (2006) estudaram os impactos da variação sazonal da matéria orgânica natural (MON) na coagulação de diferentes tipos de águas, em decorrência do aumento da concentração do COD nas estações outono e inverno. A MON presente na água bruta foi fracionada em frações hidrofóbicas (AH e AF) e hidrofílicas, para investigar a variação da carga superficial (densidade de carga total) e interações das SH com o coagulante, durante 36 meses, de novembro de 2000 a novembro de 2003. Foi verificado que ocorre uma variação significativa da fração de AF em função das estações do ano, aumentando de $31 \%$ em setembro de 2000 para $61 \%$ em novembro 2000. Em setembro de 2003 as frações relativas foram de $36 \% \mathrm{AF}, 32 \%$ de $\mathrm{AH}$ e de $32 \%$ de fração hidrofílica. Os autores concluíram que as frações hidrofóbicas possuem densidade de carga maior que as frações hidrofílicas da matéria orgânica natural. Os autores observaram que houve uma maior contribuição dos AF no aumento da densidade de carga, motivo pelos quais estes exercem influência significativa na coagulação. As frações hidrofílicas são indicativas do MOD residual após o tratamento da água, porque essas frações são menos removidas na coagulação com sais de metais.

Leenheer e Huffman (1976) analisaram aproximadamente 100 amostras de diferentes fontes de águas superficiais. Os autores encontraram um teor de MOD hidrofóbica de 56\%. Sharp et al. (2006) demonstraram que a hidrofobicidade da MOD era de $68 \%$ a $79 \%$, valores esses similares aos de águas com elevada cor que foram empregadas em pesquisas feitas no Canadá, Escandinavia e Rússia, as quais apresentaram dados de hidrofobicidade do MOD entre $60 \%$ e $80 \%$ (MALCON, 1985).

Campos et al. (2007) estudaram o efeito do tamanho molecular aparente de diferentes frações de SHT $\left(F_{1}\right.$ : maior que $100 \mathrm{kDa}, F_{2}$ : entre 30 e $100 \mathrm{kDa}$ e $F_{3}$ : 
menor que $30 \mathrm{kDa}$ ), na eficiência da coagulação, empregando o sulfato de alumínio como coagulante. Neste caso foi simulada a tecnologia de ciclo completo, utilizando quatro amostras de água preparadas em laboratório com cor igual a $100 \pm 5 \mathrm{uH}$. Os autores demonstraram claramente que, além da medida de cor verdadeira, seria importante o conhecimento da distribuição dos tamanhos moleculares das $\mathrm{SH}$. Os autores concluíram que os diferentes tamanhos moleculares aparentes das SHT apresentaram comportamentos diferentes durante a coagulação, floculação e sedimentação, sendo que as moléculas de SH de maiores tamanhos moleculares aparentes, a remoção de cor remanescente foi mais eficiente. Também concluíram através das análises de RMN e espectroscopia de infravermelho que para as SHT de menores tamanhos moleculares entre 30 e $100 \mathrm{kDa}$ e menor que $30 \mathrm{kDa}$, apresentaram elevadas concentrações de grupos oxigenados. Sendo assim, as águas preparadas com essas frações apresentaram baixa remoção de cor aparente.

Sanches (2005) estudou a influência das SHT com diferentes tamanhos moleculares aparentes na formação de trialometanos e outros subprodutos clorados, empregando cloro e dióxido de cloro na etapa de pré-oxidação da água. O autor concluiu principalmente que: i) o clorofórmio foi o subproduto majoritário nos ensaios feitos com todas as frações de SHT; ii) na oxidação da água com o cloro, ocorreu a formação de maior concentração de subprodutos clorados em relação aos ensaios realizados com oxidante dióxido de cloro; iii) nos ensaios feitos com a água preparada com SHT de menor tamanho molecular aparente, ocorreu uma maior concentração dos subprodutos clorados formados e especialmente para o clorofórmio. 


\section{OBJETIVOS}

Esta pesquisa teve como objetivos principais:

- Extrair, fracionar e caracterizar as frações das SHA empregando-se técnicas analíticas como: ressonância magnética nuclear de $\mathrm{C}^{13}(\mathrm{RMN}$ de $\mathrm{C}^{13}$ ), infravermelho (IV) e ultravioleta-Visível (UV/VIS), análise elementar e teor de cinzas.

- Avaliar a influência dos diferentes tamanhos moleculares aparentes das SHA na eficiência da coagulação, por meio de ensaios empregando-se equipamento de jarteste e filtros de areia em escala laboratorial.

- Estudar os coagulantes químicos, sulfato de alumínio e cloreto férrico na eficiência de remoção das SHA em águas para o abastecimento público, verificando essa eficiência através dos parâmetros de cor aparente e turbidez. 


\section{PARTE EXPERIMENTAL}

\subsection{Etapas deste estudo}

As etapas envolvidas nos procedimentos experimentais estão descritas no fluxograma apresentado na Figura 17.

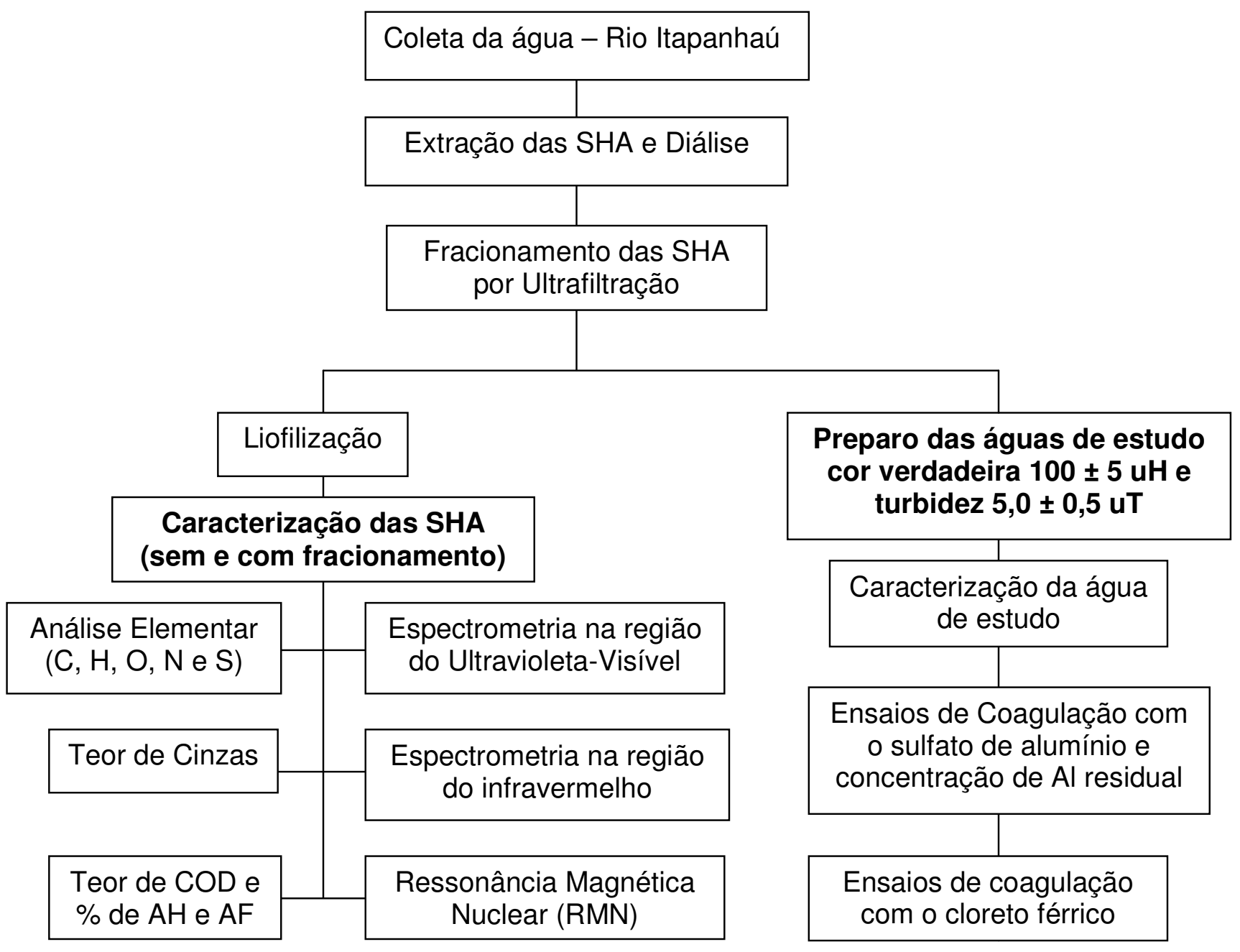

Figura 17 - Fluxograma das etapas seguidas durante os procedimentos experimentais. 


\subsection{Coleta e extração das substâncias húmicas aquáticas}

As análises foram feitas no Instituto de Química de São Carlos da Universidade de São Paulo (IQSC-USP) e no Laboratório de Saneamento da Escola de Engenharia de São Carlos (EESC-USP).

A coleta e o armazenamento das amostras de água foram feitas de acordo com as recomendações da International Humic Substances Society (IHSS).

Foram coletados aproximadamente 3.000 litros de água no Rio Itapanhaú, Bertioga-SP. A coleta foi feita em três etapas, na primeira coletou-se cerca de $600 \mathrm{~L}$, na segunda coletou-se $650 \mathrm{~L}$ e a última foram coletados $2.000 \mathrm{~L}$. Este rio pertence ao Parque Estadual da Serra do Mar, localizado no $11^{\circ}$ Grupo de Unidades de Gerenciamento de Recursos Hídricos (UGRHIs), sétima UGRHIs-Baixada Santista, município de Bertioga-SP (fotos da Figura 18). Neste estudo, as amostras de água coletada no rio Itapanhaú foram acidificadas a pH 2,5, com ácido clorídrico, a fim de prevenir a precipitação de hidróxidos metálicos e armazenada em recipientes plásticos. Foram determinados alguns parâmetros desta água como: pH, cor aparente, cor verdadeira, absorbância em 254 nm, turbidez, alcalinidade, condutividade, carbono orgânico dissolvido entre outros.
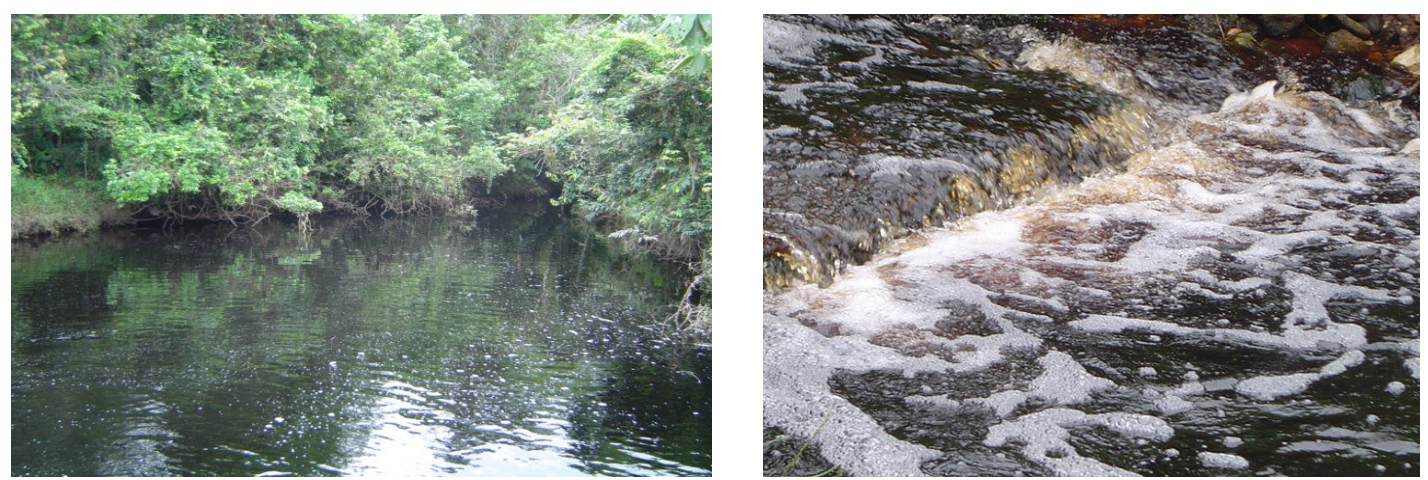

Figura 18 - Foto do Rio Itapanhaú-Bertioga-SP. 
O Rio Itapanhaú vem sendo estudado na Escola de Engenharia de São Carlos da Universidade de São Paulo (EESC-USP), na Universidade Estadual Paulista (UNESP) de Araraquara-SP e na Universidade de Ribeirão Preto (UNAERP) devido ao elevado teor de SHA, o qual apresenta cor verdadeira da ordem de 400 $\mathrm{uH}$.

\subsection{Extração das SHA e diálise}

Para a extração das SHA foi utilizada a resina macroporosa não-iônica de éster acrílico (XAD 8), de acordo com procedimento recomendado pela International Humic Substances Society (IHSS). A resina foi mantida sob agitação mecânica em metanol durante 24 horas, para que fossem eliminados possíveis grupos hidrofílicos retidos, e em seguida lavada várias vezes com água deionizada (THURMAN; MALCOLM, 1981). Após essa etapa, a resina XAD 8 foi suspensa em água deionizada e transferida para uma coluna de acrílico formando um leito trocador de $30 \mathrm{~cm}$. Em seguida, a amostra de água acidificada foi percolada através da coluna com vazão de $22 \mathrm{~mL} \mathrm{~min}^{-1}$. O líquido efluente foi monitorado por leituras de absorbância a $254 \mathrm{~nm}$ com o objetivo de estimar a saturação da resina (LARA; THOMAS, 1994). Quando o valor da absorbância do efluente apresentou aproximadamente metade do valor da absorbância da amostra de água coletada, a extração foi interrompida para posterior eluição das SHA.

A eluição foi feita com solução de hidróxido de sódio $(\mathrm{NaOH})$ 0,10 mol L'-1,

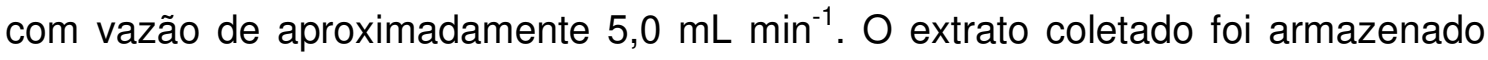
em frasco de polietileno e mantido sob refrigeração a $4^{\circ} \mathrm{C}$. Após o uso, a resina XAD 8 foi recuperada por lavagens sucessivas com metanol, até desaparecimento da 
coloração amarela do líquido sobrenadante, seguida de lavagem com água deionizada para posterior empacotamento na coluna.

Para a realização da diálise (Figura 20), os extratos foram acondicionados em embalagens de papel celofane e imersos em um banho com solução de $\mathrm{HCl}$ em $\mathrm{pH}$ em torno de 2,5 para redução do $\mathrm{pH}$ entre 6,0 e 7,0 próximo da amostra de água coletada no rio Itapanhaú. Posteriormente, as embalagens foram lavadas com água corrente, coletada do poço artesiano localizado no campus da USP de São Carlos, até teste negativo de cloretos, utilizando solução padronizada de nitrato de prata $\left(\mathrm{AgNO}_{3}\right)$ 0,10 mol L-1. Foram obtidos aproximadamente 60 litros de extrato de SHA após a extração dos 3.000 litros de água bruta. Na Figura 19 é apresentada à foto das instalações utilizadas para a extração de SHA.

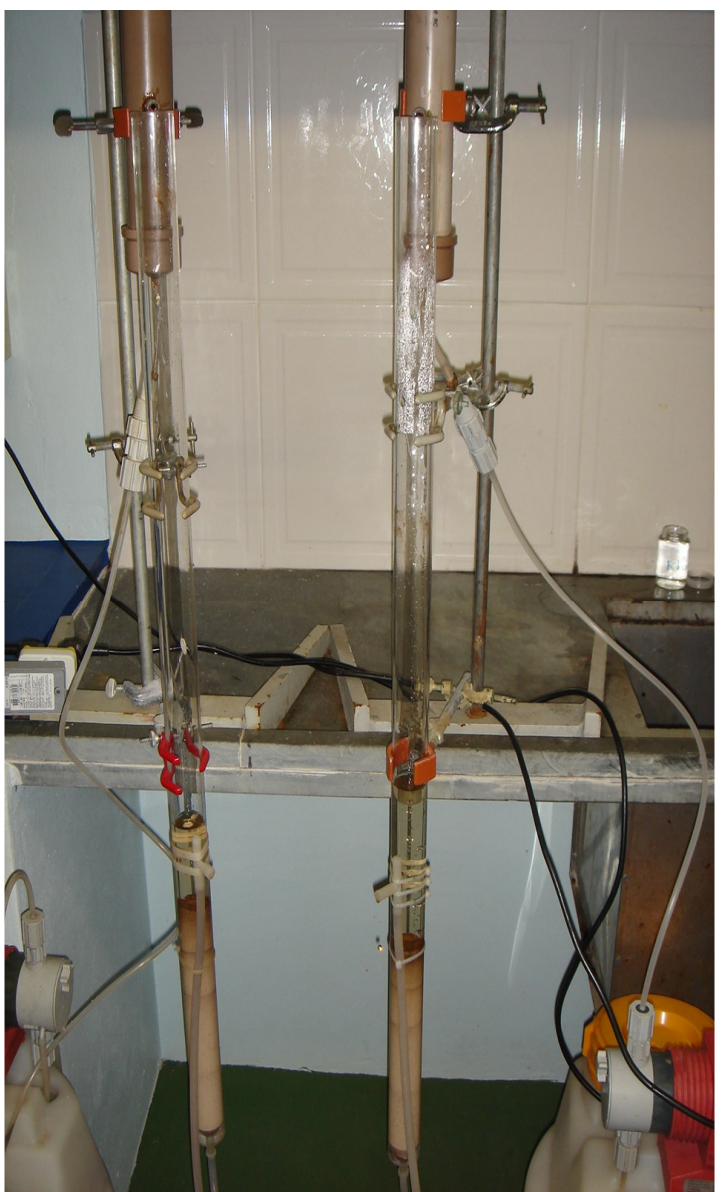

Figura 19 - Foto das instalações de extração das SHA.
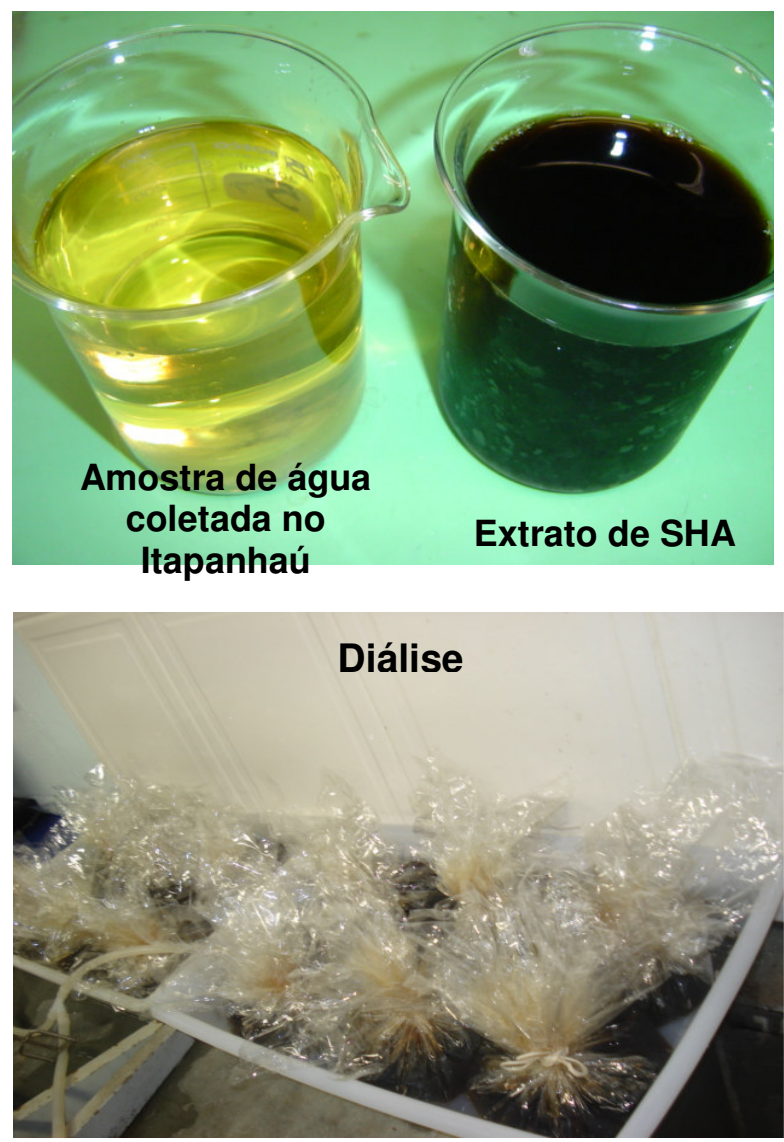

Figura 20 - Foto da água coletada no Rio Itapanhaú e extrato após diálise. 


\subsection{Fracionamento das SHA por ultrafiltração (UF)}

Primeiramente o extrato contendo as SHA foi diluído em uma porção de 1:4 de água deionizada, em seguida filtrada a vácuo em membrana 0,45 $\mu$ m (Millipore em HA em éster de celulose, $90 \mathrm{~mm}$ de diâmetro). O sistema de ultrafiltração é apresentado na foto da Figura 21.

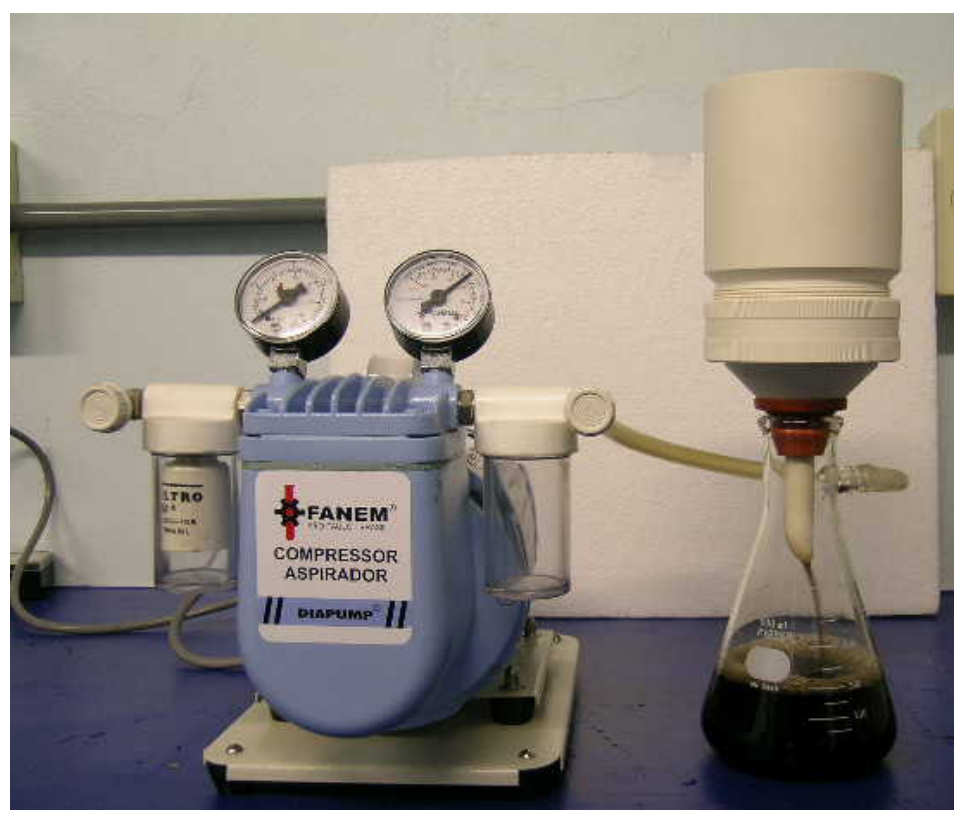

Figura 21 - Foto do sistema de filtração nas membranas de 0,45 $\mu \mathrm{m}$.

A membrana de $0,45 \mu \mathrm{m}$ foi lavada com $200 \mathrm{~mL}$ de água deionizada antes do seu uso. Após filtrar cerca de $800 \mathrm{~mL}$ de amostra, esta era descartada.

Após a filtração em membrana de $0,45 \mu \mathrm{m}$, o extrato foi fracionado por ultrafiltração, passando através de duas membranas de polietersulfonato em paralelo, sistema Vivaflow50 fabricado pela empresa Vivascience, com fluxo tangencial, como apresentado na foto da Figura 22. 


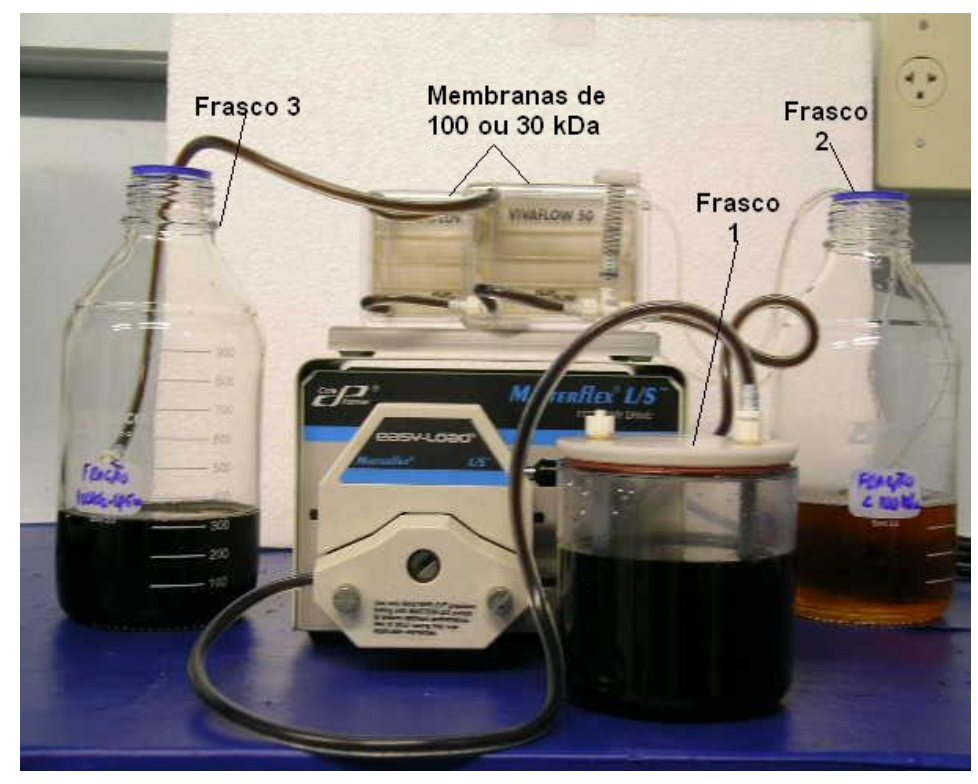

Figura 22 - Foto do fracionamento das SHA no equipamento Vivaflow 50.

Foram utilizadas as membranas de 100, 30, 10 e 5 kDa, para a obtenção das frações com diferentes tamanhos moleculares aparente: $\mathbf{F}_{\mathbf{1}}$ : menor que $0,45 \mu \mathrm{m}, \mathbf{F}_{\mathbf{2}}$ : entre $100 \mathrm{kDa}$ e 0,45 $\mu \mathrm{m}, \mathbf{F}_{\mathbf{3}}$ : entre $30 \mathrm{kDa}$ e $100 \mathrm{kDa}, \mathbf{F}_{4}$ : entre $10 \mathrm{kDa}$ e $30 \mathrm{kDa}, \mathbf{F}_{\mathbf{5}}$ : entre $5 \mathrm{kDa}$ e $10 \mathrm{kDa}$ e $\mathbf{F}_{6}$ : menor que $5 \mathrm{kDa}$.

Durante o fracionamento, foi adotado o método de concentração da amostra por recirculação (a amostra que não passou pela membrana foi concentrada no frasco 1 de alimentação), para conseguir-se um maior volume de amostra fracionada (DUARTE et al.; 2001). Utilizando-se uma membrana de 100 kDa, no Frasco 2, foi coletada a fração menor que 100 kDa. Após concentrar $90 \%$ do seu volume inicial (BUFFLE et al., 1978), desconectou-se a recirculação e a fração que não passou pela membrana de $100 \mathrm{kDa}$ foi coletada num frasco $3\left(\mathrm{~F}_{2}\right)$. Em seguida filtrou-se a fração menor que 100 kDa na membrana de $30 \mathrm{kDa}$, coletando a fração menor que $30 \mathrm{kDa}$ no frasco 2 e depois de concentrada a amostra, as frações que não passaram pela membrana de $30 \mathrm{kDa}$ foram coletadas no frasco $3\left(\mathrm{~F}_{3}\right)$. Seguiuse o mesmo procedimento para as outras membranas de 10 kDa e 5 kDa. A máxima 
vazão utilizada foi de $300 \mathrm{~mL} \mathrm{~min}{ }^{-1}$ com 1,5 bar de pressão. A vazão elevada é útil para promover o deslocamento de compostos acumulados sobre a superfície das membranas devido ao fluxo tangencial do filtrado, e isso evita possível obstrução dos poros (ROCHA; ROSA, 2003).

Para a limpeza das membranas de 100, 30 e $10 \mathrm{KDa}$ utilizou-se o procedimento recomendado no manual do equipamento Vivaflow 50 , descrito a seguir:

Antes de iniciar a filtração, fez-se as lavagens das membranas com $1 \mathrm{~L}$ de água deionizada. Após a filtração de $1 \mathrm{~L}$ da amostra, fez-se a lavagem com solução de $\mathrm{NaOH} 0,1 \mathrm{~mol} \mathrm{~L}^{-1}$, em sistema de recirculação por cerca de 7 minutos. Novamente lavou-se com $1 \mathrm{~L}$ de água deionizada. A lavagem final foi feita com solução de $\mathrm{NaOH}$ 0,5 mol L-1 em sistema de recirculação por cerca de 35 minutos. Em seguida lavou-se com $2 \mathrm{~L}$ de água deionizada e finalmente fez-se a lavagem com solução de álcool etílico $10 \%$, durante cerca de 3 minutos. As membranas foram acondicionadas em geladeira a $4^{\circ} \mathrm{C}$.

Campos (2004) estudou a influência do volume de amostra filtrada pelas membranas, em relação às principais características das estruturas das frações das substâncias SHT. O autor verificou que após 1 e $12 \mathrm{~L}$ de volume filtrado por ultrafiltração, não houve diferenças significativas nas caracterizações das frações de SHT. Assim, após serem filtradas $12 \mathrm{~L}$ de amostra as membranas de ultrafiltração foram descartadas. 


\subsection{Liofilização das frações de SHA}

Uma parte do volume dos extratos fracionados em diferentes tamanhos moleculares aparentes foi concentrado em rotaevaporador, congelados em banho de nitrogênio líquido e liofilizados a uma temperatura de $-40^{\circ} \mathrm{C}$ e pressão de $10^{-1}$ torr em Liofilizador marca Edwards, HETO. Um volume de $50 \mathrm{~mL}$ da amostra foi liofilizada em cada frasco em tempo de aproximadamente de 20 horas. Em seguida, foram feitas as caracterizações das diferentes frações. O restante do extrato foi congelado em freezer para os ensaios de coagulação posteriores.

$O$ extrato da $F_{6}$ não foi liofilizado porque o volume obtido foi insuficiente para obter a massa necessária para as caracterizações.

\subsection{Caracterização das frações de SHA}

\subsubsection{Determinação do teor de cinzas}

Amostras de $10 \mathrm{mg}$ dos extratos liofilizados foram calcinadas a $800^{\circ} \mathrm{C}$ em mufla marca EDG, modelo 1800 - 3P, durante 4 horas. Foi calculado o teor de matéria orgânica pela diferença de massa após a calcinação, considerando-se o resíduo final a matéria inorgânica. O teor de cinzas foi determinado pela Equação 58:

$\%$ cinzas $=m_{1} / m_{2} \times 100$

Onde: $\mathrm{m}_{1}=$ massa das SHA após calcinação;

$\mathrm{m}_{2}=$ massa das SHA antes da calcinação. 


\subsubsection{Análise elementar}

As análises elementares foram feitas na Central de Análises Químicas e Instrumentais do Instituto de Química de São Carlos, utilizando-se o aparelho CE Instruments EA 1110 CHNS - O, da marca Fisons, com detector de condutividade térmica.

As composições elementares das substâncias húmicas foram determinadas em relação ao teor de carbono, hidrogênio, oxigênio, nitrogênio. As porcentagens de hidrogênio $(H)$, carbono $(C)$, nitrogênio $(N)$ e fósforo $(P)$ foram determinadas diretamente e o elemento oxigênio $(\mathrm{O})$ foi calculado por diferença.

\subsubsection{Espectroscopia no infravermelho (IV)}

As análises de IV foram feitas no IQSC-USP, em um espectrômetro com transformada de Fourier, da marca Bomem MB-102. Para a análise foram preparadas pastilhas do material liofilizado na proporção de 1:100 (1 mg de amostra e $100 \mathrm{mg}$ de brometo de potássio seco a $120^{\circ} \mathrm{C}$ ). Foram feitas 16 varreduras com 4 $\mathrm{cm}^{-1}$ de resolução nos espectros obtidos na região de 400 a $4.000 \mathrm{~cm}^{-1}$.

\subsubsection{Espectroscopia na região do ultravioleta/visível (UV/VIS)}

As análises foram feitas no IQSC-USP, em um espectrômetro de UV/VIS Hitachi modelo U3501. Para a análise. dissolveu-se $2 \mathrm{mg}$ de SHA em $25 \mathrm{~mL}$ de solução de bicarbonato de sódio $\left(\mathrm{NaHCO}_{3}\right) \quad 0,05 \mathrm{~mol} \mathrm{~L}^{-1}$ e determinou-se as razões entre as absorbâncias medidas nos comprimentos de onda de 465 e 665 nm, 
referida como razão $E_{4} / E_{6}$, e nos comprimentos de onda de 250 e 365 nm, referida como razão $E_{2} / E_{3}$.

\subsubsection{Ressonância magnética nuclear (RMN)}

As análises de RMN foram feitas no Instituto de Física de São Carlos (IFSC) USP, utilizando um espectrômetro de RMN da marca VARIAN Unit INOVA, operando a uma freqüência de 100 e $400 \mathrm{MHz}$ para ${ }^{13} \mathrm{C}$. Foi utilizada uma rampa de radiofreqüência na polarização cruzada, velocidade de rotação da amostra em torno do ângulo mágico de $13 \mathrm{kHz}$ e desacoplamento em alta potência (CP/MAS). A técnica de rotação em torno do ângulo mágico é mais geral e serve para se obter espectros com resolução (distinguir entre os sinais dos diferentes grupos químicos). As SHA foram caracterizadas em estado sólido e os espectros de RMN de ${ }^{13} \mathrm{C}$, estes não permitem a identificação da estrutura da $\mathrm{SH}$, mas foi possível estimar a concentração relativa de carbonos alifáticos e aromáticos presentes. A estimativa das porcentagens dos diferentes tipos de carbono e prótons foi obtida a partir da integração dos picos nas regiões específicas dos espectros (SWIFT, 1996).

\subsubsection{Determinação de teores de carbono orgânico total (COT)}

As determinações de COT em $\mathrm{mg} \mathrm{L}^{-1}$ presente nas águas de estudo foram feitas no Departamento de Hidraúlica e Saneamento - USP de São Carlos, em um analisador de COT, marca SHIMADZU, modelo TOC-5000A pelo método de combustão a elevada temperatura $\left(680^{\circ} \mathrm{C}\right)$ seguido de leitura no infravermelho. 
Inicialmente filtrou-se $500 \mathrm{~mL}$ do extrato diluído 1:1 com água deionizada na membrana de poro $0,45 \mu \mathrm{m}$. Retirou-se uma alíquota de $100 \mathrm{~mL}$ desse extrato para posterior medida do carbono orgânico total. Fracionou-se, no equipamento de ultrafiltração, um volume de $400 \mathrm{~mL}$ do extrato passado na membrana de $0,45 \mu \mathrm{m}$, nos diferentes tamanhos moleculares aparentes para obter as frações: $F_{1}, F_{2}, F_{3}$. $F_{4}$. $\mathrm{F}_{5}$ e $\mathrm{F}_{6}$ e determinou-se o COT para cada fração de SHA.

Para estimar a porcentagem de COT de AH e AF de cada fração de diferente tamanho molecular fez-se o seguinte procedimento: foram coletados $50 \mathrm{~mL}$ de cada fração de diferentes tamanhos moleculares de SHA; acidificou-se com ácido clorídrico $\mathrm{PA}(\mathrm{HCl})$ até $\mathrm{pH}<2$; deixou-se em repouso por 24 horas para precipitação dos $\mathrm{AH}$; centrifugaram-se as amostras em $4.000 \mathrm{rpm}$ por 30 minutos e coletou-se o sobrenadante para medidas de COT.

Através da medida de COT na amostra sem acidificar e depois com a separação do $\mathrm{AH}$ e $\mathrm{AF}$, tem-se no sobrenadante a concentração de COT devido à presença de AF. Assim, a concentração de COT correspondente à presença de $\mathrm{AH}$ é obtida por diferença (GARCIA et al., 1986).

\subsubsection{Turbidez}

A turbidez foi medida pelo método nefelométrico em um turbidímetro da marca $\mathrm{HACH}$, modelo $2100 \mathrm{P}$. 


\subsubsection{Medida de $\mathrm{pH}$}

$\mathrm{O} \mathrm{pH}$ foi medido por potenciometria em um equipamento digital da marca Corning, aferido com tampões de pH 4 e 7 e com ajuste automático de temperatura.

\subsection{Preparação das águas de estudo}

Foi usada água de poço profundo do Campus-USP de São Carlos e os extratos de SHA fracionados para preparação de aproximadamente $250 \mathrm{~L}$ de cada água de estudo, todas com cor verdadeira de $100 \pm 5 \mathrm{uH}$, turbidez em torno de $5 \mathrm{uT}$ (obtida a partir da adição de suspensão-mãe de caulinita) e pH em torno de 6,0 (ajustado com solução de ácido clorídrico 0,1 $\mathrm{mol} \mathrm{L}^{-1}$ ).

A água de estudo 1 foi preparada com a $F_{1}$ (passada na $0,45 \mu \mathrm{m}$ ), a água de estudo 2 com a $F_{2}$ (entre $100 \mathrm{kDa}$ e $0,45 \mu \mathrm{m}$ ), a água de estudo 3 com a $F_{3}$ (entre $30 \mathrm{kDa}$ e $100 \mathrm{kDa}$ ) e a água de estudo 4 foi preparada com a $\mathrm{F}_{4}{ }^{\prime}$ (menor que 30 $k D a)$. As frações $F_{5}$ e $F_{6}$ não foram utilizados para a preparação das respectivas águas de estudo devido ao elevado volume necessário para obtenção de $250 \mathrm{~L}$ de água de estudo com cor verdadeira de $100 \mathrm{uH}$.

\subsubsection{Ensaios de filtração direta}

Para cada água de estudo foram construídos os diagramas de coagulação, variando-se a dosagem de sulfato de alumínio comercial líquido ou de cloreto férrico comercial líquido e o pH de coagulação, por meio da adição de solução de hidróxido de sódio ou de ácido clorídrico. 
As dosagens de sulfato de alumínio como produto comercial usado neste estudo referem-se ao produto líquido com 7,3\% $\mathrm{Al}_{2} \mathrm{O}_{3}$ (máximo de 7 a 8\%), $\mathrm{Fe}_{2} \mathrm{O}_{3}$ 1,1\% (máximo 1,2\%), insolúveis = ausente (máximo traços), acidez livre $\left(\mathrm{H}_{2} \mathrm{SO}_{4}\right)$ $0,35 \%$ (máximo $0,5 \%)$ e $\mathrm{pH}\left(20^{\circ} \mathrm{C}\right)=1,90$.

A solução de cloreto férrico comercial que foi utilizada neste trabalho possuía densidade de $1,398 \mathrm{~g} / \mathrm{cm}^{3}$ em $38 \%$ de cloreto férrico.

Como não foi variada a turbidez nas águas de estudo utilizou-se o mesmo tipo de areia para todos os ensaios, pois segundo Di Bernardo et al., (2002) em função da turbidez da água de estudo, há necessidade de utilizar areias com diferentes granulometria como meio filtrante dos filtros de laboratório de areia para determinar as condições de coagulação (dosagem do coagulante versus pH de coagulação).

Os ensaios de coagulação realizados em Jarteste para os dois coagulantes (sulfato de alumínio e cloreto férrico) foram feitos para as seguintes condições: tempo de agitação $=30 \mathrm{~s}$; gradiente de velocidade médio $=1.000 \mathrm{~s}^{-1}$; filtração em filtros de laboratório com diâmetro interno de $19 \mathrm{~mm}$, diâmetro nominal de $25 \mathrm{~mm}$, espessura do meio filtrante de $15 \mathrm{~cm}$, comprimento do filtro $40 \mathrm{~cm}$, areia com tamanho dos grãos entre 0,30 e 0,59 mm (areia tipo 1), tempo de filtração de 20 min e taxa média de filtração de 50 a $70 \mathrm{~m}^{3} / \mathrm{m}^{2}$ dia. A Figura 23 apresenta o reator estático que foi utilizado para fazer os ensaios de filtração direta. 


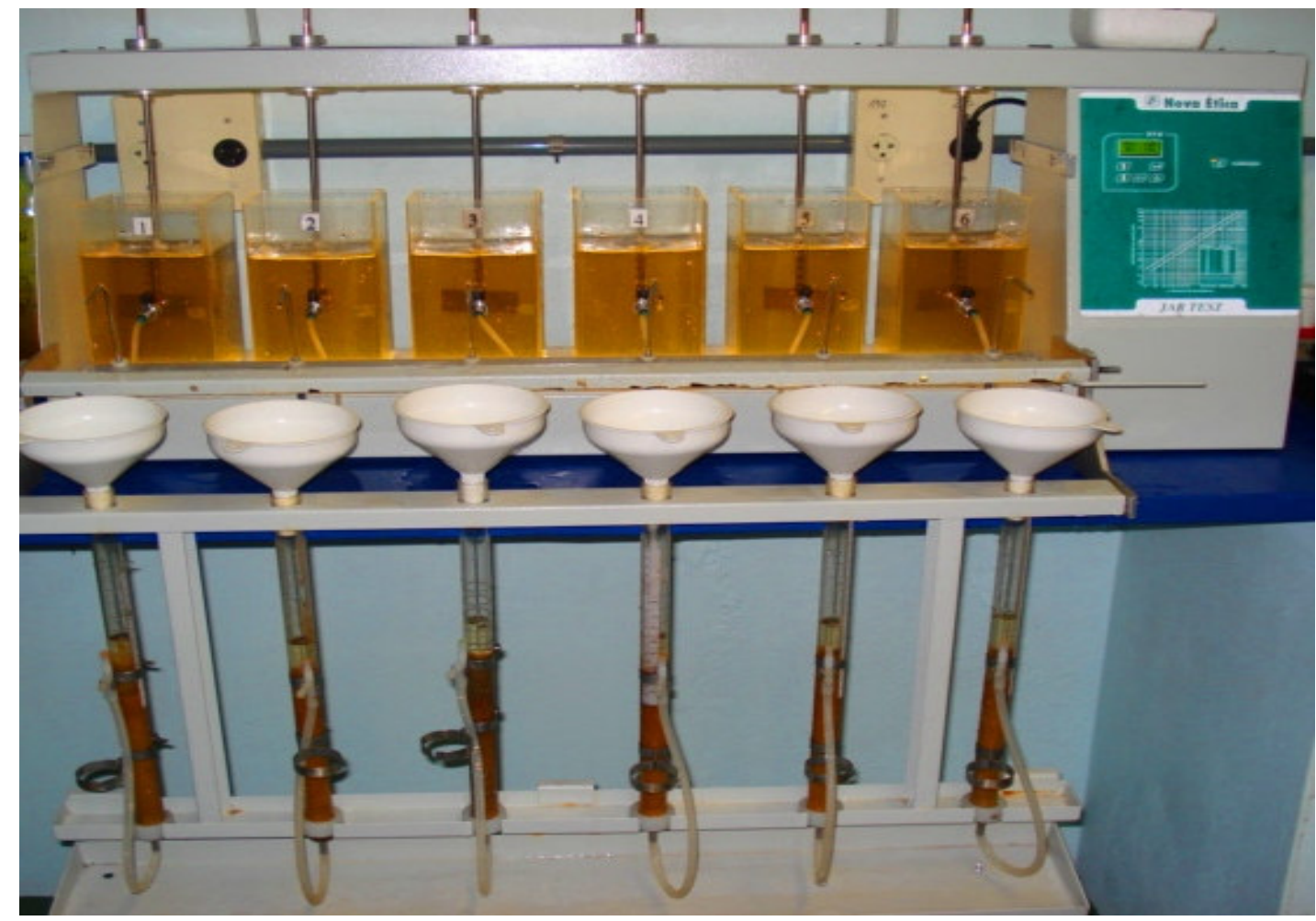

Figura 23 - Foto do reator estático (Jarteste) - Ensaio de filtração direta

Os parâmetros de controle da água filtrada foram: cor aparente da água filtrada (em espectrofotômetro DR-4000 da Hach), turbidez da água filtrada (turbidímetro $2100 \mathrm{~N}$ da Hach) e pH de coagulação (potenciômetro da Orion).

\subsubsection{Concentração de alumínio residual}

Foram escolhidos alguns pontos do diagrama com sulfato de alumino para determinar a concentração de alumínio residual.

Devido à toxicidade do alumínio na água para consumo humano, a portaria noำ 518 do Ministério da Saúde estabeleceu o valor máximo permitido igual a $0,2 \mathrm{mg} \mathrm{L}^{-1}$. 
As concentrações de alumínio residual foram determinadas segundo o procedimento estabelecido pelo Standard Methods (1998) e todas as medidas foram feitas em um espectrofotômetro DR/4000U da marca Hach. 


\section{RESULTADOS E DISCUSSÃO}

\subsection{Extração das SHA e diálise}

A extração das SHA usando resina XAD 8 apresentou algumas vantagens e desvantagens. Dentre as vantagens verificadas pode-se destacar um alto fator de concentração, elevada capacidade de sorção das SHA na resina e fácil eluição. Uma das desvantagens foi a necessidade de um grande volume de água bruta coletada no rio Itapanhaú para obtenção do volume necessário de extrato de SHA. Assim, o processo de extração foi muito lento.

\subsection{Caracterização das diferentes frações das SHA}

\subsubsection{Composição elementar das frações das SHA}

A análise elementar não fornece muitas informações a respeito da estrutura das $\mathrm{SH}$, porém auxilia nas comparações entre classes e origens de diferentes materiais húmicos e avalia a eficiência da extração e da purificação das SH obtidas (HUFFMAN; STUBER, 1985).

A análise elementar é útil na estimativa do conteúdo de grupos funcionais oxigenados, grau de condensação dos carbonos aromáticos e conteúdo de carbonos alifáticos. A Tabela 5 e a Figura 24 apresentam os resultados da composição elementar em porcentagem e as razões atômicas das frações das SHA do Rio Itapanhaú. Não foi detectado enxofre nas frações de SHA. 
Tabela 5 - Composição elementar das diferentes frações das SHA e as razões atômicas dos elementos.

\begin{tabular}{|l|l|l|l|l|l|l|l|}
\hline \multirow{2}{*}{ Frações } & \multicolumn{3}{|l|}{ \% Massa dos elementos } & \multicolumn{3}{l|}{ Razões atômicas } \\
\cline { 2 - 9 } & $\mathbf{C}$ & $\mathbf{H}$ & $\mathbf{N}$ & $\mathbf{O}^{\star}$ & $\mathbf{H} / \mathbf{C}$ & $\mathbf{O} / \mathbf{C}$ & $\mathbf{C} / \mathbf{N}$ \\
\hline $\mathrm{F}_{1}(<0,45 \mu \mathrm{m})$ & 37,35 & 3,34 & 1,44 & 57,86 & 1,07 & 1,16 & 30,23 \\
\hline $\mathrm{F}_{2}(<0,45 \mu \mathrm{m}$ a $100 \mathrm{kDa})$ & 36,01 & 3,32 & 1,29 & 59,38 & 1,10 & 1,24 & 32,57 \\
\hline $\mathrm{F}_{3}(100$ a $30 \mathrm{kDa})$ & 37,44 & 3,56 & 0,91 & 58,10 & 1,14 & 1,16 & 48,10 \\
\hline $\mathrm{F}_{4}(30$ a $10 \mathrm{kDa})$ & 37,95 & 4,34 & 0,80 & 56,90 & 1,37 & 1,12 & 55,20 \\
\hline $\mathrm{F}_{5}(10$ a $5 \mathrm{kDa})$ & 35,53 & 4,51 & 0,70 & 59,30 & 1,52 & 1,25 & 58,96 \\
\hline
\end{tabular}

* Oxigênio calculado por diferença

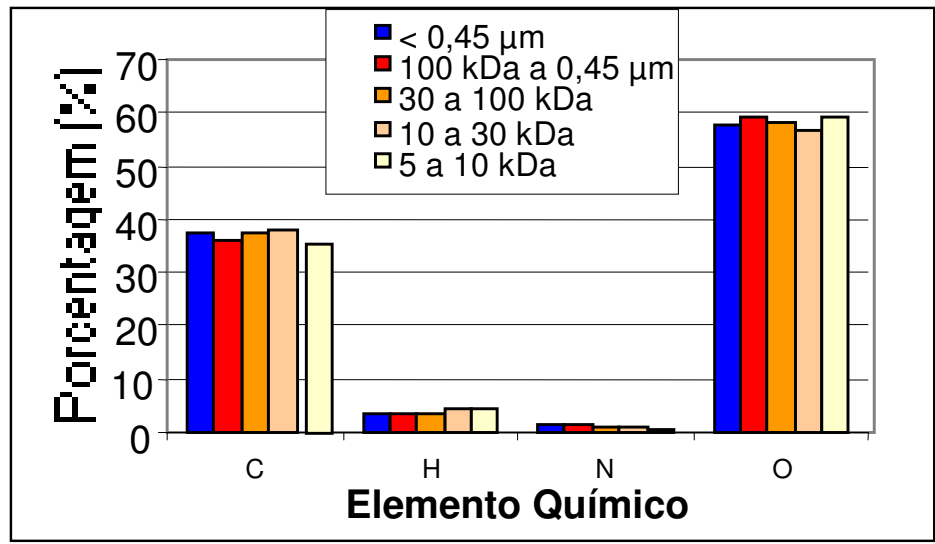

Figura 24 - Porcentagem dos elementos químicos $(\mathrm{C}, \mathrm{H}, \mathrm{N}$ e O) para as frações de SHA.

Observa-se nos resultados apresentados na Tabela 5 e na Figura 24, que há similaridade entre as frações. $A$ fração $F_{5}$ apresentou a menor porcentagem de $\mathrm{C}$ e $\mathrm{N}$, e a porcentagem de $\mathrm{H}$ e $\mathrm{O}$ relativamente aumentou com a diminuição do tamanho molecular aparente das SHA. Isto pode indicar que nas menores frações há um maior número de carbonos alifáticos $\left(\mathrm{CH}_{2}\right)$ do que de carbonos aromáticos $(\mathrm{C}=\mathrm{C})$ e concentração relativamente alta de oxigênios ligados a grupamentos alquílicos e a ácidos carboxílicos. A porcentagem de nitrogênio presente nas SHA geralmente é pequena sendo ainda menor nas frações de menor tamanho molecular aparente 
(MALCOLM, 1985). Isso pode ser observado na Figura 24, onde a porcentagem de nitrogênio é decrescente à medida que diminui o tamanho molecular aparente das SHA. Provavelmente isso ocorre porque os AF possuem menor quantidade de $\mathrm{N}$ que os $\mathrm{AH}$. A maior proporção de oxigênio, nitrogênio e hidrogênio nas $\mathrm{SH}$ indicam cadeia predominantemente alifática.

As frações $F_{2}$ e $F_{5}$ apresentaram uma maior porcentagem de oxigênio. Isto pode indicar que essas frações possuem uma concentração relativamente alta de oxigênios ligados a grupamentos alquílicos e a ácidos carboxílicos (BELZILE et al. 1997).

Os teores de $\mathrm{C}, \mathrm{H}, \mathrm{N}$ e O, Figura 24, que foram obtidos para as frações de SHA, aproximaram-se de dados publicados na literatura, não havendo muita diferença ente as SHA e as SHT (CALASE et al., 1998; SARGENTINI JUNIOR et al., 2001; ARAÚJO et al., 2002; SANCHES, 2005; CAMPOS et al., 2007). Os autores relatam uma distribuição elementar variando-se de 30 a 50\% para o C, de 0,1 a $5 \%$ para o $\mathrm{N}$ e de 3 a $8 \%$ para o $\mathrm{H}$ e a maior porcentagem cerca de 40 a $70 \%$ para o oxigênio. Para todas as frações estudadas a porcentagem de oxigênio foi a maior. Isso indica que as SHA contêm elevado teor de grupos funcionais oxigenados, o que as torna com mais hidrofílicas e mais capazes de formar complexos com metais (MACCARTHY; SUFFET, 1989).

Comparando as razões atômicas $\mathrm{H} / \mathrm{C}$ nas diferentes frações das SHA, verifica-se nos resultados apresentados na Tabela 5 que houve um aumento gradativo das razões com a diminuição dos tamanhos moleculares aparentes, o que pode indicar um menor conteúdo de anéis aromáticos presentes nas menores frações. Dentre todas as frações estudadas, a $F_{1}$ apresentou a menor razão $H / C$, indicando tratar-se da fração mais aromática e a $F_{5}$ apresentou o maior valor da 
razão $\mathrm{O} / \mathrm{C}$, indicando uma estrutura menos condensada, ou seja, menor quantidade de anéis aromáticos.

Como citado por Campos (2004), quando as razões $\mathrm{C} / \mathrm{N}$ forem maiores que 20, indica que a maior contribuição para a humificação do material é proveniente da decomposição de plantas vasculares, o que pode ser verificado na Tabela 5. Razões $\mathrm{C} / \mathrm{N}$ abaixo de 20 podem indicar que o processo de humificação foi mais favorecido pela atividade microbiana, como é verificado para SH de solo. Esses valores são maiores para as SHA do que para as SHT. Isso provavelmente seja devido a inúmeros fatores, incluindo adsorção de matéria orgânica contendo nitrogênio por argilas e precipitação de compostos orgânicos de nitrogênio (MEYERS, et al., 1993; NELSON et al., 1994;). Neste caso, provavelmente na formação das SH extraídas do rio Itapanhaú, não houve contribuições de origem antrópicas, pois o ponto de coleta da água é localizado numa área de reserva florestal.

\subsubsection{Espectroscopia no Ultravioleta-Visível (UV/VIS)}

Esta técnica vem sendo utilizada na avaliação da aromaticidade e do grau de humificação das SH. Também pode ser avaliado o grau de condensação de anéis aromáticos, já que no espectro de UV/VIS verifica-se que com o aumento no comprimento de onda ocorre um aumento no número de anéis condensados (SILVERSTEIN et al.,1994). A Tabela 6 apresenta os resultados da espectroscopia UV/VIS para todas as frações de SHA estudadas. 
Tabela 6 - Características espectroscópicas de UV/VIS para as frações das SHA.

\begin{tabular}{|c|c|c|c|c|c|c|c|}
\hline \multirow{2}{*}{ Frações } & \multicolumn{2}{|c|}{$\begin{array}{c}\text { Absorbância } \\
(\mathbf{n m})\end{array}$} & Razão & \multicolumn{2}{|c|}{$\begin{array}{c}\text { Absorbância } \\
(\mathbf{n m})\end{array}$} & Razão & \multirow{2}{*}{ Aromaticidade } \\
\cline { 2 - 7 } & $\mathbf{4 6 5}$ & $\mathbf{6 6 5}$ & $\mathrm{E}_{\mathbf{4}} / \mathrm{E}_{6}$ & $\mathbf{2 5 0}$ & $\mathbf{3 6 5}$ & $\mathrm{E}_{\mathbf{2}} / \mathrm{E}_{\mathbf{3}}$ & \\
\hline $\mathrm{F}_{1}$ & 0,314 & 0,037 & 8,40 & 0,866 & 0,274 & 3,16 & 31,07 \\
\hline $\mathrm{F}_{2}$ & 0,044 & 0,007 & 6,07 & 0,449 & 0,146 & 3,06 & 31,75 \\
\hline$F_{3}$ & 0,382 & 0,046 & 8,23 & 1,124 & 0,361 & 3,11 & 31,41 \\
\hline$F_{4}$ & 0,331 & 0,031 & 10,52 & 0,680 & 0,198 & 3,43 & 29,24 \\
\hline$F_{5}$ & 0,314 & 0,037 & 8,40 & 0,658 & 0,166 & 3,94 & 25,78 \\
\hline
\end{tabular}

A razão $E_{4} / E_{6}$, correspondente às absorbâncias em 465 e 665 nm, está relacionada à condensação estrutural, e indicando o grau de humificação, aromaticidade, massa molecular e conteúdo ácido das SH (SWIFT, 1996). Um menor valor da razão $E_{4} / E_{6}$ indica alto grau de condensação dos constituintes aromáticos, enquanto que um maior valor de $E_{4} / E_{6}$ indica predominância de estruturas alifáticas. Essa razão é influenciada pelo tamanho da molécula, pH do meio, pelo conteúdo de oxigênio, carbono, grupos carboxílicos, origem e idade (STEVENSON, 1982).

As razões $E_{2} / E_{3}$ nas frações de SHA estudadas aumentaram nas frações de menor tamanho molecular aparente, enquanto que com a aromaticidade ocorreu o inverso. Isso mostra que nas maiores frações a quantidade de anéis condensados é maior em comparação às estruturas alifáticas, em decorrência de um alto grau de humificação. Quando se compara as razões $E_{4} / E_{6}$ e $E_{2} / E_{3}$, observa-se que há uma mesma tendência, ou seja, quanto maior o tamanho molecular aparente, maior o seu grau de condensação e maior a aromaticidade. Portanto, nas SHA prevalecem os $\mathrm{AF}$ em relação aos $\mathrm{AH}$, sendo os $\mathrm{AF}$ compostos de cadeias menores, estruturas mais alifáticas, maiores teores de oxigênio e com grupos funcionais carboxilas e 
hidroxilas fenólicas e alcoólicas, o que torna as SHA com características mais hidrofílicas e mais ácidas. Isso também foi verificado por Stevenson, 1982b.

A razão $E_{4} / E_{6}$ na fração $F_{2}$ (entre $100 \mathrm{kDa}$ e $0,45 \mu \mathrm{m}$ ) foi menor que a encontrada para a fração $F_{1}$ (menor que $0,45 \mu \mathrm{m}$ ). Isso pode ser devido a essa fração absorver menos em 465 e 665 nm em relação à menor que 0,45 $\mu$ m. Assim, utilizou-se a Equação 59 para estimar-se a aromaticidade da molécula: Aromaticidade $=52,5-6,78 \times E_{2} / E_{3}$

\subsubsection{Espectroscopia na região do infravermelho (IV)}

A Figura 25 apresenta os espectros na região do IV para as diferentes frações das SHA.

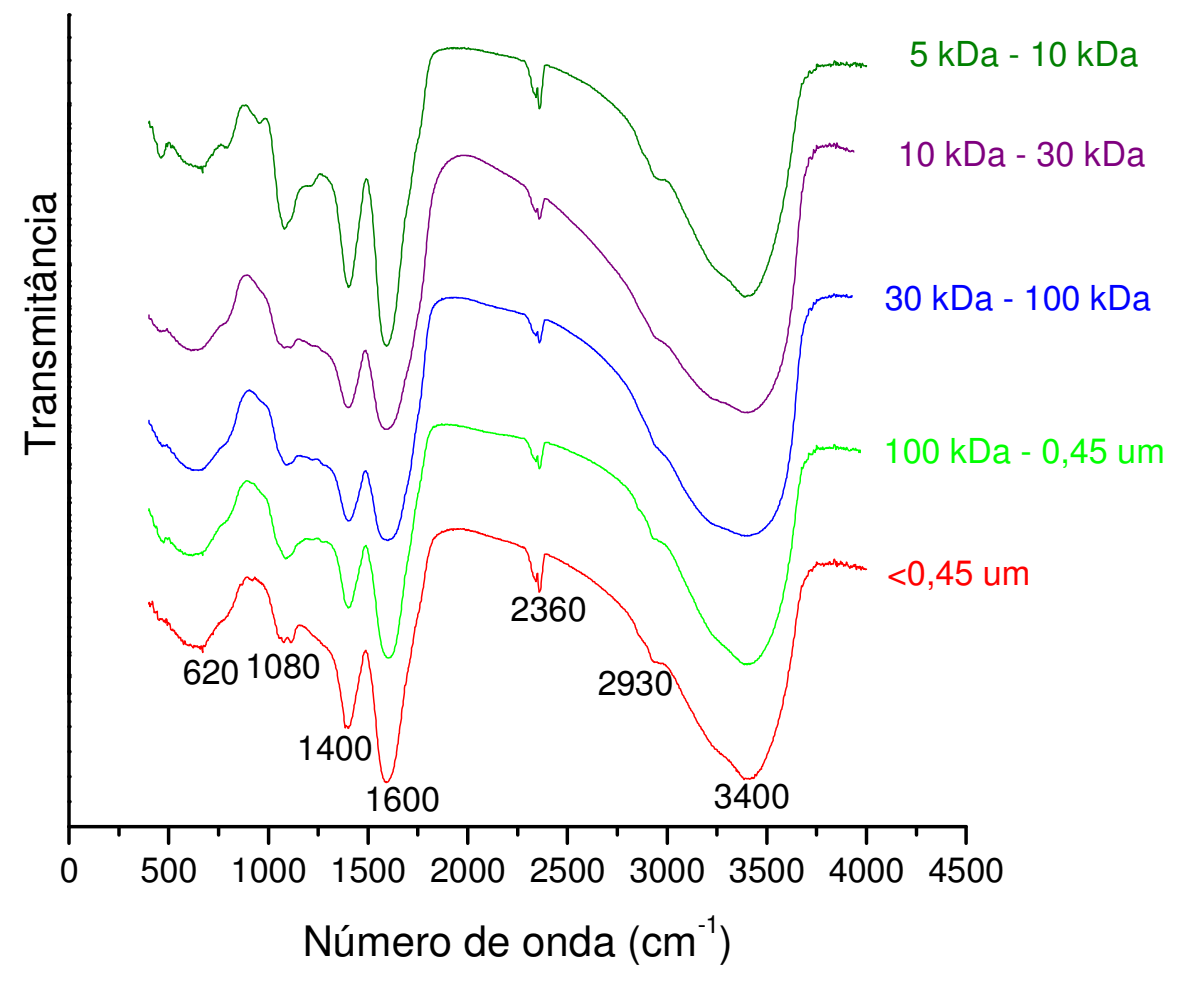

Figura 25 - Espectros no infravermelho das frações de SHA. 
Os espectros no IV apresentam bandas largas e intensas comum nos espectros das SH, atribuídas à superposição de absorções de bandas individuais (POPPI; TALAMONI, 1992). A banda larga de absorção em torno de $3.400 \mathrm{~cm}^{-1}$ é atribuída ao estiramento do $\mathrm{OH}$ livre ou ligado por ligações de hidrogênio de grupamentos carboxílicos e/ou fenólicos e/ou alcoólicos. As bandas de absorção abaixo de $3.000 \mathrm{~cm}^{-1}$, que nos espectros aparecem em $2.930 \mathrm{~cm}^{-1}$, são atribuídas ao estiramento simétrico de $\mathrm{C}-\mathrm{H}$ dos grupos metil ou metilenos alifáticos geralmente superpostos à banda larga de estiramento do OH (STEVENSON, 1982; MARCCARTHY; RICE, 1985). Na região entre 2.400 e 2.700 aparecem bandas características de estiramento $\mathrm{O}-\mathrm{H}$ de $\mathrm{H}$ ligado fortemente a grupos carboxílicos $(\mathrm{COOH})$ (PICCOLO et al., 1992; STEVENSON, 1994). As bandas em torno de 1.600 $\mathrm{cm}^{-1}$ indicam aromaticidade das SHA, características do estiramento $\mathrm{C}=\mathrm{C}$ de anel aromático, isto é, às vibrações de anel aromático conjugado com $\mathrm{C}=\mathrm{O}$ e/ou $\mathrm{COO}$. Essas bandas podem também ser devidas ao estiramento anti-simétrico do grupo carboxilato e ao estiramento $\mathrm{C}=\mathrm{O}$ do grupo $\mathrm{COOH}$, sendo que neste caso 0 hidrogênio está ligado ao grupo OH em posição orto (STEVENSON, 1982; MARCCARTHY; RICE, 1985). Na região de $1.400 \mathrm{~cm}^{-1}$ observa-se a presença de banda devido a grupos $\mathrm{C}-\mathrm{H}$ alifáticos e vibração $\mathrm{OH}$ de álcoois ou ácidos carboxílicos (ARAÚJO et al., 2002).

$\mathrm{Na}$ região entre 1.100 e $950 \mathrm{~cm}^{-1}$ observam-se bandas que podem ser atribuídas ao estiramento C-O de álcoois e/ou fenóis e/ou carboidratos ou relacionadas com as impurezas provenientes de silicatos (Si-O) (MARCCARTHY; RICE, 1985; STEVENSON, 1982). As bandas na região de $950-670 \mathrm{~cm}^{-1}$ podem ser referentes à deformação no plano e fora do plano da ligação $\mathrm{CH}$ de anéis 
aromáticos (ROCHA; ROSA, 2003, p.65). Foi observado que os resultados de IV foram semelhantes para todas as frações das SHA estudadas.

\subsubsection{Ressonância magnética nuclear de ${ }^{13} \mathrm{C}$ em estado sólido (RMN de ${ }^{13} \mathrm{C}$ )}

Na Figura 26 são apresentados os espectros de RMN CP/MAS de ${ }^{13} \mathrm{C}$ das frações de diferentes tamanhos moleculares das SHA.
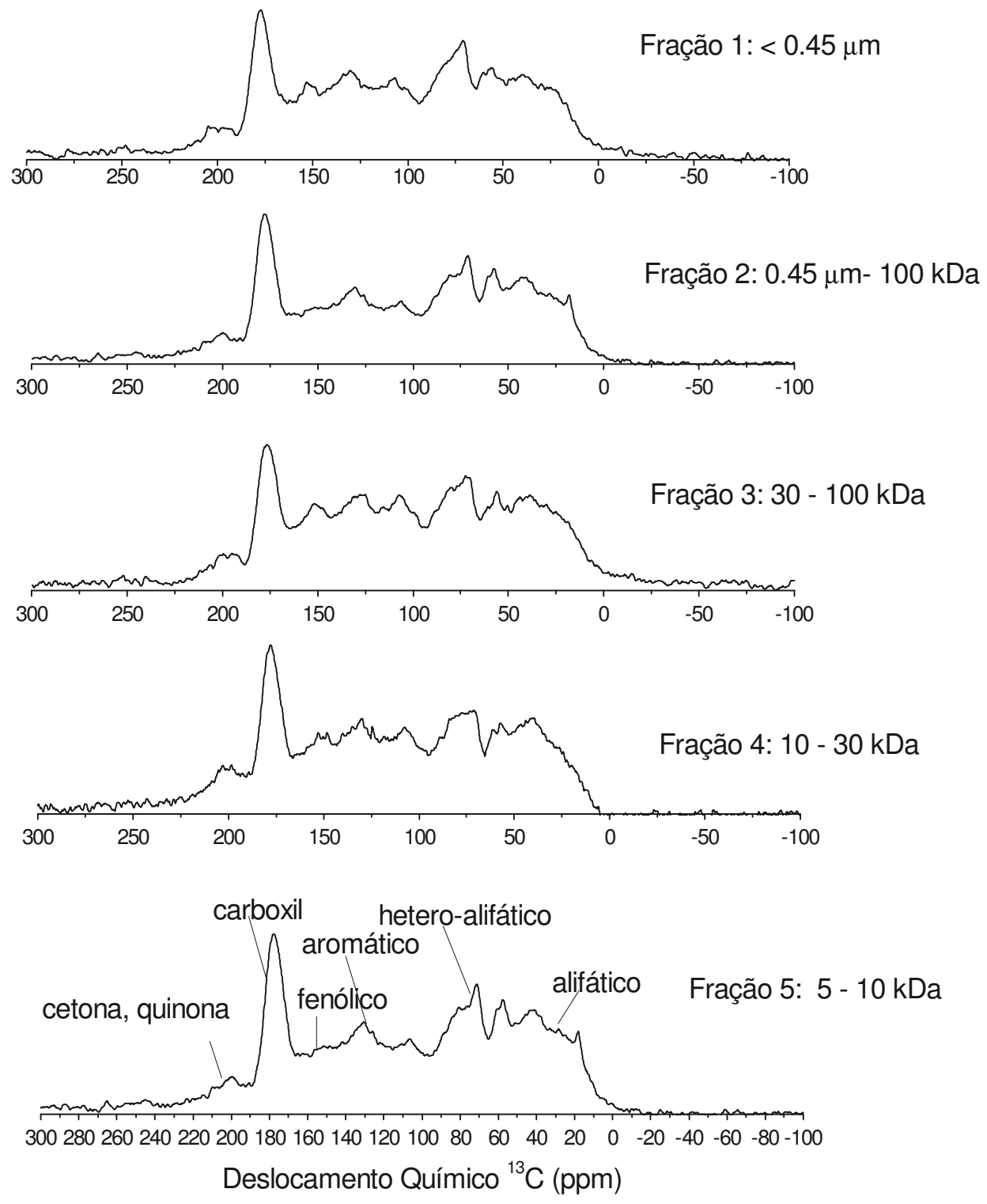

Figura 26 - Espectros de RMN de ${ }^{13} \mathrm{C}$ para as frações das SHA. 
Os espectros de RMN de SH não permitiram a identificação da sua estrutura, mas foi possível estimar a concentração relativa e tipos de carbonos, alifáticos e aromáticos presentes Os espectros das SHA geralmente podem ser divididos em quatro regiões químicas (LU et al., 2000). A região de 0-50 ppm representa a ressonância de carbonos alifáticos, metil, metileno; a região de 50-100 ppm, carbonos alifáticos ligados a oxigênio $\left(-\mathrm{OCH}_{3}\right)$; a região entre 100 a 160 ppm carbonos aromáticos e a região entre 160-220 ppm, carbonos carboxílicos, CO carboxílicos e CO de cetonas.

Analisando-se os espectros apresentados na Figura 24, verificou-se que estes apresentam os picos bastante similares, porém não se pode comparar a intensidade dos picos devido à utilização de tamanhos moleculares aparentes diferentes.

Na região dos alifáticos (0 - 50 ppm) foram observados picos para todas as frações, o que representa a ressonância de carbonos alifáticos (metil, metileno). A presença de grupos alifáticos na fração de maior tamanho molecular aparente das SHA pode ser em decorrência do tamanho dessas moléculas, com agregados que possuem grande concentração de cadeias aromáticas ligadas a carbonos lineares. Esses dados estão de acordo com a proposta da estrutura de AH obtida por meio dos espectros de RMN feita por Schulten e Schiltzer (1993). Segundo os autores, os AH são formados por grupos aromáticos com longas cadeias alifáticas ligadas. Isso contradiz as propostas anteriores, nas quais foi suposto que os $\mathrm{AH}$ são formados apenas por grupos aromáticos. Foi verificado, nesse estudo, que na fração de maior tamanho molecular, entre $100 \mathrm{kDa}$ e $0,45 \mu \mathrm{m}$, existe uma porcentagem maior de $\mathrm{AH}$, cerca de $90 \%$, do que AF.

Na região de 50 a 100 ppm observou-se que na menor fração, entre 5 a 10 $\mathrm{kDa}$, houve uma maior porcentagem relativa de carbonos alifáticos oxigenados em 
relação às outras frações. Conforme a proposta feita por Piccolo (2001), os AF são formados por uma maior quantidade de grupos com oxigênio ligados, o que thes proporcionaria um caráter repulsivo com a formação de agregados menores do que dos $\mathrm{AH}$. Dentre as frações de SHA estudadas, foi verificado que as frações menores que $30 \mathrm{kDa}$ são constituídas de $100 \%$ de AF. Esses dados podem estar relacionados aos picos observados na região dos grupos carboxílicos, amida e ésteres (162 - 190 ppm) (CARVALHO, 2003). Há pouca diferença entre os espectros das diferentes frações das SHA, e nas menores frações, a porcentagem relativa desses grupos foi um pouco maior.

Os picos na região de 71 a 73 ppm são atribuídos às cadeias de polissacarídeos, como a celulose (MALCOM, 1990). Porém, como pode ser verificado na Figura 26 não foi possível observar esses picos. Na região dos aromáticos (90 -162 ppm) observou-se que as porcentagens relativas foram proporcionais para todas as frações.

A região de 140-160 ppm é referente à ressonância de carbonos aromáticos substituídos por oxigênio e nitrogênio, como fenóis, éteres aromáticos ou aminas. Verificou-se através da Figura 26 que apenas as frações $F_{1}, F_{3}$ e $F_{4}$ apresentaram pico mais intenso em torno de 150 ppm. O pico na região de 194 ppm é atribuído a carbonos de aldeídos e cetonas (LU et al., 2000). Nesta região foram observados picos menos intensos para ambas as frações das SHA. 


\subsubsection{Teor de cinzas}

No caso de substâncias complexas e heterogêneas como as $\mathrm{SH}$, o teor de cinzas é geralmente utilizado como um indicativo da quantidade de compostos inorgânicos presentes na amostra ou grau de pureza da amostra.

Os teores de cinzas das SHA deste estudo foram elevados. Isso pode ser devido às frações das SHA não serem purificadas por meio de resinas catiônicas (IR-120) e aniônicas (IR-400) (ROSA et al., 2000; GARCIA et al., 1986; CAMPANELLA et al., 1994). Este procedimento não foi realizado neste trabalho para não submeter o material a possíveis alterações das suas principais características. A Tabela 7 apresenta os teores de cinzas nas diferentes frações de SHA.

Tabela 7 - Teores de cinzas nas frações de SHA

\begin{tabular}{|l|c|c|c|c|c|}
\hline Frações & $\mathbf{F}_{\mathbf{1}}$ & $\mathbf{F}_{\mathbf{2}}$ & $\mathbf{F}_{\mathbf{3}}$ & $\mathbf{F}_{\mathbf{4}}$ & $\mathbf{F}_{\mathbf{5}}$ \\
\hline Teor de cinzas (\%) & 29,68 & 25,24 & 15,30 & 15,92 & 17,43 \\
\hline
\end{tabular}

Existem vários fatores que podem contribuir para os valores obtidos, como a presença de complexos de cálcio, magnésio e sílica que podem elevar os teores de cinzas. Provavelmente, parte da sílica que não foi extraída com hidróxido de sódio encontra-se ligada aos AH devido ao seu tamanho coloidal (WERSHAW, 1986; BENEDETTI, 1996). A presença de compostos de fósforo, nem sempre volatilizados durante a queima, podem estar incluídos nas cinzas (HUFFMAN; STUBER, 1985). Estes fatores podem explicar o porquê dos teores em cinzas apresentados na Tabela 7 serem altos. 


\subsubsection{Carbono orgânico total (COT)}

Verifica-se pelos resultados apresentados na Tabela 8 e na Figura 27 que a distribuição de carbono nas SHA estudadas foi de $30 \%$ na fração $F_{2}, 23$ \% na fração $F_{3}, 16 \%$ na fração $F_{4}, 12$ \% na $F_{5}$ e $19 \%$ na fração $F_{6}$. Como observado na Figura 16, na fração $F_{2}$ prevaleceram os $\mathrm{AH}(92,4 \%)$ e nas frações abaixo de $30 \mathrm{kDa}$ prevaleceram os AF (100\%).

Tabela 8 - Massa de carbono nas frações das $\mathrm{SHA}$ e porcentagem de $\mathrm{AH}$ e $\mathrm{AF}$ em $500 \mathrm{~mL}$ de extrato de SHA.

\begin{tabular}{|l|c|c|c|}
\hline Frações de SHA & $\begin{array}{c}\text { Massa de C } \\
(\mathbf{A H}+\mathbf{A F}) \\
(\mathbf{m g})\end{array}$ & $\begin{array}{c}\text { \% de } \\
\mathbf{A F}\end{array}$ & $\begin{array}{c}\text { \% de } \\
\mathbf{A H}\end{array}$ \\
\hline $\mathrm{F}_{1}(<0,45 \mu \mathrm{m})$ & 106,32 & 68,7 & 31,3 \\
\hline $\mathrm{F}_{2}(100-0,45 \mu \mathrm{m})$ & 31,75 & 7,6 & 92,4 \\
\hline $\mathrm{F}_{3}(30-100 \mathrm{kDa})$ & 24,74 & 86,4 & 13,6 \\
\hline $\mathrm{F}_{4}(10-30 \mathrm{kDa})$ & 16,73 & 100,0 & 0,0 \\
\hline $\mathrm{F}_{5}(5-10 \mathrm{kDa})$ & 12,91 & 100,0 & 0,0 \\
\hline $\mathrm{F}_{6}(<5 \mathrm{kDa})$ & 19,57 & 100,0 & 0,0 \\
\hline TOTAL & 105,70 & - & - \\
\hline
\end{tabular}

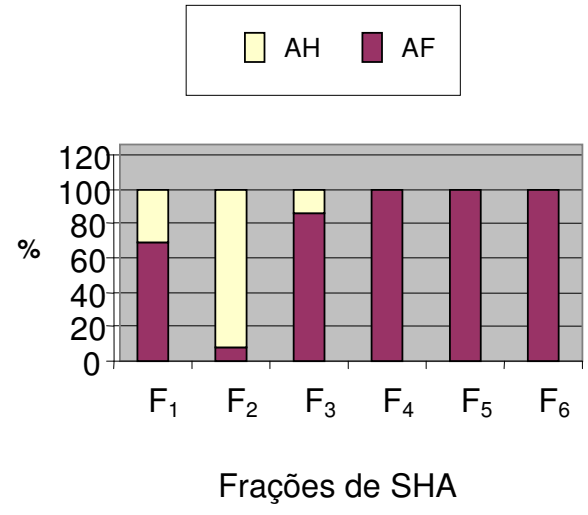

Figura 27 - Porcentagem de $\mathrm{AH}$ e AF nas frações de SHA.

Verificou-se que na fração de SHA passada na membrana de 0,45 $\mu \mathrm{m}$ a maior porcentagem é de $\mathrm{AF}$ em relação aos $\mathrm{AH}$, aproximadamente $69 \%$ formada por $\mathrm{AF}$. Isso mostra que as SHA são formadas na maior parte por AF em relação em aos $A H$. A fração $F_{2}$ apresentou aproximadamente $98 \%$ de $A H$ em relação aos $A F$. As frações menores que 30 kDa apresentaram 100\% de AF. Estes dados sâo similares aos encontrados na literatura. Conforme citado por MALCOLM (1985), os AF contribuem com $90 \%$ das $\mathrm{SH}$ dissolvidas nas águas naturais e os $10 \%$ restantes consistem de $A H$. Como os $A F$ são mais solúveis em água que os $A H$, e 
consequentemente, estão presentes em maior quantidade que os $\mathrm{AH}$, estes são os principais responsáveis pela cor nas águas naturais (DENNETT et al., 1995).

A maior porcentagem de carbono nas SHT determinada por Campos et al. (2007) foi na fração maior que $100 \mathrm{kDa}$, com cerca de $75 \%$. O autor também observou uma maior porcentagem de $\mathrm{AF}$ em relação aos $\mathrm{AH}$ para as frações entre 30 e $100 \mathrm{kDa}$ e menor que $30 \mathrm{kDa}$. Este fato mostra que tanto nas SHT como nas SHA, a maior porcentagem de carbono encontra-se nas maiores frações dessas substâncias.

Burba et al. (1995) e Rocha et al. (1999) estudaram as SHA extraídas do rio Rhur na Alemanha e do Rio Negro no Brasil, respectivamente. Os autores verificaram que a maior porcentagem de carbono das SHA encontra-se nas frações de tamanho molecular aparente entre $10 \mathrm{kDa}$ e $100 \mathrm{kDa}$.

\subsection{Caracterização da amostra de água coletada no Rio Itapanhaú}

A Tabela 9 apresenta os principais parâmetros físicos e químicos analisados da água bruta coletada no Rio Itapanhaú. 
Tabela 9 - Caracterização da amostra de água coletada no Rio Itapanhaú.

\begin{tabular}{|c|c|}
\hline Parâmetros & Valor \\
\hline Absorbância (254 nm) & 1,177 \\
\hline Condutividade elétrica ( $\left.\mu \mathrm{s} \mathrm{cm}^{-1}\right)$ & 103,9 \\
\hline Cor verdadeira $(\mathrm{uH})$ & 279 \\
\hline Cor aparente $(\mathrm{uH})$ & 303 \\
\hline $\mathrm{pH}$ & 5,56 \\
\hline Turbidez (uT) & 5,56 \\
\hline Alcalinidade total $\left(\mathrm{mg} \mathrm{L}^{-1} \mathrm{CaCO}_{3}\right)$ & 6,0 \\
\hline Dureza total $\left(\mathrm{mg} \mathrm{L}^{-1} \mathrm{CaCO}_{3}\right)$ & 27,0 \\
\hline Sulfatos $\left(\mathrm{mg} \mathrm{L}^{-1}\right)$ & ND \\
\hline Nitrogênio amoniacal $\left(\mathrm{mg} \mathrm{L}^{-1}\right)$ & 0,4996 \\
\hline Nitrogênio nitrato $\left(\mathrm{mg} \mathrm{L}^{-1}\right)$ & 0,0026 \\
\hline Nitrogênio nitrito (mg L-1) & 0,0028 \\
\hline Sólidos totais $\left(\mathrm{mg} \mathrm{L}^{-1}\right)$ & 193,0 \\
\hline Sólidos totais suspensos (mg L ${ }^{-1}$ ) & 95,0 \\
\hline Sólidos totais dissolvidos $\left(\mathrm{mg} \mathrm{L}^{-1}\right)$ & 98,0 \\
\hline Sódio $\left(\mathrm{mg} \mathrm{L}^{-1}\right)$ & 7,8 \\
\hline Potássio $\left(\mathrm{mg} \mathrm{L}^{-1}\right)$ & 1,1 \\
\hline Carbono orgânico dissolvido (mg L $\left.{ }^{-1}\right)$ & 22,60 \\
\hline Zinco - amostra não-digerida $\left(\mathrm{mg} \mathrm{L}^{-1}\right)$ & ND \\
\hline Zinco - amostra digerida $\left(\mathrm{mg} \mathrm{L}^{-1}\right)$ & 0,02 \\
\hline Chumbo - amostra não-digerida (mg L $\left.{ }^{-1}\right)$ & 0,08 \\
\hline Chumbo - amostra digerida $\left(\mathrm{mg} \mathrm{L}^{-1}\right)$ & ND \\
\hline Cádmio - amostra não-digerida $\left(\mathrm{mg} \mathrm{L}^{-1}\right)$ & ND \\
\hline Cádmio - amostra digerida $\left(\mathrm{mg} \mathrm{L}^{-1}\right)$ & ND \\
\hline Níquel - amostra não-digerida (mg L ${ }^{-1}$ ) & ND \\
\hline Níquel - amostra digerida (mg L $\left.{ }^{-1}\right)$ & ND \\
\hline Ferro - amostra não-digerida (mg L $\left.{ }^{-1}\right)$ & 0,80 \\
\hline Ferro - amostra digerida $\left(\mathrm{mg} \mathrm{L}^{-1}\right)$ & 1,70 \\
\hline Manganês - amostra não-digerida $\left(\mathrm{mg} \mathrm{L}^{-1}\right)$ & 0,02 \\
\hline Manganês - amostra digerida $\left(\mathrm{mg} \mathrm{L}^{-1}\right)$ & 0,02 \\
\hline Cobre - amostra não-digerida $\left(\mathrm{mg} \mathrm{L}^{-1}\right)$ & ND \\
\hline Cobre - amostra digerida $\left(\mathrm{mg} \mathrm{L}^{-1}\right)$ & ND \\
\hline Cromo - amostra não-digerida $\left(\mathrm{mg} \mathrm{L}^{-1}\right)$ & ND \\
\hline Cromo - amostra digerida (mg L-1) & ND \\
\hline
\end{tabular}

ND - não detectado

Observou-se elevado teor de substâncias húmicas aquáticas na água do Rio Itapanhaú em todas as coletas feitas, com cor verdadeira da ordem de $300 \mathrm{uH}$. 


\subsection{Resultados de coagulação com sulfato de alumínio}

\subsubsection{Características das amostras de águas de estudo}

As águas de estudo foram preparadas com diferentes frações das SHA até obter cor verdadeira de 100 uH e uma suspensão de caulinita para obter turbidez em torno de 5,0 uT. A água de estudo 1 foi preparada com a fração $\mathbf{F}_{1}$ : menor que 0,45 $\mu \mathrm{m}$ (fração global, possui todas as frações de SHA); a água de estudo 2 com a fração $\mathbf{F}_{2}$ : entre $100 \mathrm{kDa}$ e $0,45 \mu \mathrm{m}$; a água de estudo 3 com a fração $\mathbf{F}_{3}$ : entre 30 e 100 kDa; e a água de estudo 4 com a fração $\mathbf{F}_{4}$ : menor que 30 kDa. Para cada água

de estudo, determinaram-se alguns parâmetros físicos, químicos e biológicos, como apresentado na Tabela 10. 
Tabela 10 - Características das amostras de água de estudo de 1 a 4, para a realização dos ensaios com o sulfato de alumínio.

\begin{tabular}{|c|c|c|c|c|}
\hline \multirow[b]{2}{*}{ Parâmetros } & \multicolumn{4}{|c|}{ Valores } \\
\hline & $\begin{array}{l}\text { Água de } \\
\text { estudo } 1\end{array}$ & $\begin{array}{l}\text { Água de } \\
\text { estudo } 2\end{array}$ & $\begin{array}{l}\text { Água de } \\
\text { estudo } 3\end{array}$ & $\begin{array}{l}\text { Água de } \\
\text { Estudo } 4\end{array}$ \\
\hline Condutividade Elétrica ( $\mu \mathrm{s} / \mathrm{cm})$ & 77,5 & 87,4 & 66,3 & 95,2 \\
\hline Cor Verdadeira $(\mathrm{uH})$ & 98 & 97 & 104 & 98 \\
\hline Cor Aparente (uH) & 130 & 126 & 124 & 120 \\
\hline Absorbância (254 nm) & 0,335 & 0,337 & 0,356 & - \\
\hline $\mathrm{pH}$ & 6,0 & 6,32 & 6,20 & 6,02 \\
\hline Turbidez (uT) & 4,45 & 4,30 & 3,49 & 5,20 \\
\hline Alcalinidade Total $\left(\mathrm{mg} \mathrm{L}^{-1} \mathrm{CaCO}_{3}\right)$ & 15 & 7,0 & 10,00 & 10,23 \\
\hline Dureza Total $\left(\mathrm{mg} \mathrm{L}^{-1} \mathrm{CaCO}_{3}\right)$ & 23 & 24,0 & 24,0 & 27,0 \\
\hline Cloretos $\left(\mathrm{mg} \mathrm{L}^{-1}\right)$ & 10,5 & 13,5 & 2,0 & 11,4 \\
\hline Sulfatos $\left(\mathrm{mg} \mathrm{L}^{-1}\right)$ & ND & ND & ND & 1,0 \\
\hline Nitrogênio Nitrato $\left(\mathrm{mg} \mathrm{L}^{-1}\right)$ & 0,158 & 0,1599 & 0,1540 & 0,1017 \\
\hline Nitrogênio Nitrito $\left(\mathrm{mg} \mathrm{L}^{-1}\right)^{\prime}$ & ND & ND & 0,0026 & 0,0013 \\
\hline Sólidos Totais $\left(\mathrm{mg} \mathrm{L}^{-1}\right)$ & 96 & 98,0 & 132,0 & 192,0 \\
\hline Sólidos Totais Suspensos (mg L-1) & 4 & 7,0 & 33,0 & 14,0 \\
\hline Sólidos Totais Dissolvidos $\left(\mathrm{mg} \mathrm{L}^{-1}\right)$ & 92 & 91,0 & 104,0 & 178,0 \\
\hline Sódio $\left(\mathrm{mg} \mathrm{L}^{-1}\right)$ & 2,0 & 2,1 & 1,9 & 3,4 \\
\hline Potássio $\left(\mathrm{mg} \mathrm{L}^{-1}\right)$ & 4,6 & 4,5 & 4,1 & 4,4 \\
\hline Fosfato Total (mg L $\left.{ }^{-1}\right)$ & 0,17 & 0,1497 & 0,2150 & 0,20 \\
\hline Fluoreto $\left(\mathrm{mg} \mathrm{L}^{-1}\right)$ & 0,14 & 0,15 & 0,10 & 0,28 \\
\hline Carbono Orgânico Dissolvido $\left(\mathrm{mg} \mathrm{L}^{-1}\right)$ & 6,876 & 4,94 & 6,501 & 15,79 \\
\hline Coliformes Totais (NMP/100 mL) & 90 & 100 & - & - \\
\hline Coliformes Fecais (NMP/100 mL) & 18 & 20 & - & - \\
\hline Zinco - amostra não-digerida (mg L $\left.{ }^{-1}\right)$ & ND & ND & 0,06 & ND \\
\hline Zinco - amostra digerida $\left(\mathrm{mg} \mathrm{L}^{-1}\right)$ & 0,02 & ND & 0,14 & 0,02 \\
\hline Chumbo - amostra não-digerida $\left(\mathrm{mg} \mathrm{L}^{-1}\right)$ & ND & ND & ND & ND \\
\hline Chumbo - amostra digerida (mg L $\left.{ }^{-1}\right)$ & ND & ND & ND & ND \\
\hline Cádmio - amostra não-digerida (mg L $\left.{ }^{-1}\right)$ & ND & ND & ND & ND \\
\hline Cádmio - amostra digerida $\left(\mathrm{mg} \mathrm{L}^{-1}\right)$ & ND & ND & ND & ND \\
\hline Níquel - amostra não-digerida (mg L $\left.{ }^{-1}\right)$ & ND & ND & ND & ND \\
\hline Níquel - amostra digerida $\left(\mathrm{mg} \mathrm{L}^{-1}\right)$ & ND & ND & ND & ND \\
\hline Ferro - amostra não-digerida (mg L $\left.{ }^{-1}\right)$ & ND & ND & 0,02 & ND \\
\hline Ferro - amostra digerida $\left(\mathrm{mg} \mathrm{L}^{-1}\right)$ & 0,11 & 0,06 & 0,06 & 0,06 \\
\hline Manganês - amostra não-digerida $\left(\mathrm{mg} \mathrm{L}^{-1}\right)$ & ND & ND & ND & ND \\
\hline Manganês - amostra digerida $\left(\mathrm{mg} \mathrm{L}^{-1}\right)$ & ND & ND & ND & 0,02 \\
\hline Cobre - amostra não-digerida (mg L $\left.{ }^{-1}\right)$ & ND & 0,03 & 0,05 & 0,03 \\
\hline Cobre - amostra digerida $\left(\mathrm{mg} \mathrm{L}^{-1}\right)$ & ND & 0,03 & 0,05 & 0,06 \\
\hline Cromo - amostra não-digerida (mg L $\left.{ }^{-1}\right)$ & ND & ND & ND & ND \\
\hline Cromo - amostra digerida $\left(\mathrm{mg} \mathrm{L}^{-1}\right)$ & ND & ND & 0,04 & ND \\
\hline Cálcio $\left(\mathrm{mg} \mathrm{L}^{-1}\right)$ & 0,123 & 4,43 & 4,43 & 4,03 \\
\hline Magnésio (mg L-1) & 0,75 & 1,05 & 1,05 & 0,98 \\
\hline
\end{tabular}

$\mathrm{ND}=$ não detectado 


\subsubsection{Diagramas de remoção de cor aparente}

Os diagramas de coagulação das Figuras 28 a 31 foram construídos conforme os dados apresentados nas Tabelas no anexo A. Estas apresentam os resultados dos ensaios de filtração direta para diferentes dosagens de sulfato de alumínio e diferentes valores de $\mathrm{pH}$ de coagulação, para as quatro águas de estudo preparadas com diferentes tamanhos moleculares aparentes das SHA $F_{1}$ (menor que

$0,45 \mu \mathrm{m}), F_{2}$ (entre $100 \mathrm{kDa}$ e $\left.0,45 \mu \mathrm{m}\right), F_{3}$ (entre 30 e $100 \mathrm{kDa}$ ) e $\mathrm{F}_{4}^{\prime}$ (menor que 30 kDa). As Figuras 26 a 29, apresentam as áreas de cor aparente da água filtrada de $5,10,20,50$ e maior que $50 \mathrm{uH}$.

Características das águas de estudo: preparadas com os diferentes tamanhos moleculares aparentes das SHA apresentaram cor verdadeira de $100 \pm 5$ $\mathrm{uH}$, turbidez em torno de 5,0 uT $, \mathrm{pH}=6,0$, temperatura de $20 \pm 1{ }^{\circ} \mathrm{C}$ e alcalinidade entre 7 e15 $\mathrm{mg} \mathrm{L}^{-1} \mathrm{CaCO}_{3}$.

Nas ordenadas à esquerda dos diagramas de coagulação estão representadas as concentrações do sulfato de alumínio comercial em $\mathrm{mg} \mathrm{L}^{-1}$, à direita as concentrações de alumínio total em $\mathrm{mg} \mathrm{L}^{-1}$ e na abscissa $\circ \mathrm{pH}$ de coagulação. 


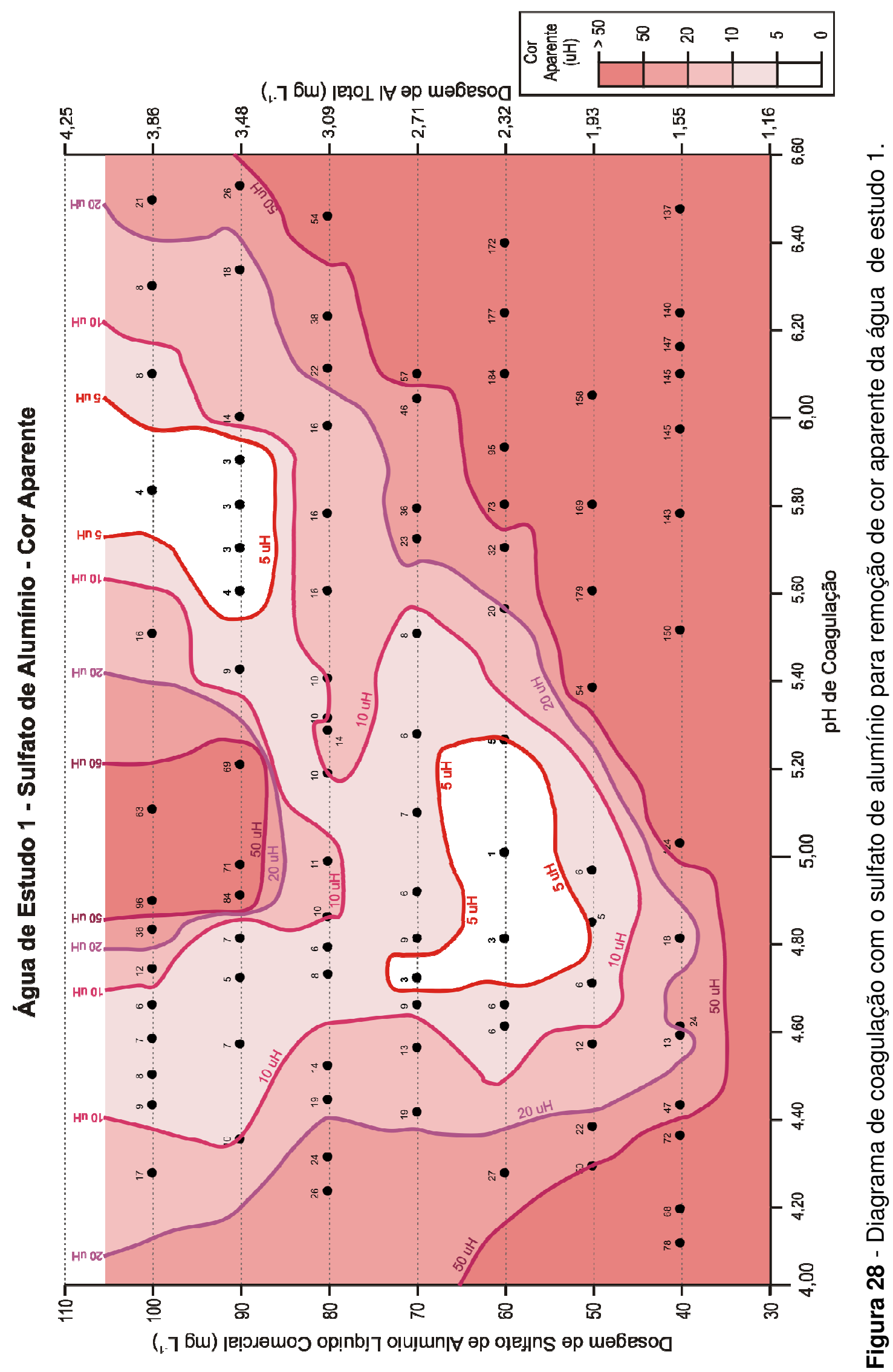




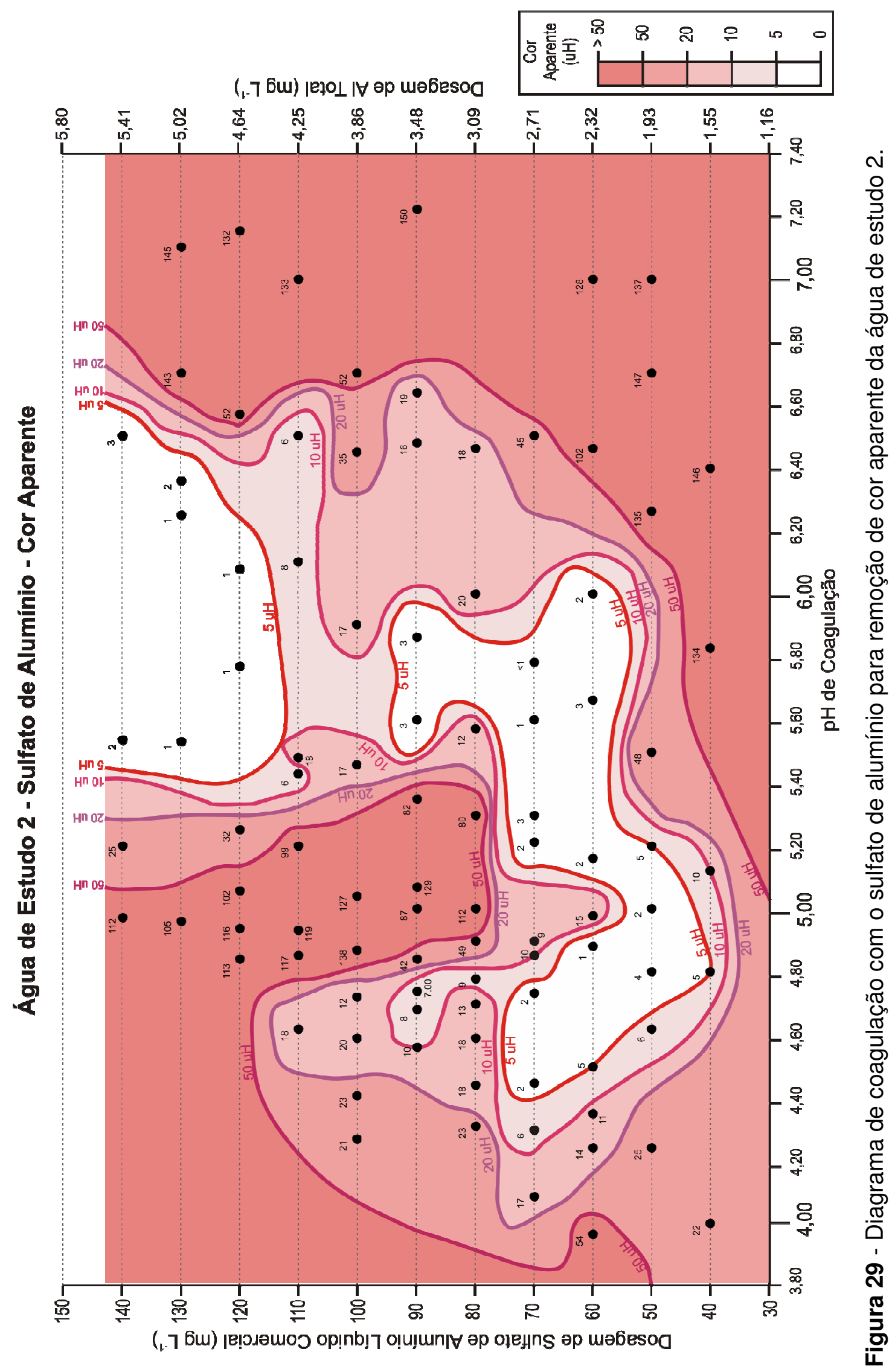




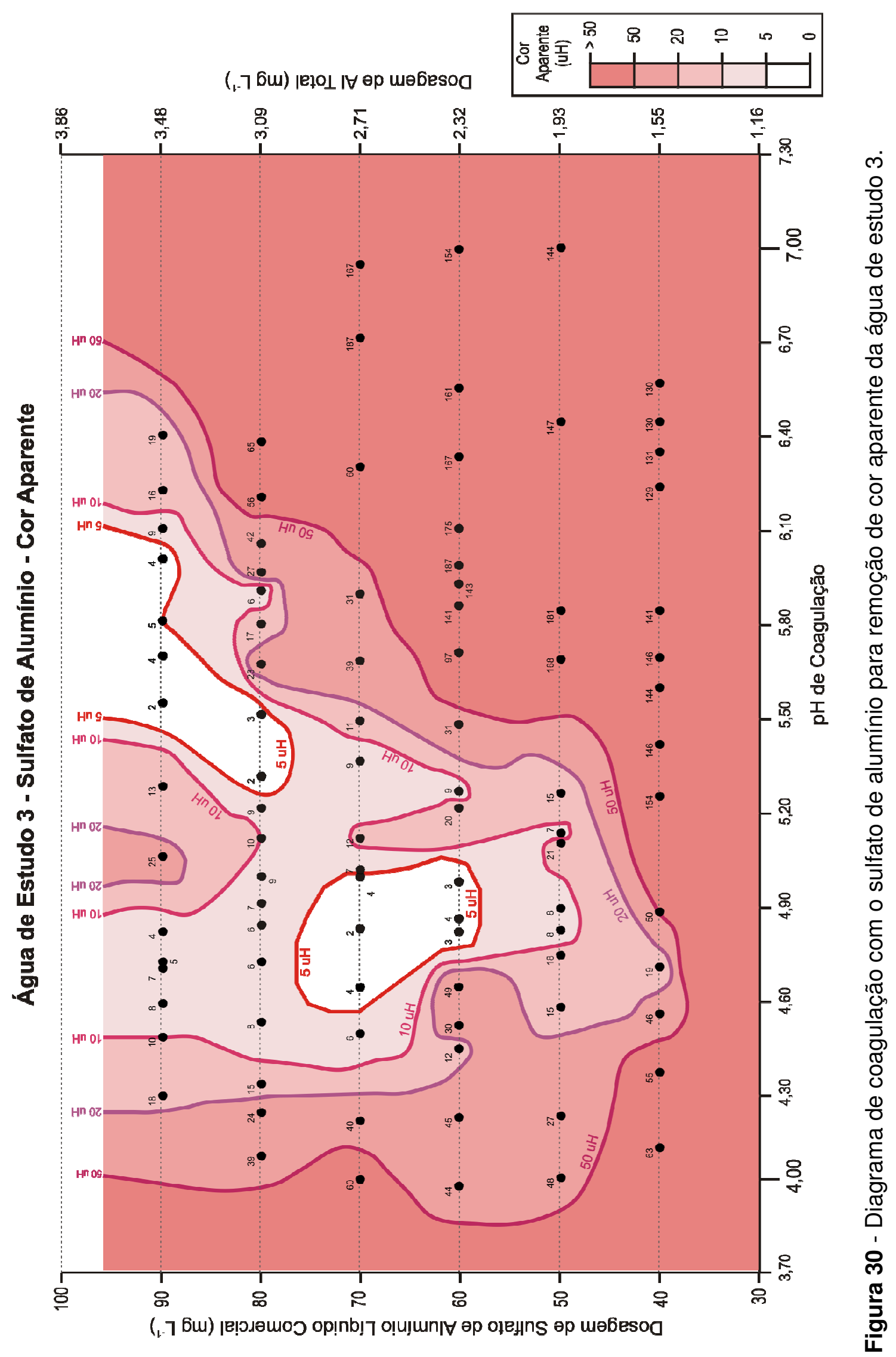




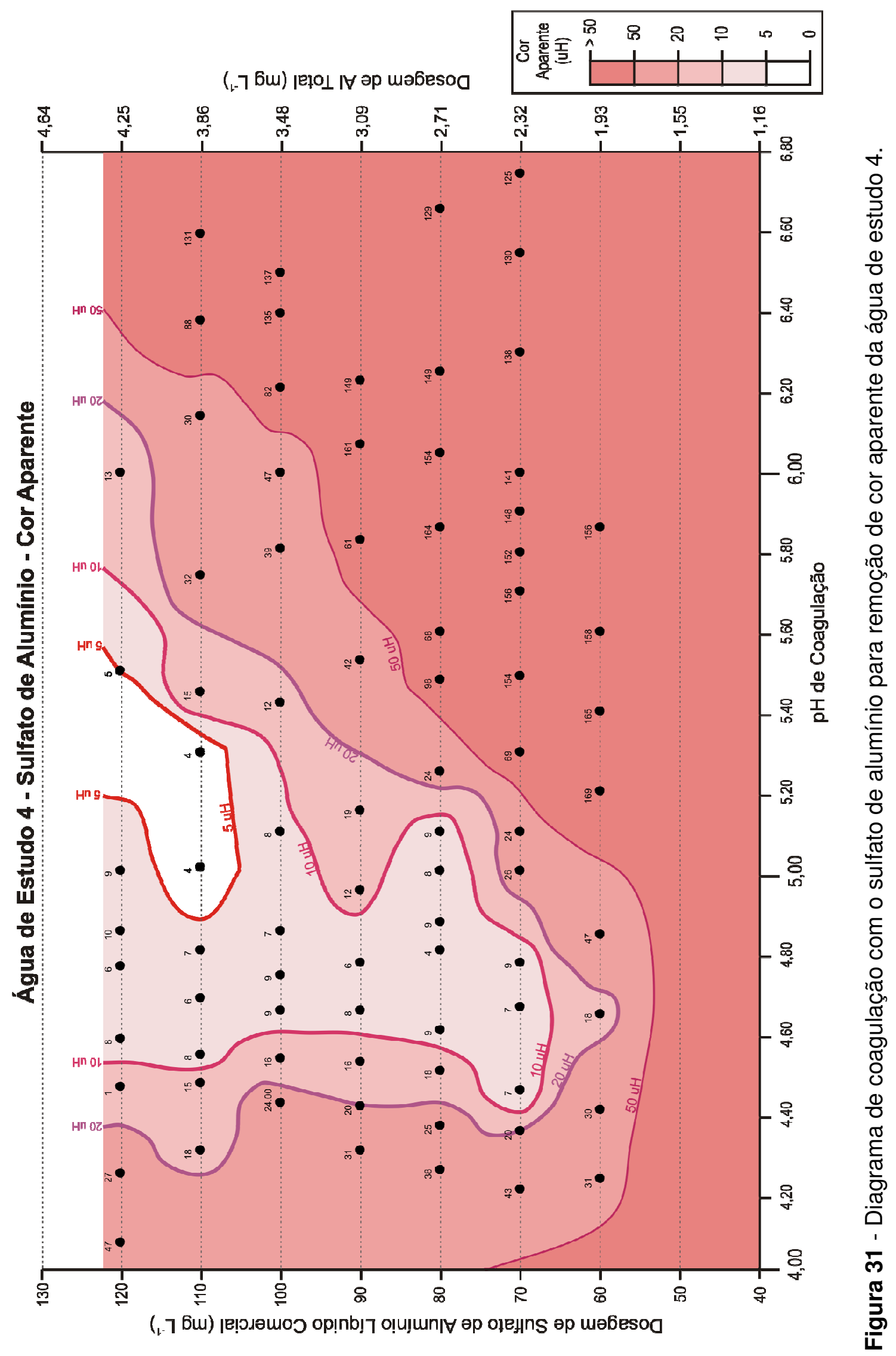


Observa-se na Figura 28 que há duas regiões de coagulação eficiente nos ensaios de filtração direta com a água de estudo 1 (fração de SHA menor que 0,45 $\mu \mathrm{m})$. A primeira região apresenta cor aparente da água filtrada menor ou igual a 5,0 $\mathrm{uH}, \mathrm{pH}$ de coagulação entre 4,6 e 5,2 e dosagens de sulfato de alumínio comercial de 50 a $70 \mathrm{mg} \mathrm{L}^{-1}$. A segunda região apresenta a mesma cor, $\mathrm{pH}$ de coagulação entre 5,5 e 5,8 e dosagens de sulfato de alumínio maiores que $90 \mathrm{mg} \mathrm{L}^{-1}$.

A Figura 29 apresenta os resultados da água de estudo 2 (fração de SHA entre $100 \mathrm{kDa}$ e $0,45 \mu \mathrm{m})$. Observou-se que há duas regiões mais amplas de coagulação eficiente, com obtenção de cor aparente menor que $5 \mathrm{uH}, \mathrm{pH}$ de coagulação entre 4,5 e 6,0 e dosagens de sulfato de alumínio comercial de 40 a 90 $\mathrm{mg} \mathrm{L}^{-1}$ e a segunda região com pH de coagulação entre 5,5 e 6,5 e dosagens de sulfato de alumínio maiores que $120 \mathrm{mg} \mathrm{L}^{-1}$. Isso se deve provavelmente ao fato de que na água de estudo 2 prevalecem os $\mathrm{AH}$, os quais geralmente possuem menor teor de grupos com cargas negativas e por isso requerem dosagens menores de coagulante para induzir a desestabilização dos colóides em suspensão, sendo que com os AF ocorre o contrário. Isto está de acordo com o relato na AWWA RESEARCH FOUNDATION (1995) que afirma que os AH contribuem mais para a cor nas águas naturais que os AF, e estes são mais efetivamente removidos por coagulação.

Nos ensaios com a água de estudo 3 (Figura 30) também houve duas regiões com cor aparente menor que $5 \mathrm{uH}$, sendo a primeira com dosagens de sulfato de alumínio entre 60 e $80 \mathrm{mg} \mathrm{L}^{-1}$ e pH de coagulação entre 4,5 e 5,0 e a segunda com dosagens superiores a $80 \mathrm{mg} \mathrm{L}^{-1}$ e pH de coagulação entre 5,3 e 6,0.

Nos ensaios com a água de estudo 4 (Figura 31) houve apenas uma região com cor aparente menor que $5 \mathrm{uH}$, entre pH de 4,8 e 5,0 e dosagens de sulfato de 
alumínio maiores que $110 \mathrm{mg} \mathrm{L}^{-1}$, comprovando que são necessárias dosagens maiores de coagulante para os menores tamanhos moleculares aparentes das SHA.

Como pode ser observado nas Figuras 28 a 31 , o tamanho molecular aparente das SHA teve influência significativa nos ensaios de coagulação. A eficiência de remoção de cor aparente teve um comportamento decrescente em relação ao tamanho molecular, observada através das áreas de remoção de cor nos diagramas. Isto pode estar associado as diferentes características das frações das SHA de diferentes tamanhos moleculares, conforme os resultados de caracterização discutidos anteriormente.

Observa-se também que as maiores frações, $F_{1}, F_{2}$ e $F_{3}$, apresentaram valores de remoção de cor aparente igual ou menor a $10 \mathrm{uH}$ em dosagens menores de coagulantes, a partir de 50 e $40 \mathrm{mg} \mathrm{L}^{-1}$, a menor fração $\mathrm{F}_{4}{ }^{\prime}$ (menor que $30 \mathrm{kDa}$ ) somente começou a mostrar valores de remoção de cor aparente igual ou menor a $10 \mathrm{uH}$ a partir da dosagem de $70 \mathrm{mg} \mathrm{L}^{-1}$. Este comportamento pode ser explicado pelo fato de que quanto menor o tamanho molecular aparente das SHA, maior é a porcentagem de $\mathrm{AF}$ em relação aos $\mathrm{AH}$. Os $\mathrm{AF}$ são compostos de cadeias menores, estruturas mais alifáticas, maiores teores de oxigênio, grupos funcionais carboxilas, hidroxilas fenólicas e alcoólicas, o que torna as SHA com características mais hidrofílicas e mais ácidas (STEVENSON, 1982b). A maior quantidade de cargas negativas presentes nos AF ocasiona à repulsão entre os elétrons e entre as partículas coloidais, motivo pelos quais estes exercem influência significativa na coagulação.

As SHA presentes em águas naturais geralmente existem como macromoléculas carregadas negativamente, devido à presença de, por exemplo, 
grupos carboxílicos e fenólicos. Com o aumento do $\mathrm{pH}$ ocorre a ionização dos grupos funcionais, resultando num aumento de cargas negativas em solução (AMIRTHARAJAH; EDWARDS, 1985).

Foram escolhidos alguns pontos no diagrama para determinar a concentração de alumínio residual. A Tabela 11 apresenta os valores dos ensaios de coagulação e filtração direta descendente em relação ao alumínio residual e a cor aparente da água filtrada.

Tabela 11 - Valores de alumínio residual e cor aparente da água após coagulação e filtração em filtros de laboratório. Tempo de filtração igual a 20 minutos.

\begin{tabular}{ccccc}
\hline Fração de SHA & $\begin{array}{c}\text { Dosagem de } \\
\text { sulfato de } \\
\text { alumínio } \\
\text { comercial (mg L-1) }\end{array}$ & $\begin{array}{c}\mathbf{p H} \\
\text { de } \\
\text { coagulação }\end{array}$ & $\begin{array}{c}\text { Alumínio } \\
\text { residual } \\
\left(\mathbf{m g ~ L}^{-1}\right)\end{array}$ & $\begin{array}{c}\text { Cor aparente } \\
\text { da água } \\
\text { filtrada }\end{array}$ \\
\hline$<0,45 \mu \mathrm{m}$ & 60 & 5,06 & 0,18 & 5 \\
$100 \mathrm{kDa}-0,45 \mu \mathrm{m}$ & 50 & 5,0 & 0,10 & 2 \\
$30-100 \mathrm{kDa}$ & 90 & 5,06 & 1,10 & 5 \\
$<30 \mathrm{kDa}$ & 50 & 4,84 & 0,50 & 9 \\
& 80 & 5,30 & 0,16 & 2 \\
\hline
\end{tabular}

Observa-se por meio dos resultados apresentados na Tabela 11 que em alguns pontos escolhidos, as concentrações de alumínio residual ficaram abaixo do valor máximo permitido (igual a $0,2 \mathrm{mg} \mathrm{L}^{-1}$ ) pelo padrão de potabilidade de água destinada ao consumo humano estabelecido pela portaria de no 518 do Ministério da Saúde. Verifica-se também, que a concentração do alumínio residual depende das dosagens do coagulante, $\mathrm{pH}$ de coagulação e tamanho molecular aparente das SHA. Nos ensaios feitos com a água preparada com a fração menor que $30 \mathrm{kDa}$ observou-se que houve menor remoção de cor aparente. 
A coagulação de águas com cor elevada requer dosagens elevadas de coagulante. Quando usado o sulfato de alumínio como coagulante, pode resultar uma concentração de alumínio residual acima do valor máximo permitido. Neste caso, é indicado o uso da pré-oxidação para diminuir a dosagem de coagulante necessária. Porém, quando é empregado o cloro como oxidante, leva à formação de subprodutos halogenados que são prejudiciais a saúde humana. Assim, será indicado utilizar carvão ativado após a pré-oxidação.

Pode ser verificado que os ensaios de filtração direta foram eficientes para remoção de cor devido à presença de SHA, porém, em alguns pontos escolhidos, a concentração de alumínio residual ficou acima do valor máximo permitido pela portaria de no 1469 do Ministério da Saúde.

\subsubsection{Diagramas de coagulação das espécies hidrolisadas de alumínio - remoção de cor aparente}

Nas Figuras 32 a 35 estão representados os diagramas do logaritmo da concentração de alumínio (log $[\mathrm{Al}])$ versus $\circ \mathrm{pH}$ de coagulação com as espécies hidrolisadas de alumínio. Estes diagramas foram construídos com base nos resultados apresentados nas Figuras 28 a 31 para a região ótima de remoção de cor aparente da água filtrada $(\leq 5,0 \mathrm{uH})$. As linhas plotadas nos diagramas representam o equilíbrio termodinâmico das espécies hidrolisadas de alumínio, onde no final das ordenadas está à concentração final do alumínio em equilíbrio com a fase sólida do hidróxido de alumínio, $\mathrm{Al}(\mathrm{OH})_{3}$. O precipitado de alumínio pode se tornar positivo ou negativo para valores de $\mathrm{pH}$ inferiores ou superiores ao $\mathrm{pH}$ do ponto isoelétrico, respectivamente (DI BERNARDO; DANTAS, 2005, p. 183). 


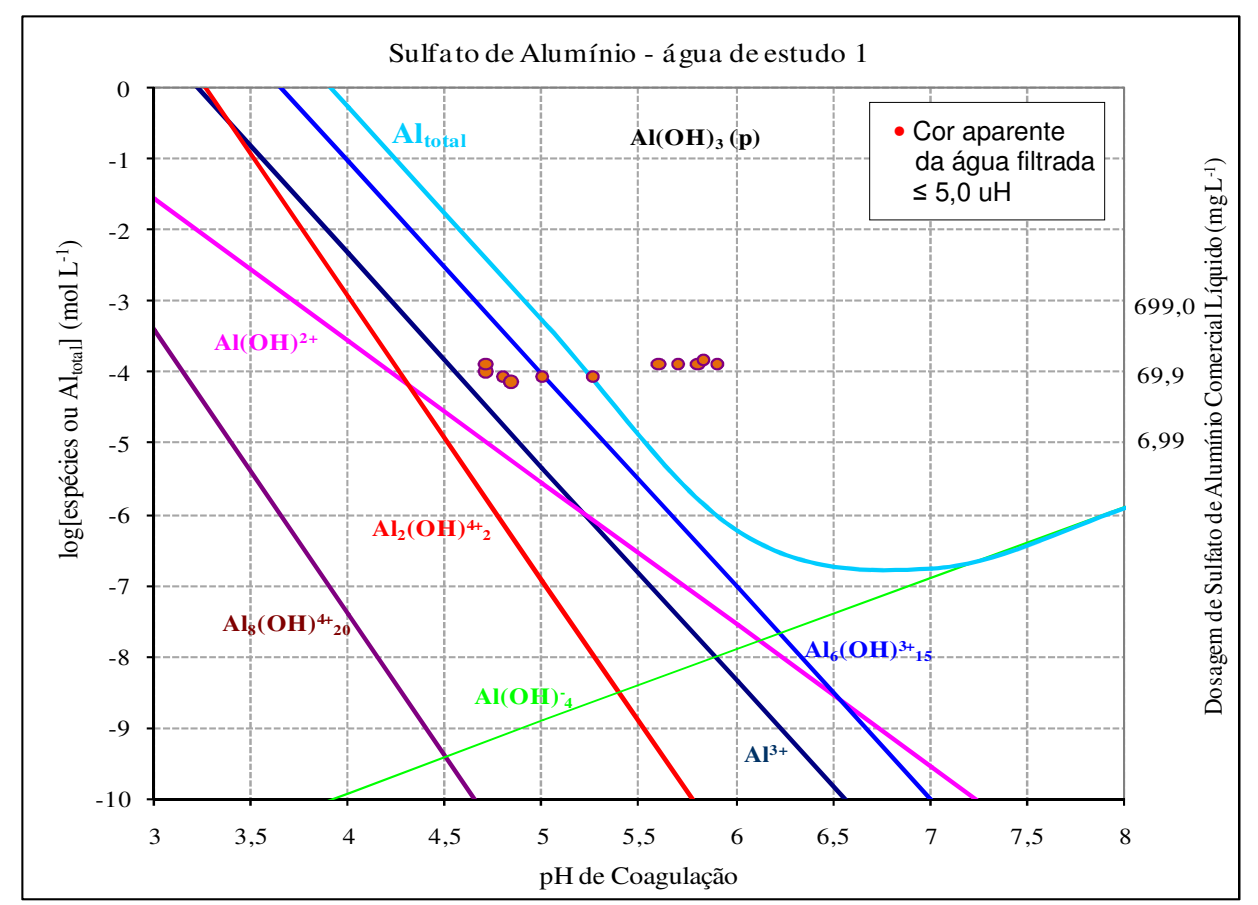

Figura 32 - Diagrama de coagulação com as espécies hidrolisadas de alumínio para a região de cor aparente da água filtrada $\leq 5 \mathrm{uH}$ - fração de SHA menor que $0,45 \mu \mathrm{m}$.

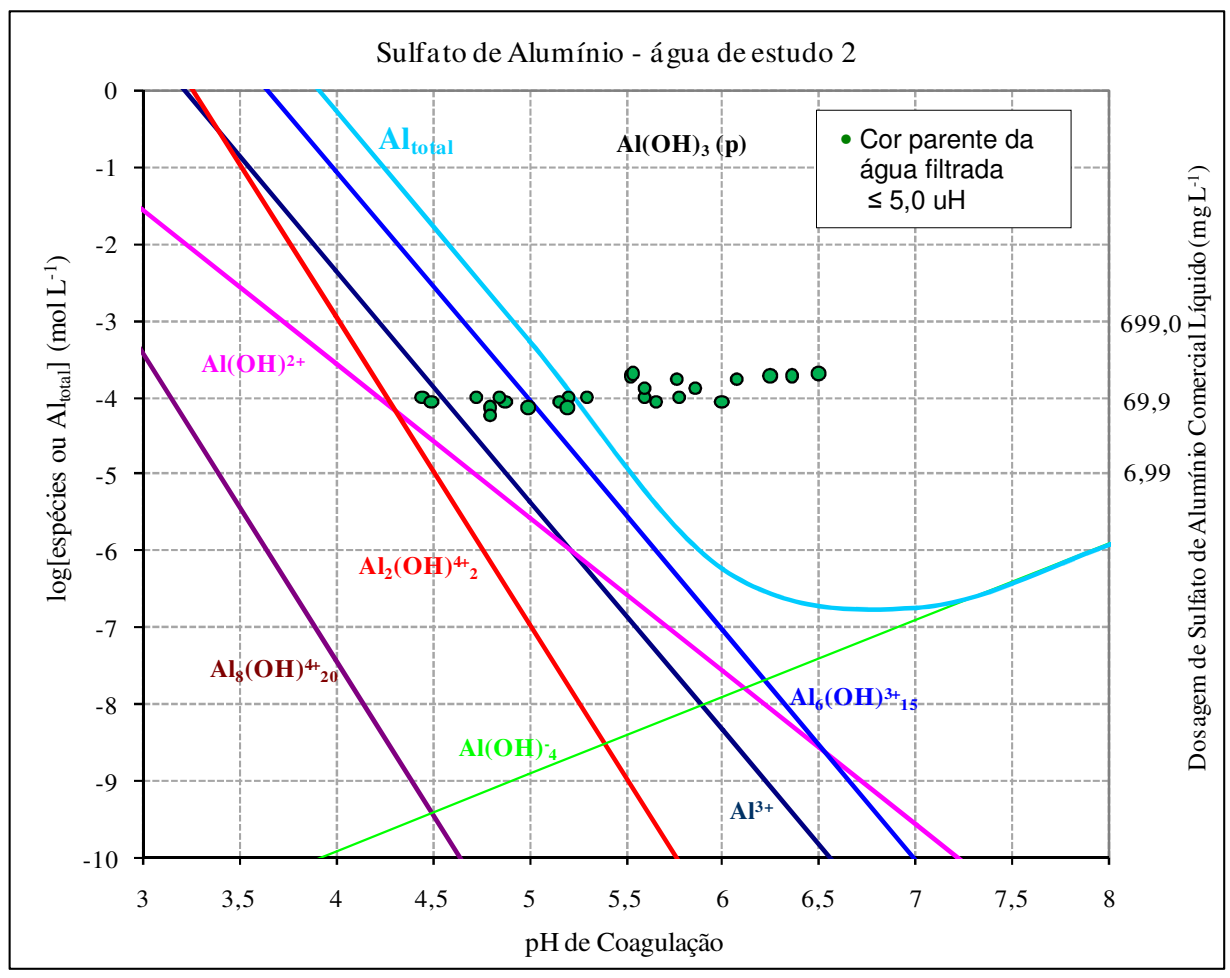

Figura 33 - Diagrama de coagulação com as espécies hidrolisadas de alumínio para a região de cor aparente da água filtrada $\leq 5 \mathrm{uH}$ - fração de SHA entre $100 \mathrm{kDa}$ e 0,45 $\mu \mathrm{m}$. 


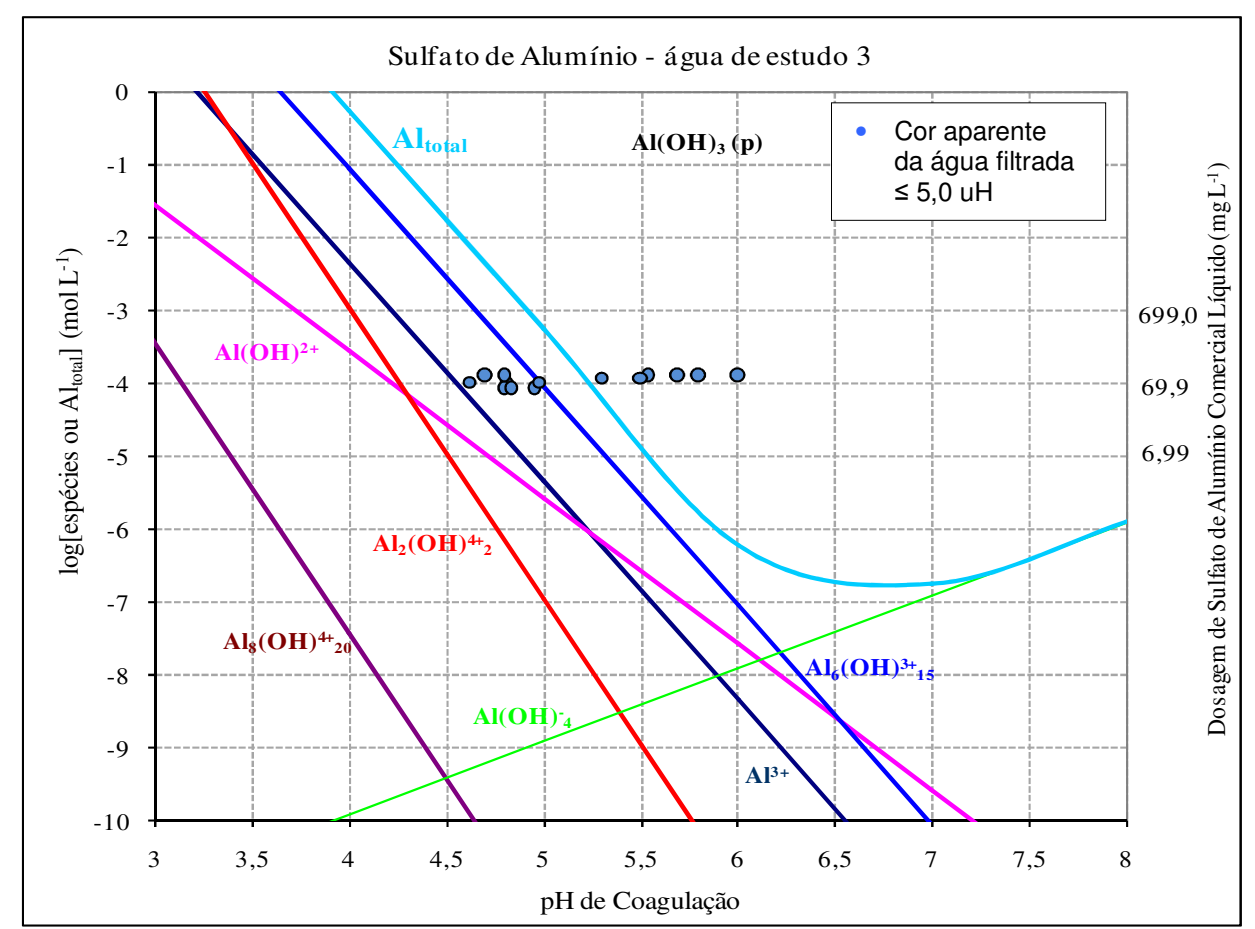

Figura 34 - Diagrama de coagulação com as espécies hidrolisadas de alumínio para a região de cor aparente da água filtrada $\leq 5 \mathrm{uH}$ - fração de SHA entre $30 \mathrm{kDa}$ e $100 \mathrm{kDa}$.

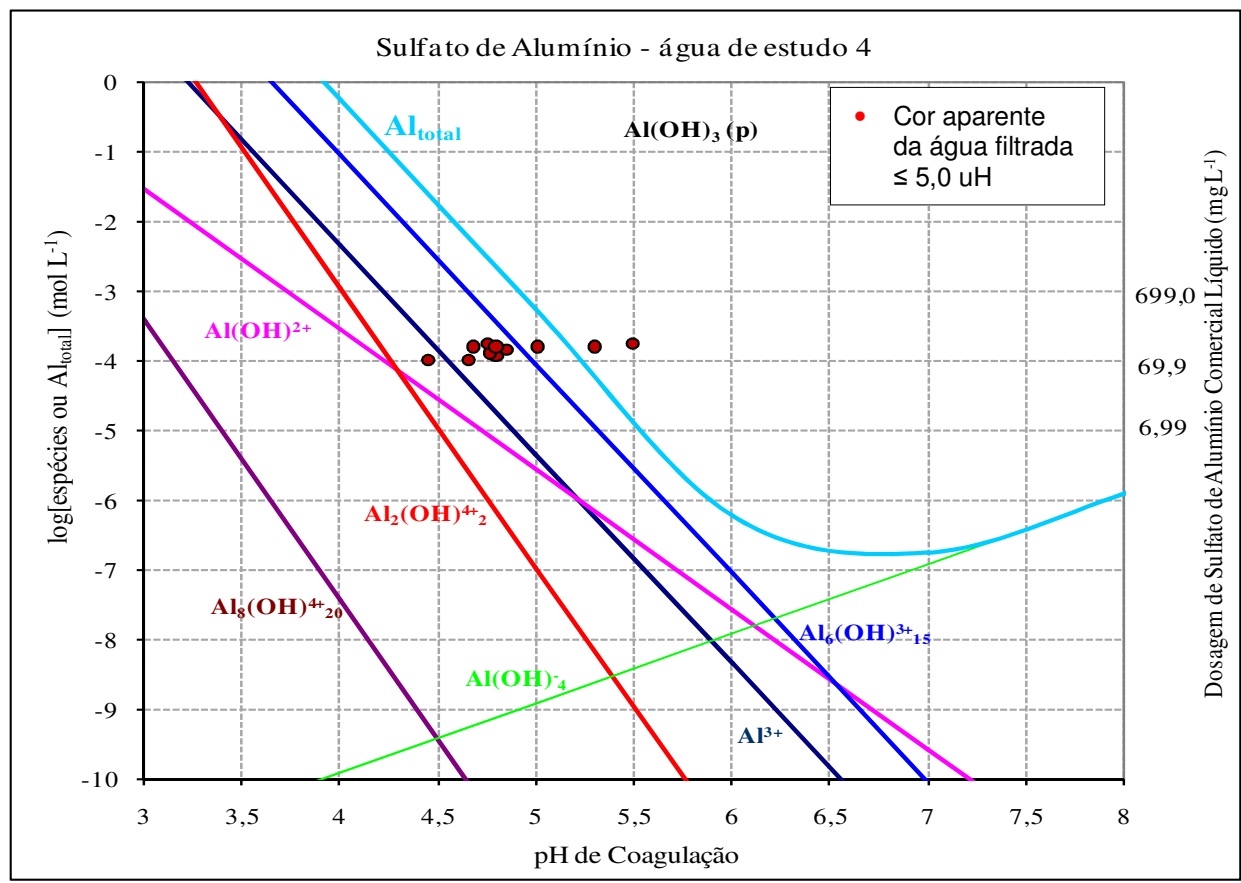

Figura 35 - Diagrama de coagulação com as espécies hidrolisadas de alumínio para a região de cor aparente da água filtrada $\leq 5 \mathrm{uH}$ - fração de SHA menor que $30 \mathrm{kDa}$. 
A coagulação das $\mathrm{SH}$ tem sido creditada a dois mecanismos principais em função do pH: região de baixo $\mathrm{pH}$ de 4,0 - 5,5, nessa região as $\mathrm{SH}$ carregadas negativamente podem precipitar pelo mecanismo de neutralização de cargas ao interagir com as espécies hidrolisadas do metal com carga positiva ou na fase sólida, formando complexos insolúveis das $\mathrm{SH}$ com o coagulante na forma de humatos ou fulvatos. Na faixa de $\mathrm{pH}$ de 6,0 a 8,0, as moléculas das $\mathrm{SH}$ podem ser adsorvidas no precipitado de hidróxido de alumínio (mecanismo de varredura) (KRASNER; AMY, 1995).

Observa-se na Figura 32 a presença de duas regiões de coagulação eficiente: a primeira é caracterizada por pH entre 4,7 e 5,2 e dosagens de sulfato de alumínio comercial de 50 a $70 \mathrm{mg} \mathrm{L}^{-1}$. Nesta região, os pontos de cor aparente estão sobre as linhas das espécies poliméricas de alumínio catiônicas, na qual possivelmente a coagulação ocorreu pelo mecanismo de adsorção - neutralização de cargas com as espécies hidrolisadas de alumínio, $\mathrm{Al}_{x}(\mathrm{OH})_{4}{ }^{{ }^{+}+} / \mathrm{Al}(\mathrm{OH})_{3(\mathrm{~S})}$. A segunda região se encontra entre o pH de coagulação de 5,5 a 5,8 e dosagens de sulfato de alumínio maiores que $90 \mathrm{mg} \mathrm{L}^{-1}$. Nessa região a coagulação ocorreu possivelmente pelo mecanismo de varredura.

$\mathrm{Na}$ Figura 33 verifica-se duas regiões mais amplas de remoção de cor aparente $\leq 5,0 \mathrm{uH}$ : a primeira região com pH de coagulação entre 4,4 e 6,0 e dosagens de sulfato de alumínio comercial de 40 a $90 \mathrm{mg} \mathrm{L}^{-1}$ e a segunda região com pH de coagulação entre 5,5 e 6,5 e dosagens de sulfato de alumínio maiores que $120 \mathrm{mg} \mathrm{L}^{-1}$. Possivelmente nessa água a coagulação ocorreu pelo mecanismo de neutralização de cargas ( $\mathrm{pH} 4,5$ a 5,0) ou próximo dessa região $(\mathrm{pH} 5,0$ a 5,5) e ainda por varredura e/ou neutralização de carga com o precipitado de alumínio, $\mathrm{Al}(\mathrm{OH})_{3}$. 
Conforme Gregor et al. (1997), o mecanismo de varredura é mais efetivo na remoção de compostos de elevada massa molecular, tipicamente os $\mathrm{AH}$. Geralmente estes possuem baixa densidade de carga e requerem menor concentração de coagulante para induzir a desestabilização de carga das partículas coloidais. Isto está relacionado com os resultados mostrados na seção 4.6 .6 os quais apresentaram que na fração entre $100 \mathrm{kDa}$ e $0,45 \mu \mathrm{m}$, há uma maior porcentagem de $\mathrm{AH}(87 \%)$ em relação aos $\mathrm{AF}$ (13\%). Porém, o mecanismo de varredura é mais apropriado quando a coagulação é feita antes da floculação e remoção de flocos por sedimentação ou flotação (tratamento da água em ciclo completo), pois a remoção é significativamente maior que na filtração direta (DI BERNARDO; DANTAS, 2005).

Observa-se na Figura 34 a presença de duas regiões com cor aparente menor que $5 \mathrm{uH}$, sendo a primeira com dosagens de sulfato de alumínio comercial entre 60 e $80 \mathrm{mg} \mathrm{L}^{-1}$ e pH de coagulação entre 4,5 e 5,0, e a segunda com dosagens de sulfato de alumínio comercial superiores a $80 \mathrm{mg} \mathrm{L}^{-1}$ e pH de coagulação entre 5,3 e 6,0. Nesta água de estudo possivelmente a coagulação ocorreu na região de neutralização de carga ( $\mathrm{pH} 4,5$ a 5,0) ou próximo dessa ( $\mathrm{pH} \mathrm{5,0} \mathrm{a} \mathrm{6,0)} \mathrm{e} \mathrm{em} \mathrm{pH}$ acima de 6,0 possivelmente pelo mecanismo de varredura.

$\mathrm{Na}$ água de estudo 4 (Figura 35) verifica-se apenas uma região com cor aparente da água filtrada menor que $5 \mathrm{uH}$, com pH entre 4,8 e 5,0 e dosagens de sulfato de alumínio comercial maiores que $110 \mathrm{mg} \mathrm{L}^{-1}$. Possivelmente o mecanismo de coagulação que prevaleceu nessa água de estudo foi adsorção - neutralização de cargas com as espécies hidrolisadas de alumínio, $\mathrm{Al}_{x}(\mathrm{OH})_{4}{ }^{\mathrm{n}} / \mathrm{Al}(\mathrm{OH})_{3}$ (S). Como apresentado nos resultados da seção 4.6.6, a fração menor que 30 kDa é constituída praticamente de $100 \%$ AF. A alta dosagem do coagulante requerida 
para a remoção de cor nessa água de estudo está relacionada com a alta porcentagem de $\mathrm{AF}$, as quais apresentam maiores porcentagens de grupos carregados negativamente e consequentemente elevada densidade de carga. Por isso, há necessidade de aumentar a quantidade de cargas positivas, resultantes da hidrólise do sulfato de alumínio, para que ocorra a desestabilização dessas moléculas e subseqüente agregação.

Foi observado que o $\mathrm{pH}$ de coagulação é um dos fatores mais importantes para maximizar a remoção das SHA. $\mathrm{O}$ pH apresenta grande influência na formação das espécies hidrolisadas do coagulante, também pela carga e potencial superficial para muitos colóides em solução, como por exemplo, a sílica e as SHA (JOHNSON; AMIRTHARAJAH, 1983). Se considerar a dosagem do coagulante fixa e se variar o $\mathrm{pH}$, conseqüentemente os mecanismos de coagulação serão modificados. O mesmo ocorre se fixar o valor do $\mathrm{pH}$ e se variar a dosagem do coagulante (DI BERNARDO; DANTAS, 2005).

A discussão dos mecanismos de coagulação ocorridos nas águas estudadas foi baseada nos resultados obtidos por Amirtharajah e Edwards (1985). Os autores prepararam águas de estudos com diferentes concentrações de $\mathrm{AH}$ e diferentes valores de turbidez. Através de ensaios de Jarteste, construíram os diagramas operacional para coagulação com alumínio, otimizando a remoção de cor e os mecanismos de coagulação. Também foi baseado nos estudos de Johnson e Amirtharajah (1983), onde os autores fizeram um estudo comparativo entre o diagrama de solubilidade do ferro (III) e do alumínio (III) e propuseram os mecanismos de coagulação. Porém, essa comparação foi apenas para se ter uma idéia de como são as regiões para os diferentes mecanismos de coagulação, pois, 
as águas de estudos usadas pelos autores foram diferentes das usadas neste estudo.

\subsubsection{Diagramas de remoção de turbidez}

As Figuras 36 a 39 apresentam os diagramas de coagulação com o sulfato de alumínio para a remoção de turbidez por ensaios feitos em Jarteste e por filtração direta em filtros de laboratório. Os ensaios foram os mesmos de remoção de cor aparente com o sulfato de alumínio. Nos diagramas as curvas representam turbidez de 0,5 uT, seguida por 1,0; 3,0 e maior que 3,0 uT. As Tabelas apresentadas no anexo A fornecem os resultados das faixas de $\mathrm{pH}$ de coagulação e dosagens de sulfato de alumínio comercial. 


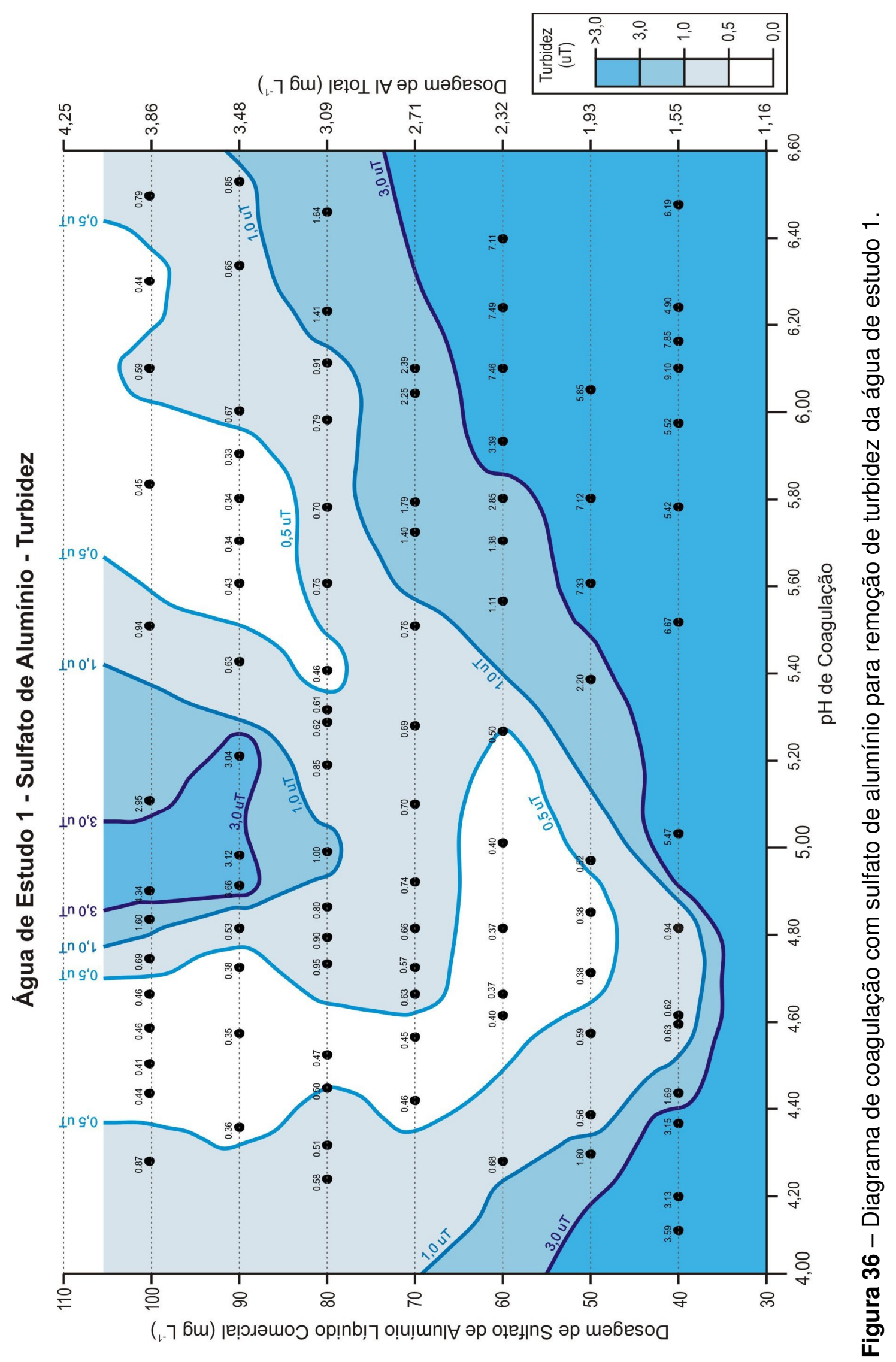




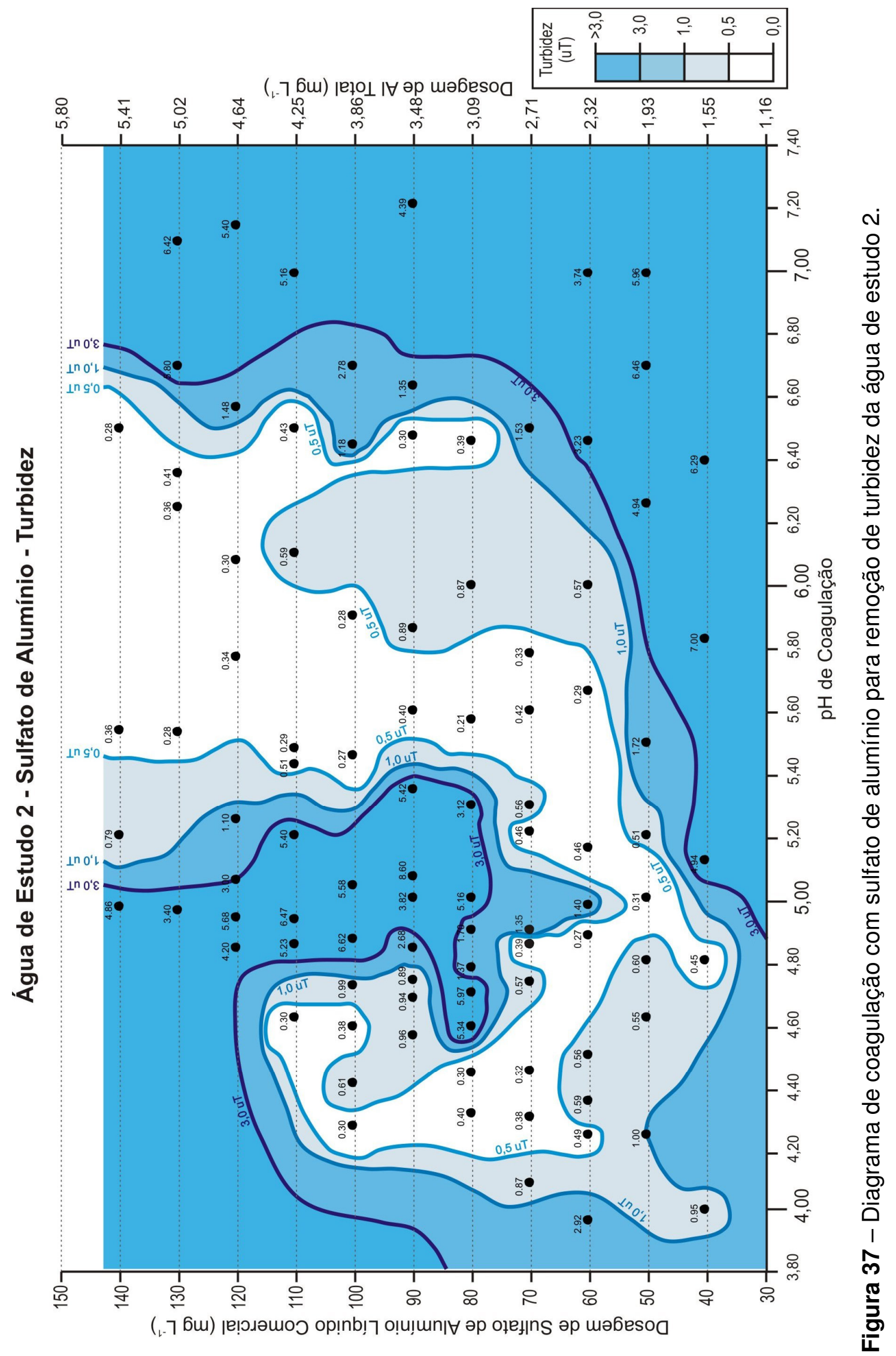




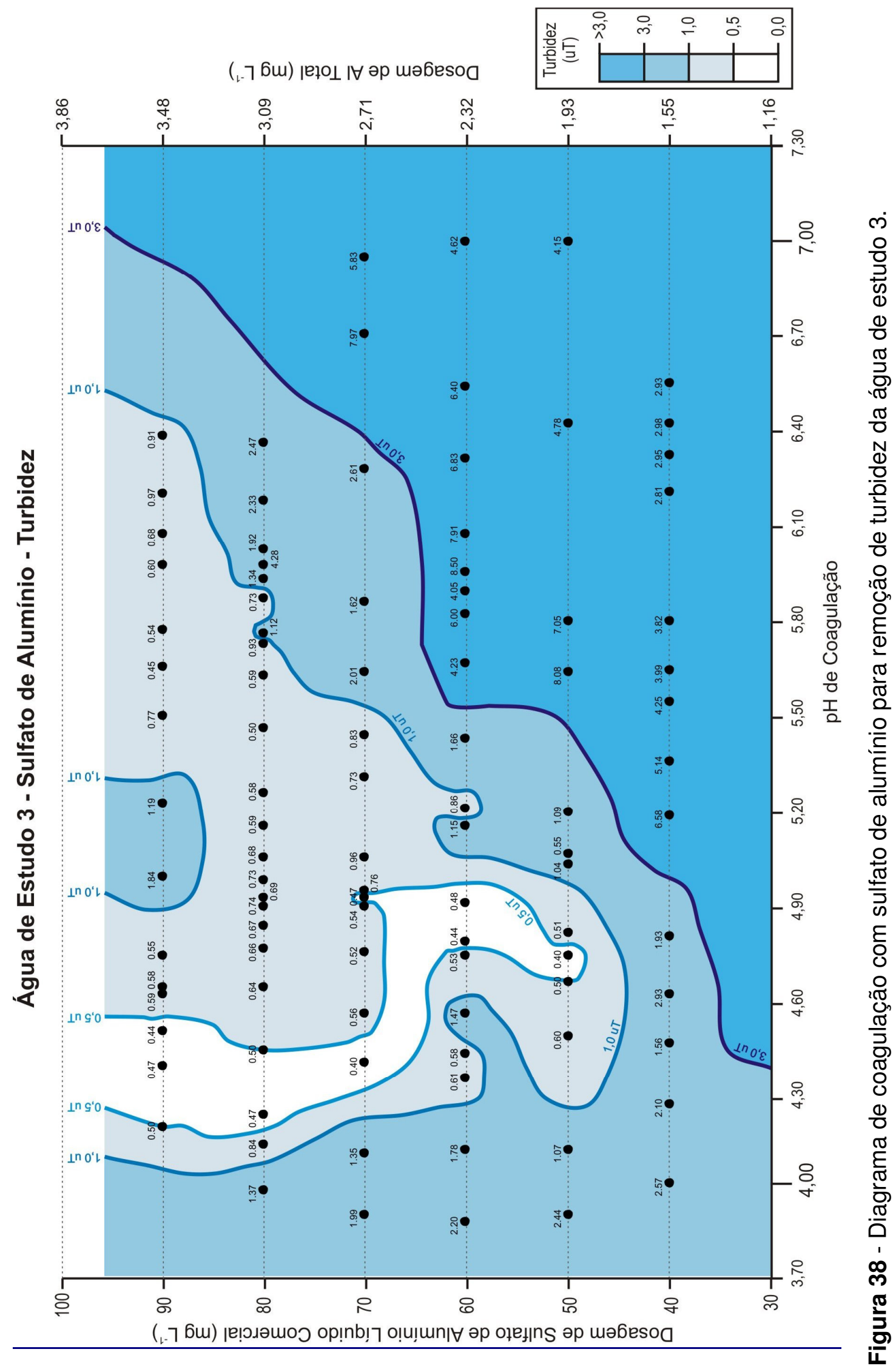




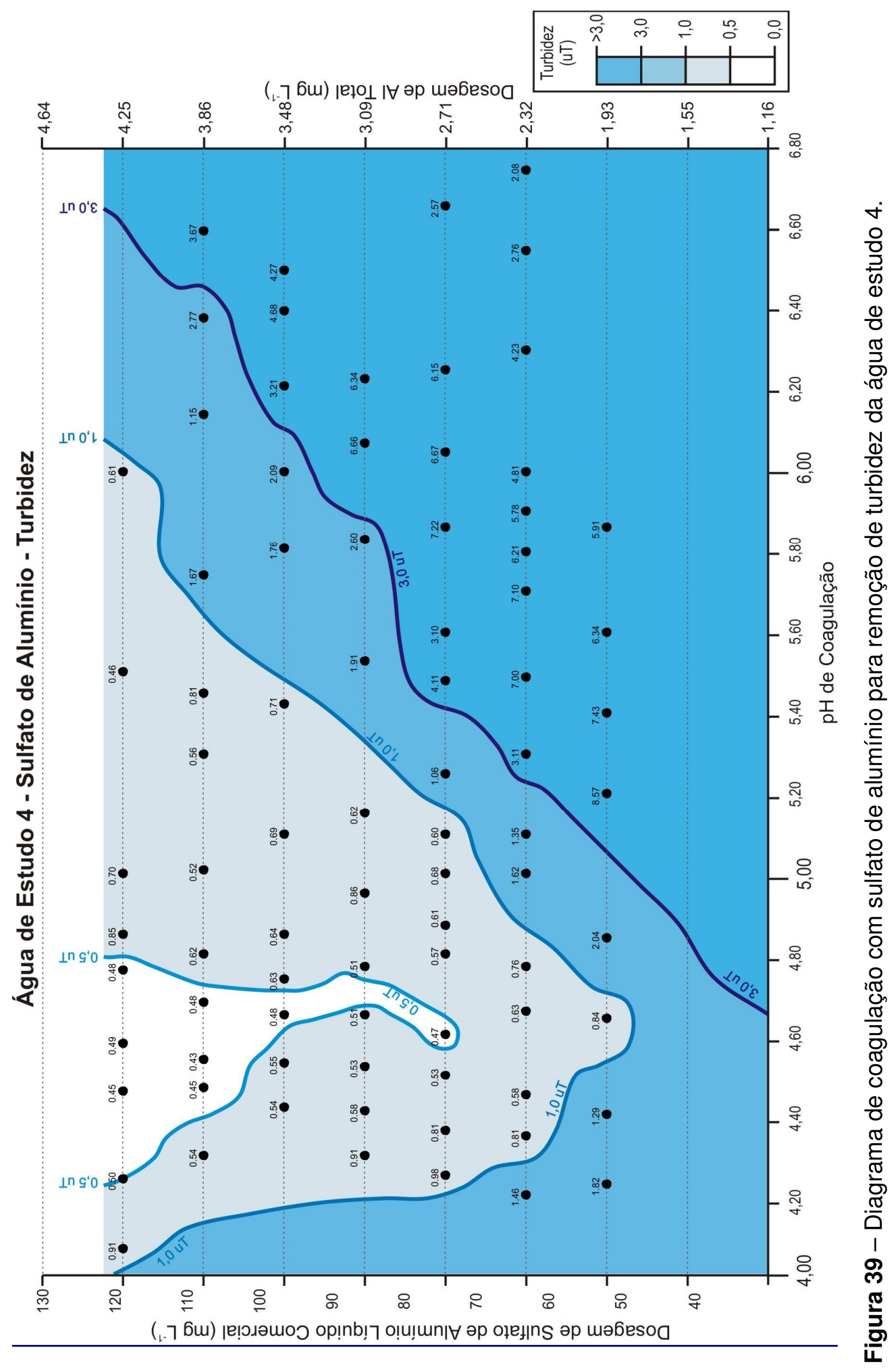


A medida de turbidez representa um procedimento experimental apropriado para a determinação da estabilidade dos colóides em suspensão. Gregor et al. (1997) observaram que um dos problemas que acontece nos ensaios de coagulação com turbidez baixa é a ineficiência na produção de flocos. Por isso, neste estudo foi empregada a filtração direta com filtros de laboratório, pois o tratamento desse tipo de água é mais efetivo quando se utiliza essa tecnologia.

Os ensaios com a água de estudo 1 (Figura 36) apresentam a existência de duas regiões distintas com remoção de turbidez menor ou igual a 0,5 uT, sendo a primeira região com pH de coagulação entre 4,3 e 5,3 e dosagens de sulfato de alumínio comercial de 50 a maiores que $100 \mathrm{mg} \mathrm{L}^{-1}$ e a segunda região com pH de coagulação de 5,40 e 6,30 e dosagens de sulfato de alumínio comercial de 80 a maiores que $100 \mathrm{mg} \mathrm{L}^{-1}$.

Observa-se no diagrama de coagulação apresentado na Figura 37 uma ampla região de remoção de turbidez menor ou igual a 0,5uT, com pH de coagulação entre 4,2 e 6,50, e dosagens de sulfato de alumínio comercial de 40 a maiores que 140 $\mathrm{mg} \mathrm{L}^{-1}$. Entretanto, a maior região de remoção foi com dosagens de coagulante acima de $100 \mathrm{mg} \mathrm{L}^{-1}$ e pH mais elevado, entre 5,3 e 6,5.

Com a água de estudo 3 (Figura 38) verifica-se apenas uma pequena região de remoção de turbidez menor ou igual a 0,5 uT, na qual o pH de coagulação ficou entre 4,3 e 4,8 e as dosagens de coagulante de 50 a maiores que $90 \mathrm{mg} \mathrm{L}^{-1}$.

Observa-se no diagrama apresentado na Figura 39 uma pequena região de remoção de turbidez menor ou igual a 0,5 uT, com pH entre 4,2 a 4,70 e dosagens de coagulantes superiores a $70 \mathrm{mg} \mathrm{L}^{-1}$. 
Os intervalos de $\mathrm{pH}$ e dosagens de sulfato de alumínio comercial para as quatro águas estudadas para a remoção de cor $\leq 5,0 \mathrm{uH}$ e turbidez $\leq 0,5$ uT estão apresentados na Tabela 12.

Tabela 12 - Valores de pH de coagulação e dosagens de sulfato de alumínio das regiões de cor aparente $\leq 5,0 \mathrm{uH}$ e turbidez. $\leq 0,5 \mathrm{uT}$.

\begin{tabular}{|c|c|c|c|c|}
\hline $\begin{array}{l}\text { Água } \\
\text { de } \\
\text { estudo }\end{array}$ & $\begin{array}{c}\text { Região de } \\
\text { remoção de cor } \\
\text { e turbidez }\end{array}$ & $\begin{array}{c}\text { pH de } \\
\text { coagulação }\end{array}$ & $\begin{array}{c}\text { Dosagem de sulfato de } \\
\text { alumínio comercial } \\
\left(\mathrm{mg} \mathrm{L}^{-1}\right)\end{array}$ & $\begin{array}{l}\text { Parâmetros } \\
\text { de controle }\end{array}$ \\
\hline \multirow{4}{*}{1} & \multirow[t]{2}{*}{ Região 1} & $4,6-5,2$ & $50-70$ & Cor aparente \\
\hline & & $4,3-5,3$ & 50 a maiores que 100 & Turbidez \\
\hline & \multirow[t]{2}{*}{ Região 2} & $5,5-5,8$ & Superiores a 90 & Cor aparente \\
\hline & & $5,4-6,3$ & Superiores a 100 & Turbidez \\
\hline \multirow{3}{*}{2} & \multirow[t]{2}{*}{ Região 1} & $4,5-6,0$ & $40-90$ & Cor aparente \\
\hline & & $4,2-6,5$ & 40 a maiores que 140 & Turbidez \\
\hline & Região 2 & $5,5-6,5$ & Superiores a 120 & Cor aparente \\
\hline \multirow{3}{*}{3} & \multirow[t]{2}{*}{ Região 1} & $4,5-5,0$ & De 60 a 80 & Cor aparente \\
\hline & & $4,3-4,8$ & 50 a maiores que 90 & Turbidez \\
\hline & Região 2 & $5,3-6,0$ & Superiores a 80 & Cor aparente \\
\hline \multirow[b]{2}{*}{4} & \multirow[b]{2}{*}{ Reqião 1} & $4,8-5,0$ & Superiores a 100 & Cor aparente \\
\hline & & $4,2-4,70$ & Superiores a 70 & Turbidez \\
\hline
\end{tabular}

Verifica-se pela Tabela 12 que os intervalos de $\mathrm{pH}$ e dosagens de coagulante para a remoção de cor aparente e turbidez foram similares. Segundo Edwards e Amirtharajah (1989), a cor aparente é causada pela presença das SH e turbidez, e a medida de cor aparente refere-se simultaneamente a remoção de ambas.

O uso dos diagramas de coagulação é de grande importância para verificar as condições apropriadas na coagulação em sistemas de filtração direta. Pois, dependendo das condições de coagulação, pode ocorrer o transpasse nos filtros, principalmente se a água for coagulada no mecanismo de varredura (DI BERNARDO; DANTAS, 2005). 


\subsection{Resultados de coagulação com cloreto férrico}

\subsubsection{Caracterização das amostras de águas de estudo}

As águas de estudo usadas nos ensaios com o cloreto férrico foram preparadas com as mesmas frações das SHA e parâmetros de controle que das águas de estudo preparadas para os ensaios com o sulfato de alumínio (seção 5.4.2). Para cada água de estudo determinaram-se alguns parâmetros físicos e químicos, como apresentado na Tabela 13. 
Tabela 13 - Caracterização das amostras de água de estudo de 1 a 4, para a realização dos ensaios com o cloreto férrico.

\begin{tabular}{|c|c|c|c|c|}
\hline \multirow[b]{2}{*}{ Parâmetros } & \multicolumn{4}{|c|}{ Valores } \\
\hline & $\begin{array}{l}\text { Água de } \\
\text { estudo } 1\end{array}$ & $\begin{array}{l}\text { Água de } \\
\text { estudo } 2\end{array}$ & $\begin{array}{l}\text { Água de } \\
\text { estudo } 3\end{array}$ & $\begin{array}{l}\text { Água de } \\
\text { estudo } 4\end{array}$ \\
\hline Condutividade Elétrica ( $\mu \mathrm{s} / \mathrm{cm})$ & 79,10 & 83,0 & 81,90 & 87,70 \\
\hline Cor Verdadeira $(\mathrm{uH})$ & 93 & 98 & 101 & 95 \\
\hline Cor Aparente $(\mathrm{uH})$ & 117 & 112 & 118 & 110 \\
\hline Absorbância (254 nm) & 0,337 & - & 0,403 & 0,515 \\
\hline $\mathrm{pH}$ & 6,30 & 6,88 & 6,03 & 6,29 \\
\hline Turbidez (uT) & 4,55 & 4,50 & 4.60 & 5,00 \\
\hline Alcalinidade Total $\left(\mathrm{CaCO}_{3} \mathrm{mg} \mathrm{L}^{-1}\right)$ & 10,0 & 10,58 & 9,0 & 11,0 \\
\hline Dureza Total $\left(\mathrm{CaCO}_{3} \mathrm{mg} \mathrm{L}^{-1}\right)$ & 32,0 & 16,0 & 24,0 & 25,0 \\
\hline Cloretos $\left(\mathrm{mg} \mathrm{L}^{-1}\right)$ & 3,80 & 10,4 & 11,0 & 6,0 \\
\hline Sulfatos $\left(\mathrm{mg} \mathrm{L}^{-1}\right)$ & 1,0 & 1,0 & 1,0 & ND \\
\hline Nitrogênio Amoniacal $\left(\mathrm{mg} \mathrm{L}^{-1}\right)$ & 0,36 & 0,36 & - & 0,1901 \\
\hline Nitrogênio Nitrato $\left(\mathrm{mg} \mathrm{L}^{-1}\right)$ & 0,0615 & 0,0615 & 0,0540 & 0,0014 \\
\hline Nitrogênio Nitrito $\left(\mathrm{mg} \mathrm{L}^{-1}\right)$ & 0,0028 & 0,0028 & 0,0026 & 0,0028 \\
\hline Sólidos Totais $\left(\mathrm{mg} \mathrm{L}^{-1}\right)$ & 376,0 & 161,0 & 97,0 & 106,0 \\
\hline Sólidos Totais Suspensos $\left(\mathrm{mg} \mathrm{L}^{-1}\right)$ & 189,0 & 28,0 & 10,0 & 52,0 \\
\hline Sólidos Totais Dissolvidos (mg L ${ }^{-1}$ ) & 187,0 & 133,0 & 87,0 & 54,0 \\
\hline Sódio $\left(\mathrm{mg} \mathrm{L}^{-1}\right)$ & 2,0 & 2,5 & 2,30 & 3,3 \\
\hline Potássio (mg L-1) & 4,5 & 4,5 & 4,4 & 5,2 \\
\hline Fluoreto $\left(\mathrm{mg} \mathrm{L}^{-1}\right)$ & 0,13 & 0,13 & 0,10 & 0,10 \\
\hline Carbono Orgânico Dissolvido $\left(\mathrm{mg} \mathrm{L}^{-1}\right)$ & 10,55 & 5,301 & 7,593 & 16,0 \\
\hline Zinco - amostra não-digerida (mg L $\left.{ }^{-1}\right)^{\prime}$ & ND & ND & ND & ND \\
\hline Zinco - amostra digerida $\left(\mathrm{mg} \mathrm{L}^{-1}\right)$ & 0,03 & 0,03 & 0,03 & 0,01 \\
\hline Chumbo - amostra não-digerida $\left(\mathrm{mg} \mathrm{L}^{-1}\right)$ & ND & ND & ND & 0,08 \\
\hline Chumbo - amostra digerida $\left(\mathrm{mg} \mathrm{L}^{-1}\right)$ & ND & ND & ND & ND \\
\hline Cádmio - amostra não-digerida (mg L $\left.{ }^{-1}\right)$ & ND & ND & ND & ND \\
\hline Cádmio - amostra digerida (mg L $\left.{ }^{-1}\right)$ & ND & ND & ND & ND \\
\hline Níquel - amostra não-digerida (mg L ${ }^{-1}$ ) & ND & ND & ND & ND \\
\hline Níquel - amostra digerida (mg L $\left.{ }^{-1}\right)$ & ND & ND & ND & ND \\
\hline Ferro - amostra não-digerida (mg L $\left.{ }^{-1}\right)$ & 0,02 & 0,03 & 0,03 & 0,04 \\
\hline Ferro - amostra digerida $\left(\mathrm{mg} \mathrm{L}^{-1}\right)$ & 0,13 & 0,13 & 0,15 & 0,09 \\
\hline Manganês - amostra não-digerida $\left(\mathrm{mg} \mathrm{L}^{-1}\right)$ & ND & ND & ND & ND \\
\hline Manganês - amostra digerida $\left(\mathrm{mg} \mathrm{L}^{-1}\right)$ & 0,02 & 0,02 & 0,02 & 0,02 \\
\hline Cobre - amostra não-digerida (mg L $\left.{ }^{-1}\right)$ & 0,02 & 0,02 & 0,02 & 0,02 \\
\hline Cobre - amostra digerida $\left(\mathrm{mg} \mathrm{L}^{-1}\right)$ & 0,05 & 0,04 & 0,05 & 0,05 \\
\hline Cromo - amostra não-digerida ( $\left.\mathrm{mg} \mathrm{L}^{-1}\right)$ & ND & ND & ND & ND \\
\hline Cromo - amostra digerida $\left(\mathrm{mg} \mathrm{L}^{-1}\right)$ & 0,04 & 0,03 & 0,04 & 0,03 \\
\hline
\end{tabular}

$\mathrm{ND}=$ não detectado 


\subsubsection{Diagramas de remoção de cor aparente}

Os diagramas de coagulação das Figuras 40 a 43 foram construídos conforme os dados apresentados nas Tabelas no anexo B. Estes apresentam os resultados dos ensaios de filtração direta para diferentes dosagens de cloreto férrico e diferentes valores de $\mathrm{pH}$ de coagulação, para as quatro águas de estudo preparadas com diferentes tamanhos moleculares aparentes das SHA $\left(F_{1}, F_{2}, F_{3} e\right.$ $\left.F_{4}\right)^{\prime}$. As Figuras 40 a 43, apresentam as áreas de cor aparente da água filtrada de 5, 10, 20, 50 e maior que 50 uH. Para construção desses diagramas, as condições de ensaio e os parâmetros de controle foram os mesmos apresentados na seção 5.4 .2 do sulfato de alumínio.

Características das águas de estudo: preparadas com os diferentes tamanhos moleculares aparentes das SHA apresentaram cor verdadeira de $100 \pm 5$ $\mathrm{uH}$, turbidez em torno de 5,0 uT, $\mathrm{pH}=6,0$, temperatura de $20 \pm 1^{\circ} \mathrm{C}$ e alcalinidade entre 9 e11 $\mathrm{mg} \mathrm{L}^{-1} \mathrm{CaCO}_{3}$.

As dosagens de coagulante nos diagramas de coagulação estão à esquerda (ordenadas) em $\mathrm{mg} \mathrm{L}^{-1}$ do cloreto férrico comercial, e a direita em $\mathrm{mg} \mathrm{L}^{-1}$ de ferro total e na abscissa está o pH de coagulação. 


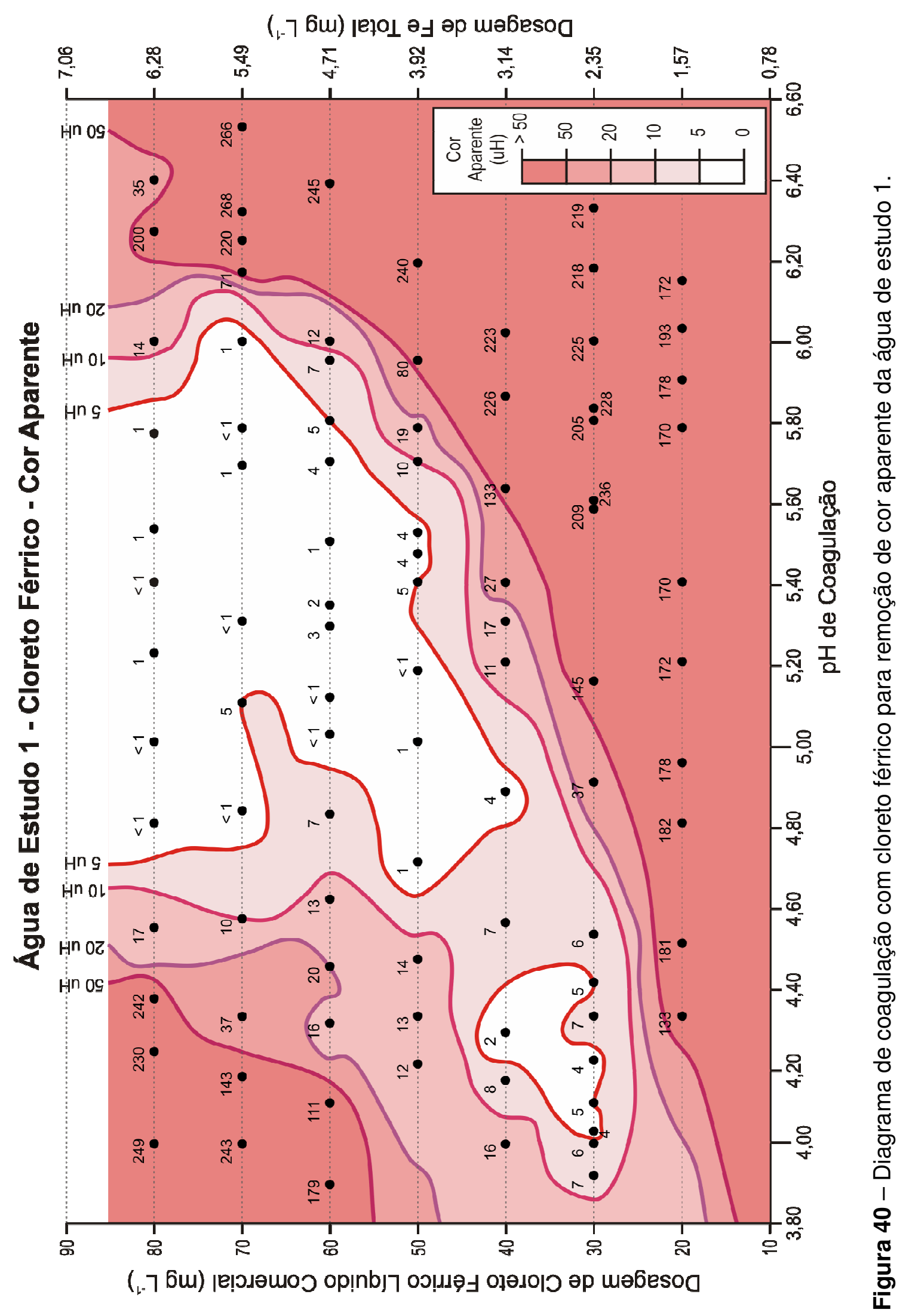




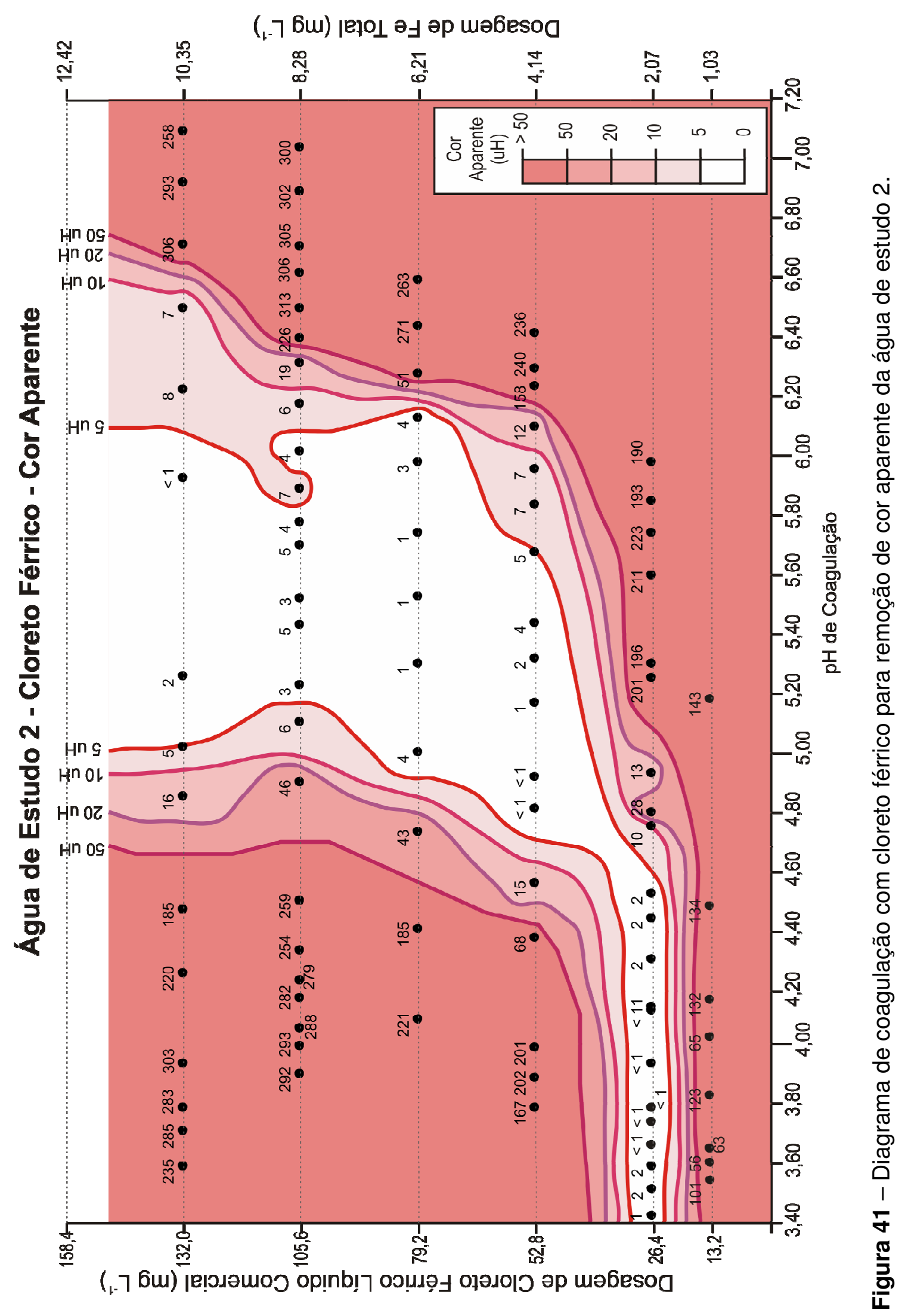




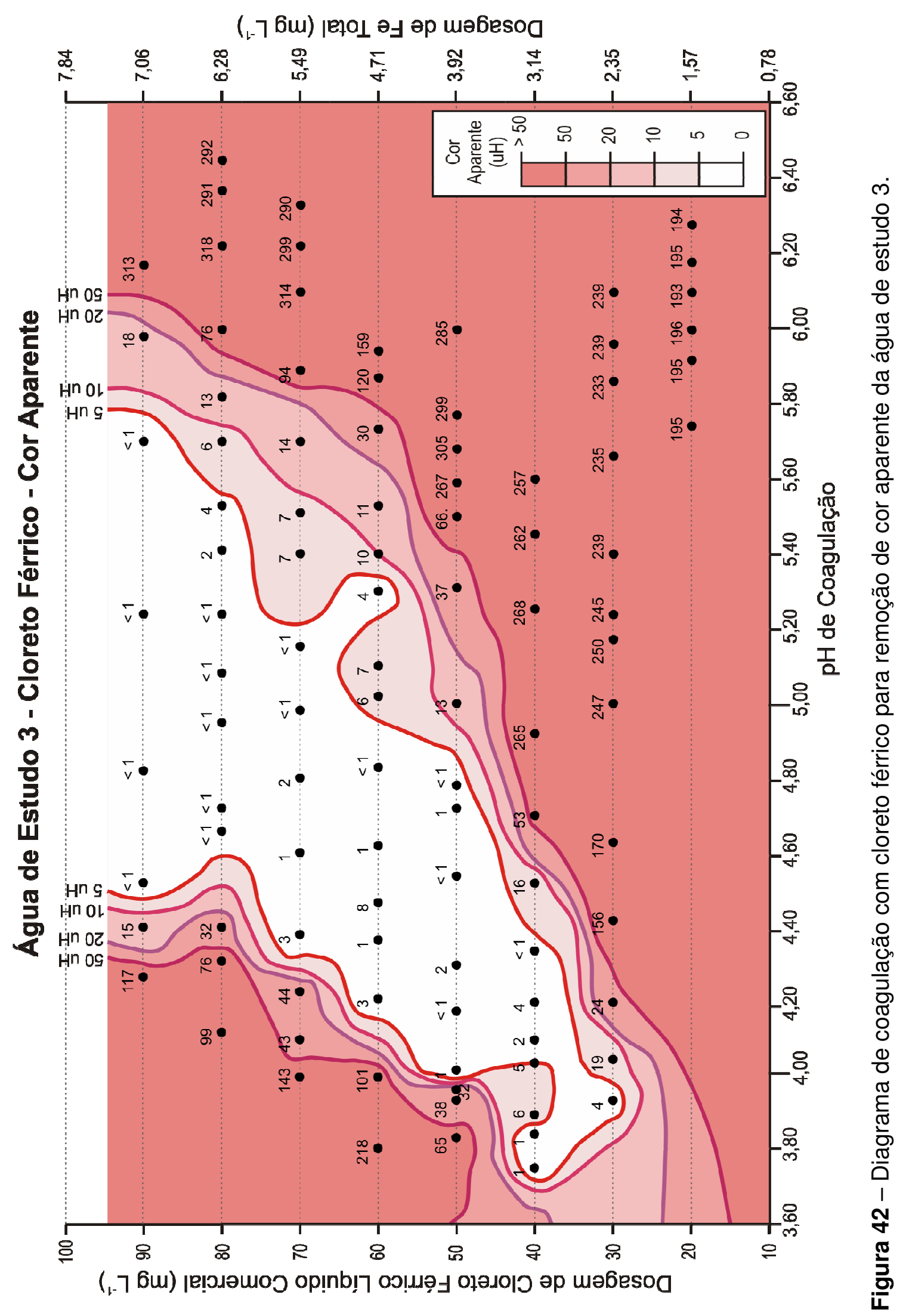




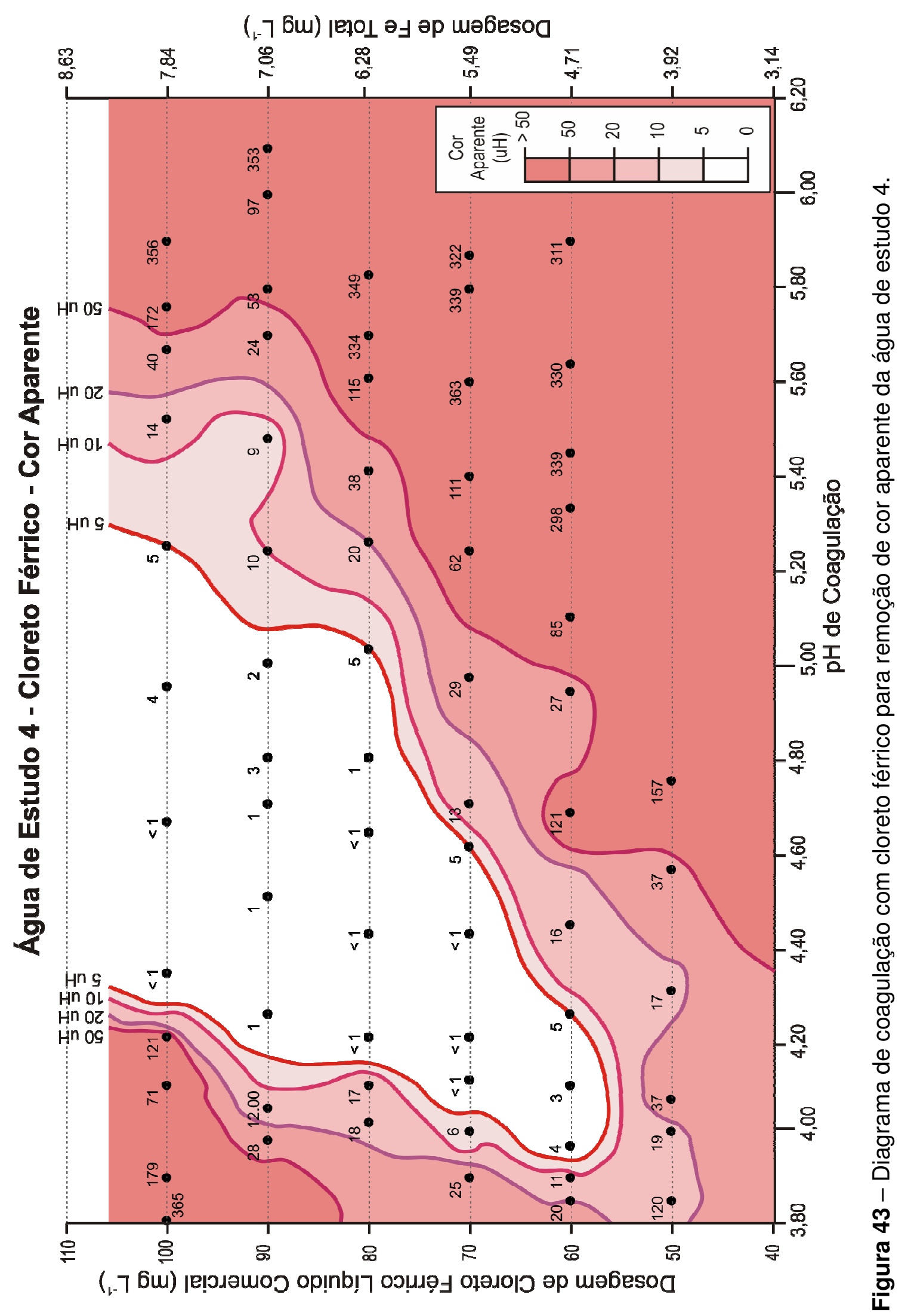


Verifica-se pelo diagrama de coagulação da Figura 40 que há duas regiões de coagulação com curvas de cor aparente da água filtrada menor ou igual a 5,0 uH. A menor região foi com pH de coagulação entre 4,0 e 4,3 e dosagens de cloreto férrico de 30 a $40 \mathrm{mg} \mathrm{L}^{-1}$. A maior região se encontrou nos valores de $\mathrm{pH}$ entre 4,8 e 6,0 e dosagens do coagulante de 40 a maiores que $80 \mathrm{mg} \mathrm{L}^{-1}$.

Observa-se nos diagramas das Figuras 41, 42 e 43 que há apenas uma região de coagulação eficiente (cor aparente $\leq 5 \mathrm{uH}$ ). $\mathrm{Na}$ água de estudo 2, as dosagens de cloreto férrico comercial foram de $26,4 \mathrm{mg} \mathrm{L}^{-1}$ a maiores que $132 \mathrm{mg} \mathrm{L}^{-1}$ e pH de coagulação entre 3,40 e 6,0. $\mathrm{Na}$ água de estudo $3,0 \mathrm{pH}$ de coagulação ficou entre 3,70 e 6,0 e as dosagens de coagulante de 30 a maiores que $90 \mathrm{mg} \mathrm{L}^{-1}$, e na água de estudo 4, o pH ficou entre 3,95 e 5,30 e as dosagens de coagulante de 60 a maiores que $100 \mathrm{mg} \mathrm{L}^{-1}$.

Verificou-se ao empregar as maiores frações de SHA ( $F_{1}$ : menor que 0,45 $\mu \mathrm{m}, \mathrm{F}_{2}$ : entre $100 \mathrm{kDa}$ e $0,45 \mu \mathrm{m}, \mathrm{F}_{3}$ : entre 30 e $100 \mathrm{kDa}$ ) que a cor aparente da água filtrada resultou menor ou igual a $10 \mathrm{uH}$ a partir de $30 \mathrm{mg} \mathrm{L}^{-1}$ de cloreto férrico comercial, já na fração de menor tamanho molecular aparente $\left(\mathrm{F}_{4}^{\prime}\right.$ : menor que 30 $\mathrm{kDa}$ ), somente apresentou cor aparente igual ou menor a $10 \mathrm{uH}$ a partir da dosagem de $60 \mathrm{mg} \mathrm{L}^{-1}$ de cloreto férrico como produto comercial. Isto comprova novamente a influência do tamanho molecular das SHA, onde quanto menor o tamanho molecular das SHA, maior o valor de cor aparente da água filtrada.

Verifica-se através dos diagramas apresentados nas Figuras 40 a 43 que, as curvas com cor aparente de 5, 10, 15, 20 e 50 uH formaram regiões subseqüentes e próximas uma da outra, mostrando que na coagulação com o cloreto férrico, as regiões de cor aparente são mais limitadas ao pH de coagulação. As quatro águas 
de estudo apresentaram amplas regiões de remoção de cor aparente menor ou igual a 5,0 uT.

\subsubsection{Diagramas de coagulação com as espécies hidrolisadas de ferro}

Os diagramas apresentados nas Figuras 44 a 47 foram construídos com base nos resultados apresentados nas Figuras 40 a 43 para a região ótima de cor aparente da água filtrada $(\leq 5,0 \mathrm{uH})$. Estes indicam as regiões e mecanismos de coagulação de remoção de cor em função da dosagem de coagulante e pH de coagulação. As linhas nos diagramas representam o equilíbrio termodinâmico das espécies hidrolisadas de ferro, onde no final das ordenadas está à concentração final do ferro em equilíbrio com a fase sólida do hidróxido de ferro, $\mathrm{Fe}(\mathrm{OH})_{3}$.

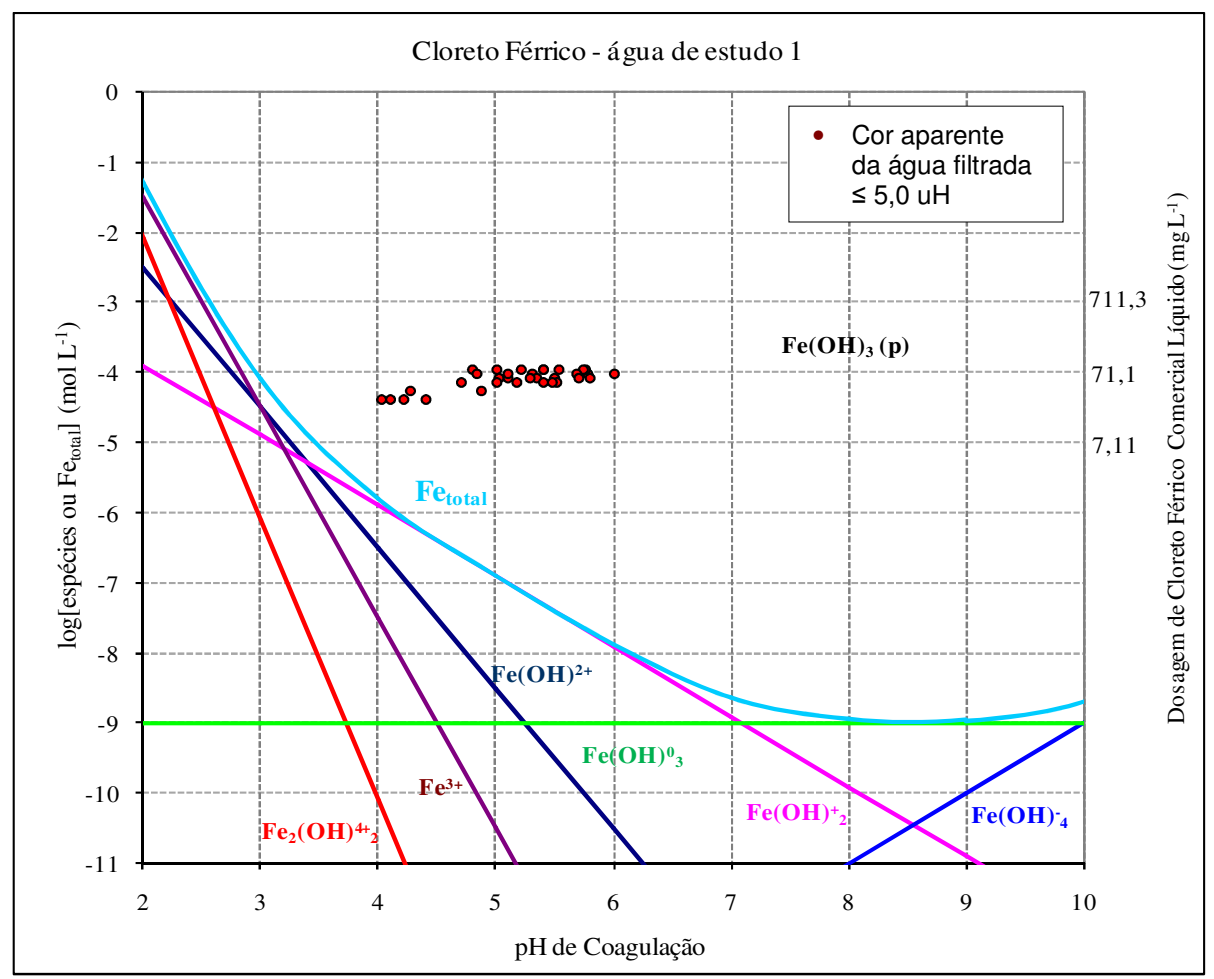

Figura 44 - Diagrama de coagulação com as espécies hidrolisadas de ferro para a região de cor aparente da água filtrada $\leq 5 \mathrm{uH}$ - fração de SHA menor que $0,45 \mu \mathrm{m}$. 


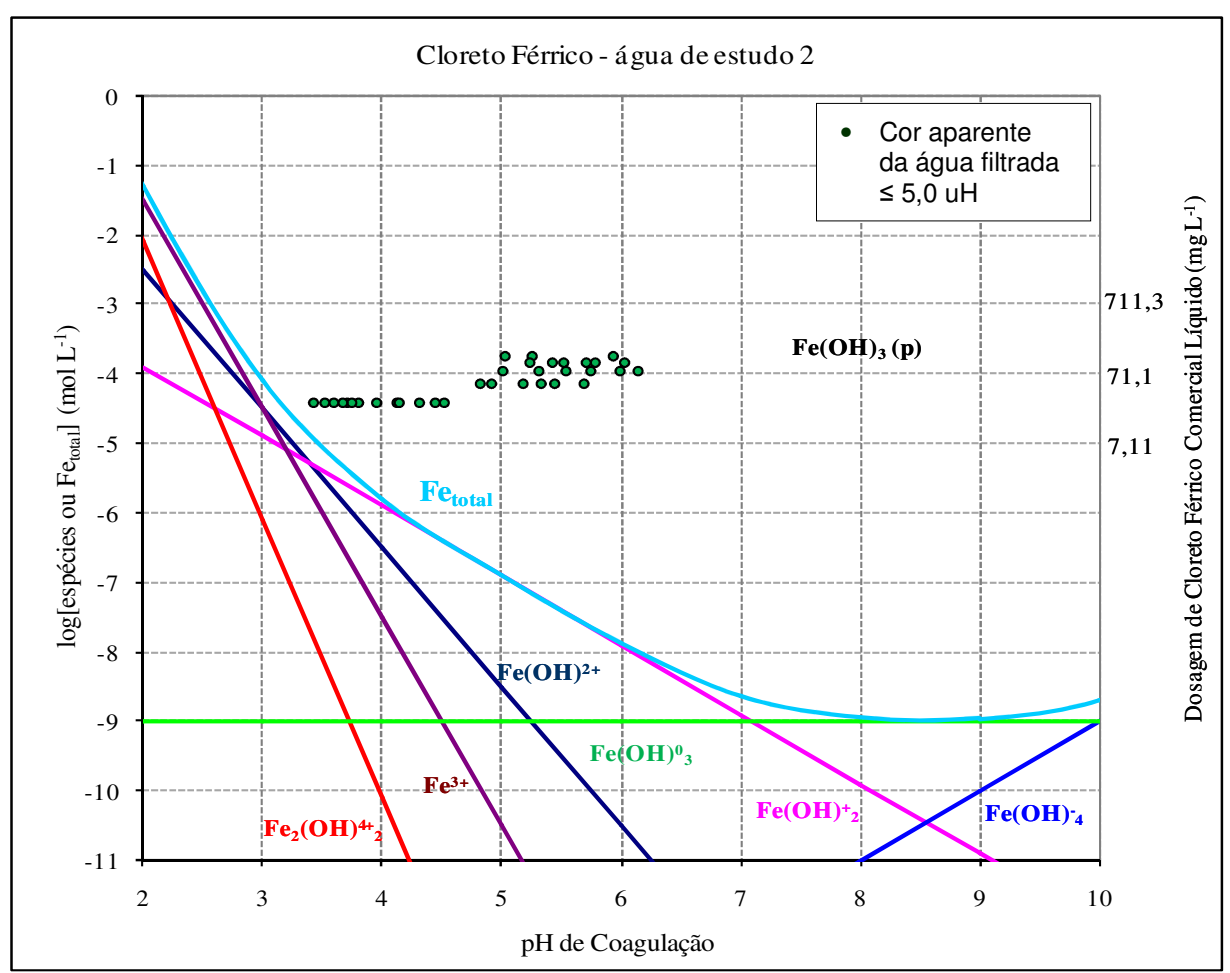

Figura 45 - Diagrama de coagulação com as espécies hidrolisadas de ferro para a região de cor aparente da água filtrada $\leq 5 \mathrm{uH}$ - fração de SHA entre $100 \mathrm{kDa}$ e $0,45 \mu \mathrm{m}$.

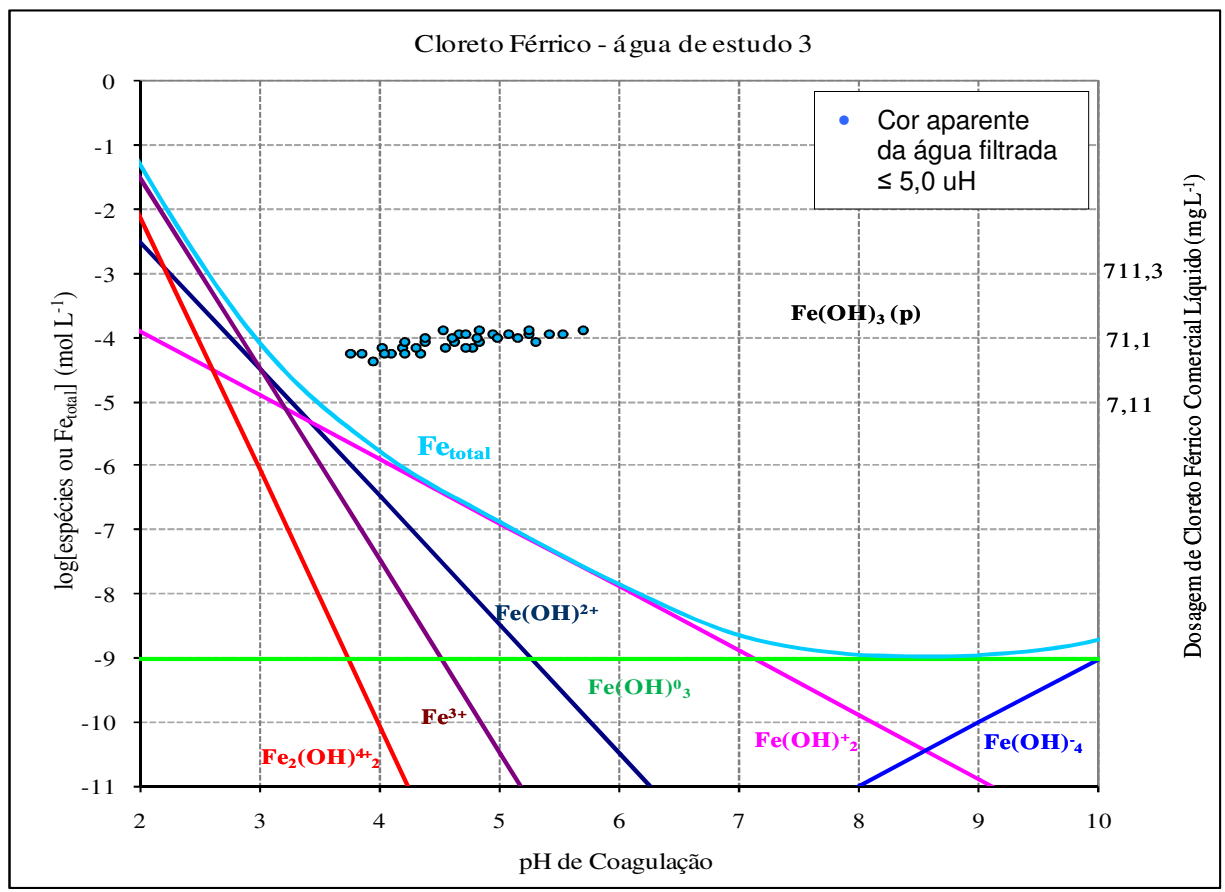

Figura 46 - Diagrama de coagulação com as espécies hidrolisadas de ferro para a região de cor aparente da água filtrada $\leq 5 \mathrm{uH}-$ fração de SHA entre $30 \mathrm{kDa}$ e $100 \mathrm{kDa}$. 


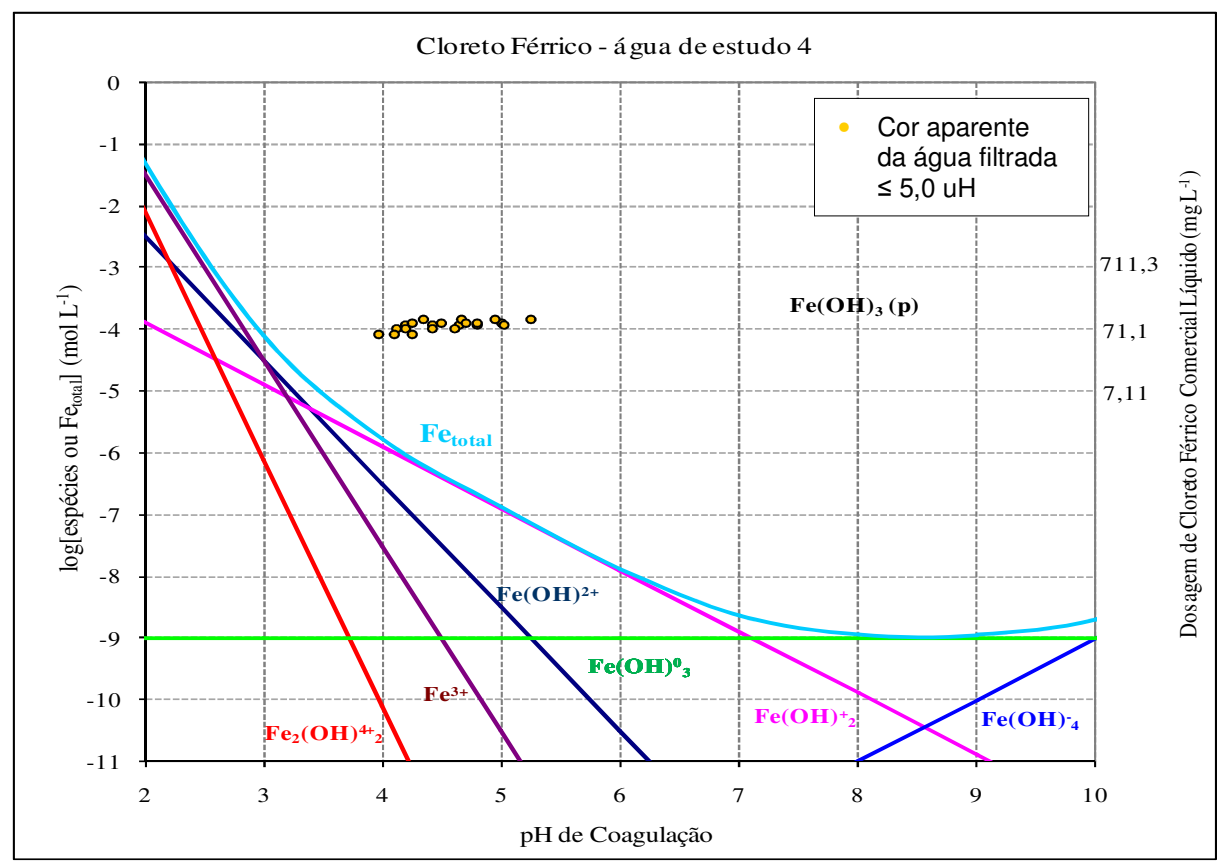

Figura 47 - Diagrama de coagulação com as espécies hidrolisadas de ferro para a região de cor aparente da água filtrada $\leq 5 \mathrm{uH}$ - fração de SHA menor que $30 \mathrm{kDa}$.

Os resultados para as águas de estudo 1, 2 e 3 apresentadas nas Figuras 44, 45 e 46 respectivamente, apresentaram pH de coagulação em torno de 4,0 a 6,0 e com a água de estudo 4 (Figura 47), o pH ficou em torno de 4,0 a 5,2. Nestes diagramas os pontos que representam a cor aparente da água filtrada menor ou igual a 5,0 uH, estão sobre a região do precipitado de hidróxido de ferro. Para estas águas, provavelmente a coagulação prevaleceu no mecanismo de varredura.

\subsubsection{Diagramas de coagulação de remoção de turbidez}

As Figuras 48 a 51 apresentam os diagramas de coagulação com o cloreto férrico para a remoção de turbidez. Os ensaios feitos para remoção de turbidez foram os mesmos para remoção de cor da água filtrada. Nestas Figuras estão 
representadas as regiões com o menor valor de turbidez de 0,5 uT, seguida pelas regiões de 1,0; 3,0 e maior que 3,0 uT.

As tabelas apresentadas no anexo B contêm os resultados dos valores de $\mathrm{pH}$ de coagulação e das dosagens de cloreto férrico comercial para a remoção de turbidez. As dosagens de coagulante nos gráficos estão à esquerda nas ordenadas em $\mathrm{mg} \mathrm{L}^{-1}$ do produto comercial, e a direita em $\mathrm{mg} \mathrm{L}^{-1}$ de ferro e nas abscissas o $\mathrm{pH}$ de coagulação. 


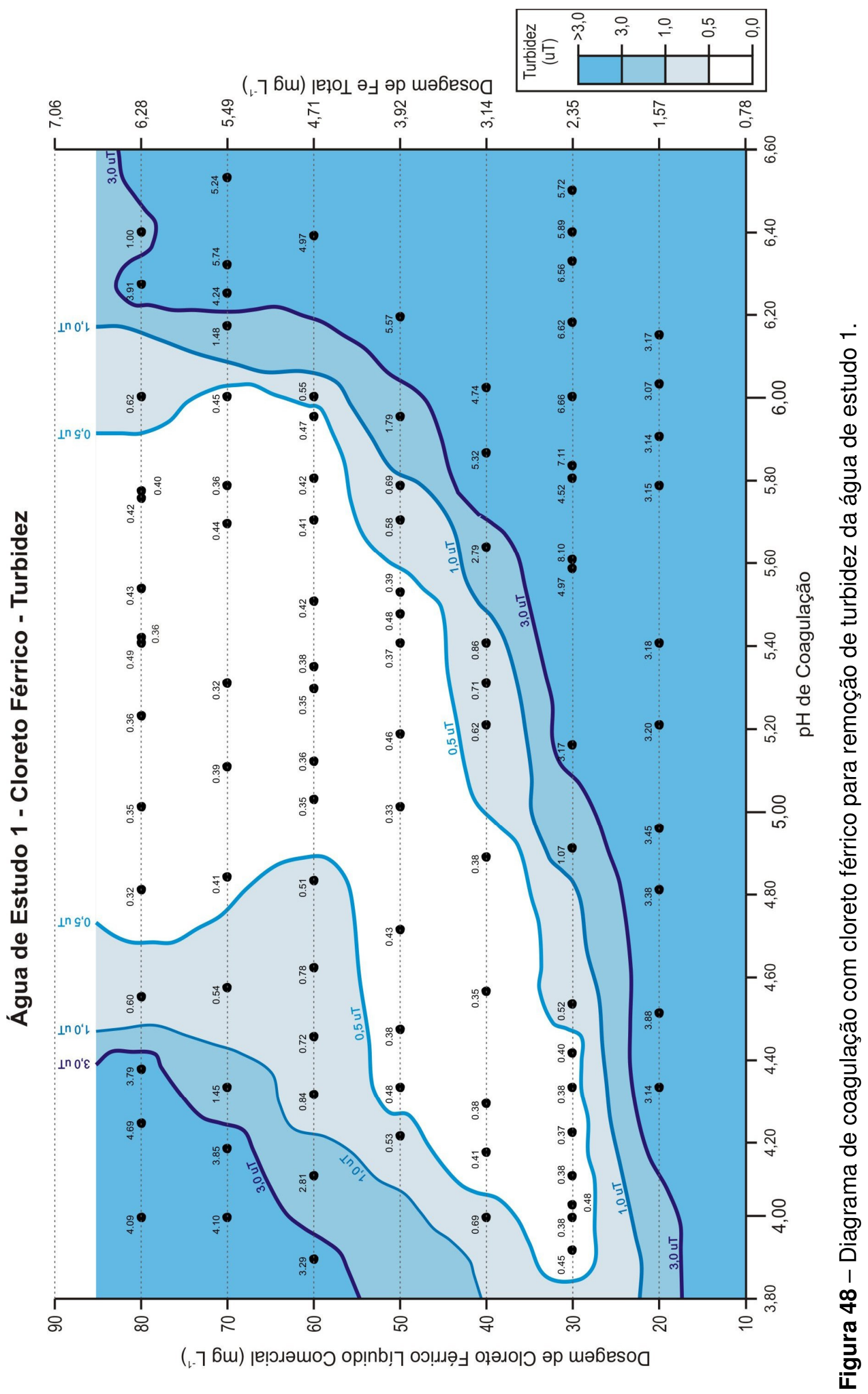




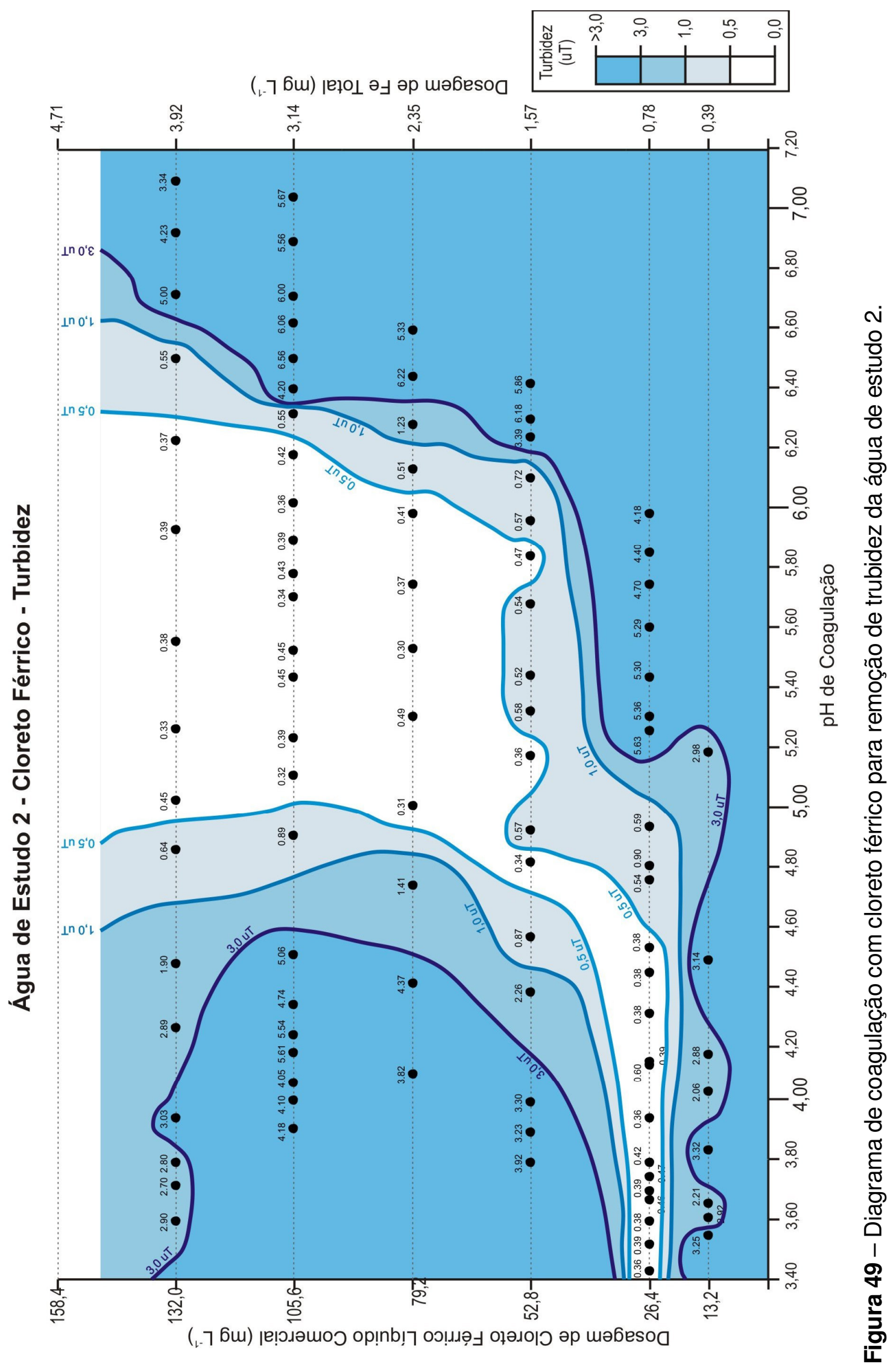




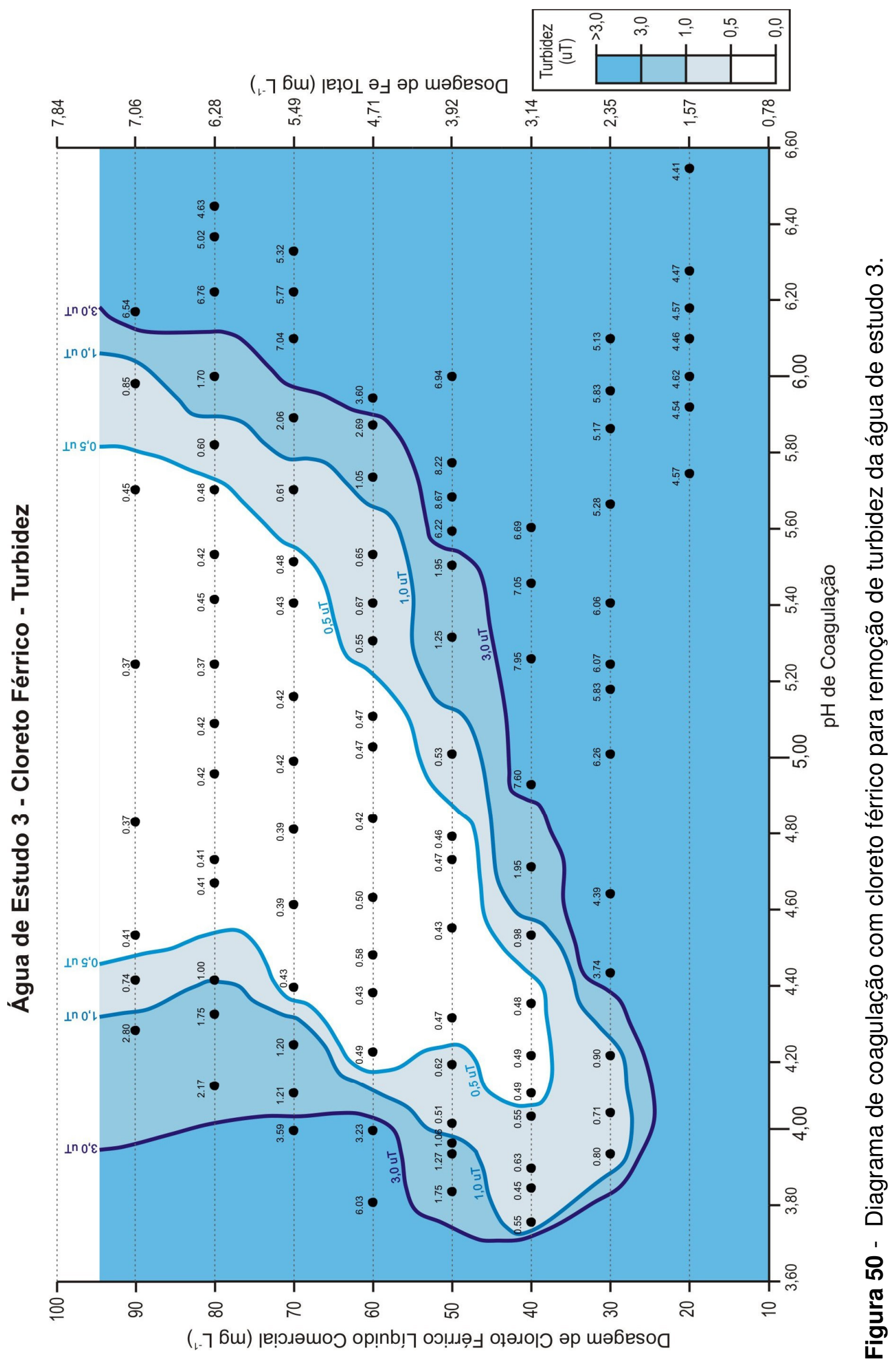




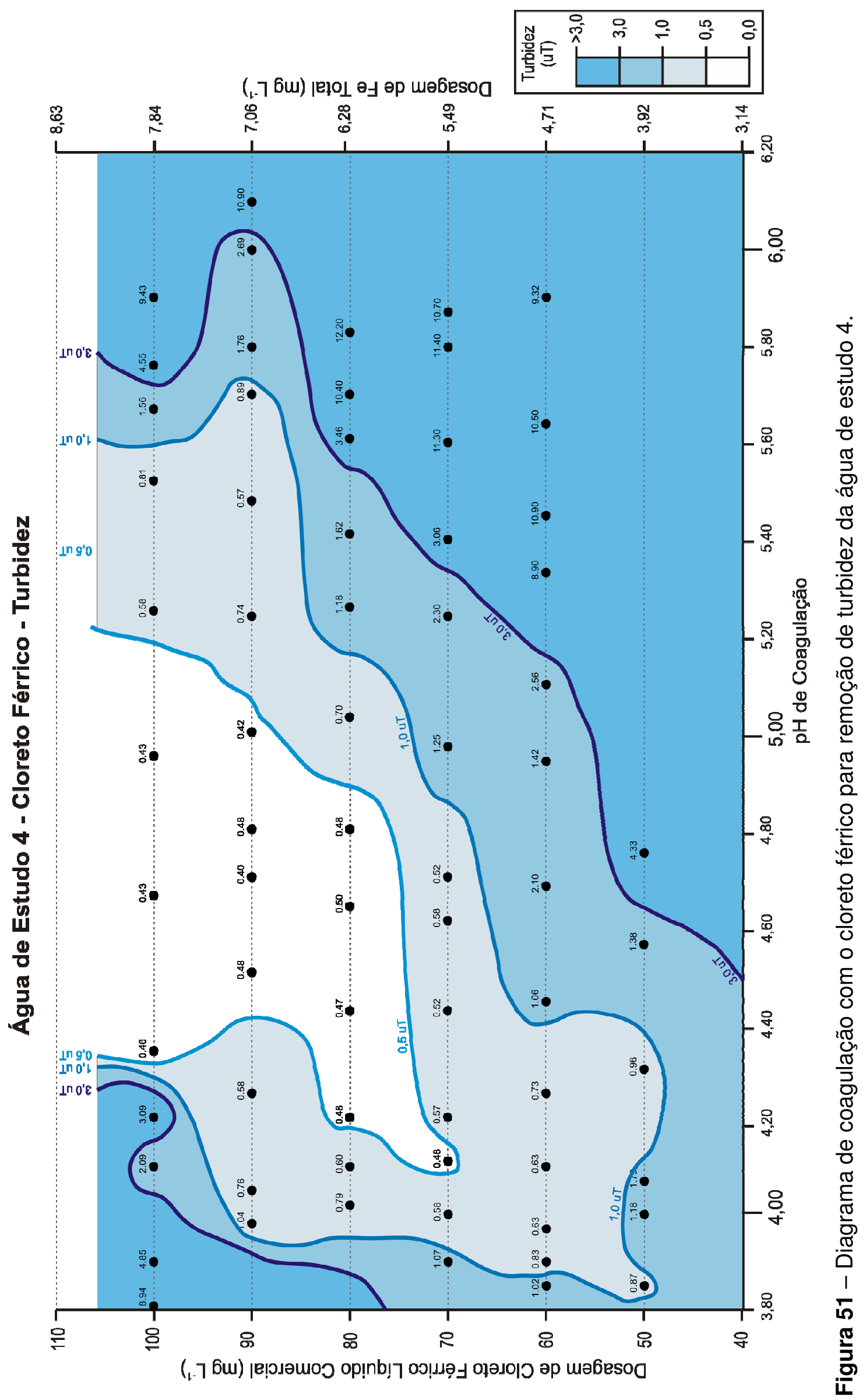


A Tabela 14 apresenta uma comparação do pH de coagulação e as dosagens de cloreto férrico comercial apresentadas nas Figuras 40 a 43 para cor aparente da água filtrada menor ou igual a 5,0 uH, com os resultados apresentados nas Figuras 48 a 51 para a turbidez da água filtrada menor ou igual a 0,5 uT.

Tabela 14 - Valores de pH de coagulação e dosagens de cloreto férrico comercial das regiões de cor aparente da água filtrata $\leq 5,0 \mathrm{uH}$ e turbidez. $\leq 0,5$ uT.

\begin{tabular}{|c|c|c|c|c|}
\hline $\begin{array}{l}\text { Água } \\
\text { de } \\
\text { estudo }\end{array}$ & $\begin{array}{l}\text { Região de } \\
\text { remoção de } \\
\text { cor e } \\
\text { turbidez }\end{array}$ & $\begin{array}{c}\text { pH de } \\
\text { coagulação }\end{array}$ & $\begin{array}{l}\text { Dosagem de cloreto } \\
\text { férrico comercial } \\
\left(\mathrm{mg} \mathrm{L}^{-1}\right)\end{array}$ & $\begin{array}{l}\text { Parâmetros } \\
\text { de controle }\end{array}$ \\
\hline \multirow{3}{*}{1} & \multirow[t]{2}{*}{ Região 1} & $4,0-4,3$ & $30-40$ & Cor aparente \\
\hline & & $3,9-6,0$ & 30 a maiores que 80 & Turbidez \\
\hline & Região 2 & $4,8-6,0$ & 40 a maiores que 80 & Cor aparente \\
\hline \multirow[b]{2}{*}{2} & \multirow[t]{2}{*}{ Região 1} & $<3,4-6,0$ & 26,4 a maiores que 132 & Cor aparente \\
\hline & & $<3,4-6,2$ & 26,4 a maiores que132 & Turbidez \\
\hline \multirow[b]{2}{*}{3} & \multirow[t]{2}{*}{ Região 1} & $3,7-6,0$ & 30 a maiores que 90 & Cor aparente \\
\hline & & $4,1-5,7$ & 40 a maiores que 90 & Turbidez \\
\hline \multirow[b]{2}{*}{4} & \multirow[b]{2}{*}{ Região 1} & $3,95-5,3$ & 60 a maiores que 100 & Cor aparente \\
\hline & & $4,1-5,2$ & 70 a maiores que 100 & Turbidez \\
\hline
\end{tabular}

Verifica-se pela Tabela 14 que os intervalos de $\mathrm{pH}$ e dosagens de coagulante para a remoção de cor e turbidez com o cloreto férrico foram similares. Também, observa-se que á medida que diminuiu o tamanho molecular aparente das SHA, aumentou-se a dosagem de coagulante tanto em relação à remoção de cor como de turbidez. 


\subsection{Comparação entre os diagramas do sulfato de alumino e cloreto férrico na remoção de cor aparente da água filtrada}

Verificou-se nos diagramas de coagulação com o cloreto férrico uma faixa de $\mathrm{pH}$ de coagulação mais ampla quando comparado com os resultados obtidos com o sulfato de alumínio em relação às regiões de cor aparente da água filtrada menor ou igual a 5,0 uH. Isto está de acordo com os diagramas de solubilidade do ferro e alumínio apresentados na revisão bibliográfica nas seções 2.8.2.1 (Figura 8) e

\subsubsection{1 (Figura 9).}

Com todas as águas de estudos coaguladas com dosagens de cloreto férrico da mesma ordem de grandeza (Figuras 40 a 43) obtiveram-se menores valores de cor aparente da água filtrada em relação às águas coaguladas com o sulfato de alumínio (Figuras 28 a 31). Os diagramas de coagulação com o cloreto férrico apresentaram a existência de regiões mais amplas de remoção de cor aparente menor ou igual a $5,0 \mathrm{uH}$, em relação às águas de estudo coagulada com o sulfato de alumínio. Isto demonstra que cloreto férrico é mais eficiente na remoção de cor.

Nos ensaios com o cloreto férrico, a coagulação ocorreu em faixas de $\mathrm{pH}$ mais baixo e as dosagens foram menores em relação aos ensaios com o sulfato de alumínio como coagulante para obtenção da mesma eficiência. Para ambos os coagulantes estudados, em pH mais elevado foram necessárias maiores dosagens de coagulante para a remoção de cor. Isto pode ser relacionado com o estudo feito por Amirtharajah e Mills (1982), os quais relataram que a formação das espécies hidrolisadas do metal é controlada pelo pH final da água após a adição do coagulante. Abaixando-se $\mathrm{opH}$ há menor quantidade de cargas negativas nas moléculas das SHA e, assim, a dosagem de coagulante requerida é menor. 
Verificou-se nos ensaios de coagulação que a dosagem de ambos coagulantes, sulfato de alumínio e cloreto férrico, aumentou à medida que diminui o tamanho molecular aparente das SHA.

Observou-se que nos diagramas apresentados nas Figuras 28 a 31 e 36 a 39 houve duas regiões de coagulação eficiente, com exceção da água de estudo 4 preparada com a menor fração de SHA (menor que $30 \mathrm{kDa}$ ). Já nos diagramas de coagulação com o cloreto férrico, apresentados nas Figuras 40 a 43 e 48 a 51 houve duas regiões de remoção de cor aparente menor ou igual a 5,0 uH apenas para água de estudo 1. As demais apresentaram apenas uma região de coagulação eficiente de cor aparente menor ou igual a 5,0 uH e turbidez menor ou igual a 0,5 uT.

A Tabela 15 apresenta os diferentes valores de pH de coagulação e dosagens dos coagulantes (sulfato de alumínio e cloreto férrico) nas regiões de remoção de cor aparente da água filtrada menor ou igual a 5,0 uH, conforme mostrados nas Figuras 28 a 32 e 40 a 43, respectivamente.

Tabela 15 - pH de coagulação e dosagens dos coagulantes: sulfato de alumínio e cloreto férrico nas regiões de cor aparente da água filtrada menor ou igual a $5,0 \mathrm{uH}$.

\begin{tabular}{|c|c|c|c|c|c|}
\hline \multirow{2}{*}{$\begin{array}{l}\text { Água } \\
\text { de } \\
\text { estudo }\end{array}$} & \multirow{2}{*}{$\begin{array}{c}\text { Cor } \\
\text { Aparente }\end{array}$} & \multicolumn{2}{|c|}{ Sulfato de Alumínio Comercial } & \multicolumn{2}{|c|}{ Cloreto Férrico Comercial } \\
\hline & & $\begin{array}{c}\text { pH de } \\
\text { coagulação }\end{array}$ & $\begin{array}{c}\text { Dosagem de } \\
\text { coagulante } \\
\left(\mathrm{mg} \mathrm{L}^{-1}\right)\end{array}$ & $\begin{array}{c}\text { pH de } \\
\text { coagulação }\end{array}$ & $\begin{array}{c}\text { Dosagem de } \\
\text { coagulante } \\
\left(\mathrm{mg} \mathrm{L}^{-1}\right)\end{array}$ \\
\hline \multirow{2}{*}{1} & Região 1 & $4,6-5,2$ & $50-70$ & $4,0-4,3$ & $30-40$ \\
\hline & Região 2 & $5,5-5,8$ & Superiores a 90 & $4,8-6,0$ & 40 a maiores que 80 \\
\hline \multirow{2}{*}{2} & Região 1 & $4,5-6,0$ & $40-90$ & $3,4-6,0$ & $\begin{array}{c}26,4 \text { a maiores que } \\
132\end{array}$ \\
\hline & Região 2 & $5,5-6,5$ & Superiores a 120 & - & - \\
\hline & Região 1 & $4,5-5,0$ & $60-80$ & $3,7-6,0$ & 30 a maiores que 90 \\
\hline & Região 2 & $5,3-6,0$ & Superiores a 80 & - & - \\
\hline 4 & Região 1 & $4,8-5,4$ & Superiores a 110 & $3,95-5,3$ & 60 a maiores que 100 \\
\hline
\end{tabular}




\subsection{CONSIDERAÇÕES FINAIS}

De acordo com os resultados encontrados, concluiu-se que:

- Todas as frações de diferentes tamanhos moleculares aparentes de SHA estudadas apresentaram comportamento semelhante em relação à coagulação com sulfato de alumínio e cloreto férrico. À medida que diminuiu o tamanho molecular aparente, foram necessárias maiores dosagens de coagulante para a remoção de cor aparente e turbidez. Relacionando-se esses resultados com as características das SHA, verificou-se que a fração de menor tamanho molecular aparente (menor que $30 \mathrm{kDa}$ ), apresentou 100\% de AF e nesta fração há uma maior concentração de grupamentos ácidos com oxigênios ligados, e isso aumenta a concentração de cargas negativas em solução, causando repulsão entre elas e entre as partículas coloidais. Desta forma, requer-se uma maior dosagem de coagulante (cargas positivas) para ocorrer a desestabilização das SHA e assim a coagulação pode ser efetiva.

- A coagulação de águas com SHA depende primeiramente do pH, dosagens e tipo do coagulante e tamanho molecular aparente das SHA. Os resultados da água de estudo 1 preparada com a maior fração de SHA (menor que $0,45 \mu \mathrm{m}$ ) e usando sulfato de alumínio comercial como coagulante, mostraram que a melhor remoção de cor aparente $(\leq 10 \mathrm{uH})$ foi nos intervalos de $\mathrm{pH}$ entre 4,5 e 6,0 e dosagem do coagulante a partir de $50 \mathrm{mg} \mathrm{L}^{-1}$. Enquanto que, para a água de estudo 4 preparada com a fração de menor tamanho molecular aparente (menor que $30 \mathrm{kDa}$ ) foi necessário uma maior concentração de coagulante, a partir de $70 \mathrm{mg} \mathrm{L}^{-1}$ e a faixa de pH de coagulação efetivo ficou em torno de 4,4 a 5,2. 
- Os resultados dos ensaios de coagulação com a água de estudo 1 preparada com a fração de tamanho molecular aparente menor que 0,45 $\mu \mathrm{m}$, usando cloreto férrico comercial como coagulante, mostraram que a faixa de $\mathrm{pH}$ de coagulação efetivo foi entre 3,90 e 6,0 e as dosagens de cloreto férrico comercial foi a partir de $30 \mathrm{mg} \mathrm{L}^{-1} \mathrm{a}$ valores maiores que $80 \mathrm{mg} \mathrm{L}^{-1}$, para se obter cor aparente da água filtrada menor ou igual a $10 \mathrm{uH}$. Os resultados dos ensaios feitos com a água de estudo 4 preparada com a fração de menor tamanho molecular aparente, menor que $30 \mathrm{kDa}$, mostraram que a faixa de pH de coagulação eficiente foi entre 3,90 e 5,5 e a concentração de cloreto férrico comercial foram de 60 a maiores que $100 \mathrm{mg} \mathrm{L}^{-1}$ para se obter remoção de cor aparente menor ou igual a $10 \mathrm{uH}$.

- Comparando-se os diagramas de coagulação do sulfato de alumínio e do cloreto férrico, obtiveram-se algumas regiões de remoção de cor aparente e turbidez da água filtrada nas mesmas dosagens de coagulante e faixas de $\mathrm{pH}$ de coagulação. Observou-se se pelo diagrama de coagulação com o cloreto férrico regiões pouco mais ampla de remoção de cor aparente $(\leq 5,0 \mathrm{uH})$ e turbidez $(\leq 0,5 \mathrm{uT})$ em comparação com a coagulação usando sulfato de alumínio. A coagulação usando cloreto férrico foi efetiva em $\mathrm{pH}$ mais baixo e em dosagens menores de coagulante quando comparado com a coagulação usando o sulfato de alumínio como coagulante. Os diagramas de coagulação para os diferentes tamanhos moleculares aparentes das SHA e ambos coagulantes estudados mostraram que à medida que aumentou $\mathrm{opH}$ de coagulação, aumentou conseqüentemente a dosagem de coagulante necessária para a remoção de cor, provavelmente pelo mecanismo de varredura. À medida que diminuiu o tamanho molecular aparente das SHA a coagulação com o cloreto férrico e com o sulfato de alumínio foram menos eficientes. 
- Os resultados da caracterização das frações de SHA feitas por meio das técnicas analíticas ressonância magnética nuclear (RMN de $\left.{ }^{13} \mathrm{C} C P / M A S\right)$, espectroscopia de infravermelho, ultravioleta/visível (UV/VIS) e análise elementar mostraram que nas frações menor que $0,45 \mu \mathrm{m}$ e entre $100 \mathrm{kDa}$ e 0,45 $\mu \mathrm{m}$, há maior grau de condensação, ou seja, esta fração possui maior teor de anéis aromáticos em relação as menores frações de SHA. As frações de tamanho molecular aparente entre 30 e 100 kDa, entre 10 e 30 kDa e entre 5 e 10 kDa são compostas de cadeias menores e estruturas mais alifáticas que aromáticas e maiores teores de oxigênio ligados, tais como: grupos funcionais carboxílicos, hidroxilas fenólicas, alcoólicas, entre outros.

- A fração de tamanho molecular aparente menor que $0,45 \mu \mathrm{m}$ apresentou maior porcentagem de AF, cerca de $69 \%$. A fração entre 100 kDa e 0,45 $\mu \mathrm{m}$ é constituída por $92,4 \%$ de $\mathrm{AH}$. As frações com menores tamanhos moleculares aparentes, entre 30 e $100 \mathrm{kDa}$, entre 10 e 30 kDa e entre 5 e 10 kDa, são constituídas por 100\% de AF. Com isso concluiu-se que as SHA são compostas na maior parte por AF.

- Os diagramas de solubilidade do alumínio e do ferro apresentaram os possíveis mecanismos de coagulação ocorridos na região de remoção de cor aparente menor ou igual a $5 \mathrm{uH}$. Os mecanismos de coagulação das águas de estudos coaguladas com sulfato de alumínio provavelmente foram o de adsorção - neutralização de cargas com as espécies hidrolisadas de alumínio, $\mathrm{Al}_{x}(\mathrm{OH})_{4}{ }^{n+} / \mathrm{Al}(\mathrm{OH})_{3}$ (s) e/ou varredura. A coagulação das águas de estudos empregando-se cloreto férrico, provavelmente prevaleceu à adsorção das moléculas das SHA no precipitado de hidróxido de ferro (mecanismo por varredura). Outro mecanismo menos provável foi o de neutralização de cargas. 


\subsection{RECOMENDAÇÕES PARA TRABALHOS FUTUROS}

> Fazer ensaios de filtração direta com o cloreto férrico e com as frações de diferentes tamanhos moleculares de SHA determinando a concentração do ferro residual;

> Estudar a influência dos diferentes tamanhos moleculares das SHA com águas de cor e turbidez elevada através de ensaios de coagulação, floculação, sedimentação e filtração.

> Fazer medidas do potencial zeta durante os ensaios de coagulação com diferentes tamanhos moleculares das SHA para propor os mecanismos de coagulação.

> Estudar a eficiência de outros coagulantes na eficiência de remoção de SHA.

"Vivemos num mundo em que a água se torna um desafio cada vez maior". 


\subsection{REFERÊNCIAS BIBLIOGRÁFICAS}

ABBT-BRAUN, G. Spectroscopic characterization of humic substances in the ultraviolet and visible region and by infrared spectroscopy. In: MATTHESS, G. Progress in hydro geochemistry. Berlin: Springer-Verlag, 1992. p. 29-32.

ABBT-BRAUN, G.; FRIMMEL, F.H.; SCHULTEN, R. H. Structural investigations of aquatic humic substances by pyrolysis-field ionization mass spectrometry and pyrolysisgas chromatography/mass spectrometry. Water Research, v. 23, n. 12, p. 1579-1591, 1989.

AlKEN, G. R. A critical evaluation of the use of macroporous resins for the isolation of aquatic humic substances. In: FRIMMEL, F. H.; CHRISTMAN, R. F. Humic substances and their role in the environment. New York: John Wiley, 1988. p. 1532.

AIKEN, G. R. Isolation and concentration techniques for aquatic humic substances. In: AIKEN, G. R.; MAcKNIGHT, M. D.; WERSHAW, R. L.; MACCARTHY P. (Eds). Humic substances in soil, sediment and water: geochemistry, isolation and characterization. New York: John Wiley, $1985 . \quad$ p. 363-385.

AIKEN, G. R.; MAcKNIGHT, M. D.; WERSHAW, R. L.; BENEDETTI, M. F.; REMSDIJK, W. H. V.; KOOPAL, L. K. Humic substances considered as a heterogeneous donnan gel phase. Environmental Science Technology., v. 30, p. 1805-13, 1996.

AIKEN, G.; McKNIGHT, D. M.; THORN, K. A.; THURMAN, E. M. Isolation of hydrophilic organic acids from water using nonionic macroporous resins. Organic Geochemistry, v. 18, n. 4, p. 567-573, 1992.

AWWA Coagulation Committee. 1989. Coagulation as an Integrated Water Treatment Process. Journal AWWA, v. 81, n. 10, p. 72-78.

AMERICAN WATER WORKS ASSOCIATION (AWWA). Water quality and treatment: a handbook of community water supplies. 4. ed. New York: McGraw-Hill, 1990. p.270.

AMIRTHARAJAH, A. The mechanisms of coagulation. In: SEMINÁRIO NACIONAL SOBRE COAGULAÇÃO E FILTRAÇÃO DIRETA, 1., 1989, São Carlos. Anais... São Carlos: [s. n.], 1989. 1v.

AMIRTHARAJAH. A.; EDWARDS, A. G. Removing color caused by humic acids. Research and Technology. Journal AWWA, v. 77, n. 3, p. 50-57, 1985.

AMIRTHARAJAH, A.; MILLS, K.L. Rapid-mix design for mechanisms of alum coagulation. Journal AWWA, v. 74, n. 4, p. 210-216, 1982.

AMY, G.; HER, N. Size exclusion chromamatography (SEC) with multiple detectors: a powerful tool in treatment process selection and performance monitoring. Water Science and Tchenology: Water Supply, v. 4, n. 4, p. 19-24, 2004. 
ARAÚJO, A. B.; ROSA, A. H.; ROCHA, J. C.; ROMÃO, L. P. C. Distribuição de metais e determinação da constante de troca de frações húmicas aquáticas de diferentes tamanho moleculares. Química Nova, v. 25, p. 1103-1107, 2002.

ASTER, B.; BURBA, P.; BROEKAERT, J. A. C. Analytical fractionation of aquatic substances and their metal species by means of multistage ultrafiltration. Fresenius Journal Analytical Chemistry, v. 354, p. 722-728, 1996.

BELZILE, N. JOLY, H. A.; LI, H. Characterization of humic substances extractedfrom Canadian lake sediments. Canadian Journal Spectroscopy, v. 75, p. 14-27, 1997.

BENEDETTI, M. F.; REMSDIJK, W. H. V.; KOOPAL, L. K. Humic substances considered as a heterogeneous donnan gel phase. Environmental Science Technology, v. 30, p. 1805-13, 1996.

BRAVARD, S.; RICHI, D. Characterization of fulvic and humic acids from an OxisolSpodosol toposequence of Amazonia, Brazil. Geoderma, v. 48, p. 151-162, 1991.

BUFLE, J.; DELADOEY, P.; HAERDI, W. The use of ultra filtration for the separation and fractionation of organic ligands in fresh waters. Analytica Chemica Acta, v. 101, p. 339-357, 1978.

BURBA, P.; SHKINEV, V.; SPIVAKOV, B. On-line fractionation and characterization of aquatic humic substances by means of sequencial stage ultrafiltration. Fresenius Journal Analytical Chemistry, v. 351, p. 72-82, 1995.

BURBA, P.; ASTER, B.; NIFANT'EVA, T.; SHKINEV, V.; SPIVAKOV, B. Membrane filtration studies of aquatic humic substances and their metal species: a concise overview. Parte 1. Analytical fractionation by means of sequential-stage ultrafiltration. Talanta, v. 45, p. 977-988, 1998.

BURBA, P. Ultrafiltration and determination of $\mathrm{Zn}$ and $\mathrm{Cu}$ humic substances complexes stability constants. Talanta, v. 53, p. $1127-1131,2001$.

BRASIL. Ministério da Saúde. Norma de Qualidade da Água para Consumo Humano. Portaria n. 518 de 25 de março de 2004. Disponível em: $<$ http://dtr2001.saude.gov.br/sas/PORTARIAS/Port2004/GM/GM-518.htm>. Acesso em: 01 jul. 2007.

CALASE, N.; DE PAOLIS, F.; MINNITI, F.; PETRONIO, B. M. Purification of soluble fulvic low concentration by a diafiltration techinique. Talanta, v. 47, p. 803-809, 1998.

CAMPANELLA, L.; PETRONIO, B. M.; BRAGUGLIA, C. Study of humic fraction from water of an Antarctic lake. International Journal Analytical Chemistry, v. 60, p. 4960, 1994.

CAMPANELLA, L.; PETRONIO, B. M.; BRAGUGLIA, C. Sduty of humic fraction from water of an artarctic lake. International Journal Anaylitical Chemistry, v. 60, p. 659-670, 1996. 
CARVALHO, E. R. Estudos da formação de trialometanos a partir de substâncias húmicas aquáticas tratadas com cloro e dióxido de cloro. 2003. 192 f. Tese (Doutorado)- Interunidades Ciências e Engenharia de Materiais da Universidade de São Paulo, Universidade de São Paulo, São Carlos, 2003.

CARVALHO, E. R.; MARTIN-NETO, L.; MILORI, D. M. B. P.; ROCHA, J. C.; ROSA, A. $\mathrm{H}$. Interactions of chorine with tropical aquatic fulvic acids and formation of intermediates observed by fluorescence spectroscopy. Journal of the Brazilian Chemical Society, v. 15, n. 3, p. 421-428, 2004.

CAMPOS, S. X., AZEVEDO, E. R.; BONAGAMBA, T. J.; VIEIRA, E. M.; DI BERNARDO, L. Color Removal by Coagulation Flocculation and Sedimentation from Water Containing Humic Substances with Different Apparent Molecular Sizes. Journal of Water Supply: Research and Technology (AQUA), v. 56, n. 5, p. 327-33, 2007.

CAMPOS, S. X. Influência de diferentes características das substâncias húmicas na coagulação, floculação e sedimentação no tratamento de água. $2004.123 \mathrm{f}$. Tese (Doutorado) - Escola de Engenharia de São Carlos, Universidade de São Paulo, São Carlos, 2004.

CHEN, Y.; SCHNITZER M. Scanning electron-microscopy of a humic- acid and of a fulvic-acid and its metal and clay complexes. Soil Science Society of American Jounal, v. 40, p. 682-686, 1976.

CHOW, A. T., GAO, S., DAHLGREN, R. A. Phusical and chemical fractionation of dissolved organic matter and trihalomethane precursors: A review. Journal of Water Supply: Research and Technology (AQUA), v. 54, n. 8, p. 475-507, 2005.

COMPANHIA DE TECNOLOGIA DE SANEAMENTO AMBIENTAL ALIADA A SECRETARIA DO ESTADO DO MEIO AMBIENTE DE SÃO PAULO (CETESB). Disponível em: $<$ www.ibge.gov.br/ibgeteen/pesquisas/condicoesdevida.html. www.ibege.gov.br/agua/rios/gesta escassez.asp >.

Acesso em: 01 set. 2007.

CONTE, P.; PICCOLO, A. Conformational arrangement of dissolved humic substances: influence of solution composition on association of humic molecules. Environmental Science Technology, v. 33, p. 1682-1690, 1999.

CROUE, J. P.; KORSHIN, G.V.; BENJAMIM, M. M. Characterization of natural organic matter in drinking water. In: DENETT, K. E.; AMIRTHARAJAH, A.; STUDSTILL, A.; MORAN, T. F.; GOULD, J. P. (Eds). Humic substance removal and minization of trihalomethanes by ferric chloride coagulation.School of civil and environmental engineering. Denver: AWWA Research Foudation: American Water Works Association, 1995.

DEMPSEY, B. A. Removal of naturally occuring compounds by coagulation and sedimentation. CRC Critical Reviews in Environmental Control, v. 14, n. 4, p. 311331, 1984. 
DEMPSEY, B. A. Reactions between fulvic acid and aluminum: effects on the coagulation process. In: AQUATIC humic substances: influence on fate and treatment of pollutants. Washington: American Chemical Society, 1989. p. 409-424.

DIALLO, M. S.; SIMPSON, A.; GASSMAN, P.; FAULON, J. L.; JOHNSON, J. H.; GODDARD, W. A.; HATCHER, P. G. 3-D Structural modeling of humic acids through experimental characterization, computer assisted structure elucidation and atomistic simulations. Environmental Science Technology, v. 37, p. 1783-1793, 2003.

DI BERNARDO, L.; DANTAS, A. Di B. Métodos e técnicas de tratamento de água. 2. ed. São Carlos: RiMa, 2005. 1600p.

DI BERNARDO, L.; AMIRTHARAJAH, A. Some fundamental and practical aspects of particle removal in upflow filtration. Atlanta: Georgia Institute of Technology, 2001. (Reported).

DI BERNARDO, L.; DI BERNARDO, A.; CENTURIONE FILHO, P. L. Ensaios de tratabilidade de água e dos resíduos gerados em estações de tratamento de água. São Carlos: RiMa, 2002. 237p.

DUARTE, M. B. O.; SANTOS, E. P. H.; DUARTE, A. P. Comparison between diafiltration and concentration operation modes for the determination of permeation coefficients of humic substances through ultrafiltration membranes. Analytica Chimica Acta, v. 442, p. 155-164, 2001.

DUTOIT, M.M. S.; PAGE, H. J. Studies on the carbon and nitrogen cycles in the soil. The formation of natural humic matter, 1930. In: DENNETT, K. E.; AMIRTHARAJAH, A.; STUDSTILL, A.; MORAN, T. F.; GOULD J. P. Humic substance removal and minimization of trihalomethanes by ferric chloride coagulation. Denver: AWWA Research Foundation: American Water Works Association, 1995. p. 478-488.

DUXBURY, J. M. Studies of the molecular size and charge of humic substance by eletrophoresis. In: HAYES, M. H. et al. (Eds). Humic substances II: in search of structure. New York: John Wiley, 1989. p. 593-620.

EDZWALD, J.K. Coagulation in drinking water treatment: particles, organics and coagulants. Water Science and Technology, v. 27, n. 11, p. 21-35, 1993.

EDWARDS, A. G.; AMIRTHARAJAH, A. Removing color caused by humic acids. Research and Technology. Journal AWWA, v. 77, n. 3, p. 50-57, 1985.

FRANCISCO, O.; SANCHEZ-CORTEZ, S.; TUGNOLI, V.; CIAVATTA, C.; GESSA, C. Infrared, Raman, and nuclear magnetic resonance $\left({ }^{1} \mathrm{H},{ }^{13} \mathrm{C}\right.$, and $\left.{ }^{31} \mathrm{P}\right)$ spectroscopy in the study of fractions of peat humic acids. Applied Spectroscopy, v. 50, p. 11651174, 1996a.

FRANCISCO, O.; SANCHEZ-CORTEZ, S.; TUGNOLI, V.; CIAVATTA, C.; GESSA, C. Characterization of peat fulvic acid fractions by means of FT-IR, SERS, and ${ }^{1} \mathrm{H}$, ${ }^{13} \mathrm{C}$ NMR spectroscopy. Applied Spectroscopy, v. 52, p. 270-277, 1996b. 
FRIMMEL, F. H. Polar organic substances and their rolo in the water saturated and unsaturated zones. In: MATTHEUS, G.; FRIMMEL, F.; HEIRSCH, P.; SCHOLZ, H. D.; USDOWSKI, H. E. (Eds.). Progress in hydrogeochemistry. Berlin: Springer Verlag, 1992. p. 7-8.

FRIMMEL, F. H.; SCHIMITT, D.; MULLER, M. B. Fractionation of natural organic matter by size exclusion chromatography-properties and stability of fractions. Environmental Science Technology, v. 34, n. 23, p. 4867-4872, 2000.

GARCIA, D.; CEGARRA, J.; ABAD, M. A comparison between alkaline and decomplexing reagents to extract humic acids from low rank coals. Fuel Processing Technology, v. 48, p. 51-60, 1986.

GHOSH, K.; SCHNITZER, M. Macromolecular structures of humic substances. Soil Science, v. 129, p. 266-276, 1980.

GREGOR, J. E.; NOKES C. J.; FENTON E. Optimising natural organic matter removal from low turbidity waters by controlled ph adjustment of aluminium coagulation. Water Research, v. 31, n. 12, p. 2949-2958, 1997.

GREGORY, J. Effect of polymers on colloid stability. In: KENNETH, J. IVES (Ed.). The scientific basis of flocculation. The Netherlands: Sijthoft and Noordoft, 1978. $376 p$.

HALL, E. S.; PACKHAM, R.F. Coagulation of organic color with hydrolyzing coagulants. Journal AWWA, v. 57, n. 9, p. 1149-1166, 1965

HAYES, M. H. B.; MACCARTHY, P.; MALCOLM R. L.; SWIFT R. S. Humic substances II: in search of structure. New York: Wiley, 1989. p. 747.

HUFFMAN, E. W. D. JUNIOR.; STUBER, H. A. Analytical methodology for elemental analysis of humic substances. In: AIKEN, G. R.; MCKNIGHT, M. D.; WERSHAW, R. L.; MACCARTHY, P. (Eds). Humic substances in soil, sediment and water: geochemistry, isolation and characterization. New York: John Wiley, 1985. p. 433451.

INSTITUTO BRASILEIRO DE GEOGRAFIA E ESTATISTICA (IBEGE). Pesquisas de Saneamento. Disponível em:

$<$ www.ibge.gov.br/ibgeteen/pesquisas/condicoesdevida.html. www.ibge.gov.br/ibgeteen/pesquisas/condvida esgotamento sanitario.html>. Acesso em: 01 set. 2007.

JOHNSON, P.N.; AMIRTHARAJAH, A. Ferric choride and alum as single and dual coagulants. Research and Technology. Journal AWWA, v. 75, n. 5, p. 232-239, 1983.

KONONOVA, M. M. Soil organic matter. Its nature, its role, in soil formation and in soil fertility. 2. ed. Oxford: Pergamon Press, 1966. 544 p. 
KUCKUK, R.; BURBA, P. Analytical fractionation of aquatic humic substances by metal affinity chromatography on iron (III) coated cellulose. Fresenius Journal Analytical Chemistry, v. 366, p. 95-101, 2000.

KRASNER, S. W.; AMY, G. Jart-test evaluations of enhance coagulation. Journal AWWA, v. 87, p. 93-107, 1995.

LARA, R. J.; THOMAS, D. N. Isolation of marine dissolved organic matters: evoluation of sequential combinations os XAD resins 2,4 and 7. Analytical Chemistry, v. 66, n. 14, p. 2417-2419, 1994.

LEENHEER ,J. A.; HUFFMAN E. W. D. Classification of organic solutes in water by using macroreticular resins. Journal Research US Geological Survey, v. 4, n. 6, p. 737-51, 1976.

LEENHEER, J. A.; CROUE, J. P. Characterizing aquatic dissolved organic matter. Environmental Science Techonology, v. 37, n. 1, p. 18a-26a, 2003.

LU, X. Q.; HANNA, J. V.; JOHNSON, W. D. Source indicators of humic substances: an elemental composition, solid state ${ }^{13} \mathrm{C}$ CP/MS NMR and Py-GC/MS study. Applied Geochemistry, v. 15, p. 1019-1033, 2000.

MACCARTHY, P. (Ed). Humic substances in soil, sediment and water: geochemistry, isolation and characterization. New York: John Wiley, 1985. p. 363385.

MACCARTHY, P.; RICE, J. A. Spectroscopic methods (other than NMR) for determining functionality in humic substances. In: AIKEN, J. R.; MCKNEIGHT, D. M.; WERSHAW, R. L.; MACCARTHY, P. (Eds). Humic substances in soil, sediment and water: geochemistry, isolation and characterization. New York: Wiley, 1985. p. 527-559.

MACCARTHY, P.; SUFFET, I. H. Aquatic humic substances and their influence on the fate and treatment of pollutants. In: AQUATIC humic susbstances: their influence on the fate and treatment of pollutants. Whashington: American Chemical Society, 1989. p.17-30.

MALCOLM, R.L. Geochemistry of stream fulvic and humic substances. In: Humic substances in soil, sediment and water. Geochemistry isolation and characterization. In: AIKEN, G.R.; MCKNIGHT, D.M.; WERSHAW, R.L.; MACCARTHY, P. (Eds.). Humic substances in soil, sediment and water: geochemistry, isolation and characterization. New York: Wiley, 1985. p. 527-559.

MALCOM, L. C. The uniqueness of humic substances in each of soil, stream and marine environments. Analytica Chimica Acta, v. 232, p. 19-30, 1990.

MEYERS, P. A.; ISHIWATARI, R. Lacustrine organic geochemistry: an overview of indicators of organic matter sources and diagenesis in lake sediments. Organic Geochemistry, v. 20, p. 867-900, 1993. 
MURRAY, C. A.; PARSONS, S. A. Removal of MON from drinking water: Fenton's and photo-Fenton's processoes. Chemosphere, v. 54, p. 1017-1023, 2004a.

MURRAY, C. A.; PARSONS, S. A. Advanced oxidation processes: flowsheet options for bulk natural organic matter removal. Water Science and Technology: Water Supply, v. 4 , n. 4 , p. 113-119, 2004b.

NELSON, P. N.; DICTOR, M. C.; SOULAS, G. Availability of organic carbon in soluble and particle-size fractions from a soil profile. Soil Biology Biochemistry, v. 26, p. 1549-1555, 1994.

O' MELIA, C. R. Coagulation e Flocculation, 1972. In: SEMINÁRIO NACIONAL SOBRE COAGULAÇÃO E FILTRAÇÃO DIRETA, 1., 1989, São Carlos. Anais...São Carlos: Escola de Engenharia de São Carlos, Universidade de São Paulo, São Carlos, 1989. 1v.

O'MELIA, C. R. Coagulation in wastewater treatment. In: The scientific basis of flocculation. The Netherlands: Sijthoff and Noordoff, 1978. In: SEMINÁRIO NACIONAL SOBRE COAGULAÇÃO E FILTRAÇÃO DIRETA, 1., 1989, São Carlos. Anais...São Carlos: Escola de Engenharia de São Carlos, Universidade de São Paulo, São Carlos, 1989. 1v.

O' MELIA, C. R.; STUMM, W. Aggregation of sílica dispersions by iron (III), 1967. In: SEMINÁRIO NACIONAL SOBRE COAGULAÇÃO E FILTRAÇÃO DIRETA, 1., 1989, São Carlos. Anais...São Carlos: Escola de Engenharia de São Carlos, Universidade de São Paulo, São Carlos, 1989. 1v.

ODEN, S. Humic Acids, 1919. In: DENETT, K. E.; AMIRTHARAJAH, A.; STUDSTILL, A.; MORAN, T. F.; GOULD, J. P. (Eds). Humic substance removal and minization of trihalomethanes by ferric chloride coagulation.School of civil and environmental engineering. Denver: AWWA Research Foudation: American Water Works Association, Atlanta, 1995. p. 75-99.

PAVANELLI, G. Eficiência de diferentes tipos de coagulantes na coagulação, floculação e sedimentação de água com turbidez elevada e cor verdadeira baixa. 2001. 205 f. Dissertação (Mestrado) - Escola de Engenharia de São Carlos, Universidade de São Paulo, São Carlos, 2001.

PERDUE, E. M.; RITCHIE, J. D. Dissolved organic matter in freshwaters. In: HOLLAND, H. D.; TUREKIAN, K. K. (Eds). Treatise on Geochemistry: surface and groundwater, weathering, and soils. Amsterdam: Pergamon, 2004. v. 5, p. 274-318.

PEURAVUORI, J.; PIHLAJA, K. Molecular size distribuition and spectroscopic properties of aquatic humic substances. Analytica Chimica Acta, v. 337, p. 133-149, 1997.

POPPI, N. R.; TALAMONI, J. Estudo dos ácidos húmico e fúlvico extraídos de solos por espectroscopia de infravermelho. Química Nova, v. 15, p. 281-285, 1992. 
POST, B.; KLAMBERG, H. Characterization of humic substances fractionated by organic solvents. In: PROGRESS in hidrogeochemistry. Berlin: Springer Verlag, 1992. p.56-61.

PICCOLO, A; ZACCHEO, P.; GENEVINI, P.G. Chemical characterization of humic substances extracted from organic-waste-amended soils. Bioresource Technology, v. 40, p. 275-282, 1992.

PICCOLO, A.; NARDI, S.; CANCHERI, G. Macromolecular changes of soil humic substances induced by interactions with organic acids. European Journal Soil Science, v. 47, p. 319-328, 1996.

PICCOLO, A.; CONTE, P. Molecular size humic substances. Supra-molecular associations versus macromolecular polymers. Advances Environmental Research, v. 3, p. 511-521, 1999.

PICCOLO, A. Differences in high performance size exclusion chromatography between humic substances and macromolecular polymers. In: CHABBOUR E. A.; DAVIES, G. (Eds.). Humic substances versatile components of plants, soil and water. Cornwall: Royal Society of Chemistry, 2000. p.111-124.

PICCOLO, A. The supramolecular structures of humic substances. Soil Science, v. 166, p. 810-832, 2001.

PICCOLO, A. The supramolecular structure of humic substances. A novel understanding of humus chemistry and implications in soil science. Advances in Agronomy, v. 75, p. 57-134, 2002.

RATNAWEERA, H.; GJESSING, E.; OUG, E. Influence of physical-chemical characteristics of natural organic matter (NOM) on coagulation properties: an analysis of eight Norwegian. Water Science Technology, v. 40, n. 9, p. 89-95, 1999.

REBOUÇAS, A. C.; BRAGA, B.; TUNDISI, J. G. Águas doces no Brasil: capital ecológico, uso e conservação. 2 ed. São Paulo: Escrituras Editora, 2002. 703 p.

RICCA, G.; SEVERINI, F.; DI SILVESTRO, G.; YUAN, C. M.; ADANI, F. Derivatization and structural studies by spectroscopic methods of humic acids from leonardite. Geoderma, v. 98, p. 115-125, 2000.

ROCHA, J. C.; SARGENTINI JUNIOR, É.; TOSCANO, I. A. S.; ROSA, A. H.; BURBA, $P$. Multi - method study on aquatic humic substances from the Rio Negro Amazonas state/ Brasil. Emphasis on molecular- size classification of their metal contentes. Journal oh the Brazilian Chemical Society, v. 10, p. 169-175, 1999.

ROCHA, J. C.; ROSA, A.H. Substâncias húmicas aquáticas: interações com espécies metálicas. São Paulo: Editora UNESP, 2003. 120 p.

ROSA, A. H.; ROCHA, J. C.; FURLAN, M. Substâncias húmicas de turfa: Estudo dos parâmetros que influenciam no processo de extração alcalina. Quimica Nova, v. 23, p. $472-476,2000$. 
ROCHA, J.C.; ZARA, L. F.; ROSA, A. H.; SARSENTINI, É. JR.; BURBA, P. Substâncias húmicas: sistema de fracionamento sequencial por ultrafiltração com base no tamanho molecular. Química Nova, v. 23, n. 3, p. 410-412, 2000.

ROCHA, J. C. Aquátic humus from na unpolluted Brazilian dark-brow stream: general characterization and size fractionation on bound heavy metals. Journal Environmental Monitoring, v. 2, p. 39-44, 2000a.

ROCHA, J. C. Aquatic humus from an unpolluted Brazilian dark-brown stream: general characterization and size fractionation on bound heavy metals. Journal

Environmental Monitoring, v. 2, p. 410-412, 2000b.

ROMÃO, L. P. C. Utilização da ultrafiltração em fluxo tangencial como nova metodologia para determinação da capacidade de complexação e constantes de equilíbrio de ínos cobre (II) complexados por matéria orgânica natural. 2003. 97 f. Tese (Doutorado) - Universidade Estadual Paulista, Araraquara, 2003.

SANCHES, S. M. Estudo da influência do tamanho molecular das substâncias húmicas na formação de ácidos haloacéticos formados durante a etapa de oxidação da água com o cloro. 2005. 125 f. Tese (Doutorado) - Escola de Engenharia de São Carlos, Universidade de São Paulo, São Carlos, 2005.

SARGENTINI JUNIOR, É. Substâncias húmicas aquáticas do Rio Negro -AM: extração e distribuição de metais. 1999.110 f. Tese (Doutorado) - Instituto de Química de Araraquara, Universidade Estadual de São Paulo, 1999.

SARGENTINI, JUNIOR, É. Substâncias húmicas aquáticas: fracionamento molecular e caracterização de rearranjos internos após complexação com íons metálicos.

Química Nova, v. 4, p. 339-344, 2001.

SHARP, E. L.; PARSONS, S. A.; JEFFERSON, B. Seasonal variations in natural organic matter and its impact on coagulation in water treatment. Science of the Total Environment, v. 363, p. $183-194,2006$.

SCHULTEN, H. R.; SCHNITZER, M. A state of the art structural concept for humic substances. Naturwissenschaften, v. 80, p. 29-30, 1993.

SCHNITZER, M.; SKINNER, S. U. Soil organic matter. Amsterdan: Elsevier, 1978. $319 \mathrm{p}$.

STEVENSON, F. J. Extraction, fractionation, and general chemical composition of soil organic matter. In: STEVENSON, F. J. Humus Chemistry: genesis, composition and reaction. New York: John Wiley, 1982. p. 26-53.

STEVENSON, F. J. Geochemistry of soil humic substances. In: AIKEN, G. R.; MCKNIGHT, D. M.; WERSHAW, R. L.; MACCARTHY, P. Humic substances in soil, sediment and water: geochemistry, isolation and characterization. New York: John Wiley, 1985. p. 13-52. 
STEVENSON, F. J. Humus Chemistry: genesis, composition and reaction. 2. ed. New York: John Wiley, 1994. 303 p.

STEVENSON, F. J. Extraction, fractionation and general chemical composition of soil organic matter. In: STEVENSON, F. J. Humus Chemistry: genesis, composition and reactions. New York: John Wiley, 1982, p. 23-56.

SILVERSTEIN, R. M.; BONLER, G. C.; MORRIL, T. C. Identificação espectrométrica de compostos orgânicos. Rio de Janeiro: Guanabara Koogan, 1994. 387p.

STEARMAN, G. K.; LEWIS, R. J.; TORTORELLI, L. J.; TYLER, D.D. Characterization of humic acid from no tilled and tilled soils using carbon-13 nuclear magnetic resonance. Soil Science Society American Jounal, v. 53, p. 744-749, 1989.

SENESI, N.; RIZZI, F. R.; DELLINO, P. E.; ACQUAFREDDA, P. Fractal dimension of humic acids in aqueous suspension as a function of $\mathrm{pH}$ and time. Soil Science Society American Journal, v. 60, p. 1773-1780, 1996.

SENESI, N. E MIANO, T. M. Humic substances in the global environment and implications on human health. In: INTERNATIONAL MEETING OF THE INTERNATIONAL HUMIC SUBSTANCES SOCIETY, 6., 1995, Monopoli. Proceedings... Monopoli: [s. n.], 1995. 1368 p.

SNOEYINK, V. L.; JENKINS, D. I. Water Chemistry. New York: John Wiley, 1980. 436p.

SKOOG, A. D.; HOLLER, J. F.; NIEMAN, A. T. Principios de análise instrumental. 5. ed. Porto Alegre: Bookman, 2002. p. 641-653.

STEELINK, C. Implications of elemental characteristics of humic substances. In: AIKEN, G. R.; McNIGHT, D.M.; WERSHAW, R. L.; McCARTHY, P. (Eds). Humic substances in soil, sediment and water: geochemistry Isolation and characterization. New York: John Wiley, 1985. p. 457- 76

STUMM, W.; O'MELIA, C. R. Stoichiometry of coagulation. Journal AWWA, v. 60, n. 5, p. 514-539, 1968.

SWIFT, R. S. Organic matter characterization. In: SPARKS, D L. Methods of soil analysis: chemical methods. Maddison: SSSA, 1996. p.1011-1069.

SWIFT, R. S. Molecular weight, size, shape, and charge characteristics of humic substances: Some basic considerations, In: HAYES, M.H.B., MacCARTHY, P.; MALCOM, R. L.; SWIFT, R. S. (Eds). Humic substances. Chichester: Wiley, 1989. p. 449-466.

SWIFT, R. S. Macromolecular properties of soil humic substances: fact, fiction, and opinion. Soil Science, v. 164, n. 11, p. 790-802, 1999. 
SCHNITZER, M. Soil organic matter - the next 75 years. Soil Science, v. 151, n. 1, p. 41-48, 1991.

SCHULTEN, H. R.; SCHNITZER, M. A state of the art structural concept for humic substances. Naturwissenschaften, v. 80, p. 29-30, 1993.

SCHULTEN, H. R.; SCHNITZER, M. Three-dimensional models for humic acids and soil organic matter. Naturwissenschaften, v. 82, p. 487-498, 1995.

SILVERSTEIN, R.M; BASSLER, G. C.; MORRIL, T. C. Spectrometric identification of organic compounds. 5. ed. New York: John Wiley, 1991. 419p.

THURMAN, E, M.; MALCOLM. R. L. Preparative isolation of aquatic substances. Environmental Science Technology, v. 15, p. 463-466, 1981.

THURMAN, E. M.; WERSHAW, R. L.; MALCOLM, R. L.; PINCKNEY, D. J. Molecular size of aquatic humic substances. Organic Geochemistry, v. 4, p. 27-35, 1982.

THURMAN, E, M, MALCOLM. R. L. Structural of humic substances: new approaches and methods. In: CHRISTMAN, R. F.; GJESSING, E. T. Aquatic and terrestrial humic materials. Ann Arbor: Ann Arbor Science, 1995. p. 1-10.

THURMAN, E. M. Humic substances in groundwater. In: AIKEN, G. R.; MCKNIGHT, M. D.; WERSHAW, R. L.; MAcCARTHY, P. (Eds). Humic substances in soil, sediment and water: geochemistry, isolation and characterization. New York: John Wiley, 1985. p. 87-104.

THURMAN, E. M. Organic geochemistry of natural waters. Dordrecht: Nihoff, M.; Junk, W. 1985a. 489 p.

TOSCANO, I. A. S. Influência das substâncias húmicas aquáticas na determinação de atrazina por imunoensaio (ELISA). 1999. $107 \mathrm{f}$. Tese (Doutorado) -Instituto de Química de Araraquara, Universidade Estadual Paulista, Araraquara, 1999.

VAN BENSCHOTEN, J. E.; EDZWALD, J. K. Chemical aspects of coagulation using aluminum salts-I. Hydrolytic reactions of alum and polyaluminun chloride. Water Research, v. 24, n. 12, p. 519-1526, 1990.

WANDRUSZKA, VON R. The micellar model of humic acid: evidence from pyrene fluorescence measurements. Soil Science, v. 163, p. 921-930, 1998.

WAKSMAN, S. A. Humus: origin, chemical compositions, and importance in nature. Baltimore: Willians and Wilkins, 1938. In: STEVENSON, F. J. Humus Chemistry: genesis, composition and reactions. New York: Willey, 1982. p. 26-53.

WERSHAW, R. L. A new model for humic materials and their interactions with hydrophobic organic chemicals in soil-water or sediment-water systems. Journal Contaminant Hydrology, v. 1, p. 29-45, 1986. 
WERSHAW, R. L. Model for humus in soils and sediments. Environmental Science Technology, v, 27, p. 814-816, 1993.

WILSON, A. L. Determinação of Fulvic Acids in Water. Journal Applied Chemistry, v. 9 , n. 10 , p. $501-510,1959$.

WILSON, M. A. NMR techniques and applications in geochemistry and soil chemistry. Oxford: Pergamon, 1987. 367p.

WILSON, M. A.; HATCHER, P. G. Detection of tannis in modern and fossil barks and plant residues by high-resolution solid state ${ }^{13} \mathrm{C}$ nuclear magnetic resonance.

Organic Geochemistry, v. 12, p. 539-546, 1988.

WILLIAMS, R. L. Colloids and surfaces engineering: application in the process industries. 2. ed. Oxford: Butterworth-Heinemann, 1994. 345p.

WILLIAMS, R. L. Microeletroporetic studies of coagulation with aluminum sulfate. Journal AWWA, v. 57, n. 6, p. 801-810, 1965. 


\section{ANEXO A}

A.1 - Tabelas referentes aos ensaios de coagulação para a água de estudo 1, empregando-se sulfato de alumínio como coagulante.

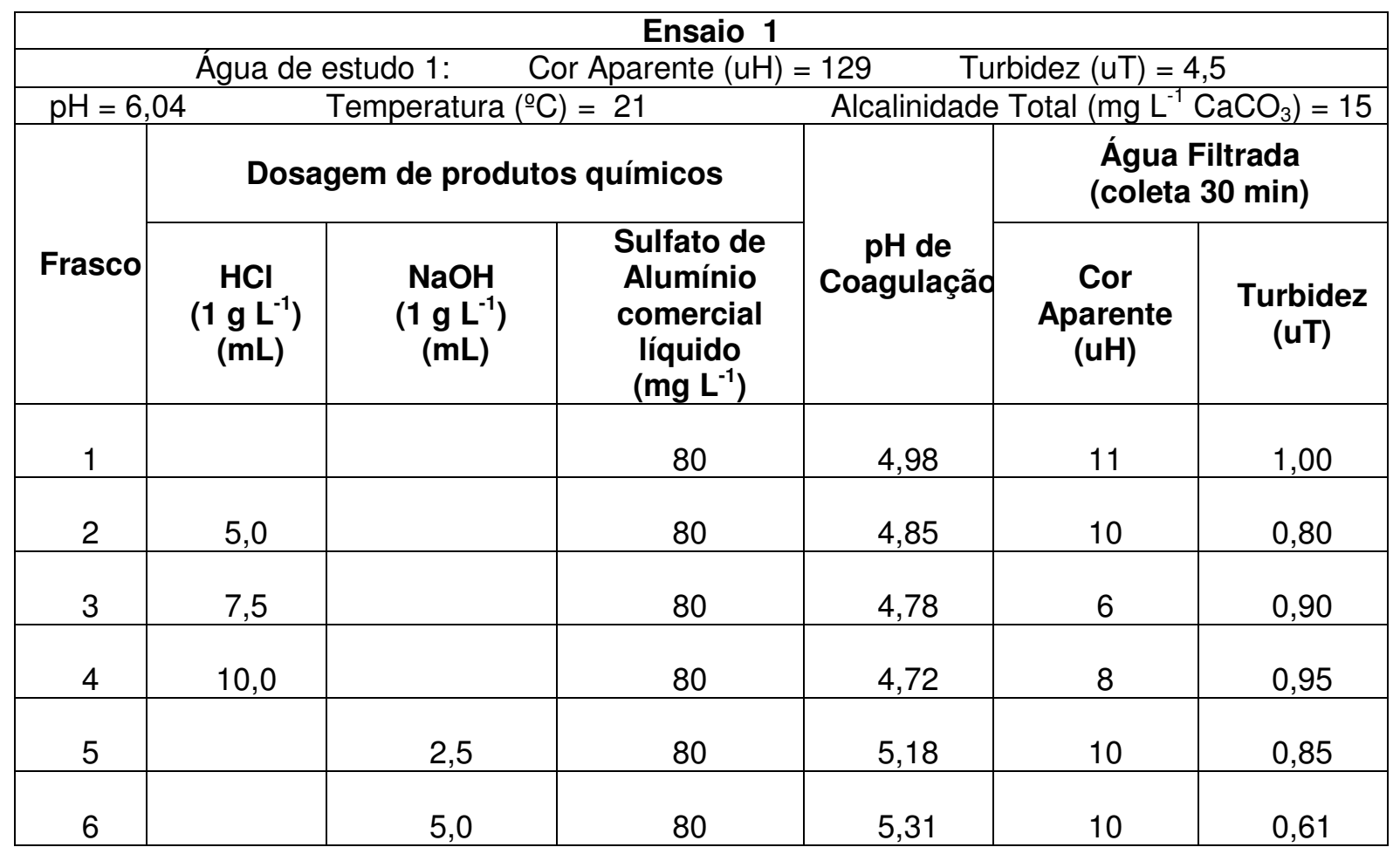

\begin{tabular}{|c|c|c|c|c|c|c|}
\hline \multicolumn{7}{|c|}{ Ensaio 2} \\
\hline \multicolumn{4}{|c|}{ Água de estudo 1: $\quad$ Cor Aparente $(\mathrm{uH})=125$} & \multicolumn{3}{|c|}{ Turbidez $(\mathrm{uT})=4,46$} \\
\hline $\mathrm{pH}=6,1$ & & emperatura & $=20$ & Alcalinidade & Total $(\mathrm{mg} \mathrm{L}$ & $\left.\mathrm{aCO}_{3}\right)=15$ \\
\hline \multirow[b]{2}{*}{ Frasco } & \multicolumn{3}{|c|}{ Dosagem de produtos químicos } & \multirow[b]{2}{*}{$\begin{array}{c}\text { pH de } \\
\text { Coagulação }\end{array}$} & \multicolumn{2}{|c|}{$\begin{array}{l}\text { Água Filtrada } \\
\text { (coleta } 30 \text { min) }\end{array}$} \\
\hline & $\begin{array}{c}\mathrm{HCl} \\
\left(1 \mathrm{~g} \mathrm{~L}^{-1}\right)\end{array}$ & $\begin{array}{c}\mathrm{NaOH} \\
\left(1 \mathrm{~g} \mathrm{~L}^{-1}\right) \\
(\mathrm{mL})\end{array}$ & $\begin{array}{c}\text { Sulfato de } \\
\text { Alumínio } \\
\text { comercial } \\
\text { líquido } \\
\left(\mathrm{mg} \mathrm{L}^{-1}\right) \\
\end{array}$ & & $\begin{array}{c}\text { Cor } \\
\text { Aparente } \\
\text { (uH) }\end{array}$ & $\begin{array}{c}\text { Turbidez } \\
\text { (uT) }\end{array}$ \\
\hline 1 & & 7,5 & 40 & 6,10 & 145 & 9,10 \\
\hline 2 & & 10,0 & 40 & 6,16 & 147 & 7,85 \\
\hline 3 & & 12,5 & 40 & 6,24 & 140 & 4,90 \\
\hline 4 & & 15 & 40 & 6,48 & 137 & 6,19 \\
\hline 5 & & 17,5 & 40 & 7,00 & 136 & 4,48 \\
\hline 6 & & 20 & 40 & 7,00 & 135 & 5,44 \\
\hline
\end{tabular}




\begin{tabular}{|c|c|c|c|c|c|c|}
\hline \multicolumn{7}{|c|}{ Ensaio 3} \\
\hline \multicolumn{7}{|c|}{ Água de estudo 1: Cor Aparente $(\mathrm{uH})=129 \quad$ Turbidez $(\mathrm{uT})=4,5$} \\
\hline \multicolumn{4}{|c|}{ Temperatura $\left({ }^{\circ} \mathrm{C}\right)=21$} & \multicolumn{3}{|c|}{ Alcalinidade Total $\left(\mathrm{mg} \mathrm{L}^{-1} \mathrm{CaCO}_{3}\right)=15$} \\
\hline \multirow[b]{2}{*}{ Frasco } & \multicolumn{3}{|c|}{ Dosagem de produtos químicos } & \multirow[b]{2}{*}{$\begin{array}{c}\text { pH de } \\
\text { Coagulação }\end{array}$} & \multicolumn{2}{|c|}{$\begin{array}{l}\text { Água Filtrada } \\
\text { (coleta } 30 \mathrm{~min} \text { ) }\end{array}$} \\
\hline & $\begin{array}{c}\mathrm{HCl} \\
\left(1 \mathrm{~g} \mathrm{~L}^{-1}\right)\end{array}$ & $\begin{array}{c}\mathrm{NaOH} \\
\left(1 \mathrm{~g} \mathrm{~L}^{-1}\right) \\
(\mathrm{mL})\end{array}$ & $\begin{array}{c}\text { Sulfato de } \\
\text { Alumínio } \\
\text { comercial } \\
\text { líquido } \\
\left(\mathrm{mg} \mathrm{L}^{-1}\right) \\
\end{array}$ & & $\begin{array}{l}\text { Cor } \\
\text { Aparente } \\
\text { (uH) }\end{array}$ & $\begin{array}{c}\text { Turbidez } \\
\text { (uT) }\end{array}$ \\
\hline 1 & & & 40 & 5,51 & 150 & 6,67 \\
\hline 2 & 5,0 & & 40 & 5,02 & 124 & 5,47 \\
\hline 3 & 7,5 & & 40 & 4,80 & 18 & 1,07 \\
\hline 4 & 10,0 & & 40 & 4,58 & 13 & 0,63 \\
\hline 5 & & 2,5 & 40 & 5,78 & 143 & 5,42 \\
\hline 6 & & 5,0 & 40 & 5,97 & 145 & 5,52 \\
\hline
\end{tabular}

\begin{tabular}{|c|c|c|c|c|c|c|}
\hline \multicolumn{7}{|c|}{ Ensaio 4} \\
\hline \multicolumn{7}{|c|}{ Água de estudo 1: $\quad$ Cor Aparente $(\mathrm{uH})=129 \quad$ Turbidez $(\mathrm{uT})=4,5$} \\
\hline \multicolumn{2}{|c|}{$\mathrm{pH}=6,1$} & \multicolumn{2}{|c|}{ Temperatura $\left({ }^{\circ} \mathrm{C}\right)=20$} & \multicolumn{3}{|c|}{ Alcalinidade Total $\left(\mathrm{mg} \mathrm{L}^{-1} \mathrm{CaCO}_{3}\right)=15$} \\
\hline \multirow[b]{2}{*}{ Frasco } & \multicolumn{3}{|c|}{ Dosagem de produtos químicos } & \multirow[b]{2}{*}{$\begin{array}{c}\mathrm{pH} \text { de } \\
\text { Coagulação }\end{array}$} & \multicolumn{2}{|c|}{$\begin{array}{l}\text { Água Filtrada } \\
\text { (coleta } 30 \mathrm{~min} \text { ) }\end{array}$} \\
\hline & $\begin{array}{c}\mathrm{HCl} \\
\left(1 \mathrm{~g} \mathrm{~L}^{-1}\right) \\
(\mathrm{mL})\end{array}$ & $\begin{array}{c}\mathrm{NaOH} \\
\left(1 \mathrm{~g} \mathrm{~L}^{-1}\right) \\
(\mathrm{mL})\end{array}$ & $\begin{array}{l}\text { Sulfato de } \\
\text { Alumínio } \\
\text { comercial } \\
\text { líquido } \\
\left(\mathrm{mg} \mathrm{L}^{-1}\right)\end{array}$ & & $\begin{array}{c}\text { Cor Aparente } \\
\text { (uH) }\end{array}$ & $\begin{array}{l}\text { Turbidez } \\
\text { (uT) }\end{array}$ \\
\hline 1 & 12,5 & & 40 & 4,8 & 19 & 0,94 \\
\hline 2 & 15 & & 40 & 4,6 & 24 & 0,62 \\
\hline 3 & 17,5 & & 40 & 4,42 & 47 & 1,69 \\
\hline 4 & 20 & & 40 & 4,35 & 72 & 3,15 \\
\hline 5 & 22,5 & & 40 & 4,18 & 68 & 3,13 \\
\hline 6 & 25 & & 40 & 4,1 & 78 & 3,59 \\
\hline
\end{tabular}




\begin{tabular}{|c|c|c|c|c|c|c|}
\hline \multicolumn{7}{|c|}{ Ensaio 5} \\
\hline \multicolumn{7}{|c|}{ Água de estudo 1: Cor Aparente $(\mathrm{uH})=128$} \\
\hline \multicolumn{2}{|c|}{$\mathrm{pH}=6,01$} & \multicolumn{2}{|c|}{ emperatura $\left({ }^{\circ} \mathrm{C}\right)=21$} & \multicolumn{3}{|c|}{ Alcalinidade Total $\left(\mathrm{mg} \mathrm{L}^{-1} \mathrm{CaCO}_{3}\right)=15$} \\
\hline \multirow[b]{2}{*}{ Frasco } & \multicolumn{3}{|c|}{ Dosagem de produtos químicos } & \multirow[b]{2}{*}{$\begin{array}{c}\text { pH de } \\
\text { Coagulação }\end{array}$} & \multicolumn{2}{|c|}{$\begin{array}{l}\text { Água Filtrada } \\
\text { (coleta } 30 \text { min) }\end{array}$} \\
\hline & $\begin{array}{c}\mathrm{HCl} \\
\left(1 \mathrm{~g} \mathrm{~L}^{-1}\right) \\
(\mathrm{mL})\end{array}$ & $\begin{array}{c}\mathrm{NaOH} \\
\left(1 \mathrm{~g} \mathrm{~L}^{-1}\right) \\
(\mathrm{mL})\end{array}$ & $\begin{array}{c}\text { Sulfato de } \\
\text { Alumínio } \\
\text { comercial } \\
\text { líquido } \\
\left(\mathrm{mg} \mathrm{L}^{-1}\right)\end{array}$ & & $\begin{array}{c}\text { Cor } \\
\text { Aparente } \\
\text { (uH) }\end{array}$ & $\begin{array}{l}\text { Turbidez } \\
\text { (uT) }\end{array}$ \\
\hline 1 & & & 70 & 4,91 & 6 & 0,74 \\
\hline 2 & 5 & & 70 & 4,80 & 9 & 0,66 \\
\hline 3 & 7,5 & & 70 & 4,71 & 3 & 0,57 \\
\hline 4 & 10 & & 70 & 4,65 & 9 & 0,63 \\
\hline 5 & & 3,5 & 70 & 5,09 & 7 & 0,70 \\
\hline 6 & & 5,0 & 70 & 5,27 & 6 & 0,69 \\
\hline
\end{tabular}

\begin{tabular}{|c|c|c|c|c|c|c|}
\hline \multicolumn{7}{|c|}{ Ensaio 6} \\
\hline \multicolumn{4}{|c|}{ Água de estudo 1: Cor Aparente $(\mathrm{uH})=130$} & \multicolumn{3}{|c|}{ Turbidez $(\mathrm{uT})=5,42$} \\
\hline \multicolumn{2}{|c|}{$\mathrm{pH}=6,00$} & \multicolumn{2}{|c|}{ Temperatura $\left({ }^{\circ} \mathrm{C}\right)=20$} & \multicolumn{3}{|c|}{ Alcalinidade Total $\left(\mathrm{mg} \mathrm{L}^{-1} \mathrm{CaCO}_{3}\right)=15$} \\
\hline \multirow[b]{2}{*}{ Frasco } & \multicolumn{3}{|c|}{ Dosagem de produtos químicos } & \multirow[b]{2}{*}{$\begin{array}{c}\text { pH de } \\
\text { Coagulação }\end{array}$} & \multicolumn{2}{|c|}{$\begin{array}{l}\text { Água Filtrada } \\
\text { (coleta } 30 \mathrm{~min} \text { ) }\end{array}$} \\
\hline & $\begin{array}{c}\mathrm{HCl} \\
\left(1 \mathrm{~g} \mathrm{~L}^{-1}\right) \\
(\mathrm{mL})\end{array}$ & $\begin{array}{c}\mathrm{NaOH} \\
\left(1 \mathrm{~g} \mathrm{~L}^{-1}\right) \\
(\mathrm{mL})\end{array}$ & $\begin{array}{l}\text { Sulfato de } \\
\text { Alumínio } \\
\text { comercial } \\
\text { líquido } \\
\left.\left(\mathrm{mg} \mathrm{L}^{-1}\right)\right)\end{array}$ & & $\begin{array}{c}\text { Cor } \\
\text { Aparente } \\
\text { (uH) }\end{array}$ & $\begin{array}{c}\text { Turbidez } \\
\text { (uT) }\end{array}$ \\
\hline 1 & & 7,5 & 70 & 5,50 & 8 & 0,76 \\
\hline 2 & & 10 & 70 & 5,72 & 23 & 1,40 \\
\hline 3 & & 12,5 & 70 & 5,79 & 36 & 1,79 \\
\hline 4 & & 15 & 70 & 6,04 & 46 & 2,25 \\
\hline 5 & & 17,5 & 70 & 6,10 & 57 & 2,39 \\
\hline
\end{tabular}




\begin{tabular}{|c|c|c|c|c|c|c|}
\hline \multicolumn{7}{|c|}{$\begin{array}{ll}\text { Ensaio } 7 \\
\end{array}$} \\
\hline \multicolumn{7}{|c|}{ Água de estudo 1: $\quad$ Cor Aparente $(\mathrm{uH})=134$} \\
\hline \multicolumn{2}{|c|}{$\mathrm{pH}=6,02$} & \multicolumn{2}{|c|}{ Temperatura $\left({ }^{\circ} \mathrm{C}\right)=20$} & \multicolumn{3}{|c|}{ Alcalinidade Total $\left(\mathrm{mg} \mathrm{L}^{-1} \mathrm{CaCO}_{3}\right)=15$} \\
\hline \multirow[b]{2}{*}{ Frasco } & \multicolumn{3}{|c|}{ Dosagem de produtos químicos } & \multirow[b]{2}{*}{$\begin{array}{c}\text { pH de } \\
\text { Coagulação }\end{array}$} & \multicolumn{2}{|c|}{$\begin{array}{l}\text { Água Filtrada } \\
\text { (coleta } 30 \text { min) }\end{array}$} \\
\hline & $\begin{array}{c}\mathrm{HCl} \\
\left(1 \mathrm{~g} \mathrm{~L}^{-1}\right)\end{array}$ & $\begin{array}{c}\mathrm{NaOH} \\
\left(1 \mathrm{~g} \mathrm{~L}^{-1}\right) \\
(\mathrm{mL})\end{array}$ & $\begin{array}{c}\text { Sulfato de } \\
\text { Alumínio } \\
\text { comercial } \\
\text { líquido } \\
\left(\mathrm{mg} \mathrm{L}^{-1}\right)\end{array}$ & & $\begin{array}{c}\text { Cor Aparente } \\
\text { (uH) }\end{array}$ & $\begin{array}{l}\text { Turbidez } \\
\text { (uT) }\end{array}$ \\
\hline 1 & 13,5 & & 70 & 4,55 & 13 & 0,45 \\
\hline 2 & 17 & & 70 & 4,40 & 19 & 0,46 \\
\hline 3 & 13,0 & & 80 & 4,51 & 14 & 0,47 \\
\hline 4 & 16 & & 80 & 4,43 & 19 & 0,50 \\
\hline 5 & 19 & & 80 & 4,30 & 24 & 0,51 \\
\hline 6 & 21 & & 80 & 4,22 & 26 & 0,58 \\
\hline
\end{tabular}

\begin{tabular}{|c|c|c|c|c|c|c|}
\hline \multicolumn{7}{|c|}{ Ensaio 8} \\
\hline \multicolumn{4}{|c|}{ Água de estudo 1: Cor Aparente $(\mathrm{uH})=134$} & \multicolumn{3}{|c|}{ Turbidez $(\mathrm{uT})=4,44$} \\
\hline \multicolumn{4}{|c|}{$\mathrm{pH}=6,04 \quad$ Temperatura $\left({ }^{\circ} \mathrm{C}\right)=20$} & \multicolumn{3}{|c|}{ Alcalinidade Total $\left(\mathrm{mg} \mathrm{L}^{-1} \mathrm{CaCO}_{3}\right)=15$} \\
\hline \multirow[b]{2}{*}{ Frasco } & \multicolumn{3}{|c|}{ Dosagem de produtos químicos } & \multirow[b]{2}{*}{$\begin{array}{c}\text { pH de } \\
\text { Coagulação }\end{array}$} & \multicolumn{2}{|c|}{$\begin{array}{l}\text { Água Filtrada } \\
\text { (coleta } 30 \mathrm{~min} \text { ) }\end{array}$} \\
\hline & $\begin{array}{c}\mathrm{HCl} \\
\left(1 \mathrm{~g} \mathrm{~L}^{-1}\right) \\
(\mathrm{mL})\end{array}$ & $\begin{array}{c}\mathrm{NaOH} \\
\left(1 \mathrm{~g} \mathrm{~L}^{-1}\right) \\
(\mathrm{mL})\end{array}$ & $\begin{array}{c}\text { Sulfato de } \\
\text { Alumínio } \\
\text { comercial líquido } \\
\left(\mathrm{mg} \mathrm{L}^{-1}\right) \\
\end{array}$ & & $\begin{array}{c}\text { Cor } \\
\text { Aparente } \\
\text { (uH) }\end{array}$ & $\begin{array}{c}\text { Turbidez } \\
\text { (uT) }\end{array}$ \\
\hline 1 & & 7,5 & 80 & 5,28 & 14 & 0,62 \\
\hline 2 & & 10 & 80 & 5,40 & 10 & 0,46 \\
\hline 3 & & 12,5 & 80 & 5,60 & 16 & 0,75 \\
\hline 4 & & 15 & 80 & 5,78 & 16 & 0,70 \\
\hline 5 & & 25 & 80 & 6,23 & 38 & 1,41 \\
\hline
\end{tabular}




\begin{tabular}{|c|c|c|c|c|c|c|}
\hline \multicolumn{7}{|c|}{$\begin{array}{ll} & \text { Ensaio } 9\end{array}$} \\
\hline \multirow{2}{*}{\multicolumn{4}{|c|}{ 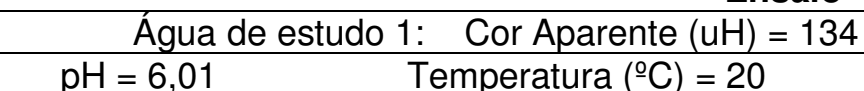 }} & \multirow{2}{*}{\multicolumn{3}{|c|}{$\begin{array}{c}\text { Turbidez (uT) }=4,50 \\
\text { Alcalinidade Total }\left(\mathrm{mg} \mathrm{L}^{-1} \mathrm{CaCO}_{3}\right)=15\end{array}$}} \\
\hline & & & & & & \\
\hline \multirow[b]{2}{*}{ Frasco } & \multicolumn{3}{|c|}{ Dosagem de produtos químicos } & \multirow[b]{2}{*}{$\begin{array}{c}\text { pH de } \\
\text { Coagulação }\end{array}$} & \multicolumn{2}{|c|}{$\begin{array}{l}\text { Água Filtrada } \\
\text { (coleta } 30 \text { min) }\end{array}$} \\
\hline & $\begin{array}{c}\mathrm{HCl} \\
\left(\operatorname{(mL}_{(\mathrm{mL})}^{-1}\right)\end{array}$ & $\begin{array}{c}\mathrm{NaOH} \\
\left(1 \mathrm{~g} \mathrm{~L}^{-1}\right) \\
(\mathrm{mL})\end{array}$ & $\begin{array}{c}\text { Sulfato de } \\
\text { Alumínio } \\
\text { comercial } \\
\text { líquido } \\
\left(\mathrm{mg} \mathrm{L}^{-1}\right) \\
\end{array}$ & & $\begin{array}{c}\text { Cor Aparente } \\
\text { (uH) }\end{array}$ & $\begin{array}{c}\text { Turbidez } \\
\text { (uT) }\end{array}$ \\
\hline 1 & & & 90 & 4,8 & 7 & 0,53 \\
\hline 2 & 5,0 & & 90 & 4,71 & 5 & 0,38 \\
\hline 3 & 10,0 & & 90 & 4,56 & 7 & 0,35 \\
\hline 4 & 15,0 & & 90 & 4,34 & 10 & 0,36 \\
\hline 5 & & 5,0 & 90 & 4,97 & 71 & 3,12 \\
\hline 6 & & 17,5 & 90 & 5,70 & 3 & 0,34 \\
\hline
\end{tabular}

\begin{tabular}{|c|c|c|c|c|c|c|}
\hline \multicolumn{7}{|c|}{ Ensaio 10} \\
\hline \multicolumn{4}{|c|}{ Água de estudo 1: Cor Aparente $(\mathrm{uH})=135$} & \multicolumn{3}{|c|}{ Turbidez (uT) $=4,44$} \\
\hline \multicolumn{2}{|c|}{$\mathrm{pH}=6,00$} & \multicolumn{2}{|c|}{ Temperatura $\left({ }^{\circ} \mathrm{C}\right)=20$} & \multicolumn{3}{|c|}{ Alcalinidade Total $\left(\mathrm{mg} \mathrm{L}^{-1} \mathrm{CaCO}_{3}\right)=15$} \\
\hline \multirow[b]{2}{*}{ Frasco } & \multicolumn{3}{|c|}{ Dosagem de produtos químicos } & \multirow[b]{2}{*}{$\begin{array}{c}\text { pH de } \\
\text { Coagulação }\end{array}$} & \multicolumn{2}{|c|}{$\begin{array}{l}\text { Água Filtrada } \\
\text { (coleta } 30 \mathrm{~min} \text { ) }\end{array}$} \\
\hline & $\begin{array}{c}\mathrm{HCl} \\
\left(1 \mathrm{~g} \mathrm{~L}^{-1}\right)\end{array}$ & $\begin{array}{c}\mathrm{NaOH} \\
\left(1 \mathrm{~g} \mathrm{~L}^{-1}\right) \\
(\mathrm{mL})\end{array}$ & $\begin{array}{c}\text { Sulfato de } \\
\text { Alumínio } \\
\text { comercial } \\
\text { líquido } \\
\left(\mathrm{mg} \mathrm{L}^{-1}\right)\end{array}$ & & $\begin{array}{c}\text { Cor Aparente } \\
\text { (uH) }\end{array}$ & $\begin{array}{l}\text { Turbidez } \\
\text { (uT) }\end{array}$ \\
\hline 1 & & 10 & 90 & 4,90 & 84 & 3,66 \\
\hline 2 & & 12,5 & 90 & 5,20 & 69 & 3,04 \\
\hline 3 & & 15 & 90 & 5,42 & 9 & 0,63 \\
\hline 4 & & 17,5 & 90 & 5,60 & 4 & 0,43 \\
\hline 5 & & 20 & 90 & 5,80 & 3 & 0,34 \\
\hline 6 & & 22,5 & 90 & 5,90 & 3 & 0,33 \\
\hline
\end{tabular}




\begin{tabular}{|c|c|c|c|c|c|c|}
\hline \multicolumn{7}{|c|}{$\begin{array}{lll} & \text { Ensaio } 11\end{array}$} \\
\hline \multirow{2}{*}{\multicolumn{4}{|c|}{ Água de estudo 1: Cor Aparente $(\mathrm{uH})=135$}} & \multirow{2}{*}{\multicolumn{3}{|c|}{$\begin{array}{c}\text { Turbidez }(\mathrm{uT})=4,46 \\
\text { Alcalinidade Total }\left(\mathrm{mg} \mathrm{L}^{-1} \mathrm{CaCO}_{3}\right)=15\end{array}$}} \\
\hline $\mathrm{pH}=6,02$ & & & Temperatura $\left({ }^{\circ} \mathrm{C}\right)=20$ & & & \\
\hline \multirow[b]{2}{*}{ Frasco } & \multicolumn{3}{|c|}{ Dosagem de produtos químicos } & \multirow[b]{2}{*}{$\begin{array}{c}\text { pH de } \\
\text { Coagulação }\end{array}$} & \multicolumn{2}{|c|}{$\begin{array}{l}\text { Agua Filtrada } \\
\text { (coleta } 30 \text { min) }\end{array}$} \\
\hline & $\begin{array}{c}\mathrm{HCl} \\
\left(\operatorname{(mL}_{(\mathrm{mL})}\right)\end{array}$ & $\begin{array}{c}\mathrm{NaOH} \\
\left(1 \mathrm{~g} \mathrm{~L}^{-1}\right) \\
(\mathrm{mL})\end{array}$ & $\begin{array}{l}\text { Sulfato de } \\
\text { Alumínio } \\
\text { comercial } \\
\text { líquido } \\
\left(\mathrm{mg} \mathrm{L}^{-1}\right) \\
\end{array}$ & & $\begin{array}{c}\text { Cor Aparente } \\
\text { (uH) }\end{array}$ & $\begin{array}{c}\text { Turbidez } \\
\text { (uT) }\end{array}$ \\
\hline 1 & & 20 & 80 & 5,98 & 16 & 0,79 \\
\hline 2 & & 22,5 & 80 & 6,11 & 22 & 0,91 \\
\hline 3 & & 30 & 80 & 6,46 & 54 & 1,64 \\
\hline 4 & & 25 & 90 & 6,00 & 14 & 0,67 \\
\hline 5 & & 30 & 90 & 6,34 & 18 & 0,65 \\
\hline 6 & & 35 & 90 & 6,53 & 26 & 0,85 \\
\hline
\end{tabular}

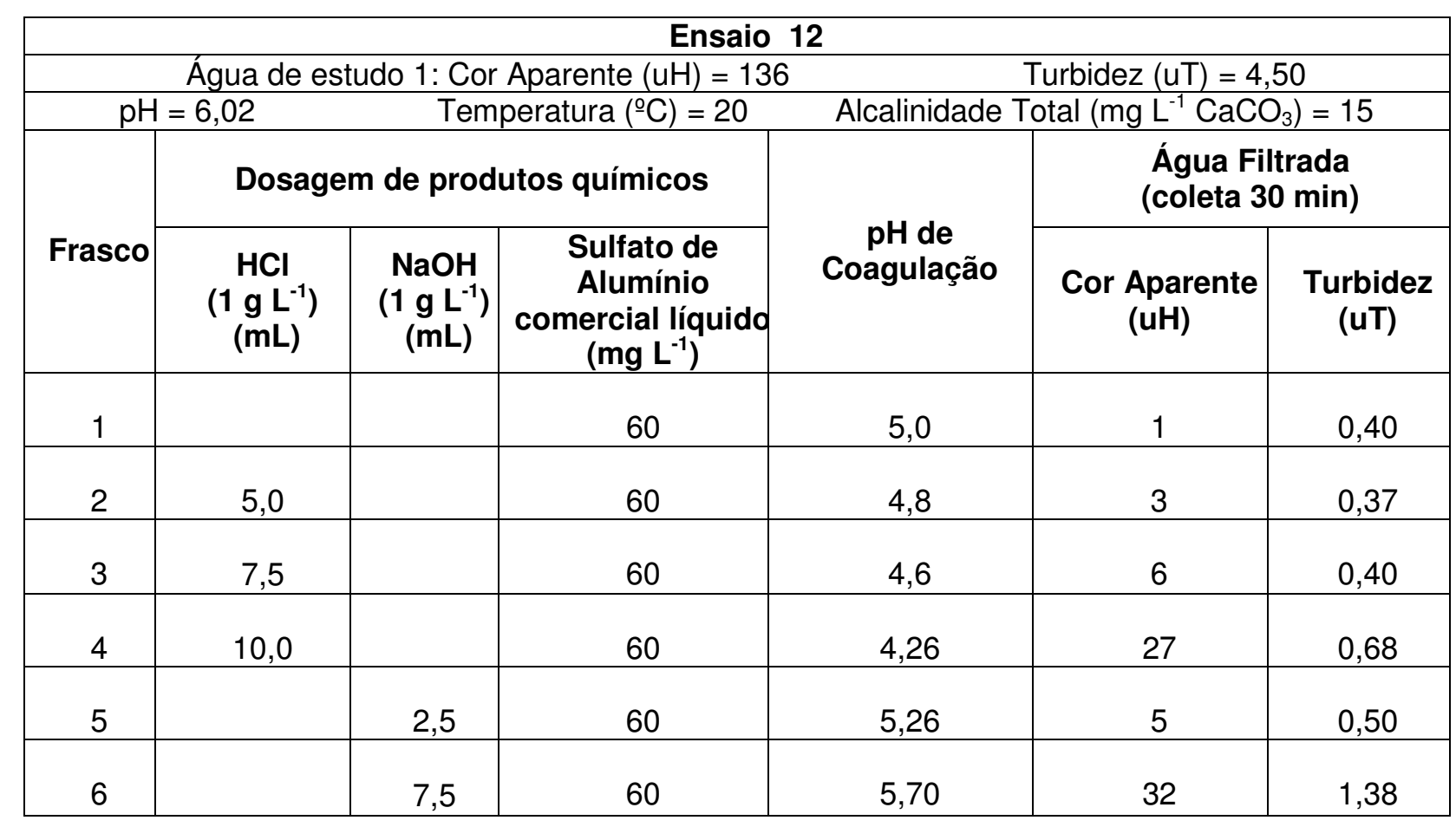




\begin{tabular}{|c|c|c|c|c|c|c|}
\hline \multicolumn{7}{|c|}{$\begin{array}{ll} & \text { Ensaio } 13 \\
\end{array}$} \\
\hline \multicolumn{4}{|c|}{ Água de estudo 1: Cor Aparente $(\mathrm{uH})=134$} & \multirow{2}{*}{\multicolumn{3}{|c|}{$\begin{array}{c}\text { Turbidez }(\mathrm{uT})=5,0 \\
\text { calinidade Total }\left(\mathrm{mg} \mathrm{L}^{-1} \mathrm{CaCO}_{3}\right)=15\end{array}$}} \\
\hline \multicolumn{2}{|c|}{$\mathrm{pH}=6,1$} & \multicolumn{2}{|c|}{$\begin{array}{l}\text { do 1: Cor Aparente }(\mathrm{uH})=134 \\
\text { Temperatura }\left({ }^{\circ} \mathrm{C}\right)=20\end{array}$} & & & \\
\hline \multirow[b]{2}{*}{ Frasco } & \multicolumn{3}{|c|}{ Dosagem de produtos químicos } & \multirow[b]{2}{*}{$\begin{array}{c}\text { pH de } \\
\text { Coagulação }\end{array}$} & \multicolumn{2}{|c|}{$\begin{array}{l}\text { Água Filtrada } \\
\text { (coleta } 30 \text { min) }\end{array}$} \\
\hline & $\begin{array}{c}\mathrm{HCl} \\
\left(1 \mathrm{~g} \mathrm{~L}^{-1}\right) \\
(\mathrm{mL})\end{array}$ & $\begin{array}{c}\mathrm{NaOH} \\
\left(1 \mathrm{~g} \mathrm{~L}^{-1}\right) \\
(\mathrm{mL})\end{array}$ & $\begin{array}{l}\text { Sulfato de } \\
\text { Alumínio } \\
\text { comercial } \\
\text { líquido } \\
\left(\mathrm{mg} \mathrm{L}^{-1}\right) \\
\end{array}$ & & $\begin{array}{c}\text { Cor } \\
\text { Aparente } \\
\text { (uH) }\end{array}$ & $\begin{array}{l}\text { Turbidez } \\
\text { (uT) }\end{array}$ \\
\hline 1 & & 10 & 60 & 5,8 & 73 & 2,85 \\
\hline 2 & & 12,5 & 60 & 5,93 & 95 & 3,39 \\
\hline 3 & & 15,0 & 60 & 6,10 & 184 & 7,46 \\
\hline 4 & & 17,5 & 60 & 6,24 & 177 & 7,49 \\
\hline 5 & & 20 & 60 & 6,40 & 172 & 7,11 \\
\hline 6 & & 25 & 60 & 6,6 & 164 & 6,24 \\
\hline
\end{tabular}

\begin{tabular}{|c|c|c|c|c|c|c|}
\hline \multicolumn{7}{|c|}{ Ensaio 14} \\
\hline \multicolumn{4}{|c|}{ Água de estudo 1: Cor Aparente $(\mathrm{uH})=134$} & \multicolumn{3}{|c|}{ Turbidez $(\mathrm{uT})=5,0$} \\
\hline $\mathrm{pH} \mathrm{6,05}$ & & Temperat & ) $=20$ & Alcalinidade & otal $\left(\mathrm{mg} \mathrm{L}^{-1}\right.$ & $\left.\mathrm{aCO}_{3}\right)=15$ \\
\hline \multirow[b]{2}{*}{ Frasco } & \multicolumn{3}{|c|}{ Dosagem de produtos químicos } & \multirow[b]{2}{*}{$\begin{array}{c}\text { pH de } \\
\text { Coagulação }\end{array}$} & \multicolumn{2}{|c|}{$\begin{array}{l}\text { Água Filtrada } \\
\text { (coleta } 30 \mathrm{~min} \text { ) }\end{array}$} \\
\hline & $\begin{array}{c}\mathrm{HCl} \\
\left(1 \mathrm{~g} \mathrm{~L}^{-1}\right) \\
(\mathrm{mL})\end{array}$ & $\begin{array}{c}\mathrm{NaOH} \\
\left(1 \mathrm{~g} \mathrm{~L}^{-1}\right) \\
(\mathrm{mL})\end{array}$ & $\begin{array}{l}\text { Sulfato de } \\
\text { Alumínio } \\
\text { comercial } \\
\text { líquido } \\
\left(\mathrm{mg} \mathrm{L}^{-1}\right) \\
\end{array}$ & & $\begin{array}{c}\text { Cor } \\
\text { Aparente } \\
\text { (uH) }\end{array}$ & $\begin{array}{l}\text { Turbidez } \\
\text { (uT) }\end{array}$ \\
\hline 1 & & 5,0 & 60 & 5,56 & 20 & 1,11 \\
\hline 2 & 10 & & 60 & 4,65 & 6 & 0,37 \\
\hline 3 & & & 50 & 5,38 & 54 & 2,20 \\
\hline 4 & 5,0 & & 50 & 4,96 & 6 & 0,52 \\
\hline 5 & 7,5 & & 50 & 4,84 & 5 & 0,38 \\
\hline 6 & 10,0 & & 50 & 4,70 & 6 & 0,38 \\
\hline
\end{tabular}




\begin{tabular}{|c|c|c|c|c|c|c|}
\hline \multicolumn{7}{|c|}{$\begin{array}{ll} & \text { Ensaio } 15\end{array}$} \\
\hline \multicolumn{4}{|c|}{ Água de Estudo 1: Cor Aparente $(\mathrm{uH})=136$} & \\
\hline \multicolumn{2}{|c|}{$\mathrm{pH}=6,1$} & \multicolumn{2}{|c|}{$\begin{array}{l}\text { o 1: Cor Aparente }(\mathrm{uH})=136 \\
\text { Temperatura }\left({ }^{\circ} \mathrm{C}\right)=20\end{array}$} & \multicolumn{2}{|c|}{ Alcalinidade Total $\left(\mathrm{mg} \mathrm{L}^{-1} \mathrm{CaCO}_{3}\right)=15$} & \\
\hline \multirow[b]{2}{*}{ Frasco } & \multicolumn{3}{|c|}{ Dosagem de produtos químicos } & \multirow[b]{2}{*}{$\begin{array}{c}\text { pH de } \\
\text { Coagulação }\end{array}$} & \multicolumn{2}{|c|}{$\begin{array}{c}\text { Água Filtrada } \\
\text { (coleta } 30 \mathrm{~min} \text { ) }\end{array}$} \\
\hline & $\begin{array}{c}\mathrm{HCl} \\
\left(\operatorname{(mL)}_{\left(\mathrm{mL} \mathrm{L}^{-1}\right.}\right)\end{array}$ & $\begin{array}{c}\mathrm{NaOH} \\
\left(1 \mathrm{~g} \mathrm{~L}^{-1}\right) \\
(\mathrm{mL})\end{array}$ & $\begin{array}{c}\text { Sulfato de } \\
\text { Alumínio } \\
\text { comercial } \\
\text { líquido } \\
\left(\mathrm{mg} \mathrm{L}^{-1}\right)\end{array}$ & & $\begin{array}{c}\text { Cor } \\
\text { Aparente } \\
\text { (uH) }\end{array}$ & $\begin{array}{l}\text { Turbidez } \\
\text { (uT) }\end{array}$ \\
\hline 1 & 12,5 & & 50 & 4,56 & 12 & 0,59 \\
\hline 2 & 15 & & 50 & 4,37 & 22 & 0,56 \\
\hline 3 & 17,5 & & 50 & 4,28 & 50 & 1,60 \\
\hline 4 & & 2,5 & 50 & 5,60 & 179 & 7,33 \\
\hline 5 & & 5,0 & 50 & 5,80 & 169 & 7,12 \\
\hline 6 & & 10 & 50 & 6,05 & 158 & 5,85 \\
\hline
\end{tabular}

\begin{tabular}{|c|c|c|c|c|c|c|}
\hline \multicolumn{7}{|c|}{$\begin{array}{ll}\text { Ensaio } 16 \\
\end{array}$} \\
\hline \multicolumn{4}{|c|}{ Água de Estudo 1: Cor Aparente $(\mathrm{uH})=117$} & \multirow{2}{*}{\multicolumn{3}{|c|}{$\begin{array}{c}\text { Turbidez }(\mathrm{uT})=4,85 \\
\text { calinidade Total }\left(\mathrm{mg} \mathrm{L}^{-1} \mathrm{CaCO}_{3}\right)=15\end{array}$}} \\
\hline \multicolumn{2}{|c|}{$\mathrm{pH}=6,1$} & \multicolumn{2}{|c|}{ Temperatura $\left({ }^{\circ} \mathrm{C}\right)=20$} & & & \\
\hline \multirow[b]{2}{*}{ Frasco } & \multicolumn{3}{|c|}{ Dosagem de produtos Químicos (mg/L) } & \multirow[b]{2}{*}{$\begin{array}{c}\text { pH de } \\
\text { Coagulação }\end{array}$} & \multicolumn{2}{|c|}{$\begin{array}{l}\text { Agua Filtrada } \\
\text { (coleta } 30 \text { min) }\end{array}$} \\
\hline & $\begin{array}{c}\mathrm{HCl} \\
\left(1 \mathrm{~g} \mathrm{~L}^{-1}\right)\end{array}$ & $\begin{array}{c}\mathrm{NaOH} \\
\left(1 \mathrm{~g} \mathrm{~L}^{-1}\right) \\
(\mathrm{mL})\end{array}$ & $\begin{array}{l}\text { Sulfato de } \\
\text { Alumínio } \\
\text { comercial } \\
\text { líquido } \\
\left(\mathrm{mg} \mathrm{L}^{-1}\right)\end{array}$ & & $\begin{array}{c}\text { Cor } \\
\text { Aparente } \\
\text { (uH) }\end{array}$ & $\begin{array}{c}\text { Turbidez } \\
\text { (uT) }\end{array}$ \\
\hline 1 & & & 100 & 4,73 & 12 & 0,69 \\
\hline 2 & 2,5 & & 100 & 4,65 & 6 & 0,46 \\
\hline 3 & 5,0 & & 100 & 4,57 & 7 & 0,46 \\
\hline 4 & 7,5 & & 100 & 4,49 & 8 & 0,41 \\
\hline 5 & 10 & & 100 & 4,42 & 9 & 0,44 \\
\hline 6 & 15 & & 100 & 4,26 & 17 & 0,87 \\
\hline
\end{tabular}




\begin{tabular}{|c|c|c|c|c|c|c|}
\hline \multicolumn{7}{|c|}{ Ensaio 17} \\
\hline \multicolumn{4}{|c|}{ Água de Estudo 1: Cor Aparente $(\mathrm{uH})=117$} & \multicolumn{3}{|c|}{ Turbidez $(u T)=4,85$} \\
\hline \multicolumn{2}{|c|}{$\mathrm{pH}=6,1$} & \multicolumn{2}{|c|}{ Temperatura $\left({ }^{\circ} \mathrm{C}\right)=20$} & \multicolumn{3}{|c|}{ Alcalinidade Total $\left(\mathrm{mg} \mathrm{L}^{-1} \mathrm{CaCO}_{3}\right)=15$} \\
\hline \multirow[b]{2}{*}{ Frasco } & \multicolumn{3}{|c|}{ Dosagem de produtos químicos } & \multirow[b]{2}{*}{$\begin{array}{c}\text { pH de } \\
\text { Coagulação }\end{array}$} & \multicolumn{2}{|c|}{$\begin{array}{l}\text { Água Filtrada } \\
\text { (coleta } 30 \text { min) }\end{array}$} \\
\hline & $\begin{array}{c}\mathrm{HCl} \\
\left(1 \mathrm{~g} \mathrm{~L}^{-1}\right) \\
(\mathrm{mL})\end{array}$ & $\begin{array}{c}\mathrm{NaOH} \\
\left(1 \mathrm{~g} \mathrm{~L}^{-1}\right) \\
(\mathrm{mL})\end{array}$ & $\begin{array}{l}\text { Sulfato de } \\
\text { Alumínio } \\
\text { comercial } \\
\text { líquido } \\
\left(\mathrm{mg} \mathrm{L}^{-1}\right)\end{array}$ & & $\begin{array}{c}\text { Cor } \\
\text { Aparente } \\
\text { (uH) }\end{array}$ & $\begin{array}{l}\text { Turbidez } \\
\text { (uT) }\end{array}$ \\
\hline 1 & & 5 & 100 & 4,82 & 36 & 1,6 \\
\hline 2 & & 10 & 100 & 4,89 & 96 & 4,34 \\
\hline 3 & & 15 & 100 & 5,1 & 63 & 2,95 \\
\hline 4 & & 20 & 100 & 5,5 & 16 & 0,94 \\
\hline 5 & & 25 & 100 & 5,83 & 4 & 0,45 \\
\hline 6 & & 30 & 100 & 6,1 & 8 & 0,59 \\
\hline
\end{tabular}

\begin{tabular}{|c|c|c|c|c|c|c|}
\hline \multicolumn{7}{|c|}{$\begin{array}{r}\text { Ensaio } 18 \\
\end{array}$} \\
\hline \multirow{2}{*}{\multicolumn{4}{|c|}{\begin{tabular}{cc}
\multicolumn{2}{c}{ Água de Estudo1: Cor Aparente $(\mathrm{uH})=117$} \\
$\mathrm{pH}=6,0$ & Temperatura $\left({ }^{\circ} \mathrm{C}\right)=20$ \\
\end{tabular}}} & \multicolumn{3}{|c|}{ Turbidez $(\mathrm{uT})=4,85$} \\
\hline & & & & Icalinidade To & al $\left(\mathrm{mg} \mathrm{L}^{-1} \mathrm{C}\right.$ & $\left.\mathrm{O}_{3}\right)=15$ \\
\hline \multirow[b]{2}{*}{ Frasco } & \multicolumn{3}{|c|}{ Dosagem de produtos químicos } & \multirow[b]{2}{*}{$\begin{array}{c}\text { pH de } \\
\text { Coagulação }\end{array}$} & \multicolumn{2}{|c|}{$\begin{array}{l}\text { Água Filtrada } \\
\text { (coleta } 30 \text { min) }\end{array}$} \\
\hline & $\begin{array}{c}\mathrm{HCl} \\
\left(\mathrm{(mL}^{1} \mathrm{~g} \mathrm{~L}^{-1}\right)\end{array}$ & $\begin{array}{c}\mathrm{NaOH} \\
\left(1 \mathrm{~g} \mathrm{~L}^{-1}\right) \\
(\mathrm{mL})\end{array}$ & $\begin{array}{c}\text { Sulfato de } \\
\text { Alumínio } \\
\text { comercial } \\
\text { líquido } \\
\left(\mathrm{mg} \mathrm{L}^{-1}\right) \\
\end{array}$ & & $\begin{array}{c}\text { Cor } \\
\text { Aparente } \\
\text { (uH) }\end{array}$ & $\begin{array}{l}\text { Turbidez } \\
\quad \text { (uT) }\end{array}$ \\
\hline 1 & & & 60 & 4,83 & 6 & 0,43 \\
\hline 2 & & & 60 & 4,84 & 6 & 0,43 \\
\hline 3 & & 35 & 100 & 6,30 & 8 & 0,44 \\
\hline 4 & & 40 & 100 & 6,5 & 21 & 0,79 \\
\hline
\end{tabular}


A.2 Tabelas referentes aos ensaios de coagulação para a água de estudo 2, empregando-se sulfato de sulfato de alumínio como coagulante.

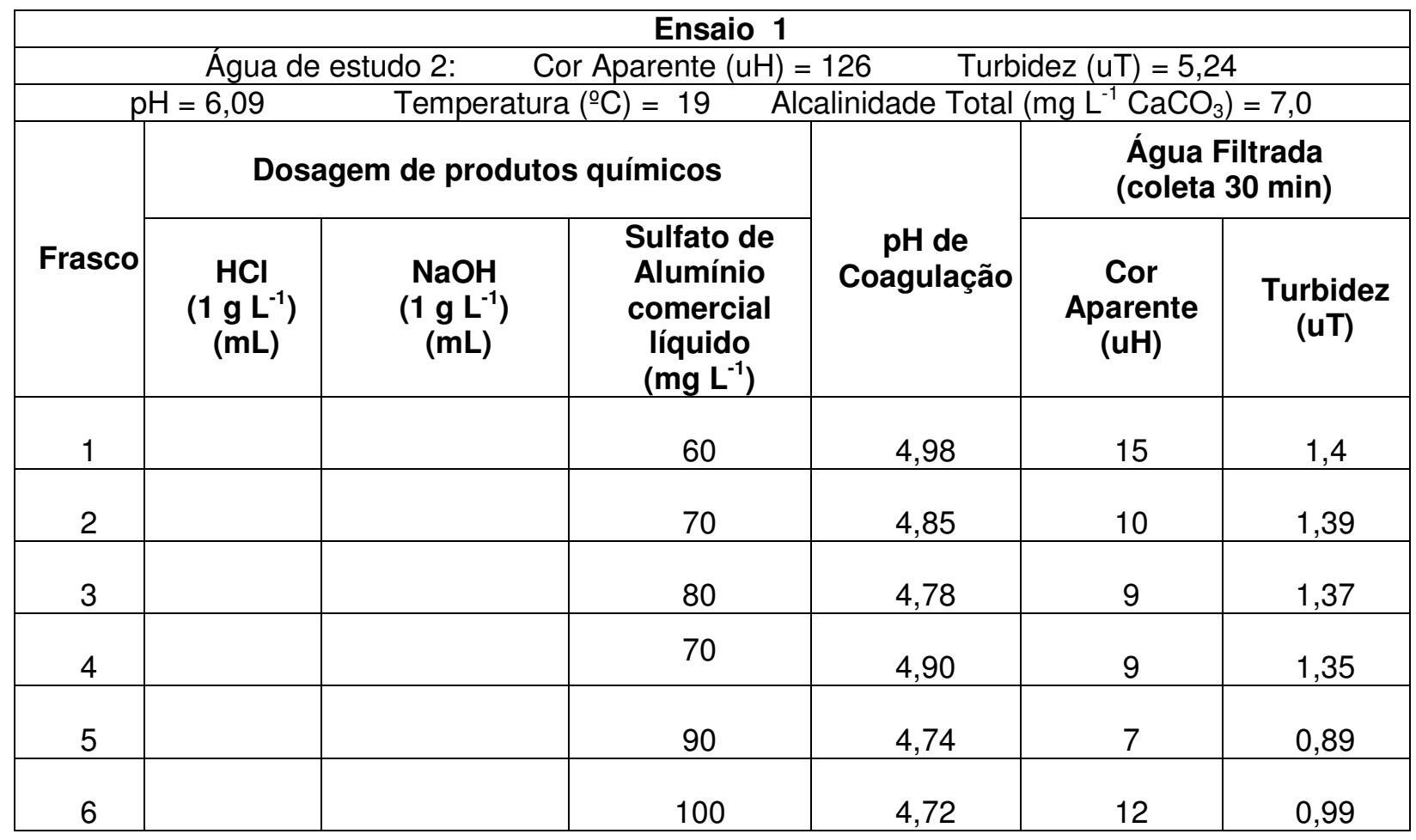

\begin{tabular}{|c|c|c|c|c|c|c|}
\hline \multicolumn{7}{|c|}{ Ensaio 2} \\
\hline \multicolumn{4}{|c|}{ Água de estudo $2: \quad$ Cor Aparente $(\mathrm{uH})=127$} & \multicolumn{3}{|c|}{ Turbidez $(\mathrm{uT})=5,20$} \\
\hline \multicolumn{4}{|c|}{$\mathrm{pH}=6,00 \quad$ Temperatura $\left({ }^{\circ} \mathrm{C}\right)=20$} & \multicolumn{3}{|c|}{ Alcalinidade Total $\left(\mathrm{mg} \mathrm{L}^{-1} \mathrm{CaCO}_{3}\right)=7,0$} \\
\hline \multirow[b]{2}{*}{ Frasco } & \multicolumn{3}{|c|}{ Dosagem de produtos químicos } & \multirow[b]{2}{*}{$\begin{array}{c}\text { pH de } \\
\text { Coagulação }\end{array}$} & \multicolumn{2}{|c|}{$\begin{array}{c}\text { Água Filtrada } \\
\text { (coleta } 30 \mathrm{~min} \text { ) }\end{array}$} \\
\hline & $\begin{array}{c}\mathrm{HCl} \\
\left(1 \mathrm{~g} \mathrm{~L}^{-1}\right) \\
(\mathrm{mL})\end{array}$ & $\begin{array}{c}\mathrm{NaOH} \\
\left(1 \mathrm{~g} \mathrm{~L}^{-1}\right) \\
(\mathrm{mL})\end{array}$ & $\begin{array}{l}\text { Sulfato de } \\
\text { Alumínio } \\
\text { comercial } \\
\text { líquido } \\
\left(\mathrm{mg} \mathrm{L}^{-1}\right) \\
\end{array}$ & & $\begin{array}{c}\text { Cor } \\
\text { Aparente } \\
\text { (uH) }\end{array}$ & $\begin{array}{l}\text { Turbidez } \\
\text { (uT) }\end{array}$ \\
\hline 1 & 3,0 & & 90 & 4,68 & 8 & 0,94 \\
\hline 2 & 6,0 & & 90 & 4,56 & 10 & 0,96 \\
\hline 3 & & 6,0 & 90 & 4,84 & 42 & 2,68 \\
\hline 4 & & 12 & 90 & 5,07 & 129 & 8,60 \\
\hline 5 & & 18 & 90 & 5,35 & 82 & 5,42 \\
\hline 6 & & 24 & 90 & 5,86 & 3 & 0,89 \\
\hline
\end{tabular}




\begin{tabular}{|c|c|c|c|c|c|c|}
\hline \multicolumn{7}{|c|}{ Ensaio 3} \\
\hline \multicolumn{7}{|c|}{ Água de estudo 2: Cor Aparente $(\mathrm{uH})=128$} \\
\hline \multicolumn{4}{|c|}{$\mathrm{pH}=6,04 \quad$ Temperatura $\left({ }^{\circ} \mathrm{C}\right)=20$} & \multicolumn{3}{|c|}{ Alcalinidade Total $\left(\mathrm{mg} \mathrm{L}^{-1} \mathrm{CaCO}_{3}\right)=7,0$} \\
\hline \multirow[b]{2}{*}{ Frasco } & \multicolumn{3}{|c|}{ Dosagem de produtos químicos } & \multirow[b]{2}{*}{$\begin{array}{c}\text { pH de } \\
\text { Coagulação }\end{array}$} & \multicolumn{2}{|c|}{$\begin{array}{l}\text { Água Filtrada } \\
\text { (coleta } 30 \text { min) }\end{array}$} \\
\hline & $\begin{array}{c}\mathrm{HCl} \\
\left(1 \mathrm{~g} \mathrm{~L}^{-1}\right) \\
(\mathrm{mL})\end{array}$ & $\begin{array}{c}\mathrm{NaOH} \\
\left(1 \mathrm{~g} \mathrm{~L}^{-1}\right) \\
(\mathrm{mL})\end{array}$ & $\begin{array}{l}\text { Sulfato de } \\
\text { Alumínio } \\
\text { comercial } \\
\text { líquido } \\
\left(\mathrm{mg} \mathrm{L}^{-1}\right)\end{array}$ & & $\begin{array}{c}\text { Cor } \\
\text { Aparente } \\
\text { (uH) }\end{array}$ & $\begin{array}{l}\text { Turbidez } \\
\text { (uT) }\end{array}$ \\
\hline 1 & & 30,0 & 90 & 6,64 & 19 & 1,35 \\
\hline 2 & & 36,0 & 90 & 7,22 & 150 & 4,39 \\
\hline 3 & & 10 & 80 & 5,3 & 80 & 3,12 \\
\hline 4 & & 30 & 110 & 6,1 & 8 & 0,59 \\
\hline 5 & 3,0 & & 80 & 4,70 & 13 & 5,97 \\
\hline 6 & 6,0 & & 80 & 4,59 & 18 & 5,34 \\
\hline
\end{tabular}

\begin{tabular}{|c|c|c|c|c|c|c|}
\hline \multicolumn{7}{|c|}{ Ensaio 4} \\
\hline \multicolumn{7}{|c|}{ Água de estudo 2: $\quad$ Cor Aparente $(u H)=127 \quad$ Turbidez $(u T)=5,3$} \\
\hline \multicolumn{2}{|c|}{$\mathrm{pH}=6,03$} & \multicolumn{2}{|c|}{ Temperatura $\left({ }^{\circ} \mathrm{C}\right)=20$} & \multicolumn{3}{|c|}{ Alcalinidade Total $\left(\mathrm{mg} \mathrm{L}^{-1} \mathrm{CaCO}_{3}\right)=7,0$} \\
\hline \multirow[b]{2}{*}{ Frasco } & \multicolumn{3}{|c|}{ Dosagem de produtos químicos } & \multirow[b]{2}{*}{$\begin{array}{c}\text { pH de } \\
\text { Coagulação }\end{array}$} & \multicolumn{2}{|c|}{$\begin{array}{c}\text { Água Filtrada } \\
\text { (coleta } 30 \text { min) }\end{array}$} \\
\hline & $\begin{array}{c}\mathrm{HCl} \\
\left(1 \mathrm{~g} \mathrm{~L}^{-1}\right) \\
(\mathrm{mL})\end{array}$ & $\begin{array}{c}\mathrm{NaOH} \\
\left(1 \mathrm{~g} \mathrm{~L}^{-1}\right) \\
(\mathrm{mL})\end{array}$ & $\begin{array}{l}\text { Sulfato de } \\
\text { Alumínio } \\
\text { comercial } \\
\text { líquido } \\
\left(\mathrm{mg} \mathrm{L}^{-1}\right)\end{array}$ & & $\begin{array}{c}\text { Cor Aparente } \\
\text { (uH) }\end{array}$ & $\begin{array}{c}\text { Turbidez } \\
\text { (uT) }\end{array}$ \\
\hline 1 & & 6 & 80 & 4,90 & 49 & 1,7 \\
\hline 2 & & 12 & 80 & 5,00 & 112 & 5,16 \\
\hline 3 & & 18 & 80 & 5,57 & 12 & 0.21 \\
\hline 4 & & 24 & 80 & 6,46 & 18 & 0,39 \\
\hline 5 & 10 & & 80 & 4,44 & 18 & 0,3 \\
\hline 6 & 15 & & 80 & 4,31 & 23 & 0,4 \\
\hline
\end{tabular}




\begin{tabular}{|c|c|c|c|c|c|c|}
\hline \multicolumn{7}{|c|}{$\begin{array}{r}\text { Ensaio } 5 \\
\end{array}$} \\
\hline \multicolumn{7}{|c|}{ Água de estudo 2: Cor Aparente $(\mathrm{uH})=128$} \\
\hline \multicolumn{2}{|c|}{$\mathrm{pH}=6,01$} & \multicolumn{2}{|c|}{ Temperatura $\left({ }^{\circ} \mathrm{C}\right)=20$} & \multicolumn{3}{|c|}{ Alcalinidade Total $\left(\mathrm{mg} \mathrm{L}^{-1} \mathrm{CaCO}_{3}\right)=7,0$} \\
\hline \multirow[b]{2}{*}{ Frasco } & \multicolumn{3}{|c|}{ Dosagem de produtos químicos } & \multirow[b]{2}{*}{$\begin{array}{c}\text { pH de } \\
\text { Coagulação }\end{array}$} & \multicolumn{2}{|c|}{$\begin{array}{l}\text { Água Filtrada } \\
\text { (coleta } 30 \text { min) }\end{array}$} \\
\hline & $\begin{array}{c}\mathrm{HCl} \\
\left(1 \mathrm{~g} \mathrm{~L}^{-1}\right) \\
(\mathrm{mL})\end{array}$ & $\begin{array}{c}\mathrm{NaOH} \\
\left(1 \mathrm{~g} \mathrm{~L}^{-1}\right) \\
(\mathrm{mL})\end{array}$ & $\begin{array}{l}\text { Sulfato de } \\
\text { Alumínio } \\
\text { comercial } \\
\text { líquido } \\
\left(\mathrm{mg} \mathrm{L}^{-1}\right)\end{array}$ & & $\begin{array}{c}\text { Cor } \\
\text { Aparente } \\
\text { (uH) }\end{array}$ & $\begin{array}{l}\text { Turbidez } \\
\quad \text { (uT) }\end{array}$ \\
\hline 1 & & 12 & 100 & 4,87 & 138 & 6,62 \\
\hline 2 & & 18 & 100 & 5,04 & 127 & 5,58 \\
\hline 3 & & 24 & 100 & 5,46 & 17 & 0,27 \\
\hline 4 & & 27 & 100 & 5,9 & 17 & 0,28 \\
\hline 5 & & 33 & 100 & 6,7 & 52 & 2,78 \\
\hline 6 & & 27 & 90 & 6,48 & 16 & 0,3 \\
\hline
\end{tabular}

\begin{tabular}{|c|c|c|c|c|c|c|}
\hline \multicolumn{7}{|c|}{ Ensaio 6} \\
\hline \multicolumn{5}{|c|}{ Água de estudo 2: Cor Aparente $(\mathrm{uH})=126$} & \multicolumn{2}{|c|}{ Turbidez $(\mathrm{uT})=5,42$} \\
\hline \multicolumn{2}{|c|}{$\mathrm{pH}=6,00$} & \multicolumn{2}{|c|}{ Temperatura $\left({ }^{\circ} \mathrm{C}\right)=20$} & \multicolumn{3}{|c|}{ Alcalinidade Total $\left(\mathrm{mg} \mathrm{L}^{-1} \mathrm{CaCO}_{3}\right)=7,0$} \\
\hline \multirow[b]{2}{*}{ Frasco } & \multicolumn{3}{|c|}{ Dosagem de produtos químicos } & \multirow[b]{2}{*}{$\begin{array}{c}\text { pH de } \\
\text { Coagulação }\end{array}$} & \multicolumn{2}{|c|}{$\begin{array}{l}\text { Água Filtrada } \\
\text { (coleta } 30 \mathrm{~min} \text { ) }\end{array}$} \\
\hline & $\begin{array}{c}\mathrm{HCL} \\
\left(1 \mathrm{~g} \mathrm{~L}^{-1}\right) \\
(\mathrm{mL})\end{array}$ & $\begin{array}{c}\mathrm{NaOH} \\
\left(1 \mathrm{~g} \mathrm{~L}^{-1}\right) \\
(\mathrm{mL})\end{array}$ & $\begin{array}{l}\text { Sulfato de } \\
\text { Alumínio } \\
\text { comercial } \\
\text { líquido } \\
\left(\mathrm{mg} \mathrm{L}^{-1}\right)\end{array}$ & & $\begin{array}{l}\text { Cor Aparente } \\
\text { (uH) }\end{array}$ & $\begin{array}{c}\text { Turbidez } \\
\text { (uT) }\end{array}$ \\
\hline 1 & 5,0 & & 100 & 4,59 & 20 & 0,38 \\
\hline 2 & 10,0 & & 100 & 4,41 & 23 & 0,61 \\
\hline 3 & 15,0 & & 100 & 4,27 & 21 & 0,30 \\
\hline 4 & 0 & 0 & 110 & 4,62 & 18 & 0,30 \\
\hline 5 & & 15 & 110 & 4,85 & 117 & 5,23 \\
\hline
\end{tabular}




\begin{tabular}{|c|c|c|c|c|c|c|}
\hline \multicolumn{7}{|c|}{$\begin{array}{l}\text { Ensaio } 7 \\
\end{array}$} \\
\hline \multicolumn{7}{|c|}{ Água de estudo 2: $\quad$ Cor Aparente $(\mathrm{uH})=125 \quad$ Turbidez $(\mathrm{uT})=5,40$} \\
\hline \multicolumn{4}{|c|}{$\mathrm{pH}=6,02 \quad$ Temperatura $\left({ }^{\circ} \mathrm{C}\right)=20$} & \multirow{2}{*}{\multicolumn{3}{|c|}{$\begin{array}{r}\text { Alcalinidade Total }\left(\mathrm{mg} \mathrm{L}^{-1} \mathrm{CaCO}_{3}\right)=7,0 \\
\begin{array}{c}\text { Água Filtrada } \\
\text { (coleta } 30 \text { min) }\end{array}\end{array}$}} \\
\hline \multirow[b]{2}{*}{ Frasco } & \multicolumn{3}{|c|}{ Dosagem de produtos químicos } & & & \\
\hline & $\begin{array}{c}\mathrm{HCl} \\
\left(1 \mathrm{~g} \mathrm{~L}^{-1}\right)\end{array}$ & $\begin{array}{l}\mathrm{NaOH} \\
\left(1 \mathrm{~g} \mathrm{~L}^{-1}\right) \\
(\mathrm{mL})\end{array}$ & $\begin{array}{c}\text { Sulfato de } \\
\text { Alumínio } \\
\text { comercial } \\
\text { líquido } \\
\left(\mathrm{mg} \mathrm{L}^{-1}\right)\end{array}$ & $\begin{array}{c}\text { pH de } \\
\text { Coagulação }\end{array}$ & $\begin{array}{c}\text { Cor Aparente } \\
\text { (uH) }\end{array}$ & $\begin{array}{c}\text { Turbidez } \\
\text { (uT) }\end{array}$ \\
\hline 1 & & 15 & 120 & 4,84 & 113 & 4,2 \\
\hline 2 & & 25 & 120 & 5,06 & 102 & 3,0 \\
\hline 3 & & 35 & 120 & 6,08 & 1 & 0,30 \\
\hline 4 & & 45 & 120 & 7,15 & 132 & 5,4 \\
\hline 5 & & 25 & 130 & 4,96 & 105 & 3,4 \\
\hline 6 & & 35 & 130 & 5,53 & 1 & 0,28 \\
\hline
\end{tabular}

\begin{tabular}{|c|c|c|c|c|c|c|}
\hline \multicolumn{7}{|c|}{ Ensaio 8 } \\
\hline \multicolumn{7}{|c|}{ Água de estudo 2: Cor Aparente $(\mathrm{uH})=125$} \\
\hline \multirow{2}{*}{ Frasco }
\end{tabular}




\begin{tabular}{|c|c|c|c|c|c|c|}
\hline \multicolumn{7}{|c|}{ Ensaio 9} \\
\hline \multicolumn{4}{|c|}{ Água de estudo 2: $\quad$ Cor Aparente $(\mathrm{uH})=124$} & \multicolumn{3}{|c|}{ Turbidez $(\mathrm{uT})=5,30$} \\
\hline \multicolumn{2}{|c|}{$\mathrm{pH}=6,01$} & \multicolumn{2}{|c|}{ Temperatura $\left({ }^{\circ} \mathrm{C}\right)=20$} & \multicolumn{3}{|c|}{ Alcalinidade Total $\left(\mathrm{mg} \mathrm{L}^{-1} \mathrm{CaCO}_{3}\right)=7,0$} \\
\hline \multirow[b]{2}{*}{ Frasco } & \multicolumn{3}{|c|}{ Dosagem de produtos químicos } & \multirow[b]{2}{*}{$\begin{array}{c}\text { pH de } \\
\text { Coagulação }\end{array}$} & \multicolumn{2}{|c|}{$\begin{array}{l}\text { Água Filtrada } \\
\text { (coleta } 30 \mathrm{~min} \text { ) }\end{array}$} \\
\hline & $\begin{array}{c}\mathrm{HCl} \\
\left(1 \mathrm{~g} \mathrm{~L}^{-1}\right) \\
(\mathrm{mL})\end{array}$ & $\begin{array}{c}\mathrm{NaOH} \\
\left(1 \mathrm{~g} \mathrm{~L}^{-1}\right) \\
(\mathrm{mL})\end{array}$ & $\begin{array}{l}\text { Sulfato de } \\
\text { Alumínio } \\
\text { comercial } \\
\text { líquido } \\
\left(\mathrm{mg} \mathrm{L}^{-1}\right)\end{array}$ & & $\begin{array}{c}\text { Cor Aparente } \\
\text { (uH) }\end{array}$ & $\begin{array}{c}\text { Turbidez } \\
\text { (uT) }\end{array}$ \\
\hline 1 & & 15 & 60 & 5,66 & 3 & 0,29 \\
\hline 2 & & 20 & 60 & 6,46 & 102 & 3,23 \\
\hline 3 & & 25 & 60 & 7,00 & 128 & 3,74 \\
\hline 4 & 5 & & 60 & 4,35 & 11 & 0,59 \\
\hline 5 & 5 & & 70 & 4,30 & 6 & 0,38 \\
\hline 6 & & & 70 & 4,45 & 2 & 0,32 \\
\hline
\end{tabular}

\begin{tabular}{|c|c|c|c|c|c|c|}
\hline \multicolumn{7}{|c|}{$\begin{array}{ll}\text { Ensaio } 10 \\
\end{array}$} \\
\hline \multicolumn{4}{|c|}{ Água de estudo2: Cor Aparente $(\mathrm{uH})=125$} & \multicolumn{3}{|c|}{ Turbidez $(\mathrm{uT})=5,24$} \\
\hline \multicolumn{2}{|c|}{$\mathrm{pH}=6,00$} & \multicolumn{2}{|c|}{ Temperatura $\left({ }^{\circ} \mathrm{C}\right)=20$} & \multicolumn{3}{|c|}{ Alcalinidade Total $\left(\mathrm{mg} \mathrm{L}^{-1} \mathrm{CaCO}_{3}\right)=7,0$} \\
\hline \multirow[b]{2}{*}{ Frasco } & \multicolumn{3}{|c|}{ Dosagem de produtos químicos } & \multirow[b]{2}{*}{$\begin{array}{c}\text { pH de } \\
\text { Coagulação }\end{array}$} & \multicolumn{2}{|c|}{$\begin{array}{c}\text { Água Filtrada } \\
\text { (coleta } 30 \mathrm{~min} \text { ) }\end{array}$} \\
\hline & $\begin{array}{c}\mathrm{HCl} \\
\left(1 \mathrm{~g} \mathrm{~L}^{-1}\right)\end{array}$ & $\begin{array}{c}\mathrm{NaOH} \\
\left(1 \mathrm{~g} \mathrm{~L}^{-1}\right) \\
(\mathrm{mL})\end{array}$ & $\begin{array}{l}\text { Sulfato de } \\
\text { Alumínio } \\
\text { comercial } \\
\text { líquido } \\
\left(\mathrm{mg} \mathrm{L}^{-1}\right)\end{array}$ & & $\begin{array}{c}\text { Cor Aparente } \\
\text { (uH) }\end{array}$ & $\begin{array}{l}\text { Turbidez } \\
\text { (uT) }\end{array}$ \\
\hline 1 & & & 50 & 4,62 & 6 & 0,55 \\
\hline 2 & 10 & & 50 & 4,24 & 25 & 1,00 \\
\hline 3 & & 7,5 & 50 & 5,00 & 2 & 0,31 \\
\hline 4 & & 15 & 50 & 6,26 & 135 & 4,94 \\
\hline 5 & & 7,5 & 70 & 4,85 & 3 & 0,39 \\
\hline 6 & & 15 & 70 & 5,21 & 2 & 0,46 \\
\hline
\end{tabular}




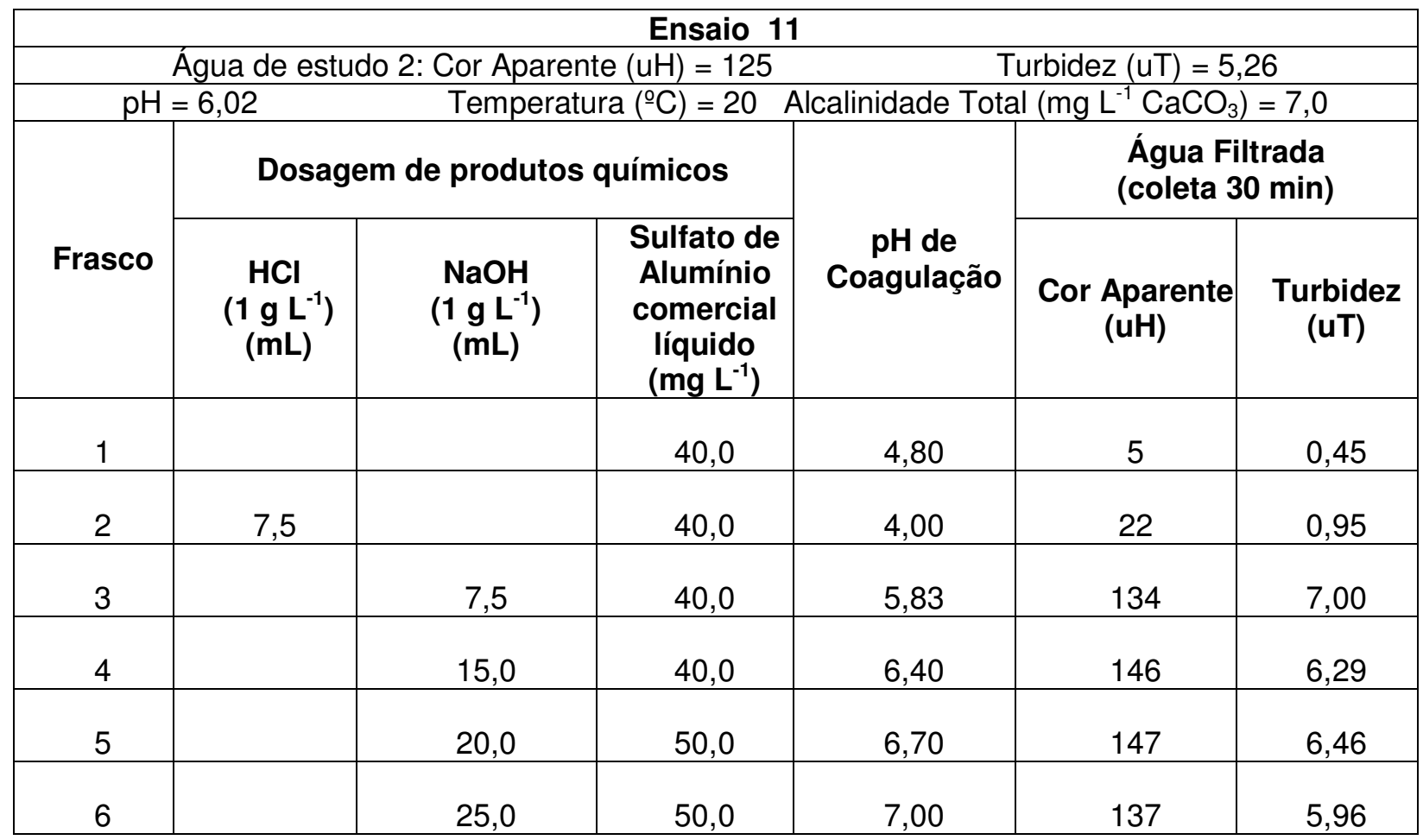

\begin{tabular}{|c|c|c|c|c|c|c|}
\hline \multicolumn{7}{|c|}{ Ensaio 12} \\
\hline \multicolumn{4}{|c|}{ Água de estudo 2: Cor Aparente $(\mathrm{uH})=126$} & \multicolumn{3}{|c|}{ Turbidez $(\mathrm{uT})=5,00$} \\
\hline \multicolumn{2}{|c|}{$\mathrm{pH}=6,00$} & \multicolumn{2}{|c|}{ Temperatura $\left({ }^{\circ} \mathrm{C}\right)=20$} & \multicolumn{3}{|c|}{ Icalinidade Total $\left(\mathrm{mg} \mathrm{L}^{-1} \mathrm{CaCO}_{3}\right)=7,0$} \\
\hline \multirow[b]{2}{*}{ Frasco } & \multicolumn{3}{|c|}{ Dosagem de produtos químicos } & \multirow[b]{2}{*}{$\begin{array}{c}\text { pH de } \\
\text { Coagulação }\end{array}$} & \multicolumn{2}{|c|}{$\begin{array}{c}\text { Água Filtrada } \\
\text { (coleta } 30 \mathrm{~min} \text { ) }\end{array}$} \\
\hline & $\begin{array}{c}\mathrm{HCl} \\
\left(\underset{(\mathrm{mL})}{\left(\mathrm{g} \mathrm{L}^{-1}\right)}\right.\end{array}$ & $\begin{array}{c}\mathrm{NaOH} \\
\left(1 \mathrm{~g} \mathrm{~L}^{-1}\right) \\
(\mathrm{mL})\end{array}$ & $\begin{array}{l}\text { Sulfato de } \\
\text { Alumínio } \\
\text { comercial } \\
\text { líquido } \\
\left(\mathrm{mg} \mathrm{L}^{-1}\right)\end{array}$ & & $\begin{array}{c}\text { Cor Aparente } \\
\text { (uH) }\end{array}$ & $\begin{array}{l}\text { Turbidez } \\
\quad \text { (uT) }\end{array}$ \\
\hline 1 & & & 60,0 & 4,50 & 5 & 0,56 \\
\hline 2 & & 10,0 & 60,0 & 5,16 & 2 & 0,46 \\
\hline 3 & & 17,5 & 60,0 & 6,00 & 2 & 0,57 \\
\hline 4 & & 17,5 & 70,0 & 5,60 & $<1$ & 0,42 \\
\hline 5 & & 5,0 & 70,0 & 4,73 & 2 & 0,57 \\
\hline 6 & & 15,0 & 70,0 & 5,30 & 3 & 0,56 \\
\hline
\end{tabular}




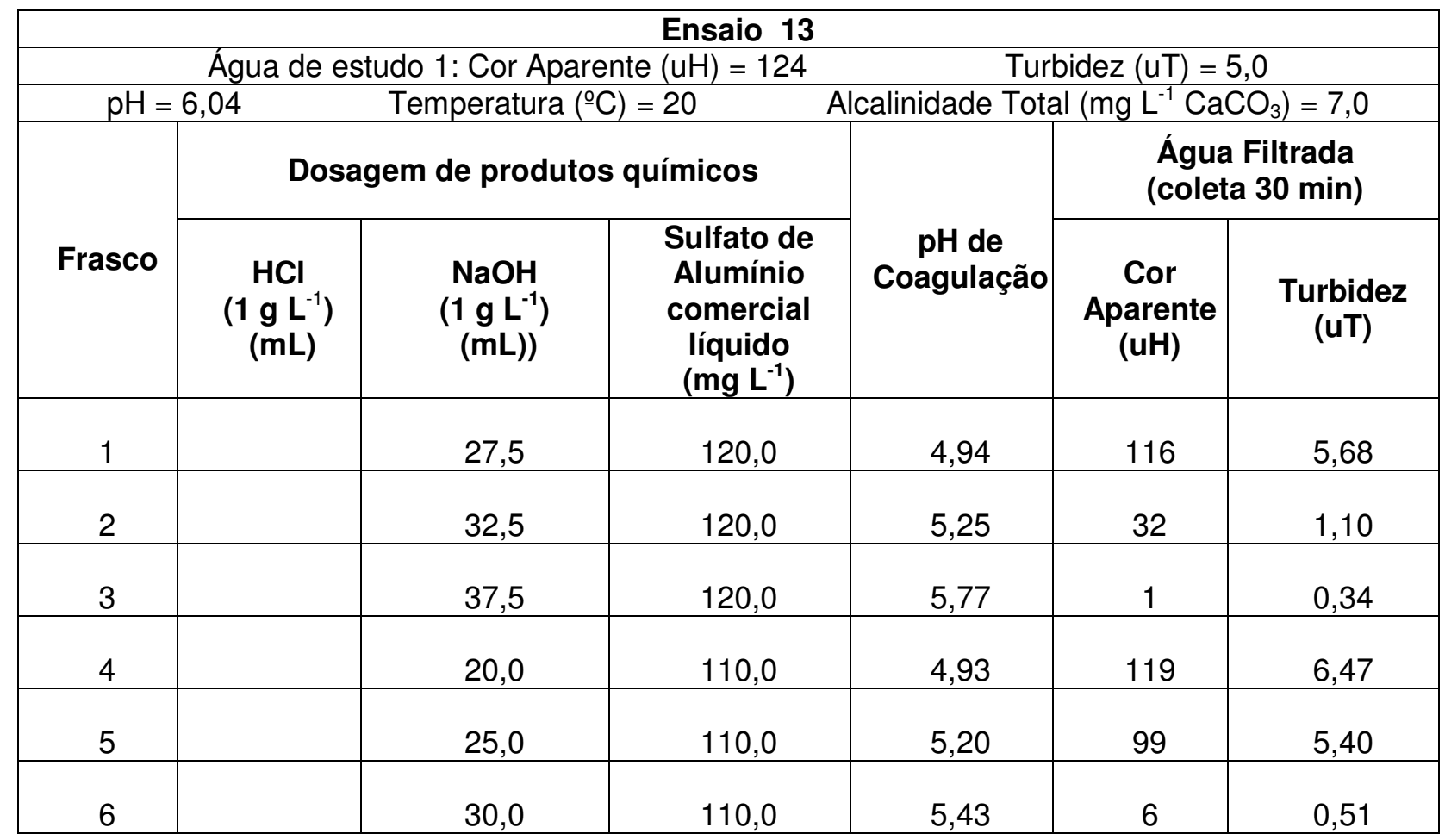

\begin{tabular}{|c|c|c|c|c|c|c|}
\hline \multicolumn{7}{|c|}{ Ensaio 14} \\
\hline \multicolumn{4}{|c|}{ Água de estudo 2: Cor Aparente $(\mathrm{uH})=124$} & \multicolumn{3}{|c|}{ Turbidez $($ uT $)=5,0$} \\
\hline \multicolumn{2}{|c|}{$\mathrm{pH} 6,05$} & \multicolumn{2}{|c|}{ Temperatura $\left({ }^{\circ} \mathrm{C}\right)=20$} & alinidade Tota & $\mathrm{mg} \mathrm{L}^{-1} \mathrm{CaC}$ & $=7,0$ \\
\hline \multirow[b]{2}{*}{ Frasco } & \multicolumn{3}{|c|}{ Dosagem de produtos químicos } & \multirow[b]{2}{*}{$\begin{array}{c}\text { pH de } \\
\text { Coagulação }\end{array}$} & \multicolumn{2}{|c|}{$\begin{array}{l}\text { Água Filtrada } \\
\text { (coleta } 30 \mathrm{~min} \text { ) }\end{array}$} \\
\hline & $\begin{array}{c}\mathrm{HCl} \\
\left(1 \mathrm{~g} \mathrm{~L}^{-1}\right) \\
(\mathrm{mL})\end{array}$ & $\begin{array}{c}\mathrm{NaOH} \\
\left(1 \mathrm{~g} \mathrm{~L}^{-1}\right) \\
(\mathrm{mL})\end{array}$ & $\begin{array}{c}\text { Sulfato de } \\
\text { Alumínio } \\
\text { comercial } \\
\text { líquido } \\
\left(\mathrm{mg} \mathrm{L}^{-1}\right)\end{array}$ & & $\begin{array}{c}\text { Cor } \\
\text { Aparente } \\
\text { (uH) }\end{array}$ & $\begin{array}{c}\text { Turbidez } \\
\text { (uT) }\end{array}$ \\
\hline 1 & & 30 & 130,0 & 6,36 & 2 & 0,41 \\
\hline 2 & & 40 & 130,0 & 7,10 & 145 & 6,42 \\
\hline 3 & & 45 & 130,0 & 6,25 & 1 & 0,36 \\
\hline 4 & & 30 & 140,0 & 4,97 & 112 & 4,86 \\
\hline 5 & & 35 & 140,0 & 5,20 & 25 & 0,79 \\
\hline 6 & & 40 & 140,0 & 5,54 & 2 & 0,36 \\
\hline
\end{tabular}




\begin{tabular}{|c|c|c|c|c|c|c|}
\hline \multicolumn{7}{|c|}{ Ensaio 15} \\
\hline \multicolumn{4}{|c|}{ Água de estudo 2: Cor Aparente $(\mathrm{uH})=124$} & \multicolumn{3}{|c|}{ Turbidez $(\mathrm{uT})=4,90$} \\
\hline \multicolumn{2}{|c|}{$\mathrm{pH}=6,05$} & \multicolumn{2}{|c|}{ Temperatura $\left({ }^{\circ} \mathrm{C}\right)=20$} & \multicolumn{3}{|c|}{ Alcalinidade Total $\left(\mathrm{mg} \mathrm{L}^{-1} \mathrm{CaCO}_{3}\right)=7,0$} \\
\hline \multirow[b]{2}{*}{ Frasco } & \multicolumn{3}{|c|}{ Dosagem de produtos químicos } & \multirow[b]{2}{*}{$\begin{array}{c}\text { pH de } \\
\text { Coagulação }\end{array}$} & \multicolumn{2}{|c|}{$\begin{array}{l}\text { Água Filtrada } \\
\text { (coleta } 30 \text { min) }\end{array}$} \\
\hline & $\begin{array}{c}\mathrm{HCl} \\
\left(\operatorname{(mL}_{(\mathrm{mL})}^{-1}\right)\end{array}$ & $\begin{array}{c}\mathrm{NaOH} \\
\left(1 \mathrm{~g} \mathrm{~L}^{-1}\right) \\
(\mathrm{mL})\end{array}$ & $\begin{array}{l}\text { Sulfato de } \\
\text { Alumínio } \\
\text { comercial } \\
\text { líquido } \\
\left(\mathrm{mg} \mathrm{L}^{-1}\right)\end{array}$ & & $\begin{array}{c}\text { Cor } \\
\text { Aparente } \\
\text { (uH) }\end{array}$ & $\begin{array}{c}\text { Turbidez } \\
\text { (uT) }\end{array}$ \\
\hline 1 & & 50 & 140 & 6,50 & 3 & 0,28 \\
\hline 2 & & 50 & 130 & 6,70 & 143 & 5,80 \\
\hline 3 & & 45 & 120 & 6,57 & 52 & 1,48 \\
\hline 4 & & 40 & 110 & 6,50 & 6 & 0,43 \\
\hline 5 & & 45 & 110 & 7,00 & 133 & 5,16 \\
\hline 6 & & 32,5 & 100 & 6,45 & 35 & 1,18 \\
\hline
\end{tabular}

\begin{tabular}{|c|c|c|c|c|c|c|}
\hline \multicolumn{7}{|c|}{$\begin{array}{ll}\text { Ensaio } 16 \\
\end{array}$} \\
\hline \multicolumn{4}{|c|}{ Água de estudo 2: Cor Aparente $(\mathrm{uH})=117$} & \\
\hline \multicolumn{2}{|c|}{$\mathrm{pH}=6,1$} & \multicolumn{2}{|c|}{ Temperatura $\left({ }^{\circ} \mathrm{C}\right)=20$} & \multicolumn{3}{|c|}{ Alcalinidade Total $\left(\mathrm{mg} \mathrm{L}^{-1} \mathrm{CaCO}_{3}\right)=7,0$} \\
\hline \multirow[b]{2}{*}{ Frasco } & \multicolumn{3}{|c|}{ Dosagem de produtos Químicos } & \multirow[b]{2}{*}{$\begin{array}{c}\text { pH de } \\
\text { Coagulação }\end{array}$} & \multicolumn{2}{|c|}{$\begin{array}{l}\text { Água Filtrada } \\
\text { (coleta } 30 \text { min) }\end{array}$} \\
\hline & $\begin{array}{c}\mathrm{HCl} \\
\left(1 \mathrm{~g} \mathrm{~L}^{-1}\right) \\
(\mathrm{mL})\end{array}$ & $\begin{array}{c}\mathrm{NaOH} \\
\left(\mathrm{g} \mathrm{L} \mathrm{L}^{-1}\right)\end{array}$ & $\begin{array}{l}\text { Sulfato de } \\
\text { Alumínio } \\
\text { comercial } \\
\text { líquido } \\
\left(\mathrm{mg} \mathrm{L}^{-1}\right)\end{array}$ & & $\begin{array}{c}\text { Cor } \\
\text { Aparente } \\
\text { (uH) }\end{array}$ & $\begin{array}{l}\text { Turbidez } \\
\text { (uT) }\end{array}$ \\
\hline 1 & & 5 & 50 & 4,80 & 4 & 0,60 \\
\hline 2 & & 10,0 & 50 & 5,20 & 5 & 0,51 \\
\hline 3 & & 15,0 & 50 & 5,50 & 48 & 1,72 \\
\hline 4 & & 5,0 & 40 & 5,12 & 10 & 4,94 \\
\hline 5 & & 20,0 & 70 & 5,78 & 0 & 0,33 \\
\hline 6 & & 25,0 & 70 & 6,5 & 45 & 1,53 \\
\hline
\end{tabular}




\begin{tabular}{|c|c|c|c|c|c|c|}
\hline \multicolumn{7}{|c|}{$\begin{array}{ll}\text { Ensaio } 17 \\
\end{array}$} \\
\hline & \multicolumn{3}{|c|}{ Água de Estudo 2: Cor Aparente $(\mathrm{uH})=120$} & \multicolumn{3}{|c|}{ Turbidez $(\mathrm{uT})=4,85$} \\
\hline \multicolumn{2}{|c|}{$\mathrm{pH}=6,1$} & \multicolumn{2}{|c|}{ Temperatura $\left({ }^{\circ} \mathrm{C}\right)=21$} & \multicolumn{3}{|c|}{ Alcalinidade Total $\left(\mathrm{mg} \mathrm{L}^{-1} \mathrm{CaCO}_{3}\right)=7,0$} \\
\hline \multirow[b]{2}{*}{ Frasco } & \multicolumn{3}{|c|}{ Dosagem de produtos químicos } & \multirow[b]{2}{*}{$\begin{array}{c}\text { pH de } \\
\text { Coagulação }\end{array}$} & \multicolumn{2}{|c|}{$\begin{array}{c}\text { Água Filtrada } \\
\text { (coleta } 30 \text { min) }\end{array}$} \\
\hline & $\begin{array}{c}\mathrm{HCl} \\
\left(1 \mathrm{~g} \mathrm{~L}^{-1}\right) \\
(\mathrm{mL})\end{array}$ & $\begin{array}{c}\mathrm{NaOH} \\
\left(1 \mathrm{~g} \mathrm{~L}^{-1}\right) \\
(\mathrm{mL})\end{array}$ & $\begin{array}{l}\text { Sulfato de } \\
\text { Alumínio } \\
\text { comercial } \\
\text { líquido } \\
\left(\mathrm{mg} \mathrm{L}^{-1}\right)\end{array}$ & & $\begin{array}{c}\text { Cor } \\
\text { Aparente } \\
\text { (uH) }\end{array}$ & $\begin{array}{l}\text { Turbidez } \\
\text { (uT) }\end{array}$ \\
\hline 1 & & 20 & 90 & 5,00 & 87 & 3,82 \\
\hline 2 & & 25 & 90 & 5,60 & 3 & 0,40 \\
\hline 3 & & 25 & 80 & 6,00 & 20 & 0,87 \\
\hline
\end{tabular}


A.3 Tabelas referentes aos ensaios de coagulação da água de estudo 3, empregando-se sulfato de alumínio como coagulante.

\begin{tabular}{|c|c|c|c|c|c|c|}
\hline \multicolumn{7}{|c|}{ Ensaio 1} \\
\hline \multicolumn{4}{|c|}{ Água de estudo 3: Cor Aparente $(\mathrm{uH})=134$} & erdadeira (uH & $=103$ Turbidez & $\Lambda T)=4,00$ \\
\hline \multicolumn{2}{|c|}{$\mathrm{pH}=6,05$} & \multicolumn{2}{|c|}{ Temperatura $\left({ }^{\circ} \mathrm{C}\right)=20$} & \multicolumn{3}{|c|}{ Alcalinidade Total $\left(\mathrm{mg} \mathrm{L}^{-1} \mathrm{CaCO}_{3}\right)=10,0$} \\
\hline \multirow[b]{2}{*}{ Frasco } & \multicolumn{3}{|c|}{ Dosagem de produtos químicos } & \multirow[b]{2}{*}{$\begin{array}{c}\text { pH de } \\
\text { Coagulação }\end{array}$} & \multicolumn{2}{|c|}{$\begin{array}{l}\text { Água Filtrada } \\
\text { (coleta } 30 \mathrm{~min} \text { ) }\end{array}$} \\
\hline & $\begin{array}{c}\mathrm{HCl} \\
\left(\underset{(\mathrm{mL})}{\left.\mathrm{g} \mathrm{L}^{-1}\right)}\right)\end{array}$ & $\begin{array}{c}\mathrm{NaOH} \\
\left(1 \mathrm{~g} \mathrm{~L}^{-1}\right) \\
(\mathrm{mL})\end{array}$ & $\begin{array}{c}\text { Sulfato de } \\
\text { Alumínio } \\
\text { comercial } \\
\text { líquido } \\
\left(\mathrm{mg} \mathrm{L}^{-1}\right)\end{array}$ & & $\begin{array}{c}\text { Cor Aparente } \\
\text { (uH) }\end{array}$ & $\begin{array}{c}\text { Turbidez } \\
\text { (uT) }\end{array}$ \\
\hline 1 & - & & $\begin{array}{c}60 \\
(12 \mathrm{~mL})\end{array}$ & 5,20 & 20 & 1,15 \\
\hline 2 & 5,0 & & 60 & 4,96 & 3 & 0,48 \\
\hline 3 & 7,5 & & 60 & 4,84 & 4 & 0,44 \\
\hline 4 & 10,0 & & 60 & 4,80 & 3 & 0,53 \\
\hline 5 & & 2,5 & 60 & 5,92 & 143 & 143 \\
\hline 6 & & 5,0 & 60 & 6,33 & 167 & 6,83 \\
\hline
\end{tabular}

\begin{tabular}{|c|c|c|c|c|c|c|}
\hline \multicolumn{7}{|c|}{$\begin{array}{r}\text { Ensaio } 2 \\
\end{array}$} \\
\hline \multirow{2}{*}{\multicolumn{4}{|c|}{ Água de estudo 3: $\quad$ Cor Aparente $(\mathrm{uH})=132$}} & \multicolumn{3}{|c|}{$2 \quad$ Turbidez $(\mathrm{uT})=4,00$} \\
\hline & & & Temperatura $\left({ }^{\circ} \mathrm{C}\right)=20$ & \multicolumn{3}{|c|}{ Alcalinidade Total $\left(\mathrm{mg} \mathrm{L}^{-1} \mathrm{CaCO}_{3}\right)=10,0$} \\
\hline \multirow[b]{2}{*}{ Frasco } & \multicolumn{3}{|c|}{ Dosagem de produtos químicos } & \multirow[b]{2}{*}{$\begin{array}{c}\text { pH de } \\
\text { Coagulação }\end{array}$} & \multirow[b]{2}{*}{$\begin{array}{c}\text { Cor } \\
\text { Aparente } \\
\text { (uH) }\end{array}$} & \multirow[b]{2}{*}{$\begin{array}{c}\text { Turbidez } \\
\text { (uT) }\end{array}$} \\
\hline & $\begin{array}{c}\mathrm{HCl} \\
\left(\operatorname{(mL}^{-1} \mathrm{~g} \mathrm{~L}^{-1}\right)\end{array}$ & $\begin{array}{c}\mathrm{NaOH} \\
\left(1 \mathrm{~g} \mathrm{~L}^{-1}\right) \\
(\mathrm{mL})\end{array}$ & $\begin{array}{l}\text { Sulfato de } \\
\text { Alumínio } \\
\text { comercial } \\
\text { líquido } \\
\left(\mathrm{mg} \mathrm{L}^{-1}\right)\end{array}$ & & & \\
\hline 1 & 15,0 & & 60 & 4,42 & 12 & 0,61 \\
\hline 2 & 20,0 & & 60 & 4,20 & 45 & 1,78 \\
\hline 3 & 25,0 & & 60 & 3,98 & 44 & 2,20 \\
\hline 4 & & 7,5 & 60 & 6,55 & 161 & 6,40 \\
\hline 5 & & 10 & 60 & 7,00 & 154 & 4,62 \\
\hline 6 & & 12,5 & 60 & 7,54 & 144 & 4,00 \\
\hline
\end{tabular}




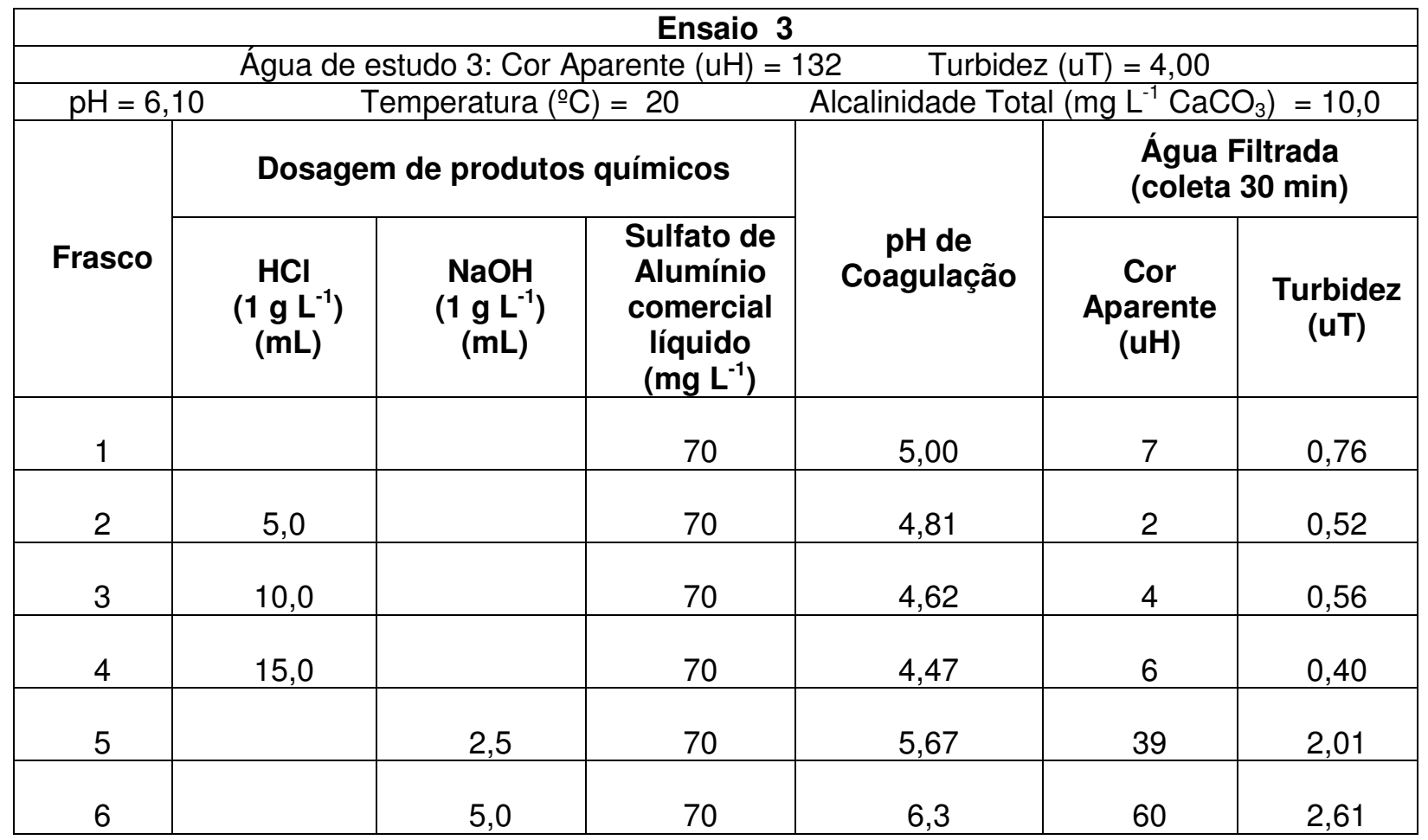

\begin{tabular}{|c|c|c|c|c|c|c|}
\hline \multicolumn{7}{|c|}{$\begin{array}{ll}\text { Ensaio } 4 \\
\end{array}$} \\
\hline \multicolumn{7}{|c|}{ Água de estudo 3: $\quad$ Cor Aparente $(\mathrm{uH})=133$} \\
\hline \multicolumn{2}{|c|}{$\mathrm{pH}=6,03$} & \multicolumn{2}{|c|}{ Temperatura $\left({ }^{\circ} \mathrm{C}\right)=21$} & \multicolumn{3}{|c|}{ Alcalinidade Total $\left(\mathrm{mg} \mathrm{L}^{-1} \mathrm{CaCO}_{3}\right)=10,0$} \\
\hline \multirow[b]{2}{*}{ Frasco } & \multicolumn{3}{|c|}{ Dosagem de produtos químicos } & \multirow[b]{2}{*}{$\begin{array}{c}\text { pH de } \\
\text { Coagulação }\end{array}$} & \multicolumn{2}{|c|}{$\begin{array}{l}\text { Água Filtrada } \\
\text { (coleta } 30 \mathrm{~min} \text { ) }\end{array}$} \\
\hline & $\begin{array}{c}\mathrm{HCl} \\
\left(1 \mathrm{~g} \mathrm{~L}^{-1}\right) \\
(\mathrm{mL})\end{array}$ & $\begin{array}{c}\mathrm{NaOH} \\
\left(1 \mathrm{~g} \mathrm{~L}^{-1}\right) \\
(\mathrm{mL})\end{array}$ & $\begin{array}{l}\text { Sulfato de } \\
\text { Alumínio } \\
\text { comercial } \\
\text { líquido } \\
\left(\mathrm{mg} \mathrm{L}^{-1}\right)\end{array}$ & & $\begin{array}{c}\text { Cor Aparente } \\
\text { (uH) }\end{array}$ & $\begin{array}{c}\text { Turbidez } \\
\text { (uT) }\end{array}$ \\
\hline 1 & & 7,5 & 70 & 6,71 & 187 & 7,97 \\
\hline 2 & & 10 & 70 & 6,95 & 167 & 5,83 \\
\hline 3 & & 12,5 & 70 & 7,36 & 155 & 4,33 \\
\hline 4 & & 15,0 & 70 & 7,82 & 148 & 3,84 \\
\hline 5 & & 17,5 & 70 & 8,42 & 150 & 3,87 \\
\hline 6 & & 20 & 70 & 9,02 & 156 & 3,71 \\
\hline
\end{tabular}




\begin{tabular}{|c|c|c|c|c|c|c|}
\hline \multicolumn{7}{|c|}{$\begin{array}{l}\text { Ensaio } 5 \\
\end{array}$} \\
\hline \multicolumn{7}{|c|}{ Água de estudo 3: Cor Aparente $(\mathrm{uH})=133 \quad$ Turbidez $(\mathrm{uT})=4,20$} \\
\hline \multicolumn{2}{|c|}{$\mathrm{pH}=6,02$} & \multicolumn{2}{|c|}{ Temperatura $\left({ }^{\circ} \mathrm{C}\right)=20$} & \multicolumn{3}{|c|}{ Alcalinidade Total $\left(\mathrm{mg} \mathrm{L}^{-1} \mathrm{CaCO}_{3}\right)=10,0$} \\
\hline \multirow[b]{2}{*}{ Frasco } & \multicolumn{3}{|c|}{ Dosagem de produtos químicos } & \multirow[b]{2}{*}{$\begin{array}{c}\text { pH de } \\
\text { Coagulação }\end{array}$} & \multicolumn{2}{|c|}{$\begin{array}{c}\text { Água Filtrada } \\
\text { (coleta } 30 \mathrm{~min} \text { ) }\end{array}$} \\
\hline & $\begin{array}{c}\mathrm{HCl} \\
(\underbrace{\left.1 \mathrm{~g} \mathrm{~L}^{-1}\right)}_{(\mathrm{mL})}\end{array}$ & $\begin{array}{c}\mathrm{NaOH} \\
\left(1 \mathrm{~g} \mathrm{~L}^{-1}\right) \\
(\mathrm{mL})\end{array}$ & $\begin{array}{l}\text { Sulfato de } \\
\text { Alumínio } \\
\text { comercial } \\
\text { líquido } \\
\left(\mathrm{mg} \mathrm{L}^{-1}\right)\end{array}$ & & $\begin{array}{c}\text { Cor Aparente } \\
\text { (uH) }\end{array}$ & $\begin{array}{c}\text { Turbidez } \\
\text { (uT) }\end{array}$ \\
\hline 1 & 20 & & 70 & 4,19 & 40 & 1,35 \\
\hline 2 & 25 & & 70 & 4,00 & 60 & 1,99 \\
\hline 3 & & 1,00 & 70 & 4,95 & 6 & 0,54 \\
\hline 4 & & & 50 & 5,08 & 21 & 1,04 \\
\hline 5 & 2,5 & & 50 & 4,87 & 8 & 0,51 \\
\hline 6 & 5,00 & & 50 & 4,80 & 8 & 0,40 \\
\hline
\end{tabular}

\begin{tabular}{|c|c|c|c|c|c|c|}
\hline \multicolumn{7}{|c|}{ Ensaio 6} \\
\hline \multicolumn{7}{|c|}{ Água de estudo 3: Cor Aparente $(\mathrm{uH})=131 \quad$ Turbidez $(\mathrm{uT})=4,20$} \\
\hline \multicolumn{2}{|c|}{$\mathrm{pH}=6,10$} & \multicolumn{2}{|c|}{ Temperatura $\left({ }^{\circ} \mathrm{C}\right)=20$} & \multicolumn{3}{|c|}{ Alcalinidade Total $\left(\mathrm{mg} \mathrm{L}^{-1} \mathrm{CaCO}_{3}\right)=10,0$} \\
\hline \multirow[b]{2}{*}{ Frasco } & \multicolumn{3}{|c|}{ Dosagem de produtos químicos } & \multirow[b]{2}{*}{$\begin{array}{c}\text { pH de } \\
\text { Coagulação }\end{array}$} & \multicolumn{2}{|c|}{$\begin{array}{c}\text { Água Filtrada } \\
\text { (coleta } 30 \mathrm{~min} \text { ) }\end{array}$} \\
\hline & $\begin{array}{c}\mathrm{HCL} \\
\left(\underset{(\mathrm{mL})}{\left.\mathrm{g} \mathrm{L}^{-1}\right)}\right.\end{array}$ & $\begin{array}{c}\mathrm{NaOH} \\
\left(1 \mathrm{~g} \mathrm{~L}^{-1}\right) \\
(\mathrm{mL})\end{array}$ & $\begin{array}{l}\text { Sulfato de } \\
\text { Alumínio } \\
\text { comercial } \\
\text { líquido } \\
\left.\left(\mathrm{mg} \mathrm{L}^{-1}\right)\right) \\
\end{array}$ & & $\begin{array}{c}\text { Cor } \\
\text { Aparente } \\
\text { (uH) }\end{array}$ & $\begin{array}{l}\text { Turbidez } \\
\text { (uT) }\end{array}$ \\
\hline 1 & 10 & & 50 & 4,72 & 18 & 0,50 \\
\hline 2 & 15 & & 50 & 4,55 & 15 & 0,60 \\
\hline 3 & 20 & & 50 & 4,20 & 27 & 1,07 \\
\hline 4 & 25 & & 50 & 4,00 & 48 & 2,44 \\
\hline 5 & & 5,0 & 50 & 6,44 & 147 & 4,78 \\
\hline
\end{tabular}




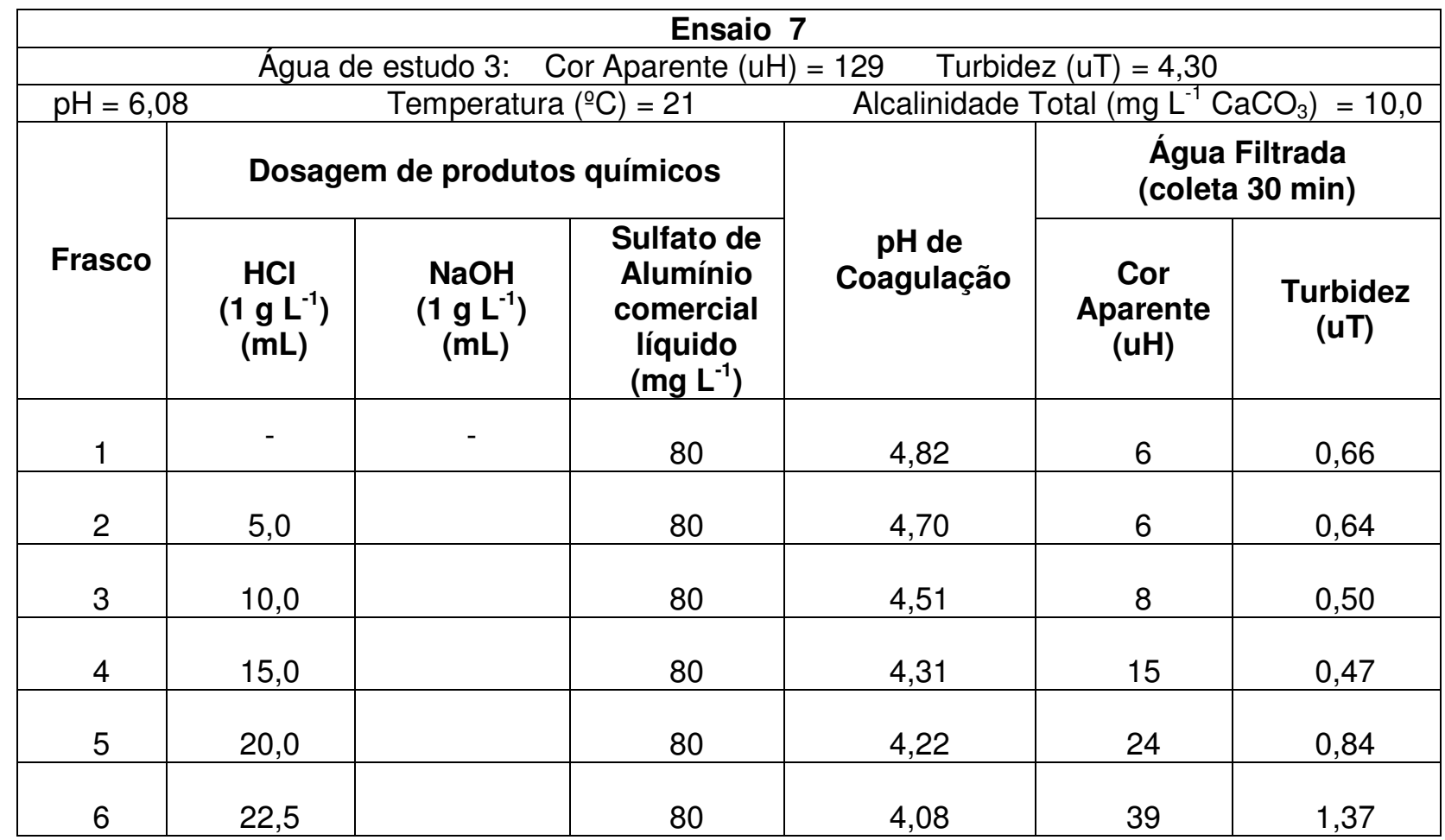

\begin{tabular}{|c|c|c|c|c|c|c|}
\hline \multicolumn{7}{|c|}{ Ensaio 8} \\
\hline \multicolumn{4}{|c|}{ Água de estudo 3: Cor Aparente $(\mathrm{uH})=130$} & \multicolumn{3}{|c|}{ Turbidez $(\mathrm{uT})=4,20$} \\
\hline $\mathrm{pH}=6,07$ & & peratura & $=20$ & Alcalinidade 1 & $\left(\mathrm{mg} \mathrm{L}^{-1} \mathrm{Ca}\right.$ & $\left.\mathrm{O}_{3}\right)=10,0$ \\
\hline \multirow[b]{2}{*}{ Frasco } & \multicolumn{3}{|c|}{ Dosagem de produtos químicos } & \multirow[b]{2}{*}{$\begin{array}{c}\text { pH de } \\
\text { Coagulação }\end{array}$} & \multicolumn{2}{|c|}{$\begin{array}{l}\text { Água Filtrada } \\
\text { (coleta } 30 \text { min) }\end{array}$} \\
\hline & $\begin{array}{c}\mathrm{HCl} \\
\left(1 \mathrm{~g} \mathrm{~L}^{-1}\right) \\
(\mathrm{mL})\end{array}$ & $\begin{array}{c}\mathrm{NaOH} \\
\left(1 \mathrm{~g} \mathrm{~L}^{-1}\right) \\
(\mathrm{mL})\end{array}$ & $\begin{array}{c}\text { Sulfato de } \\
\text { Alumínio } \\
\text { comercial } \\
\text { líquido } \\
\left(\mathrm{mg} \mathrm{L}^{-1}\right)\end{array}$ & & $\begin{array}{c}\text { Cor } \\
\text { Aparente } \\
\text { (uH) }\end{array}$ & $\begin{array}{c}\text { Turbidez } \\
\text { (uT) }\end{array}$ \\
\hline 1 & & 1,5 & 80 & 4,89 & 7 & 0,67 \\
\hline 2 & & 3,0 & 80 & 4,95 & 10 & 0,74 \\
\hline 3 & & 4,5 & 80 & 4,98 & 9 & 0,69 \\
\hline 4 & & 6,0 & 80 & 5,03 & 4 & 0,48 \\
\hline 5 & & 7,5 & 80 & 5,1 & 10 & 0,68 \\
\hline 6 & & 9,0 & 80 & 5,2 & 9 & 0,59 \\
\hline
\end{tabular}




\begin{tabular}{|c|c|c|c|c|c|c|}
\hline \multicolumn{7}{|c|}{ Ensaio 9} \\
\hline \multirow{2}{*}{\multicolumn{4}{|c|}{ 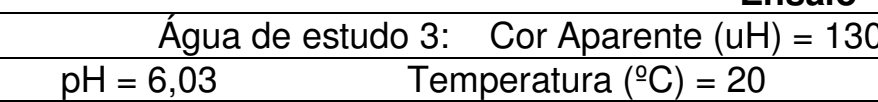 }} & \multicolumn{3}{|c|}{ Turbidez $(\mathrm{uT})=4,00$} \\
\hline & & & & \multicolumn{3}{|c|}{ Alcalinidade Total $\left(\mathrm{mg} \mathrm{L}^{-1} \mathrm{CaCO}_{3}\right)=10,0$} \\
\hline \multirow[b]{2}{*}{ Frasco } & \multicolumn{3}{|c|}{ Dosagem de produtos químicos } & \multirow[b]{2}{*}{$\begin{array}{c}\text { pH de } \\
\text { Coagulação }\end{array}$} & \multicolumn{2}{|c|}{$\begin{array}{l}\text { Água Filtrada } \\
\text { (coleta } 30 \mathrm{~min} \text { ) }\end{array}$} \\
\hline & $\begin{array}{c}\mathrm{HCl} \\
\left(1 \mathrm{~g} \mathrm{~L}^{-1}\right)\end{array}$ & $\begin{array}{c}\mathrm{NaOH} \\
\left(1 \mathrm{~g} \mathrm{~L}^{-1}\right) \\
(\mathrm{mL})\end{array}$ & $\begin{array}{l}\text { Sulfato de } \\
\text { Alumínio } \\
\text { comercial } \\
\text { líquido } \\
\left(\mathrm{mg} \mathrm{L}^{-1}\right)\end{array}$ & & $\begin{array}{c}\text { Cor } \\
\text { Aparente } \\
\text { (uH) }\end{array}$ & $\begin{array}{l}\text { Turbidez } \\
\text { (uT) }\end{array}$ \\
\hline 1 & & 1,5 & 60 & 5,25 & 9 & 0,86 \\
\hline 2 & & 3,5 & 60 & 5,47 & 31 & 1,66 \\
\hline 3 & & 6,5 & 60 & 5,70 & 97 & 4,23 \\
\hline 4 & & 8,5 & 60 & 5,85 & 141 & 6,00 \\
\hline 5 & & 11,0 & 60 & 5,98 & 187 & 8,50 \\
\hline 6 & & 12,0 & 60 & 6,1 & 175 & 7,91 \\
\hline
\end{tabular}

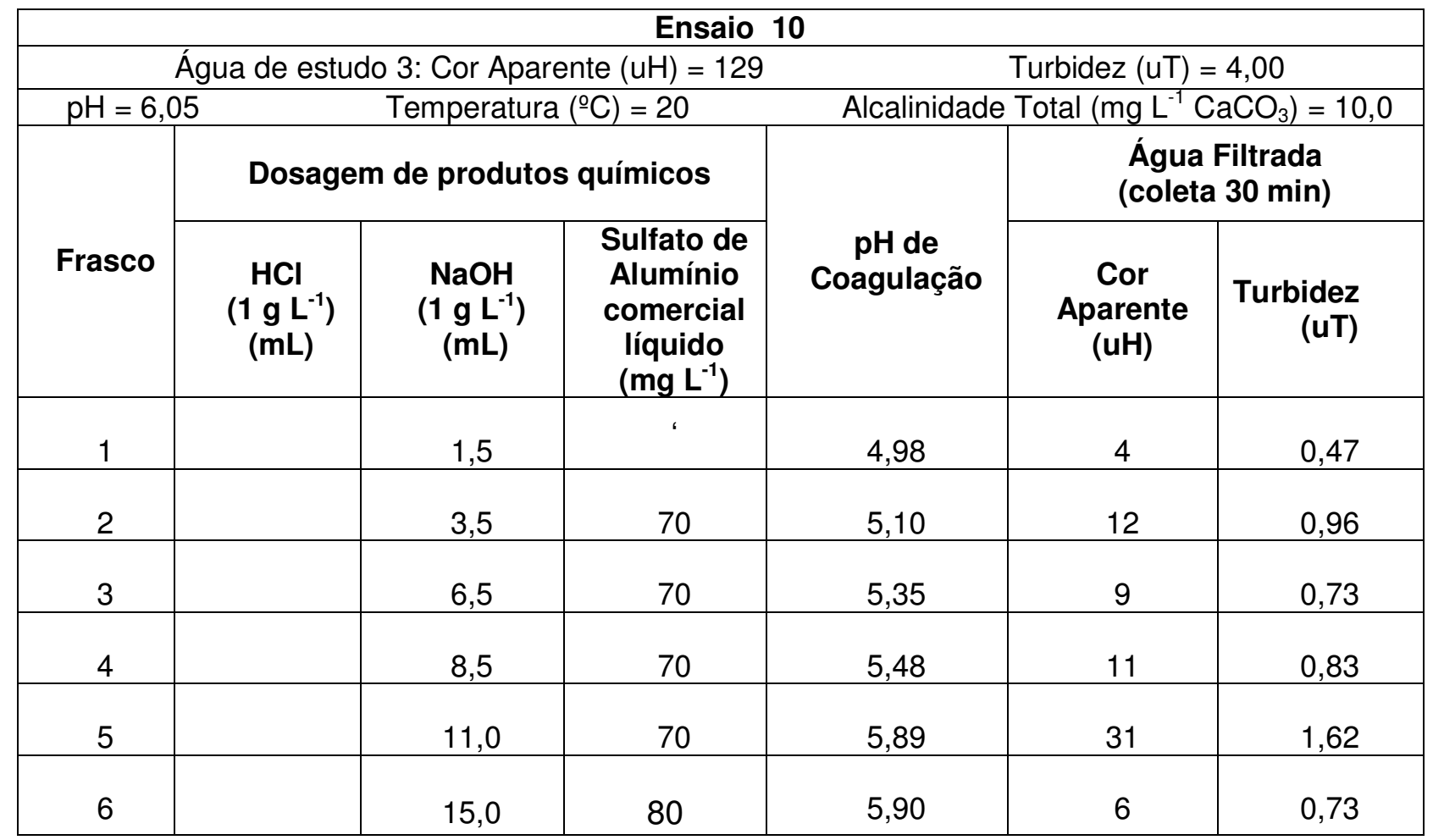




\begin{tabular}{|c|c|c|c|c|c|c|}
\hline \multicolumn{7}{|c|}{$\begin{array}{ll} & \text { Ensaio } 11 \\
\end{array}$} \\
\hline \multirow{2}{*}{\multicolumn{4}{|c|}{\begin{tabular}{cc}
\multicolumn{2}{c}{ Água de estudo 3: Cor Aparente $(\mathrm{uH})=129$} \\
$\mathrm{pH}=6,02$ & Temperatura $\left({ }^{\circ} \mathrm{C}\right)=20$
\end{tabular}}} & \multicolumn{3}{|c|}{ Turbidez $(\mathrm{uT})=4,10$} \\
\hline & & & & Alcalinidade 7 & $\mathrm{l}\left(\mathrm{mg} \mathrm{L}^{-1} \mathrm{Ca}\right.$ & $\left.D_{3}\right)=10,0$ \\
\hline \multirow[b]{2}{*}{ Frasco } & \multicolumn{3}{|c|}{ Dosagem de produtos químicos } & \multirow[b]{2}{*}{$\begin{array}{c}\text { pH de } \\
\text { Coagulação }\end{array}$} & \multicolumn{2}{|c|}{$\begin{array}{l}\text { Água Filtrada } \\
\text { (coleta } 30 \text { min) }\end{array}$} \\
\hline & $\begin{array}{c}\mathrm{HCl} \\
\left(1 \mathrm{~g} \mathrm{~L}^{-1}\right) \\
(\mathrm{mL})\end{array}$ & $\begin{array}{c}\mathrm{NaOH} \\
\left(1 \mathrm{~g} \mathrm{~L}^{-1}\right) \\
(\mathrm{mL})\end{array}$ & $\begin{array}{l}\text { Sulfato de } \\
\text { Alumínio } \\
\text { comercial } \\
\text { líquido } \\
\left(\mathrm{mg} \mathrm{L}^{-1}\right)\end{array}$ & & $\begin{array}{c}\text { Cor } \\
\text { Aparente } \\
\text { (uH) }\end{array}$ & $\begin{array}{l}\text { Turbidez } \\
\quad \text { (uT) }\end{array}$ \\
\hline 1 & & 1,5 & 50 & 5,11 & 7 & 0,55 \\
\hline 2 & & 3,0 & 50 & 5,24 & 15 & 1,09 \\
\hline 3 & & 6,5 & 50 & 5,67 & 168 & 8,08 \\
\hline 4 & & 8,5 & 50 & 5,83 & 181 & 7,05 \\
\hline 5 & & 17,0 & 80 & 5,76 & 11 & 0,93 \\
\hline 6 & & 19,0 & 80 & 6,00 & 76 & 4,28 \\
\hline
\end{tabular}

\begin{tabular}{|c|c|c|c|c|c|c|}
\hline \multicolumn{7}{|c|}{$\begin{array}{ll} & \text { Ensaio } 12\end{array}$} \\
\hline \multicolumn{4}{|c|}{ Água de estudo 3: Cor Aparente $(\mathrm{uH})=126$} & \multirow{2}{*}{\multicolumn{3}{|c|}{$\begin{array}{c}\text { Turbidez (uT) }=4,00 \\
\text { Alcalinidade Total }\left(\mathrm{mg} \mathrm{L}^{-1} \mathrm{CaCO}_{3}\right)=10,0\end{array}$}} \\
\hline \multicolumn{2}{|c|}{$\mathrm{pH}=6,00$} & \multicolumn{2}{|c|}{ Temperatura $\left({ }^{\circ} \mathrm{C}\right)=20$} & & & \\
\hline \multirow[b]{2}{*}{ Frasco } & \multicolumn{3}{|c|}{ Dosagem de produtos químicos } & \multirow[b]{2}{*}{$\begin{array}{c}\text { pH de } \\
\text { Coagulação }\end{array}$} & \multicolumn{2}{|c|}{$\begin{array}{l}\text { Água Filtrada } \\
\text { (coleta } 30 \text { min) }\end{array}$} \\
\hline & $\begin{array}{c}\mathrm{HCl} \\
\left(\mathrm{g}_{(\mathrm{mL})}^{-1}\right)\end{array}$ & $\begin{array}{c}\mathrm{NaOH} \\
\left(1 \mathrm{~g} \mathrm{~L}^{-1}\right) \\
(\mathrm{mL})\end{array}$ & $\begin{array}{l}\text { Sulfato de } \\
\text { Alumínio } \\
\text { comercial } \\
\text { líquido } \\
\left(\mathrm{mg} \mathrm{L}^{-1}\right)\end{array}$ & & $\begin{array}{c}\text { Cor } \\
\text { Aparente } \\
\text { (uH) }\end{array}$ & $\begin{array}{c}\text { Turbidez } \\
\text { (uT) }\end{array}$ \\
\hline 1 & & 10,0 & 80 & 5,66 & 23 & 0,59 \\
\hline 2 & & 12,5 & 80 & 5,79 & 17 & 1,12 \\
\hline 3 & & 15,0 & 80 & 5,96 & 27 & 1,34 \\
\hline 4 & & 17,5 & 80 & 6,05 & 42 & 1,92 \\
\hline 5 & & 20,0 & 80 & 6,20 & 56 & 2,33 \\
\hline 6 & & 22,5 & 80 & 6,38 & 65 & 2,47 \\
\hline
\end{tabular}




\begin{tabular}{|c|c|c|c|c|c|c|}
\hline \multicolumn{7}{|c|}{ Ensaio 13} \\
\hline \multicolumn{4}{|c|}{ Água de estudo 3: Cor Aparente $(\mathrm{uH})=125$} & \multicolumn{3}{|c|}{ Turbidez $(u T)=4,0$} \\
\hline \multicolumn{2}{|c|}{$\mathrm{pH}=6,04$} & \multicolumn{2}{|c|}{ Temperatura $\left({ }^{\circ} \mathrm{C}\right)=20$} & \multicolumn{3}{|c|}{ Alcalinidade Total $\left(\mathrm{mg} \mathrm{L}^{-1} \mathrm{CaCO}_{3}\right)=10,0$} \\
\hline \multirow[b]{2}{*}{ Frasco } & \multicolumn{3}{|c|}{ Dosagem de produtos químicos } & \multirow[b]{2}{*}{$\begin{array}{c}\text { pH de } \\
\text { Coagulação }\end{array}$} & \multicolumn{2}{|c|}{$\begin{array}{l}\text { Água Filtrada } \\
\text { (coleta } 30 \mathrm{~min} \text { ) }\end{array}$} \\
\hline & $\begin{array}{c}\mathrm{HCl} \\
\left(1 \mathrm{~g} \mathrm{~L}^{-1}\right) \\
(\mathrm{mL})\end{array}$ & $\begin{array}{c}\mathrm{NaOH} \\
\left(1 \mathrm{~g} \mathrm{~L}^{-1}\right) \\
(\mathrm{mL})\end{array}$ & $\begin{array}{l}\text { Sulfato de } \\
\text { Alumínio } \\
\text { comercial } \\
\text { líquido } \\
\left(\mathrm{mg} \mathrm{L}^{-1}\right)\end{array}$ & & $\begin{array}{c}\text { Cor } \\
\text { Aparente } \\
\text { (uH) }\end{array}$ & $\begin{array}{c}\text { Turbidez } \\
\text { (uT) }\end{array}$ \\
\hline 1 & & & 40,0 & 5,40 & 146 & 5,14 \\
\hline 2 & 2,5 & & 40,0 & 5,23 & 154 & 6,58 \\
\hline 3 & 7,5 & & 40,0 & 4,86 & 50 & 1,93 \\
\hline 4 & & 1,5 & 40,0 & 5,58 & 144 & 4,25 \\
\hline 5 & & 3,0 & 40,0 & 5,68 & 146 & 3,99 \\
\hline 6 & & 4,5 & 40,0 & 5,83 & 141 & 3,82 \\
\hline
\end{tabular}

\begin{tabular}{|c|c|c|c|c|c|c|}
\hline \multicolumn{7}{|c|}{ Ensaio 14} \\
\hline \multicolumn{4}{|c|}{ Água de estudo 3: Cor Aparente $(\mathrm{uH})=131$} & \multicolumn{3}{|c|}{ Turbidez $(\mathrm{uT})=4,10$} \\
\hline $\mathrm{pH} \mathrm{6,05}$ & & emperatu & C) $=20$ & Alcalinidade & al $\left(\mathrm{mg} \mathrm{L}^{-1} \mathrm{C}\right.$ & $\left.\mathrm{O}_{3}\right)=10,0$ \\
\hline \multirow[b]{2}{*}{ Frasco } & \multicolumn{3}{|c|}{ Dosagem de produtos químicos } & \multirow[b]{2}{*}{$\begin{array}{c}\text { pH de } \\
\text { Coagulação }\end{array}$} & \multicolumn{2}{|c|}{$\begin{array}{l}\text { Água Filtrada } \\
\text { (coleta } 30 \mathrm{~min} \text { ) }\end{array}$} \\
\hline & $\begin{array}{c}\mathrm{HCl} \\
\left(1 \mathrm{~g} \mathrm{~L}^{-1}\right) \\
(\mathrm{mL})\end{array}$ & $\begin{array}{c}\mathrm{NaOH} \\
\left(1 \mathrm{~g} \mathrm{~L}^{-1}\right) \\
(\mathrm{mL})\end{array}$ & $\begin{array}{l}\text { Sulfato de } \\
\text { Alumínio } \\
\text { comercial } \\
\text { líquido } \\
\left(\mathrm{mg} \mathrm{L}^{-1}\right)\end{array}$ & & $\begin{array}{c}\text { Cor } \\
\text { Aparente } \\
\text { (uH) }\end{array}$ & $\begin{array}{l}\text { Turbidez } \\
\text { (uT) }\end{array}$ \\
\hline 1 & & & 90 & 4,70 & 5 & 0,58 \\
\hline 2 & 2,5 & & 90 & 4,68 & 7 & 0,59 \\
\hline 3 & 5,0 & & 90 & 4,57 & 8 & 0,44 \\
\hline 4 & 10 & & 90 & 4,46 & 10 & 0,47 \\
\hline 5 & 15 & & 90 & 4,27 & 18 & 0,50 \\
\hline 6 & & 2,0 & 90 & 4,80 & 4 & 0,55 \\
\hline
\end{tabular}




\begin{tabular}{|c|c|c|c|c|c|c|}
\hline \multicolumn{7}{|c|}{$\begin{array}{ll}\text { Ensaio } 15 \\
\end{array}$} \\
\hline \multicolumn{4}{|c|}{ Água de estudo 3: Cor Aparente $(\mathrm{uH})=130$} & \multicolumn{3}{|c|}{ Turbidez $(\mathrm{uT})=4,10$} \\
\hline \multicolumn{2}{|c|}{$\mathrm{pH}=6,02$} & \multicolumn{2}{|c|}{ emperatura $\left({ }^{\circ} \mathrm{C}\right)=20$} & \multicolumn{3}{|c|}{ Alcalinidade Total $\left(\mathrm{mg} \mathrm{L}^{-1} \mathrm{CaCO}_{3}\right)=10,0$} \\
\hline \multirow[b]{2}{*}{ Frasco } & \multicolumn{3}{|c|}{ Dosagem de produtos químicos } & \multirow[b]{2}{*}{$\begin{array}{c}\text { pH de } \\
\text { Coagulação }\end{array}$} & \multicolumn{2}{|c|}{$\begin{array}{c}\text { Água Filtrada } \\
\text { (coleta } 30 \mathrm{~min} \text { ) }\end{array}$} \\
\hline & $\begin{array}{c}\mathrm{HCl} \\
\left(1 \mathrm{~g} \mathrm{~L}^{-1}\right) \\
(\mathrm{mL})\end{array}$ & $\begin{array}{c}\mathrm{NaOH} \\
\left(\mathrm{g}_{(\mathrm{mL})}^{-1}\right)\end{array}$ & $\begin{array}{l}\text { Sulfato de } \\
\text { Alumínio } \\
\text { comercial } \\
\text { líquido } \\
\left(\mathrm{mg} \mathrm{L}^{-1}\right)\end{array}$ & & $\begin{array}{c}\text { Cor } \\
\text { Aparente } \\
\text { (uH) }\end{array}$ & $\begin{array}{c}\text { Turbidez } \\
\text { (uT) }\end{array}$ \\
\hline 1 & & 10,0 & 90 & 5,04 & 25 & 1,84 \\
\hline 2 & & 12,5 & 90 & 5,27 & 13 & 1,19 \\
\hline 3 & & 15,0 & 90 & 5,54 & 2 & 0,77 \\
\hline 4 & & 20,0 & 90 & 6,00 & 4 & 0,60 \\
\hline 5 & & 17,5 & 90 & 5,69 & 4 & 0,45 \\
\hline 6 & & 22,5 & 90 & 6,10 & 9 & 0,68 \\
\hline
\end{tabular}

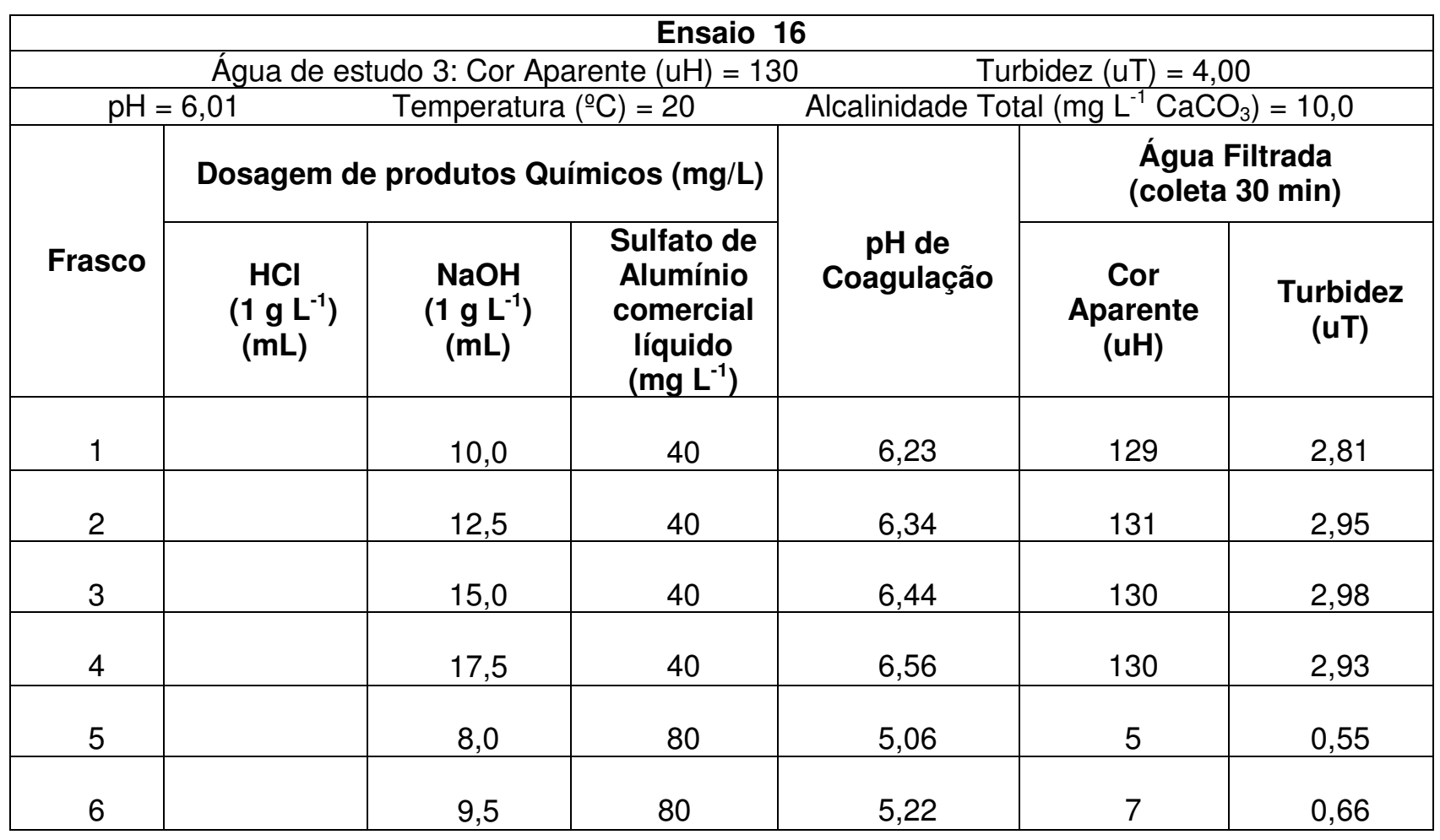




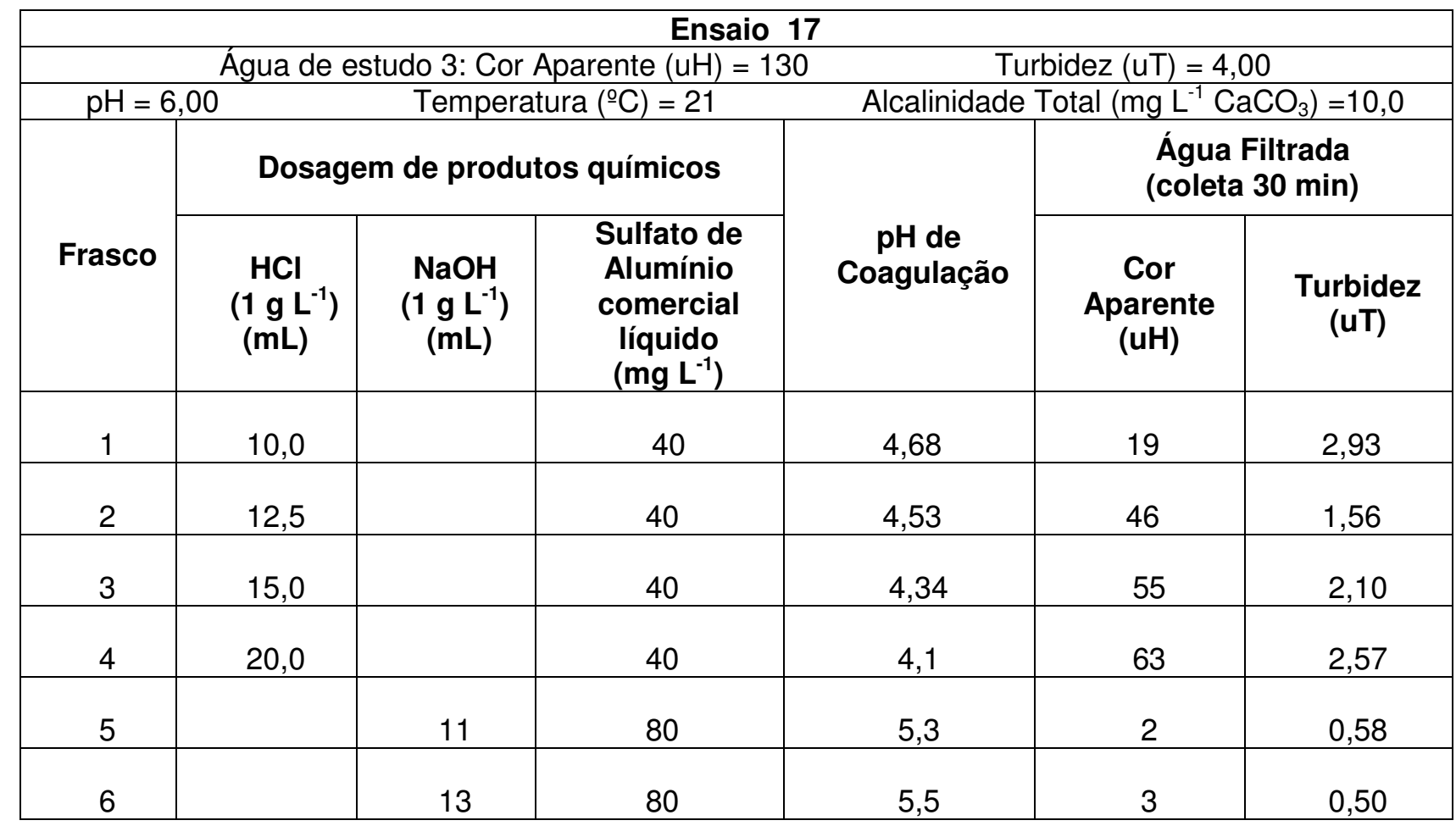

\begin{tabular}{|c|c|c|c|c|c|c|}
\hline \multicolumn{7}{|c|}{$\begin{array}{ll} & \text { Ensaio } 18 \\
\end{array}$} \\
\hline & \multicolumn{3}{|c|}{ Água de estudo 3: Cor Aparente $(\mathrm{uH})=130$} & \multicolumn{3}{|c|}{ Turbidez $(\mathrm{uT})=4,00$} \\
\hline \multicolumn{2}{|c|}{$\mathrm{pH}=6,03$} & \multicolumn{2}{|c|}{ Temperatura $\left({ }^{\circ} \mathrm{C}\right)=21$} & \multicolumn{3}{|c|}{ Alcalinidade Total $\left(\mathrm{mg} \mathrm{L}^{-1} \mathrm{CaCO}_{3}\right)=10,0$} \\
\hline \multirow[b]{2}{*}{ Frasco } & \multicolumn{3}{|c|}{ Dosagem de produtos químicos } & \multirow[b]{2}{*}{$\begin{array}{c}\text { pH de } \\
\text { Coagulação }\end{array}$} & \multicolumn{2}{|c|}{$\begin{array}{c}\text { Água Filtrada } \\
\text { (coleta } 30 \text { min) }\end{array}$} \\
\hline & $\begin{array}{c}\mathrm{HCl} \\
\left(1 \mathrm{~g} \mathrm{~L}^{-1}\right) \\
(\mathrm{mL})\end{array}$ & $\begin{array}{c}\mathrm{NaOH} \\
\left(1 \mathrm{~g} \mathrm{~L}^{-1}\right) \\
(\mathrm{mL})\end{array}$ & $\begin{array}{l}\text { Sulfato de } \\
\text { Alumínio } \\
\text { comercial } \\
\text { líquido } \\
\left(\mathrm{mg} \mathrm{L}^{-1}\right)\end{array}$ & & $\begin{array}{c}\text { Cor } \\
\text { Aparente } \\
(\mathrm{uH})\end{array}$ & $\begin{array}{l}\text { Turbidez } \\
\text { (uT) }\end{array}$ \\
\hline 1 & & 25 & 90 & 6,22 & 16 & 0,97 \\
\hline 2 & 11,0 & & 60 & 4,50 & 30 & 0,58 \\
\hline 3 & 12,5 & & 60 & 4,62 & 49 & 1,47 \\
\hline 4 & & 18,5 & 90 & 5,8 & 5 & 0,54 \\
\hline 5 & & 10,0 & 80 & 5,3 & 3 & 0,58 \\
\hline 6 & & 27,5 & 90 & 6,4 & 19 & 0,91 \\
\hline
\end{tabular}




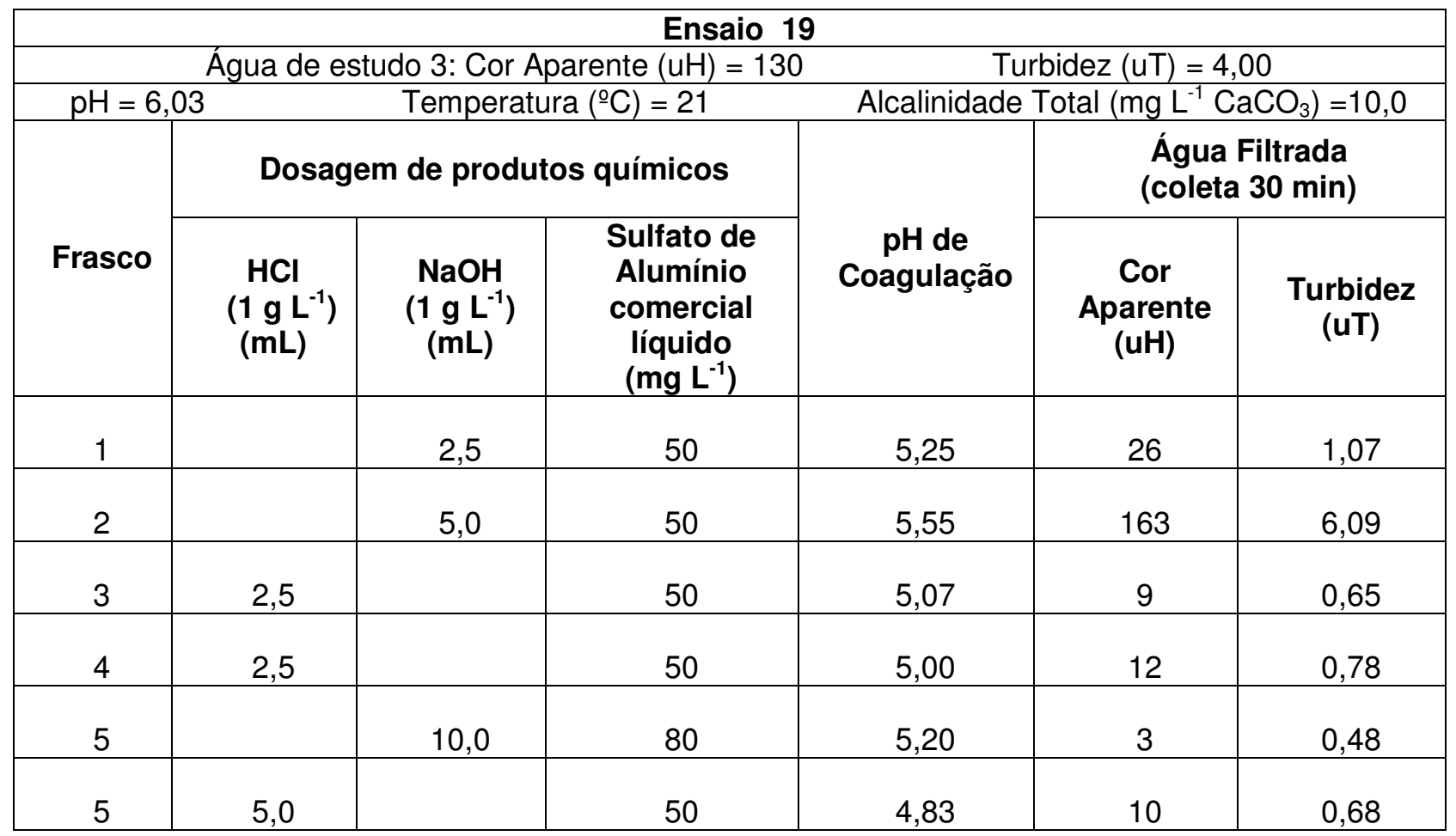

A.4 Tabelas referentes aos ensaios de coagulação da água de estudo 4, empregrando-se sulfato de alumínio comercial como coagulante.

\begin{tabular}{|c|c|c|c|c|c|c|}
\hline \multicolumn{7}{|c|}{ Ensaio 1} \\
\hline \multicolumn{7}{|c|}{$\begin{aligned} \text { Água de estudo 4: } & \text { Cor Aparente }(\mathrm{uH})=139 \\
& \text { Turbidez }(\mathrm{uT})=4,96\end{aligned}$} \\
\hline \multicolumn{2}{|c|}{$\mathrm{pH}=6,02$} & \multicolumn{2}{|c|}{ Temperatura $\left({ }^{\circ} \mathrm{C}\right)=21$} & \multicolumn{3}{|c|}{ Alcalinidade Total $\left(\mathrm{mg} \mathrm{L}^{-1} \mathrm{CaCO}_{3}\right)=10,23$} \\
\hline \multirow[b]{2}{*}{ Frasco } & \multicolumn{3}{|c|}{ Dosagem de produtos químicos } & \multirow[b]{2}{*}{$\begin{array}{c}\text { pH de } \\
\text { Coagulação }\end{array}$} & \multicolumn{2}{|c|}{$\begin{array}{l}\text { Água Filtrada } \\
\text { (coleta } 30 \text { min) }\end{array}$} \\
\hline & $\begin{array}{c}\mathrm{HCl} \\
\left(1 \mathrm{~g} \mathrm{~L}^{-1}\right)\end{array}$ & $\begin{array}{c}\mathrm{NaOH} \\
\left(1 \mathrm{~g} \mathrm{~L}^{-1}\right) \\
(\mathrm{mL})\end{array}$ & $\begin{array}{l}\text { Sulfato de } \\
\text { Alumínio } \\
\text { comercial } \\
\text { líquido } \\
\left(\mathrm{mg} \mathrm{L}^{-1}\right)\end{array}$ & & $\begin{array}{c}\text { Cor } \\
\text { Aparente } \\
\text { (uH) }\end{array}$ & $\begin{array}{c}\text { Turbidez } \\
\text { (uT) }\end{array}$ \\
\hline 1 & & & 60 & 5,40 & 165 & 7,43 \\
\hline 2 & 5,0 & & 60 & 5,20 & 169 & 8,57 \\
\hline 3 & 10,0 & & 60 & 4,84 & 47 & 2,04 \\
\hline 4 & 15.0 & & 60 & 4,64 & 18 & 0,84 \\
\hline 5 & & 2,5 & 60 & 5,60 & 158 & 6,34 \\
\hline 6 & & 5,0 & 60 & 5,86 & 156 & 5,91 \\
\hline
\end{tabular}




\begin{tabular}{|c|c|c|c|c|c|c|}
\hline \multicolumn{7}{|c|}{ Ensaio 2} \\
\hline \multicolumn{5}{|c|}{ Água de estudo 4: Cor Aparente $(\mathrm{uH})=139$} & \multicolumn{2}{|c|}{ urbidez $(\mathrm{uT})=4,96$} \\
\hline \multicolumn{2}{|c|}{$\mathrm{pH}=6,10$} & \multicolumn{2}{|c|}{ Temperatura $\left({ }^{\circ} \mathrm{C}\right)=21$} & \multicolumn{3}{|c|}{ Alcalinidade Total $\left(\mathrm{mg} \mathrm{L}^{-1} \mathrm{CaCO}_{3}\right)=10,20$} \\
\hline \multirow[b]{2}{*}{ Frasco } & \multicolumn{3}{|c|}{ Dosagem de produtos químicos } & \multirow[b]{2}{*}{$\begin{array}{c}\text { pH de } \\
\text { Coagulação }\end{array}$} & \multicolumn{2}{|c|}{$\begin{array}{l}\text { Água Filtrada } \\
\text { (coleta } 30 \mathrm{~min} \text { ) }\end{array}$} \\
\hline & $\begin{array}{c}\mathrm{HCl} \\
\left(1 \mathrm{~g} \mathrm{~L}^{-1}\right)\end{array}$ & $\begin{array}{c}\mathrm{NaOH} \\
\left(1 \mathrm{~g} \mathrm{~L}^{-1}\right) \\
(\mathrm{mL})\end{array}$ & $\begin{array}{l}\text { Sulfato de } \\
\text { Alumínio } \\
\text { comercial } \\
\text { líquido } \\
\left(\mathrm{mg} \mathrm{L}^{-1}\right)\end{array}$ & & $\begin{array}{c}\text { Cor } \\
\text { Aparente } \\
\text { (uH) }\end{array}$ & $\begin{array}{c}\text { Turbidez } \\
\text { (uT) }\end{array}$ \\
\hline 1 & 20 & & 60 & 4,40 & 30 & 1,29 \\
\hline 2 & 25 & & 60 & 4,23 & 31 & 1,82 \\
\hline 3 & & & 70 & 5,00 & 26 & 1,62 \\
\hline 4 & 5,0 & & 70 & 4,77 & 9 & 0,76 \\
\hline 5 & 10,0 & & 70 & 4,66 & 7 & 0,63 \\
\hline 6 & 15,0 & & 70 & 4,45 & 7 & 0,58 \\
\hline
\end{tabular}

\begin{tabular}{|c|c|c|c|c|c|c|}
\hline \multicolumn{7}{|c|}{$\begin{array}{r}\text { Ensaio } 3 \\
\end{array}$} \\
\hline \multicolumn{7}{|c|}{ Água de estudo 4: Cor Aparente $(\mathrm{uH})=149 \quad$ Turbidez $(\mathrm{uT})=4,89$} \\
\hline \multicolumn{2}{|c|}{$\mathrm{pH}=6,10$} & \multicolumn{2}{|c|}{ Temperatura $\left({ }^{\circ} \mathrm{C}\right)=20$} & \multicolumn{3}{|c|}{ Alcalinidade Total $\left(\mathrm{mg} \mathrm{L}^{-1} \mathrm{CaCO}_{3}\right)=10,00$} \\
\hline \multirow[b]{2}{*}{ Frasco } & \multicolumn{3}{|c|}{ Dosagem de produtos químicos } & \multirow[b]{2}{*}{$\begin{array}{c}\text { pH de } \\
\text { Coagulação }\end{array}$} & \multicolumn{2}{|c|}{$\begin{array}{l}\text { Água Filtrada } \\
\text { (coleta } 30 \text { min) }\end{array}$} \\
\hline & $\begin{array}{c}\mathrm{HCl} \\
\left(1 \mathrm{~g} \mathrm{~L}^{-1}\right) \\
(\mathrm{mL})\end{array}$ & $\begin{array}{c}\mathrm{NaOH} \\
\left(1 \mathrm{~g} \mathrm{~L}^{-1}\right)\end{array}$ & $\begin{array}{l}\text { Sulfato de } \\
\text { Alumínio } \\
\text { comercial } \\
\text { líquido } \\
\left(\mathrm{mg} \mathrm{L}^{-1}\right)\end{array}$ & & $\begin{array}{c}\text { Cor Aparente } \\
\text { (uH) }\end{array}$ & $\begin{array}{l}\text { Turbidez } \\
\text { (uT) }\end{array}$ \\
\hline 1 & 20,0 & & 70 & 4,35 & 20 & 0,81 \\
\hline 2 & 25,0 & & 70 & 4,20 & 43 & 1,46 \\
\hline 3 & & 2,5 & 70 & 5,10 & 24 & 1,35 \\
\hline 4 & & 5,0 & 70 & 5,30 & 69 & 3,11 \\
\hline 5 & & 7,5 & 70 & 5,49 & 154 & 7,00 \\
\hline 6 & & 10,0 & 70 & 5,70 & 156 & 7,1 \\
\hline
\end{tabular}




\begin{tabular}{|c|c|c|c|c|c|c|}
\hline \multicolumn{7}{|c|}{$\begin{array}{ll} & \text { Ensaio } 4 \\
\end{array}$} \\
\hline \multicolumn{7}{|c|}{ Água de estudo 4: $\quad$ Cor Aparente $(\mathrm{uH})=147 \quad$ Turbidez $(\mathrm{uT})=4,88$} \\
\hline \multicolumn{4}{|c|}{ Temperatura $\left({ }^{\circ} \mathrm{C}\right)=21$} & \multicolumn{3}{|c|}{ Alcalinidade Total $\left(\mathrm{mg} \mathrm{L}^{-1} \mathrm{CaCO}_{3}\right)=10,20$} \\
\hline \multirow[b]{2}{*}{ Frasco } & \multicolumn{3}{|c|}{ Dosagem de produtos químicos } & \multirow[b]{2}{*}{$\begin{array}{c}\text { pH de } \\
\text { Coagulação }\end{array}$} & \multicolumn{2}{|c|}{$\begin{array}{l}\text { Água Filtrada } \\
\text { (coleta } 30 \mathrm{~min} \text { ) }\end{array}$} \\
\hline & $\begin{array}{c}\mathrm{HCl} \\
\left(1 \mathrm{~g} \mathrm{~L}^{-1}\right) \\
(\mathrm{mL})\end{array}$ & $\begin{array}{c}\mathrm{NaOH} \\
\left(1 \mathrm{~g} \mathrm{~L}^{-1}\right) \\
(\mathrm{mL})\end{array}$ & $\begin{array}{c}\text { Sulfato de } \\
\text { Alumínio } \\
\text { comercial } \\
\text { líquido } \\
\left(\mathrm{mg} \mathrm{L}^{-1}\right)\end{array}$ & & $\begin{array}{c}\text { Cor } \\
\text { Aparente } \\
\text { (uH) }\end{array}$ & $\begin{array}{c}\text { Turbidez } \\
\text { (uT) }\end{array}$ \\
\hline 1 & & 15,0 & 70 & 5,80 & 152 & 6,21 \\
\hline 2 & & 17,5 & 70 & 5,90 & 148 & 5,78 \\
\hline 3 & & 20,0 & 70 & 6,00 & 141 & 4,81 \\
\hline 4 & & 25 & 70 & 6,30 & 138 & 4,23 \\
\hline 5 & & - & 80 & 4,87 & 9 & 0,61 \\
\hline 6 & & 2,5 & 80 & 4,80 & 4 & 0,57 \\
\hline
\end{tabular}

\begin{tabular}{|c|c|c|c|c|c|c|}
\hline \multicolumn{7}{|c|}{$\begin{array}{l}\text { Ensaio } 5 \\
\end{array}$} \\
\hline \multicolumn{7}{|c|}{ Água de estudo 4: Cor Aparente $(\mathrm{uH})=147$} \\
\hline \multicolumn{2}{|c|}{$\mathrm{pH}=6,01$} & \multicolumn{2}{|c|}{ emperatura $\left({ }^{\circ} \mathrm{C}\right)=21$} & \multicolumn{3}{|c|}{ Alcalinidade Total $\left(\mathrm{mg} \mathrm{L}^{-1} \mathrm{CaCO}_{3}\right)=10,20$} \\
\hline \multirow[b]{2}{*}{ Frasco } & \multicolumn{3}{|c|}{ Dosagem de produtos químicos } & \multirow[b]{2}{*}{$\begin{array}{c}\text { pH de } \\
\text { Coagulação }\end{array}$} & \multicolumn{2}{|c|}{$\begin{array}{l}\text { Água Filtrada } \\
\text { (coleta } 30 \mathrm{~min} \text { ) }\end{array}$} \\
\hline & $\begin{array}{c}\mathrm{HCl} \\
\left(\mathrm{(mL}^{-1} \mathrm{~g} \mathrm{~L}^{-1}\right)\end{array}$ & $\begin{array}{c}\mathrm{NaOH} \\
\left(1 \mathrm{~g} \mathrm{~L}^{-1}\right) \\
(\mathrm{mL})\end{array}$ & $\begin{array}{l}\text { Sulfato de } \\
\text { Alumínio } \\
\text { comercial } \\
\text { líquido } \\
\left(\mathrm{mg} \mathrm{L}^{-1}\right)\end{array}$ & & $\begin{array}{c}\text { Cor } \\
\text { Aparente } \\
\text { (uH) }\end{array}$ & $\begin{array}{l}\text { Turbidez } \\
\text { (uT) }\end{array}$ \\
\hline 1 & 5,0 & & 80 & 4,60 & 9 & 0,47 \\
\hline 2 & 10,0 & & 80 & 4,50 & 18 & 0,53 \\
\hline 3 & 15,0 & & 80 & 4,36 & 25 & 0,81 \\
\hline 4 & 20,0 & & 80 & 4,25 & 38 & 0,98 \\
\hline 5 & & 5,0 & 80 & 5,00 & 8 & 0,68 \\
\hline 6 & & 7,5 & 80 & 5,10 & 9 & 0,60 \\
\hline
\end{tabular}




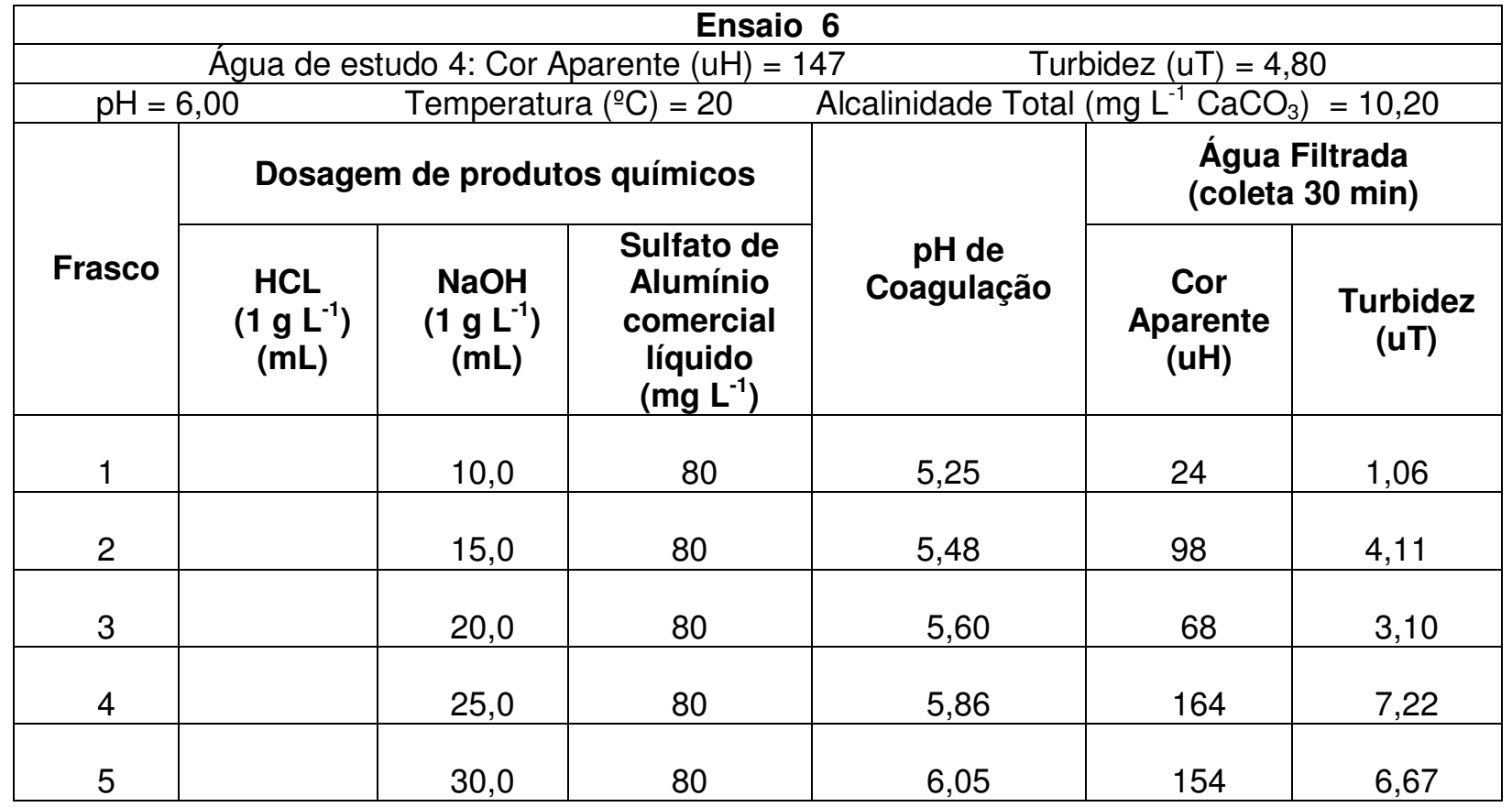

\begin{tabular}{|c|c|c|c|c|c|c|}
\hline \multicolumn{7}{|c|}{ Ensaio 7} \\
\hline & Água c & estudo 4: & or Aparente & $\mathrm{H})=132$ & $\operatorname{dez}(u T)=4,57$ & \\
\hline \multicolumn{2}{|c|}{$\mathrm{pH}=6,08$} & \multicolumn{2}{|c|}{ Temperatura $\left({ }^{\circ} \mathrm{C}\right)=20$} & \multicolumn{3}{|c|}{ Alcalinidade Total $\left(\mathrm{mg} \mathrm{L}^{-1} \mathrm{CaCO}_{3}\right)=10,20$} \\
\hline \multirow[b]{2}{*}{ Frasco } & \multicolumn{3}{|c|}{ Dosagem de produtos químicos } & \multirow[b]{2}{*}{$\begin{array}{c}\text { pH de } \\
\text { Coagulação }\end{array}$} & \multicolumn{2}{|c|}{$\begin{array}{l}\text { Água Filtrada } \\
\text { (coleta } 30 \mathrm{~min} \text { ) }\end{array}$} \\
\hline & $\begin{array}{c}\mathrm{HCl} \\
\left(1 \mathrm{~g} \mathrm{~L}^{-1}\right) \\
(\mathrm{mL})\end{array}$ & $\begin{array}{c}\mathrm{NaOH} \\
\left(1 \mathrm{~g} \mathrm{~L}^{-1}\right) \\
(\mathrm{mL})\end{array}$ & $\begin{array}{c}\text { Sulfato de } \\
\text { Alumínio } \\
\text { comercial } \\
\text { líquido } \\
\left(\mathrm{mg} \mathrm{L}^{-1}\right)\end{array}$ & & $\begin{array}{c}\text { Cor Aparente } \\
\text { (uH) }\end{array}$ & $\begin{array}{c}\text { Turbidez } \\
\text { (uT) }\end{array}$ \\
\hline 1 & & 40 & 80 & 6,66 & 129 & 2,57 \\
\hline 2 & & 45 & 80 & 6,87 & 127 & 2,04 \\
\hline 3 & & 50 & 80 & 7,00 & 124 & 1,96 \\
\hline 4 & & 30 & 70 & 6,55 & 130 & 2,76 \\
\hline 5 & & 35 & 70 & 6,75 & 125 & 2,08 \\
\hline 6 & & 40 & 70 & 6,8 & 122 & 1,91 \\
\hline
\end{tabular}




\begin{tabular}{|c|c|c|c|c|c|c|}
\hline \multicolumn{7}{|c|}{$\begin{array}{ll} & \text { Ensaio } 8 \\
\end{array}$} \\
\hline \multicolumn{4}{|c|}{ Água de estudo 4: Cor Aparente $(\mathrm{uH})=13$} & \multicolumn{3}{|c|}{ Turbidez (uT) = 4,57 } \\
\hline $\mathrm{pH}=6,08$ & \multicolumn{3}{|c|}{ Temperatura $\left({ }^{\circ} \mathrm{C}\right)=20$} & \multicolumn{3}{|c|}{ Alcalinidade Total $\left(\mathrm{mg} \mathrm{L}^{-1} \mathrm{CaCO}_{3}\right)=10,20$} \\
\hline \multirow[b]{2}{*}{ Frasco } & \multicolumn{3}{|c|}{ Dosagem de produtos químicos } & \multirow[b]{2}{*}{$\begin{array}{c}\text { pH de } \\
\text { Coagulação }\end{array}$} & \multicolumn{2}{|c|}{$\begin{array}{l}\text { Água Filtrada } \\
\text { (coleta } 30 \text { min) }\end{array}$} \\
\hline & $\begin{array}{c}\mathrm{HCl} \\
\left(1 \mathrm{~g} \mathrm{~L}^{-1}\right) \\
(\mathrm{mL})\end{array}$ & $\begin{array}{c}\mathrm{NaOH} \\
\left(1 \mathrm{~g} \mathrm{~L}^{-1}\right) \\
(\mathrm{mL})\end{array}$ & $\begin{array}{l}\text { Sulfato de } \\
\text { Alumínio } \\
\text { comercial } \\
\text { líquido } \\
\left(\mathrm{mg} \mathrm{L}^{-1}\right) \\
\end{array}$ & & $\begin{array}{c}\text { Cor } \\
\text { Aparente } \\
\text { (uH) }\end{array}$ & $\begin{array}{l}\text { Turbidez } \\
\quad \text { (uT) }\end{array}$ \\
\hline 1 & & & 90 & 4,65 & 8 & 0,51 \\
\hline 2 & 5,0 & & 90 & 4,52 & 16 & 0,53 \\
\hline 3 & 10,0 & & 90 & 4,41 & 20 & 0,58 \\
\hline 4 & 15,0 & & 90 & 4,30 & 31 & 0,91 \\
\hline 5 & & 5,0 & 90 & 4,77 & 6 & 0,51 \\
\hline 6 & & 10,0 & 90 & 4,95 & 12 & 0,86 \\
\hline
\end{tabular}

\begin{tabular}{|c|c|c|c|c|c|c|}
\hline \multicolumn{7}{|c|}{$\begin{aligned} & \text { Ensaio } 9 \\
&\end{aligned}$} \\
\hline \multicolumn{5}{|c|}{ Água de estudo 4: $\quad$ Cor Aparente $(\mathrm{uH})=132$} & \multicolumn{2}{|c|}{ Turbidez (uT) $=4,57$} \\
\hline \multicolumn{2}{|c|}{$\mathrm{pH}=6,06$} & \multicolumn{2}{|c|}{ Temperatura $\left({ }^{\circ} \mathrm{C}\right)=20$} & \multicolumn{3}{|c|}{ Alcalinidade Total $\left(\mathrm{mg} \mathrm{L}^{-1} \mathrm{CaCO}_{3}\right)=10,20$} \\
\hline \multirow[b]{2}{*}{ Frasco } & \multicolumn{3}{|c|}{ Dosagem de produtos químicos } & \multirow[b]{2}{*}{$\begin{array}{c}\text { pH de } \\
\text { Coagulação }\end{array}$} & \multicolumn{2}{|c|}{$\begin{array}{l}\text { Água Filtrada } \\
\text { (coleta } 30 \mathrm{~min} \text { ) }\end{array}$} \\
\hline & $\begin{array}{c}\mathrm{HCl} \\
\left(1 \mathrm{~g} \mathrm{~L}^{-1}\right) \\
(\mathrm{mL})\end{array}$ & $\begin{array}{c}\mathrm{NaOH} \\
\left(1 \mathrm{~g} \mathrm{~L}^{-1}\right) \\
(\mathrm{mL})\end{array}$ & $\begin{array}{l}\text { Sulfato de } \\
\text { Alumínio } \\
\text { comercial } \\
\text { líquido } \\
\left(\mathrm{mg} \mathrm{L}^{-1}\right)\end{array}$ & & $\begin{array}{c}\text { Cor Aparente } \\
\text { (uH) }\end{array}$ & $\begin{array}{l}\text { Turbidez } \\
\text { (uT) }\end{array}$ \\
\hline 1 & & 15 & 90 & 5,15 & 19 & 0,62 \\
\hline 2 & & 20 & 90 & 5,53 & 42 & 1,91 \\
\hline 3 & & 25 & 90 & 5,83 & 61 & 2,60 \\
\hline 4 & & 30 & 90 & 6,07 & 161 & 6,66 \\
\hline 5 & & 35 & 90 & 6,23 & 149 & 6,34 \\
\hline 6 & & 40 & 90 & 6,40 & 140 & 5,35 \\
\hline
\end{tabular}




\begin{tabular}{|c|c|c|c|c|c|c|}
\hline \multicolumn{7}{|c|}{$\begin{array}{ll}\text { Ensaio } 10 \\
\end{array}$} \\
\hline \multicolumn{5}{|c|}{ Água de estudo 4: Cor Aparente $(\mathrm{uH})=132$} & \multicolumn{2}{|c|}{ Turbidez $(\mathrm{uT})=4,57$} \\
\hline \multicolumn{2}{|c|}{$\mathrm{pH}=6,04$} & \multicolumn{2}{|c|}{ Temperatura $\left({ }^{\circ} \mathrm{C}\right)=20$} & \multicolumn{3}{|c|}{ Alcalinidade Total $\left(\mathrm{mg} \mathrm{L}^{-1} \mathrm{CaCO}_{3}\right)=10,20$} \\
\hline \multirow[b]{2}{*}{ Frasco } & \multicolumn{3}{|c|}{ Dosagem de produtos químicos } & \multirow[b]{2}{*}{$\begin{array}{c}\text { pH de } \\
\text { Coagulação }\end{array}$} & \multicolumn{2}{|c|}{$\begin{array}{c}\text { Água Filtrada } \\
\text { (coleta } 30 \mathrm{~min} \text { ) }\end{array}$} \\
\hline & $\begin{array}{c}\mathrm{HCl} \\
\left(1 \mathrm{~g} \mathrm{~L}^{-1}\right) \\
(\mathrm{mL})\end{array}$ & $\begin{array}{c}\mathrm{NaOH} \\
\left(1 \mathrm{~g} \mathrm{~L}^{-1}\right) \\
(\mathrm{mL})\end{array}$ & $\begin{array}{l}\text { Sulfato de } \\
\text { Alumínio } \\
\text { comercial } \\
\text { líquido } \\
\left(\mathrm{mg} \mathrm{L}^{-1}\right)\end{array}$ & & $\begin{array}{c}\text { Cor Aparente } \\
\text { (uH) }\end{array}$ & $\begin{array}{c}\text { Turbidez } \\
\text { (uT) }\end{array}$ \\
\hline 1 & & & 100 & 4,65 & 9 & 0,48 \\
\hline 2 & 5,0 & & 100 & 4,53 & 16 & 0,55 \\
\hline 3 & 10,0 & & 100 & 4,42 & 24 & 0,54 \\
\hline 4 & & 5,0 & 100 & 4,74 & 9 & 0,63 \\
\hline 5 & & 10,0 & 100 & 4,85 & 7 & 0,64 \\
\hline 6 & & 15,0 & 100 & 5,10 & 8 & 0,69 \\
\hline
\end{tabular}

\begin{tabular}{|c|c|c|c|c|c|c|}
\hline \multicolumn{7}{|c|}{$\begin{array}{ll} & \text { Ensaio } 11 \\
\end{array}$} \\
\hline \multicolumn{5}{|c|}{ Água de estudo 4: Cor Aparente $(\mathrm{uH})=134$} & \multicolumn{2}{|c|}{ Turbidez $(\mathrm{uT})=4,50$} \\
\hline \multicolumn{2}{|c|}{$\mathrm{pH}=6,10$} & \multicolumn{2}{|c|}{ Temperatura $\left({ }^{\circ} \mathrm{C}\right)=20$} & \multicolumn{3}{|c|}{ Alcalinidade Total $\left(\mathrm{mg} \mathrm{L}^{-1} \mathrm{CaCO}_{3}\right)=10,0$} \\
\hline \multirow[b]{2}{*}{ Frasco } & \multicolumn{3}{|c|}{ Dosagem de produtos químicos } & \multirow[b]{2}{*}{$\begin{array}{c}\text { pH de } \\
\text { Coagulação }\end{array}$} & \multicolumn{2}{|c|}{$\begin{array}{c}\text { Água Filtrada } \\
\text { (coleta } 30 \text { min) }\end{array}$} \\
\hline & $\begin{array}{c}\mathrm{HCl} \\
\left(\mathrm{g} \mathrm{L} \mathrm{L}^{-1}\right)\end{array}$ & $\begin{array}{c}\mathrm{NaOH} \\
\left(1 \mathrm{~g} \mathrm{~L}^{-1}\right) \\
(\mathrm{mL})\end{array}$ & $\begin{array}{l}\text { Sulfato de } \\
\text { Alumínio } \\
\text { comercial } \\
\text { líquido } \\
\left(\mathrm{mg} \mathrm{L}^{-1}\right)\end{array}$ & & $\begin{array}{c}\text { Cor } \\
\text { Aparente } \\
\text { (uH) }\end{array}$ & $\begin{array}{c}\text { Turbidez } \\
\text { (uT) }\end{array}$ \\
\hline 1 & & 20,0 & 100 & 5,42 & 12 & 0,71 \\
\hline 2 & & 25,0 & 100 & 5,81 & 39 & 1,76 \\
\hline 3 & & 30,0 & 100 & 6,00 & 47 & 2,09 \\
\hline 4 & & 35,0 & 100 & 6,21 & 82 & 3,21 \\
\hline 5 & & 40,0 & 100 & 6,40 & 135 & 4,68 \\
\hline 6 & & 45,0 & 100 & 6,50 & 137 & 4,27 \\
\hline
\end{tabular}




\begin{tabular}{|c|c|c|c|c|c|c|}
\hline \multicolumn{7}{|c|}{$\begin{array}{ll} & \text { Ensaio } 12 \\
\end{array}$} \\
\hline \multicolumn{5}{|c|}{ Água de estudo 4: Cor Aparente $(\mathrm{uH})=134$} & & \\
\hline \multicolumn{2}{|c|}{$\mathrm{pH}=6,00$} & \multicolumn{2}{|c|}{ Temperatura $\left({ }^{\circ} \mathrm{C}\right)=20$} & & & \\
\hline \multirow[b]{2}{*}{ Frasco } & \multicolumn{3}{|c|}{ Dosagem de produtos químicos } & \multirow[b]{2}{*}{$\begin{array}{c}\text { pH de } \\
\text { Coagulação }\end{array}$} & \multicolumn{2}{|c|}{$\begin{array}{l}\text { Água Filtrada } \\
\text { (coleta } 30 \mathrm{~min} \text { ) }\end{array}$} \\
\hline & $\begin{array}{c}\mathrm{HCl} \\
(\underbrace{\left.1 \mathrm{~g} \mathrm{~L}^{-1}\right)}_{(\mathrm{mL})}\end{array}$ & $\begin{array}{c}\mathrm{NaOH} \\
\left(1 \mathrm{~g} \mathrm{~L}^{-1}\right) \\
(\mathrm{mL})\end{array}$ & $\begin{array}{c}\text { Sulfato de } \\
\text { Alumínio } \\
\text { comercial } \\
\text { líquido } \\
\left(\mathrm{mg} \mathrm{L}^{-1}\right) \\
\end{array}$ & & $\begin{array}{c}\text { Cor } \\
\text { Aparente } \\
\text { (uH) }\end{array}$ & $\begin{array}{l}\text { Turbidez } \\
\text { (uT) }\end{array}$ \\
\hline 1 & & & 110 & 4,54 & 8 & 0,43 \\
\hline 2 & 5,0 & & 110 & 4,47 & 15 & 0,45 \\
\hline 3 & 10,0 & & 110 & 4,30 & 18 & 0,54 \\
\hline 4 & & 7,5 & 110 & 4,68 & 6 & 0,48 \\
\hline 5 & & 15,0 & 110 & 4,80 & 7 & 0,62 \\
\hline 6 & & 22,5 & 110 & 5,30 & 4 & 0,56 \\
\hline
\end{tabular}

\begin{tabular}{|c|c|c|c|c|c|c|}
\hline \multicolumn{7}{|c|}{ Ensaio 13 } \\
\hline \multicolumn{7}{|c|}{ Água de estudo 4: Cor Aparente $(\mathrm{uH})=132$} \\
\hline \multirow{2}{*}{ Frasco }
\end{tabular}




\begin{tabular}{|c|c|c|c|c|c|c|}
\hline \multicolumn{7}{|c|}{ Ensaio 14} \\
\hline \multicolumn{4}{|c|}{ Água de estudo 4: Cor Aparente $(\mathrm{uH})=138$} & \multicolumn{3}{|c|}{ Turbidez $(\mathrm{uT})=4,55$} \\
\hline $\mathrm{pH}=6,0$ & & Temper & $\left({ }^{\circ} \mathrm{C}\right)=20$ & Alcalinidade & tal $\left(\mathrm{mg} \mathrm{L}^{-1}\right.$ & $\left.\mathrm{CO}_{3}\right)=10,0$ \\
\hline \multirow[b]{2}{*}{ Frasco } & \multicolumn{3}{|c|}{ Dosagem de produtos químicos } & \multirow[b]{2}{*}{$\begin{array}{c}\text { pH de } \\
\text { Coagulação }\end{array}$} & \multicolumn{2}{|c|}{$\begin{array}{l}\text { Água Filtrada } \\
\text { (coleta } 30 \mathrm{~min} \text { ) }\end{array}$} \\
\hline & $\begin{array}{c}\mathrm{HCl} \\
\left(1 \mathrm{~g} \mathrm{~L}^{-1}\right) \\
(\mathrm{mL})\end{array}$ & $\begin{array}{c}\mathrm{NaOH} \\
\left(1 \mathrm{~g} \mathrm{~L}^{-1}\right) \\
(\mathrm{mL})\end{array}$ & $\begin{array}{c}\text { Sulfato de } \\
\text { Alumínio } \\
\text { comercial } \\
\text { líquido } \\
\left(\mathrm{mg} \mathrm{L}^{-1}\right)\end{array}$ & & $\begin{array}{c}\text { Cor } \\
\text { Aparente } \\
\text { (uH) }\end{array}$ & $\begin{array}{c}\text { Turbidez } \\
\text { (uT) }\end{array}$ \\
\hline 1 & & & 120 & 4,46 & 12 & 0,45 \\
\hline 2 & 7,5 & & 120 & 4,24 & 27 & 0,50 \\
\hline 3 & 15,0 & & 120 & 4,07 & 47 & 0,91 \\
\hline 4 & & 7,5 & 120 & 4,58 & 8 & 0,49 \\
\hline 5 & & 15,0 & 120 & 4,76 & 6 & 0,48 \\
\hline 6 & & 20,0 & 120 & 4,85 & 10 & 0,85 \\
\hline
\end{tabular}

\begin{tabular}{|c|c|c|c|c|c|c|}
\hline \multicolumn{7}{|c|}{ Ensaio 15} \\
\hline \multicolumn{4}{|c|}{ Água de estudo 4: Cor Aparente $(\mathrm{uH})=138$} & \multicolumn{3}{|c|}{ Turbidez $(u T)=4,55$} \\
\hline \multicolumn{2}{|c|}{$\mathrm{pH}=6,03$} & \multicolumn{2}{|c|}{ Temperatura $\left({ }^{\circ} \mathrm{C}\right)=20$} & \multicolumn{3}{|c|}{ Alcalinidade Total $\left(\mathrm{mg} \mathrm{L}^{-1} \mathrm{CaCO}_{3}\right)=10,0$} \\
\hline \multirow[b]{2}{*}{ Frasco } & \multicolumn{3}{|c|}{ Dosagem de produtos químicos } & \multirow[b]{2}{*}{$\begin{array}{c}\text { pH de } \\
\text { Coagulação }\end{array}$} & \multicolumn{2}{|c|}{$\begin{array}{l}\text { Água Filtrada } \\
\text { (coleta } 30 \mathrm{~min} \text { ) }\end{array}$} \\
\hline & $\begin{array}{c}\mathrm{HCl} \\
\left(1 \mathrm{~g} \mathrm{~L}^{-1}\right) \\
(\mathrm{mL})\end{array}$ & $\begin{array}{c}\mathrm{NaOH} \\
\left(1 \mathrm{~g} \mathrm{~L}^{-1}\right) \\
(\mathrm{mL})\end{array}$ & $\begin{array}{l}\text { Sulfato de } \\
\text { Alumínio } \\
\text { comercial } \\
\text { líquido } \\
\left(\mathrm{mg} \mathrm{L}^{-1}\right) \\
\end{array}$ & & $\begin{array}{l}\text { Cor } \\
\text { Aparente } \\
\text { (uH) }\end{array}$ & $\begin{array}{l}\text { Turbidez } \\
\text { (uT) }\end{array}$ \\
\hline 1 & & 18,5 & 110 & 5,01 & 4 & 0,52 \\
\hline 2 & & 27,5 & 120 & 5,00 & 9 & 0,70 \\
\hline 3 & & 35 & 120 & 5,50 & 5 & 0,46 \\
\hline 4 & & 42,5 & 120 & 6,00 & 13 & 0,61 \\
\hline 5 & & 2,5 & 80 & 4,58 & 7 & 0,43 \\
\hline 6 & & 2,5 & 80 & 4,85 & 6 & 0,40 \\
\hline
\end{tabular}




\section{ANEXO B}

B.1 - Tabelas referentes aos ensaios de coagulação da água de estudo 1, empregandose cloreto férrico como coagulante.

\begin{tabular}{|c|c|c|c|c|c|c|}
\hline \multicolumn{7}{|c|}{ Ensaio 1} \\
\hline \multicolumn{7}{|c|}{ 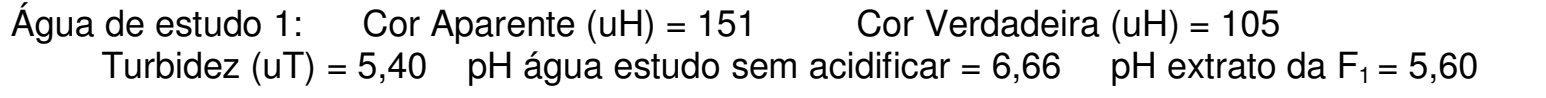 } \\
\hline \multicolumn{2}{|c|}{$\mathrm{pH}=6,10$} & \multicolumn{2}{|c|}{ Temperatura $\left({ }^{\circ} \mathrm{C}\right)=19$} & \multirow{2}{*}{\multicolumn{3}{|c|}{\begin{tabular}{|l|r}
\multicolumn{2}{|c|}{ Alcalinidade Total $\left(\mathrm{mg} \mathrm{L}^{-1} \mathrm{CaCO}_{3}\right)=10$} \\
$\begin{array}{r}\text { Água Filtrada } \\
\text { (coleta 30 min) }\end{array}$
\end{tabular}}} \\
\hline \multirow[b]{2}{*}{ Frasco } & \multicolumn{3}{|c|}{ Dosagem de produtos químicos } & & & \\
\hline & $\begin{array}{c}\mathrm{HCl} \\
\left(1 \underset{(m L)}{g^{-1}}\right)\end{array}$ & $\begin{array}{c}\mathrm{NaOH} \\
\left(4 \mathrm{~g} \mathrm{~L}^{-1}\right) \\
(\mathrm{mL})\end{array}$ & $\begin{array}{c}\text { Cloreto Férrico } \\
\text { comercial líquido } \\
\left(\mathrm{mg} \mathrm{L}^{-1}\right)\end{array}$ & $\begin{array}{c}\text { pH de } \\
\text { Coagulação }\end{array}$ & $\begin{array}{l}\text { Cor } \\
\text { Aparente } \\
\text { (uH) }\end{array}$ & $\begin{array}{c}\text { Turbidez } \\
\text { (uT) }\end{array}$ \\
\hline 1 & & 6,0 & 30 & 6,40 & 211 & 5,89 \\
\hline 2 & & 7,0 & 30 & 6,50 & 189 & 5,72 \\
\hline 3 & & 8,0 & 30 & 6,60 & 213 & 5,72 \\
\hline 4 & & 9,0 & 30 & 6,75 & 204 & 5,66 \\
\hline 5 & & 10,0 & 30 & 6,90 & 203 & 5,57 \\
\hline 6 & & 11,0 & 30 & 7,1 & 203 & 5,60 \\
\hline
\end{tabular}

\begin{tabular}{|c|c|c|c|c|c|c|}
\hline \multicolumn{7}{|c|}{ Ensaio 2} \\
\hline \multicolumn{3}{|c|}{ Água de estudo 1: } & \multicolumn{2}{|c|}{ or Aparente $(\mathrm{uH})=147$} & Turbidez ( & $=4,88$ \\
\hline \multicolumn{2}{|c|}{$\mathrm{pH}=6,08$} & \multicolumn{2}{|c|}{ emperatura $\left({ }^{\circ} \mathrm{C}\right)=20$} & \multicolumn{3}{|c|}{ Alcalinidade Total $\left(\mathrm{mg} \mathrm{L}^{-1} \mathrm{CaCO}_{3}\right)=10$} \\
\hline \multirow[b]{2}{*}{ Frasco } & \multicolumn{3}{|c|}{ Dosagem de produtos químicos } & \multirow[b]{2}{*}{$\begin{array}{c}\text { pH de } \\
\text { Coagulação }\end{array}$} & \multicolumn{2}{|c|}{$\begin{array}{l}\text { Água Filtrada } \\
\text { (coleta } 30 \mathrm{~min} \text { ) }\end{array}$} \\
\hline & $\begin{array}{c}\mathrm{HCl} \\
\left(1 \mathrm{~g} \mathrm{~L}^{-1}\right) \\
(\mathrm{mL})\end{array}$ & $\begin{array}{c}\mathrm{NaOH} \\
\left(4 \mathrm{~g} \mathrm{~L}^{-1}\right) \\
(\mathrm{mL})\end{array}$ & $\begin{array}{l}\text { Cloreto Férrico } \\
\text { comercial } \\
\text { líquido } \\
\left(\mathrm{mg} \mathrm{L}^{-1}\right)\end{array}$ & & $\begin{array}{c}\text { Cor } \\
\text { Aparente } \\
\text { (uH) }\end{array}$ & $\begin{array}{l}\text { Turbidez } \\
\text { (uT) }\end{array}$ \\
\hline 1 & & 1,0 & 30 & 5,60 & 236 & 8,1 \\
\hline 2 & & 2,0 & 30 & 5,83 & 228 & 7,11 \\
\hline 3 & & 3,0 & 30 & 6,00 & 225 & 6,66 \\
\hline 4 & & 4,0 & 30 & 6,18 & 218 & 6,62 \\
\hline 5 & & 5,0 & 30 & 6,33 & 219 & 6,56 \\
\hline
\end{tabular}




\begin{tabular}{|c|c|c|c|c|c|c|}
\hline \multicolumn{7}{|c|}{$\begin{array}{r}\text { Ensaio } 3 \\
\end{array}$} \\
\hline \multirow{2}{*}{\multicolumn{2}{|c|}{$\begin{array}{l}\text { Água de estu } \\
\mathrm{pH}=6,00\end{array}$}} & 1: $\quad \operatorname{Cor} A$ & rente $(u H)=147$ & \multirow{2}{*}{\multicolumn{3}{|c|}{$\begin{array}{l}\text { Turbidez }(\mathrm{uT})=4,88 \\
\text { inidade Total }\left(\mathrm{mg} \mathrm{L}^{-1} \mathrm{CaCO}_{3}\right)=10\end{array}$}} \\
\hline & & mperatur & C) $=19 \quad$ Alca & & & \\
\hline \multirow[b]{2}{*}{ Frasco } & \multicolumn{3}{|c|}{ Dosagem de produtos químicos } & \multirow[b]{2}{*}{$\begin{array}{c}\text { pH de } \\
\text { Coagulação }\end{array}$} & \multicolumn{2}{|c|}{$\begin{array}{c}\text { Água Filtrada } \\
\text { (coleta } 30 \mathrm{~min} \text { ) }\end{array}$} \\
\hline & $\begin{array}{c}\mathrm{HCl} \\
\left(1 \mathrm{~g} \mathrm{~L}^{-1}\right) \\
(\mathrm{mL})\end{array}$ & $\begin{array}{c}\mathrm{NaOH} \\
4 \mathrm{~g} \mathrm{~L}^{-1} \\
(\mathrm{~mL})\end{array}$ & $\begin{array}{c}\text { Cloreto Férrico } \\
\text { comercial } \\
\text { líquido } \\
\left(\mathrm{mg} \mathrm{L}^{-1}\right)\end{array}$ & & $\begin{array}{l}\text { Cor } \\
\text { Aparente } \\
\text { (uH) }\end{array}$ & $\begin{array}{l}\text { Turbidez } \\
\text { (uT) }\end{array}$ \\
\hline 1 & & & 80 & 3,80 & 268 & 4,3 \\
\hline 2 & & 5,0 & 80 & 4,00 & 249 & 4,09 \\
\hline 3 & & 10,0 & 80 & 5,77 & 1 & 0,40 \\
\hline 4 & & 15,0 & 80 & 6,40 & 35 & 1,00 \\
\hline 5 & & 20,0 & 80 & 6,70 & 301 & 5,89 \\
\hline 6 & & 25,0 & 80 & 8,90 & 254 & 4,98 \\
\hline
\end{tabular}

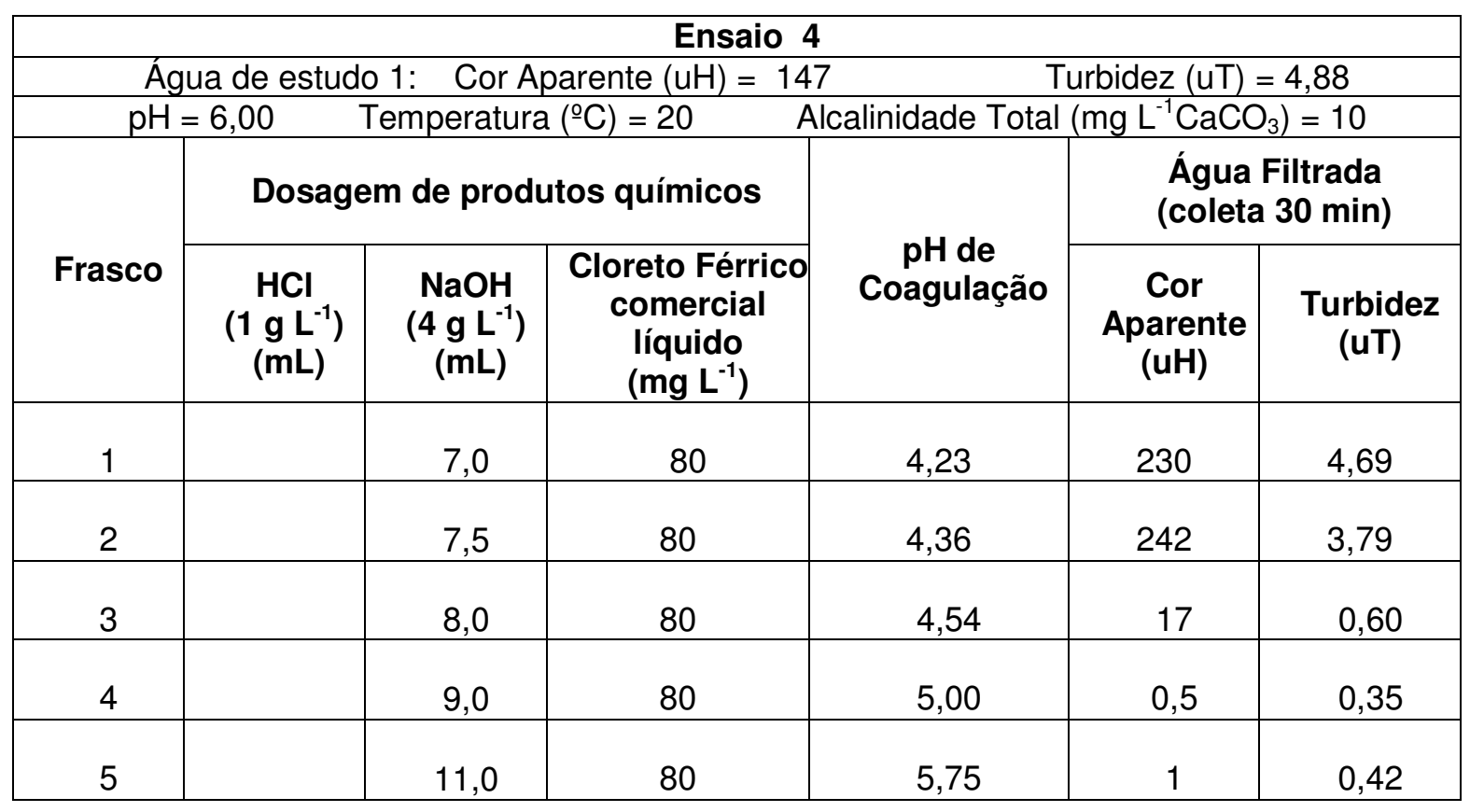




\begin{tabular}{|c|c|c|c|c|c|c|}
\hline \multicolumn{7}{|c|}{ Ensaio 5} \\
\hline \multirow{2}{*}{\multicolumn{4}{|c|}{\begin{tabular}{lcr}
\multicolumn{2}{c}{ Água de estudo 1: } & Cor Aparente $(\mathrm{uH})=147$ \\
$\mathrm{pH}=6,00$ & Temperatura $\left({ }^{\circ} \mathrm{C}\right)=19$
\end{tabular}}} & \multicolumn{3}{|c|}{ Turbidez $(\mathrm{uT})=4,88$} \\
\hline & & & & alinidade Total & $\left(\mathrm{mg} \mathrm{L}^{-1} \mathrm{CaO}\right.$ & $\left.D_{3}\right)=10$ \\
\hline \multirow[b]{2}{*}{ Frasco } & \multicolumn{3}{|c|}{ Dosagem de produtos químicos } & \multirow[b]{2}{*}{$\begin{array}{c}\text { pH de } \\
\text { Coagulação }\end{array}$} & \multicolumn{2}{|c|}{$\begin{array}{c}\text { Água Filtrada } \\
\text { (coleta } 30 \mathrm{~min} \text { ) }\end{array}$} \\
\hline & $\begin{array}{c}\mathrm{HCl} \\
\left(1 \mathrm{~g} \mathrm{~L}^{-1}\right) \\
(\mathrm{mL})\end{array}$ & $\begin{array}{c}\mathrm{NaOH} \\
\left(0,15 \mathrm{~mol} \mathrm{~L}^{-1}\right) \\
(\mathrm{mL})\end{array}$ & $\begin{array}{l}\text { Cloreto } \\
\text { Férrico } \\
\text { comercial } \\
\text { líquido } \\
\left(\mathrm{mg} \mathrm{L}^{-1}\right)\end{array}$ & & $\begin{array}{c}\text { Cor } \\
\text { Aparente } \\
\text { (uH) }\end{array}$ & $\begin{array}{l}\text { Turbidez } \\
\text { (uT) }\end{array}$ \\
\hline 1 & & 8,5 & 80 & 4,80 & 0,5 & 0,32 \\
\hline 2 & & 9,5 & 80 & 5,40 & 0,5 & 0,36 \\
\hline 3 & & 13,0 & 80 & 6,27 & 200 & 3,91 \\
\hline 4 & & 7,5 & 70 & 5,30 & 0,5 & 0,32 \\
\hline 5 & & 8,0 & 70 & 5,69 & 1 & 0,44 \\
\hline 6 & & 8,5 & 70 & 5,78 & 0,5 & 0,36 \\
\hline
\end{tabular}

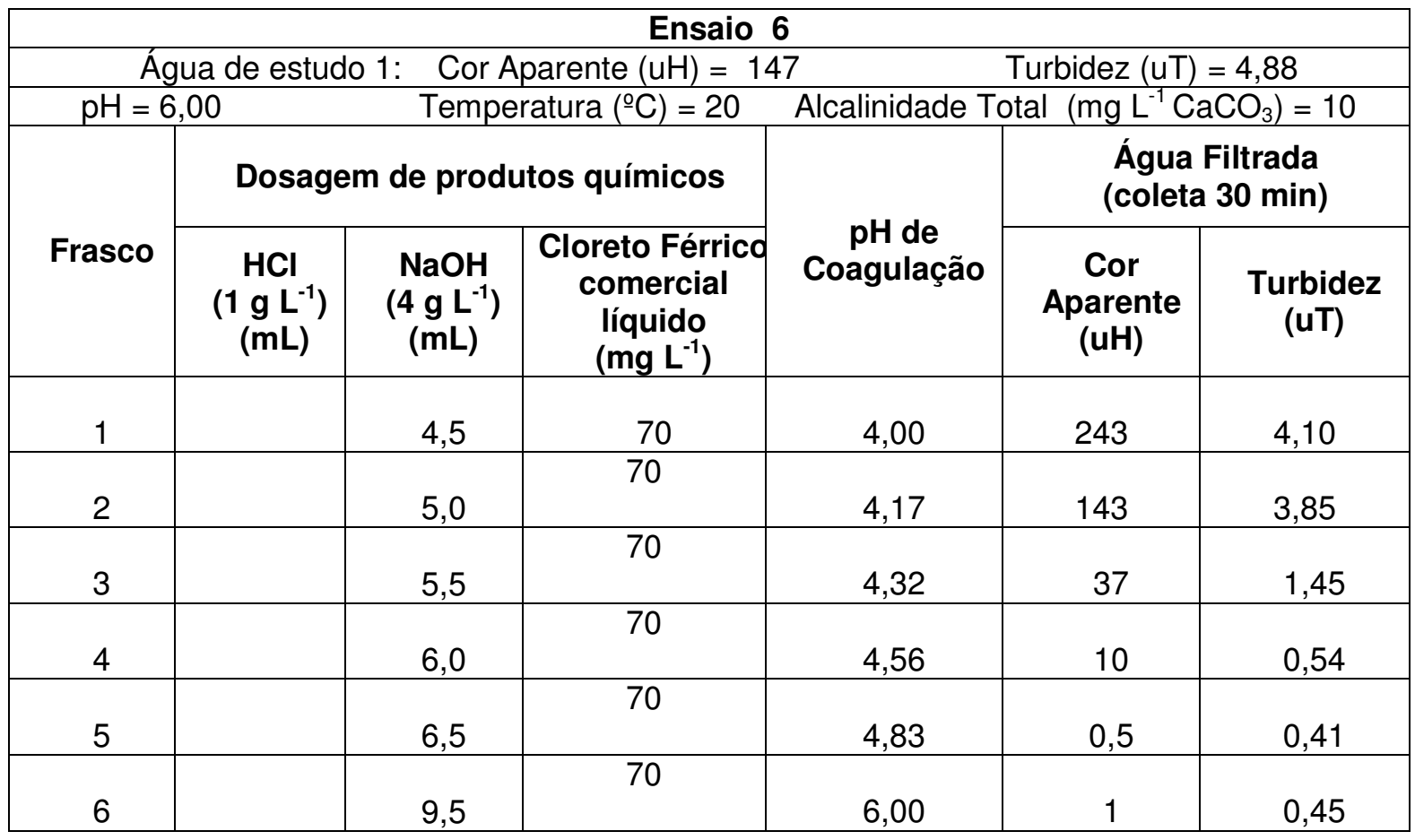




\begin{tabular}{|c|c|c|c|c|c|c|}
\hline \multicolumn{7}{|c|}{ Ensaio 7} \\
\hline \multicolumn{5}{|c|}{ Água de estudo 1: $\quad$ Cor Aparente $(\mathrm{uH})=142$} & \multicolumn{2}{|c|}{ arbidez $(\mathrm{uT})=4,55$} \\
\hline \multicolumn{2}{|c|}{$\mathrm{pH}=6,00$} & \multicolumn{2}{|c|}{ Temperatura $\left({ }^{\circ} \mathrm{C}\right)=20$} & \multicolumn{3}{|c|}{ Alcalinidade Total $\left(\mathrm{mg} \mathrm{L}^{-1} \mathrm{CaCO}_{3}\right)=10$} \\
\hline \multirow[b]{2}{*}{ Frasco } & \multicolumn{3}{|c|}{ Dosagem de produtos químicos } & \multirow[b]{2}{*}{$\begin{array}{c}\text { pH de } \\
\text { Coagulação }\end{array}$} & \multicolumn{2}{|c|}{$\begin{array}{l}\text { Água Filtrada } \\
\text { (coleta } 30 \mathrm{~min} \text { ) }\end{array}$} \\
\hline & $\begin{array}{c}\mathrm{HCl} \\
\left(1 \mathrm{~g} \mathrm{~L}^{-1}\right) \\
(\mathrm{mL})\end{array}$ & $\begin{array}{c}\mathrm{NaOH} \\
\left(4 \mathrm{~g} \mathrm{~L}^{-1}\right) \\
(\mathrm{mL})\end{array}$ & $\begin{array}{l}\text { Cloreto } \\
\text { Férrico } \\
\text { comercial } \\
\text { líquido } \\
\left(\mathrm{mg} \mathrm{L}^{-1}\right)\end{array}$ & & $\begin{array}{c}\text { Cor } \\
\text { Aparente } \\
\text { (uH) }\end{array}$ & $\begin{array}{c}\text { Turbidez } \\
\text { (uT) }\end{array}$ \\
\hline 1 & & 7,0 & 70 & 5,10 & 5 & 0,39 \\
\hline 2 & & 10,0 & 70 & 6,17 & 71 & 1,48 \\
\hline 3 & & 10,5 & 70 & 6,25 & 220 & 4,24 \\
\hline 4 & & 11,0 & 70 & 6,32 & 268 & 5,74 \\
\hline 5 & & 11,5 & 70 & 6,53 & 266 & 5,24 \\
\hline 6 & & 12,0 & 70 & 6,60 & 263 & 5,06 \\
\hline
\end{tabular}

\begin{tabular}{|c|c|c|c|c|c|c|}
\hline \multicolumn{7}{|c|}{ Ensaio 8} \\
\hline \multicolumn{7}{|c|}{ Água de estudo 1: $\quad$ Cor Aparente $(\mathrm{uH})=142 \quad$ Turbidez $(\mathrm{uT})=4,55$} \\
\hline \multicolumn{4}{|c|}{$\mathrm{pH}=6,09 \quad$ Temperatura $\left({ }^{\circ} \mathrm{C}\right)=20$} & \multicolumn{3}{|c|}{ Alcalinidade Total $\left(\mathrm{mg} \mathrm{L}^{-1} \mathrm{CaCO}_{3}\right)=10$} \\
\hline \multirow[b]{2}{*}{ Frasco } & \multicolumn{3}{|c|}{ Dosagem de produtos químicos } & \multirow[b]{2}{*}{$\begin{array}{c}\text { pH de } \\
\text { Coagulação }\end{array}$} & \multicolumn{2}{|c|}{$\begin{array}{c}\text { Água Filtrada } \\
\text { (coleta } 30 \mathrm{~min} \text { ) }\end{array}$} \\
\hline & $\begin{array}{c}\mathrm{HCl} \\
\left(1 \mathrm{~g} \mathrm{~L}^{-1}\right) \\
(\mathrm{mL})\end{array}$ & $\begin{array}{c}\mathrm{NaOH} \\
\left(4 \mathrm{~g} \mathrm{~L}^{-1}\right) \\
(\mathrm{mL})\end{array}$ & $\begin{array}{l}\text { Cloreto } \\
\text { Férrico } \\
\text { comercial } \\
\text { líquido } \\
\left(\mathrm{mg} \mathrm{L}^{-1}\right)\end{array}$ & & $\begin{array}{c}\text { Cor Aparente } \\
\text { (uH) }\end{array}$ & $\begin{array}{l}\text { Turbidez } \\
\text { (uT) }\end{array}$ \\
\hline 1 & & 5,0 & 60 & 5,02 & 0,5 & 0,35 \\
\hline 2 & & 5,5 & 60 & 5,11 & 0,5 & 0,36 \\
\hline 3 & & 6,0 & 60 & 5,29 & 3 & 0,35 \\
\hline 4 & & 6,5 & 60 & 5,50 & 1 & 0,42 \\
\hline 5 & & 7,0 & 60 & 5,70 & 4 & 0,41 \\
\hline 6 & & 7,5 & 60 & 5,80 & 5 & 0,42 \\
\hline
\end{tabular}




\begin{tabular}{|c|c|c|c|c|c|c|}
\hline \multicolumn{7}{|c|}{ Ensaio 9 } \\
\hline \multicolumn{7}{|c|}{ Água de estudo 1: Cor Aparente $(\mathrm{uH})=142$} \\
\hline \multirow{2}{*}{ Frasco }
\end{tabular}

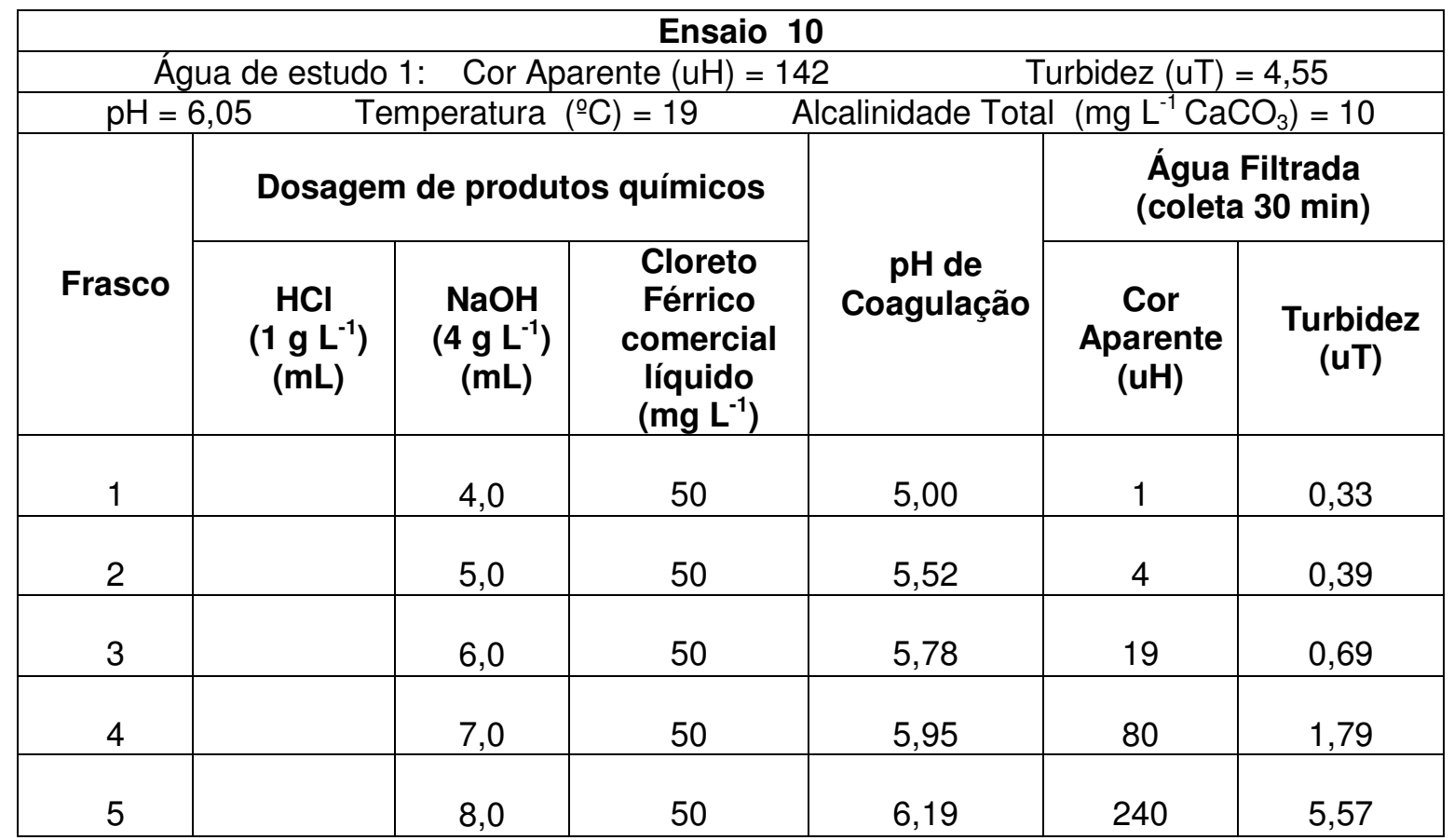




\begin{tabular}{|c|c|c|c|c|c|c|}
\hline \multicolumn{7}{|c|}{ Ensaio 11} \\
\hline \multicolumn{5}{|c|}{ Água de estudo 1: $\quad$ Cor Aparente $(\mathrm{uH})=142$} & \multicolumn{2}{|c|}{ Гurbidez $(\mathrm{uT})=4,55$} \\
\hline \multicolumn{4}{|c|}{$\mathrm{pH}=6,00 \quad$ Temperatura $\left({ }^{\circ} \mathrm{C}\right)=20$} & \multicolumn{3}{|c|}{ Alcalinidade Total $\left(\mathrm{mg} \mathrm{L}^{-1} \mathrm{CaCO}_{3}\right)=10$} \\
\hline \multirow[b]{2}{*}{ Frasco } & \multicolumn{3}{|c|}{ Dosagem de produtos químicos } & \multirow[b]{2}{*}{$\begin{array}{c}\text { pH de } \\
\text { Coagulação }\end{array}$} & \multicolumn{2}{|c|}{$\begin{array}{l}\text { Água Filtrada } \\
\text { (coleta } 30 \mathrm{~min} \text { ) }\end{array}$} \\
\hline & $\begin{array}{c}\mathrm{HCl} \\
\left(\operatorname{(mL}^{-1} \mathrm{~g} \mathrm{~L}^{-1}\right)\end{array}$ & $\begin{array}{l}\mathrm{NaOH} \\
\left(4 \mathrm{~g} \mathrm{~L}^{-1}\right) \\
(\mathrm{mL})\end{array}$ & $\begin{array}{l}\text { Cloreto } \\
\text { Férrico } \\
\text { comercial } \\
\text { líquido } \\
\left(\mathrm{mg} \mathrm{L}^{-1}\right) \\
\end{array}$ & & $\begin{array}{c}\text { Cor } \\
\text { Aparente } \\
\text { (uH) }\end{array}$ & $\begin{array}{l}\text { Turbidez } \\
\quad \text { (uT) }\end{array}$ \\
\hline 1 & & & 40 & 4,00 & 16 & 0,69 \\
\hline 2 & & 1,5 & 50 & 4,20 & 12 & 0,53 \\
\hline 3 & & 2,5 & 50 & 4,32 & 13 & 0,48 \\
\hline 4 & & 3,0 & 50 & 4,46 & 14 & 0,38 \\
\hline 5 & & 3,5 & 50 & 4,70 & 1 & 0,43 \\
\hline 6 & & 4,5 & 50 & 5,40 & 5 & 0,37 \\
\hline
\end{tabular}

\begin{tabular}{|c|c|c|c|c|c|c|}
\hline \multicolumn{7}{|c|}{ Ensaio 12} \\
\hline \multicolumn{7}{|c|}{ Água de estudo 1: $\quad$ Cor Aparente $(\mathrm{uH})=137 \quad$ Turbidez $(\mathrm{uT})=4,88$} \\
\hline \multicolumn{4}{|c|}{$\mathrm{pH}=6,09 \quad$ Temperatura $\left({ }^{\circ} \mathrm{C}\right)=20$} & \multicolumn{3}{|c|}{ Alcalinidade Total $\left(\mathrm{mg} \mathrm{L}^{-1} \mathrm{CaCO}_{3}\right)=10$} \\
\hline \multirow[b]{2}{*}{ Frasco } & \multicolumn{3}{|c|}{ Dosagem de produtos químicos } & \multirow[b]{2}{*}{$\begin{array}{c}\text { pH de } \\
\text { Coagulação }\end{array}$} & \multicolumn{2}{|c|}{$\begin{array}{c}\text { Água Filtrada } \\
\text { (coleta } 30 \mathrm{~min} \text { ) }\end{array}$} \\
\hline & $\begin{array}{c}\mathrm{HCl} \\
\left(1 \mathrm{~g} \mathrm{~L}^{-1}\right) \\
(\mathrm{mL})\end{array}$ & $\begin{array}{l}\mathrm{NaOH} \\
\left(4 \mathrm{~g} \mathrm{~L}^{-1}\right) \\
(\mathrm{mL})\end{array}$ & $\begin{array}{l}\text { Cloreto } \\
\text { Férrico } \\
\text { comercial } \\
\text { líquido } \\
\left(\mathrm{mg} \mathrm{L}^{-1}\right)\end{array}$ & & $\begin{array}{c}\text { Cor } \\
\text { Aparente } \\
\text { (uH) }\end{array}$ & $\begin{array}{c}\text { Turbidez } \\
\text { (uT) }\end{array}$ \\
\hline 1 & & & 40 & 4,28 & 2 & 0,38 \\
\hline 2 & & 1,0 & 40 & 4,88 & 4 & 0,38 \\
\hline 3 & & 2,0 & 40 & 5,40 & 27 & 0,86 \\
\hline 4 & & 3,0 & 40 & 5,63 & 133 & 2,79 \\
\hline 5 & & 4,0 & 40 & 5,86 & 226 & 5,32 \\
\hline 6 & & 5,0 & 40 & 6,02 & 223 & 4,74 \\
\hline
\end{tabular}




\begin{tabular}{|c|c|c|c|c|c|c|}
\hline \multicolumn{7}{|c|}{$\begin{array}{ll} & \text { Ensaio } 13 \\
\end{array}$} \\
\hline \multicolumn{7}{|c|}{ Água de Estudo1: $\quad$ Cor Aparente $(\mathrm{uH})=137$} \\
\hline \multicolumn{2}{|c|}{$\mathrm{pH}=6,09$} & \multicolumn{2}{|c|}{$\begin{array}{l}\text { udo1: } \text { Cor Aparente }(\mathrm{uH})=1 \\
\text { Temperatura }\left({ }^{\circ} \mathrm{C}\right)=20\end{array}$} & \multicolumn{3}{|c|}{ calinidade Total $\left(\mathrm{mg} \mathrm{L}^{-1} \mathrm{CaCO}_{3}\right)=10$} \\
\hline \multirow[b]{2}{*}{ Frasco } & \multicolumn{3}{|c|}{ Dosagem de produtos químicos } & \multirow[b]{2}{*}{$\begin{array}{c}\text { pH de } \\
\text { Coagulação }\end{array}$} & \multicolumn{2}{|c|}{$\begin{array}{c}\text { Água Filtrada } \\
\text { (coleta } 30 \mathrm{~min} \text { ) }\end{array}$} \\
\hline & $\begin{array}{c}\mathrm{HCl} \\
\left(1 \mathrm{~g} \mathrm{~L}^{-1}\right) \\
(\mathrm{mL})\end{array}$ & $\begin{array}{c}\mathrm{NaOH} \\
\left(4 \mathrm{~g} \mathrm{~L}^{-1}\right) \\
(\mathrm{mL})\end{array}$ & $\begin{array}{l}\text { Cloreto Férrico } \\
\text { comercial } \\
\text { líquido } \\
\left(\mathrm{mg} \mathrm{L}^{-1}\right)\end{array}$ & & $\begin{array}{l}\text { Cor } \\
\text { Aparente } \\
\text { (uH) }\end{array}$ & $\begin{array}{l}\text { Turbidez } \\
\text { (uT) }\end{array}$ \\
\hline 1 & & 0,5 & 40 & 4,16 & 8 & 0,41 \\
\hline 2 & & 1,5 & 40 & 4,55 & 7 & 0,35 \\
\hline 3 & 2,5 & & 30 & 4,32 & 7 & 0,38 \\
\hline 4 & 5,0 & & 30 & 4,21 & 4 & 0,37 \\
\hline 5 & 7,5 & & 30 & 4,10 & 5 & 0,38 \\
\hline 6 & 10,0 & & 30 & 4,00 & 6 & 0,38 \\
\hline
\end{tabular}

\begin{tabular}{|c|c|c|c|c|c|c|}
\hline \multicolumn{7}{|c|}{$\begin{array}{rr}\text { Ensaio } 14 \\
\end{array}$} \\
\hline \multicolumn{5}{|c|}{ Água de estudo 1: $\quad$ Cor Aparente $(\mathrm{uH})=137$} & \multicolumn{2}{|c|}{ urbidez $(\mathrm{UT})=4,88$} \\
\hline \multicolumn{4}{|c|}{ Temperatura $\left({ }^{\circ} \mathrm{C}\right)=20$} & \multicolumn{3}{|c|}{ Alcalinidade Total $\left(\mathrm{mg} \mathrm{L}^{-1} \mathrm{CaCO}_{3}\right)=10$} \\
\hline \multirow[b]{2}{*}{ Frasco } & \multicolumn{3}{|c|}{ Dosagem de produtos químicos } & \multirow[b]{2}{*}{$\begin{array}{c}\text { pH de } \\
\text { Coagulação }\end{array}$} & \multicolumn{2}{|c|}{$\begin{array}{l}\text { Água Filtrada } \\
\text { (coleta } 30 \text { min) }\end{array}$} \\
\hline & $\begin{array}{c}\mathrm{HCl} \\
\left(1 \mathrm{~g} \mathrm{~L}^{-1}\right) \\
(\mathrm{mL})\end{array}$ & $\begin{array}{c}\mathrm{NaOH} \\
\left(4 \mathrm{~g} \mathrm{~L}^{-1}\right) \\
(\mathrm{mL})\end{array}$ & $\begin{array}{l}\text { Cloreto } \\
\text { Férrico } \\
\text { comercial } \\
\text { líquido) } \\
\left(\mathrm{mg} \mathrm{L}^{-1}\right)\end{array}$ & & $\begin{array}{c}\text { Cor Aparente } \\
\text { (uH) }\end{array}$ & $\begin{array}{c}\text { Turbidez } \\
\text { (uT) }\end{array}$ \\
\hline 1 & & & 30 & 4,52 & 6 & 0,52 \\
\hline 2 & 1,5 & & 30 & 4,40 & 5 & 0,40 \\
\hline 3 & & 1,0 & 20 & 5,78 & 170 & 3,15 \\
\hline 4 & & 1,5 & 20 & 5.90 & 178 & 3,14 \\
\hline 5 & & 2,0 & 20 & 6,03 & 193 & 3,07 \\
\hline 6 & & 2,5 & 20 & 6,15 & 172 & 3,17 \\
\hline
\end{tabular}




\begin{tabular}{|c|c|c|c|c|c|c|}
\hline \multicolumn{7}{|c|}{ Ensaio 15} \\
\hline \multicolumn{5}{|c|}{ Cor Aparente $(\mathrm{uH})=137$} & \multicolumn{2}{|c|}{ Turbidez $(\mathrm{uT})=4,88$} \\
\hline \multicolumn{2}{|c|}{$\mathrm{pH}=6,05$} & \multicolumn{2}{|c|}{ emperatura $\left({ }^{\circ} \mathrm{C}\right)=20$} & \multicolumn{3}{|c|}{ Alcalinidade Total $\left(\mathrm{mg} \mathrm{L}^{-1} \mathrm{CaCO}_{3}\right)=10$} \\
\hline \multirow[b]{2}{*}{ Frasco } & \multicolumn{3}{|c|}{ Dosagem de produtos químicos } & \multirow[b]{2}{*}{$\begin{array}{c}\text { pH de } \\
\text { Coagulação }\end{array}$} & \multicolumn{2}{|c|}{$\begin{array}{l}\text { Água Filtrada } \\
\text { (coleta } 30 \mathrm{~min} \text { ) }\end{array}$} \\
\hline & $\begin{array}{c}\mathrm{HCl} \\
\left(1 \mathrm{~g} \mathrm{~L}^{-1}\right) \\
(\mathrm{mL})\end{array}$ & $\begin{array}{c}\mathrm{NaOH} \\
\left(4 \mathrm{~g} \mathrm{~L}^{-1}\right) \\
(\mathrm{mL})\end{array}$ & $\begin{array}{l}\text { Cloreto } \\
\text { Férrico } \\
\text { comercial } \\
\text { líquido } \\
\left(\mathrm{mg} \mathrm{L}^{-1}\right)\end{array}$ & & $\begin{array}{c}\text { Cor } \\
\text { Aparente } \\
\text { (uH) }\end{array}$ & $\begin{array}{l}\text { Turbidez } \\
\quad \text { (uT) }\end{array}$ \\
\hline 1 & & 1,0 & 30 & 5,15 & 145 & 3,17 \\
\hline 2 & & 2,0 & 30 & 5,58 & 209 & 4,97 \\
\hline 3 & & 3,0 & 30 & 5,80 & 205 & 4,52 \\
\hline 4 & & & 20 & 5,40 & 170 & 3,18 \\
\hline 5 & 2,0 & & 20 & 5,20 & 172 & 3,20 \\
\hline 6 & 4,0 & & 20 & 4,95 & 178 & 3,45 \\
\hline
\end{tabular}

\begin{tabular}{|c|c|c|c|c|c|c|}
\hline \multicolumn{7}{|c|}{ Ensaio 16} \\
\hline \multicolumn{5}{|c|}{ Água de estudo 1: $\quad$ Cor Aparente $(\mathrm{uH})=137$} & \multicolumn{2}{|c|}{ rbidez $(\mathrm{UT})=4,88$} \\
\hline \multicolumn{2}{|c|}{$\mathrm{pH}=6,04$} & \multicolumn{2}{|c|}{ emperatura $\left({ }^{\circ} \mathrm{C}\right)=20$} & \multicolumn{3}{|c|}{ Alcalinidade Total $\left(\mathrm{mg} \mathrm{L}^{-1} \mathrm{CaCO}_{3}\right)=10$} \\
\hline \multirow[b]{2}{*}{ Frasco } & \multicolumn{3}{|c|}{ Dosagem de produtos químicos } & \multirow[b]{2}{*}{$\begin{array}{c}\text { pH de } \\
\text { Coagulação }\end{array}$} & \multicolumn{2}{|c|}{$\begin{array}{c}\text { Água Filtrada } \\
\text { (coleta } 30 \mathrm{~min} \text { ) }\end{array}$} \\
\hline & $\begin{array}{c}\mathrm{HCl} \\
\left(1 \mathrm{~g} \mathrm{~L}^{-1}\right)\end{array}$ & $\begin{array}{c}\mathrm{NaOH} \\
\left(4 \mathrm{~g} \mathrm{~L}^{-1}\right) \\
(\mathrm{mL})\end{array}$ & $\begin{array}{l}\text { Cloreto } \\
\text { Férrico } \\
\text { comercial } \\
\text { líquido } \\
\left(\mathrm{mg} \mathrm{L}^{-1}\right) \\
\end{array}$ & & $\begin{array}{c}\text { Cor } \\
\text { Aparente } \\
\text { (uH) }\end{array}$ & $\begin{array}{l}\text { Turbidez } \\
\text { (uT) }\end{array}$ \\
\hline 1 & 6,0 & & 20 & 4,80 & 182 & 3,38 \\
\hline 2 & 8,0 & & 20 & 4,50 & 181 & 3,88 \\
\hline 3 & 10,0 & & 20 & 4,32 & 133 & 3,14 \\
\hline 4 & & 0,5 & 30 & 4,90 & 37 & 1,07 \\
\hline 5 & 12,5 & & 30 & 4,03 & 4 & 0,48 \\
\hline 6 & 15,0 & & 30 & 3,92 & 7 & 0,45 \\
\hline
\end{tabular}




\begin{tabular}{|c|c|c|c|c|c|c|}
\hline \multicolumn{7}{|c|}{ Ensaio 17} \\
\hline \multicolumn{7}{|c|}{ Água de Estudo 1: $\quad$ Cor Aparente $(\mathrm{uH})=138$} \\
\hline \multicolumn{4}{|c|}{$\mathrm{pH}=6,06 \quad$ Temperatura $\left({ }^{\circ} \mathrm{C}\right)=20$} & \multicolumn{3}{|c|}{ Alcalinidade Total $\left(\mathrm{mg} \mathrm{L}^{-1} \mathrm{CaCO}_{3}\right)=10$} \\
\hline \multirow[b]{2}{*}{ Frasco } & \multicolumn{3}{|c|}{ Dosagem de produtos químicos } & \multirow[b]{2}{*}{$\begin{array}{c}\text { pH de } \\
\text { Coagulação }\end{array}$} & \multicolumn{2}{|c|}{$\begin{array}{c}\text { Água Filtrada } \\
\text { (coleta } 30 \mathrm{~min} \text { ) }\end{array}$} \\
\hline & $\begin{array}{c}\mathrm{HCl} \\
\left(\underset{(\mathrm{mL})}{\left(\mathrm{g} \mathrm{L}^{-1}\right)}\right)\end{array}$ & $\begin{array}{c}\mathrm{NaOH} \\
\left(4 \mathrm{~g} \mathrm{~L}^{-1}\right) \\
(\mathrm{mL})\end{array}$ & $\begin{array}{c}\text { Cloreto } \\
\text { férrico } \\
\text { comercial } \\
\text { líquido }\end{array}$ & & $\begin{array}{c}\text { Cor } \\
\text { Aparente } \\
\text { (uH) }\end{array}$ & $\begin{array}{c}\text { Turbidez } \\
\text { (uT) }\end{array}$ \\
\hline 1 & & 1,5 & 40 & 5,2 & 11 & 0,62 \\
\hline 2 & & 1,7 & 40 & 5,3 & 17 & 0,71 \\
\hline 3 & & 4,3 & 50 & 5,70 & 10 & 0,58 \\
\hline 4 & & 3,7 & 50 & 5,47 & 4 & 0,48 \\
\hline 5 & & 12,0 & 80 & 6,00 & 14 & 0,62 \\
\hline 6 & & 9,2 & 80 & 5,22 & 1 & 0,36 \\
\hline
\end{tabular}

\begin{tabular}{|c|c|c|c|c|c|c|}
\hline \multicolumn{7}{|c|}{ Ensaio 18} \\
\hline \multicolumn{7}{|c|}{ Água de Estudo 1: $\quad$ Cor Aparente $(\mathrm{uH})=138$} \\
\hline \multicolumn{2}{|c|}{$\mathrm{pH}=6,06$} & \multicolumn{2}{|c|}{ Temperatura $\left({ }^{\circ} \mathrm{C}\right)=19$} & \multicolumn{3}{|c|}{ Alcalinidade Total $\left(\mathrm{mg} \mathrm{L}^{-1} \mathrm{CaCO}_{3}\right)=10$} \\
\hline \multirow[b]{2}{*}{ Frasco } & \multicolumn{3}{|c|}{ Dosagem de produtos químicos } & \multirow[b]{2}{*}{$\begin{array}{c}\text { pH de } \\
\text { Coagulação }\end{array}$} & \multicolumn{2}{|c|}{$\begin{array}{l}\text { Água Filtrada } \\
\text { (coleta } 30 \mathrm{~min} \text { ) }\end{array}$} \\
\hline & $\begin{array}{c}\mathrm{HCl} \\
\left(1 \mathrm{~g} \mathrm{~L}^{-1}\right) \\
(\mathrm{mL})\end{array}$ & $\begin{array}{c}\mathrm{NaOH} \\
\left(4 \mathrm{~g} \mathrm{~L}^{-1}\right) \\
(\mathrm{mL})\end{array}$ & $\begin{array}{c}\text { Cloreto } \\
\text { férrico } \\
\text { comercial } \\
\text { líquido } \\
\left(\mathrm{mg} \mathrm{L}^{-1}\right)\end{array}$ & & $\begin{array}{c}\text { Cor } \\
\text { Aparente } \\
\text { (uH) }\end{array}$ & $\begin{array}{c}\text { Turbidez } \\
\text { (uT) }\end{array}$ \\
\hline 1 & & 4,2 & 60 & 4,30 & 16 & 0,84 \\
\hline 2 & & 4,6 & 60 & 4,61 & 13 & 0,78 \\
\hline 3 & & 4,8 & 60 & 4,82 & 7 & 0,51 \\
\hline 4 & & 4,2 & 50 & 5,18 & 0,5 & 0,46 \\
\hline 5 & & 9,5 & 80 & 5,41 & 0,5 & 0,49 \\
\hline 6 & & 9,7 & 80 & 5,53 & 1 & 0,43 \\
\hline
\end{tabular}


B.2 - Tabelas referentes aos ensaios de coagulação da água de estudo 2, empregandose cloreto férrico como coagulante

\begin{tabular}{|c|c|c|c|c|c|c|}
\hline \multicolumn{7}{|c|}{ Ensaio 1} \\
\hline \multirow{2}{*}{\multicolumn{7}{|c|}{$\begin{array}{ccc}\text { Água de estudo 2: } & \text { Cor Aparente }(\mathrm{uH})=133 & \text { Cor verdadeira }(\mathrm{uH})=101 \quad \text { Turbidez }(\mathrm{uT})=4,50 \\
\mathrm{pH}=6,05 & \text { Temperatura }=20^{\circ} \mathrm{C} & \text { Alcalinidade Total }\left(\mathrm{mg} \mathrm{L}^{-1} \mathrm{CaCO}_{3}\right)=10,58\end{array}$}} \\
\hline & & & & & & \\
\hline \multirow[b]{2}{*}{ Frasco } & \multicolumn{3}{|c|}{ Dosagem de produtos químicos } & \multirow[b]{2}{*}{$\begin{array}{c}\text { pH de } \\
\text { Coagulação }\end{array}$} & \multicolumn{2}{|c|}{$\begin{array}{l}\text { Água Filtrada } \\
\text { (coleta } 30 \mathrm{~min} \text { ) }\end{array}$} \\
\hline & $\begin{array}{c}\mathrm{HCl} \\
1 \mathrm{~g} \mathrm{~L}^{-1} \\
(\mathrm{~mL})\end{array}$ & $\begin{array}{c}\mathrm{NaOH} \\
\left(4 \mathrm{~g} \mathrm{~L}^{-1}\right) \\
(\mathrm{mL})\end{array}$ & $\begin{array}{l}\text { Cloreto Férrico } \\
\text { comercial } \\
\text { líquido } \\
\left(\mathrm{mg} \mathrm{L}^{-1}\right)\end{array}$ & & $\begin{array}{c}\text { Cor Aparente } \\
(\mathrm{uH})\end{array}$ & $\begin{array}{l}\text { Turbidez } \\
\text { (uT) }\end{array}$ \\
\hline 1 & & 7 & 105,6 & 3,91 & 292 & 4,18 \\
\hline 2 & & 8 & 105,6 & 4,01 & 293 & 4,10 \\
\hline 3 & & 8,5 & 105,6 & 4,07 & 288 & 4,05 \\
\hline 4 & & 9,0 & 105,6 & 4,17 & 282 & 5,61 \\
\hline 5 & & 9,5 & 105,6 & 4,23 & 279 & 5,54 \\
\hline 6 & & 10 & 105,6 & 4,33 & 254 & 4,74 \\
\hline
\end{tabular}

\begin{tabular}{|c|c|c|c|c|c|c|}
\hline \multicolumn{7}{|c|}{ Ensaio 2} \\
\hline \multirow{2}{*}{\multicolumn{7}{|c|}{$\begin{array}{l}\text { Água de estudo 2: } \\
\begin{array}{cccc}\text { Cor Aparente }(\mathrm{uH})=132 & \text { Cor verdadeira }(\mathrm{uH})=108 & \text { Turbidez }(\mathrm{uT})=4,50 \\
\mathrm{pH}=6,05 & \text { Temperatura }\left({ }^{\circ} \mathrm{C}\right)=20 & \text { Alcalinidade Total }\left(\mathrm{mg} \mathrm{L}^{-1} \mathrm{CaCO}_{3}\right)=10,58\end{array}\end{array}$}} \\
\hline & & & & & & \\
\hline \multirow[b]{2}{*}{ Frasco } & \multicolumn{3}{|c|}{ Dosagem de produtos químicos } & \multirow[b]{2}{*}{$\begin{array}{c}\text { pH de } \\
\text { Coagulação }\end{array}$} & \multicolumn{2}{|c|}{$\begin{array}{l}\text { Água Filtrada } \\
\text { (coleta } 30 \mathrm{~min} \text { ) }\end{array}$} \\
\hline & $\begin{array}{c}\mathrm{HCl} \\
\left(1 \mathrm{~g} \mathrm{~L}^{-1}\right) \\
(\mathrm{mL})\end{array}$ & $\begin{array}{c}\mathrm{NaOH} \\
\left(4 \mathrm{~g} \mathrm{~L}^{-1}\right) \\
(\mathrm{mL})\end{array}$ & $\begin{array}{c}\text { Cloreto Férrico } \\
\text { comercial líquido } \\
\left(\mathrm{mg} \mathrm{L}^{-1}\right)\end{array}$ & & $\begin{array}{l}\text { Cor } \\
\text { Aparente } \\
\text { (uH) }\end{array}$ & $\begin{array}{l}\text { Turbidez } \\
\text { (uT) }\end{array}$ \\
\hline 1 & 1,5 & & 52,8 & 5,74 & 195 & 4,57 \\
\hline 2 & & & 79,2 & 5,17 & 250 & 5,83 \\
\hline 3 & & 0,5 & 79,2 & 5,40 & 239 & 6,06 \\
\hline 4 & & 1,0 & 79,2 & 5,66 & 235 & 5,28 \\
\hline 5 & & 2,0 & 79,2 & 5,86 & 233 & 5,17 \\
\hline 6 & & 3,0 & 79,2 & 5,96 & 239 & 5,83 \\
\hline 7 & & 4,0 & 79,2 & 6,10 & 239 & 5,13 \\
\hline
\end{tabular}




\begin{tabular}{|c|c|c|c|c|c|c|}
\hline \multicolumn{7}{|c|}{$\begin{array}{ccc}\text { Água de estudo 2: } & \text { Cor Aparente }(\mathrm{uH})=132 & \text { Cor verdadeira }(\mathrm{uH})=108 \text { Turbidez }(\mathrm{uT})=4,60 \\
\mathrm{pH}=6,03 & \text { Temperatura }\left({ }^{\circ} \mathrm{C}\right)=20 & \text { Alcalinidade Total }\left(\mathrm{mg} \mathrm{L}^{-1} \mathrm{CaCO}_{3}\right)=10,58\end{array}$} \\
\hline \multirow[b]{2}{*}{ Frasco } & \multicolumn{3}{|c|}{ Dosagem de produtos químicos } & \multirow[b]{2}{*}{$\begin{array}{c}\text { pH de } \\
\text { Coagulação }\end{array}$} & \multicolumn{2}{|c|}{$\begin{array}{l}\text { Água Filtrada } \\
\text { (coleta } 30 \text { min) }\end{array}$} \\
\hline & $\begin{array}{c}\mathrm{HCl} \\
\left(1 \mathrm{~g} \mathrm{~L}^{-1}\right) \\
(\mathrm{mL})\end{array}$ & $\begin{array}{c}\mathrm{NaOH} \\
\left(4 \mathrm{~g} \mathrm{~L}^{-1}\right) \\
(\mathrm{mL})\end{array}$ & $\begin{array}{l}\text { Cloreto Férrico } \\
\text { comercial } \\
\text { líquido } \\
\left(\mathrm{mg} \mathrm{L}^{-1}\right)\end{array}$ & & $\begin{array}{c}\text { Cor } \\
\text { Aparente } \\
\text { (uH) }\end{array}$ & $\begin{array}{l}\text { Turbidez } \\
\text { (uT) }\end{array}$ \\
\hline 1 & & 11,3 & 105,6 & 4,90 & 46 & 0,89 \\
\hline 2 & & 11,7 & 105,6 & 5,10 & 6 & 0,32 \\
\hline 3 & & 12,5 & 105,6 & 5,43 & 5 & 0,45 \\
\hline 4 & & 13,5 & 105,6 & 5,70 & 5 & 0,34 \\
\hline 5 & & 14,5 & 105,6 & 5,89 & 7 & 0,39 \\
\hline 6 & & 17,0 & 105,6 & 6,32 & 19 & 0,55 \\
\hline
\end{tabular}

\begin{tabular}{|c|c|c|c|c|c|c|}
\hline \multicolumn{7}{|c|}{ Ensaio 4} \\
\hline \multirow{2}{*}{\multicolumn{7}{|c|}{$\begin{array}{ccc}\text { Água de estudo 2: } & \text { Cor Aparente }(\mathrm{uH})=133 & \text { Cor verdadeira }(\mathrm{uH})=106 \quad \text { Turbidez }(\mathrm{uT})=4,54 \\
\mathrm{pH}=6,05 & \text { Temperatura }\left({ }^{\circ} \mathrm{C}\right)=20 & \text { Alcalinidade Total }\left(\mathrm{mg} \mathrm{L}^{-1} \mathrm{CaCO}_{3}\right)=10,58\end{array}$}} \\
\hline & & & & & & \\
\hline \multirow[b]{2}{*}{ Frasco } & \multicolumn{3}{|c|}{ Dosagem de produtos químicos } & \multirow[b]{2}{*}{$\begin{array}{c}\text { pH de } \\
\text { Coagulação }\end{array}$} & \multicolumn{2}{|c|}{$\begin{array}{l}\text { Água Filtrada } \\
\text { (coleta } 30 \text { min) }\end{array}$} \\
\hline & $\begin{array}{c}\mathrm{HCl} \\
\left(1 \mathrm{~g} \mathrm{~L}^{-1}\right) \\
(\mathrm{mL})\end{array}$ & $\begin{array}{c}\mathrm{NaOH} \\
\left(4 \mathrm{~g} \mathrm{~L}^{-1}\right) \\
(\mathrm{mL})\end{array}$ & $\begin{array}{l}\text { Cloreto Férrico } \\
\text { comercial } \\
\text { líquido } \\
\left(\mathrm{mg} \mathrm{L}^{-1}\right)\end{array}$ & & $\begin{array}{c}\text { Cor } \\
\text { Aparente } \\
\text { (uH) }\end{array}$ & $\begin{array}{l}\text { Turbidez } \\
\text { (uT) }\end{array}$ \\
\hline 1 & & 18,0 & 105,6 & 6,40 & 226 & 4,2 \\
\hline 2 & & 18,5 & 105,6 & 6,50 & 313 & 6,56 \\
\hline 3 & & 19,0 & 105,6 & 6,62 & 306 & 6,06 \\
\hline 4 & & 19,5 & 105,6 & 6,71 & 305 & 6,00 \\
\hline 5 & & 20,0 & 105,6 & 6,90 & 302 & 5,56 \\
\hline 6 & & 20,5 & 105,6 & 7,05 & 300 & 5,67 \\
\hline
\end{tabular}




\begin{tabular}{|c|c|c|c|c|c|c|}
\hline \multicolumn{7}{|c|}{ Ensaio 5} \\
\hline \multirow{2}{*}{\multicolumn{7}{|c|}{ 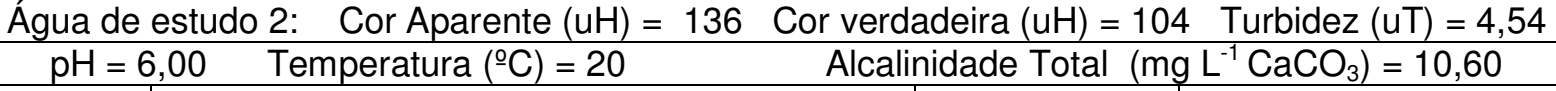 }} \\
\hline & & & & & & \\
\hline \multirow[b]{2}{*}{ Frasco } & \multicolumn{3}{|c|}{ Dosagem de produtos químicos } & \multirow[b]{2}{*}{$\begin{array}{c}\text { pH de } \\
\text { Coagulação }\end{array}$} & \multicolumn{2}{|c|}{$\begin{array}{l}\text { Água Filtrada } \\
\text { (coleta } 30 \text { min) }\end{array}$} \\
\hline & $\begin{array}{c}\mathrm{HCl} \\
\left(1 \mathrm{~g} \mathrm{~L}^{-1}\right) \\
(\mathrm{mL})\end{array}$ & $\begin{array}{c}\mathrm{NaOH} \\
\left(4 \mathrm{~g} \mathrm{~L}^{-1}\right) \\
(\mathrm{mL})\end{array}$ & $\begin{array}{l}\text { Cloreto Férrico } \\
\text { comercial } \\
\text { líquido } \\
\left(\mathrm{mg} \mathrm{L}^{-1}\right)\end{array}$ & & $\begin{array}{c}\text { Cor } \\
\text { Aparente } \\
\text { (uH) }\end{array}$ & $\begin{array}{l}\text { Turbidez } \\
\quad(\text { uT) }\end{array}$ \\
\hline 1 & & 8,0 & 79,2 & 5,00 & 4 & 0,31 \\
\hline 2 & & 9,0 & 79,2 & 5,53 & 1 & 0,30 \\
\hline 3 & & 10,0 & 79,2 & 5,74 & 1 & 0,37 \\
\hline 4 & & 11,0 & 79,2 & 5,98 & 3 & 0,41 \\
\hline 5 & & 12,0 & 79,2 & 6,13 & 4 & 0,51 \\
\hline 6 & & 13,0 & 79,2 & 6,28 & 51 & 1,23 \\
\hline
\end{tabular}

\begin{tabular}{|c|c|c|c|c|c|c|}
\hline \multicolumn{7}{|c|}{ Ensaio 6} \\
\hline \multicolumn{7}{|c|}{ Água de estudo 2: $\quad$ Cor Aparente $(\mathrm{uH})=136 \quad$ Cor verdadeira $(\mathrm{uH})=104 \quad$ Turbidez $(\mathrm{uT})=4,54$} \\
\hline \multicolumn{4}{|c|}{$\mathrm{pH}=6,06 \quad$ Temperatura $\left({ }^{\circ} \mathrm{C}\right)=20 \quad$ Alca } & dade Total $(\mathrm{m}$ & $\left.\mathrm{L}^{-1} \mathrm{CaCO}_{3}\right)$ & $=10,60$ \\
\hline \multirow[b]{2}{*}{ Frasco } & \multicolumn{3}{|c|}{ Dosagem de produtos químicos } & \multirow[b]{2}{*}{$\begin{array}{c}\text { pH de } \\
\text { Coagulação }\end{array}$} & \multicolumn{2}{|c|}{$\begin{array}{l}\text { Água Filtrada } \\
\text { (coleta } 30 \mathrm{~min} \text { ) }\end{array}$} \\
\hline & $\begin{array}{c}\mathrm{HCl} \\
\left(1 \mathrm{~g} \mathrm{~L}^{-1}\right) \\
(\mathrm{mL})\end{array}$ & $\begin{array}{c}\mathrm{NaOH} \\
\left(4 \mathrm{~g} \mathrm{~L}^{-1}\right) \\
(\mathrm{mL})\end{array}$ & $\begin{array}{c}\text { Cloreto Férrico } \\
\text { comercial } \\
\text { líquido } \\
\left(\mathrm{mg} \mathrm{L}^{-1}\right)\end{array}$ & & $\begin{array}{c}\text { Cor } \\
\text { Aparente } \\
\text { (uH) }\end{array}$ & $\begin{array}{c}\text { Turbidez } \\
\text { (uT) }\end{array}$ \\
\hline 1 & & 6,0 & 79,2 & 4,10 & 221 & 3,82 \\
\hline 2 & & 7,0 & 79,2 & 4,40 & 185 & 4,37 \\
\hline 3 & & 7,5 & 79,2 & 4,73 & 43 & 1,41 \\
\hline 4 & & 8,5 & 79,2 & 5,30 & 1 & 0,49 \\
\hline 5 & & 14 & 79,2 & 6,44 & 271 & 6,22 \\
\hline 6 & & 15 & 79,2 & 6,60 & 263 & 5,33 \\
\hline
\end{tabular}




\begin{tabular}{|c|c|c|c|c|c|c|}
\hline \multicolumn{7}{|c|}{ Ensaio 7} \\
\hline \multirow{2}{*}{\multicolumn{7}{|c|}{$\begin{array}{ccc}\text { Água de estudo 2: } & \text { Cor Aparente }(\mathrm{uH})=136 \text { Cor verdadeira }(\mathrm{uH})=104 \quad \text { Turbidez }(\mathrm{uT})=4,54 \\
\mathrm{pH}=6,00 & \text { Temperatura }\left({ }^{\circ} \mathrm{C}\right)=20 & \text { Alcalinidade Total }\left(\mathrm{mg} \mathrm{L}^{-1} \mathrm{CaCO}_{3}\right)=10,60\end{array}$}} \\
\hline & & & & & & \\
\hline \multirow[b]{2}{*}{ Frasco } & \multicolumn{3}{|c|}{ Dosagem de produtos químicos } & \multirow[b]{2}{*}{$\begin{array}{c}\text { pH de } \\
\text { Coagulação }\end{array}$} & \multicolumn{2}{|c|}{$\begin{array}{l}\text { Água Filtrada } \\
\text { (coleta } 30 \text { min) }\end{array}$} \\
\hline & $\begin{array}{c}\mathrm{HCl} \\
\left(1 \mathrm{~g} \mathrm{~L}^{-1}\right) \\
(\mathrm{mL})\end{array}$ & $\begin{array}{c}\mathrm{NaOH} \\
\left(4 \mathrm{~g} \mathrm{~L}^{-1}\right) \\
(\mathrm{mL})\end{array}$ & $\begin{array}{l}\text { Cloreto Férrico } \\
\text { comercial } \\
\text { líquido } \\
\left(\mathrm{mg} \mathrm{L}^{-1}\right)\end{array}$ & & $\begin{array}{c}\text { Cor } \\
\text { Aparente } \\
\text { (uH) }\end{array}$ & $\begin{array}{l}\text { Turbidez } \\
\quad(\text { uT) }\end{array}$ \\
\hline 1 & & 5,0 & 52,8 & 5,44 & 4 & 0,52 \\
\hline 2 & & 6,0 & 52,8 & 5,68 & 5 & 0,54 \\
\hline 3 & & 6,5 & 52,8 & 5,84 & 7 & 0,47 \\
\hline 4 & & 7,0 & 52,8 & 5,96 & 7 & 0,57 \\
\hline 5 & & 7,5 & 52,8 & 6,10 & 12 & 0,72 \\
\hline 6 & & 8,0 & 52,8 & 6,24 & 158 & 3,39 \\
\hline
\end{tabular}

\begin{tabular}{|c|c|c|c|c|c|c|}
\hline \multicolumn{7}{|c|}{ Ensaio 8} \\
\hline \multirow{2}{*}{\multicolumn{7}{|c|}{$\begin{array}{ccc}\text { Água de estudo 2: } & \text { Cor Aparente }(\mathrm{uH})=136 & \text { Cor verdadeira }(\mathrm{uH})=104 \quad \text { Turbidez }(\mathrm{uT})=4,54 \\
\mathrm{pH}=6,00 & \text { Temperatura }\left({ }^{\circ} \mathrm{C}\right)=20 & \text { Alcalinidade Total }\left(\mathrm{mg} \mathrm{L}^{-1} \mathrm{CaCO}_{3}\right)=10,60\end{array}$}} \\
\hline & & & & & & \\
\hline \multirow[b]{2}{*}{ Frasco } & \multicolumn{3}{|c|}{ Dosagem de produtos químicos } & \multirow[b]{2}{*}{$\begin{array}{c}\text { pH de } \\
\text { Coagulação }\end{array}$} & \multicolumn{2}{|c|}{$\begin{array}{l}\text { Água Filtrada } \\
\text { (coleta } 30 \text { min) }\end{array}$} \\
\hline & $\begin{array}{c}\mathrm{HCl} \\
\left(1 \mathrm{~g} \mathrm{~L}^{-1}\right) \\
(\mathrm{mL})\end{array}$ & $\begin{array}{c}\mathrm{NaOH} \\
\left(4 \mathrm{~g} \mathrm{~L}^{-1}\right) \\
(\mathrm{mL})\end{array}$ & $\begin{array}{l}\text { Cloreto Férrico } \\
\text { comercial } \\
\text { líquido } \\
\left(\mathrm{mg} \mathrm{L}^{-1}\right)\end{array}$ & & $\begin{array}{c}\text { Cor } \\
\text { Aparente } \\
\text { (uH) }\end{array}$ & $\begin{array}{l}\text { Turbidez } \\
\text { (uT) }\end{array}$ \\
\hline 1 & & 3,0 & 52,8 & 4,37 & 68 & 2,26 \\
\hline 2 & & 3,5 & 52,8 & 4,56 & 15 & 0,87 \\
\hline 3 & & 4,0 & 52,8 & 4,92 & $<1$ & 0,57 \\
\hline 4 & & 4,5 & 52,8 & 5,32 & 2 & 0,58 \\
\hline 5 & & 8,5 & 52,8 & 6,30 & 240 & 6,18 \\
\hline 6 & & 9,0 & 52,8 & 6,42 & 236 & 5,86 \\
\hline
\end{tabular}




\begin{tabular}{|c|c|c|c|c|c|c|}
\hline \multicolumn{7}{|c|}{ Ensaio 9} \\
\hline \multirow{2}{*}{\multicolumn{7}{|c|}{$\begin{array}{ccc}\text { Água de estudo 2: } & \text { Cor Aparente }(\mathrm{uH})=134 & \text { Cor verdadeira }(\mathrm{uH})=104 \quad \text { Turbidez }(\mathrm{uT})=4,38 \\
\mathrm{pH}=6,02 & \text { Temperatura }\left({ }^{\circ} \mathrm{C}\right)=20 & \text { Alcalinidade Total }\left(\mathrm{mg} \mathrm{L}^{-1} \mathrm{CaCO}_{3}\right)=10,58\end{array}$}} \\
\hline & & & & & & \\
\hline \multirow[b]{2}{*}{ Frasco } & \multicolumn{3}{|c|}{ Dosagem de produtos químicos } & \multirow[b]{2}{*}{$\begin{array}{c}\text { pH de } \\
\text { Coagulação }\end{array}$} & \multicolumn{2}{|c|}{$\begin{array}{l}\text { Água Filtrada } \\
\text { (coleta } 30 \text { min) }\end{array}$} \\
\hline & $\begin{array}{c}\mathrm{HCl} \\
\left(1 \mathrm{~g} \mathrm{~L}^{-1}\right) \\
(\mathrm{mL})\end{array}$ & $\begin{array}{c}\mathrm{NaOH} \\
\left(4 \mathrm{~g} \mathrm{~L}^{-1}\right) \\
(\mathrm{mL})\end{array}$ & $\begin{array}{l}\text { Cloreto Férrico } \\
\text { comercial } \\
\text { líquido } \\
\left(\mathrm{mg} \mathrm{L}^{-1}\right)\end{array}$ & & $\begin{array}{c}\text { Cor } \\
\text { Aparente } \\
\text { (uH) }\end{array}$ & $\begin{array}{l}\text { Turbidez } \\
\text { (uT) }\end{array}$ \\
\hline 1 & & 3,8 & 52,8 & 4,81 & $<1$ & 0,34 \\
\hline 2 & & 4,3 & 52,8 & 5,17 & 1 & 0,36 \\
\hline 3 & & & 26,4 & 4,93 & 13 & 0,59 \\
\hline 4 & & 1,0 & 26,4 & 5,25 & 201 & 5,63 \\
\hline 5 & & 2,0 & 26,4 & 5,30 & 196 & 5,36 \\
\hline 6 & & 3,0 & 26,4 & 5,43 & 201 & 5,30 \\
\hline
\end{tabular}

\begin{tabular}{|c|c|c|c|c|c|c|}
\hline \multicolumn{7}{|c|}{ Ensaio 10} \\
\hline \multirow{2}{*}{\multicolumn{7}{|c|}{$\begin{array}{ccc}\text { Água de estudo 2: } & \text { Cor Aparente }(\mathrm{uH})=134 & \text { Cor verdadeira }(\mathrm{uH})=104 \text { Turbidez }(\mathrm{uT})=4,38 \\
\mathrm{pH}=6,04 & \text { Temperatura }\left({ }^{\circ} \mathrm{C}\right)=20 & \text { Alcalinidade Total }\left(\mathrm{mg} \mathrm{L}^{-1} \mathrm{CaCO}_{3}\right)=10,60\end{array}$}} \\
\hline & & & & & & \\
\hline \multirow[b]{2}{*}{ Frasco } & \multicolumn{3}{|c|}{ Dosagem de produtos químicos } & \multirow[b]{2}{*}{$\begin{array}{l}\text { pH de } \\
\text { Coagulação }\end{array}$} & \multicolumn{2}{|c|}{$\begin{array}{l}\text { Água Filtrada } \\
\text { (coleta } 30 \text { min) }\end{array}$} \\
\hline & $\begin{array}{c}\mathrm{HCl} \\
\left(1 \mathrm{~g} \mathrm{~L}^{-1}\right) \\
(\mathrm{mL})\end{array}$ & $\begin{array}{c}\mathrm{NaOH} \\
\left(1 \mathrm{~g} \mathrm{~L}^{-1}\right) \\
(\mathrm{mL})\end{array}$ & $\begin{array}{l}\text { Cloreto } \\
\text { Férrico } \\
\text { comercial } \\
\text { líquido } \\
\left(\mathrm{mg} \mathrm{L}^{-1}\right)\end{array}$ & & $\begin{array}{c}\text { Cor } \\
\text { Aparente } \\
\text { (uH) }\end{array}$ & $\begin{array}{l}\text { Turbidez } \\
\text { (uT) }\end{array}$ \\
\hline 1 & & 4,0 & 26,4 & 5,60 & 211 & 5,29 \\
\hline 2 & & 5,0 & 26,4 & 5,74 & 223 & 4,70 \\
\hline 3 & & 6,0 & 26,4 & 5,85 & 193 & 4,40 \\
\hline 4 & & 7,0 & 26,4 & 5,98 & 190 & 4,18 \\
\hline
\end{tabular}




\begin{tabular}{|c|c|c|c|c|c|c|}
\hline \multicolumn{7}{|c|}{ Ensaio 11} \\
\hline \multicolumn{7}{|c|}{ Água de estudo 2: $\quad$ Cor Aparente $(\mathrm{uH})=$} \\
\hline \multicolumn{7}{|c|}{$\mathrm{pH}=6,02 \quad$ Temperatura $\left({ }^{\circ} \mathrm{C}\right)=20$} \\
\hline \multirow[b]{2}{*}{ Frasco } & \multicolumn{3}{|c|}{ Dosagem de produtos químicos } & \multirow[b]{2}{*}{$\begin{array}{c}\mathrm{pH} \text { de } \\
\text { Coagulação }\end{array}$} & \multicolumn{2}{|c|}{$\begin{array}{l}\text { Água Filtrada } \\
\text { (coleta } 30 \mathrm{~min} \text { ) }\end{array}$} \\
\hline & $\begin{array}{c}\mathrm{HCl} \\
\left(1 \mathrm{~g} \mathrm{~L}^{-1}\right) \\
(\mathrm{mL})\end{array}$ & $\begin{array}{c}\mathrm{NaOH} \\
\left(4 \mathrm{~g} \mathrm{~L}^{-1}\right) \\
(\mathrm{mL})\end{array}$ & $\begin{array}{l}\text { Cloreto Férrico } \\
\text { comercial } \\
\text { líquido } \\
\left(\mathrm{mg} \mathrm{L}^{-1}\right)\end{array}$ & & $\begin{array}{c}\text { Cor } \\
\text { Aparente } \\
\text { (uH) }\end{array}$ & $\begin{array}{l}\text { Turbidez } \\
\text { (uT) }\end{array}$ \\
\hline 1 & 1,0 & & 26,4 & 4,80 & 28 & 0,90 \\
\hline 2 & 2,5 & & 26,4 & 4,75 & 10 & 0,54 \\
\hline 3 & 3,5 & & 26,4 & 4,52 & 2 & 0,38 \\
\hline 4 & 4,5 & & 26,4 & 4,44 & 2 & 0,38 \\
\hline 5 & 5,5 & & 26,4 & 4,30 & 2 & 0,38 \\
\hline 6 & 6,5 & & 26,4 & 4,14 & 1 & 0,39 \\
\hline
\end{tabular}

\begin{tabular}{|c|c|c|c|c|c|c|}
\hline \multicolumn{7}{|c|}{ Ensaio 12} \\
\hline \multirow{2}{*}{\multicolumn{7}{|c|}{$\begin{array}{cccc}\text { Água de estudo 2: } & \text { Cor Aparente }(\mathrm{uH})=134 & \text { Cor verdadeira }(\mathrm{uH})=104 & \text { Turbidez }(\mathrm{uT})=4,38 \\
\mathrm{pH}=6,02 & \text { Temperatura }\left({ }^{\circ} \mathrm{C}\right)=20 & \text { Alcalinidade Total }\left(\mathrm{mg} \mathrm{L}^{-1} \mathrm{CaCO}_{3}\right)=10,58\end{array}$}} \\
\hline & & & & & & \\
\hline \multirow[b]{2}{*}{ Frasco } & \multicolumn{3}{|c|}{ Dosagem de produtos químicos } & \multirow[b]{2}{*}{$\begin{array}{l}\text { pH de } \\
\text { Coagulação }\end{array}$} & \multicolumn{2}{|c|}{$\begin{array}{l}\text { Água Filtrada } \\
\text { (coleta } 30 \mathrm{~min} \text { ) }\end{array}$} \\
\hline & $\begin{array}{c}\mathrm{HCl} \\
\left(1 \mathrm{~g} \mathrm{~L}^{-1}\right) \\
(\mathrm{mL})\end{array}$ & $\begin{array}{c}\mathrm{NaOH} \\
\left(4 \mathrm{~g} \mathrm{~L}^{-1}\right) \\
(\mathrm{mL})\end{array}$ & $\begin{array}{l}\text { Cloreto Férrico } \\
\text { comercial } \\
\text { líquido } \\
\left(\mathrm{mg} \mathrm{L}^{-1}\right)\end{array}$ & & $\begin{array}{c}\text { Cor } \\
\text { Aparente } \\
\text { (uH) }\end{array}$ & $\begin{array}{c}\text { Turbidez } \\
\text { (uT) }\end{array}$ \\
\hline 1 & 7,0 & & 26,4 & 4,13 & $<1$ & 0,43 \\
\hline 2 & 7,5 & & 26,4 & 4,04 & $<1$ & 0,42 \\
\hline 3 & 8,0 & & 26,4 & 3,94 & $<1$ & 0,47 \\
\hline 4 & 8,5 & & 26,4 & 3,88 & $<1$ & 0,35 \\
\hline 5 & 9,0 & & 26,4 & 3,80 & $<1$ & 0,34 \\
\hline 6 & & & 26,4 & 5,90 & 138 & 3,18 \\
\hline
\end{tabular}




\begin{tabular}{|c|c|c|c|c|c|c|}
\hline \multicolumn{7}{|c|}{ Ensaio 13} \\
\hline \multicolumn{7}{|c|}{134 Cor verdadeira $(\mathrm{uH})=104$ Turbidez $(\mathrm{uT})=4,38$} \\
\hline \multicolumn{7}{|c|}{$\mathrm{pH}=6,03 \quad$ Temperatura $\left({ }^{\circ} \mathrm{C}\right)=20$} \\
\hline \multirow[b]{2}{*}{ Frasco } & \multicolumn{3}{|c|}{ Dosagem de produtos químicos } & \multirow[b]{2}{*}{$\begin{array}{c}\mathrm{pH} \text { de } \\
\text { Coagulação }\end{array}$} & \multicolumn{2}{|c|}{$\begin{array}{l}\text { Água Filtrada } \\
\text { (coleta } 30 \mathrm{~min} \text { ) }\end{array}$} \\
\hline & $\begin{array}{c}\mathrm{HCl} \\
\left(1 \mathrm{~g} \mathrm{~L}^{-1}\right) \\
(\mathrm{mL})\end{array}$ & $\begin{array}{c}\mathrm{NaOH} \\
\left(4 \mathrm{~g} \mathrm{~L}^{-1}\right) \\
(\mathrm{mL})\end{array}$ & $\begin{array}{l}\text { Cloreto Férrico } \\
\text { comercial } \\
\text { líquido } \\
\left(\mathrm{mg} \mathrm{L}^{-1}\right)\end{array}$ & & $\begin{array}{c}\text { Cor } \\
\text { Aparente } \\
\text { (uH) }\end{array}$ & $\begin{array}{l}\text { Turbidez } \\
\text { (uT) }\end{array}$ \\
\hline 1 & 13 & & 26,4 & 3,75 & $<1$ & 0,47 \\
\hline 2 & 15 & & 26,4 & 3,67 & $<1$ & 0,46 \\
\hline 3 & 5,0 & & 13,2 & 5.18 & 143 & 2,98 \\
\hline 4 & 10,0 & & 13,2 & 4,48 & 134 & 3,14 \\
\hline 5 & 15,0 & & 13,2 & 4,16 & 132 & 2,88 \\
\hline 6 & 20,0 & & 13,2 & 4,04 & 65 & 2,06 \\
\hline
\end{tabular}

\begin{tabular}{|c|c|c|c|c|c|c|}
\hline \multicolumn{7}{|c|}{ Ensaio 14} \\
\hline \multirow{2}{*}{\multicolumn{7}{|c|}{$\begin{array}{ccc}\text { Água de estudo 2: } & \text { Cor Aparente }(\mathrm{uH})=134 & \text { Cor verdadeira }(\mathrm{uH})=104 \text { Turbidez }(\mathrm{uT})=4,38 \\
\mathrm{pH}=6,10 \quad \text { Temperatura }\left({ }^{\circ} \mathrm{C}\right)=20 & \text { Alcalinidade Total }\left(\mathrm{mg} \mathrm{L}^{-1} \mathrm{CaCO}_{3}\right)=10,58\end{array}$}} \\
\hline & & & & & & \\
\hline \multirow[b]{2}{*}{ Frasco } & \multicolumn{3}{|c|}{ Dosagem de produtos químicos } & \multirow[b]{2}{*}{$\begin{array}{c}\text { pH de } \\
\text { Coagulação }\end{array}$} & \multicolumn{2}{|c|}{$\begin{array}{l}\text { Água Filtrada } \\
\text { (coleta } 30 \text { min) }\end{array}$} \\
\hline & $\begin{array}{c}\mathrm{HCl} \\
\left(1 \mathrm{~g} \mathrm{~L}^{-1}\right) \\
(\mathrm{mL})\end{array}$ & $\begin{array}{c}\mathrm{NaOH} \\
\left(4 \mathrm{~g} \mathrm{~L}^{-1}\right) \\
(\mathrm{mL})\end{array}$ & $\begin{array}{c}\text { Cloreto Férrico } \\
\text { comercial } \\
\text { líquido } \\
\left(\mathrm{mg} \mathrm{L}^{-1}\right)\end{array}$ & & $\begin{array}{c}\text { Cor } \\
\text { Aparente } \\
\text { (uH) }\end{array}$ & $\begin{array}{l}\text { Turbidez } \\
\text { (uT) }\end{array}$ \\
\hline 1 & 10 & & 26,4 & 4,13 & $<1$ & 0,60 \\
\hline 2 & 15 & & 26,4 & 3,95 & $<1$ & 0,36 \\
\hline 3 & 20 & & 26,4 & 3,80 & $<1$ & 0,42 \\
\hline 4 & 25 & & 26,4 & 3,70 & $<1$ & 0,39 \\
\hline 5 & 30 & & 26,4 & 3,60 & 2 & 0,38 \\
\hline 6 & 35 & & 26,4 & 3,52 & 2 & 0,39 \\
\hline
\end{tabular}




\begin{tabular}{|c|c|c|c|c|c|c|}
\hline \multicolumn{7}{|c|}{ Ensaio 15} \\
\hline \multirow{2}{*}{\multicolumn{7}{|c|}{$\begin{array}{ccc}\text { Água de estudo 2: } & \text { Cor Aparente }(\mathrm{uH})=134 & \text { Cor verdadeira }(\mathrm{uH})=104 \quad \text { Turbidez }(\mathrm{uT})=4,38 \\
\mathrm{pH}=6,08 & \text { Temperatura }\left({ }^{\circ} \mathrm{C}\right)=20 & \text { Alcalinidade Total }\left(\mathrm{mg} \mathrm{L}^{-1} \mathrm{CaCO}_{3}\right)=10,58 \\
\end{array}$}} \\
\hline & & & & & & \\
\hline \multirow[b]{2}{*}{ Frasco } & \multicolumn{3}{|c|}{ Dosagem de produtos químicos } & \multirow[b]{2}{*}{$\begin{array}{c}\text { pH de } \\
\text { Coagulação }\end{array}$} & \multicolumn{2}{|c|}{$\begin{array}{l}\text { Água Filtrada } \\
\text { (coleta } 30 \text { min) }\end{array}$} \\
\hline & $\begin{array}{c}\mathrm{HCl} \\
\left(1 \mathrm{~g} \mathrm{~L}^{-1}\right) \\
(\mathrm{mL})\end{array}$ & $\begin{array}{c}\mathrm{NaOH} \\
\left(4 \mathrm{~g} \mathrm{~L}^{-1}\right) \\
(\mathrm{mL})\end{array}$ & $\begin{array}{l}\text { Cloreto Férrico } \\
\text { comercial } \\
\text { líquido } \\
\left(\mathrm{mg} \mathrm{L}^{-1}\right)\end{array}$ & & $\begin{array}{c}\text { Cor } \\
\text { Aparente } \\
\text { (uH) }\end{array}$ & $\begin{array}{l}\text { Turbidez } \\
\text { (uT) }\end{array}$ \\
\hline 1 & 40 & & 26,4 & 3,43 & 1 & 0,36 \\
\hline 2 & 25 & & 13,2 & 3,84 & 123 & 3,32 \\
\hline 3 & 30 & & 13,2 & 3,66 & 63 & 2,21 \\
\hline 4 & 35 & & 13,2 & 3,61 & 56 & 2,92 \\
\hline 5 & 40 & & 13,2 & 3,55 & 101 & 3,25 \\
\hline 6 & & & 52,8 & 4,00 & 201 & 3,30 \\
\hline
\end{tabular}

\begin{tabular}{|c|c|c|c|c|c|c|}
\hline \multicolumn{7}{|c|}{ Ensaio 16} \\
\hline \multirow{2}{*}{\multicolumn{7}{|c|}{$\begin{array}{cccc}\text { Água de estudo 2: } & \text { Cor Aparente }(\mathrm{uH})=130 & \text { Cor verdadeira }(\mathrm{uH})=104 & \text { Turbidez }(\mathrm{uT})=4,40 \\
\mathrm{pH}=6,00 & \text { Temperatura }\left({ }^{\circ} \mathrm{C}\right)=20 & \text { Alcalinidade Total }\left(\mathrm{mg} \mathrm{L}^{-1} \mathrm{CaCO}_{3}\right)=10,58\end{array}$}} \\
\hline & & & & & & \\
\hline \multirow[b]{2}{*}{ Frasco } & \multicolumn{3}{|c|}{ Dosagem de produtos químicos } & \multirow[b]{2}{*}{$\begin{array}{c}\text { pH de } \\
\text { Coagulação }\end{array}$} & \multicolumn{2}{|c|}{$\begin{array}{l}\text { Água Filtrada } \\
\text { (coleta } 30 \mathrm{~min} \text { ) }\end{array}$} \\
\hline & $\begin{array}{c}\mathrm{HCl} \\
\left(1 \mathrm{~g} \mathrm{~L}^{-1}\right) \\
(\mathrm{mL})\end{array}$ & $\begin{array}{c}\mathrm{NaOH} \\
\left(4 \mathrm{~g} \mathrm{~L}^{-1}\right) \\
(\mathrm{mL})\end{array}$ & $\begin{array}{c}\text { Cloreto Férrico } \\
\text { comercial } \\
\text { líquido } \\
\left(\mathrm{mg} \mathrm{L}^{-1}\right)\end{array}$ & & $\begin{array}{c}\text { Cor } \\
\text { Aparente } \\
\text { (uH) }\end{array}$ & $\begin{array}{l}\text { Turbidez } \\
\text { (uT) }\end{array}$ \\
\hline 1 & 2,5 & & 52,8 & 3,90 & 202 & 3,23 \\
\hline 2 & 5,0 & & 52,8 & 3,80 & 167 & 3,92 \\
\hline 3 & & & 132 & 3,60 & 235 & 2,90 \\
\hline 4 & & 11,0 & 132 & 3,72 & 285 & 2,70 \\
\hline
\end{tabular}


Ensaio 17

Água de estudo 2: Cor Aparente $(\mathrm{uH})=136$ Cor verdadeira $(\mathrm{uH})=104 \quad$ Turbidez $(\mathrm{uT})=4,32$ $\mathrm{pH}=6,02 \quad$ Temperatura $\left({ }^{\circ} \mathrm{C}\right)=20 \quad$ Alcalinidade Total $\left(\mathrm{mg} \mathrm{L}^{-1} \mathrm{CaCO}_{3}\right)=10,60$

\begin{tabular}{|c|c|c|c|c|c|c|}
\hline \multirow[b]{2}{*}{ Frasco } & \multicolumn{3}{|c|}{ Dosagem de produtos químicos } & \multirow{2}{*}{$\begin{array}{c}\text { pH de } \\
\text { Coagulação }\end{array}$} & \multicolumn{2}{|c|}{$\begin{array}{l}\text { Água Filtrada } \\
\text { (coleta } 30 \text { min) }\end{array}$} \\
\hline & $\begin{array}{c}\mathrm{HCl} \\
\left(1 \mathrm{~g} \mathrm{~L}^{-1}\right) \\
(\mathrm{mL})\end{array}$ & $\begin{array}{c}\mathrm{NaOH} \\
\left(4 \mathrm{~g} \mathrm{~L}^{-1}\right) \\
(\mathrm{mL})\end{array}$ & $\begin{array}{l}\text { Cloreto Férrico } \\
\text { comercial } \\
\text { líquido } \\
\left(\mathrm{mg} \mathrm{L}^{-1}\right)\end{array}$ & & $\begin{array}{c}\text { Cor } \\
\text { Aparente } \\
\text { (uH) }\end{array}$ & $\begin{array}{c}\text { Turbidez } \\
\text { (uT) }\end{array}$ \\
\hline 1 & & 12,0 & 132 & 3,80 & 283 & 2,80 \\
\hline 2 & & 13,0 & 132 & 3,95 & 303 & 3,03 \\
\hline 3 & & 14,0 & 132 & 4,25 & 220 & 2,89 \\
\hline 4 & & 15,0 & 132 & 4,47 & 185 & 1,90 \\
\hline 5 & & 16,0 & 132 & 4,85 & 16 & 0,64 \\
\hline 6 & & 17,5 & 132 & 5,02 & 5 & 0,45 \\
\hline
\end{tabular}

Ensaio 18

Água de estudo 2: $\quad$ Cor Aparente $(\mathrm{uH})=136$ Cor verdadeira $(\mathrm{uH})=104 \quad$ Turbidez $(\mathrm{uT})=4,36$ $\mathrm{pH}=6,02 \quad$ Temperatura $\left({ }^{\circ} \mathrm{C}\right)=20$ Alcalinidade Total $\left(\mathrm{mg} \mathrm{L}^{-1} \mathrm{CaCO}_{3}\right)=10,58$

\begin{tabular}{|c|c|c|c|c|c|c|}
\hline \multirow[b]{2}{*}{ Frasco } & \multicolumn{3}{|c|}{ Dosagem de produtos químicos } & \multirow[b]{2}{*}{$\begin{array}{c}\text { pH de } \\
\text { Coagulação }\end{array}$} & \multicolumn{2}{|c|}{$\begin{array}{l}\text { Água Filtrada } \\
\text { (coleta } 30 \mathrm{~min} \text { ) }\end{array}$} \\
\hline & $\begin{array}{c}\mathrm{HCl} \\
\left(1 \mathrm{~g} \mathrm{~L}^{-1}\right) \\
(\mathrm{mL})\end{array}$ & $\begin{array}{c}\mathrm{NaOH} \\
\left(4 \mathrm{~g} \mathrm{~L}^{-1}\right) \\
(\mathrm{mL})\end{array}$ & $\begin{array}{c}\text { Cloreto Férrico } \\
\text { comercial } \\
\text { líquido } \\
\left(\mathrm{mg} \mathrm{L}^{-1}\right)\end{array}$ & & $\begin{array}{c}\text { Cor } \\
\text { Aparente } \\
\text { (uH) }\end{array}$ & $\begin{array}{c}\text { Turbidez } \\
\text { (uT) }\end{array}$ \\
\hline 1 & & 18,5 & 132 & 5,26 & 2 & 0,33 \\
\hline 2 & & 19,5 & 132 & 5,55 & 7 & 0,38 \\
\hline 3 & & 21 & 132 & 5,93 & $<1$ & 0,39 \\
\hline 4 & & 23 & 132 & 6,23 & 8 & 0,37 \\
\hline 5 & & 25 & 132 & 6,50 & 7 & 0,55 \\
\hline 6 & & 27 & 132 & 6,72 & 306 & 5,00 \\
\hline 7 & & 29 & 132 & 6,93 & 293 & 4,23 \\
\hline 8 & & 31 & 132 & 7,10 & 258 & 3,34 \\
\hline
\end{tabular}


B.3 - Tabelas referentes aos ensaios de coagulação da água de estudo 3, empregandose cloreto férrico como coagulante

\begin{tabular}{|c|c|c|c|c|c|c|}
\hline \multicolumn{7}{|c|}{ Ensaio 1} \\
\hline \multicolumn{3}{|c|}{$\begin{array}{l}\text { Água de estudo 3: } \\
\text { Turbidez }(\mathrm{uT})=4,90\end{array}$} & $\begin{array}{r}\text { Aparente }(\mathrm{uH})=1 \\
\text { pH extrato }=5,5\end{array}$ & \multicolumn{3}{|c|}{$\begin{array}{l}\text { Cor verdadeira }(\mathrm{uH})=108 \\
\text { pH água de estudo sem } \mathrm{HCl}=6,40\end{array}$} \\
\hline \multicolumn{2}{|c|}{$\mathrm{pH}=6,03$} & \multicolumn{2}{|c|}{ Temperatura $\left({ }^{\circ} \mathrm{C}\right)=20$} & linidade Total & $\mathrm{g} \mathrm{L}^{-1} \mathrm{CaCO}$ & $=9,0$ \\
\hline \multirow[b]{2}{*}{ Frasco } & \multicolumn{3}{|c|}{ Dosagem de produtos químicos } & \multirow{2}{*}{$\begin{array}{c}\text { pH de } \\
\text { Coagulação }\end{array}$} & \multicolumn{2}{|c|}{$\begin{array}{l}\text { Água Filtrada } \\
\text { (coleta } 30 \text { min) }\end{array}$} \\
\hline & $\begin{array}{c}\mathrm{HCl} \\
\left(\underset{(\mathrm{mL})}{\left.\mathrm{g} \mathrm{L}^{-1}\right)}\right.\end{array}$ & $\begin{array}{c}\mathrm{NaOH} \\
\left(4 \mathrm{~g} \mathrm{~L}^{-1}\right) \\
(\mathrm{mL})\end{array}$ & $\begin{array}{c}\text { Cloreto Férrico } \\
\text { comercial líquido } \\
\left(\mathrm{mg} \mathrm{L}^{-1}\right)\end{array}$ & & $\begin{array}{c}\text { Cor } \\
\text { Aparente } \\
\text { (uH) }\end{array}$ & $\begin{array}{c}\text { Turbidez } \\
\text { (uT) }\end{array}$ \\
\hline 1 & & 3,0 & 20 & 6,10 & 193 & 4,46 \\
\hline 2 & & 3,5 & 20 & 6,18 & 195 & 4,57 \\
\hline 3 & & 4,0 & 20 & 6,28 & 194 & 4,47 \\
\hline 4 & & 5,5 & 20 & 6,55 & 193 & 4,41 \\
\hline 5 & & & 20 & 5,92 & 195 & 4,54 \\
\hline 6 & & 2,0 & 20 & 6,00 & 196 & 4,62 \\
\hline
\end{tabular}

\begin{tabular}{|c|c|c|c|c|c|c|}
\hline \multicolumn{7}{|c|}{ Ensaio 2} \\
\hline \multicolumn{7}{|c|}{ Água de estudo 3: $\quad$ Cor Aparente $(\mathrm{uH})=151 \quad$ Cor verdadeira $(\mathrm{uH})=108$} \\
\hline \multicolumn{2}{|c|}{$\mathrm{pH}=6,00 \quad \mathrm{~T}$} & atura $\left({ }^{\circ} \mathrm{C}\right)$ & $=20$ & \multirow{2}{*}{\multicolumn{3}{|c|}{\begin{tabular}{c|c}
\multicolumn{2}{|c|}{ Alcalinidade Total $\left(\mathrm{mg} \mathrm{L}^{-1} \mathrm{CaCO}_{3}\right)=9,0$} \\
$\begin{array}{c}\text { Água Filtrada } \\
\text { (coleta 30 min) }\end{array}$
\end{tabular}}} \\
\hline \multirow[b]{2}{*}{ Frasco } & \multicolumn{3}{|c|}{ Dosagem de produtos químicos } & & & \\
\hline & $\begin{array}{c}\mathrm{HCl} \\
\left(1 \mathrm{~g} \mathrm{~L}^{-1}\right)\end{array}$ & $\begin{array}{l}\mathrm{NaOH} \\
\left(4 \mathrm{~g} \mathrm{~L}^{-1}\right) \\
(\mathrm{mL})\end{array}$ & $\begin{array}{l}\text { Cloreto Férrico } \\
\text { comercial } \\
\text { líquido } \\
\left(\mathrm{mg} \mathrm{L}^{-1}\right)\end{array}$ & $\begin{array}{c}\text { pH de } \\
\text { Coagulação }\end{array}$ & $\begin{array}{l}\text { Cor } \\
\text { Aparente } \\
\text { (uH) }\end{array}$ & $\begin{array}{l}\text { Turbidez } \\
\text { (uT) }\end{array}$ \\
\hline 1 & 1,5 & & 20 & 5,74 & 195 & $\begin{array}{c}] \\
4,57\end{array}$ \\
\hline 2 & & & 30 & 5,17 & 250 & 5,83 \\
\hline 3 & & 0,5 & 30 & 5,40 & 239 & 6,06 \\
\hline 4 & & 1,0 & 30 & 5,66 & 235 & 5,28 \\
\hline 5 & & 2,0 & 30 & 5,86 & 233 & 5,17 \\
\hline 6 & & 3,0 & 30 & 5,96 & 239 & 5,83 \\
\hline
\end{tabular}




\begin{tabular}{|c|c|c|c|c|c|c|}
\hline \multicolumn{7}{|c|}{$\begin{array}{ll} & \text { Ensaio } 3 \\
\end{array}$} \\
\hline \multirow{2}{*}{\multicolumn{4}{|c|}{$\begin{array}{ccc}\text { Água de estudo 3: } & \text { Cor Aparente }(\mathrm{uH})=151 & \text { Cor ver } \\
\mathrm{pH}=6,03 & \text { Temperatura }\left({ }^{\circ} \mathrm{C}\right)=20 & \text { Al }\end{array}$}} & \multirow{2}{*}{\multicolumn{3}{|c|}{$\frac{\text { erdadeira }(\mathrm{uH})=108 \text { Turbidez }(\mathrm{uT})=4,90}{\text { Alcalinidade Total }\left(\mathrm{mg} \mathrm{L}^{-1} \mathrm{CaCO}_{3}\right)=9,0}$}} \\
\hline & & & & & & \\
\hline \multirow[t]{2}{*}{+2} & \multicolumn{3}{|c|}{ Dosagem de produtos químicos } & \multirow[b]{2}{*}{$\begin{array}{c}\text { pH de } \\
\text { Coagulação }\end{array}$} & \multicolumn{2}{|c|}{$\begin{array}{l}\text { Água Filtrada } \\
\text { (coleta } 30 \text { min) }\end{array}$} \\
\hline & $\begin{array}{c}\mathrm{HCl} \\
\left(\underset{(\mathrm{mL})}{\left.\mathrm{g} \mathrm{L}^{-1}\right)}\right)\end{array}$ & $\begin{array}{c}\mathrm{NaOH} \\
\left(4 \mathrm{~g} \mathrm{~L}^{-1}\right) \\
(\mathrm{mL})\end{array}$ & $\begin{array}{c}\text { Cloreto Férrico } \\
\text { comercial } \\
\text { líquido } \\
\left(\mathrm{mg} \mathrm{L}^{-1}\right)\end{array}$ & & $\begin{array}{l}\text { Cor } \\
\text { Aparente } \\
\text { (uH) }\end{array}$ & $\begin{array}{l}\text { Turbidez } \\
\text { (uT) }\end{array}$ \\
\hline 1 & 2,0 & & 30 & 5,24 & 245 & 6,07 \\
\hline 2 & 5,0 & & 30 & 5,00 & 247 & 6,26 \\
\hline 3 & 7,5 & & 30 & 4,63 & 170 & 4,39 \\
\hline 4 & 10,0 & & 30 & 4,42 & 156 & 3,74 \\
\hline 5 & 12,5 & & 30 & 4,20 & 24 & 0,90 \\
\hline 6 & 15,0 & & 30 & 4,05 & 19 & 0,71 \\
\hline
\end{tabular}

\begin{tabular}{|c|c|c|c|c|c|c|}
\hline \multicolumn{7}{|c|}{ Ensaio 4} \\
\hline \multicolumn{7}{|c|}{ Água de estudo 3: $\quad$ Cor Aparente $(\mathrm{uH})=150 \quad$ Cor verdadeira $(\mathrm{uH})=106 \quad$ Turbidez $(\mathrm{uT})=4,94$} \\
\hline \multicolumn{7}{|c|}{$\mathrm{pH}=6,06 \quad$ Temperatura $\left({ }^{\circ} \mathrm{C}\right)=21$} \\
\hline \multirow[b]{2}{*}{ Frasco } & \multicolumn{3}{|c|}{ Dosagem de produtos químicos } & \multirow[b]{2}{*}{$\begin{array}{c}\text { pH de } \\
\text { Coagulação }\end{array}$} & \multicolumn{2}{|c|}{$\begin{array}{l}\text { Água Filtrada } \\
\text { (coleta } 30 \mathrm{~min} \text { ) }\end{array}$} \\
\hline & $\begin{array}{c}\mathrm{HCl} \\
\left(1 \mathrm{~g} \mathrm{~L}^{-1}\right) \\
(\mathrm{mL})\end{array}$ & $\begin{array}{c}\mathrm{NaOH} \\
\left(4 \mathrm{~g} \mathrm{~L}^{-1}\right) \\
(\mathrm{mL})\end{array}$ & $\begin{array}{l}\text { Cloreto Férrico } \\
\text { comercial } \\
\text { líquido } \\
\left(\mathrm{mg} \mathrm{L}^{-1}\right)\end{array}$ & & $\begin{array}{c}\text { Cor } \\
\text { Aparente } \\
\text { (uH) }\end{array}$ & $\begin{array}{c}\text { Turbidez } \\
\text { (uT) }\end{array}$ \\
\hline 1 & & 4,5 & 60 & 5,30 & 4 & 0,55 \\
\hline 2 & & 5,0 & 60 & 5,40 & 10 & 0,67 \\
\hline 3 & & 5,5 & 60 & 5,53 & 11 & 0,65 \\
\hline 4 & & 6,0 & 60 & 5,73 & 30 & 1,05 \\
\hline 5 & & 6,5 & 60 & 5,87 & 120 & 2,69 \\
\hline 6 & & 7,0 & 60 & 5,94 & 159 & 3,60 \\
\hline
\end{tabular}




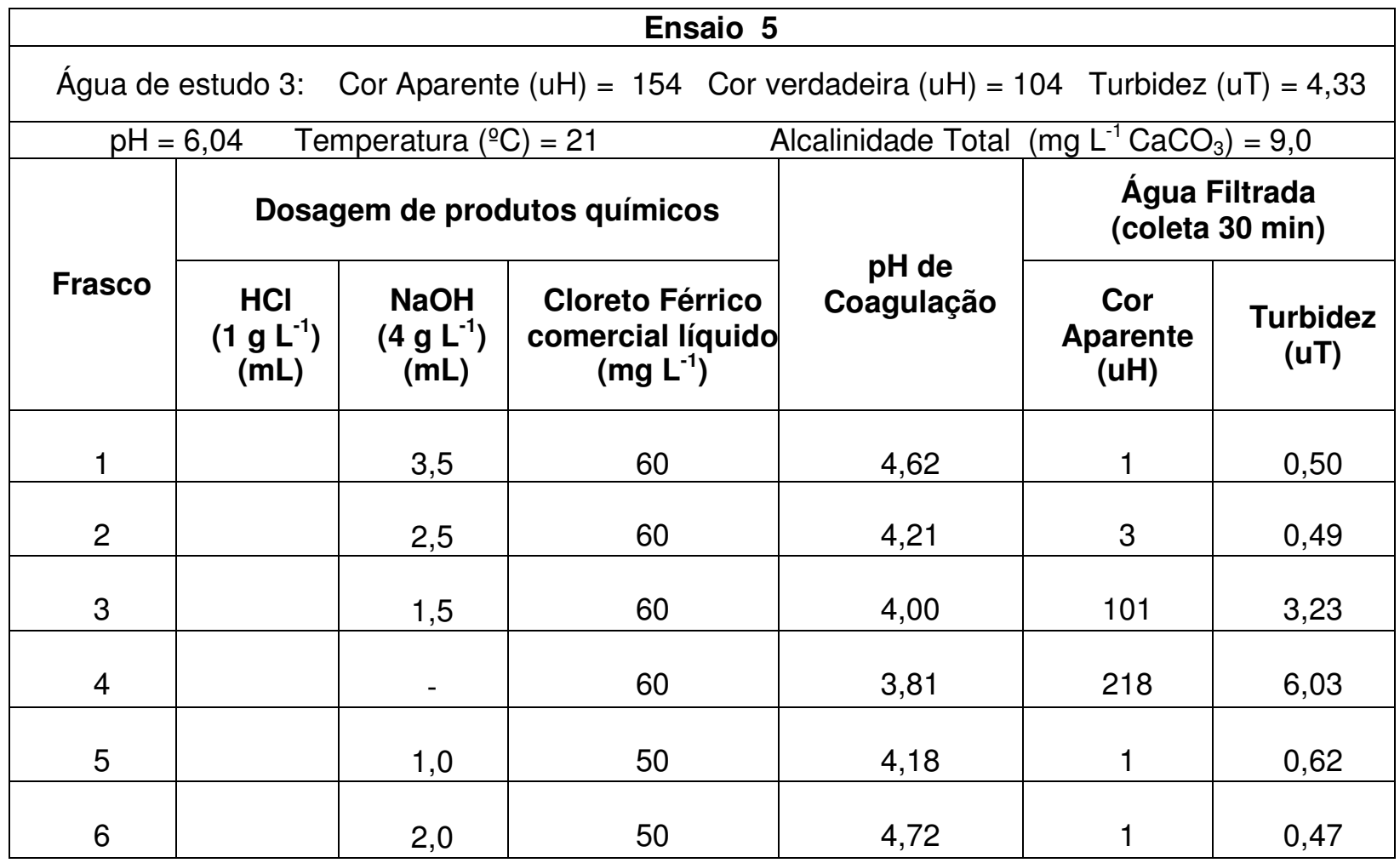

\begin{tabular}{|c|c|c|c|c|c|c|}
\hline \multicolumn{7}{|c|}{ Ensaio 6} \\
\hline \multirow{2}{*}{\multicolumn{4}{|c|}{$\begin{array}{ccc}\text { Água de estudo 3: } & \text { Cor Aparente }(\mathrm{uH})=154 & \text { Cor ver } \\
\mathrm{pH}=6,06 & \text { Temperatura }\left({ }^{\circ} \mathrm{C}\right)=21 & \text { Alc }\end{array}$}} & eira $(u H)=10$ & Turbidez (u & T) $=4,33$ \\
\hline & & & & idade Total $(\mathrm{m}$ & $\left.\mathrm{L}^{-1} \mathrm{CaCO}_{3}\right)$ & $=9,0$ \\
\hline \multirow[b]{2}{*}{ Frasco } & \multicolumn{3}{|c|}{ Dosagem de produtos químicos } & \multirow[b]{2}{*}{$\begin{array}{c}\text { pH de } \\
\text { Coagulação }\end{array}$} & \multicolumn{2}{|c|}{$\begin{array}{l}\text { Água Filtrada } \\
\text { (coleta } 30 \mathrm{~min} \text { ) }\end{array}$} \\
\hline & $\begin{array}{c}\mathrm{HCl} \\
\left(1 \mathrm{~g} \mathrm{~L}^{-1}\right) \\
(\mathrm{mL})\end{array}$ & $\begin{array}{c}\mathrm{NaOH} \\
\left(4 \mathrm{~g} \mathrm{~L}^{-1}\right) \\
(\mathrm{mL})\end{array}$ & $\begin{array}{c}\text { Cloreto Férrico } \\
\text { comercial } \\
\text { líquido } \\
\left(\mathrm{mg} \mathrm{L}^{-1}\right)\end{array}$ & & $\begin{array}{c}\text { Cor } \\
\text { Aparente } \\
\text { (uH) }\end{array}$ & $\begin{array}{l}\text { Turbidez } \\
\text { (uT) }\end{array}$ \\
\hline 1 & & 3,0 & 60 & 4,37 & 1 & 0,43 \\
\hline 2 & & 4,0 & 60 & 5,02 & 6 & 0,47 \\
\hline 3 & & 4,3 & 60 & 5,10 & 7 & 0,47 \\
\hline 4 & & 1,5 & 50 & 4,54 & $<1$ & 0,43 \\
\hline 5 & & 3,0 & 50 & 5,31 & 37 & 1,25 \\
\hline 6 & & 3,5 & 50 & 5,50 & 66 & 1,95 \\
\hline
\end{tabular}




\begin{tabular}{|c|c|c|c|c|c|c|}
\hline \multicolumn{7}{|c|}{ Ensaio 7} \\
\hline \multicolumn{7}{|c|}{ Água de estudo 3: $\quad$ Cor Aparente $(\mathrm{uH})=154$} \\
\hline \multicolumn{2}{|c|}{$\mathrm{pH}=6,08$} & eratura $(\stackrel{0}{-}$ & $=21$ & \multirow{2}{*}{\multicolumn{3}{|c|}{\begin{tabular}{c|c}
\multicolumn{2}{|c}{ Alcalinidade Total $\left(\mathrm{mg} \mathrm{L}^{-1} \mathrm{CaCO}_{3}\right)=9,0$} \\
$\begin{array}{c}\text { Água Filtrada } \\
\text { (coleta } 30 \text { min) }\end{array}$
\end{tabular}}} \\
\hline \multirow[b]{2}{*}{ Frasco } & \multicolumn{3}{|c|}{ Dosagem de produtos químicos } & & & \\
\hline & $\begin{array}{c}\mathrm{HCl} \\
\left(1 \mathrm{~g} \mathrm{~L}^{-1}\right)\end{array}$ & $\begin{array}{l}\mathrm{NaOH} \\
\left(4 \mathrm{~g} \mathrm{~L}^{-1}\right) \\
(\mathrm{mL})\end{array}$ & $\begin{array}{l}\text { Cloreto Férrico } \\
\text { comercial líquido } \\
\left(\mathrm{mg} \mathrm{L}^{-1}\right)\end{array}$ & $\begin{array}{c}\text { pH de } \\
\text { Coagulação }\end{array}$ & $\begin{array}{l}\text { Cor } \\
\text { Aparente } \\
\text { (uH) }\end{array}$ & $\begin{array}{c}\text { Turbidez } \\
\text { (uT) }\end{array}$ \\
\hline 1 & & 2,5 & 50 & 5,00 & 13 & 0,53 \\
\hline 2 & & 4,0 & 50 & 5,59 & 267 & 6,22 \\
\hline 3 & & 4,5 & 50 & 5,68 & 305 & 8,67 \\
\hline 4 & & 5,0 & 50 & 5,77 & 299 & 8,22 \\
\hline 5 & & 6,0 & 50 & 6,00 & 285 & 6,94 \\
\hline 6 & & - & 50 & 4,02 & 1 & 0,51 \\
\hline
\end{tabular}

\begin{tabular}{|c|c|c|c|c|c|c|}
\hline \multicolumn{7}{|c|}{ Ensaio 8} \\
\hline \multicolumn{7}{|c|}{ Cor Aparente $(\mathrm{uH})=154$ Cor verdadeira $(\mathrm{uH})=104$} \\
\hline \multicolumn{4}{|c|}{ Temperatura $\left({ }^{\circ} \mathrm{C}\right)=21$} & \multicolumn{3}{|c|}{ Icalinidade Total $\left(\mathrm{mg} \mathrm{L}^{-1} \mathrm{CaCO}_{3}\right)=9,0$} \\
\hline \multirow[b]{2}{*}{ Frasco } & \multicolumn{3}{|c|}{ Dosagem de produtos químicos } & \multirow[b]{2}{*}{$\begin{array}{c}\text { pH de } \\
\text { Coagulação }\end{array}$} & \multicolumn{2}{|c|}{$\begin{array}{c}\text { Água Filtrada } \\
\text { (coleta } 30 \mathrm{~min} \text { ) }\end{array}$} \\
\hline & $\begin{array}{c}\mathrm{HCl} \\
\left(1 \mathrm{~g} \mathrm{~L}^{-1}\right) \\
(\mathrm{mL})\end{array}$ & $\begin{array}{c}\mathrm{NaOH} \\
\left(4 \mathrm{~g} \mathrm{~L}^{-1}\right) \\
(\mathrm{mL})\end{array}$ & $\begin{array}{l}\text { Cloreto Férrico } \\
\text { comercial } \\
\text { líquido } \\
\left(\mathrm{mg} \mathrm{L}^{-1}\right)\end{array}$ & & $\begin{array}{c}\text { Cor } \\
\text { Aparente } \\
\text { (uH) }\end{array}$ & $\begin{array}{l}\text { Turbidez } \\
\text { (uT) }\end{array}$ \\
\hline 1 & & & 40 & 4,52 & 16 & 0,98 \\
\hline 2 & & 0,5 & 40 & 4,70 & 53 & 1,95 \\
\hline 3 & & 1,0 & 40 & 4,92 & 265 & 7,60 \\
\hline 4 & & 1,5 & 40 & 5,25 & 268 & 7,95 \\
\hline 5 & & 2,0 & 40 & 5,45 & 262 & 7,05 \\
\hline 6 & - & 2,5 & 40 & 5,60 & 257 & 6,69 \\
\hline
\end{tabular}




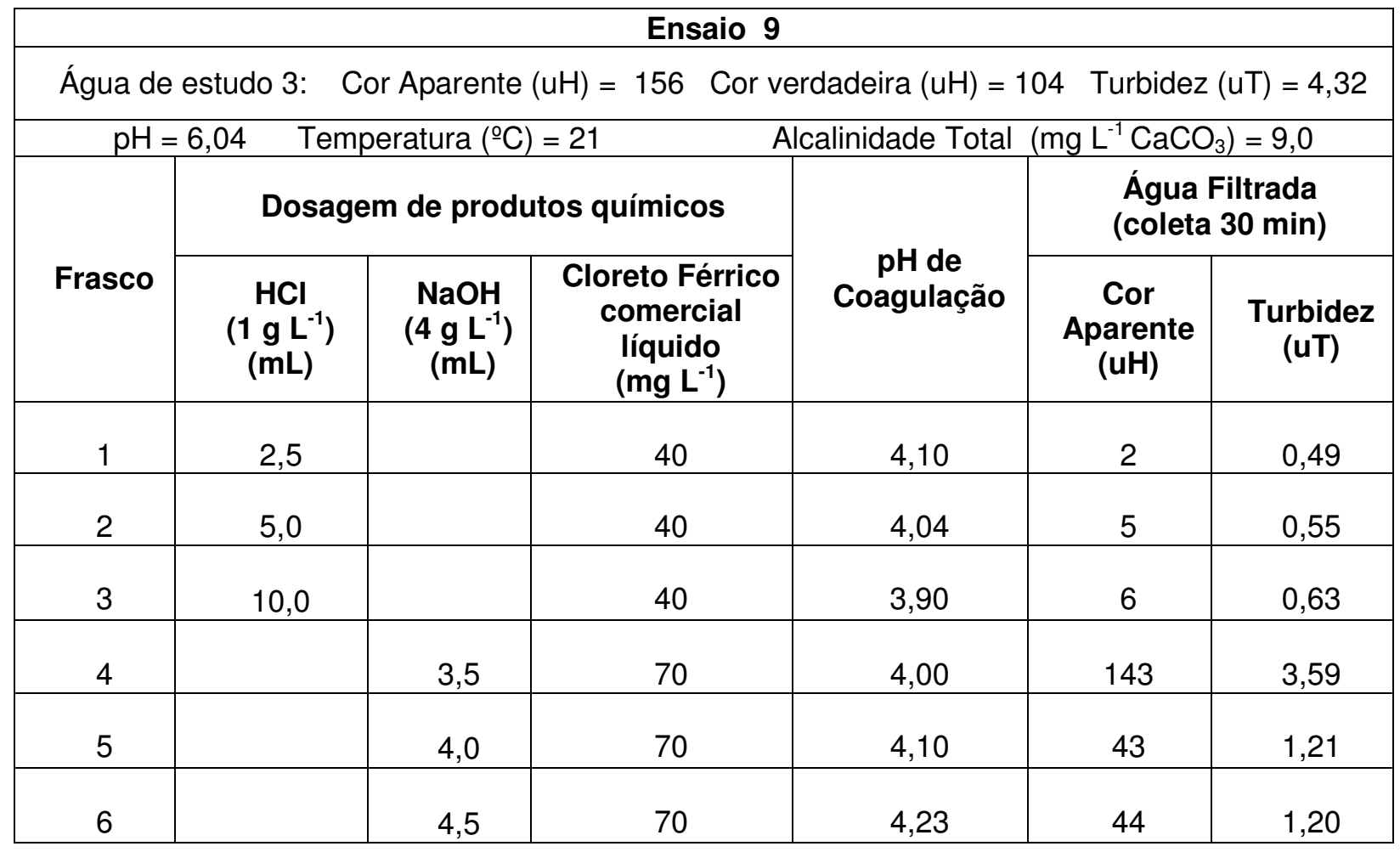

\begin{tabular}{|c|c|c|c|c|c|c|}
\hline \multicolumn{7}{|c|}{ Ensaio 10} \\
\hline \multicolumn{2}{|c|}{ Água de estudo 3: } & or Aparen & $(u H)=156$ Cor ve & dadeira $(\mathrm{uH})=$ & 44 Turbidez & $\mathrm{uT})=4,32$ \\
\hline \multicolumn{2}{|c|}{$\mathrm{pH}=6,04$} & eratura $(0$ & $=21$ & \multicolumn{3}{|c|}{ Alcalinidade Total $\left(\mathrm{mg} \mathrm{L}^{-1} \mathrm{CaCO}_{3}\right)=9,0$} \\
\hline \multirow[b]{2}{*}{ Frasco } & \multicolumn{3}{|c|}{ Dosagem de produtos químicos } & \multirow{2}{*}{$\begin{array}{c}\text { pH de } \\
\text { Coagulação }\end{array}$} & \multicolumn{2}{|c|}{$\begin{array}{c}\text { Água Filtrada } \\
\text { (coleta } 30 \mathrm{~min} \text { ) }\end{array}$} \\
\hline & $\begin{array}{c}\mathrm{HCl} \\
\left(1 \mathrm{~g} \mathrm{~L}^{-1}\right)\end{array}$ & $\begin{array}{c}\mathrm{NaOH} \\
\left(4 \mathrm{~g} \mathrm{~L}^{-1}\right) \\
(\mathrm{mL})\end{array}$ & $\begin{array}{c}\text { Cloreto Férrico } \\
\text { comercial líquido } \\
\left(\mathrm{mg} \mathrm{L}^{-1}\right)\end{array}$ & & $\begin{array}{c}\text { Cor } \\
\text { Aparente } \\
\text { (uH) }\end{array}$ & $\begin{array}{c}\text { Turbidez } \\
\text { (uT) }\end{array}$ \\
\hline 1 & 1,0 & & 40 & 4,20 & 4 & 0,49 \\
\hline 2 & & 5,0 & 70 & 4,38 & 3 & 0,43 \\
\hline 3 & & 6,0 & 70 & 4,80 & 2 & 0,39 \\
\hline 4 & & 7,0 & 70 & 5,40 & 7 & 0,43 \\
\hline 5 & & 8,0 & 70 & 5,70 & 14 & 0,61 \\
\hline 6 & & 9,0 & 70 & 5,89 & 94 & 2,06 \\
\hline
\end{tabular}




\begin{tabular}{|c|c|c|c|c|c|c|}
\hline \multicolumn{7}{|c|}{ Ensaio 11} \\
\hline \multicolumn{7}{|c|}{ Cor verdadeira $(\mathrm{uH})=104$} \\
\hline \multicolumn{4}{|c|}{ Temperatura $\left({ }^{\circ} \mathrm{C}\right)=21$} & \multicolumn{3}{|c|}{ Alcalinidade Total $\left(\mathrm{mg} \mathrm{L}^{-1} \mathrm{CaCO}_{3}\right)=9,0$} \\
\hline \multirow[b]{2}{*}{ Frasco } & \multicolumn{3}{|c|}{ Dosagem de produtos químicos } & \multirow{2}{*}{$\begin{array}{c}\text { pH de } \\
\text { Coagulação }\end{array}$} & \multicolumn{2}{|c|}{$\begin{array}{c}\text { Água Filtrada } \\
\text { (coleta } 30 \mathrm{~min} \text { ) }\end{array}$} \\
\hline & $\begin{array}{c}\mathrm{HCl} \\
\left(1 \mathrm{~g} \mathrm{~L}^{-1}\right) \\
(\mathrm{mL})\end{array}$ & $\begin{array}{c}\mathrm{NaOH} \\
\left(4 \mathrm{~g} \mathrm{~L}^{-1}\right) \\
(\mathrm{mL})\end{array}$ & $\begin{array}{c}\text { Cloreto Férrico } \\
\text { comercial líquido } \\
\left(\mathrm{mg} \mathrm{L}^{-1}\right)\end{array}$ & & $\begin{array}{l}\text { Cor } \\
\text { Aparente } \\
\text { (uH) }\end{array}$ & $\begin{array}{l}\text { Turbidez } \\
\text { (uT) }\end{array}$ \\
\hline 1 & & 5,5 & 70 & 4,60 & 1 & 0,39 \\
\hline 2 & & 6,5 & 70 & 5,15 & $<1$ & 0,42 \\
\hline 3 & & 7,5 & 70 & 5,51 & 7 & 0,48 \\
\hline 4 & & 10 & 70 & 6,10 & 314 & 7,04 \\
\hline 5 & & 11 & 70 & 6,22 & 299 & 5,77 \\
\hline 6 & & 12 & 70 & 6,33 & 290 & 5,32 \\
\hline
\end{tabular}

\begin{tabular}{|c|c|c|c|c|c|c|}
\hline \multicolumn{7}{|c|}{ Ensaio 12} \\
\hline \multicolumn{2}{|c|}{ Água de estudo 3: } & r Aparente & $(u H)=156$ Cor ve & ladeira $(\mathrm{uH})=1$ & Turbidez & $\mathrm{UT})=4,32$ \\
\hline \multicolumn{4}{|c|}{ Temperatura $\left({ }^{\circ} \mathrm{C}\right)=21$} & \multirow{2}{*}{\multicolumn{3}{|c|}{\begin{tabular}{|c|c|} 
alinidade Total $\left(\mathrm{mg} \mathrm{L}^{-1} \mathrm{CaCO}_{3}\right)=9,0$ \\
$\begin{array}{r}\text { Água Filtrada } \\
\text { (coleta } 30 \text { min) }\end{array}$
\end{tabular}}} \\
\hline \multirow[b]{2}{*}{ Frasco } & \multicolumn{3}{|c|}{ Dosagem de produtos químicos } & & & \\
\hline & $\begin{array}{c}\mathrm{HCl} \\
\left(1 \mathrm{~g} \mathrm{~L}^{-1}\right)\end{array}$ & $\begin{array}{l}\mathrm{NaOH} \\
\left(4 \mathrm{~g} \mathrm{~L}^{-1}\right)\end{array}$ & $\begin{array}{l}\text { Cloreto Férrico } \\
\text { comercial líquido } \\
\left(\mathrm{mg} \mathrm{L}^{-1}\right)\end{array}$ & $\begin{array}{c}\text { pH de } \\
\text { Coagulação }\end{array}$ & $\begin{array}{l}\text { Cor } \\
\text { Aparente } \\
\text { (uH) }\end{array}$ & $\begin{array}{c}\text { Turbidez } \\
\text { (uT) }\end{array}$ \\
\hline 1 & & 7,0 & 80 & 4,66 & $<1$ & 0,41 \\
\hline 2 & & 8,0 & 80 & 5,24 & $<1$ & 0,37 \\
\hline 3 & & 9,0 & 80 & 5,53 & 4 & 0,42 \\
\hline 4 & & 10,0 & 80 & 5,82 & 13 & 0,60 \\
\hline 5 & & 11,0 & 80 & 6,00 & 76 & 1,70 \\
\hline 6 & & 12,0 & 80 & 6,22 & 318 & 6,76 \\
\hline
\end{tabular}




\begin{tabular}{|c|c|c|c|c|c|c|}
\hline \multicolumn{7}{|c|}{ Ensaio 13} \\
\hline \multirow{2}{*}{\multicolumn{7}{|c|}{ 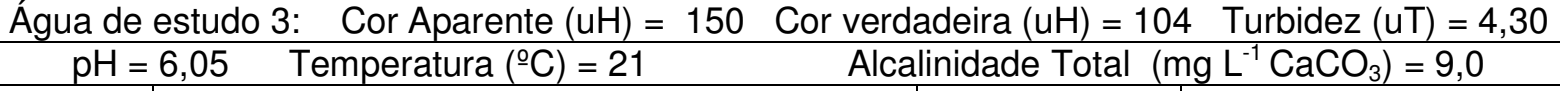 }} \\
\hline & & & & & & \\
\hline \multirow[b]{2}{*}{ Frasco } & \multicolumn{3}{|c|}{ Dosagem de produtos químicos } & \multirow[b]{2}{*}{$\begin{array}{c}\text { pH de } \\
\text { Coagulação }\end{array}$} & \multicolumn{2}{|c|}{$\begin{array}{l}\text { Água Filtrada } \\
\text { (coleta } 30 \text { min) }\end{array}$} \\
\hline & $\begin{array}{c}\mathrm{HCl} \\
\left(1 \mathrm{~g} \mathrm{~L}^{-1}\right) \\
(\mathrm{mL})\end{array}$ & $\begin{array}{c}\mathrm{NaOH} \\
\left(4 \mathrm{~g} \mathrm{~L}^{-1}\right) \\
(\mathrm{mL})\end{array}$ & $\begin{array}{l}\text { Cloreto Férrico } \\
\text { comercial } \\
\text { líquido } \\
\left(\mathrm{mg} \mathrm{L}^{-1}\right)\end{array}$ & & $\begin{array}{c}\text { Cor } \\
\text { Aparente } \\
\text { (uH) }\end{array}$ & $\begin{array}{l}\text { Turbidez } \\
\quad(\text { uT) }\end{array}$ \\
\hline 1 & & 6,0 & 80 & 4,12 & 99 & 2,17 \\
\hline 2 & & 6,5 & 80 & 4,31 & 76 & 1,75 \\
\hline 3 & & 7,3 & 80 & 4,72 & $<1$ & 0,41 \\
\hline 4 & & 7,6 & 80 & 4,95 & $<1$ & 0,42 \\
\hline 5 & & 8,5 & 80 & 5,41 & 2 & 0,45 \\
\hline 6 & & 9,5 & 80 & 5,70 & 6 & 0,48 \\
\hline
\end{tabular}

\begin{tabular}{|c|c|c|c|c|c|c|}
\hline \multicolumn{7}{|c|}{ Ensaio 14} \\
\hline \multicolumn{7}{|c|}{ Água de estudo 3: Cor Aparente $(\mathrm{uH})=150$ Cor verdadeira $(\mathrm{uH})=104$ Turbidez $(\mathrm{uT})=4,30$} \\
\hline \multicolumn{4}{|c|}{$\mathrm{pH}=6,05$} & \multirow{2}{*}{\multicolumn{3}{|c|}{\begin{tabular}{|c|c}
\multicolumn{1}{|c}{ Alcalinidade Total $\left(\mathrm{mg} \mathrm{L}^{-1} \mathrm{CaCO}_{3}\right)=9,0$} \\
$\begin{array}{c}\text { Água Filtrada } \\
\text { (coleta 30 min) }\end{array}$
\end{tabular}}} \\
\hline \multirow[b]{2}{*}{ Frasco } & \multicolumn{3}{|c|}{ Dosagem de produtos químicos } & & & \\
\hline & $\begin{array}{c}\mathrm{HCl} \\
\left(1 \mathrm{~g} \mathrm{~L}^{-1}\right)\end{array}$ & $\begin{array}{l}\mathrm{NaOH} \\
\left(4 \mathrm{~g} \mathrm{~L}^{-1}\right) \\
(\mathrm{mL})\end{array}$ & $\begin{array}{l}\text { Cloreto Férrico } \\
\text { comercial líquido } \\
\left(\mathrm{mg} \mathrm{L}^{-1}\right)\end{array}$ & $\begin{array}{c}\text { pH de } \\
\text { Coagulação }\end{array}$ & $\begin{array}{l}\text { Cor } \\
\text { Aparente } \\
\text { (uH) }\end{array}$ & $\begin{array}{c}\text { Turbidez } \\
\text { (uT) }\end{array}$ \\
\hline 1 & & 6,7 & 80 & 4,40 & 32 & 1,00 \\
\hline 2 & & 13 & 80 & 6,37 & 291 & 5,02 \\
\hline 3 & & 14 & 80 & 6,45 & 292 & 4,63 \\
\hline 4 & & 9,0 & 90 & 4,52 & $<1$ & 0,41 \\
\hline 5 & & 9,5 & 90 & 4,82 & $<1$ & 0,37 \\
\hline 6 & & 10,0 & 90 & 5,24 & $<1$ & 0,37 \\
\hline
\end{tabular}




\section{Ensaio 15}

Água de estudo 3: Cor Aparente $(\mathrm{uH})=140$ Cor verdadeira $(\mathrm{uH})=104$ Turbidez $(\mathrm{uT})=4,30$

\begin{tabular}{|c|c|c|c|c|c|c|}
\hline \multirow[b]{3}{*}{ Frasco } & \multicolumn{3}{|c|}{ Temperatura $\left({ }^{\circ} \mathrm{C}\right)=21$} & \multicolumn{3}{|c|}{ Alcalinidade Total $\left(\mathrm{mg} \mathrm{L}^{-1} \mathrm{CaCO}_{3}\right)=9,0$} \\
\hline & \multicolumn{3}{|c|}{ Dosagem de produtos químicos } & \multirow{2}{*}{$\begin{array}{c}\text { pH de } \\
\text { Coagulação }\end{array}$} & \multicolumn{2}{|c|}{$\begin{array}{c}\text { Água Filtrada } \\
\text { (coleta } 30 \text { min) }\end{array}$} \\
\hline & $\begin{array}{c}\mathrm{HCl} \\
\left(1 \mathrm{~g} \mathrm{~L}^{-1}\right) \\
(\mathrm{mL})\end{array}$ & $\begin{array}{c}\mathrm{NaOH} \\
\left(4 \mathrm{~g} \mathrm{~L}^{-1}\right) \\
(\mathrm{mL})\end{array}$ & $\begin{array}{c}\text { Cloreto Férrico } \\
\text { comercial líquido } \\
\left(\mathrm{mg} \mathrm{L}^{-1}\right)\end{array}$ & & $\begin{array}{c}\text { Cor } \\
\text { Aparente } \\
\text { (uH) }\end{array}$ & $\begin{array}{l}\text { Turbidez } \\
\text { (uT) }\end{array}$ \\
\hline 1 & 0,7 & & 40 & 4,34 & $<1$ & 0,48 \\
\hline 2 & & 1,3 & 50 & 4,30 & 2 & 0,47 \\
\hline 3 & & 2,3 & 50 & 4,78 & $<1$ & 0,46 \\
\hline 4 & & 3,2 & 60 & 4,47 & 8 & 0,58 \\
\hline 5 & & 3,7 & 60 & 4,83 & $<1$ & 0,42 \\
\hline 6 & & 6,3 & 70 & 4,98 & $<1$ & 0,42 \\
\hline
\end{tabular}

\section{Ensaio 16}

Água de estudo 3: Cor Aparente $(\mathrm{uH})=156$ Cor verdadeira $(\mathrm{uH})=104$ Turbidez $(\mathrm{uT})=4,32$ $\mathrm{pH}=6,05 \quad$ Temperatura $\left({ }^{\circ} \mathrm{C}\right)=21$ Alcalinidade Total $\left(\mathrm{mg} \mathrm{L}^{-1} \mathrm{CaCO}_{3}\right)=9,0$

\begin{tabular}{|c|c|c|c|c|c|c|}
\hline \multirow[b]{2}{*}{ Frasco } & \multicolumn{3}{|c|}{ Dosagem de produtos químicos } & \multirow{2}{*}{$\begin{array}{c}\text { pH de } \\
\text { Coagulação }\end{array}$} & \multicolumn{2}{|c|}{$\begin{array}{l}\text { Água Filtrada } \\
\text { (coleta } \mathbf{3 0} \text { min) }\end{array}$} \\
\hline & $\begin{array}{c}\mathrm{HCl} \\
\left(1 \mathrm{~g} \mathrm{~L}^{-1}\right)\end{array}$ & $\begin{array}{c}\mathrm{NaOH} \\
\left(4 \mathrm{~g} \mathrm{~L}^{-1}\right) \\
(\mathrm{mL})\end{array}$ & $\begin{array}{c}\text { Cloreto Férrico } \\
\text { comercial líquido } \\
\left(\mathrm{mg} \mathrm{L}^{-1}\right)\end{array}$ & & $\begin{array}{l}\text { Cor } \\
\text { Aparente } \\
\text { (uH) }\end{array}$ & $\begin{array}{l}\text { Turbidez } \\
\text { (uT) }\end{array}$ \\
\hline 1 & & 7,8 & 80 & 5,08 & $<1$ & 0,42 \\
\hline 2 & & 8,0 & 90 & 4,27 & 117 & 2,80 \\
\hline 3 & & 8,5 & 90 & 4,40 & 15 & 0,74 \\
\hline 4 & & 11 & 90 & 5,70 & $<1$ & 0,45 \\
\hline 5 & & 12 & 90 & 5,98 & 18 & 0,85 \\
\hline 6 & & 13 & 90 & 6,17 & 313 & 6,54 \\
\hline
\end{tabular}




\begin{tabular}{|c|c|c|c|c|c|c|}
\hline \multicolumn{7}{|c|}{ Ensaio 17} \\
\hline \multirow{2}{*}{\multicolumn{7}{|c|}{$\begin{array}{ccc}\text { Água de estudo 3: } & \text { Cor Aparente }(\mathrm{uH})=156 & \text { Cor verdadeira }(\mathrm{uH})=104 \quad \text { Turbidez }(\mathrm{uT})=4,32 \\
\mathrm{pH}=6,05 & \text { Temperatura }\left({ }^{\circ} \mathrm{C}\right)=21 & \text { Alcalinidade Total }\left(\mathrm{mg} \mathrm{L}^{-1} \mathrm{CaCO}_{3}\right)=9,0\end{array}$}} \\
\hline & & & & & & \\
\hline \multirow[b]{2}{*}{ Frasco } & \multicolumn{3}{|c|}{ Dosagem de produtos químicos } & \multirow[b]{2}{*}{$\begin{array}{c}\text { pH de } \\
\text { Coagulação }\end{array}$} & \multicolumn{2}{|c|}{$\begin{array}{l}\text { Água Filtrada } \\
\text { (coleta } 30 \text { min) }\end{array}$} \\
\hline & $\begin{array}{c}\mathrm{HCl} \\
\left(\mathrm{f}_{(\mathrm{mL})}^{-1}\right)\end{array}$ & $\begin{array}{c}\mathrm{NaOH} \\
\left(4 \mathrm{~g} \mathrm{~L}^{-1}\right) \\
(\mathrm{mL})\end{array}$ & $\begin{array}{l}\text { Cloreto Férrico } \\
\text { comercial } \\
\text { líquido } \\
\left(\mathrm{mg} \mathrm{L}^{-1}\right)\end{array}$ & & $\begin{array}{c}\text { Cor } \\
\text { Aparente } \\
\text { (uH) }\end{array}$ & $\begin{array}{l}\text { Turbidez } \\
\text { (uT) }\end{array}$ \\
\hline 1 & 1,5 & & 50 & 3,97 & 32 & 1,06 \\
\hline 2 & 3,0 & & 50 & 3,94 & 38 & 1,27 \\
\hline 3 & 6,0 & & 50 & 3,84 & 65 & 1,75 \\
\hline 4 & 15 & & 40 & 3,85 & 1 & 0,45 \\
\hline 5 & 20 & & 40 & 3,76 & 1 & 0,55 \\
\hline 6 & 18 & & 30 & 3,94 & 4 & 0,80 \\
\hline
\end{tabular}

\begin{tabular}{|c|c|c|c|c|c|c|}
\hline \multicolumn{7}{|c|}{ Ensaio 17} \\
\hline \multicolumn{7}{|c|}{ Cor Aparente $(\mathrm{uH})=156$} \\
\hline \multicolumn{2}{|c|}{$\mathrm{pH}=6,05$} & ratura $\left({ }^{\circ} \mathrm{C}\right.$ & $=21$ & \multirow{2}{*}{\multicolumn{3}{|c|}{\begin{tabular}{|c|c|}
\multicolumn{2}{|c|}{ Alcalinidade Total $\left(\mathrm{mg} \mathrm{L}^{-1} \mathrm{CaCO}_{3}\right)=9,0$} \\
$\begin{array}{c}\text { Água Filtrada } \\
\text { (coleta 30 min) }\end{array}$
\end{tabular}}} \\
\hline \multirow[b]{2}{*}{ Frasco } & \multicolumn{3}{|c|}{ Dosagem de produtos químicos } & & & \\
\hline & $\begin{array}{c}\mathrm{HCl} \\
\left(1 \mathrm{~g} \mathrm{~L}^{-1}\right)\end{array}$ & $\begin{array}{l}\mathrm{NaOH} \\
\left(4 \mathrm{~g} \mathrm{~L}^{-1}\right) \\
(\mathrm{mL})\end{array}$ & $\begin{array}{c}\text { Cloreto Férrico } \\
\text { comercial líquido } \\
\left(\mathrm{mg} \mathrm{L}^{-1}\right)\end{array}$ & $\begin{array}{c}\text { pH de } \\
\text { Coagulação }\end{array}$ & $\begin{array}{l}\text { Cor } \\
\text { Aparente } \\
\text { (uH) }\end{array}$ & $\begin{array}{c}\text { Turbidez } \\
\text { (uT) }\end{array}$ \\
\hline 1 & 1,5 & & 50 & 3,97 & 32 & 1,06 \\
\hline 2 & 3,0 & & 50 & 3,94 & 38 & 1,27 \\
\hline 3 & 6,0 & & 50 & 3,84 & 65 & 1,75 \\
\hline 4 & 15 & & 40 & 3,85 & 1 & 0,45 \\
\hline 5 & 20 & & 40 & 3,76 & 1 & 0,55 \\
\hline 6 & 18 & & 30 & 3,94 & 4 & 0,80 \\
\hline 7 & & 4,0 & 30 & 6,10 & 239 & 5,13 \\
\hline
\end{tabular}


B.4 - Tabelas referentes aos ensaios de coagulação para á água de estudo 4, empregando-se cloreto férrico como coagulante

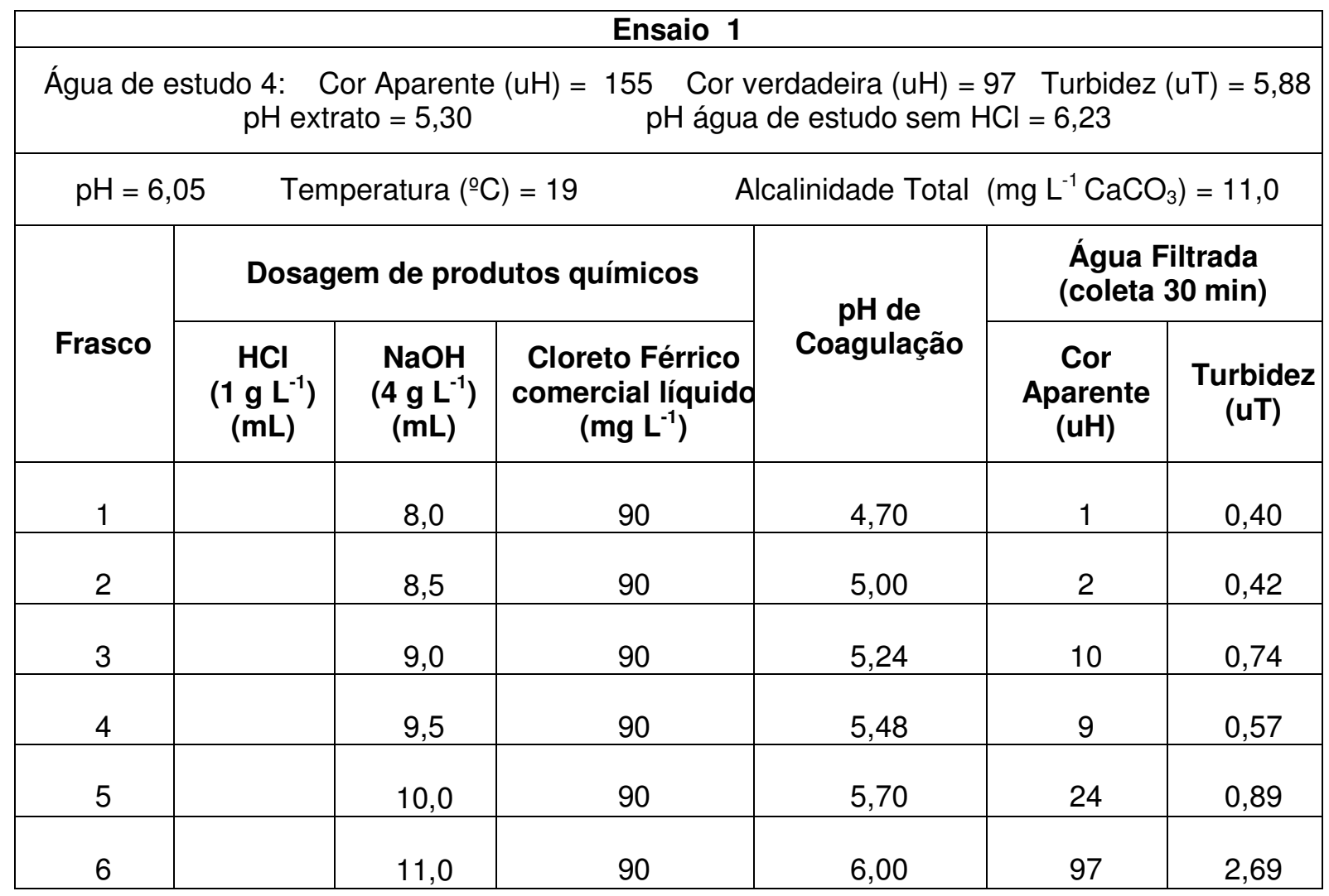

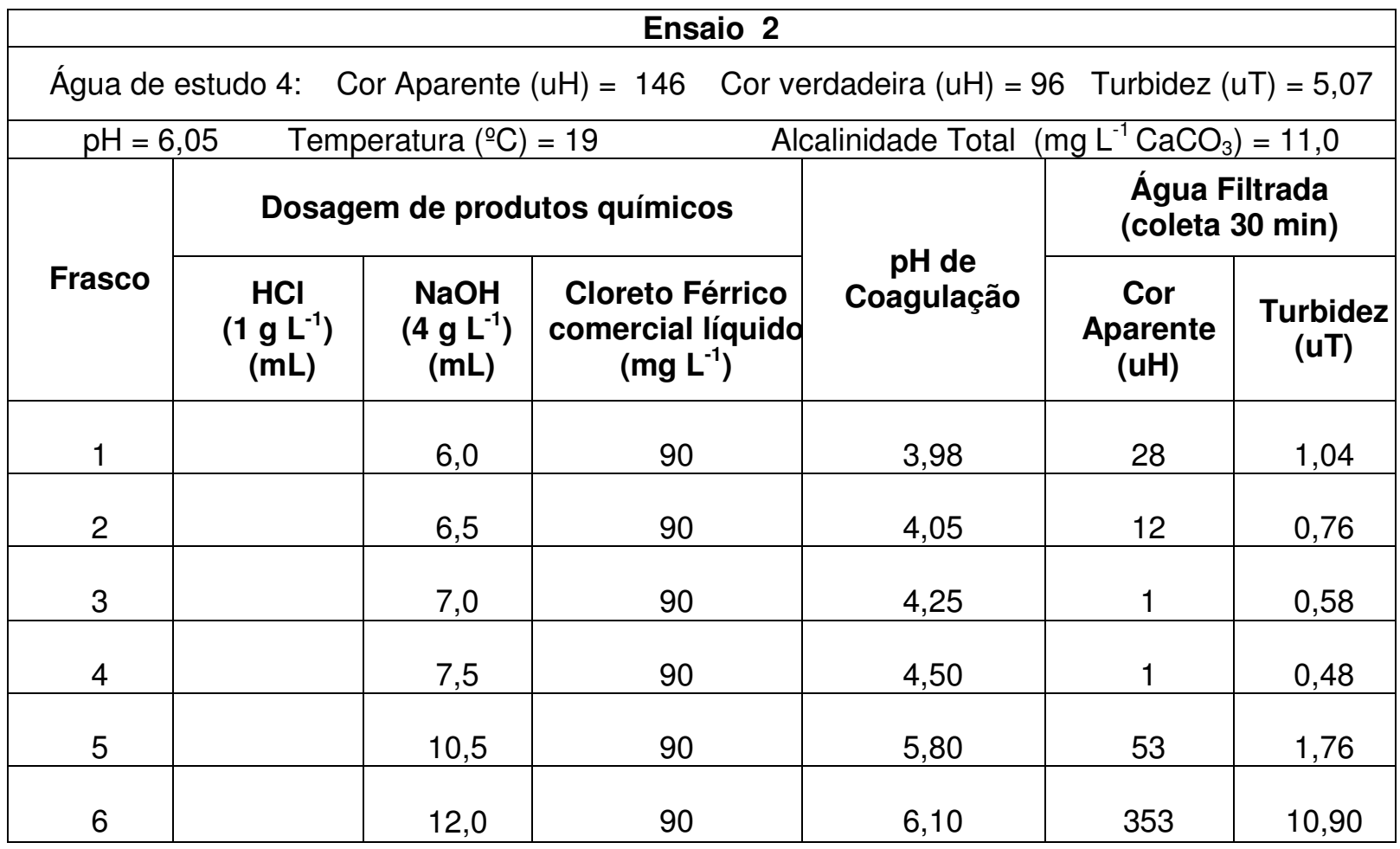




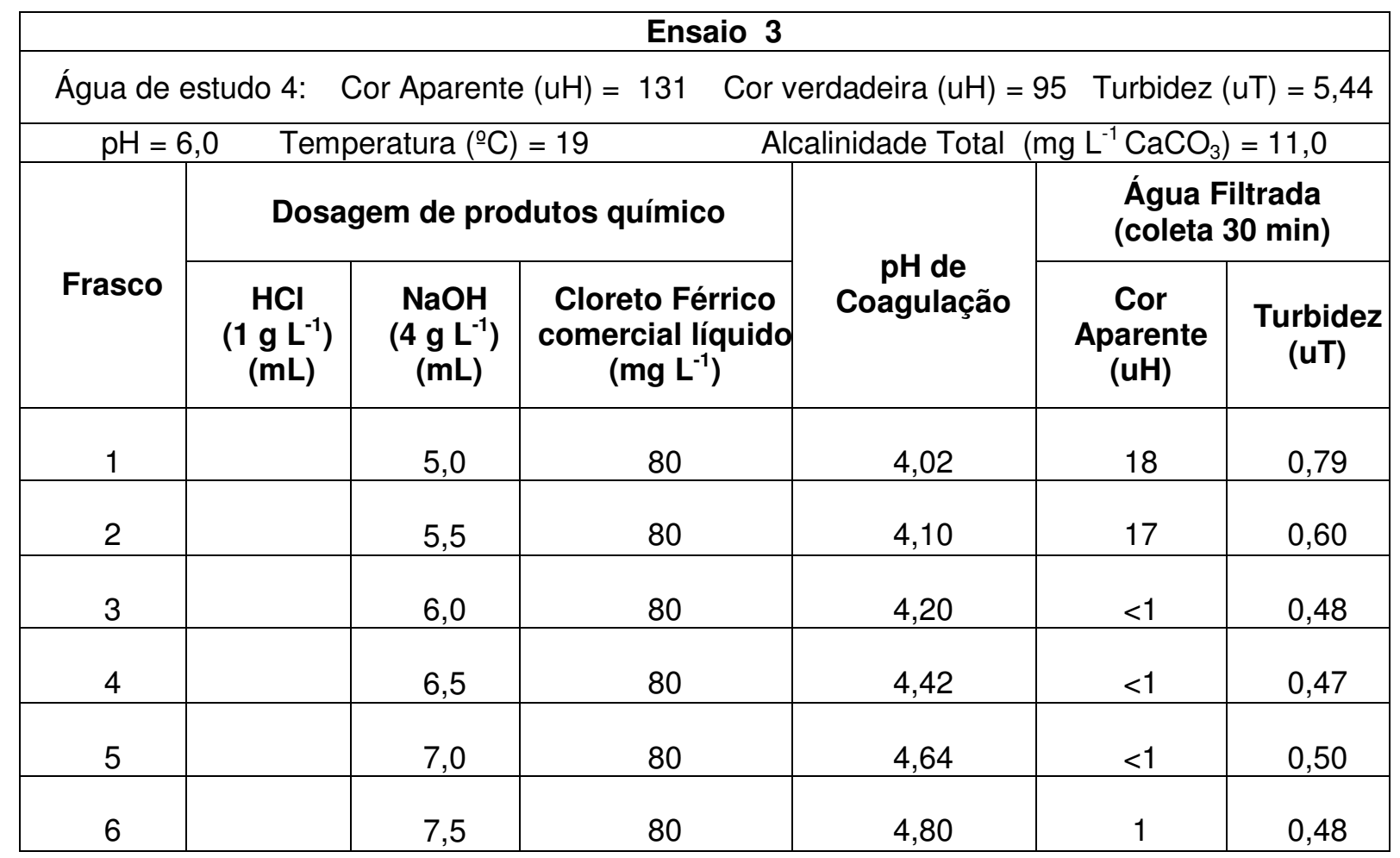

\begin{tabular}{|c|c|c|c|c|c|c|}
\hline \multicolumn{7}{|c|}{ Ensaio 4} \\
\hline \multicolumn{7}{|c|}{ Água de estudo 4: $\quad$ Cor Aparente $(\mathrm{uH})=146$} \\
\hline \multicolumn{4}{|c|}{ Temperatura $\left({ }^{\circ} \mathrm{C}\right)=19,5$} & \multicolumn{3}{|c|}{ Alcalinidade Total $\left(\mathrm{mg} \mathrm{L}^{-1} \mathrm{CaCO}_{3}\right)=11,0$} \\
\hline \multirow[b]{2}{*}{ Frasco } & \multicolumn{3}{|c|}{ Dosagem de produtos químicos } & \multirow[b]{2}{*}{$\begin{array}{c}\text { pH de } \\
\text { Coagulação }\end{array}$} & \multicolumn{2}{|c|}{$\begin{array}{l}\text { Água Filtrada } \\
\text { (coleta } 30 \text { min) }\end{array}$} \\
\hline & $\begin{array}{c}\mathrm{HCl} \\
\left(1 \mathrm{~g} \mathrm{~L}^{-1}\right) \\
(\mathrm{mL})\end{array}$ & $\begin{array}{c}\mathrm{NaOH} \\
\left(4 \mathrm{~g} \mathrm{~L}^{-1}\right) \\
(\mathrm{mL})\end{array}$ & $\begin{array}{c}\text { Cloreto Férrico } \\
\text { comercial } \\
\text { líquido } \\
\left(\mathrm{mg} \mathrm{L}^{-1}\right)\end{array}$ & & $\begin{array}{l}\text { Cor } \\
\text { Aparente } \\
\text { (uH) }\end{array}$ & $\begin{array}{c}\text { Turbidez } \\
\text { (uT) }\end{array}$ \\
\hline 1 & & 8,0 & 80 & 5,03 & 5 & 0,70 \\
\hline 2 & & 8,5 & 80 & 5,26 & 20 & 1,18 \\
\hline 3 & & 9,0 & 80 & 5,41 & 38 & 1,62 \\
\hline 4 & & 9,5 & 80 & 5,61 & 115 & 3,46 \\
\hline 5 & & 10,0 & 80 & 5,70 & 334 & 10,4 \\
\hline 6 & & 10,5 & 80 & 5,83 & 349 & 12,2 \\
\hline
\end{tabular}


Ensaio 5

\begin{tabular}{|c|c|c|c|c|c|c|}
\hline \multicolumn{7}{|c|}{ Ensaio 5} \\
\hline \multicolumn{2}{|c|}{ Água de estudo 4: } & or Aparen & $(u H)=146$ Cor $v$ & dadeira $(\mathrm{uH})=$ & 96 Turbidez & $\mathrm{T})=5,60$ \\
\hline \multicolumn{2}{|c|}{$\mathrm{pH}=5,96$} & eratura $\left(^{\circ}\right.$ & $=19$ & \multirow{2}{*}{\multicolumn{3}{|c|}{\begin{tabular}{c|c|c}
\multicolumn{2}{c}{ Alcalinidade Total $\left(\mathrm{mg} \mathrm{L}^{-1} \mathrm{CaCO}_{3}\right)=11,0$} \\
0 & $\begin{array}{r}\text { Água Filtrada } \\
\text { (coleta 30 min) }\end{array}$
\end{tabular}}} \\
\hline \multirow[b]{2}{*}{ Frasco } & \multicolumn{3}{|c|}{ Dosagem de produtos químico } & & & \\
\hline & $\begin{array}{c}\mathrm{HCl} \\
\left(1 \mathrm{~g} \mathrm{~L}^{-1}\right)\end{array}$ & $\begin{array}{l}\mathrm{NaOH} \\
\left(4 \mathrm{~g} \mathrm{~L}^{-1}\right) \\
(\mathrm{mL})\end{array}$ & $\begin{array}{l}\text { Cloreto Férrico } \\
\text { comercial líquido } \\
\left(\mathrm{mg} \mathrm{L}^{-1}\right)\end{array}$ & $\begin{array}{c}\text { pH de } \\
\text { Coagulação }\end{array}$ & $\begin{array}{l}\text { Cor } \\
\text { Aparente } \\
\text { (uH) }\end{array}$ & $\begin{array}{c}\text { Turbidez } \\
\text { (uT) }\end{array}$ \\
\hline 1 & & 3,0 & 70 & 3,90 & 25 & 1,07 \\
\hline 2 & & 3,5 & 70 & 4,00 & 6 & 0,58 \\
\hline 3 & & 4,0 & 70 & 4,11 & $<1$ & 0,48 \\
\hline 4 & & 4,5 & 70 & 4,20 & $<1$ & 0,57 \\
\hline 5 & & 5,0 & 70 & 4,42 & $<1$ & 0,52 \\
\hline 6 & & 5,5 & 70 & 4,70 & 13 & 0,52 \\
\hline
\end{tabular}

\begin{tabular}{|c|c|c|c|c|c|c|}
\hline \multicolumn{7}{|c|}{ Ensaio 6} \\
\hline \multicolumn{7}{|c|}{ Cor Aparente $(\mathrm{uH})=146$} \\
\hline \multicolumn{4}{|c|}{ Temperatura $\left({ }^{\circ} \mathrm{C}\right)=19,5$} & \multicolumn{3}{|c|}{ Alcalinidade Total $\left(\mathrm{mg} \mathrm{L}^{-1} \mathrm{CaCO}_{3}\right)=11,0$} \\
\hline \multirow[b]{2}{*}{ Frasco } & \multicolumn{3}{|c|}{ Dosagem de produtos químico } & \multirow{2}{*}{$\begin{array}{c}\text { pH de } \\
\text { Coagulação }\end{array}$} & \multicolumn{2}{|c|}{$\begin{array}{l}\text { Água Filtrada } \\
\text { (coleta } 30 \text { min) }\end{array}$} \\
\hline & $\begin{array}{c}\mathrm{HCl} \\
\left(1 \mathrm{~g} \mathrm{~L}^{-1}\right) \\
(\mathrm{mL})\end{array}$ & $\begin{array}{c}\mathrm{NaOH} \\
\left(4 \mathrm{~g} \mathrm{~L}^{-1}\right) \\
(\mathrm{mL})\end{array}$ & $\begin{array}{l}\text { Cloreto Férrico } \\
\text { comercial } \\
\text { líquido } \\
\left(\mathrm{mg} \mathrm{L}^{-1}\right)\end{array}$ & & $\begin{array}{c}\text { Cor } \\
\text { Aparente } \\
\text { (uH) }\end{array}$ & $\begin{array}{l}\text { Turbidez } \\
\text { (uT) }\end{array}$ \\
\hline 1 & & 6,0 & 70 & 4,97 & 29 & 1,25 \\
\hline 2 & & 6,5 & 70 & 5,24 & 62 & 2,30 \\
\hline 3 & & 7,0 & 70 & 5,40 & 111 & 3,06 \\
\hline 4 & & 7,5 & 70 & 5,60 & 363 & 11,3 \\
\hline 5 & & 8,0 & 70 & 5,80 & 339 & 11,4 \\
\hline 6 & & 8,5 & 70 & 5,87 & 322 & 10,7 \\
\hline
\end{tabular}




\begin{tabular}{|c|c|c|c|c|c|c|}
\hline \multicolumn{7}{|c|}{ Ensaio 7} \\
\hline \multicolumn{7}{|c|}{ Cor Aparente $(\mathrm{uH})=132$ Cor verdadeira $(\mathrm{uH})=94$} \\
\hline \multicolumn{2}{|c|}{$\mathrm{pH}=6,05$} & eratura $(\stackrel{0}{-}$ & $=19$ & \multicolumn{3}{|c|}{ Alcalinidade Total $\left(\mathrm{mg} \mathrm{L}^{-1} \mathrm{CaCO}_{3}\right)=11,0$} \\
\hline \multirow[b]{2}{*}{ Frasco } & \multicolumn{3}{|c|}{ Dosagem de produtos químico } & \multirow{2}{*}{$\begin{array}{c}\text { pH de } \\
\text { Coagulação }\end{array}$} & \multicolumn{2}{|c|}{$\begin{array}{c}\text { Água Filtrada } \\
\text { (coleta } 30 \mathrm{~min} \text { ) }\end{array}$} \\
\hline & $\begin{array}{c}\mathrm{HCl} \\
\left(1 \mathrm{~g} \mathrm{~L}^{-1}\right) \\
(\mathrm{mL})\end{array}$ & $\begin{array}{c}\mathrm{NaOH} \\
\left(4 \mathrm{~g} \mathrm{~L}^{-1}\right) \\
(\mathrm{mL})\end{array}$ & $\begin{array}{l}\text { Cloreto Férrico } \\
\text { comercial líquido } \\
\left(\mathrm{mg} \mathrm{L}^{-1}\right)\end{array}$ & & $\begin{array}{l}\text { Cor } \\
\text { Aparente } \\
\text { (uH) }\end{array}$ & $\begin{array}{c}\text { Turbidez } \\
\text { (uT) }\end{array}$ \\
\hline 1 & & & 60 & 3,85 & 20 & 1,02 \\
\hline 2 & & 1,0 & 60 & 3,90 & 11 & 0,83 \\
\hline 3 & & 1,5 & 60 & 3,97 & 4 & 0,63 \\
\hline 4 & & 2,5 & 60 & 4,10 & 3 & 0,63 \\
\hline 5 & & 3,0 & 60 & 4,25 & 5 & 0,73 \\
\hline 6 & & 3,5 & 60 & 4,44 & 16 & 1,06 \\
\hline
\end{tabular}

\begin{tabular}{|c|c|c|c|c|c|c|}
\hline \multicolumn{7}{|c|}{ Ensaio 8} \\
\hline \multicolumn{2}{|c|}{ Água de estudo 4: } & r Aparent & $(u H)=132$ Cor ve & dadeira $(\mathrm{uH})=$ & Turbidez & $\mathrm{T})=4,80$ \\
\hline $\mathrm{pH}=6,0$ & \multicolumn{3}{|c|}{ Temperatura $\left({ }^{\circ} \mathrm{C}\right)=19,5$} & \multicolumn{3}{|c|}{ calinidade Total $\left(\mathrm{mg} \mathrm{L}^{-1} \mathrm{CaCO}_{3}\right)=11,0$} \\
\hline \multirow[b]{2}{*}{ Frasco } & \multicolumn{3}{|c|}{ Dosagem de produtos químicos } & \multirow{2}{*}{$\begin{array}{c}\text { pH de } \\
\text { Coagulação }\end{array}$} & \multicolumn{2}{|c|}{$\begin{array}{l}\text { Água Filtrada } \\
\text { (coleta } 30 \text { min) }\end{array}$} \\
\hline & $\begin{array}{c}\mathrm{HCl} \\
\left(1 \mathrm{~g} \mathrm{~L}^{-1}\right) \\
(\mathrm{mL})\end{array}$ & $\begin{array}{c}\mathrm{NaOH} \\
\left(4 \mathrm{~g} \mathrm{~L}^{-1}\right) \\
(\mathrm{mL})\end{array}$ & $\begin{array}{c}\text { Cloreto Férrico } \\
\text { comercial líquido } \\
\left(\mathrm{mg} \mathrm{L}^{-1}\right)\end{array}$ & & $\begin{array}{l}\text { Cor } \\
\text { Aparente } \\
\text { (uH) }\end{array}$ & $\begin{array}{l}\text { Turbidez } \\
\text { (uT) }\end{array}$ \\
\hline 1 & & 4,0 & 60 & 4,94 & 27 & 1,42 \\
\hline 2 & & 4,5 & 60 & 5,10 & 85 & 2,56 \\
\hline 3 & & 5,0 & 60 & 5,33 & 298 & 8,90 \\
\hline 4 & & 5,5 & 60 & 5,45 & 339 & 10,9 \\
\hline 5 & & 6,0 & 60 & 5,64 & 330 & 10,5 \\
\hline 6 & & 6,5 & 60 & 5,90 & 311 & 9,32 \\
\hline
\end{tabular}




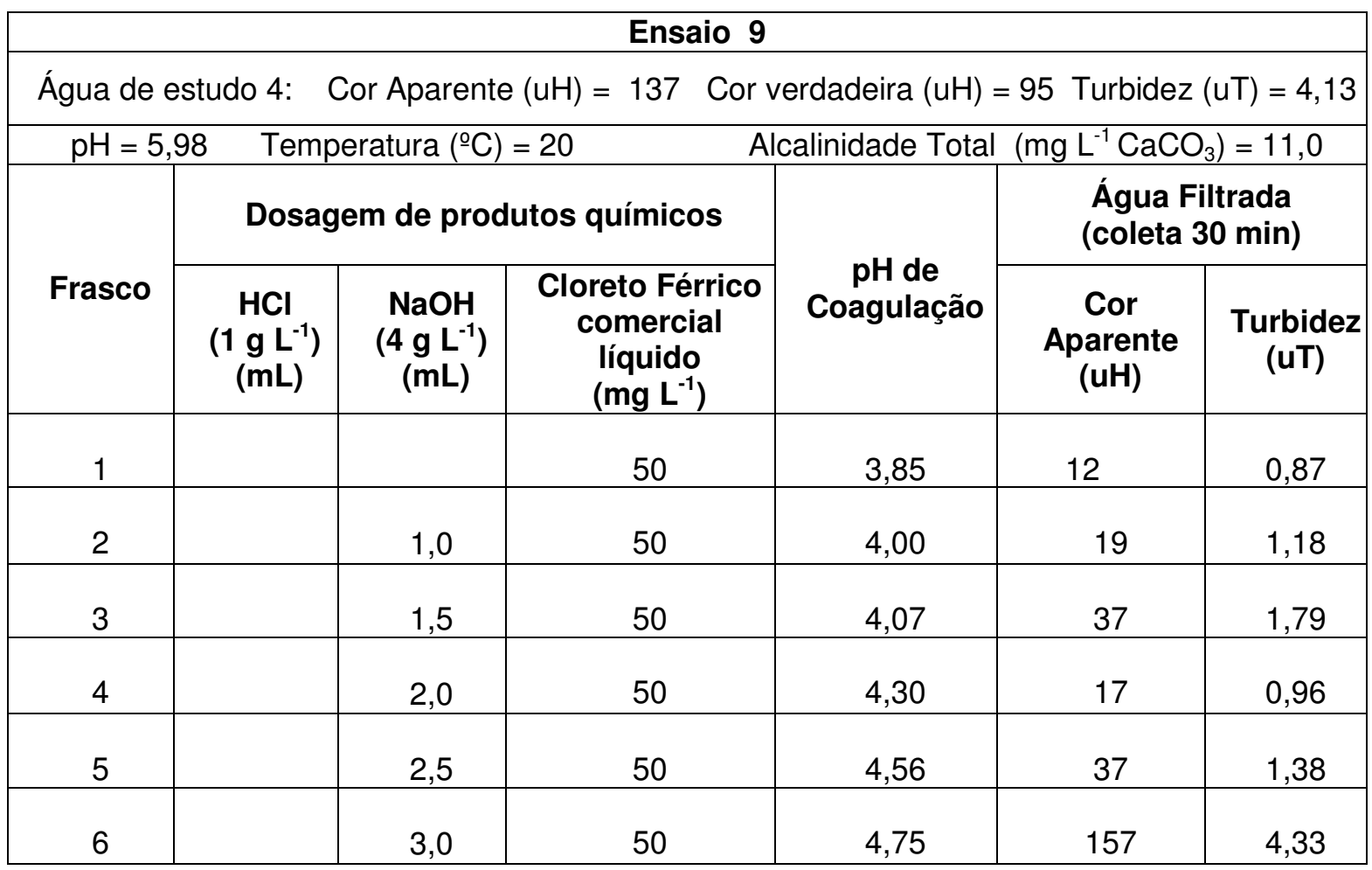

\begin{tabular}{|c|c|c|c|c|c|c|}
\hline \multicolumn{7}{|c|}{ Ensaio 10} \\
\hline \multirow{2}{*}{\multicolumn{7}{|c|}{$\begin{array}{ccc}\text { Água de estudo 4: } & \text { Cor Aparente }(\mathrm{uH})=137 \text { Cor verdadeira }(\mathrm{uH})=95 \text { Turbidez }(\mathrm{uT})=4,50 \\
\mathrm{pH}=5,98 & \text { Temperatura }\left({ }^{\circ} \mathrm{C}\right)=20 & \text { Alcalinidade Total }\left(\mathrm{mg} \mathrm{L}^{-1} \mathrm{CaCO}_{3}\right)=11,0\end{array}$}} \\
\hline & & & & & & \\
\hline \multirow[b]{2}{*}{ Frasco } & \multicolumn{3}{|c|}{ Dosagem de produtos químicos } & \multirow[b]{2}{*}{$\begin{array}{c}\text { pH de } \\
\text { Coagulação }\end{array}$} & \multicolumn{2}{|c|}{$\begin{array}{l}\text { Água Filtrada } \\
\text { (coleta } 30 \text { min) }\end{array}$} \\
\hline & $\begin{array}{c}\mathrm{HCl} \\
\left(1 \mathrm{~g} \mathrm{~L}^{-1}\right)\end{array}$ & $\begin{array}{c}\mathrm{NaOH} \\
\left(4 \mathrm{~g} \mathrm{~L}^{-1}\right) \\
(\mathrm{mL})\end{array}$ & $\begin{array}{l}\text { Cloreto Férrico } \\
\text { comercial } \\
\text { líquido } \\
\left(\mathrm{mg} \mathrm{L}^{-1}\right)\end{array}$ & & $\begin{array}{c}\text { Cor } \\
\text { Aparente } \\
\text { (uH) }\end{array}$ & $\begin{array}{l}\text { Turbidez } \\
\text { (uT) }\end{array}$ \\
\hline 1 & & 7,0 & 100 & 3,81 & 365 & 8,94 \\
\hline 2 & & 7,5 & 100 & 3,90 & 179 & 4,85 \\
\hline 3 & & 8,0 & 100 & 4,10 & 71 & 2,09 \\
\hline 4 & & 9,0 & 100 & 4,20 & 121 & 3,09 \\
\hline 5 & & 9,5 & 100 & 4,34 & $<1$ & 0,46 \\
\hline 6 & & 10,0 & 100 & 4,66 & $<1$ & 0,43 \\
\hline
\end{tabular}




\begin{tabular}{|c|c|c|c|c|c|c|}
\hline \multicolumn{7}{|c|}{ Ensaio 11} \\
\hline \multicolumn{7}{|c|}{ Água de estudo 4: Cor Aparente $(\mathrm{uH})=137$ Cor verdadeira $(\mathrm{uH})=94$ Turbidez $(\mathrm{uT})=4,50$} \\
\hline \multicolumn{4}{|c|}{ Temperatura $\left({ }^{\circ} \mathrm{C}\right)=20$} & \multirow{2}{*}{\multicolumn{3}{|c|}{\begin{tabular}{|c|c}
\multicolumn{1}{|c|}{ Alcalinidade Total $\left(\mathrm{mg} \mathrm{L}^{-1} \mathrm{CaCO}_{3}\right)=11,0$} \\
$\begin{array}{c}\text { Água Filtrada } \\
\text { (coleta 30 min) }\end{array}$
\end{tabular}}} \\
\hline \multirow[b]{2}{*}{ Frasco } & \multicolumn{3}{|c|}{ Dosagem de produtos químicos } & & & \\
\hline & $\begin{array}{c}\mathrm{HCl} \\
\left(1 \mathrm{~g} \mathrm{~L}^{-1}\right)\end{array}$ & $\begin{array}{c}\mathrm{NaOH} \\
\left(4 \mathrm{~g} \mathrm{~L}^{-1}\right) \\
(\mathrm{mL})\end{array}$ & $\begin{array}{c}\text { Cloreto Férrico } \\
\text { comercial líquido } \\
\left(\mathrm{mg} \mathrm{L}^{-1}\right)\end{array}$ & $\begin{array}{c}\text { pH de } \\
\text { Coagulação }\end{array}$ & $\begin{array}{l}\text { Cor } \\
\text { Aparente } \\
\text { (uH) }\end{array}$ & $\begin{array}{c}\text { Turbidez } \\
\text { (uT) }\end{array}$ \\
\hline 1 & & 10,5 & 100 & 4,95 & 4 & 0,43 \\
\hline 2 & & 11,0 & 100 & 5,25 & 5 & 0,58 \\
\hline 3 & & 11,5 & 100 & 5,52 & 14 & 0,81 \\
\hline 4 & & 12,5 & 100 & 5,67 & 40 & 1,56 \\
\hline 5 & & 13,0 & 100 & 5,76 & 172 & 4,55 \\
\hline 6 & & 13,5 & 100 & 5,90 & 356 & 9,43 \\
\hline
\end{tabular}

\begin{tabular}{|c|c|c|c|c|c|c|}
\hline \multicolumn{7}{|c|}{$\begin{array}{l}\text { Ensaio } 12 \\
\end{array}$} \\
\hline \multirow{2}{*}{\multicolumn{7}{|c|}{$\begin{array}{ccc}\text { Água de estudo 4: } & \text { Cor Aparente }(\mathrm{uH})=130 & \text { Cor verdadeira }(\mathrm{uH})=94 \quad \text { Turbidez }(\mathrm{uT})=4,52 \\
\mathrm{pH}=6,00 & \text { Temperatura }\left({ }^{\circ} \mathrm{C}\right)=20 & \text { Alcalinidade Total }\left(\mathrm{mg} \mathrm{L}^{-1} \mathrm{CaCO}_{3}\right)=11,0\end{array}$}} \\
\hline & & & & & & \\
\hline \multirow[b]{2}{*}{ Frasco } & \multicolumn{3}{|c|}{ Dosagem de produtos químicos } & \multirow[b]{2}{*}{$\begin{array}{c}\text { pH de } \\
\text { Coagulação }\end{array}$} & \multicolumn{2}{|c|}{$\begin{array}{l}\text { Água Filtrada } \\
\text { (coleta } 30 \mathrm{~min} \text { ) }\end{array}$} \\
\hline & $\begin{array}{c}\mathrm{HCl} \\
\left(1 \mathrm{~g} \mathrm{~L}^{-1}\right)\end{array}$ & $\begin{array}{c}\mathrm{NaOH} \\
\left(4 \mathrm{~g} \mathrm{~L}^{-1}\right) \\
(\mathrm{mL})\end{array}$ & $\begin{array}{c}\text { Cloreto Férrico } \\
\text { comercial } \\
\text { líquido } \\
\left(\mathrm{mg} \mathrm{L}^{-1}\right)\end{array}$ & & $\begin{array}{c}\text { Cor } \\
\text { Aparente } \\
\text { (uH) }\end{array}$ & $\begin{array}{l}\text { Turbidez } \\
\text { (uT) }\end{array}$ \\
\hline 1 & & 8,3 & 90 & 4,80 & 3 & 0,48 \\
\hline 2 & & 5,3 & 70 & 4,61 & 5 & 0,58 \\
\hline
\end{tabular}

